
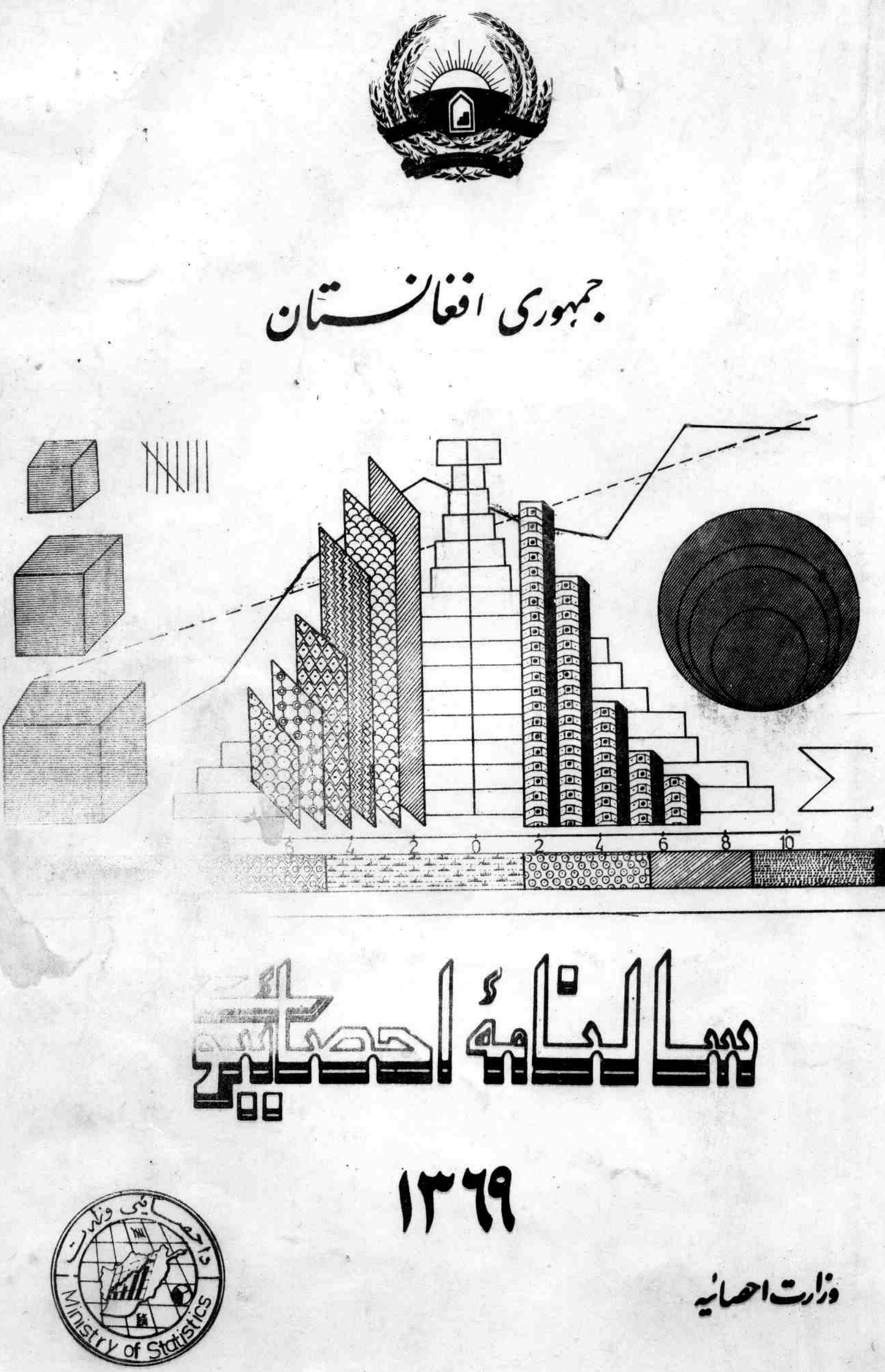

\title{
Iry9
}


PCKU:

رنارتهائح

سالنامهُ احصائوى Ir 49

ivr.de 


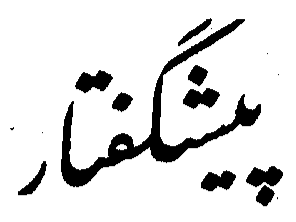

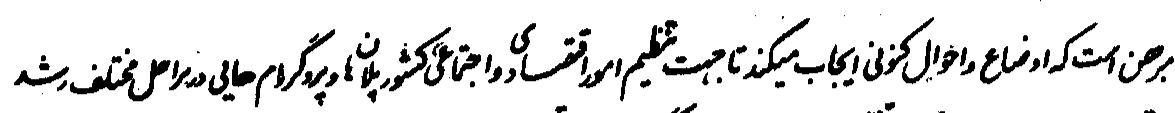

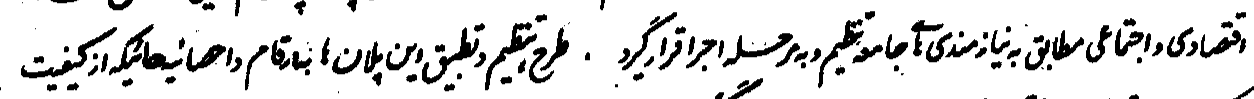

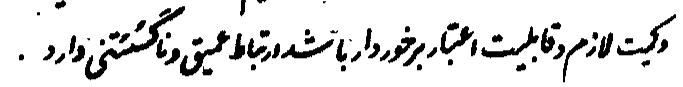

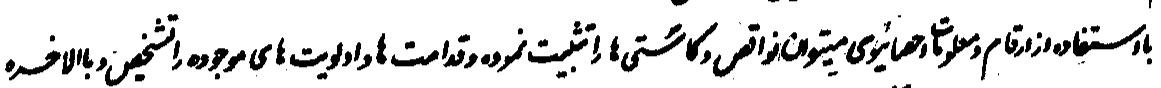

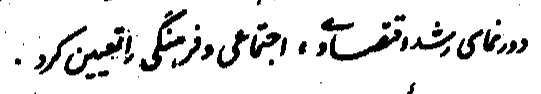

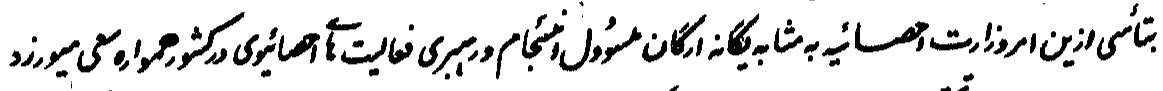

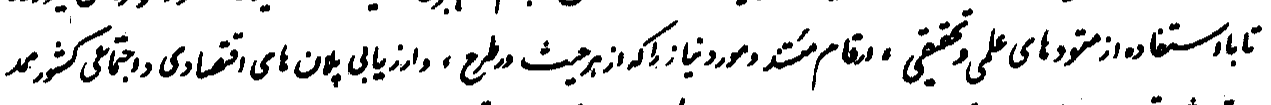

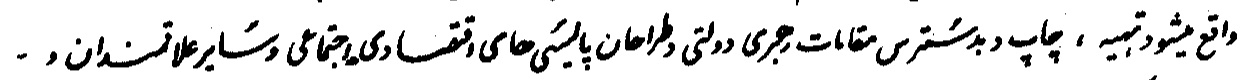

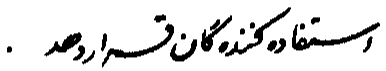

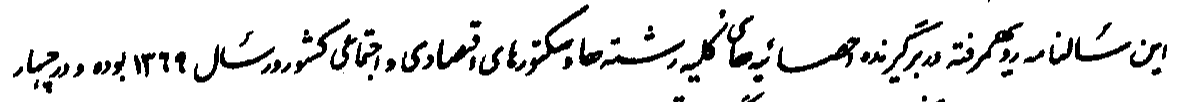

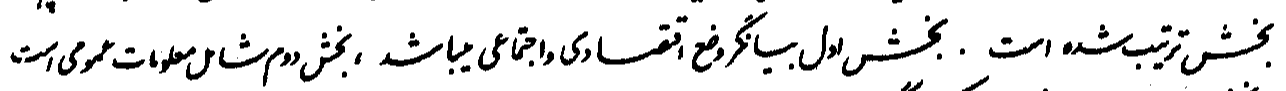

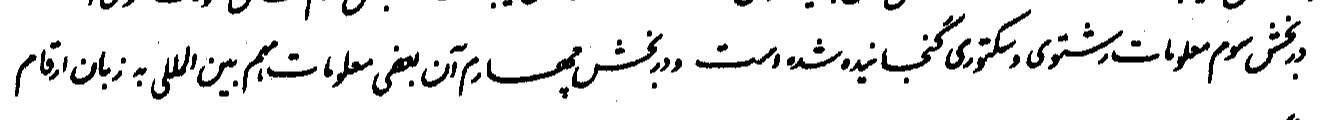

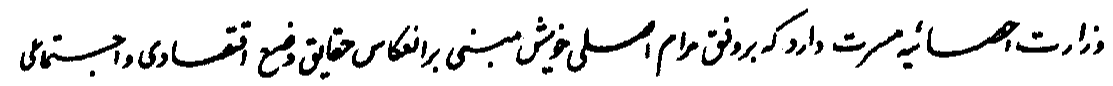

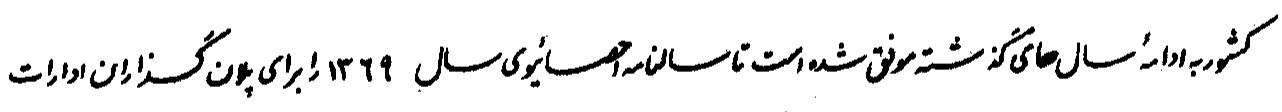

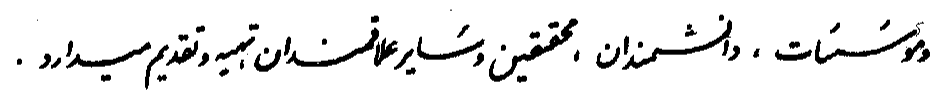

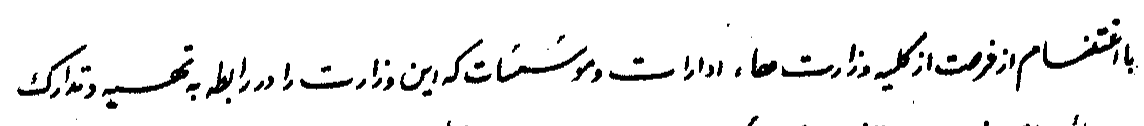

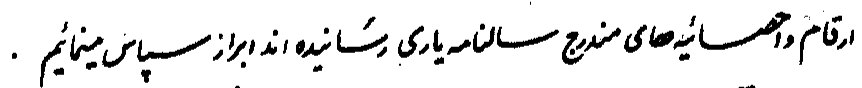

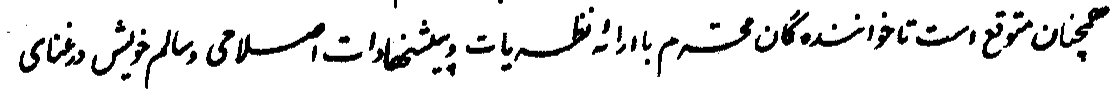

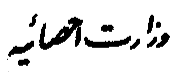




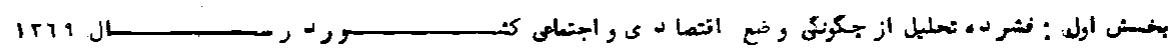

السن

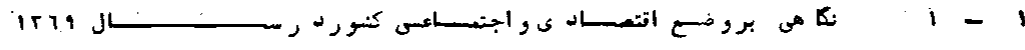

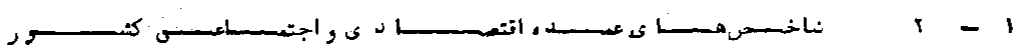

بغق دور:

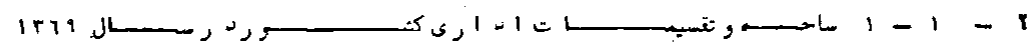

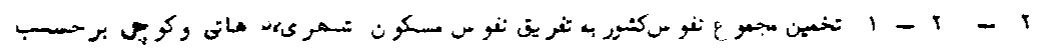

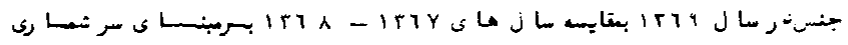

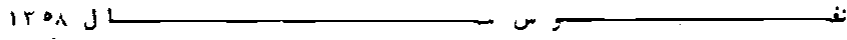

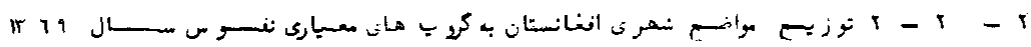

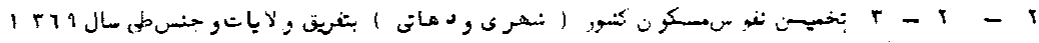

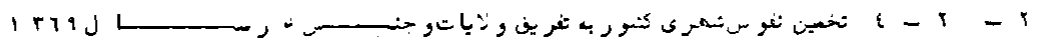

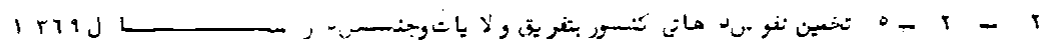

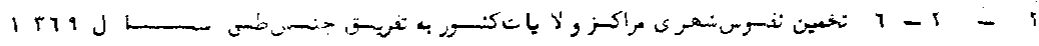

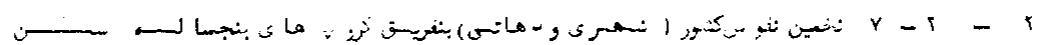

itima

$\sim 2$

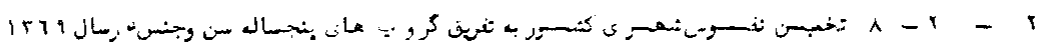

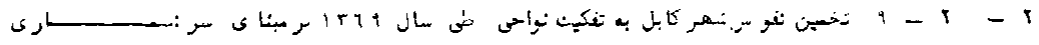

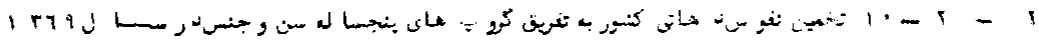




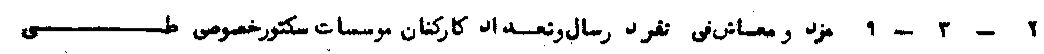

r

rr

re.

$r$

r

(1)

er

i.

EY

69

o.

01

or

09

Ir1, Iris s

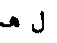

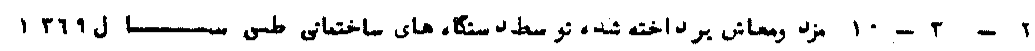

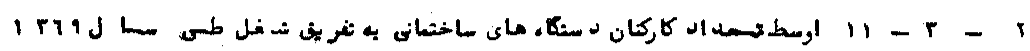

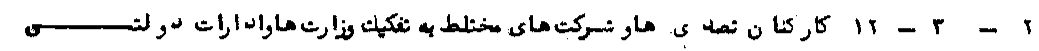

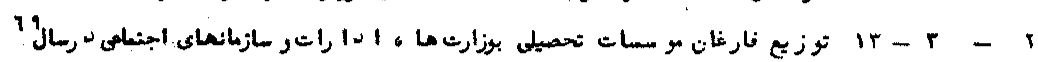

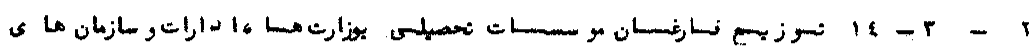

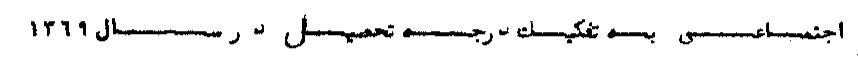
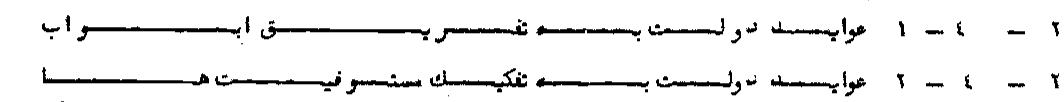

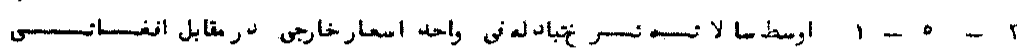

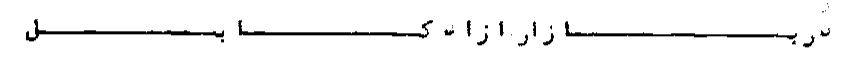

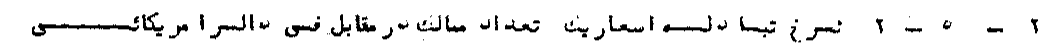

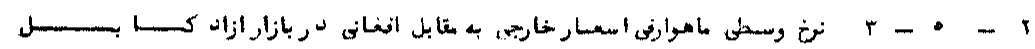
irra J

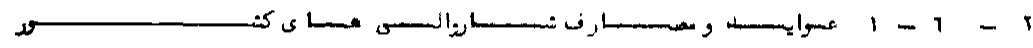

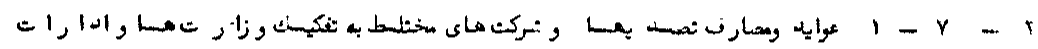

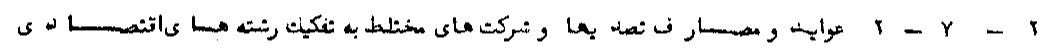

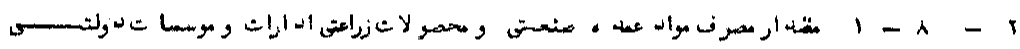

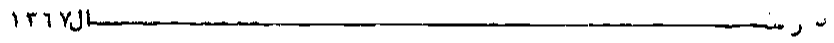

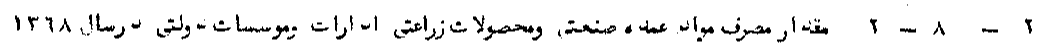

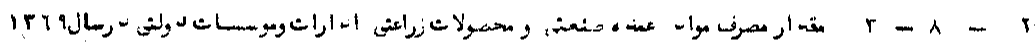

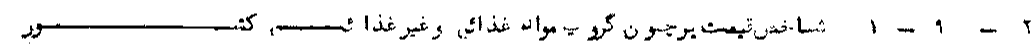

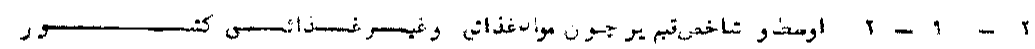

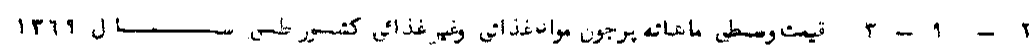

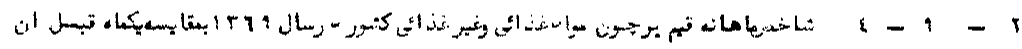

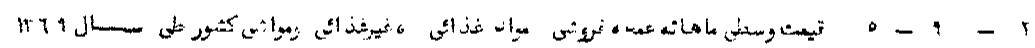
I - 1 Y Y - T - Y

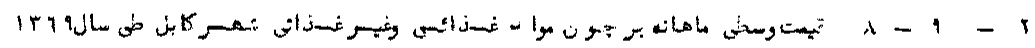

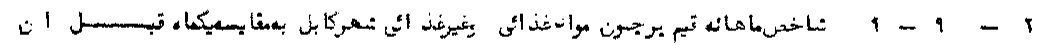

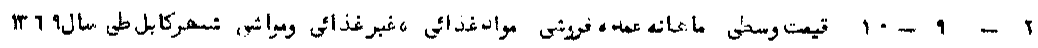

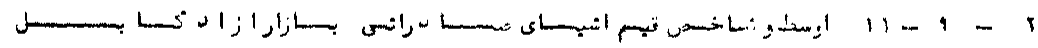

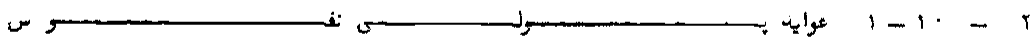

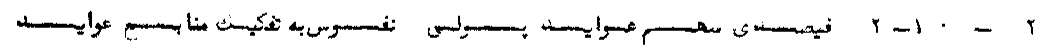
r r 


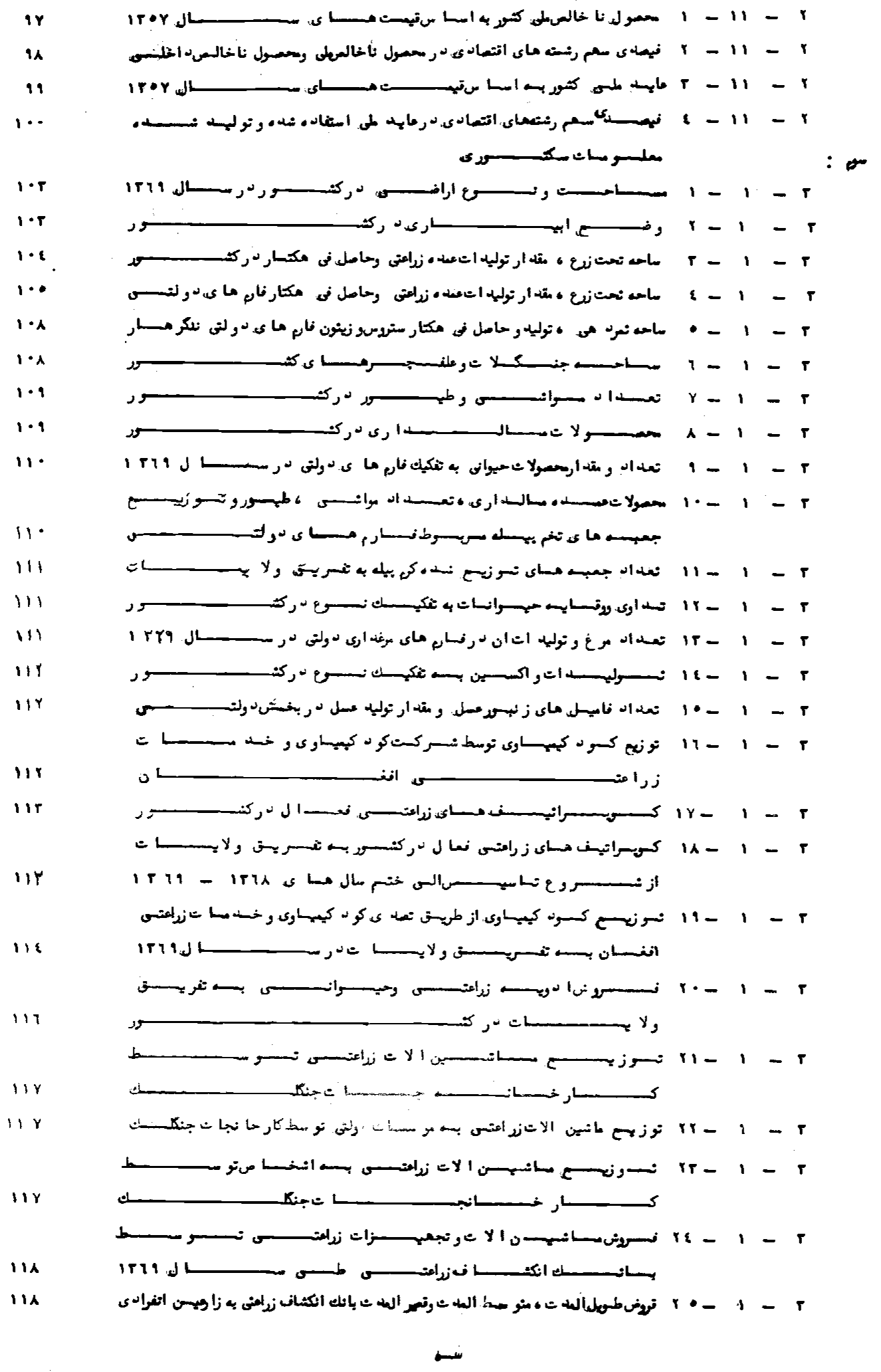




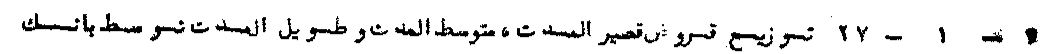

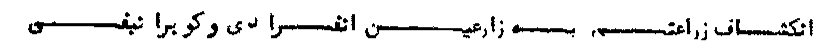




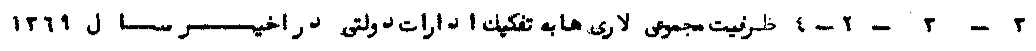

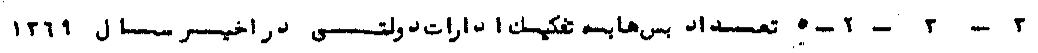

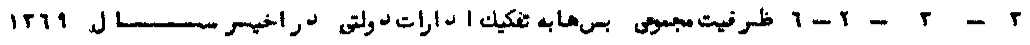

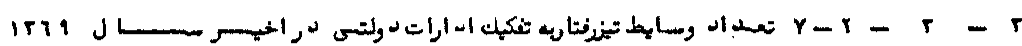




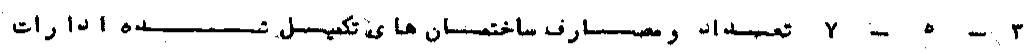
Ir79 ل

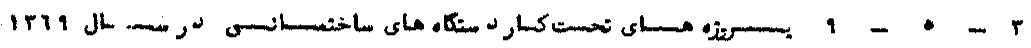

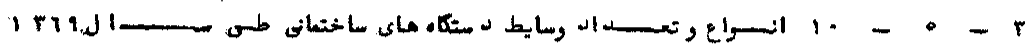

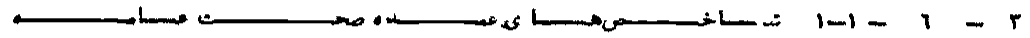
ه ا

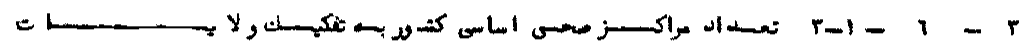

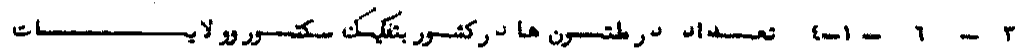

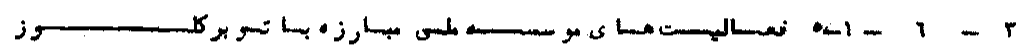

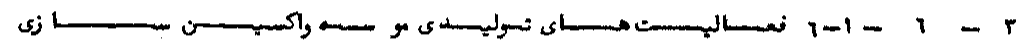

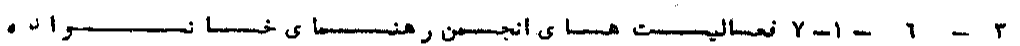
ـ

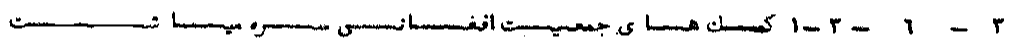
r - r

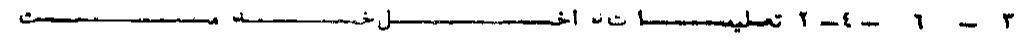
r

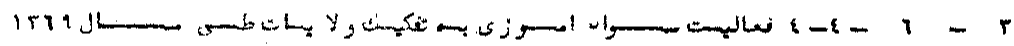

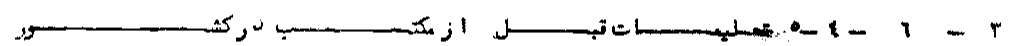

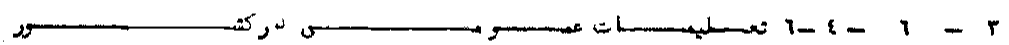

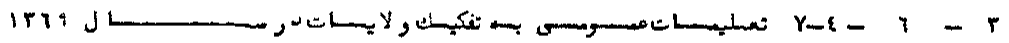

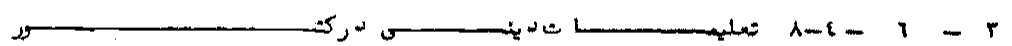
r- 1 - 1 - 1 -

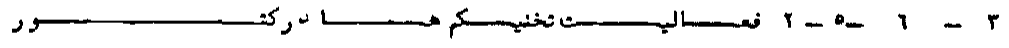

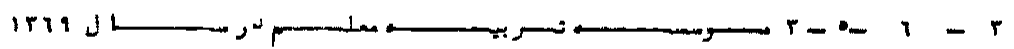

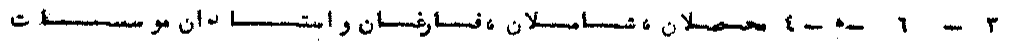

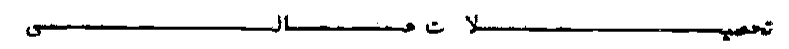

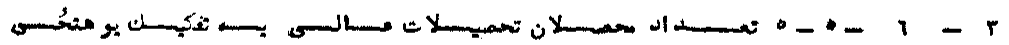

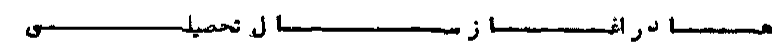

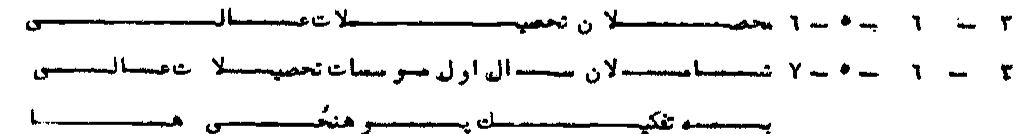




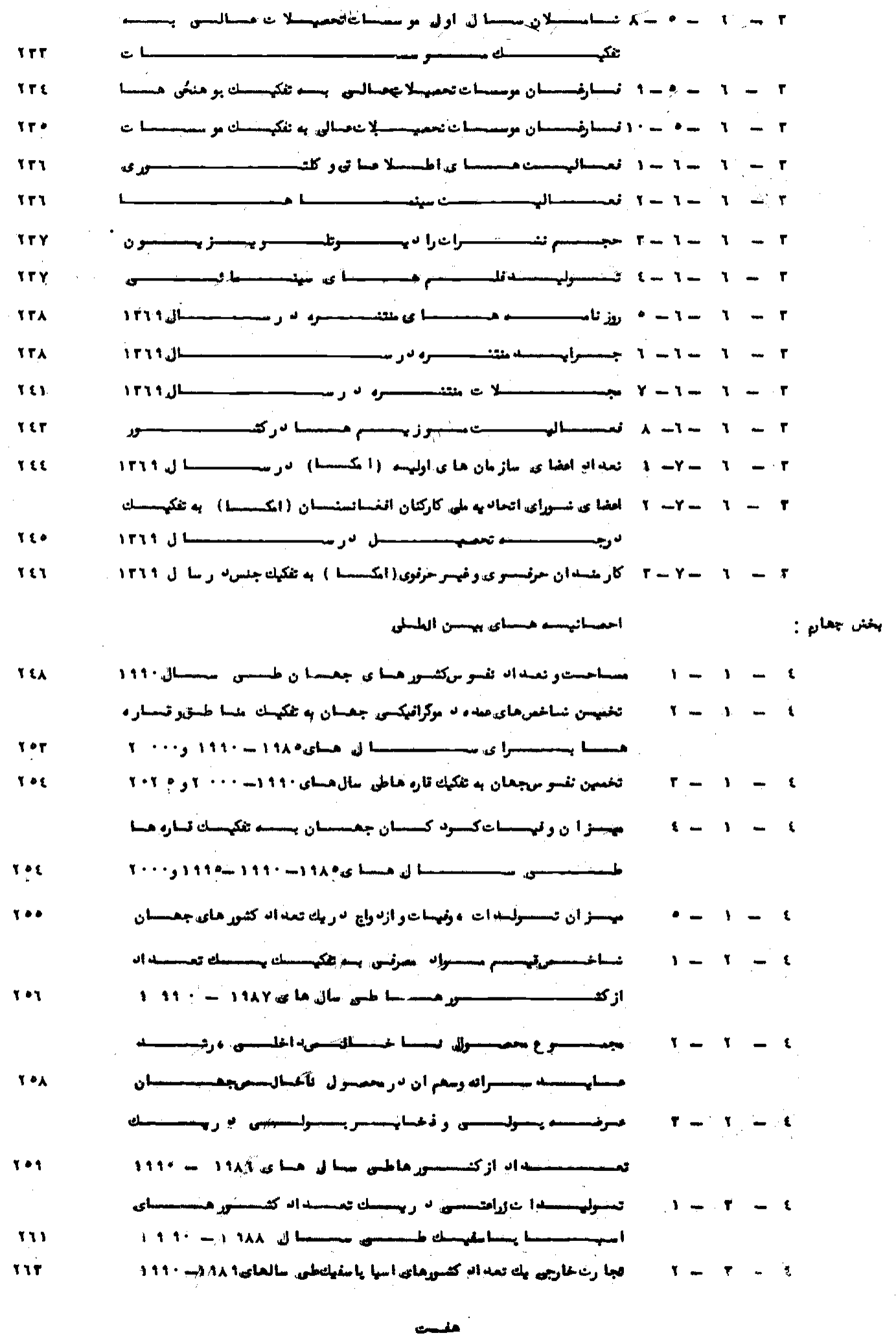




\section{عزمام اخصارى}

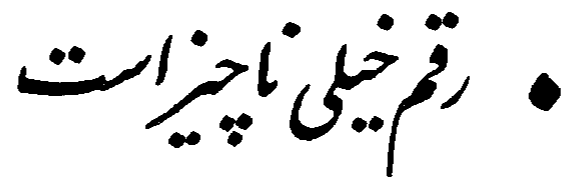

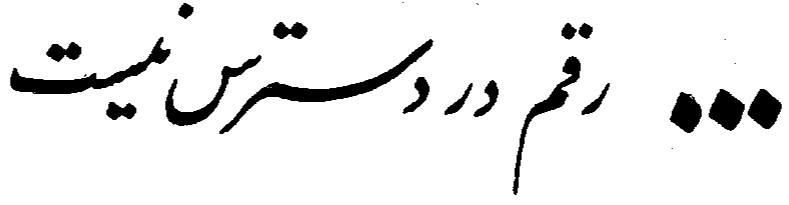

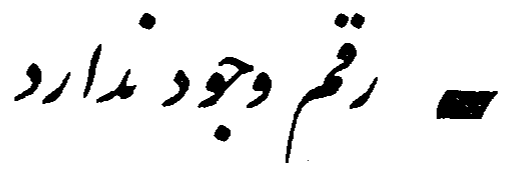

$$
\begin{aligned}
& \int_{\infty}^{\infty}
\end{aligned}
$$

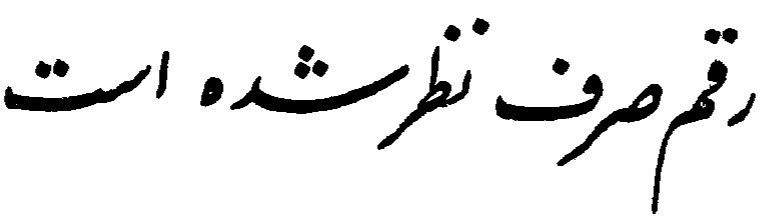


كنش اول

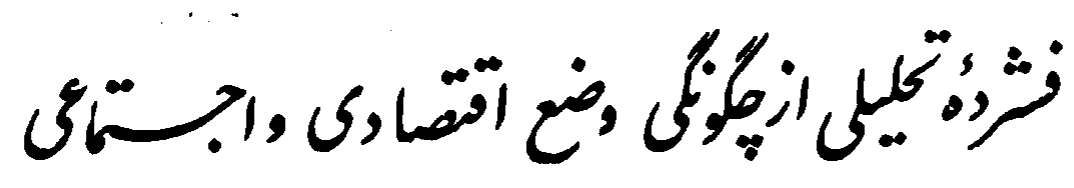
? جمورى إنقانتان. 
الف

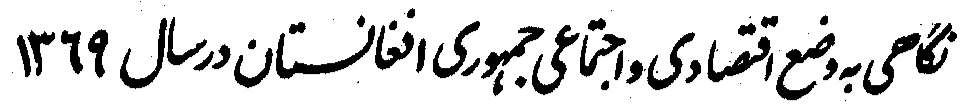

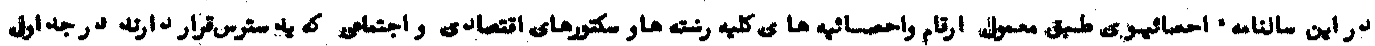

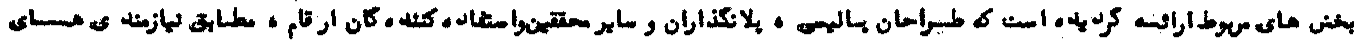

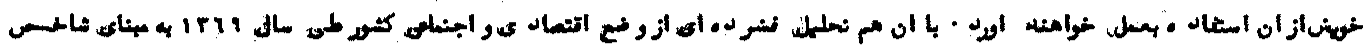

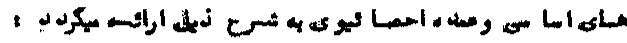

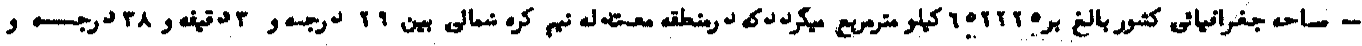

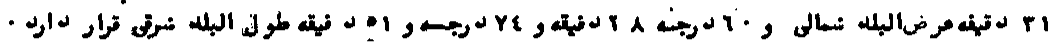

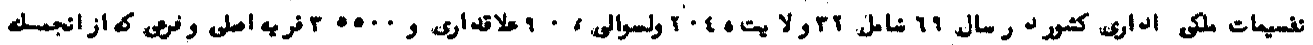

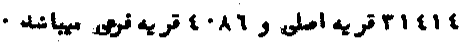

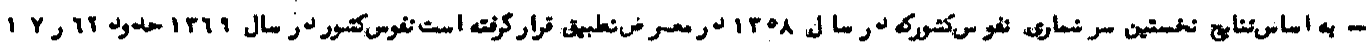

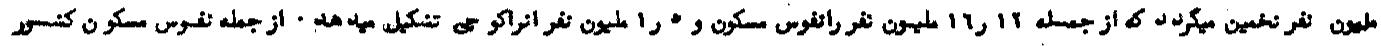

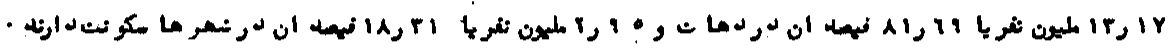

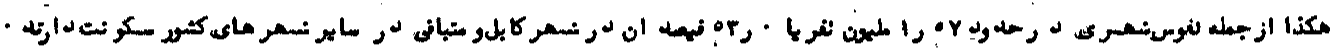

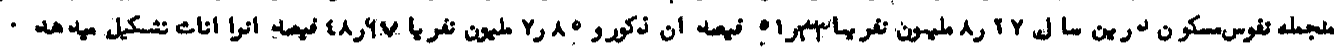

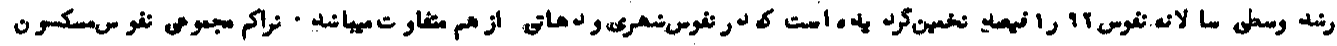

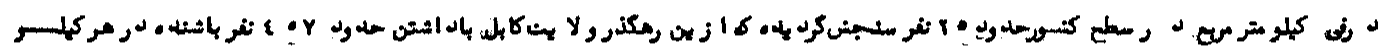

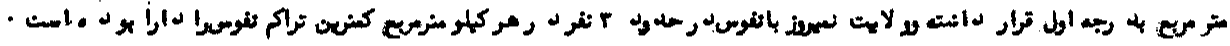

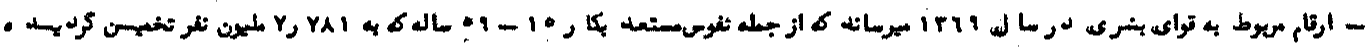

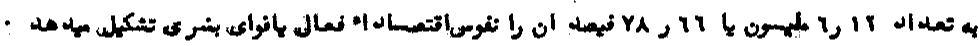

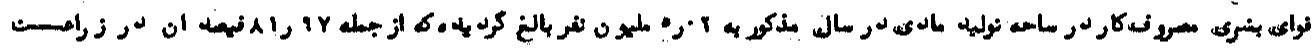

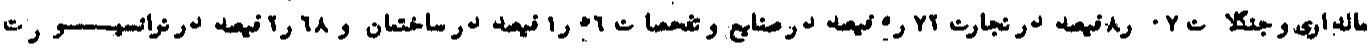

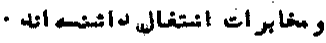

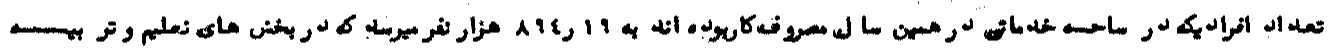

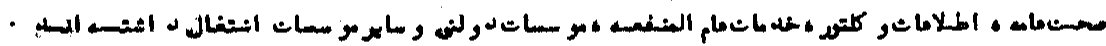

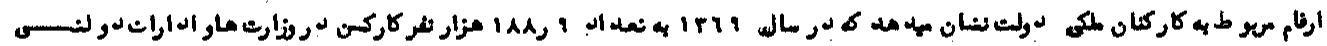

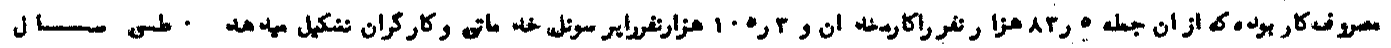

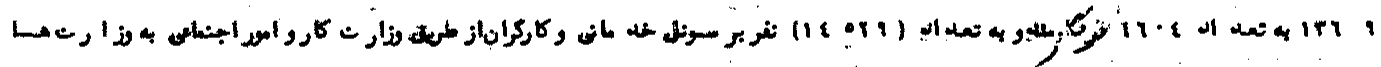

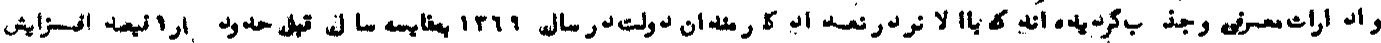
-

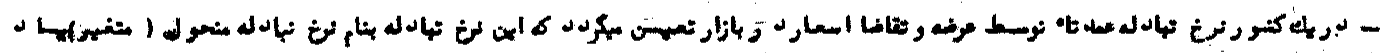

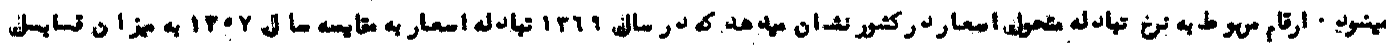

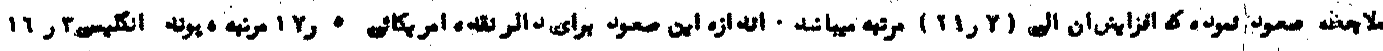

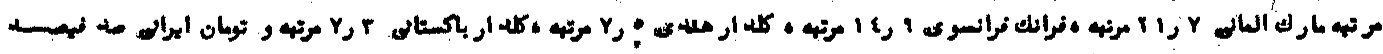

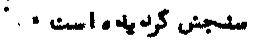




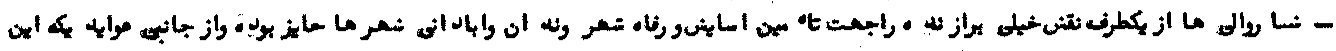

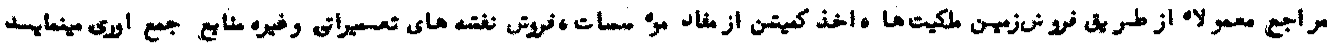

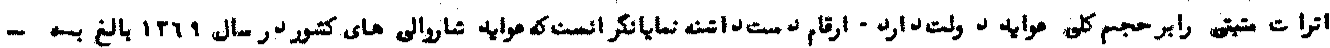

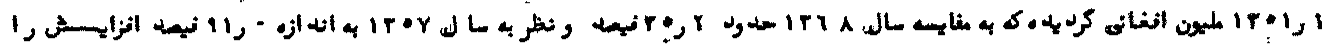

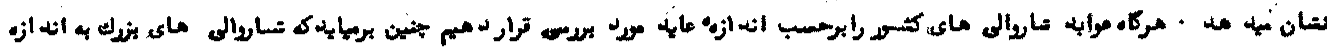

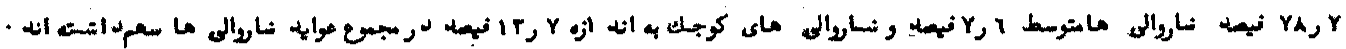

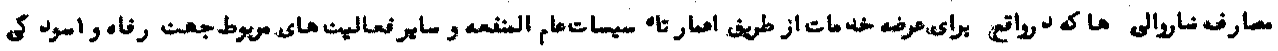

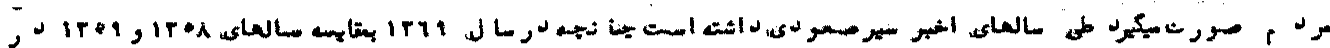

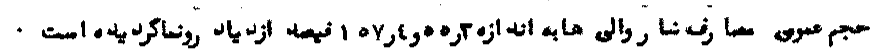

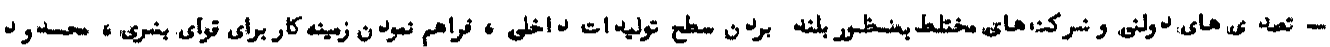

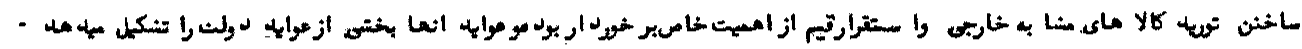

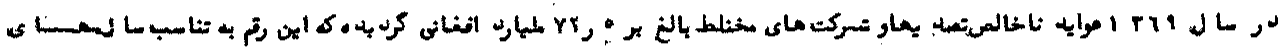

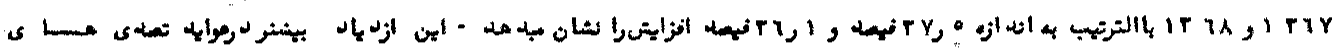

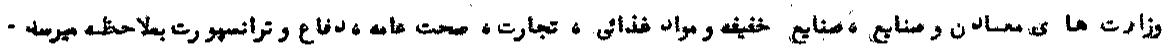

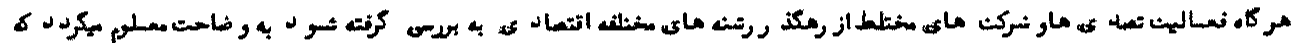

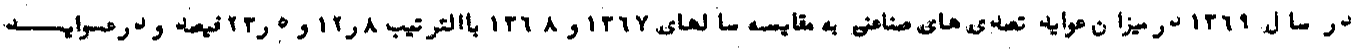

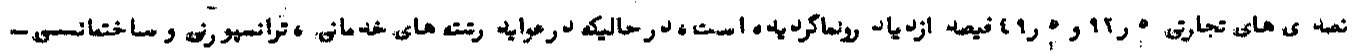

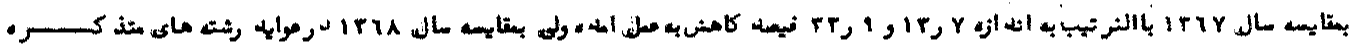

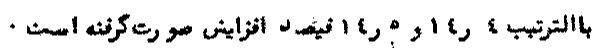

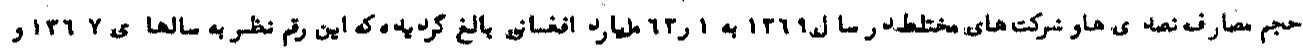

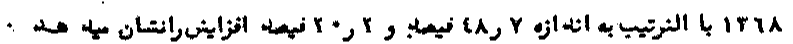

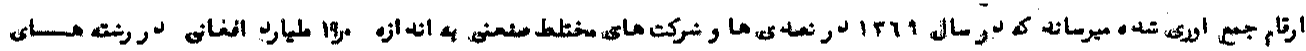

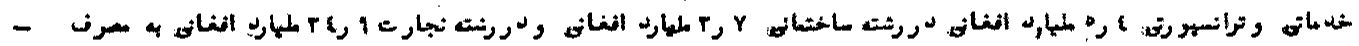

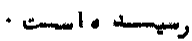

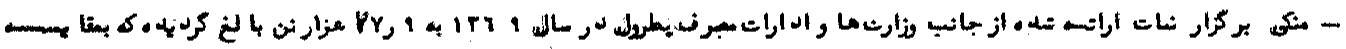

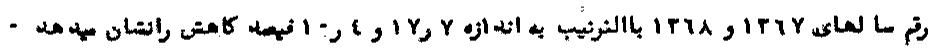

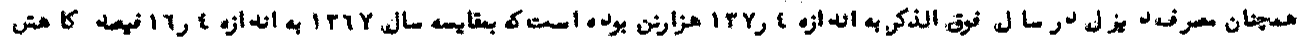

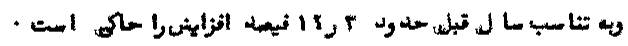

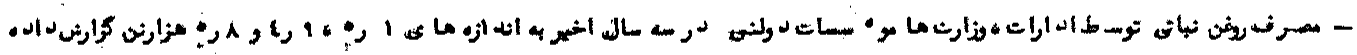

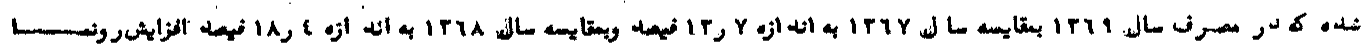
•

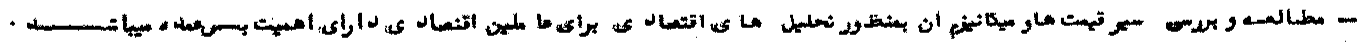

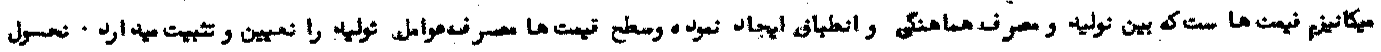

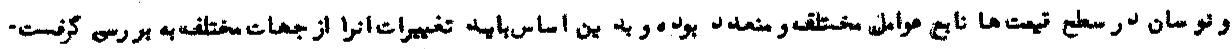




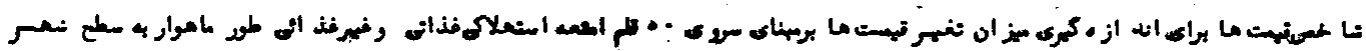

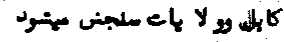

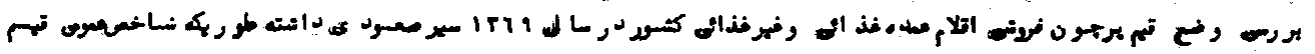

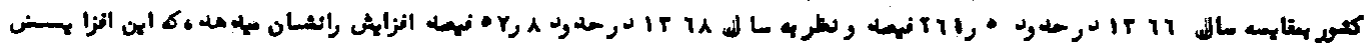

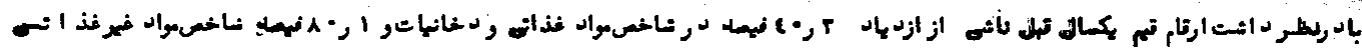

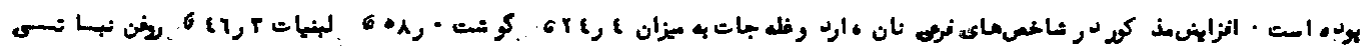

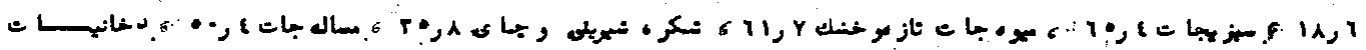

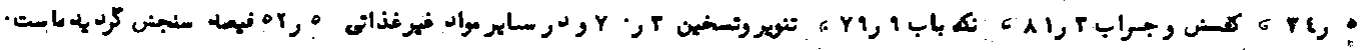

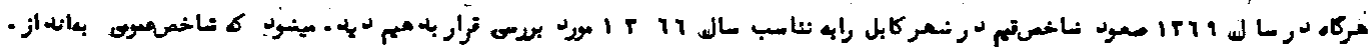

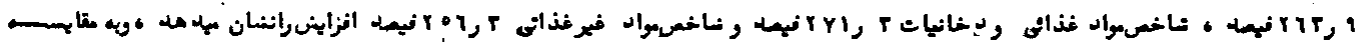

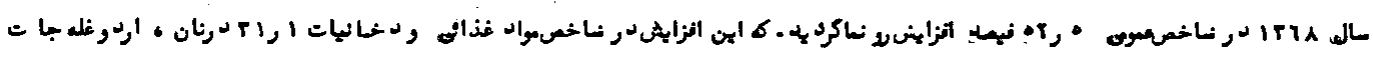

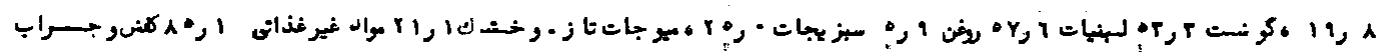

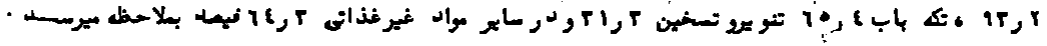

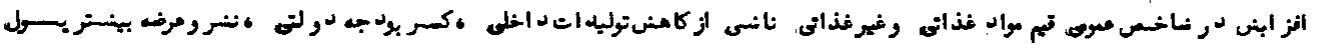

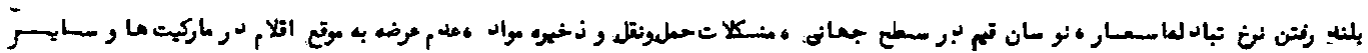

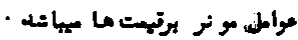

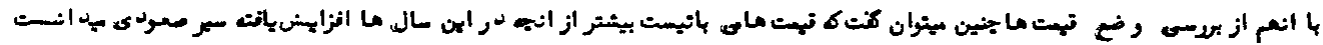

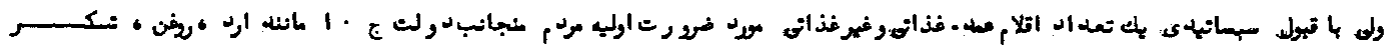

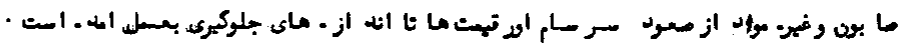

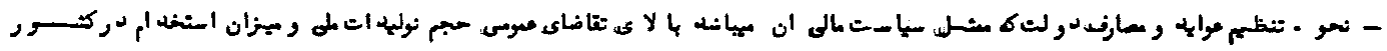

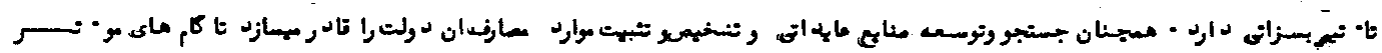

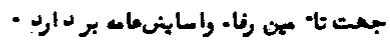

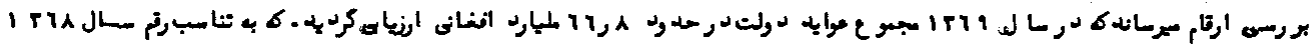

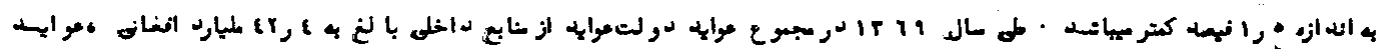

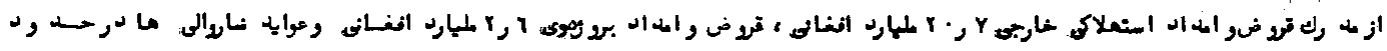

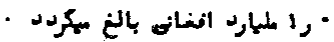

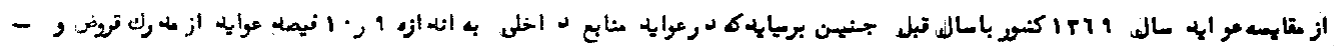

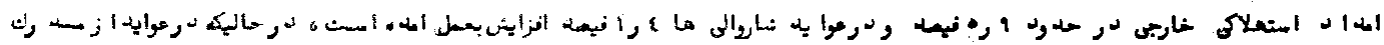

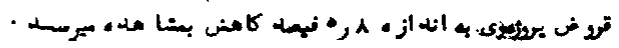

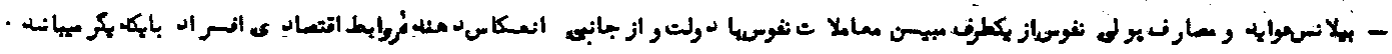

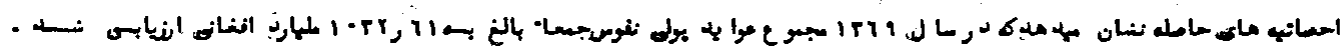

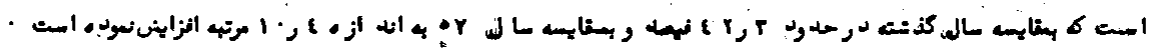

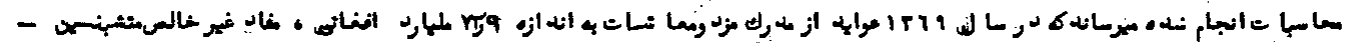

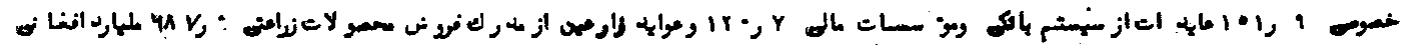




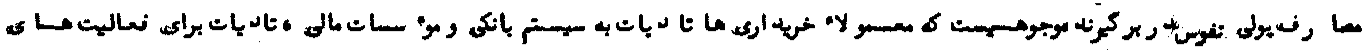

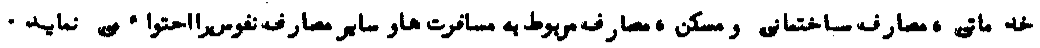

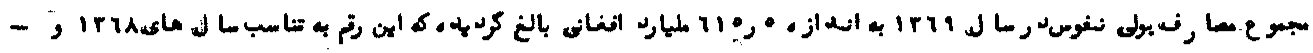

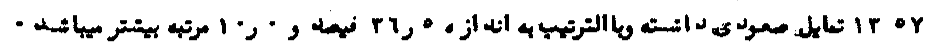

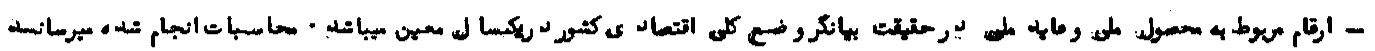

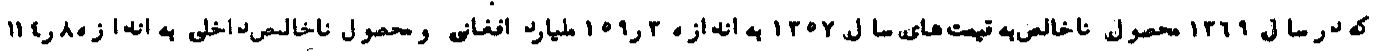

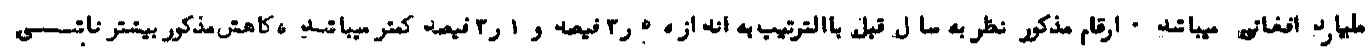

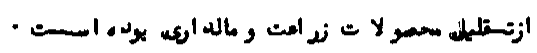

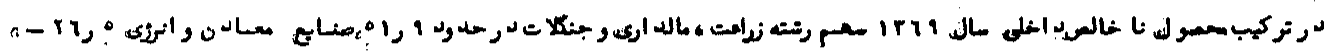

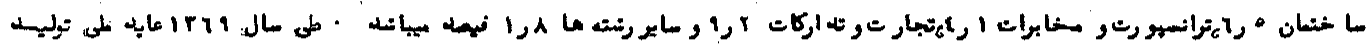

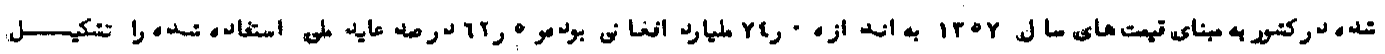

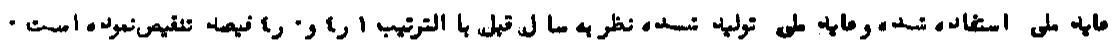

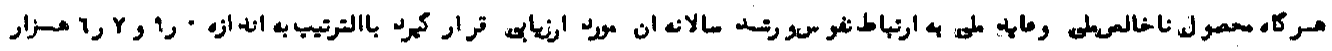

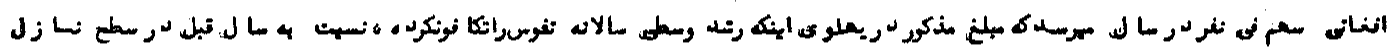
ترار دانتسه استص

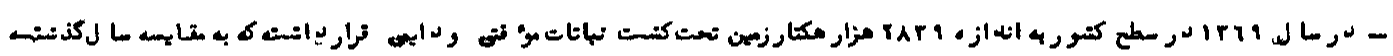
•

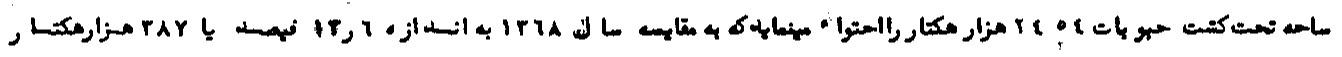
كتمر ميبانسمد

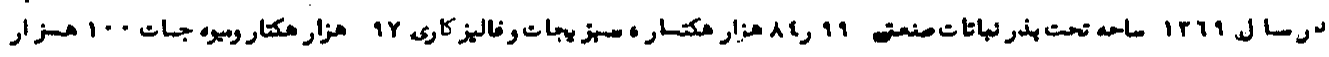

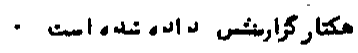

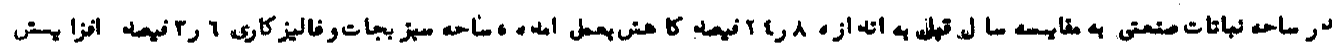

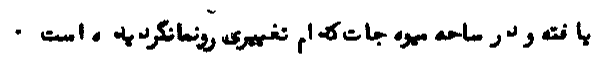

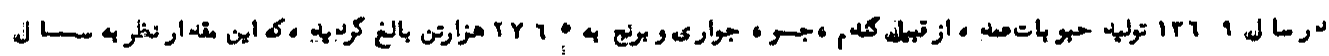

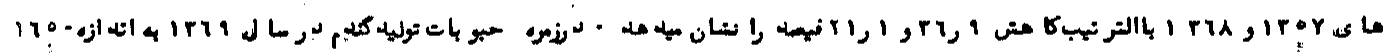

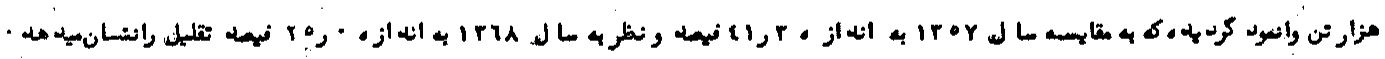

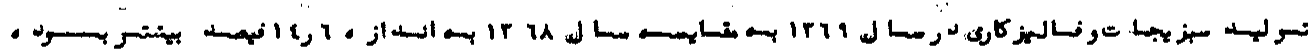
-

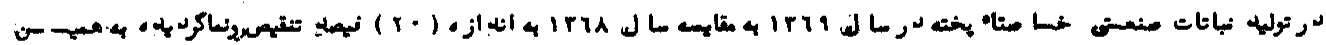

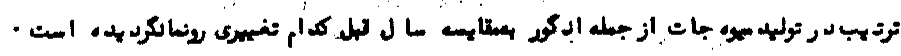

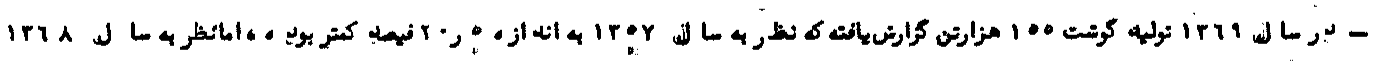

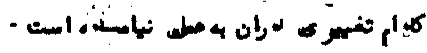




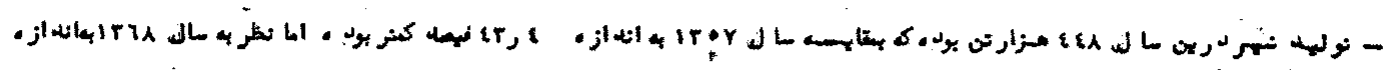

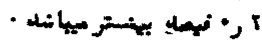

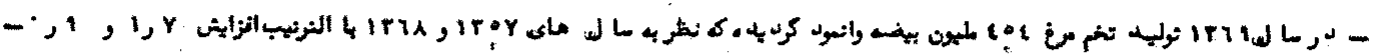

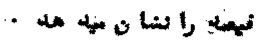

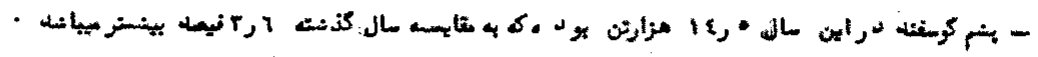

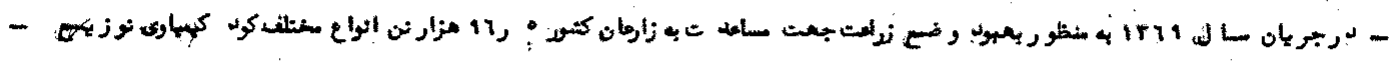

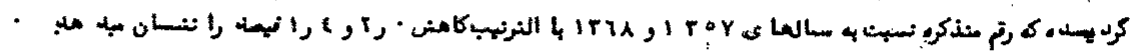

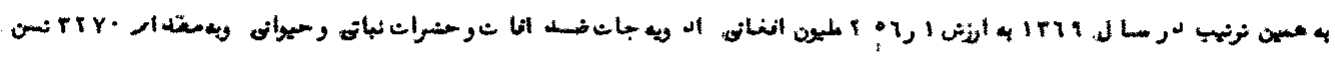

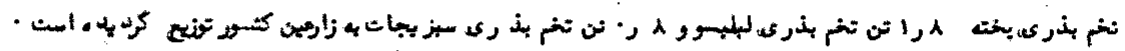

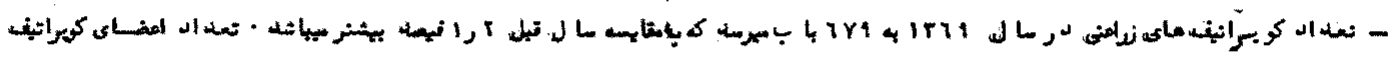

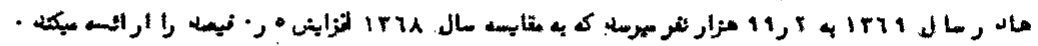

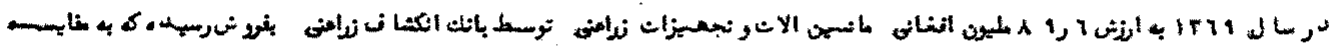

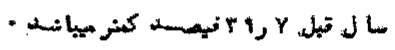

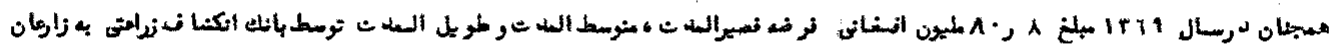

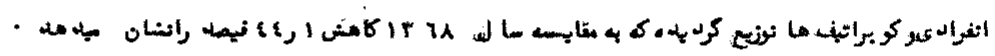

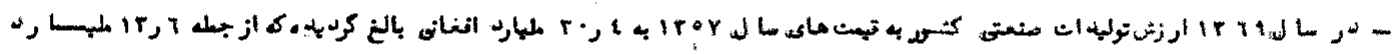

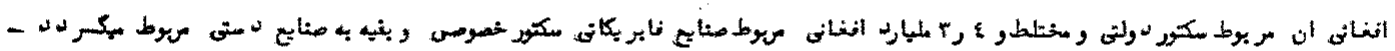

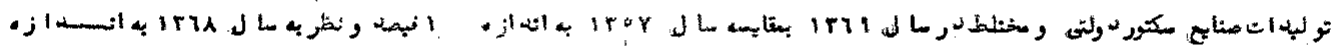

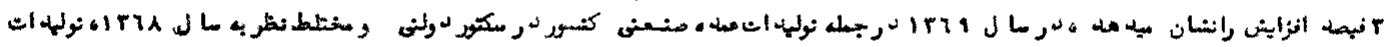

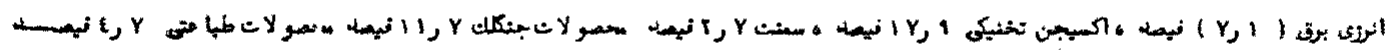

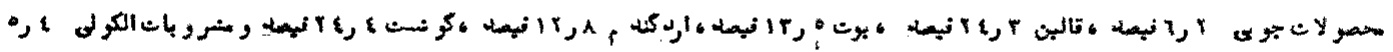

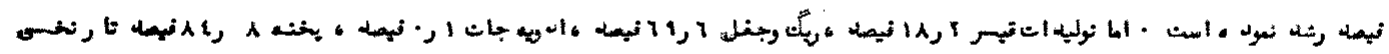

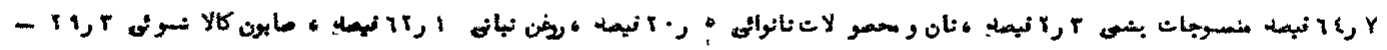

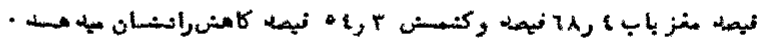

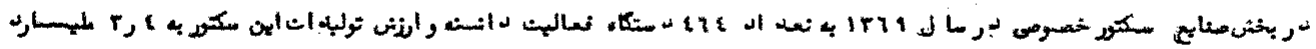

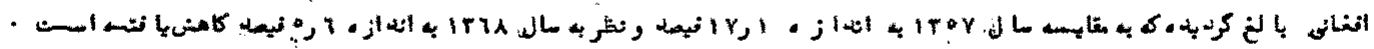

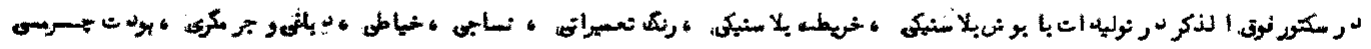

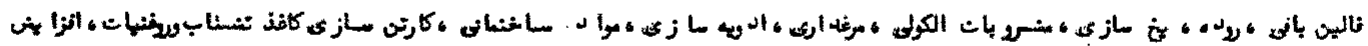

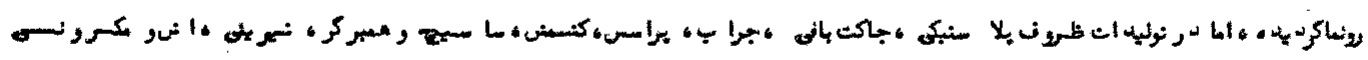

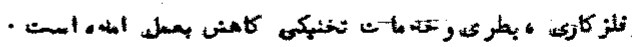

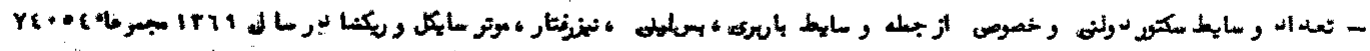

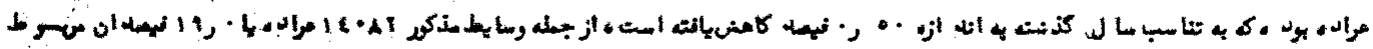


?

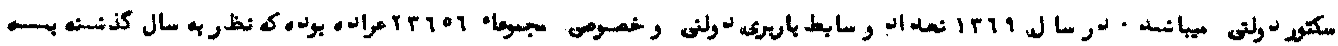

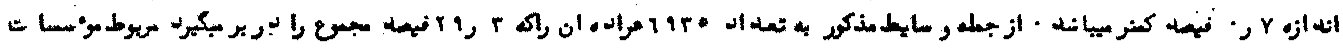

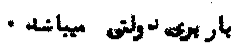

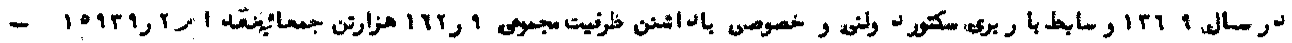

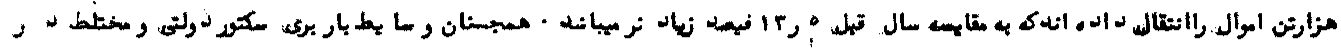

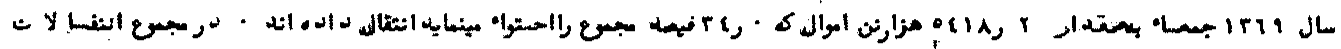

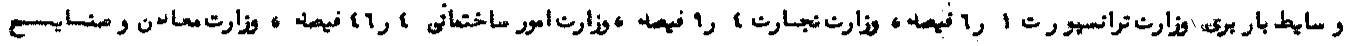

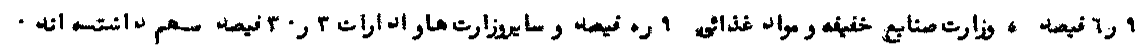

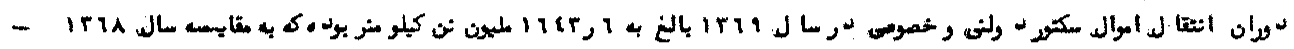

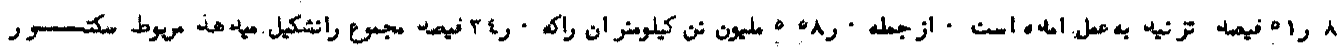

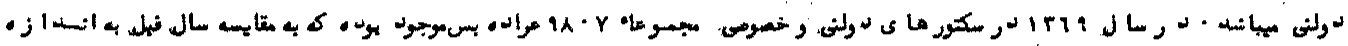
9

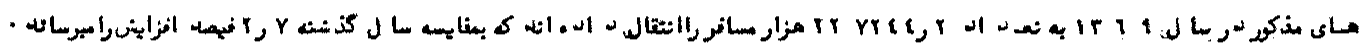

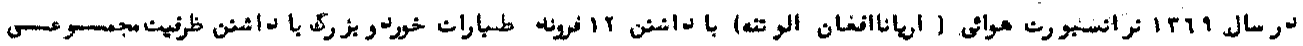

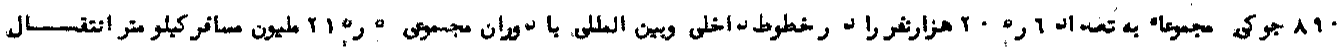

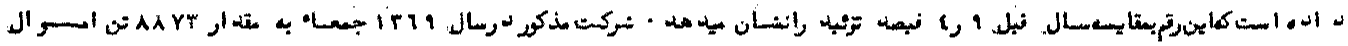

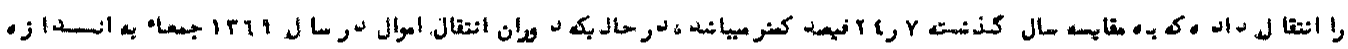

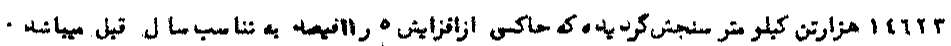

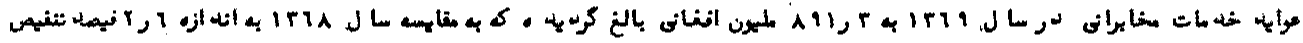
يانتسم است

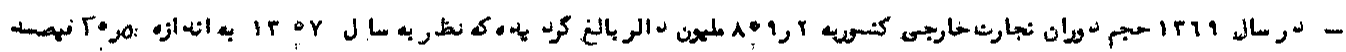

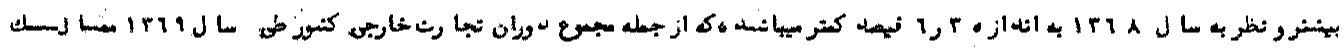

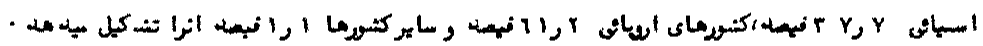

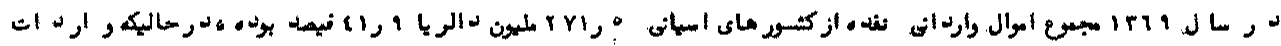

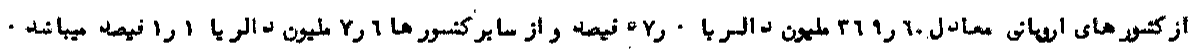

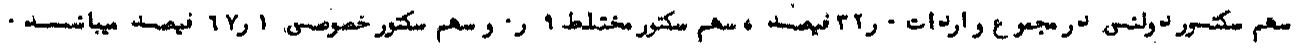

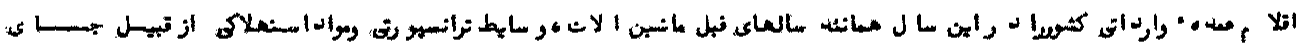

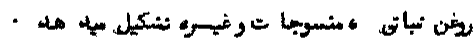

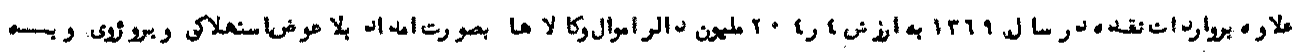

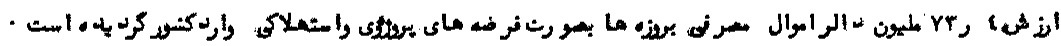

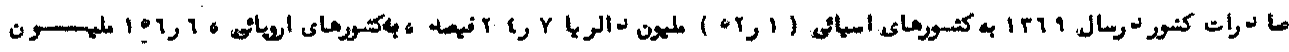

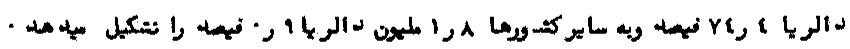

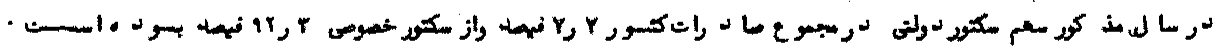

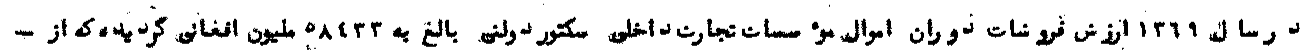

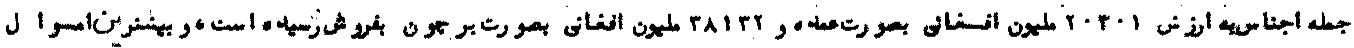




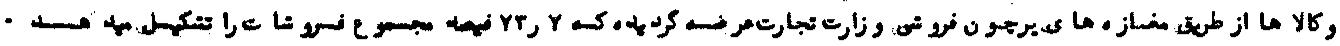

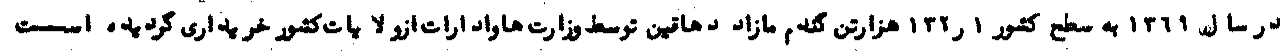

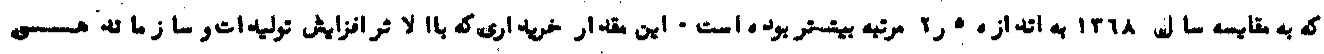

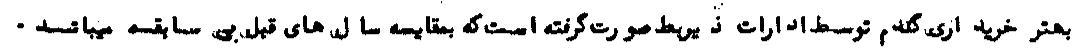

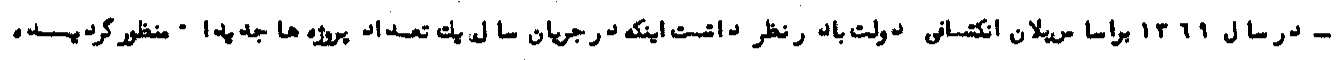

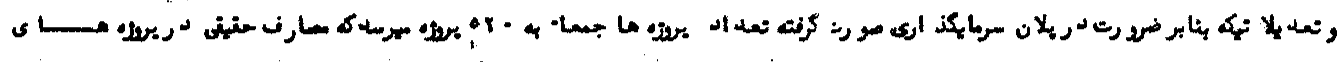

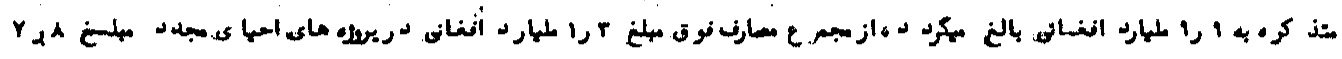

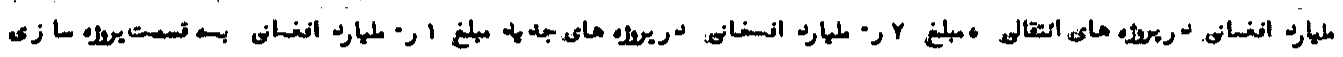

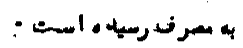

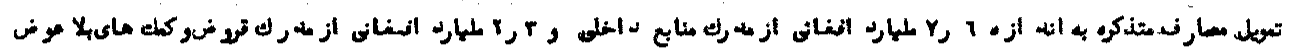

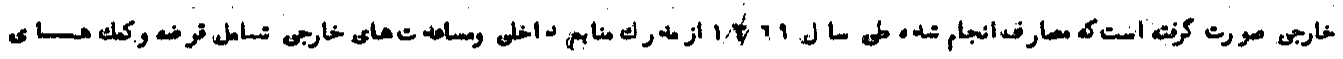

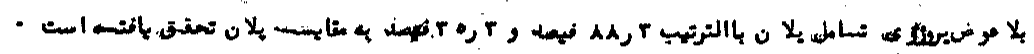

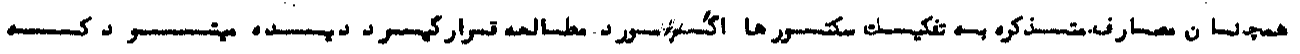

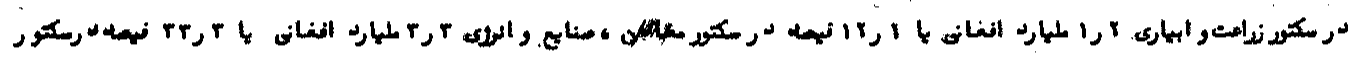

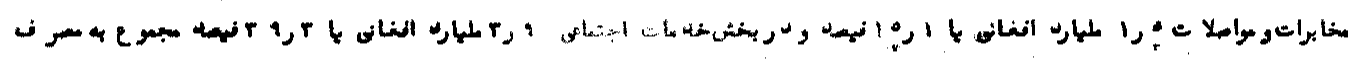

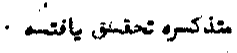

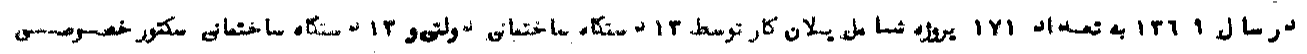

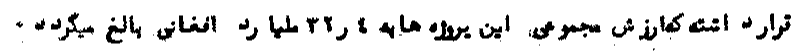

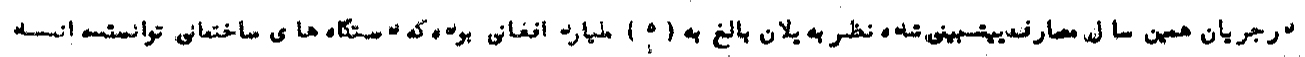

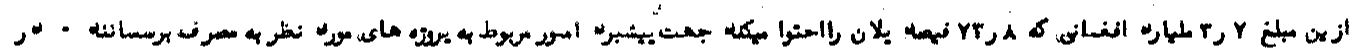

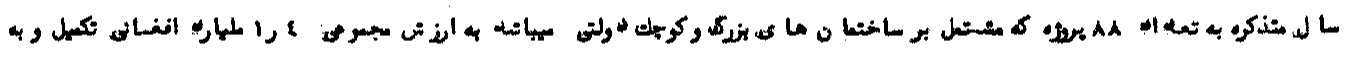

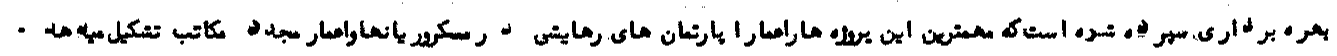

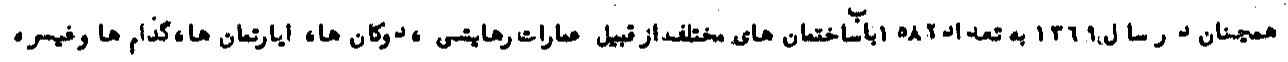

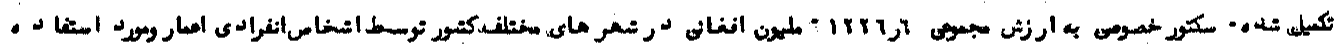

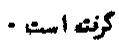

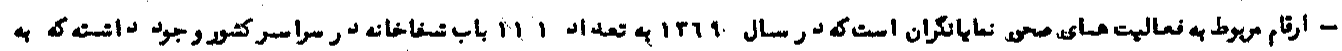

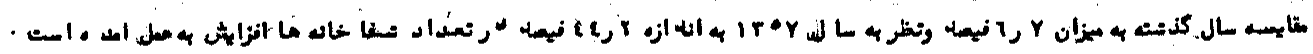

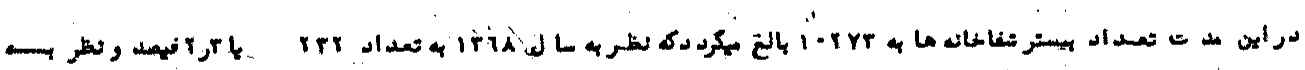

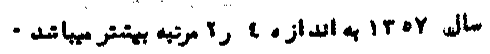

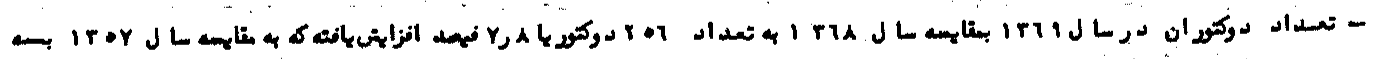


c

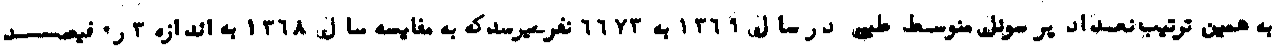

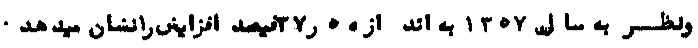

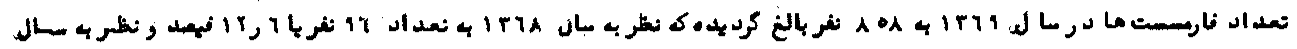
•

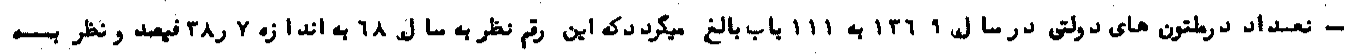
مال

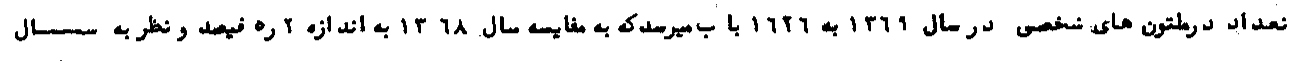

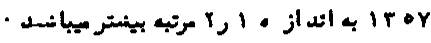

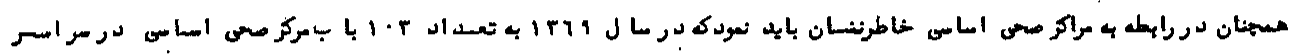

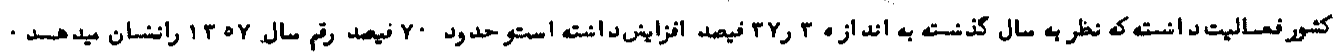

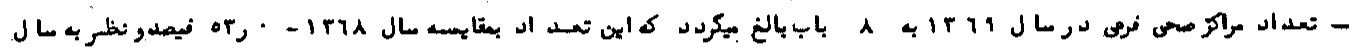

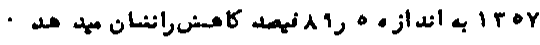

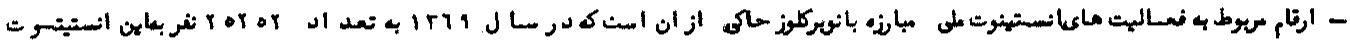

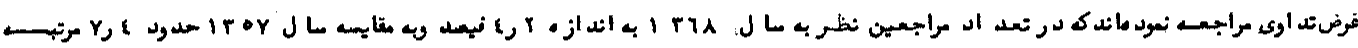

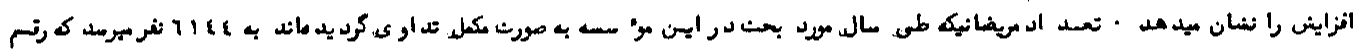

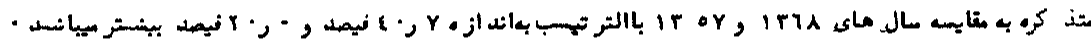

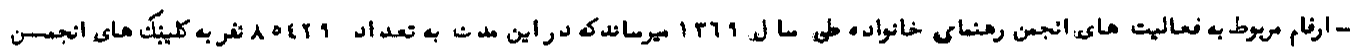

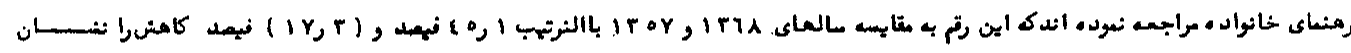

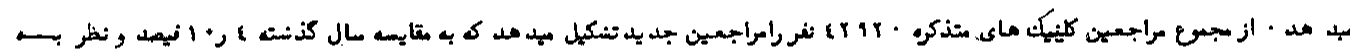

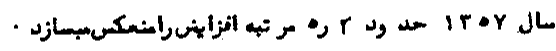

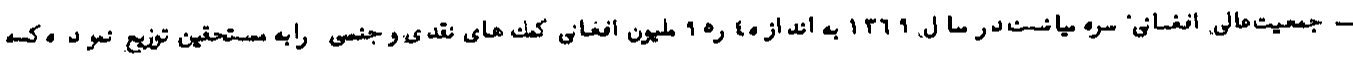

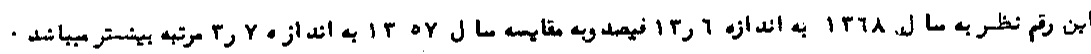

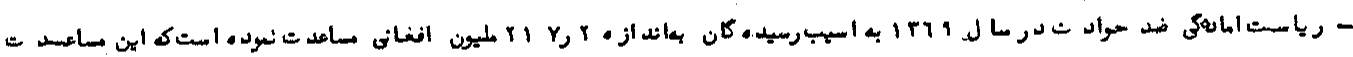

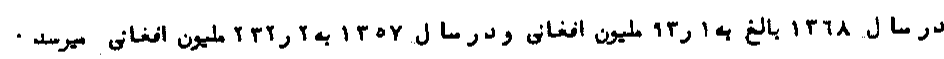

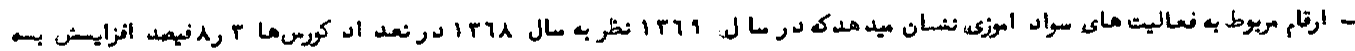

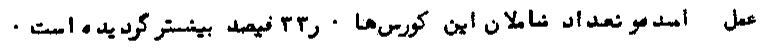

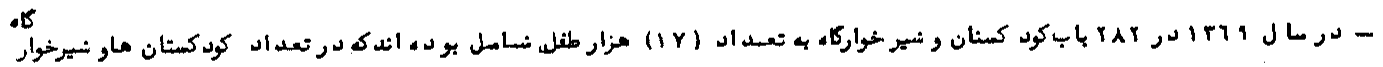

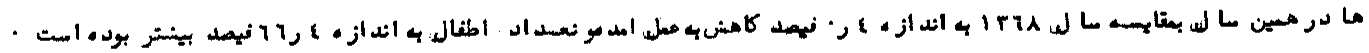

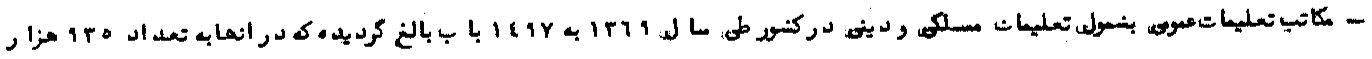

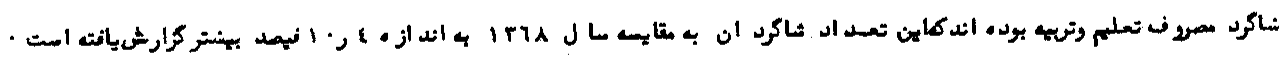




\section{$b$}

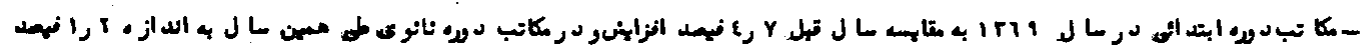

$$
\text { • انززاين بمطل امدهـاست }
$$

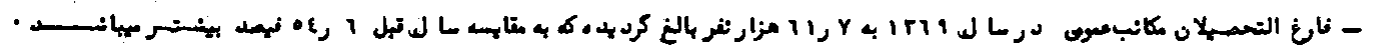

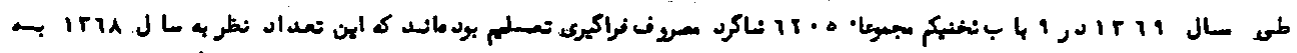

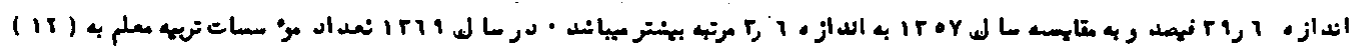

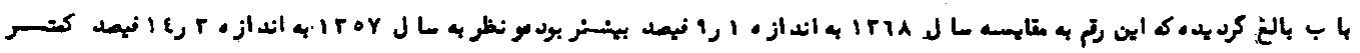

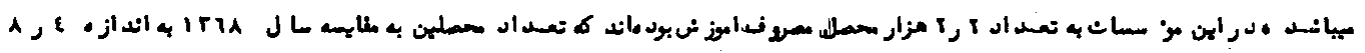

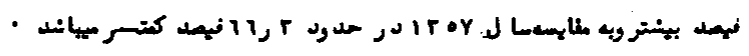

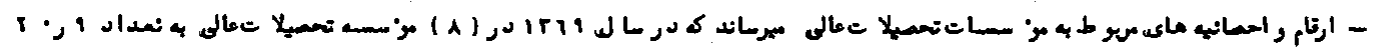

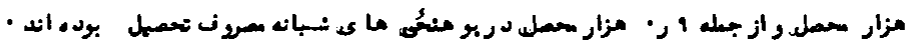

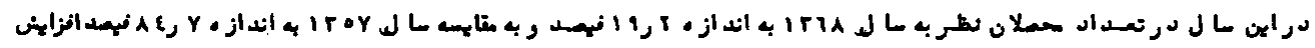

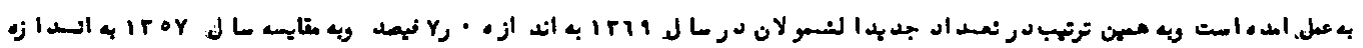

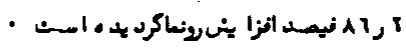

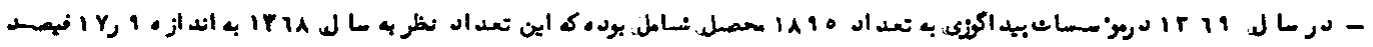

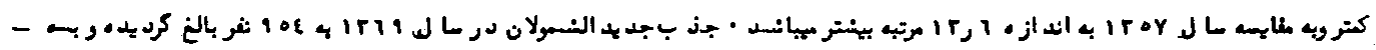

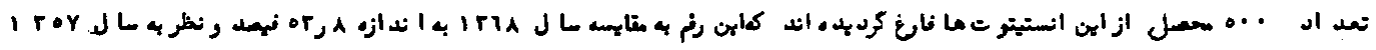

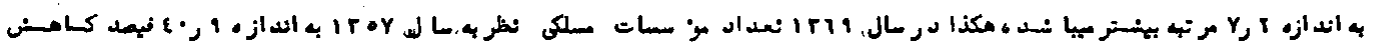
بافتسم است

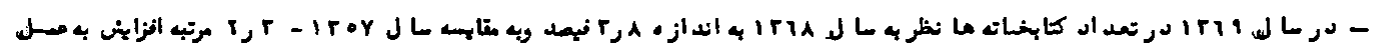
امسده أست

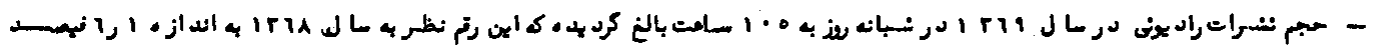

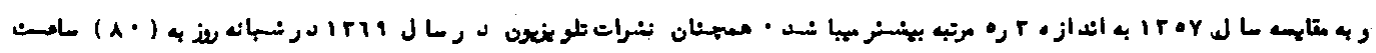

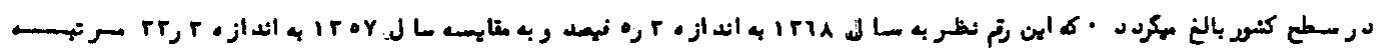
افزائن بافنهم است

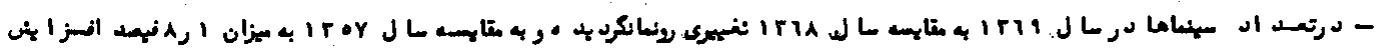

$$
\text { ب. }
$$

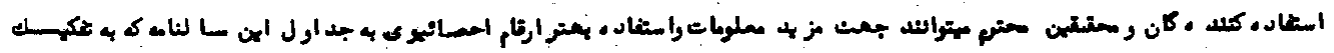

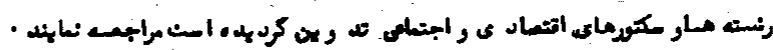




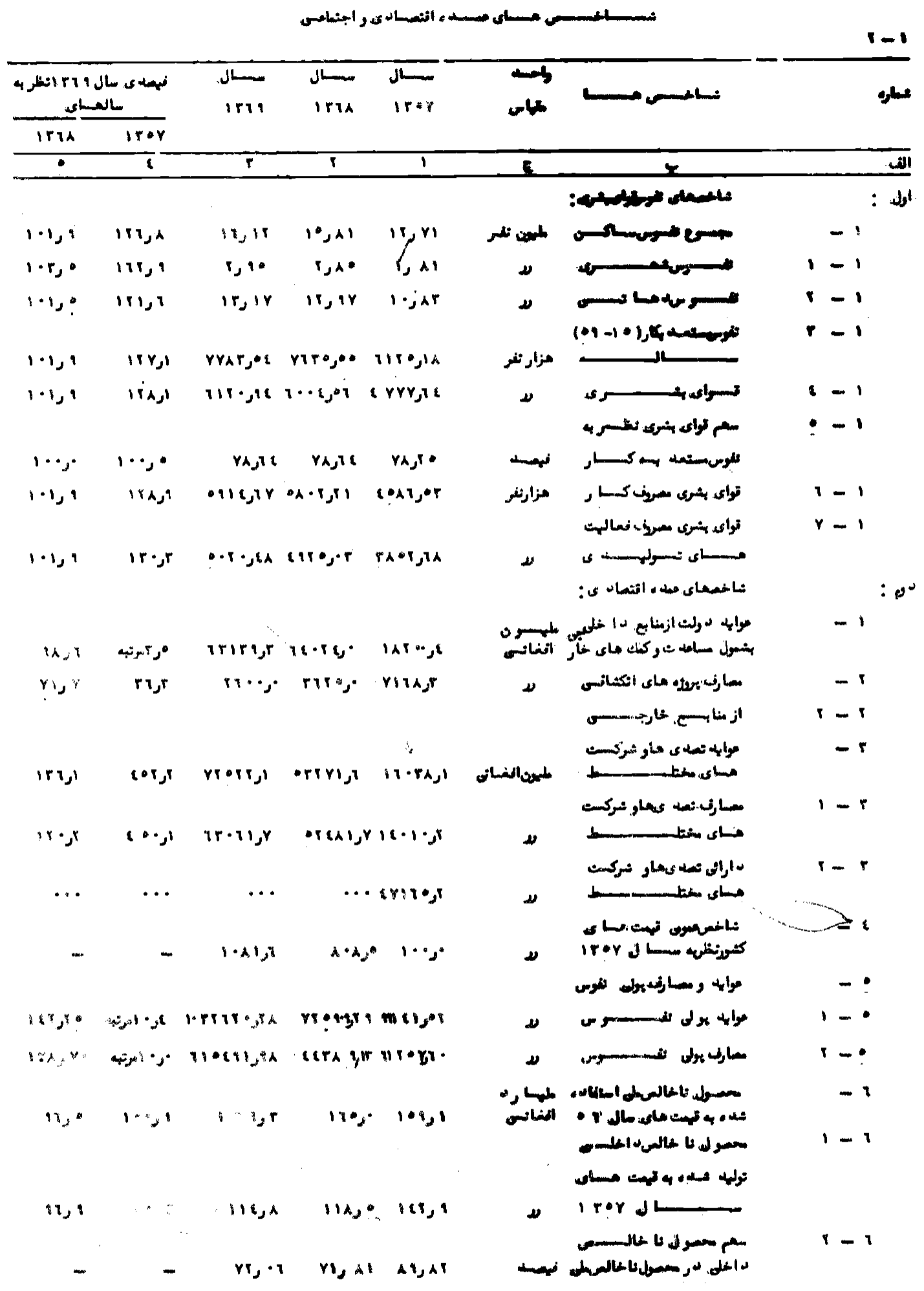




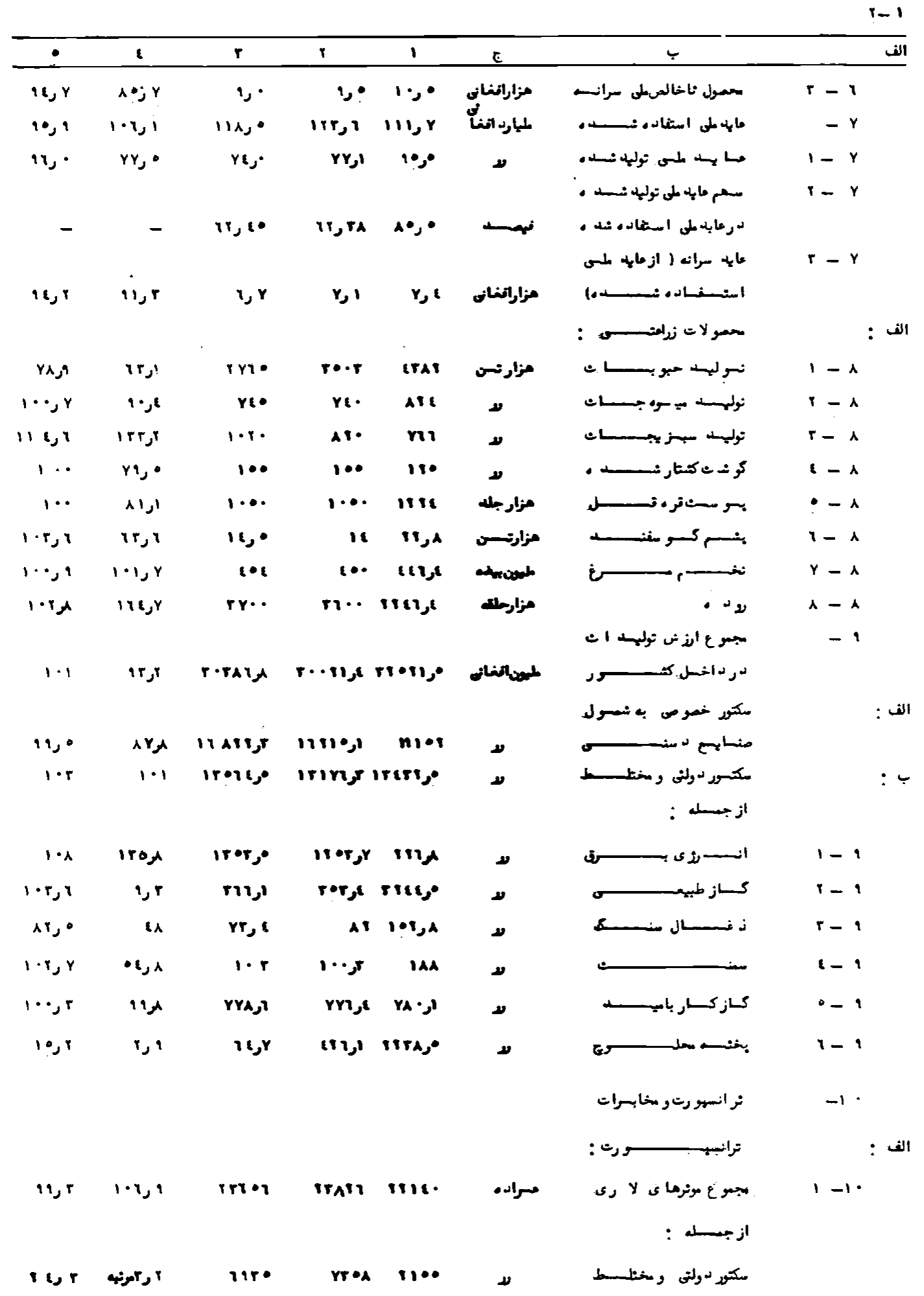




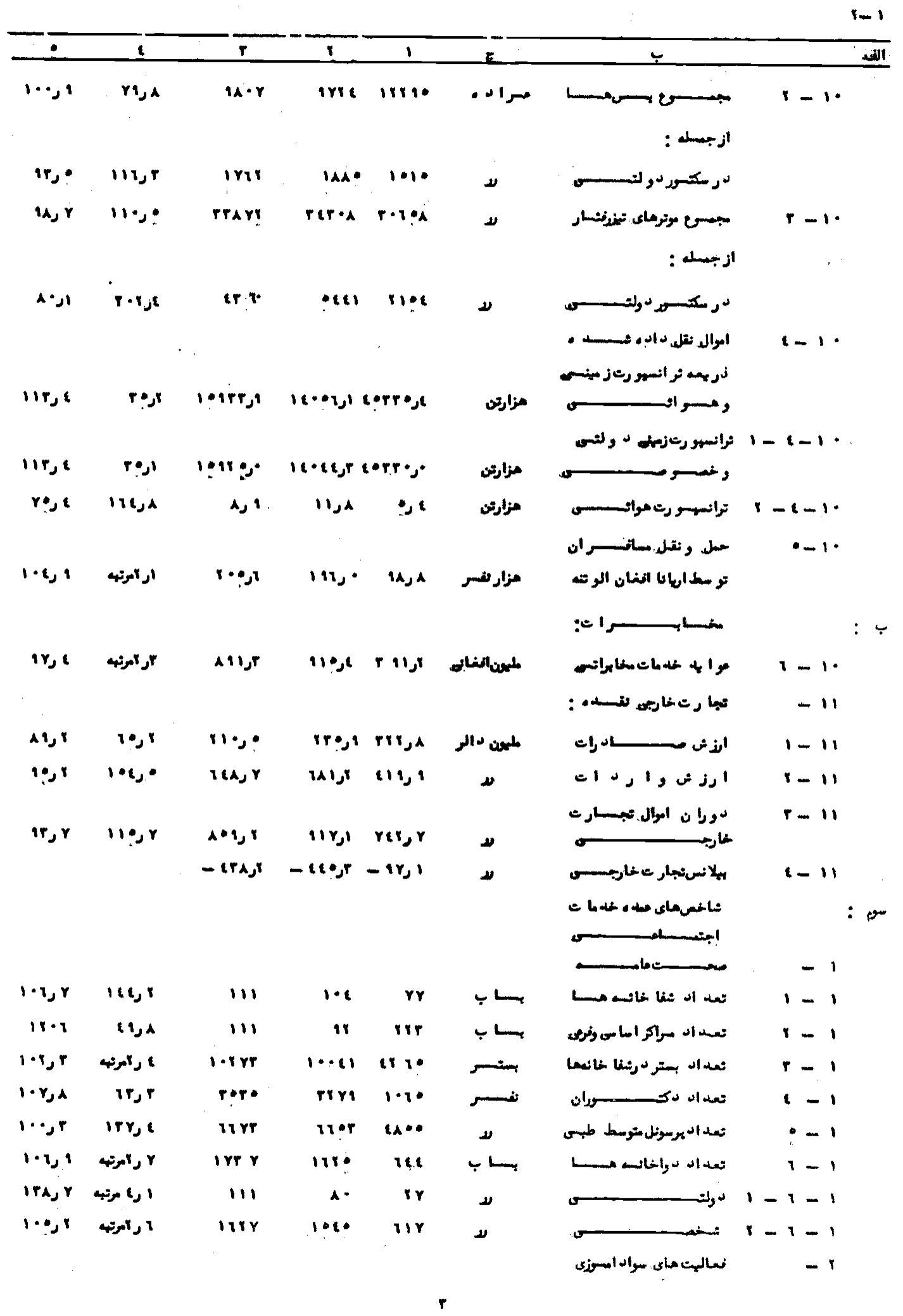




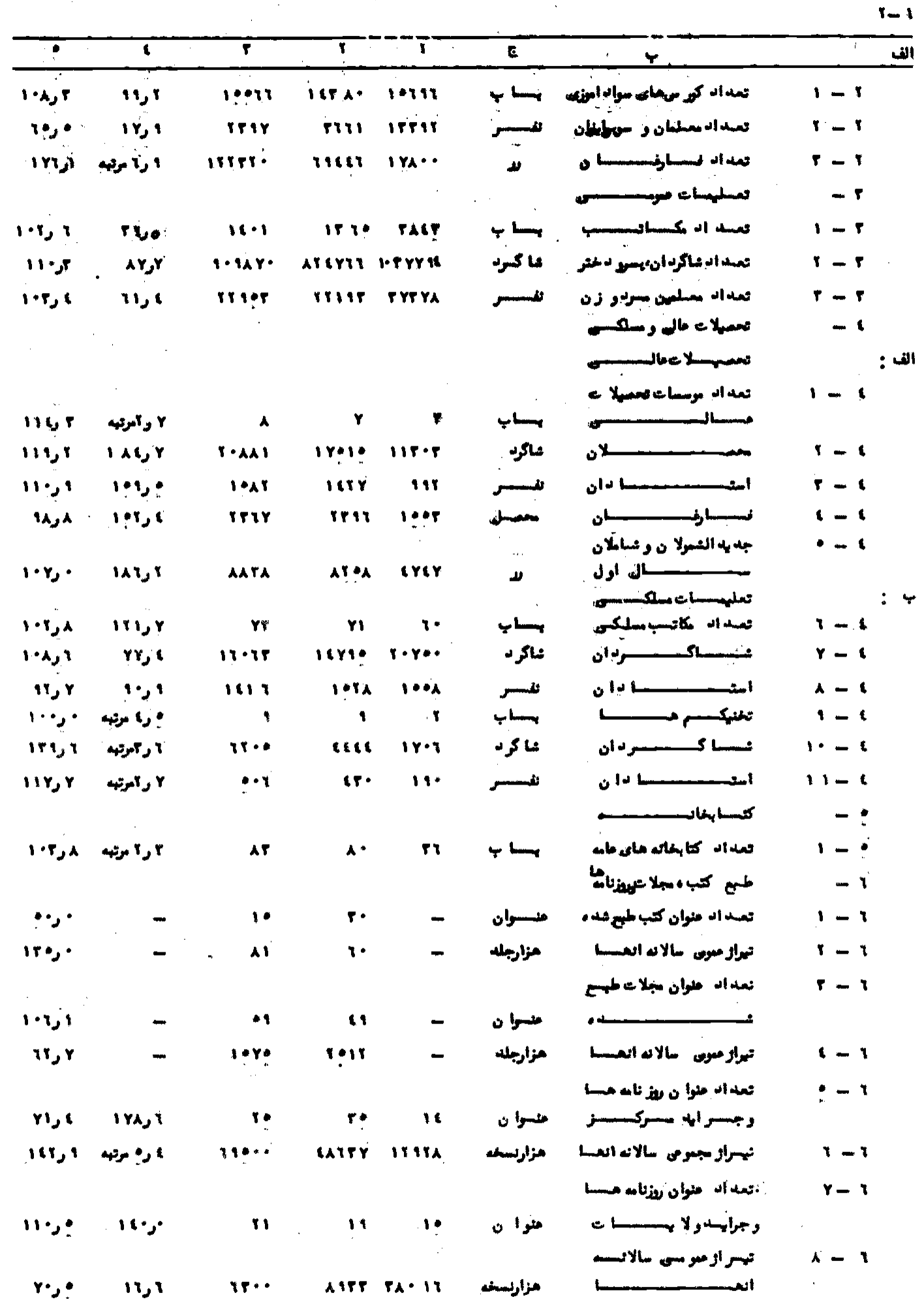




$$
\begin{aligned}
& \text { بثشיתי } \\
& \text { معلوا ت }
\end{aligned}
$$




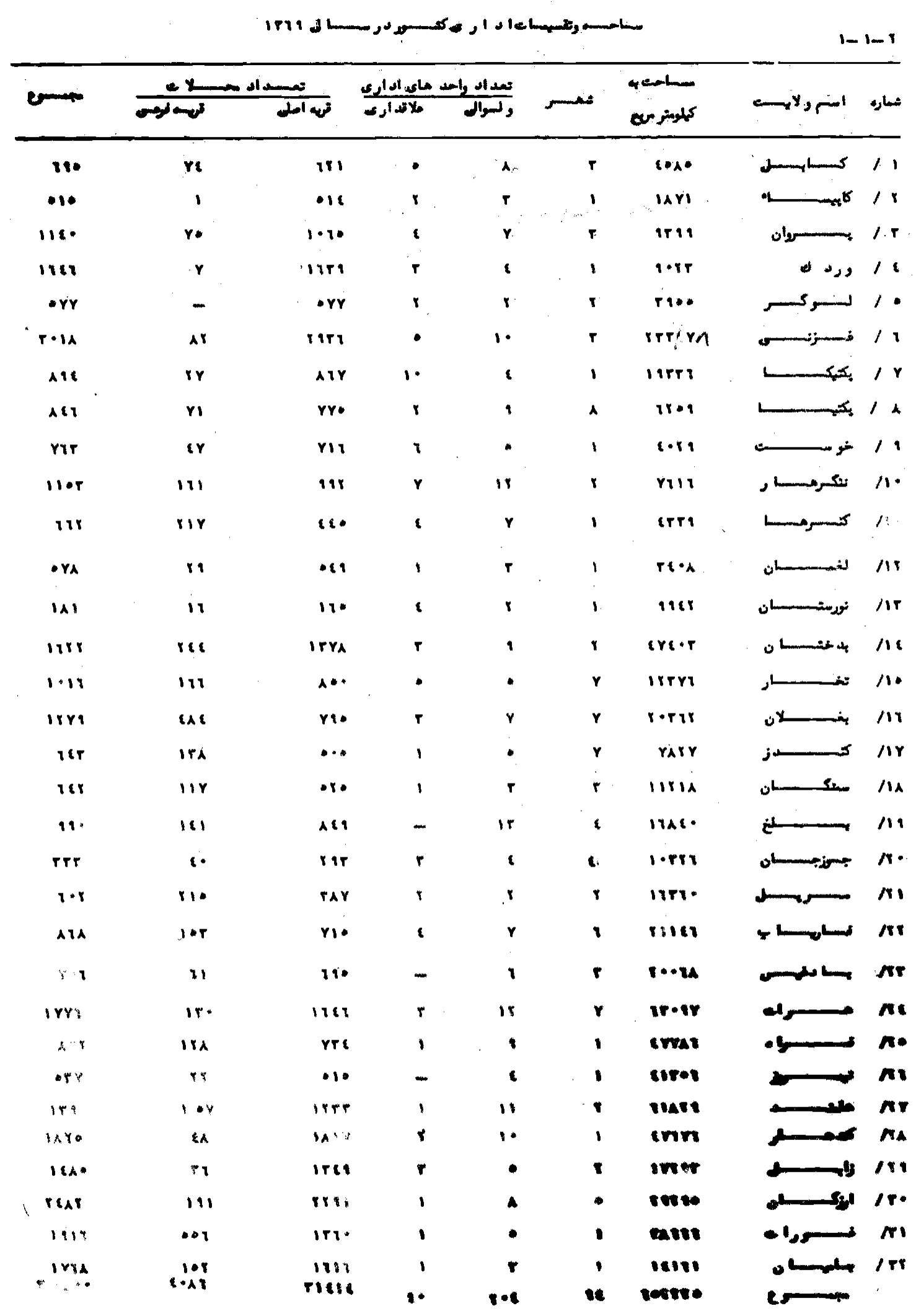




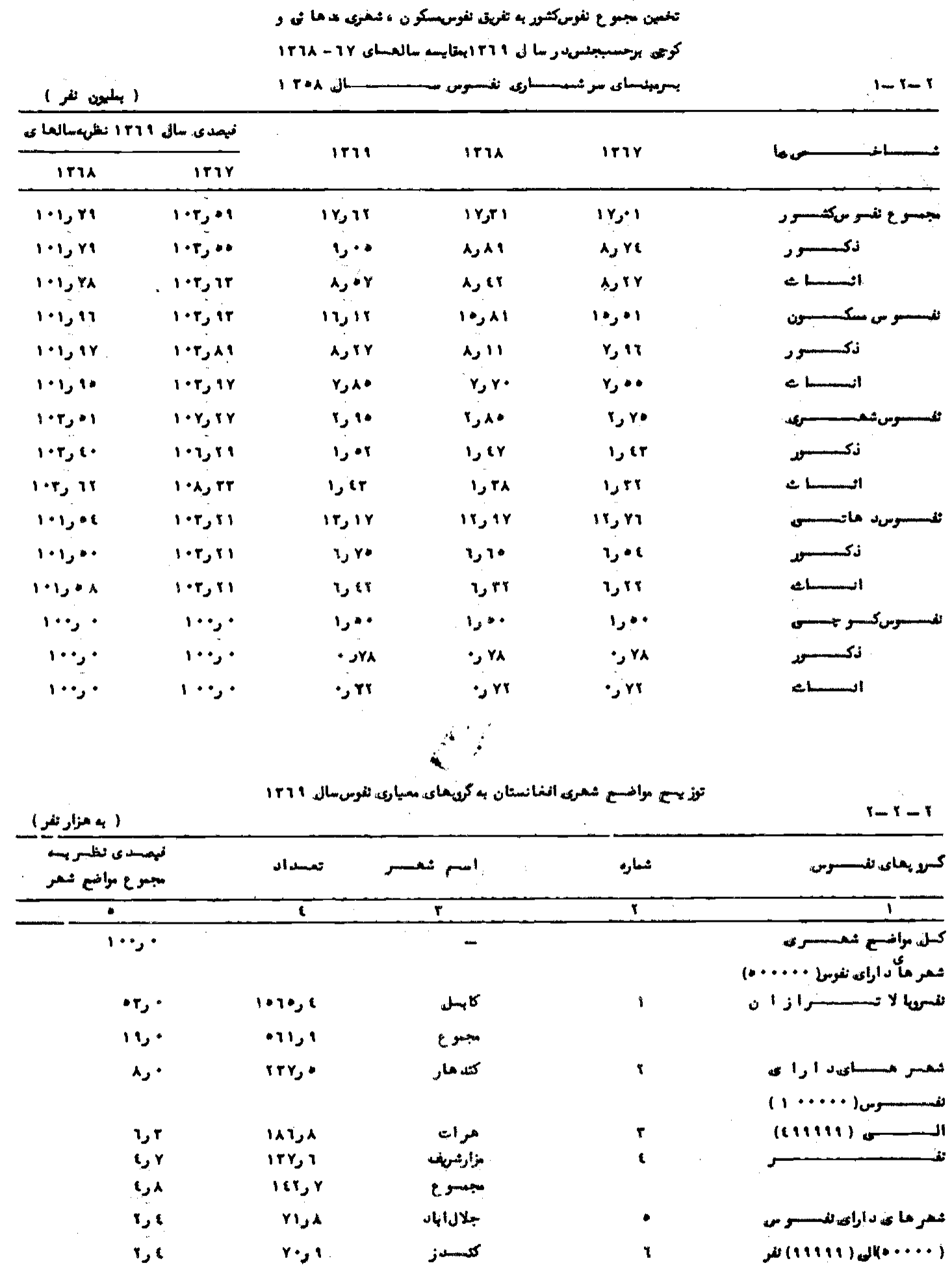




\begin{tabular}{|c|c|c|c|c|}
\hline$\bullet$ & 1 & $r$ & 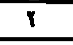 & 1 \\
\hline 1,9 & $r 1, r$ & ل & & 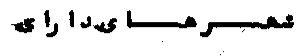 \\
\hline ז נו & \&A & 0 & $\mathbf{Y}$ & 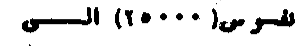 \\
\hline T & 87 & مغلسس. & $\wedge$ & (2११ــ19) \\
\hline $1, r$ & $r A, 1$ & كلفمصة & 1 & \\
\hline $1, r$ & $r y, r$ & غسـزنه & $1 \cdot$ & \\
\hline $1, r$ & $r \varepsilon, 8$ & خلسم & 11 & \\
\hline 1,1 & $r \boldsymbol{~} \boldsymbol{A}$ & حان & ir & \\
\hline נ & $r r_{j}$ & جار كار & ir & \\
\hline , & • נדו & ل ل لنكركسا. & 18 & \\
\hline$r_{j} \cdot$ & rur & " مجستع & & شعسر ما ك د 1 را ى \\
\hline •s & $r \varepsilon$ & ت تالتسان & $1 \cdot$ & تغسو س ( + ( ) السى \\
\hline A & $r r_{j}:$ & 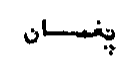 & 17 & ( \\
\hline • A & $r r$ & 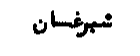 & ir & \\
\hline •رA & $r r^{*}$ & نسمـراء & 11 & \\
\hline ا & 19,8 & مسرل & 19 & \\
\hline ا & ותו & اند اندوى & $r \cdot$ & \\
\hline • & $1 \bullet$, & مضرت امام & 11 & \\
\hline • • & $1 \bullet, x$ & فسو ريان ن & ir & \\
\hline •• & 18,1 & تلعه زا J & ir & \\
\hline \& & $|r|$ & باه اب & r & \\
\hline ع & $11, x$ & كرد يحز & $r \cdot$ & \\
\hline$\cdot 2$ & 11,1 & فيضاباد & it & \\
\hline ن & $1 \cdot 1$ & اتبســـ. & ir & \\
\hline$r$ & 10,9 & مجسع & & ثعسير مساى د ا را' ى \\
\hline$\cdot r$ & נים & سنكبارك & $M$ & نغسوس • • • 1 السـى \\
\hline •r & • • & باسيا ن & 19 & (9११ ن (9) \\
\hline$\varphi r$ & $A, A$ & i & $r \cdot$ & \\
\hline • & A 1 & رستــاة & $r$ & \\
\hline$\cdot r$ & $A_{J} \cdot$ & ندلســ & rr & \\
\hline ر r & $r_{\boldsymbol{\jmath}} \cdot$ & دولمتابهاد & $r r$ & \\
\hline r & $r_{\jmath}:$ & تسلي & rq & . \\
\hline
\end{tabular}




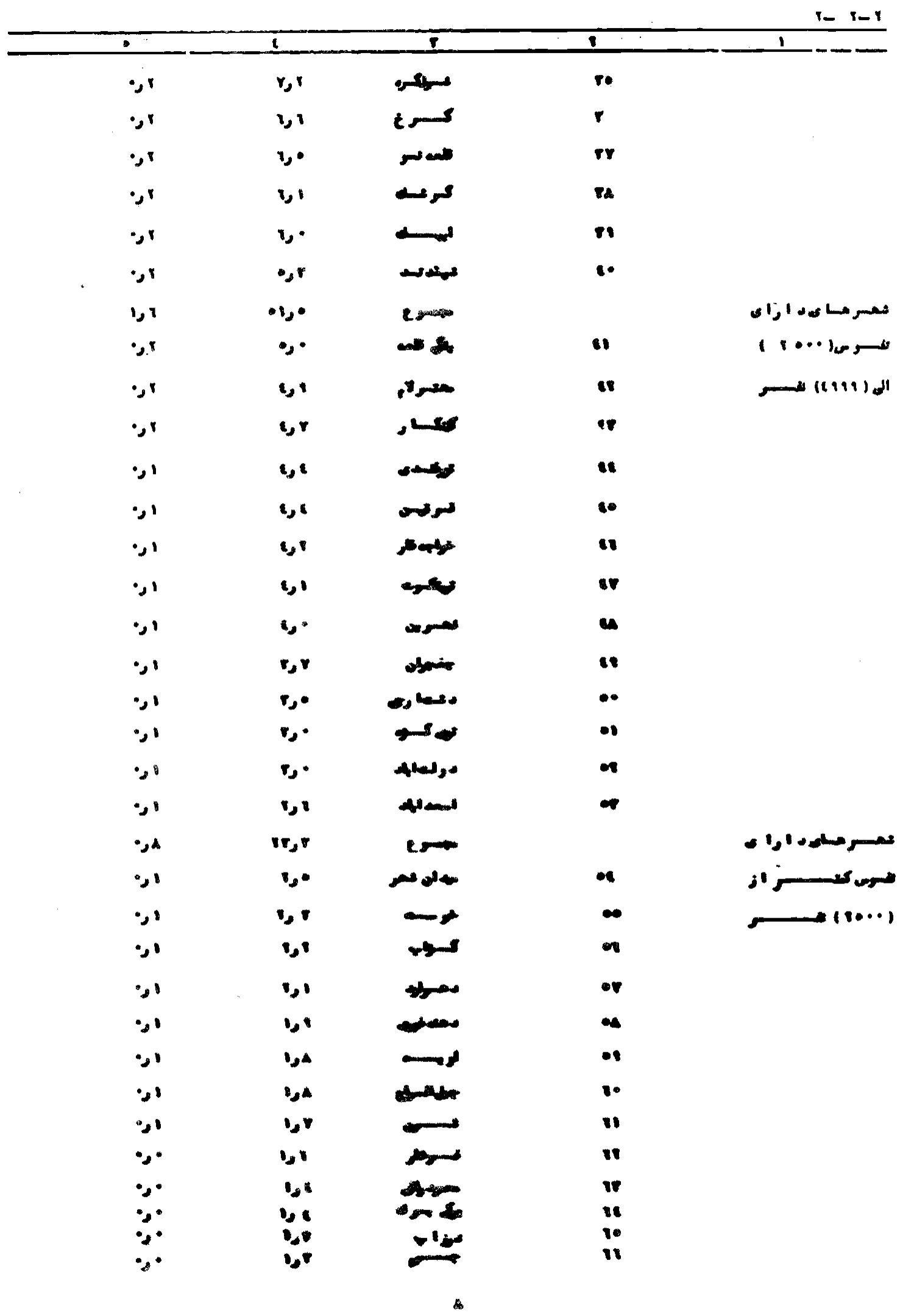




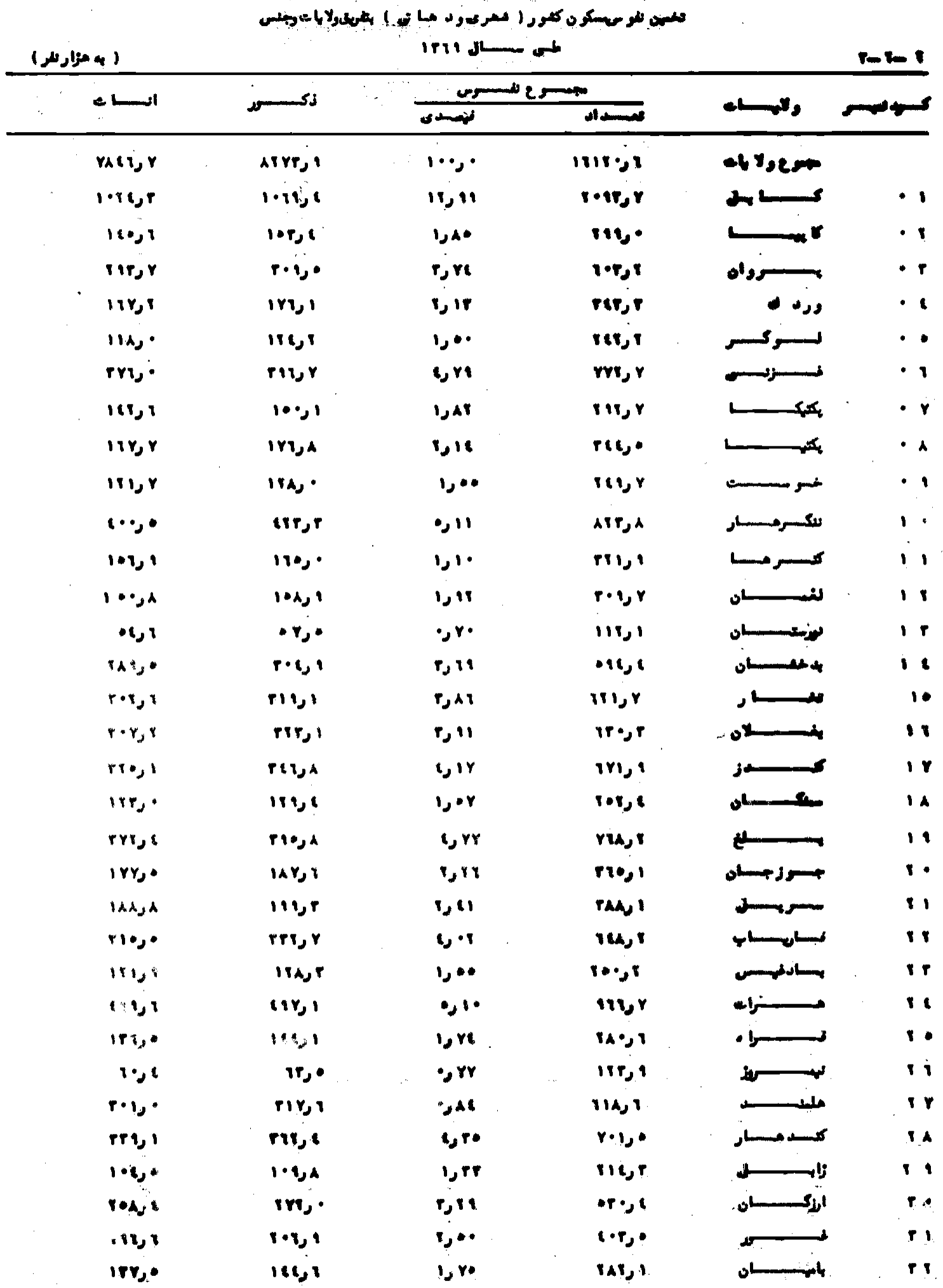




\begin{tabular}{|c|c|c|c|c|c|}
\hline \multirow{3}{*}{ 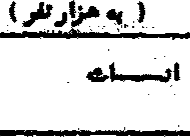 } & \multirow{3}{*}{ נكسـسرو } & & & & \multirow{3}{*}{ كسردفهر } \\
\hline & & \multicolumn{2}{|c|}{ d } & \multirow{2}{*}{$=4$, } & \\
\hline & & نهمت هي & STlis & & \\
\hline lerris & $\mid 0+1,1$ & $1 \cdots j \cdot$ & $x+1,5$ & m & \\
\hline rris. & $1+4,1$ & 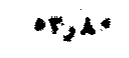 & 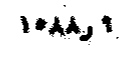 & كـــا بهد & $\cdot 1$ \\
\hline i & is & s"* & $4 t$ & كL بيستس & - r \\
\hline $\mid 81$ & $\mid 0,1$ & 20 & $14 \%$ & Q & $\cdot r$ \\
\hline 1,1 & is & $\cdot 9 \cdot 4$ & $x_{j}$ & ورد & - \\
\hline$r_{j}$ * & $r$ & inti & 1,1 & لمسروكسر & • \\
\hline$i r, r$ & 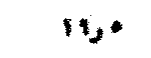 & ijor & $r x_{j}$, & غستســزنستسه & $\cdot 1$ \\
\hline $2 k$ & it & נ. & by & بكهـســـــ & - $y$ \\
\hline *j $Y$ & $s^{*}$ & ot & $14, y$ & 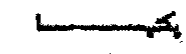 & $\cdot A$ \\
\hline 11 & 3,1 & $\cdot 2 \cdot x$ & s, & سسر سـسـ & $\cdot 1$ \\
\hline rest & $r i, r$ & r,or & 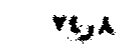 & لكــر هبـــر & 1 \\
\hline $1, r$ & $1, r$ & 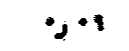 & 1,1 & كـــــــــ & 11 \\
\hline$r, r$ & I, & 314 & 8,1 & 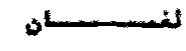 & ix \\
\hline- & - & - & - & لسرستستسـان & ir \\
\hline \&1 & $8=$ & in & 15,6 & 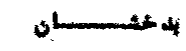 & 18 \\
\hline$r y, y$ & 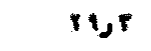 & $1 j 11$ & "x. & بـ & 10 \\
\hline (t) 1 & $(y, z)$ & r & 15. & ג' & 11 \\
\hline$x_{j} \cdot$ & $x, t$ & isti & iry, & كتمستسـسنس ز & Iy \\
\hline$x, 1$ & ו & jr* & $i$. & س & 11 \\
\hline 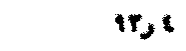 & $\left|+y_{j}\right|$ & yit & 100, & المستســن & 19 \\
\hline 141 & 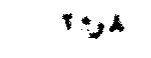 & 1,8 & ru & بسر بـسان & $r *$ \\
\hline $1 r_{1} \gamma$ & 10. & קי ני & $\| \mu, \gamma$ & 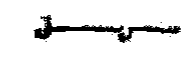 & 1 \\
\hline$r i, \lambda$ & Pest & ter & 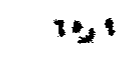 & نسا & $r$ \\
\hline$r, r$ & $r$ & ry & s. & تسـ د نهس & r \\
\hline $1 \cdots, 1$ & 118,1 & Y, 10 & ros & $=1$, & 14 \\
\hline 11, & IIי. & •, $\gamma$ & $r_{2}$ & سرب & $v$ \\
\hline 1,1 & is & ry & $\Delta \cdot$ & لهستســـ ن & 1 \\
\hline 10. & $|r|$ & 1) & $r x_{j} t$ & 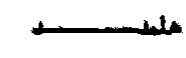 & $y$ \\
\hline IIrs & 186, & $A_{j} \cdot t$ & $I+Y_{3}$ & كسـدمسلسـار & $\boldsymbol{1}$ \\
\hline , I & $P$ & siv & $r, r$ & ; إهـــ & 14 \\
\hline s. & s, & ix & Ast & ن & $r$ \\
\hline $1, A$ & 1 & 218 & $r, r$ & :بسس & $M$ \\
\hline st & is & $3 r$ & $y^{\circ}$ & بابهـ & 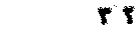 \\
\hline
\end{tabular}




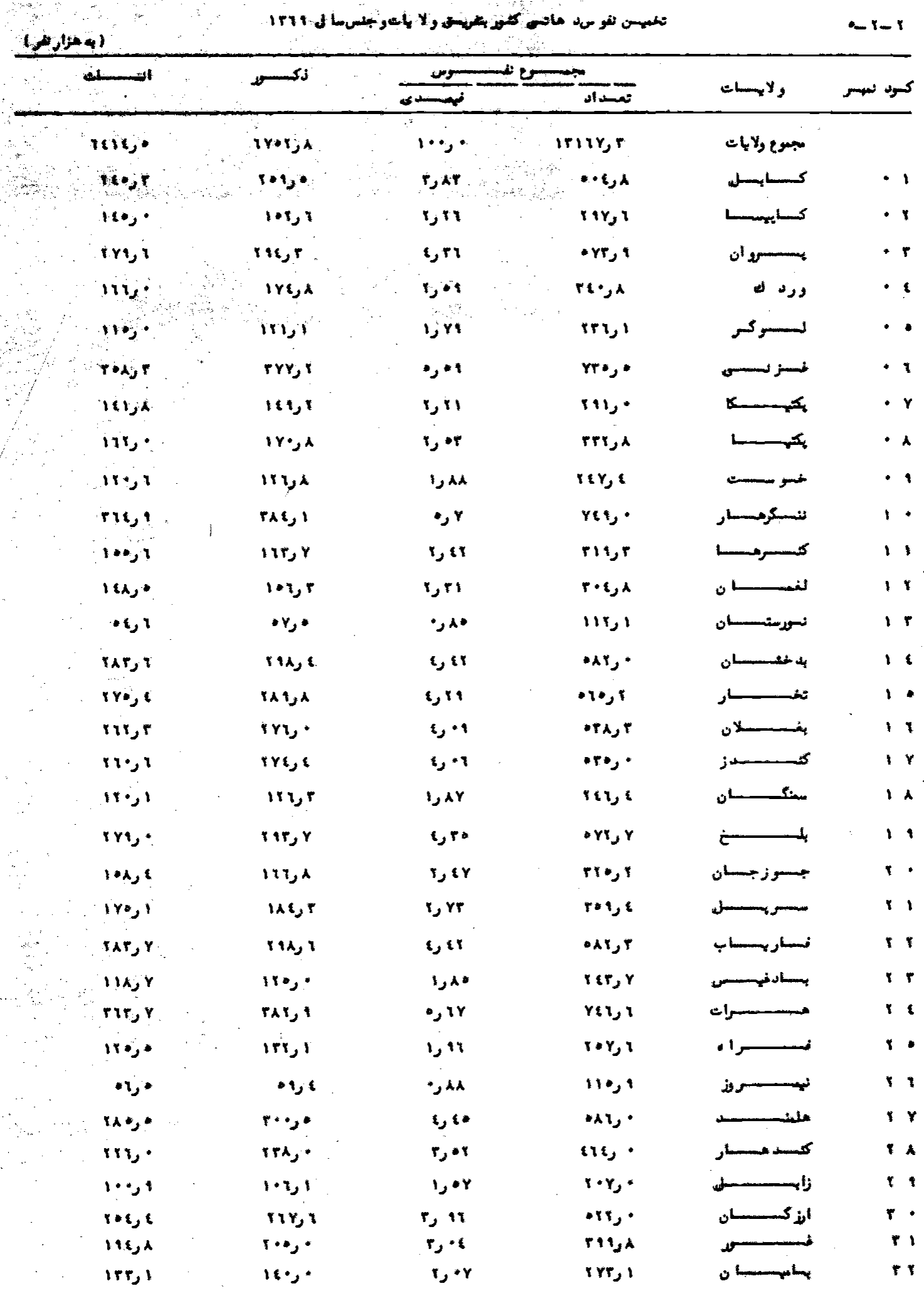




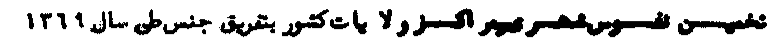

( ب مزارثر )

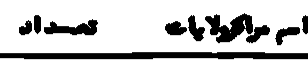

irie, irris

rir, A

, 1

ir, $r$

$1, \gamma$

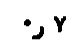

$1 Y$,

, $\wedge$

$\bullet r$

1,1

it,

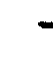

I,

-

or

s.

us

rt.

10

res

11,

28

sto

5

At)

11.

5

18,

IIT)

I,

,

en

be
YiY 1

ر

it, $P$

i, $r$

$\bullet Y$

11,

, 1

b.

1,8

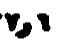

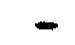

8

-

os

8

100

rys?

50

n.

18,1

$1 \cdot 9$

Q6

to

16?

18.

60

irso

184

$5 \%$

1.

b)

48

$$
\text { sans }
$$

i.e. Teit,

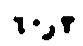

, 1

i,

, 1

is

, 1

is

, 1

ot

s.

-

• 8

-

, 1

or

30

s,

08

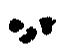

02

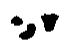

b.

$\rightarrow$

Ts

ק,

ק,

b.

o1

0

, 1

01

is iere.

tot.

sro

50

be

Irs

DV

10,1

st

nos

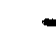

b)

-

11,

bo

ra.

ros

5

15r?

ifot

18,

2ton

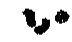

inya

85 .

as.

120

IrY,

r,

is

$r, Y$

i.

- $\quad$ ت

dist

המקt

ats

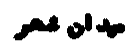

cos

كس3 نصم

s

is

אחקוy

thrts

STS

rin

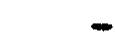

atury

sones

sin

كستر

ingens

trents

20.

the

مוn

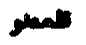

هـر

كسرا

زريه

لنصكره

كم ما ر

تمس

تر يكرث

بهنبران

بإن
- 1

كساتקسח

י

נג

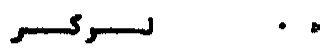

غستسكر كستس

r

L

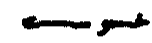

2

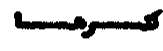

لהa

1

or

obcent 11

1 , 1

oris 12

I 1

or 1

11

r

is

نسابر

بr

$\stackrel{+}{\rightarrow}$

i.

نيمس

ملصنـ

كهسبد مـسـار

I

ا إنكســا

r 1

it 


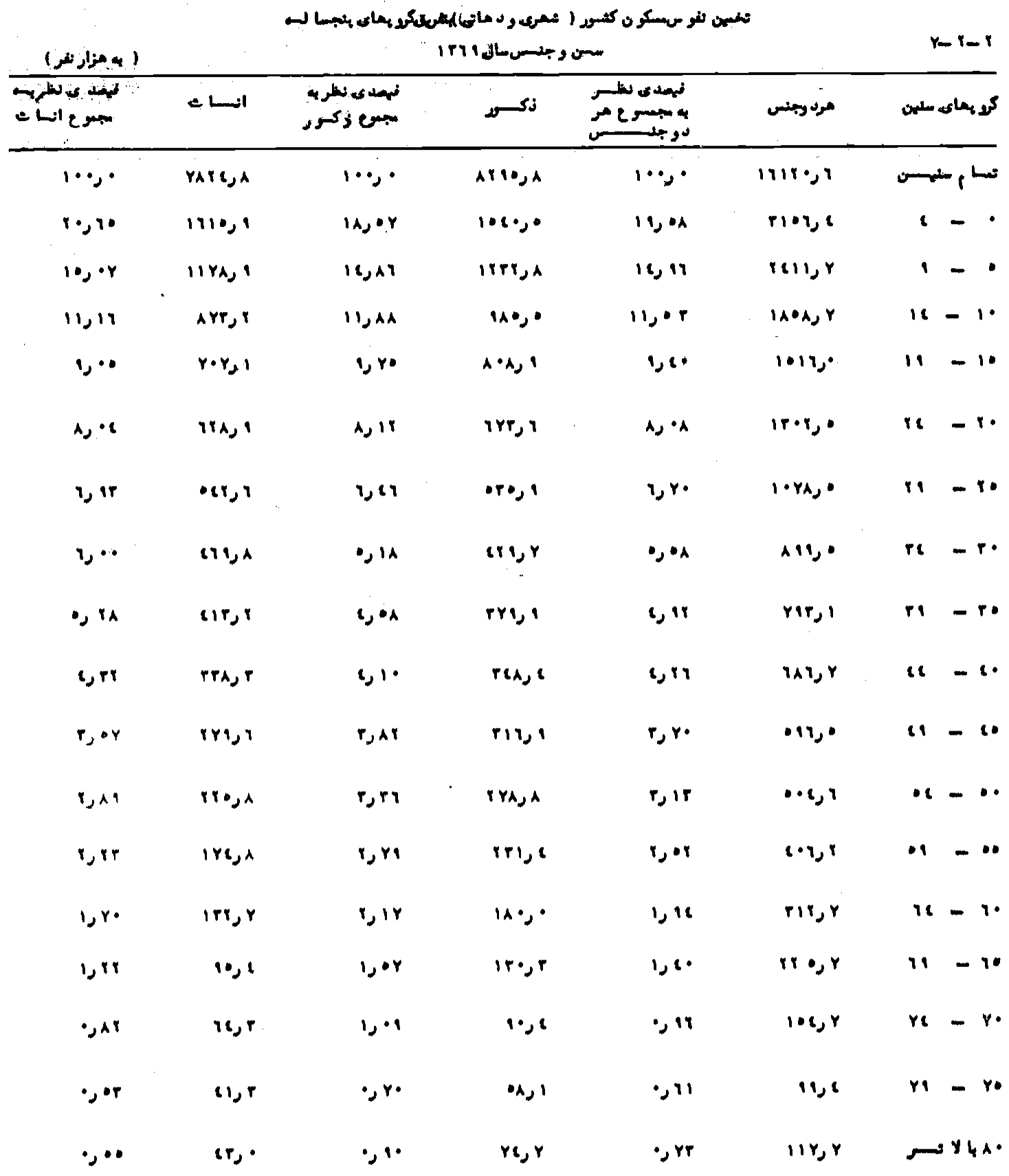




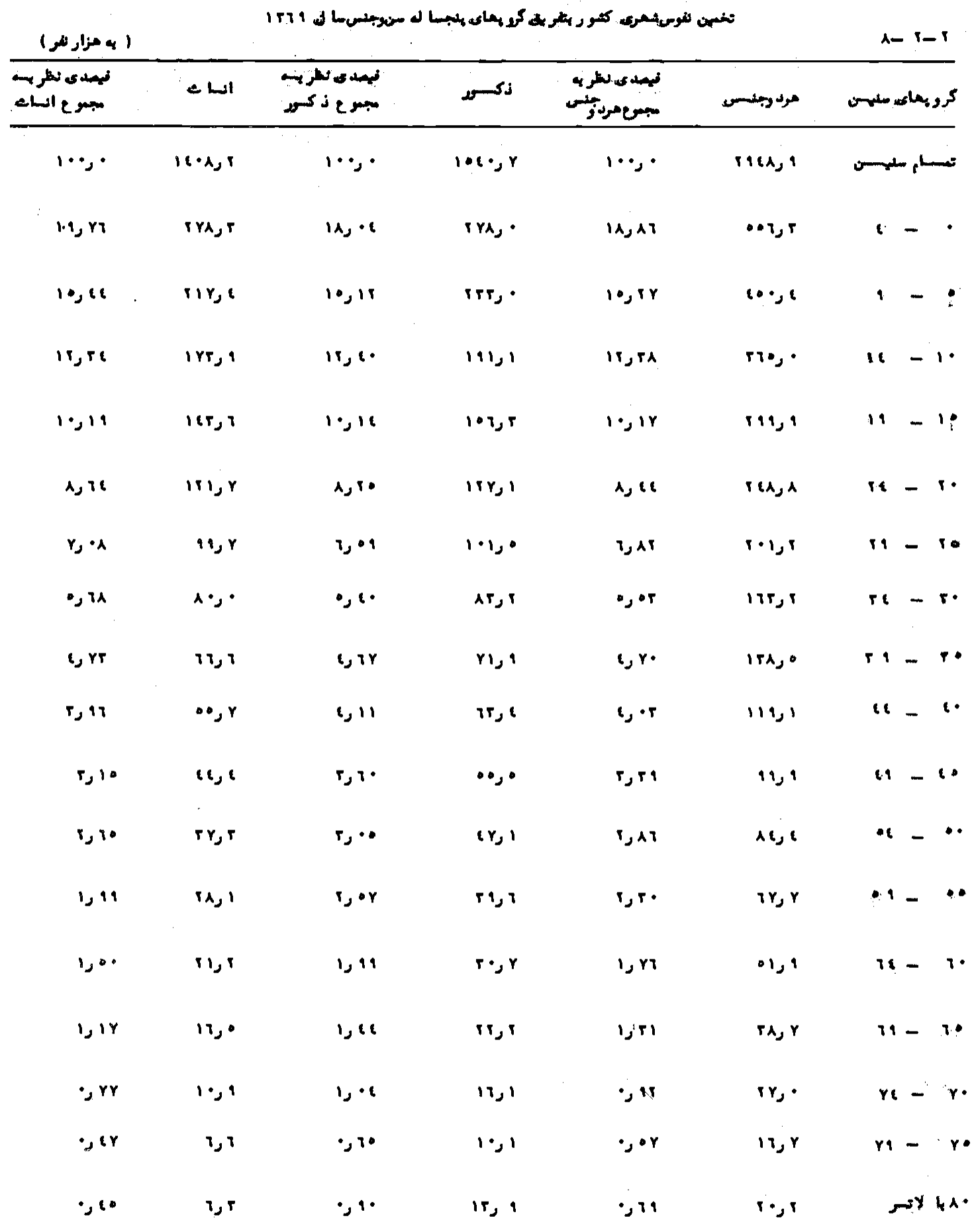




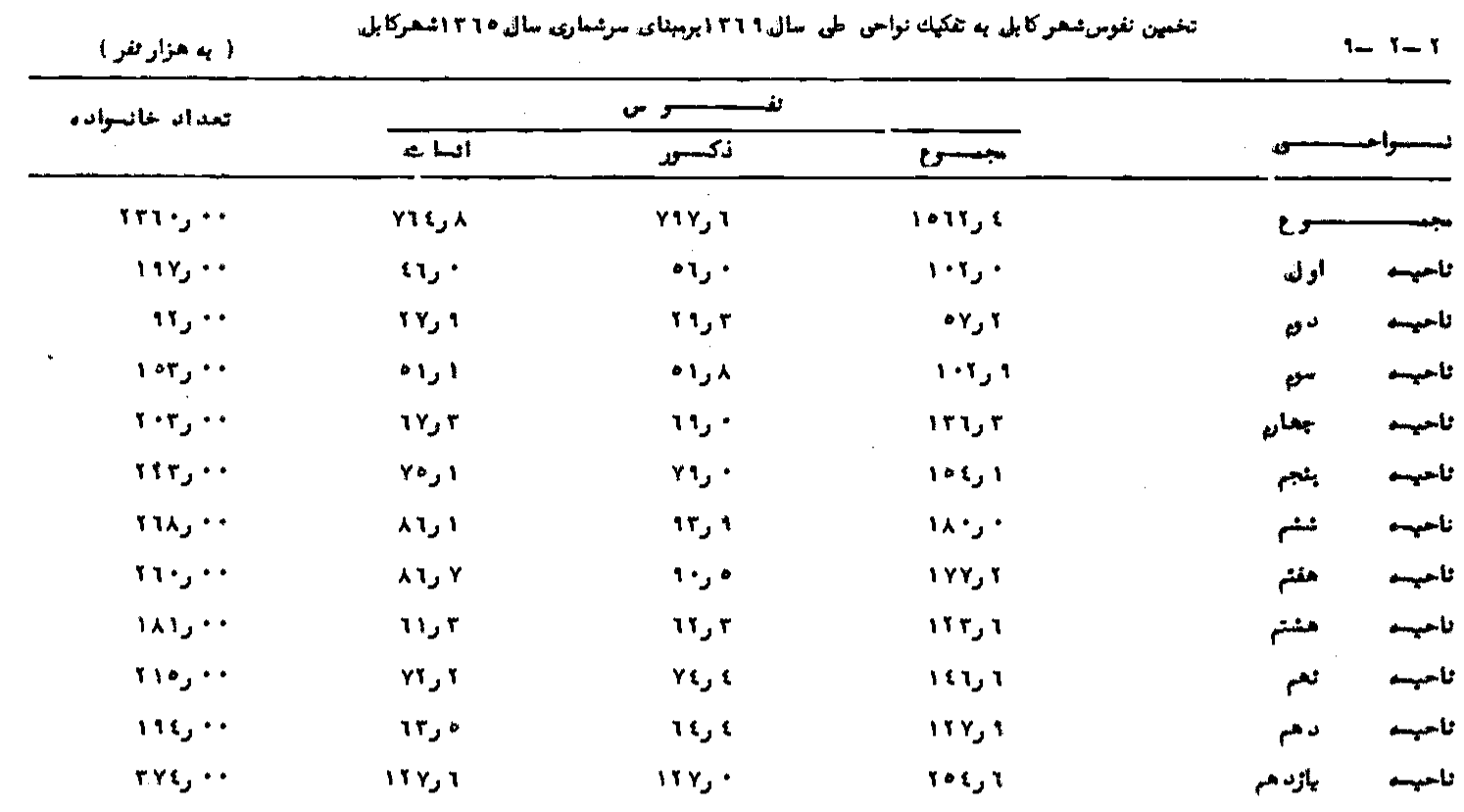

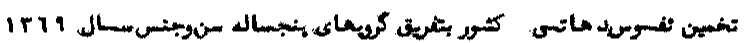

\begin{tabular}{|c|c|c|c|c|c|c|c|}
\hline 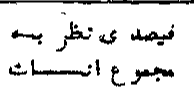 & انسيسات & فيصد ى نظر بسه ذكسر & نكسهور & فيسمدى نظر بجسي & مرد وجلسي & كه مئيسن & كمو بـسطاs \\
\hline $1 \cdots$, & 1011 & $1 \cdots$, & $7 x=0,1$ & $1 \cdots$ & Iriri, & منه- & تعســــار \\
\hline$r \cdot, h=$ & Irry, & 11,1 & iriso & $19, r$ & $r, \cdots, 1$ & $\varepsilon$ & - \\
\hline 18,91 & 971,0 & $18,1^{\circ}$ & 199,1 & 18,1 & $1911, r$ & 9 & -0 \\
\hline $1,1 \times 9$ & $r q 9, r$ & $11, v_{1}$ & Pqs & $11, r$ & IqqT, $Y$ & 18 & -10 \\
\hline$\Lambda, \lambda$. & $07 \&$, & Iו & ror, & $9, r$ & $|r| r, \mid$ & 19 & -10 \\
\hline$r, q$. & $0 \cdot \gamma, \gamma$ & $A_{3} \cdot 9$ & $0 \& 1,0$ & $\wedge, \cdot$ & $1 \circ r, r$ & rq & $-r \cdot$ \\
\hline 1. & $\varepsilon \varepsilon 8, q$ & 1,8 & $\varepsilon r \varepsilon, r$ & וני & $A Y Y, r$ & 89 & $-r_{0}$ \\
\hline צ• ני & $r \wedge 9, \lambda$ & o, ir & ris, & 0,1 & $r r i, r$ & re & $-r$ \\
\hline 0,8 & $r\{1, r$ & $\varepsilon, \circ 1$ & $r \cdot \wedge, \cdot$ & 0, & 108,1 & $r q$ & $-r_{0}$ \\
\hline$\varepsilon, 8$ & rAr, & $\varepsilon, r$ & $x \wedge, 1$ & $\varepsilon r$ & $\bullet r, y$ & $8 \varepsilon$ & -80 \\
\hline וינת & rras & $r, \wedge r$ & $r i, \varepsilon$ & $r, \lambda$ & \&q1อ & $\& 9$ & -80 \\
\hline$r, q \varepsilon$ & $\mid 1 \lambda \mu^{\circ}$ & $r, \&$ & $r r i, r$ & $r, r$ & $q r \cdot, r$ & .8 & $-\cdots$ \\
\hline$r, r$ & $1 \leqslant 1, y$ & 8,18 & $\| 11,1$ & $r, r$ & rra, & $: 1$ & $-\infty$ \\
\hline $1, Y_{2}$ & 11,0 & $r, r$ & $1 \varepsilon q, r$ & $r^{*}$ & ג & 18 & -1. \\
\hline i,rr & $r A, q$ & $1,1$. & $1 \cdot 1,1$ & 1,8 & $\| \wedge Y_{3} \cdot$ & 19 & \\
\hline , st & or, & 1,9 & $Y \&, r$ & 1, & $\mid r, y, 1$ & $Y \varepsilon$ & $-r \cdot$ \\
\hline e or & $r r, r$ & 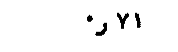 & $\{\wedge$, & ית & $A 1, Y$ & Yq & $-r i$ \\
\hline • J Y & $r u r$ & $\rho^{9}$ & $\lambda \cdot \lambda \lambda$ & $\cdot r$ & $9 r, 0$ & تسر & У 4 人1 \\
\hline
\end{tabular}




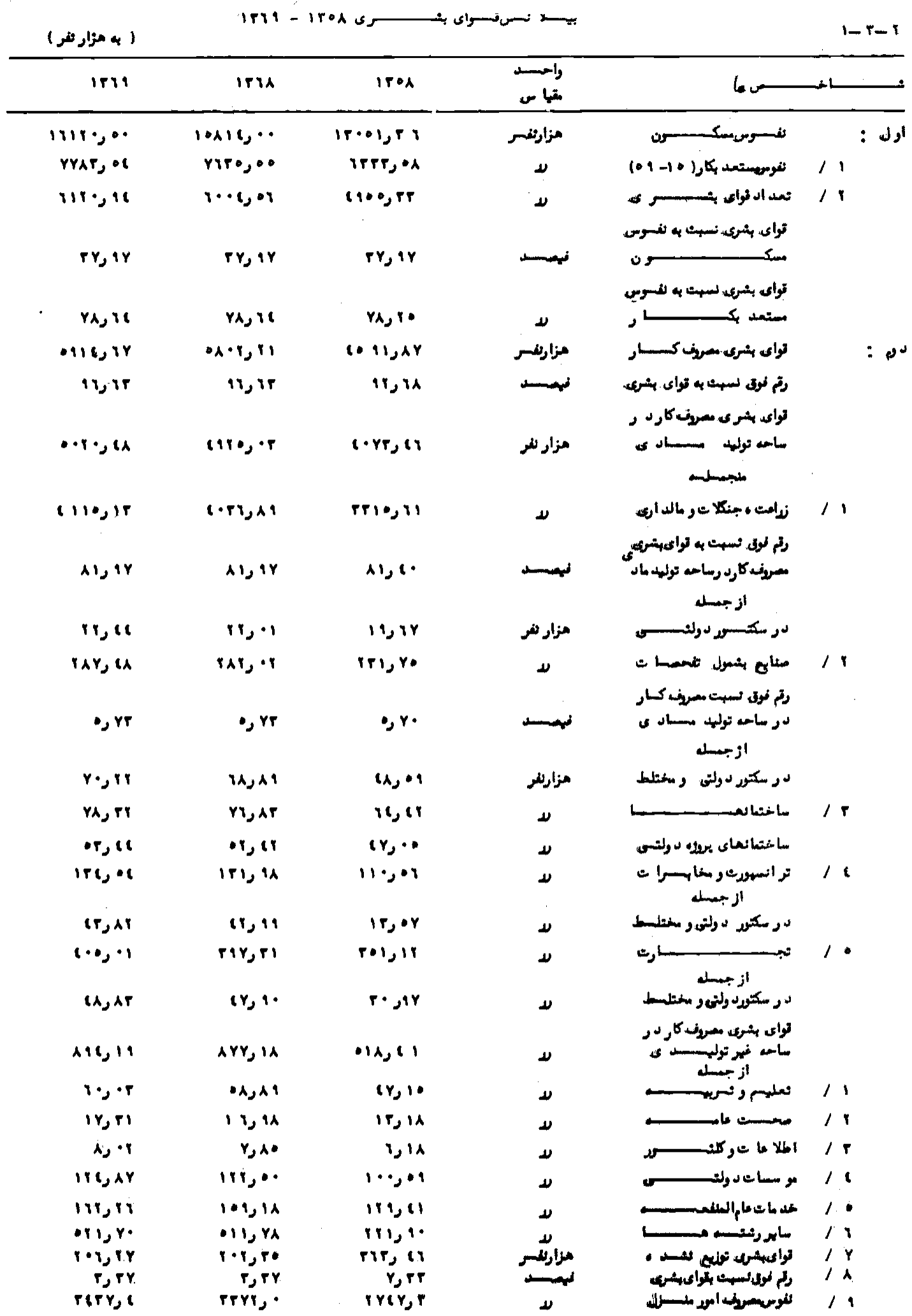




\begin{tabular}{|c|c|c|c|c|c|c|c|c|}
\hline \multicolumn{3}{|c|}{ بريونل خدماني بنسولكاركـرا ن } & \multicolumn{3}{|c|}{ كسـارمنســــسـد ان } & \multicolumn{2}{|c|}{ سمبمو ع كاركتسـان } & \multirow{2}{*}{, } \\
\hline اثاث & ذكسور & مجنسوت & انساث & ذكسـد & (ب) & انستـاث & jك- & \\
\hline ITRT & $18 \cdot(1$ & borre & rirea & -rtre & ATOYA & a) & |खtr) & سمس \\
\hline 8011 & terit & rull & $\cdot A \cdot r$ & 1110 & rTOY & $1<+1$ & 0 orr & 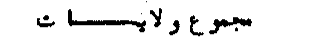 \\
\hline $1 \cdot 118$ & orrol & uert & $r \cdot c+1$ & rillo & - tori & $r \cdot{ }^{\prime}$ & AA11 & س \\
\hline I.rT & 1011 & $|r T|$ & r.1 & irgo & $10 \cdot 8$ & rir & rAst & , I \\
\hline 1 & iri. & irr & ir & $r \cdot r$ & 11 & 18 & rrr & r \\
\hline 1 & irr & ict & ir & $r \cdot 1$ & rik & rr & rre & 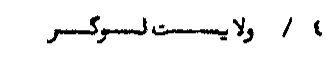 \\
\hline$r \cdot$ & rri & 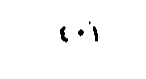 & $\therefore$ & rar & ira & Yi & $Y \bullet \lambda$ & 只 \\
\hline ir & \& Y & (1) & ro & rri & יווז & (1 & $\lambda \cdot 1$ & I , / \\
\hline ist & rit & rul & rea & rol & rire & ir. & $\operatorname{sil})^{\circ}$ & 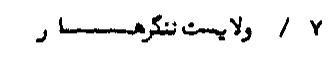 \\
\hline - 1 & $8 \cdot 8$ & 101 & ir & ווי & $r \cdot r$ & 11 & $1 \cdot 10$ & 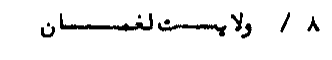 \\
\hline$I Y \varepsilon$ & $|Y|$ & 1180 & $\mathrm{ra} \cdot$ & $1 \cdot 11$ & Irr| & cos & $\gamma \cdot r \cdot$ & 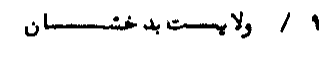 \\
\hline ro & lal & 0.1 & ir & (1) & - rr & ir & 10 & -11. \\
\hline YAᄉ & - YAA & $1 \cdot Y 1$ & $\mathfrak{1 \cdot 1}$ & 1811 & larr & in & $r Y \cdot T$ & $\longrightarrow$, 11 \\
\hline 11 & rrr & $r 91$ & $Y=$ & ren & irt & IrI & $10^{0}$ & r / ر الايست سنكســـــــن \\
\hline irl & 1००r & 111 & 111 & $11 r 1$ & $\operatorname{lri1}$ & $\operatorname{rrr}$ & ris & 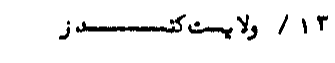 \\
\hline irt & I Yos & rrat & in & rrri & 0.18 & rrre & $1 \cdots y_{0}$ & \\
\hline rAT & $\ln \mid r$ & $.1 \cdots$ & rri & $\operatorname{lrg} r$ & $r \cdot \lambda t$ & $1 \cdot r r$ & 1118 & $=x^{\prime}, 10$ \\
\hline $1 \cdot 1$ & ror & Yos & 801 & $11 \lambda$ & $I T \circ Y$ & .1 . & 1001 & 1111 \\
\hline$r Y$ & 11 & $Y \cdot Y$ & re & ודו & 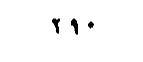 & .1 & 167 & ry \\
\hline 189 & $r r \cdot r$ & reoo & iry & irir & rrre & דו & $8 \cdot 11$ & 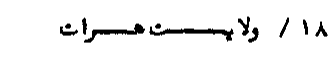 \\
\hline r & $e \cdot r$ & irs & 18 & $11^{\circ}$ & or & 111 & $\wedge \wedge Y$ & 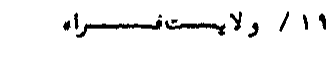 \\
\hline$r r$ & ril & rix & $\bullet \wedge$ & $r \cdots$ & rir & $1 *$ & יוי & 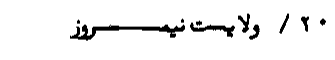 \\
\hline 1 or & $\operatorname{lra}$ & 10.1 & irs & Yir & 111 & pri & $r \cdot 11$ & 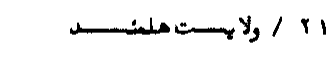 \\
\hline 11 & $|r \wedge|$ & $\log 4$ & $1 \cdots$ & rol & $1 \cdot 8$ & rri & rir. & 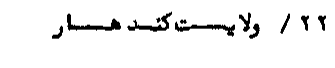 \\
\hline 10 & $r \cdot r$ & ris & ir & 111 & irs & $\boldsymbol{r}^{\prime}$ & ris & r / / \\
\hline 1 & 10 & 11 & $\mathfrak{q}$ & $1 \cdot r$ & $1 \cdot 1$ & - & $\operatorname{lir}$ & ع / ر الهستـن الذ كسـان \\
\hline$r$ & $\operatorname{rir}$ & ril & re & er & $\operatorname{lir}$ & ו & 17 & 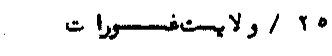 \\
\hline- & rr & rr & - & 10 & ८० & - & $r Y$ & r \\
\hline 11 & irr & $1 \cdots$ & $\because$ & 11. & 100 & ir & ret & r / \\
\hline- & rr & it & - & 18 & 18 & - & ry & ג / I / \\
\hline re & $r Y r$ & Y & 11 & 11 . & 111 & $11 \pi$ & $1 \cdot k r$ & 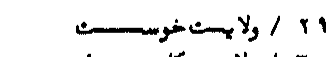 \\
\hline- & - & - & $\begin{array}{l}- \\
-\end{array}$ & - & - & - & $\overline{-}$ & 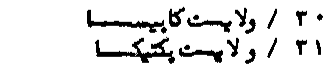 \\
\hline$\overline{-}$ & $\overline{-}$ & $\overline{-}$ & - & - & - & - & - & זr / , لابست كتسروا \\
\hline
\end{tabular}




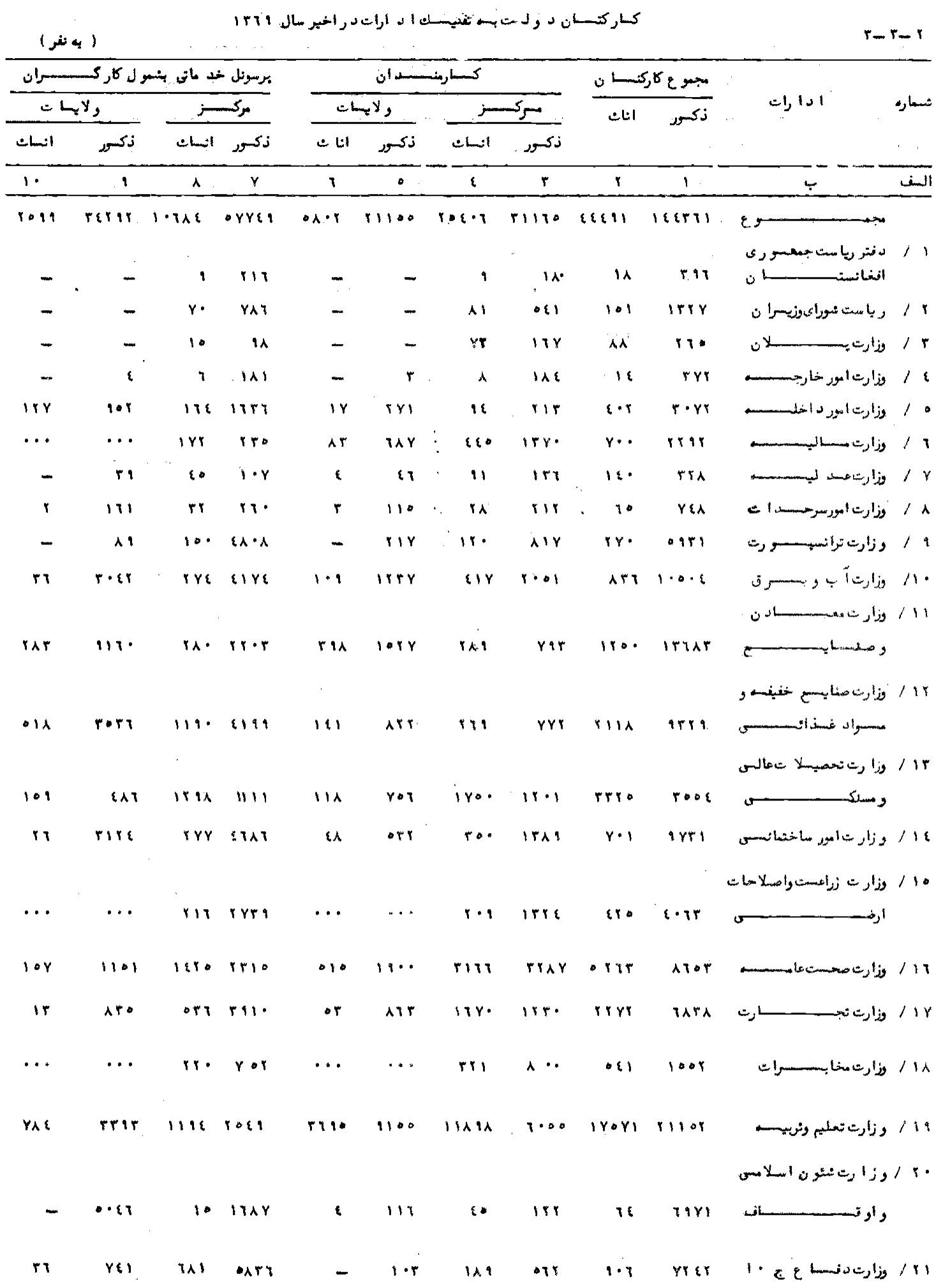




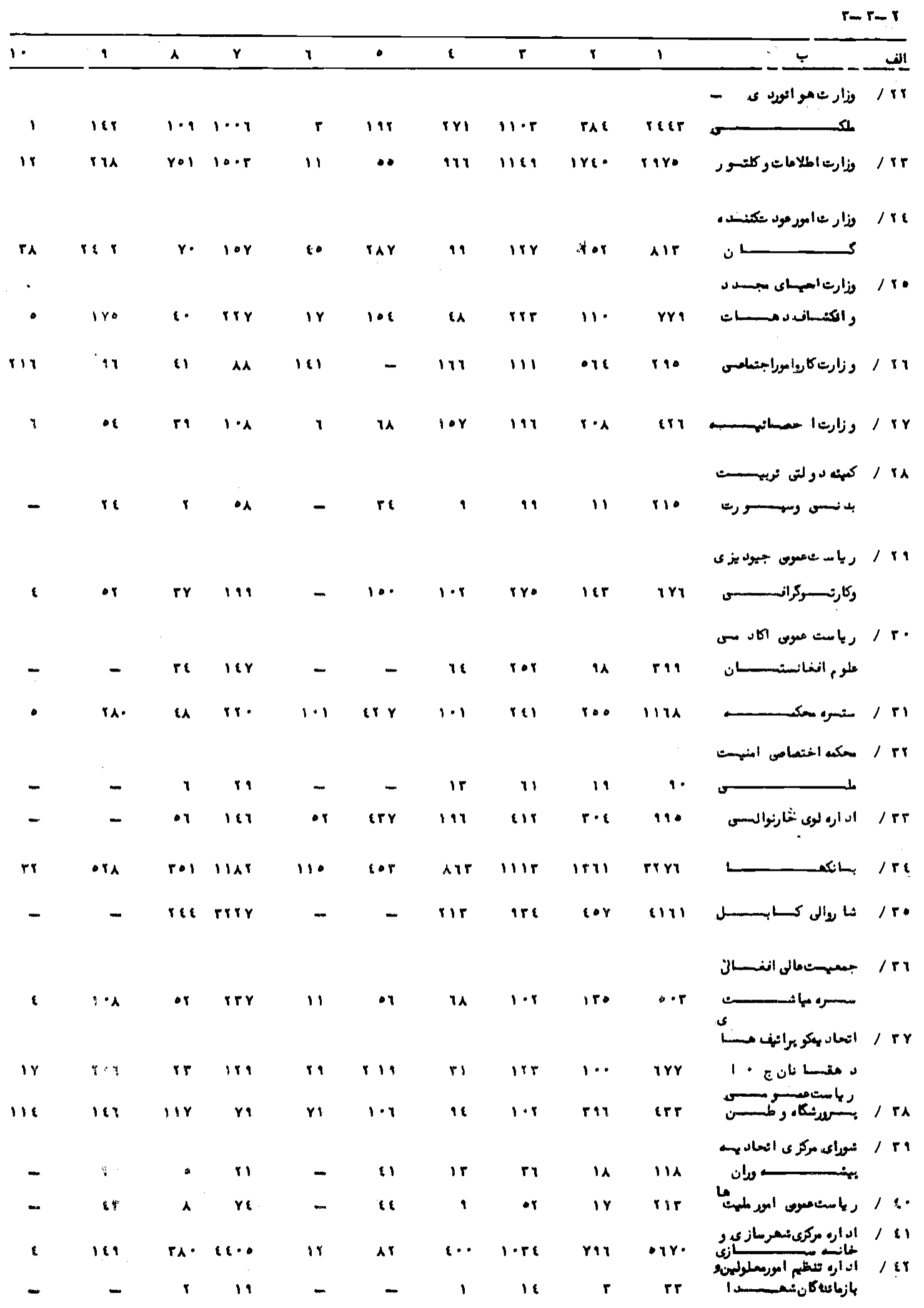




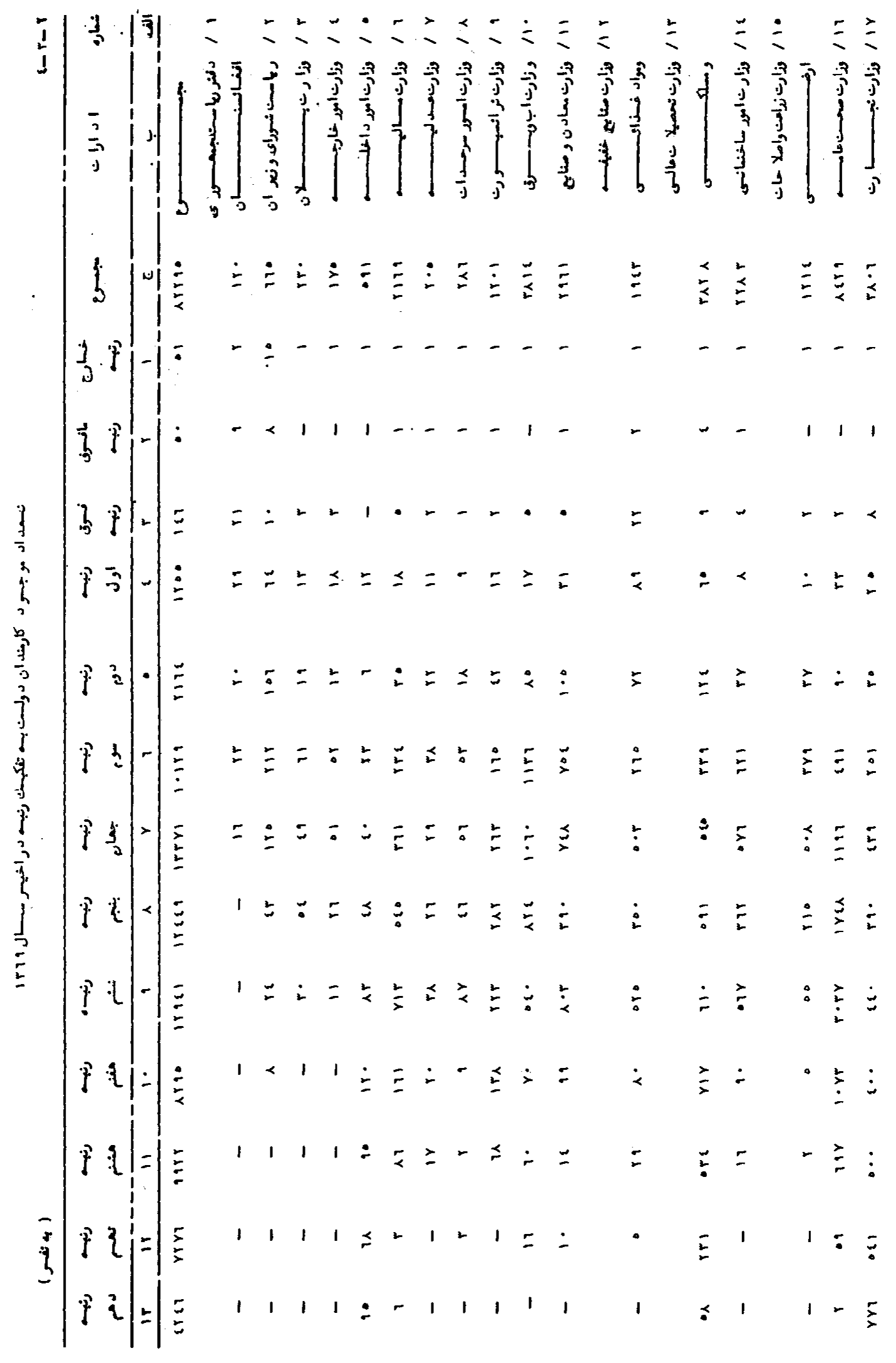




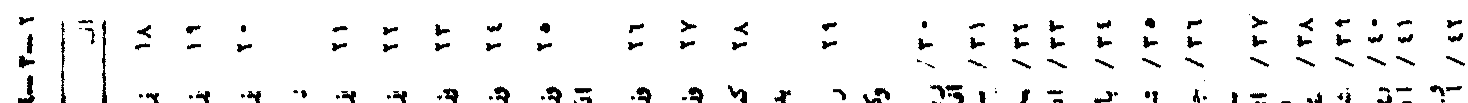

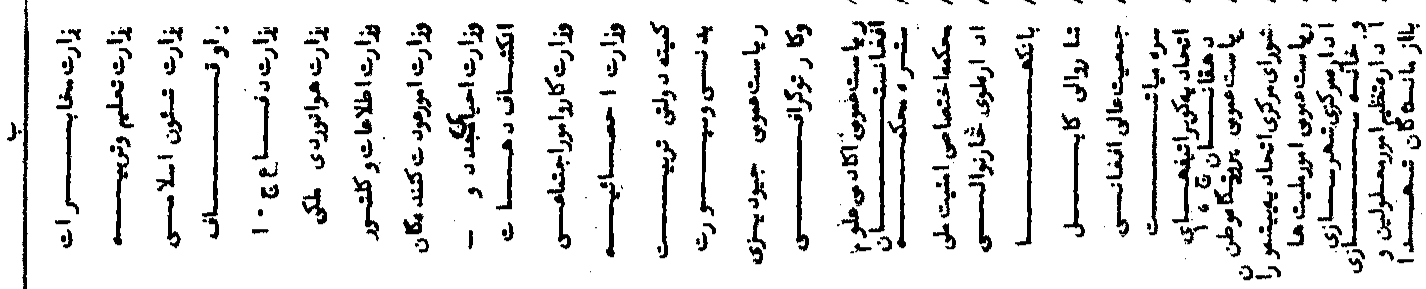

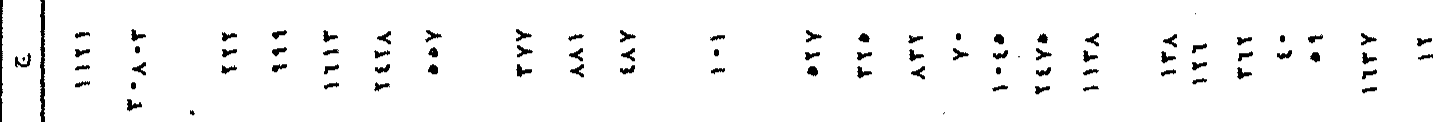
$-1-\ldots+1-1-1-1-1$ $1+21 \ldots+1 \ldots+\ldots 1 \ldots 1$

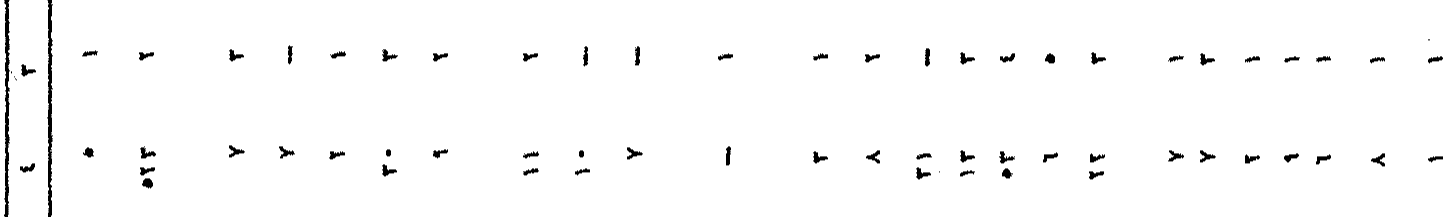

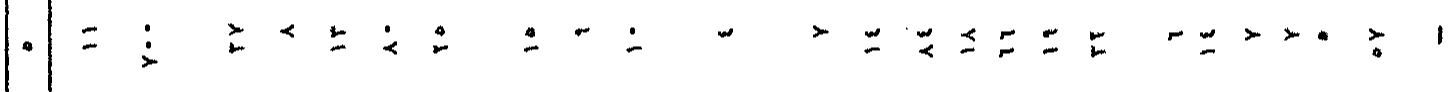

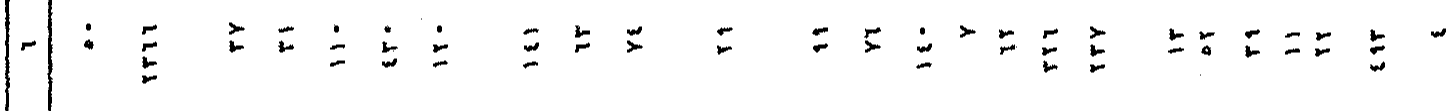

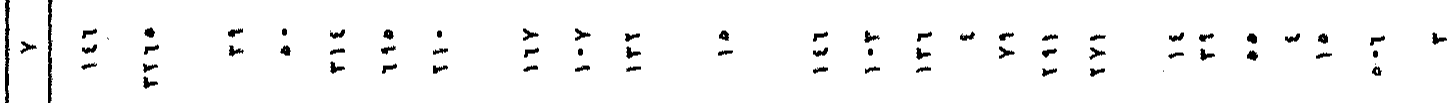

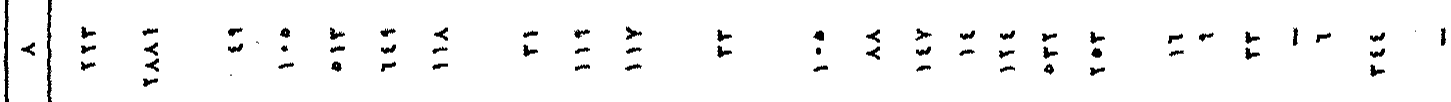

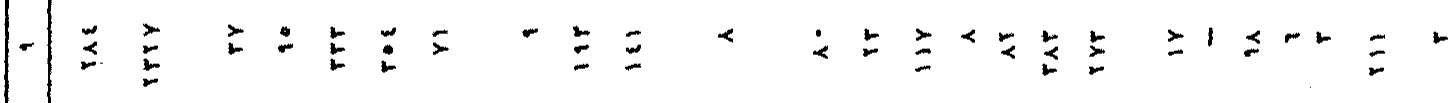

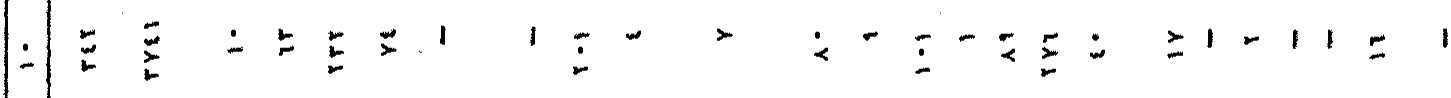
$=\leq \pm \leq \leq \leq 1 \leq 1-01 \leq 1=2 \pm-1 \pm 1111$

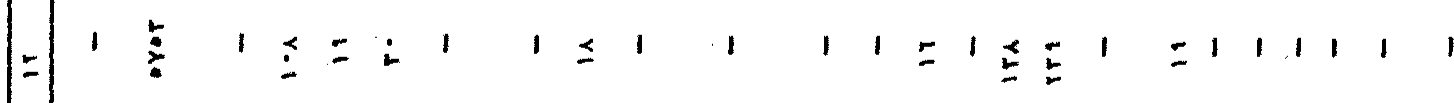

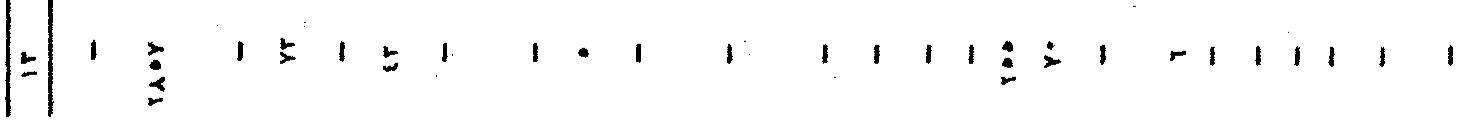




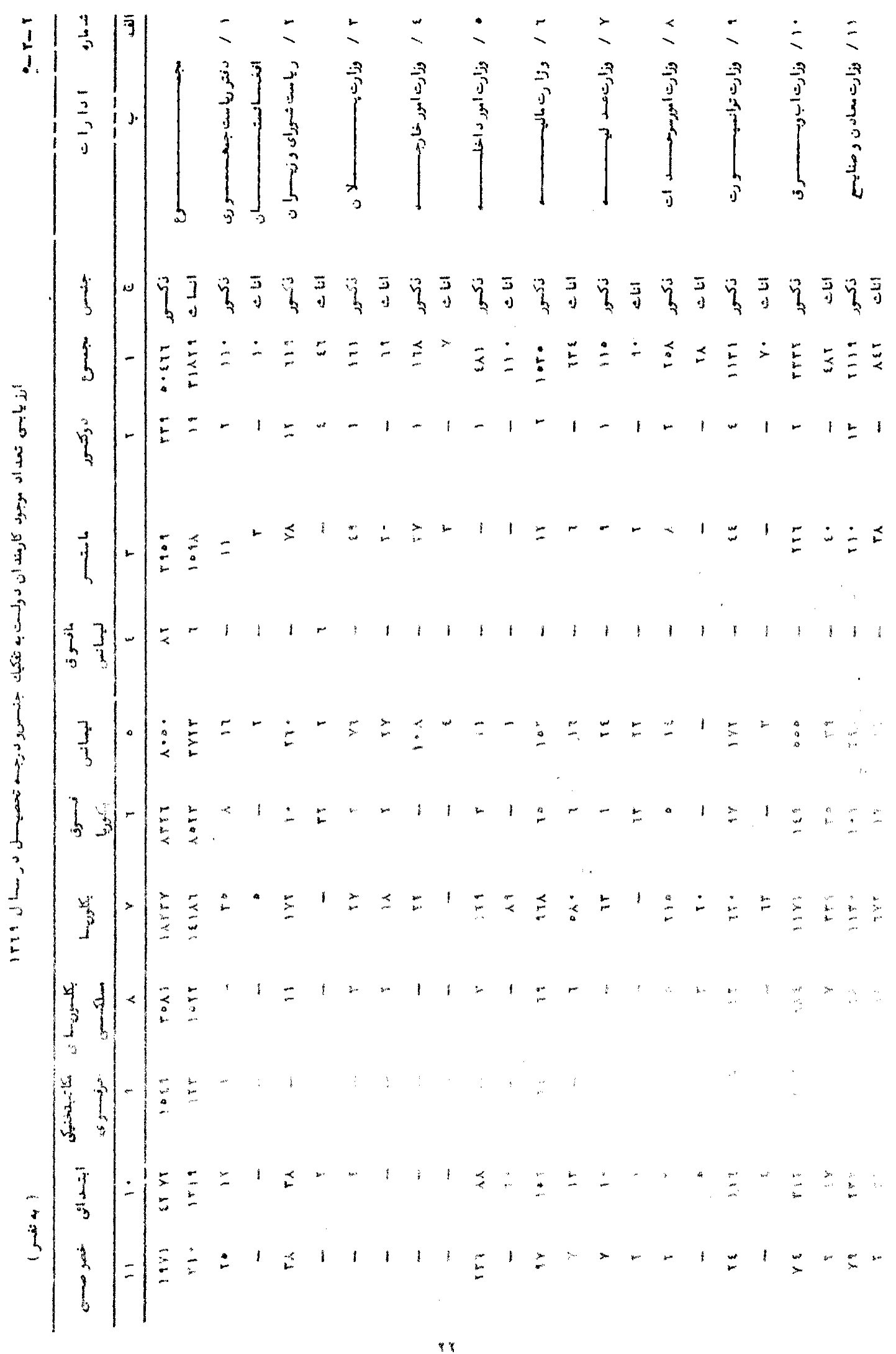




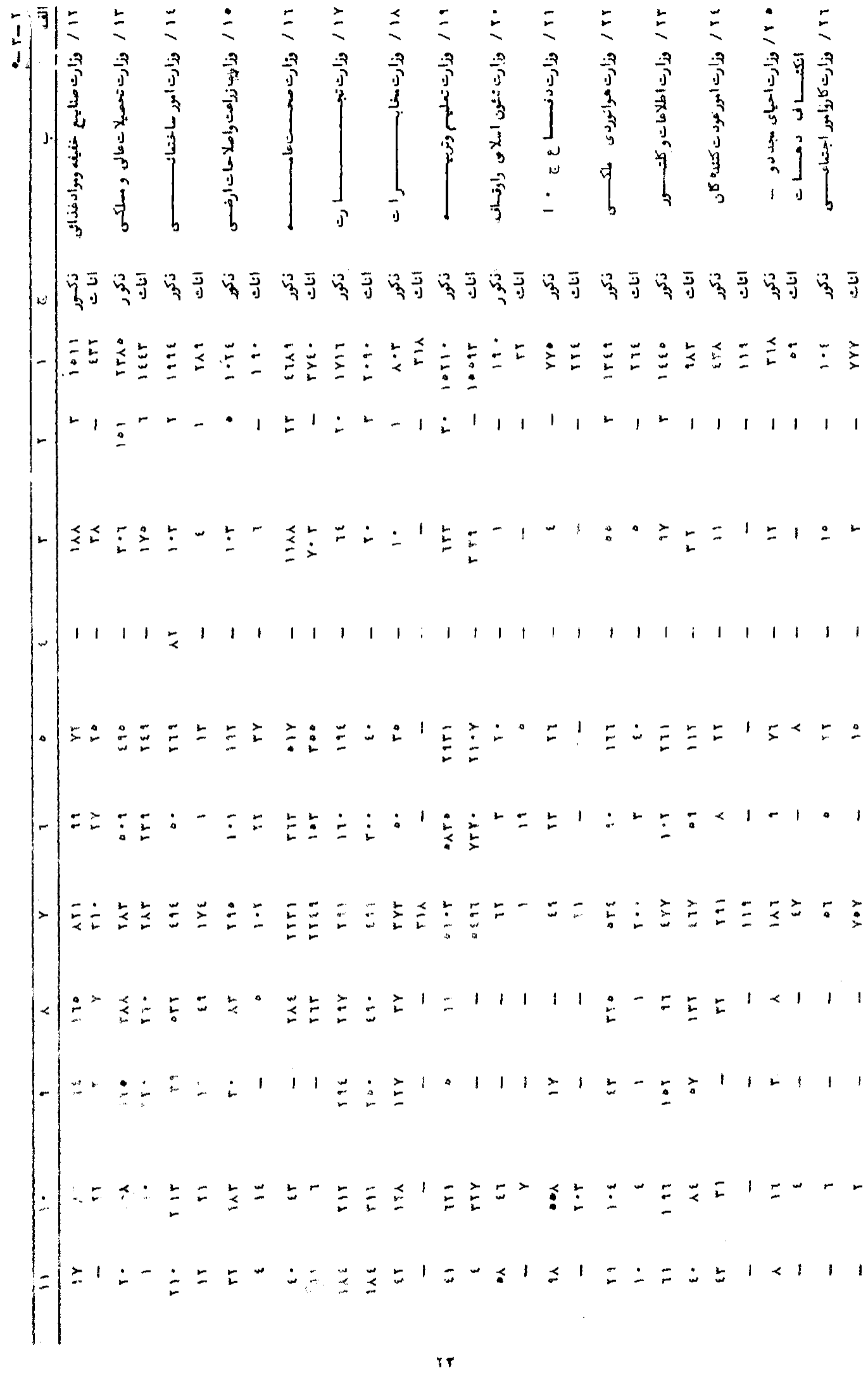




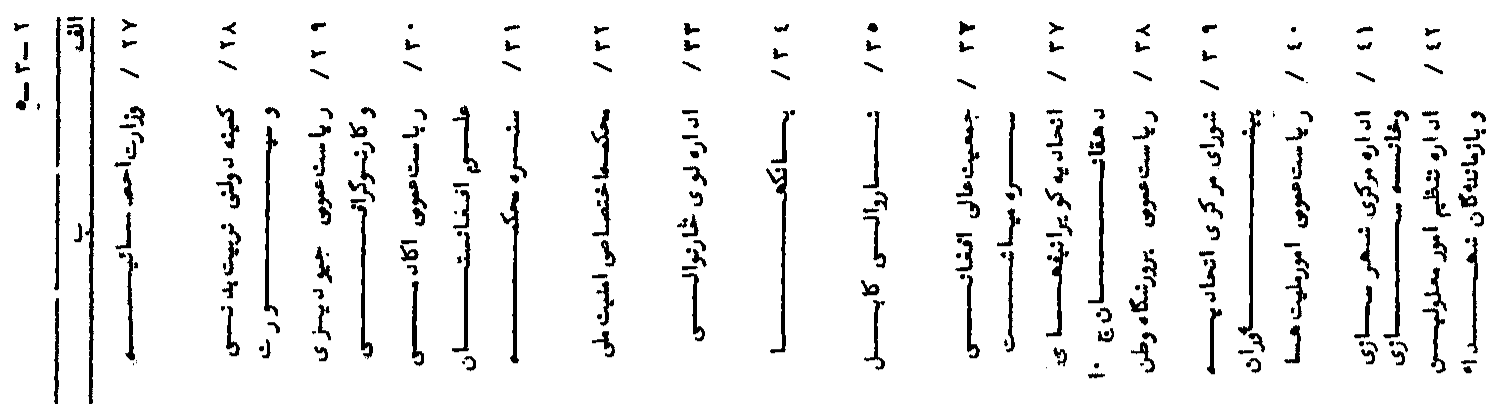

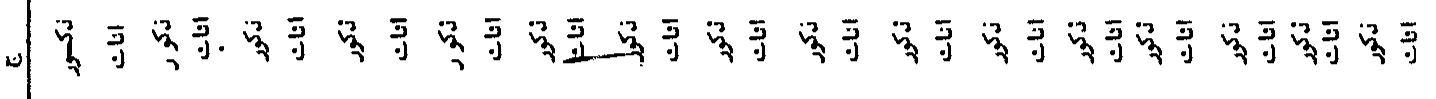
$-\Rightarrow>111-1 \leq-11 \leq 2-1-1,1,11111111111-111$

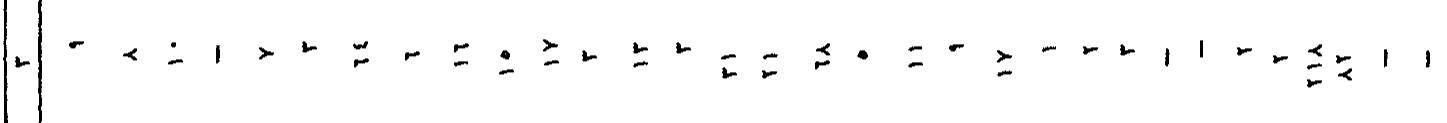

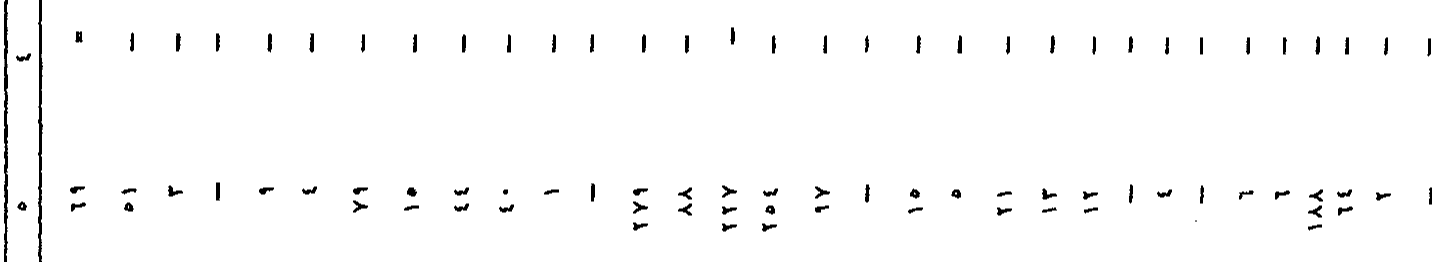

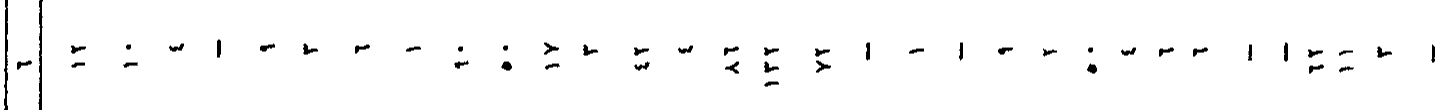

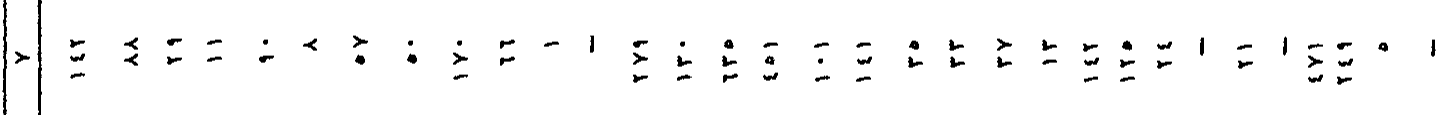

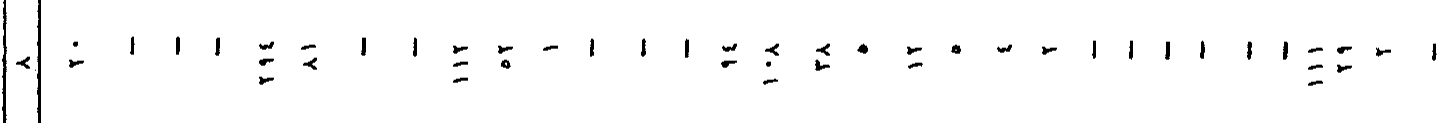

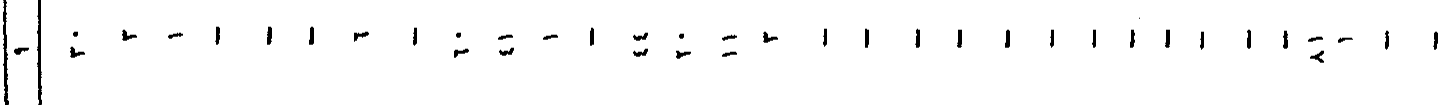

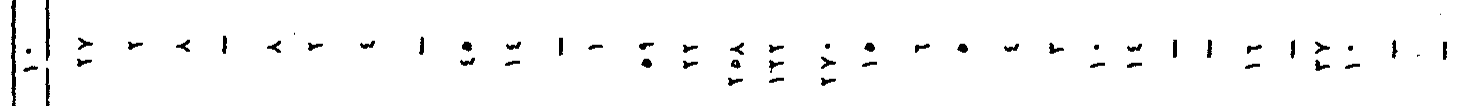

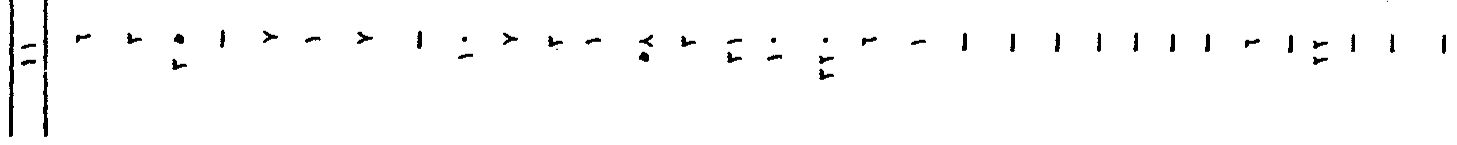
$\mathbf{1}$ 


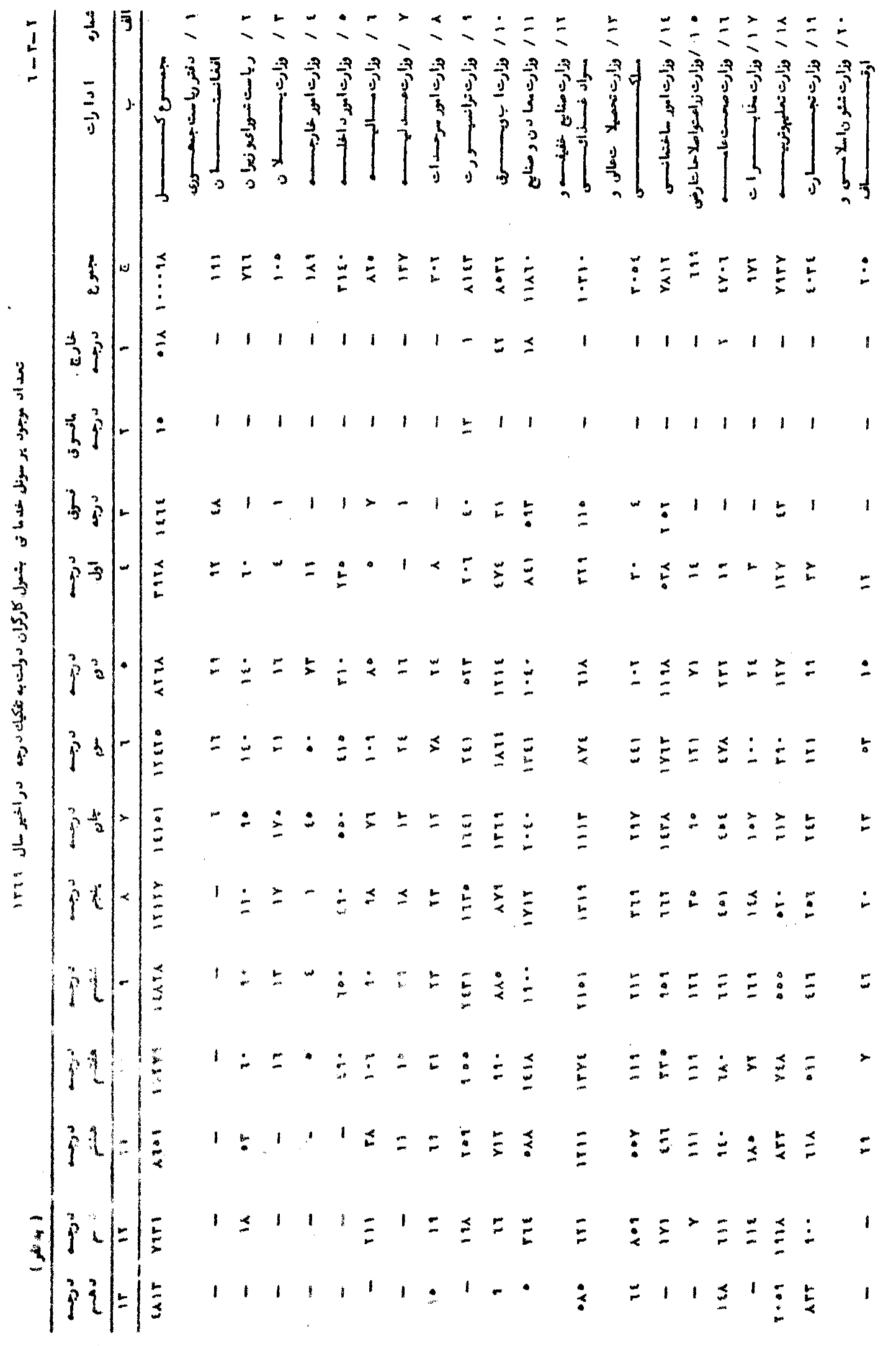




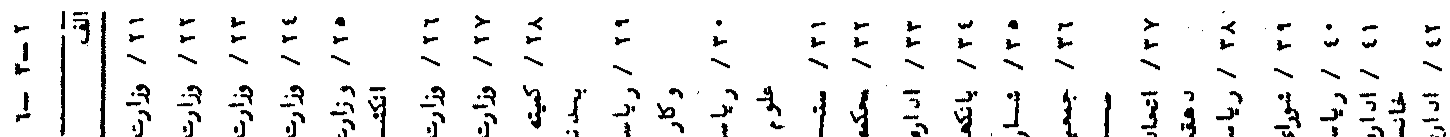

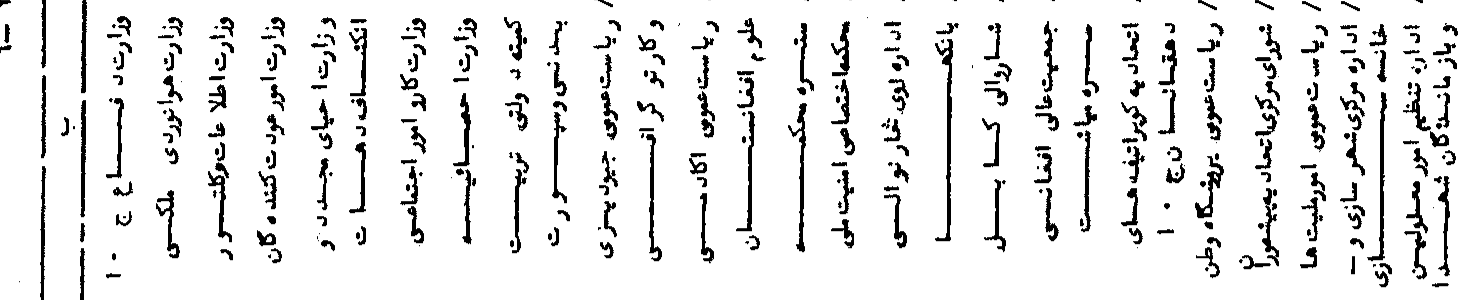

W

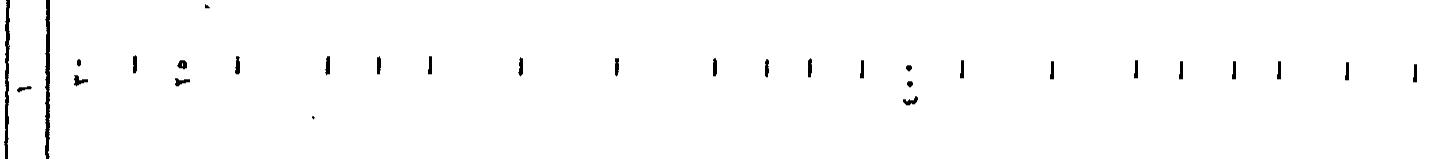

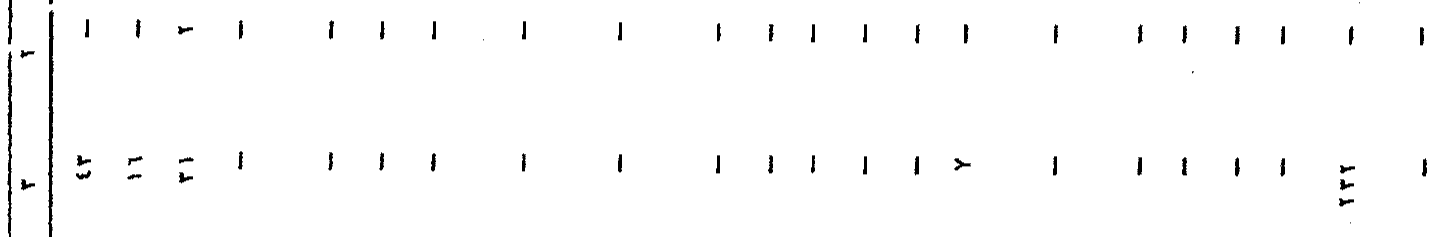

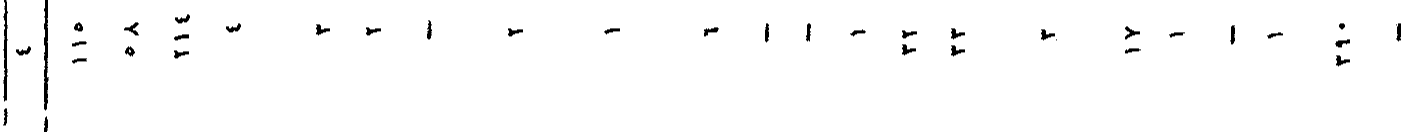

1

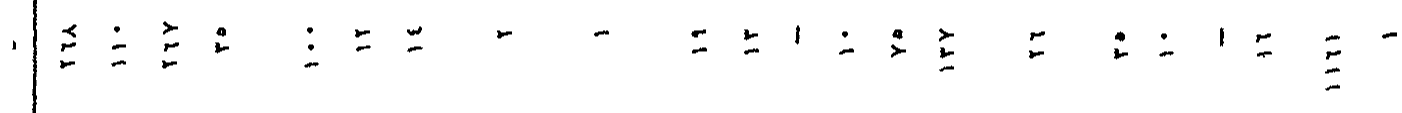

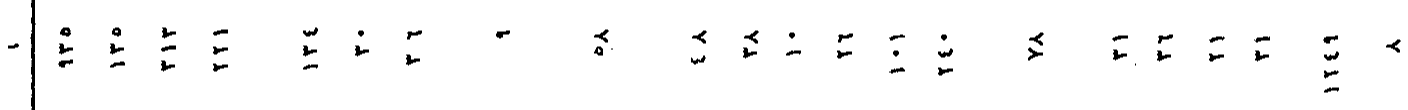

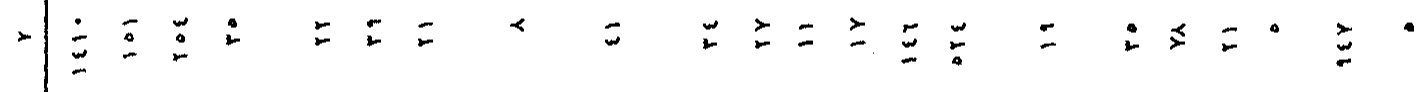

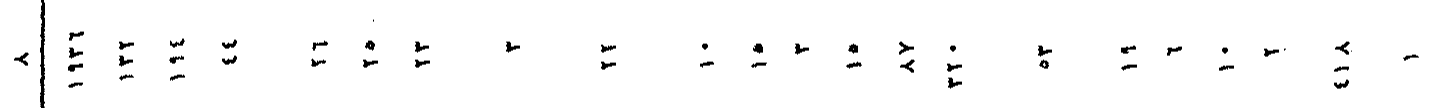

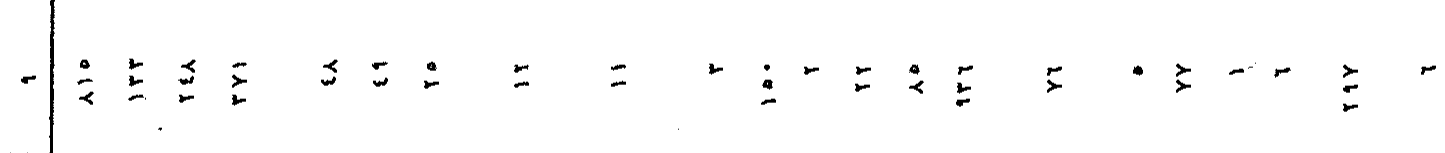

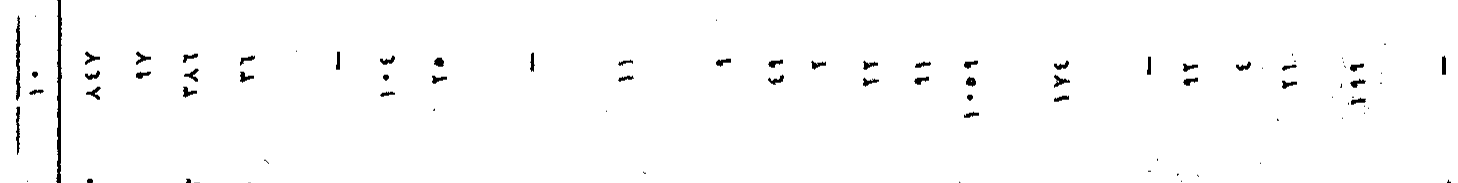

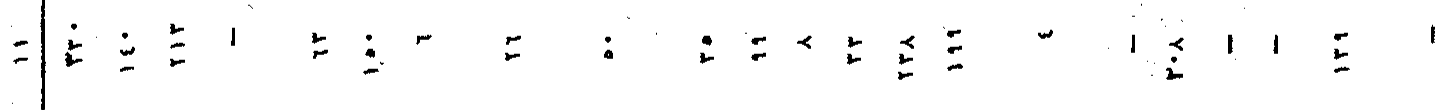

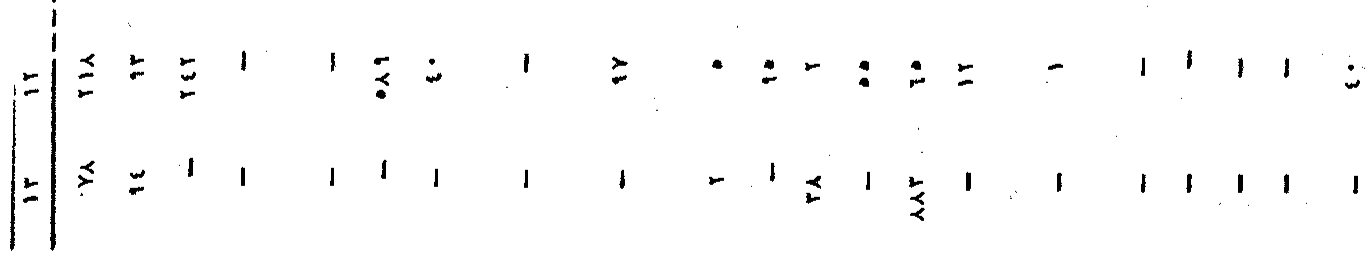




\begin{tabular}{|c|c|c|c|c|c|c|c|c|c|c|}
\hline & به نمو 1) & & ل ل لدر & | & t. & ורוט & لئ ماتئ & أرخد & (1) & $r-r-r$ \\
\hline نكرد ده & مسوسى : & ابند ائه & ترنيكي & مسلكى بكياى & كيلوسط & نكلمريا & لبهانس تر & مجسهو & جنسس & اسعـم اد اره \\
\hline 1 & $\hat{A}$ & $r$ & 1 & $\cdot$ & $\varepsilon$ & $r$ & $r$ & 1 & $\varepsilon$ & الف \\
\hline$\{\bullet \bullet\}$ & iroro & 11911 & $r r \cdot 1$ & $\{* 1$ & rort & $r \varepsilon$ & I 98 & $\lambda \cdot 12$. & نكور & 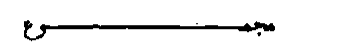 \\
\hline Iro. & rirr & $r r \Delta$ & rry & 119 & ri q & rr & r & $16 \cdot 1$ & ثان & \\
\hline $1 \cdot 1$ & $1 \cdot$ & $1 \cdot$ & - & - & $\mathbf{r}$ & - & - & 19. & 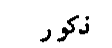 & ا 1 / دفتر رياستجعـ \\
\hline- & - & - & - & - & 1 & - & - & 1 & 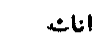 & انفـــانمتـــــــــــــــــ ن \\
\hline rq & $r \cdots$ & $r \&$ & - & - & - & - & - & rri & ذكور & 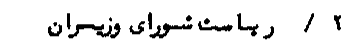 \\
\hline $1 \cdot$ & ir & $\lambda$ & - & - & - & - & - & $r$ & الاث & \\
\hline १० & - & - & - & - & 1 & 1 & - & $1 \cdot r$ & ذكور & 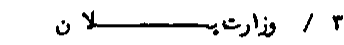 \\
\hline 1 & - & $r$ & - & - & - & - & - & $r$ & انان & \\
\hline$|\lambda|$ & - & - & - & - & \{ & - & - & $11 \cdot$ & ذكور & أ / وزارت امور خاربســــــ \\
\hline- & - & - & - & \{ & - & - & - & \{ & اناث & \\
\hline 1110 & . $\{0$ & $\circ$ P. $^{\circ}$ & - & - & $1 \wedge 1$ & irr & - & $r \circ \lambda_{0}$ & ذكور & 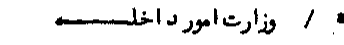 \\
\hline$r r \cdot$ & 18 & 90 & - & - & - & - & - & 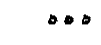 & ثان & \\
\hline ०ᄉ 9 & 10 & iro & - & - & $1 \cdot$ & 1 & - & $y_{0}$. & ذكور & 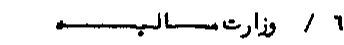 \\
\hline$\bullet 1$ & $r$ & ir & - & - & - & - & - & ro & I & \\
\hline$r \cdot$ & $r r$ & $0 \lambda$ & - & - & - & - & - & 111 & ن كور & 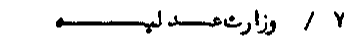 \\
\hline 1 & 1 & 12 & - & - & - & - & - & r & ا انا & \\
\hline ris & 1 & 1. & - & - & - & - & - & $\mathrm{rAq}$ & زكور. & 1 / وزارتامسور سرحسد ات \\
\hline 1 & $r$ & 18 & - & - & - & - & - & 11 & ا اناث & \\
\hline 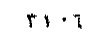 & ४ is & $\because Y Y:$ & $\approx 11$ & - & ris & 9 & 10 & Y9ห & 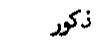 & 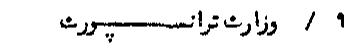 \\
\hline$\therefore$ & 11 & \rceil$\varepsilon$ & - & - & $\varepsilon$ & - & - & iro & ا اناث & \\
\hline$\infty \varepsilon$ & 1907 & by & $9 \lambda$ & $\circ$ & $r$ & $\therefore 1$ & $\varepsilon \varepsilon$ & ?१i & 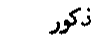 & 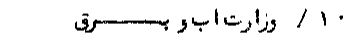 \\
\hline$r r$ & $1 \& 8$ & it & 19 & \{ & $r 7$ & - & $\because$ & otr & اناث & \\
\hline$\circ 19$ & $r \cdot r t$ & $r y+\varepsilon$ & $1 \leqslant 0$ & $v$ & $i \varepsilon$ & $\wedge \wedge$ & $\{q$ & $11 \cdot 1$. & ذكود & 1111 رنا رتمعادن و صنائي \\
\hline$r i s$ & in & $r \cdot q$ & rT & - & $r$ & $r$ & 11 & ra. & ا اناث & \\
\hline$r \lambda \cdot q$ & $\mid \wedge 91$ & Yiso & \&०Y & - & $\{9$ & - & - & $A \& \cdot 1$ & 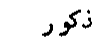 & r / ارارتصنايع شخيغســ \\
\hline $9 \pi$ & rat & $\Delta r$ & Irs & - & - & - & - & $19 \cdot 9$ & انان & وموا د غسذانســـــــ \\
\hline YAr & $\{Y r$ & rir & 198 & - & - & - & - & $1 \lambda \varepsilon \varepsilon$ & نكور & 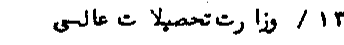 \\
\hline$\cdots$ & ral & rYT & $\{1$ & - & - & - & - & 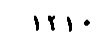 & ثان & و مسلكSـ \\
\hline rqrr & Irr & Irra & $Y=$ & $r q$ & n & - & 11 & $r \cdot r r$ & ن - اكور & ا $1 /$ وزارثامص ساختهانسسى \\
\hline $1 \cdot 9$ & $\wedge 9$ & 1• & $1 \cdot$ & - & • & 1 & - & YYq & اناث & \\
\hline \&1 & \& $Y$ & $\bullet 1$ & - & $r$ & $\wedge$ & - & - & or. & نكور & • 1 / وزارث زراعتواملاحسات \\
\hline iro & 1. & 11 & - & - & 1 & - & - & 179 & انl & 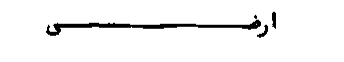 \\
\hline $\operatorname{rru}$ & IIX & $r \cdot r$ & - & $r \cdot r$ & ir & $\varepsilon$ & 18 & rige & 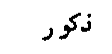 & 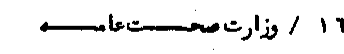 \\
\hline $11 \leqslant Y$ & $r_{\lambda}$ & ir & - & $1 \cdot 1$ & ir & - & - & I\&ry & & \\
\hline
\end{tabular}




\begin{tabular}{|c|c|c|c|c|c|c|c|c|c|c|}
\hline 1 & A & $Y$ & 1 & $\cdot$ & $\mathbf{i}$ & $r$ & $r$ & 1 & $\varepsilon$ & الفـي - \\
\hline $1 \cdots r$ & irtr & 111 & - & - & - & - & - & tite & 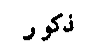 & 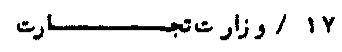 \\
\hline ir॰ & $r \bullet$ & rit & - & - & - & - & - & .91 & ا & \\
\hline$r \wedge \cdot$ & $r$ re & $r \cdots$ & ir & - & - & 1. & - & Alr & ذكسول & 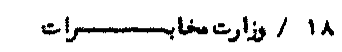 \\
\hline ry & $1 \cdot$ & 19 & $\mathfrak{i}$ & - & - & - & - & $1 \cdot 1$ & ثl & \\
\hline ry.. & IYrY & $a ! r$ & - & - & $\wedge \wedge$ & - & $r$ & •Ara & ذكور & 19 / وزارث تعليهم وتربيهســ \\
\hline - 1 & 114 & ora & i & - & $\cdot 1$ & - & - & $r \cdot \Re$ & ثان & \\
\hline$\cdots$ & irr & 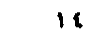 & - & - & - & - & - & $r \cdot r$ & ندور & 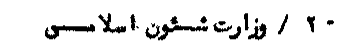 \\
\hline- & 4 & - & - & - & - & - & - & \& & $=4$ & 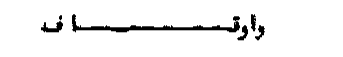 \\
\hline$r \cdots r$ & 111 & $m$ & $r_{1}$ & - & $1 \cdots 1$ & - & - & iris & ذكور & 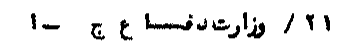 \\
\hline rat & - & rir & - & - & 100 & - & - & $y \circ y$ & اناث & \\
\hline$\left\{\Lambda^{\circ}\right.$ & int & $r \cdot 1$ & 11 & Y० & 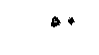 & $r$ & $r \bullet$ & 1.11 & 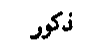 & 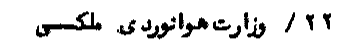 \\
\hline as & 10 & ro & 1 & - & - & - & - & ir & أti & \\
\hline Yry & ir. & tir & $r a$ & $1 \cdot$ & 14 & $\cdot$ & - & $\mid r+1$ & ذكور. & rr / وارتأطلاعاتو كلتسسود \\
\hline rrs & lat & rur & 9 & - & - & - & - & rod & ثl & \\
\hline$\cdots$ & $i r$ & ir. & - & - & 18 & - & $\wedge$ & 711 & ذكور & 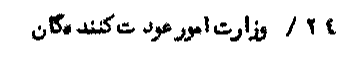 \\
\hline -r & - & ro & - & - & - & - & - & ra & + & \\
\hline rYT & $\mathfrak{k} \cdot$ & $\varepsilon$ & - & - & - & - & - & rar & 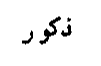 & •r / وارث الحياي سجدد و - \\
\hline in & - & 19 & - & - & - & - & - & $\$ r$ & ثtit & انكنـسـات د لمســــا ت \\
\hline AAT & - & $r$ & - & - & - & - & - & ^^શ & ذكود & צr/ نارتكاليامور اجتماعسى \\
\hline $1 \cdot 1$ & - & $\wedge$ & - & - & - & - & - & 114 & St & \\
\hline $\operatorname{lir}$ & ir & $r$ & - & - & - & - & - & ira & ز ت مور & 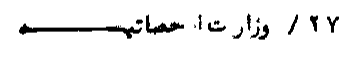 \\
\hline$\circ$ & $y$ & - & - & - & $\gamma$ & - & - & 11 & البLاe & \\
\hline$r q$ & - & $\therefore$ & - & - & - & - & - & $r$ & 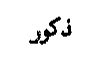 & A R / كيته دولتى تريبت بد نسى \\
\hline rr & - & - & - & - & - & - & - & $r$ & اناث & تر \\
\hline rrt & $1 \cdot$ & r & - & - & - & - & - & rio & 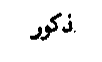 & 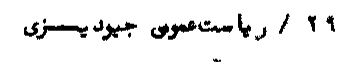 \\
\hline ro & 11 & ? & - & - & - & - & - & $q$ & اباث & وكستر تيو كرانسـ \\
\hline it & ri & $r$ & $\checkmark *$ & - & - & - & - & 118 & ذكسور & 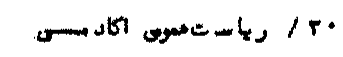 \\
\hline ir & ri & $r$ & $\cdot$ & - & - & - & - & -4 & النان & طلسمر انفانستيجـــــــان \\
\hline$r \cdots$ & $1 \cdot$ & $\because$ & - & - & - & - & - & ir. & ذكور & 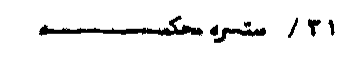 \\
\hline$r r$ & - & $\boldsymbol{r}_{\wedge}$ & - & - & - & - & - & 11 & 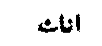 & \\
\hline
\end{tabular}




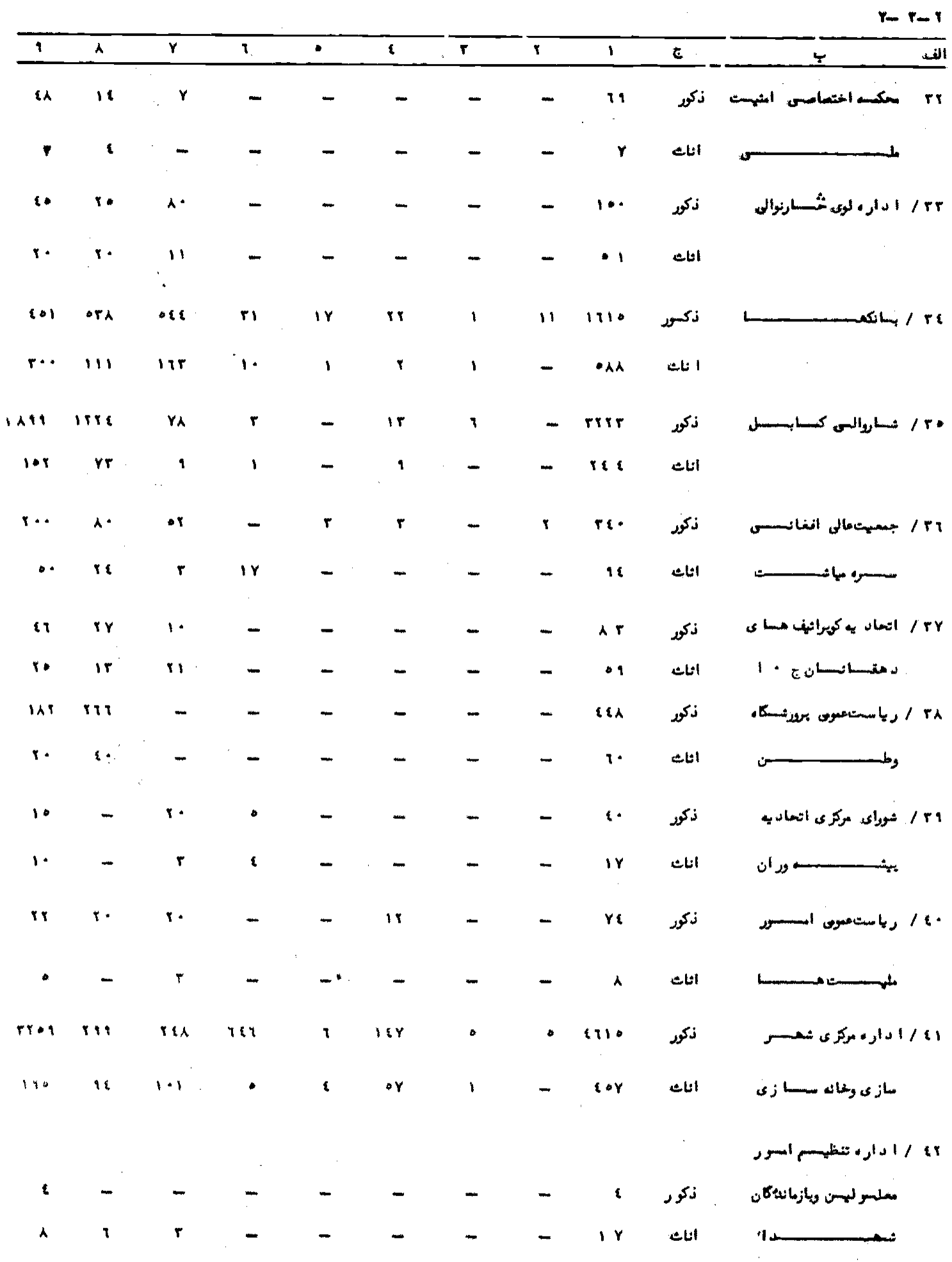




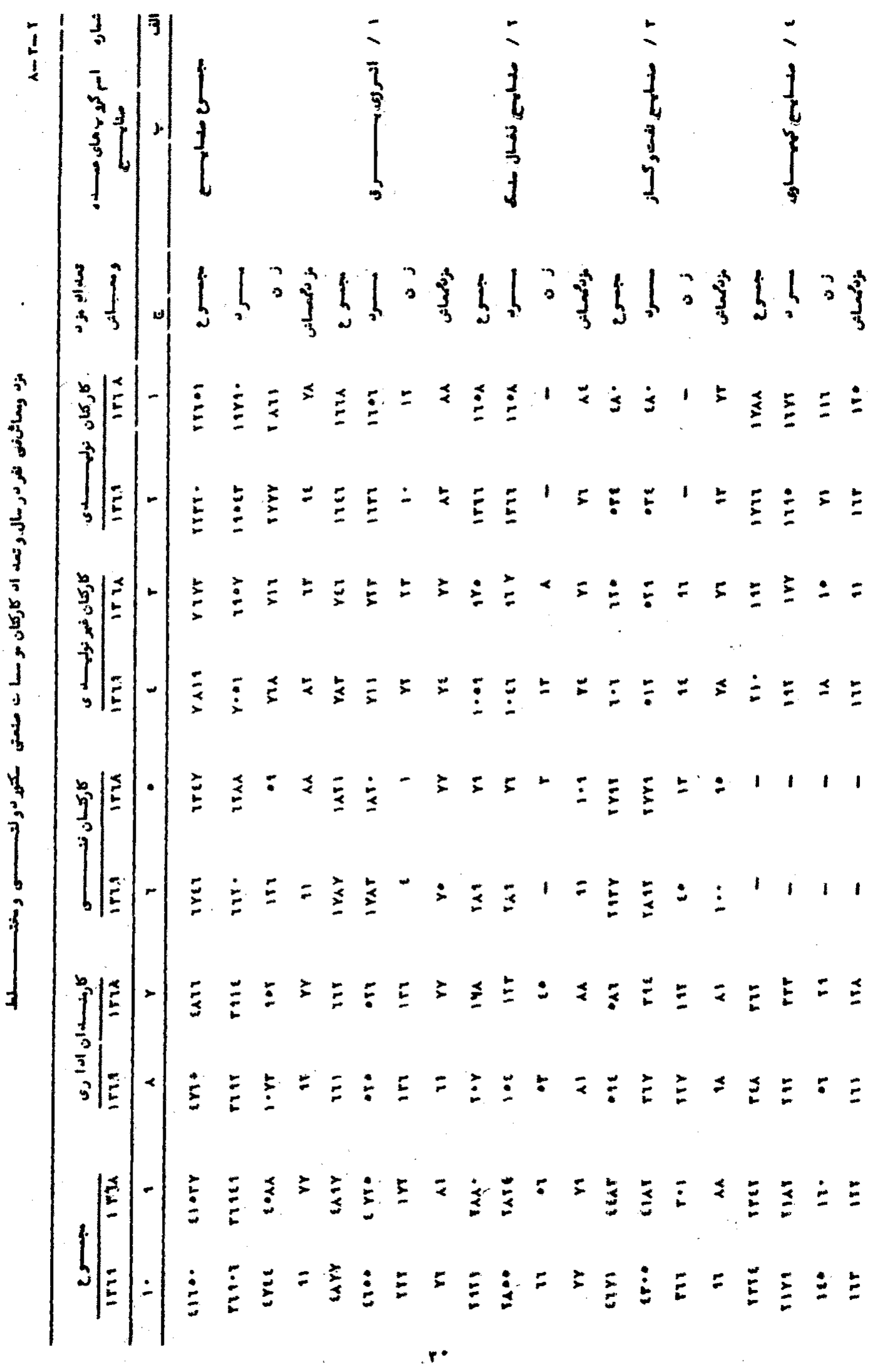




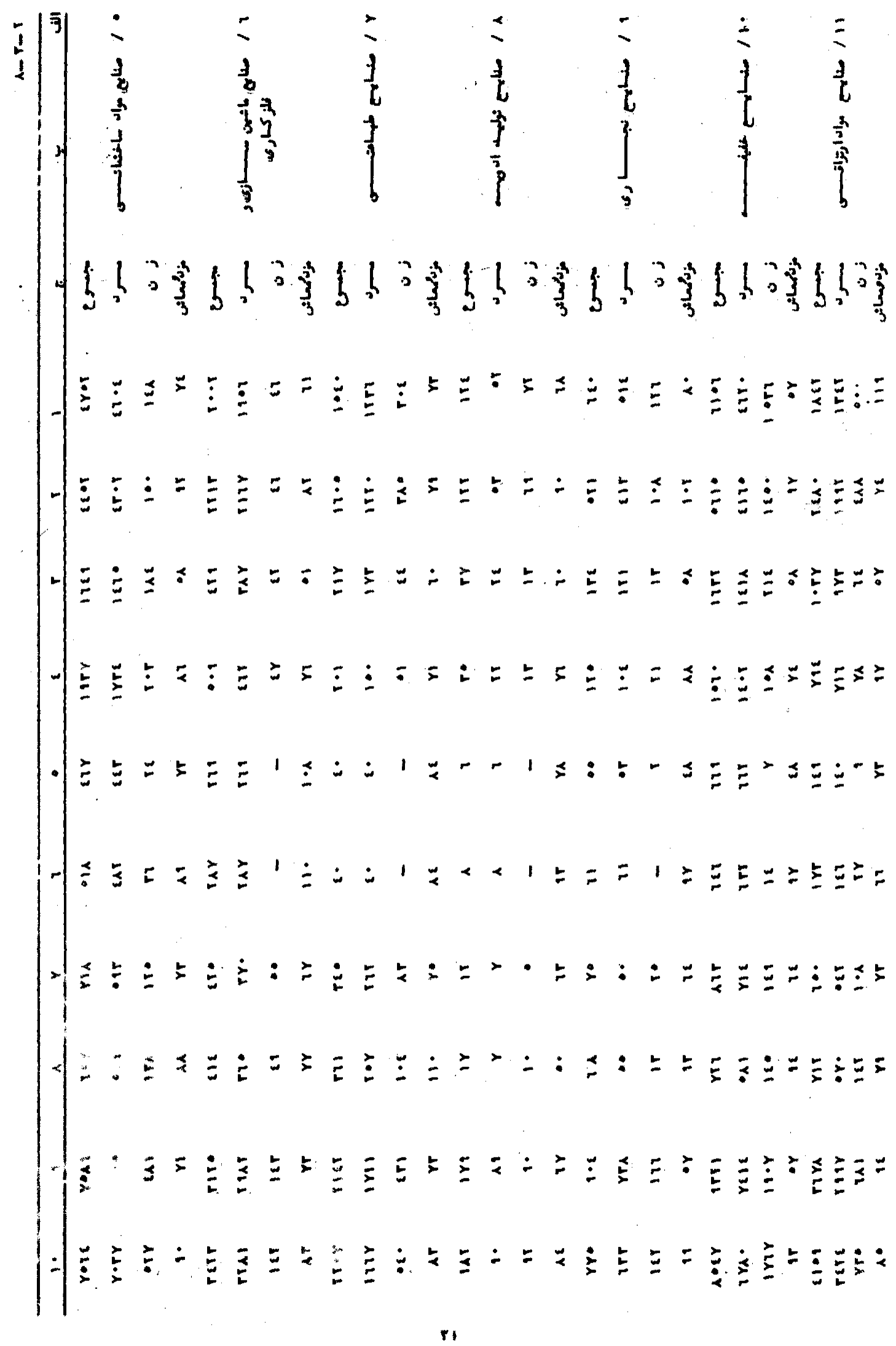




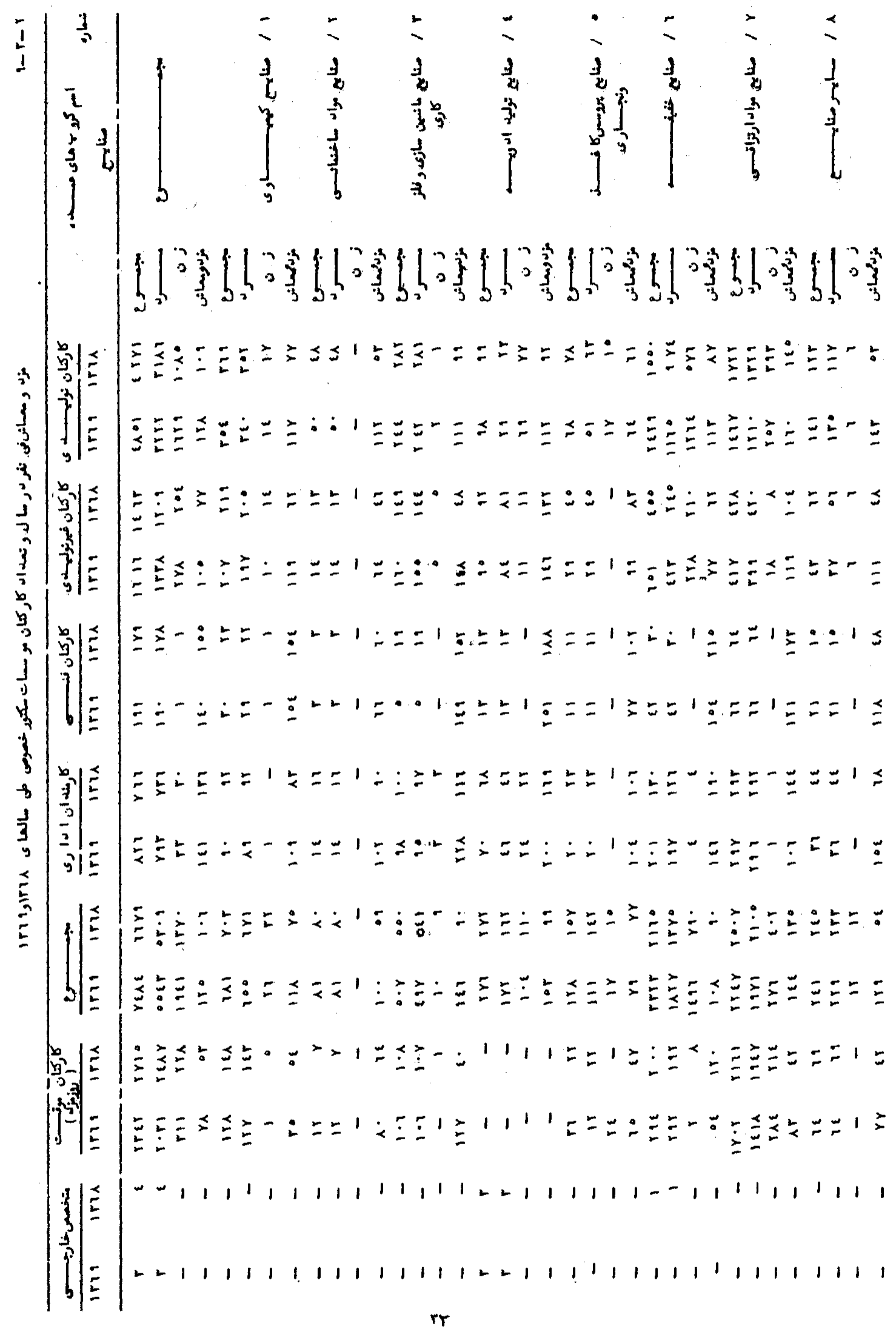




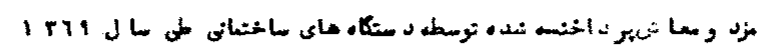

$1 \cdot-r-r$

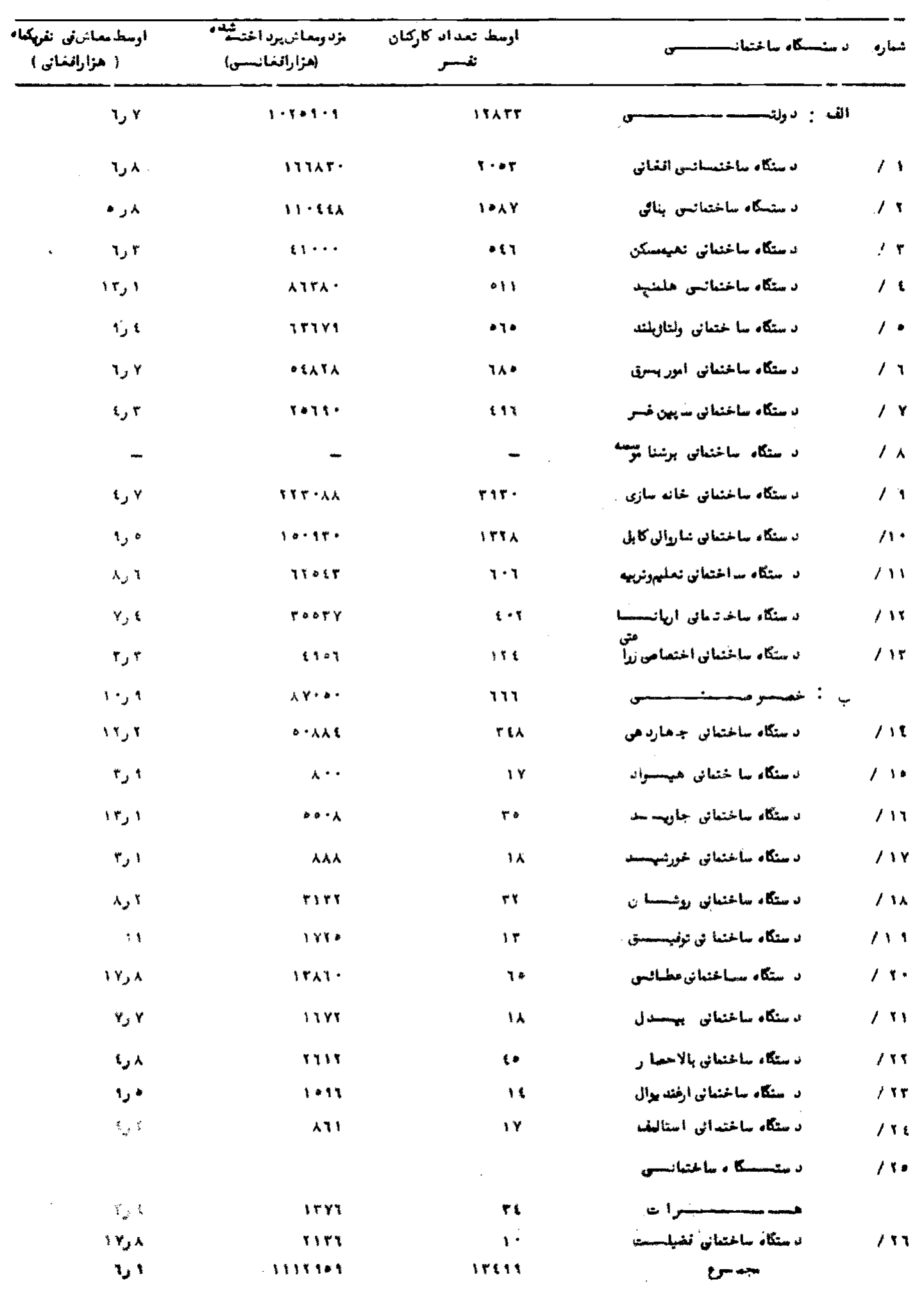




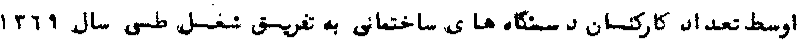

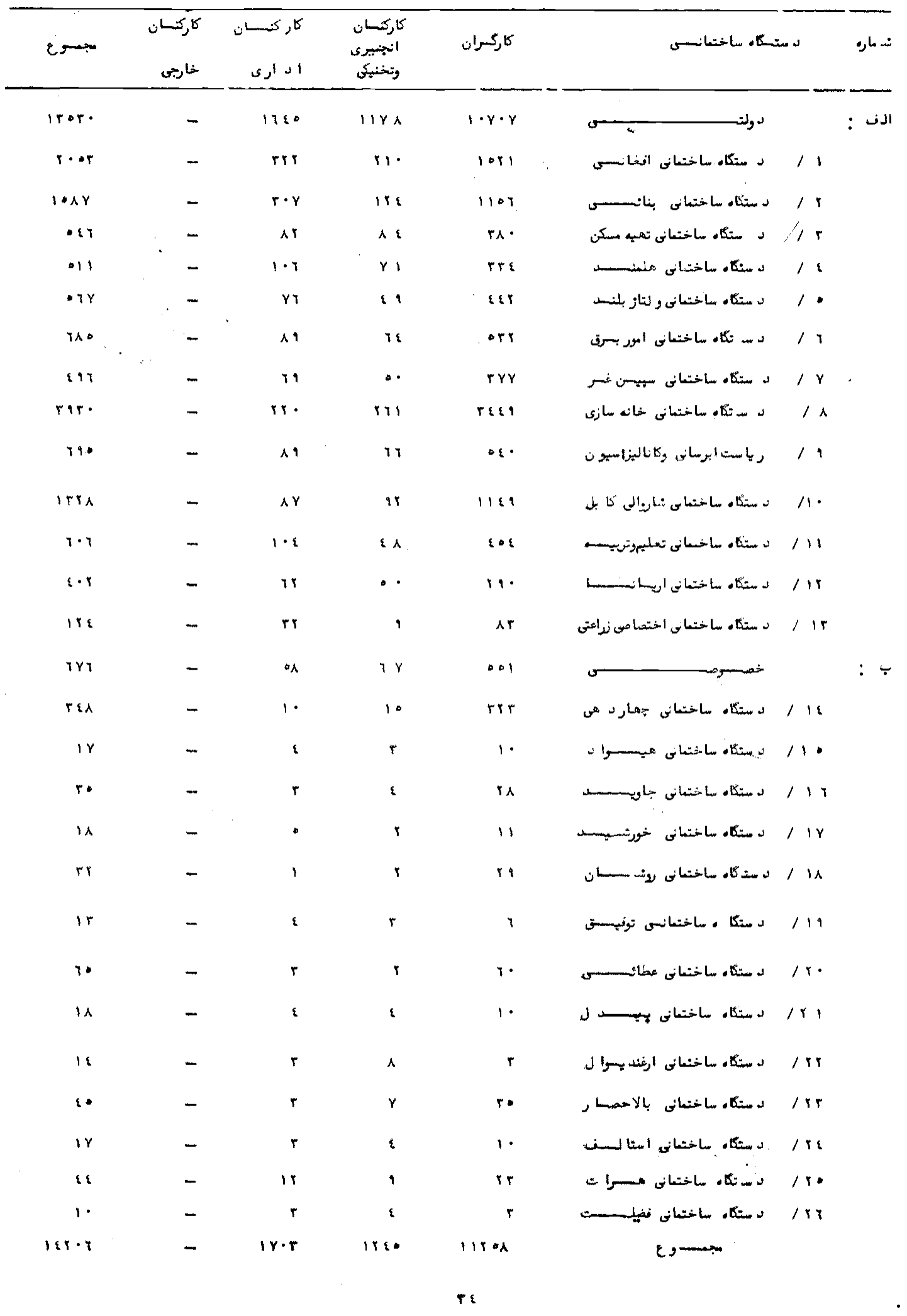




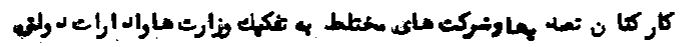

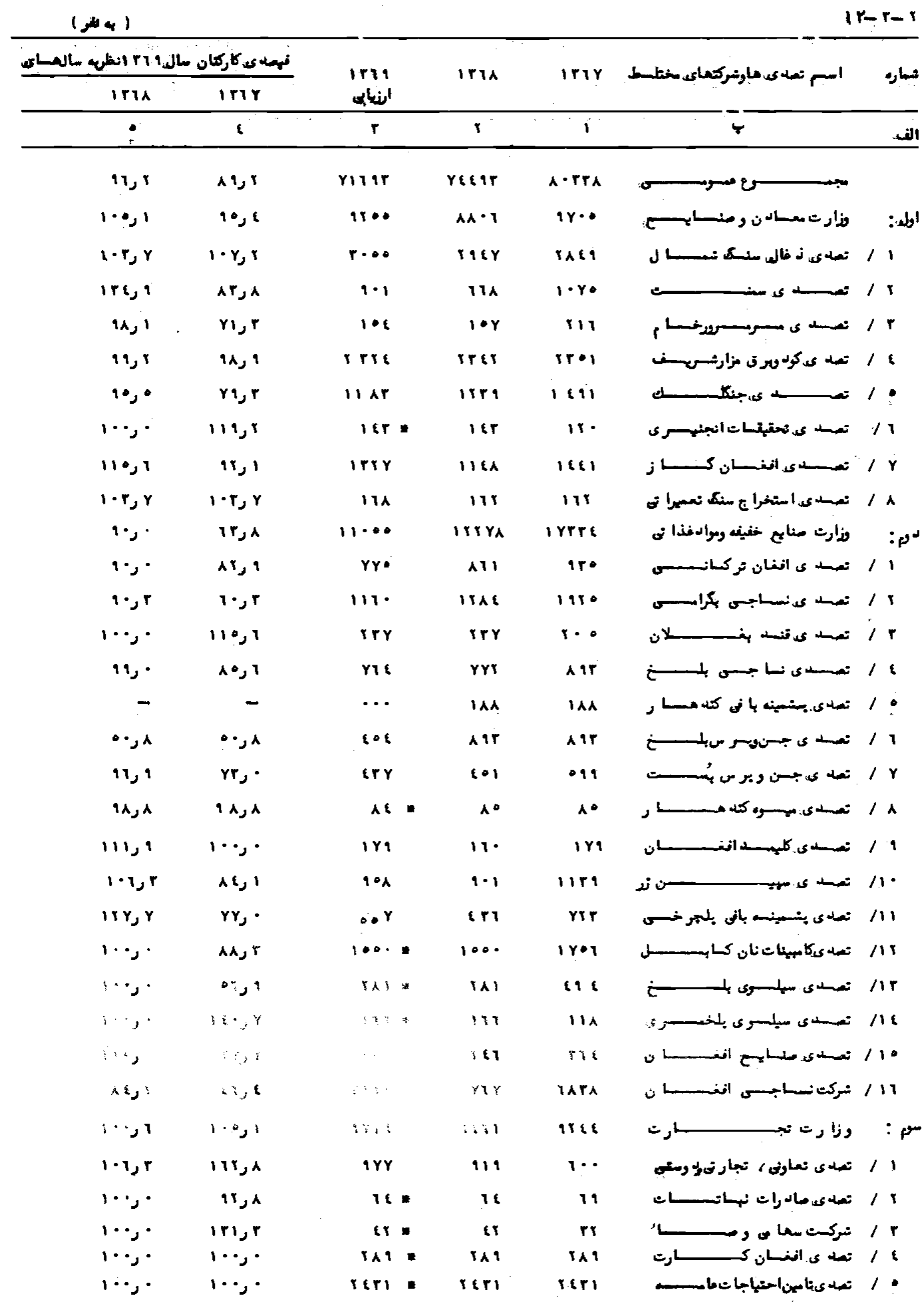


$1 Y-r-r$

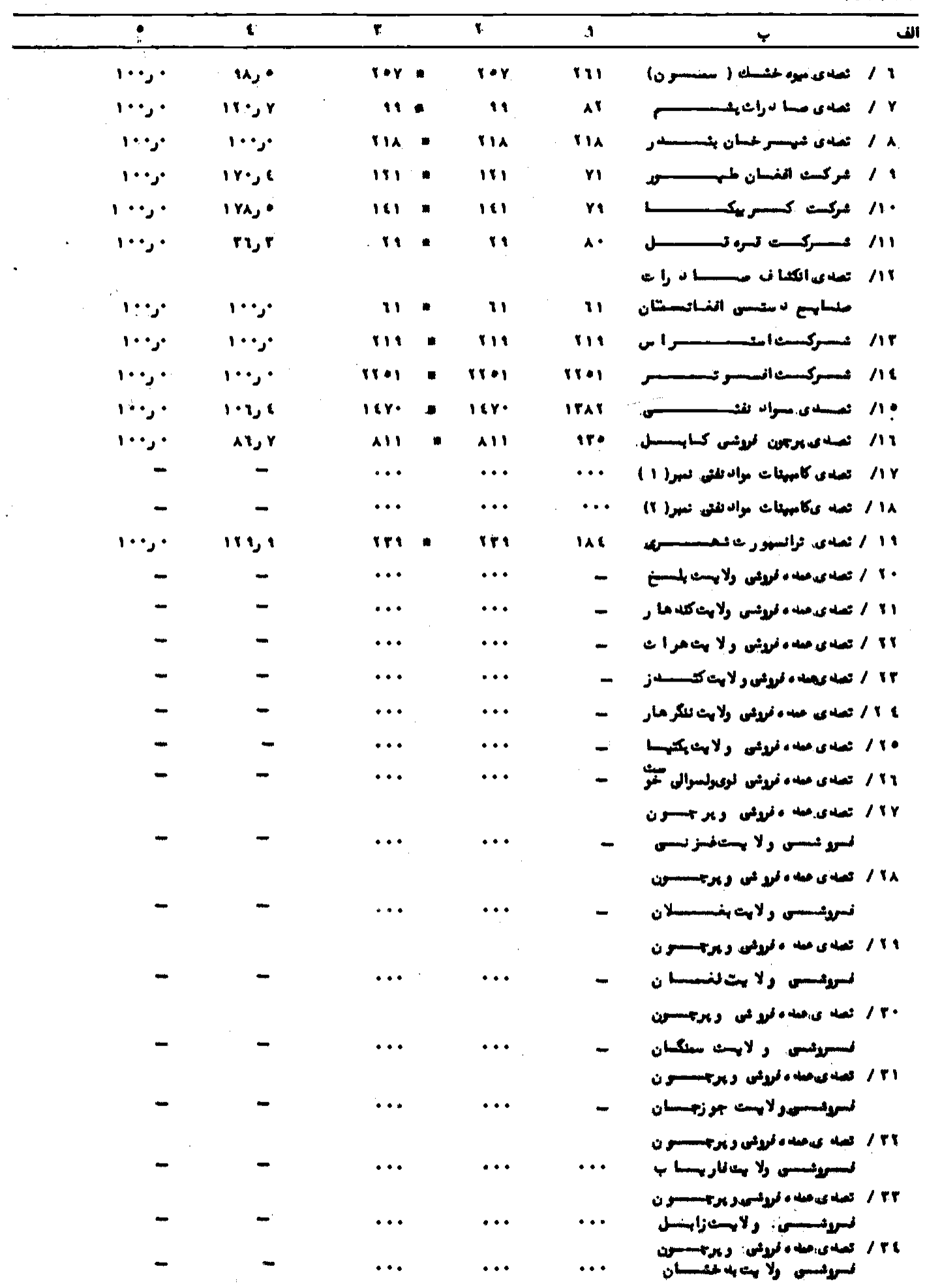


$\mid 1-r-1$

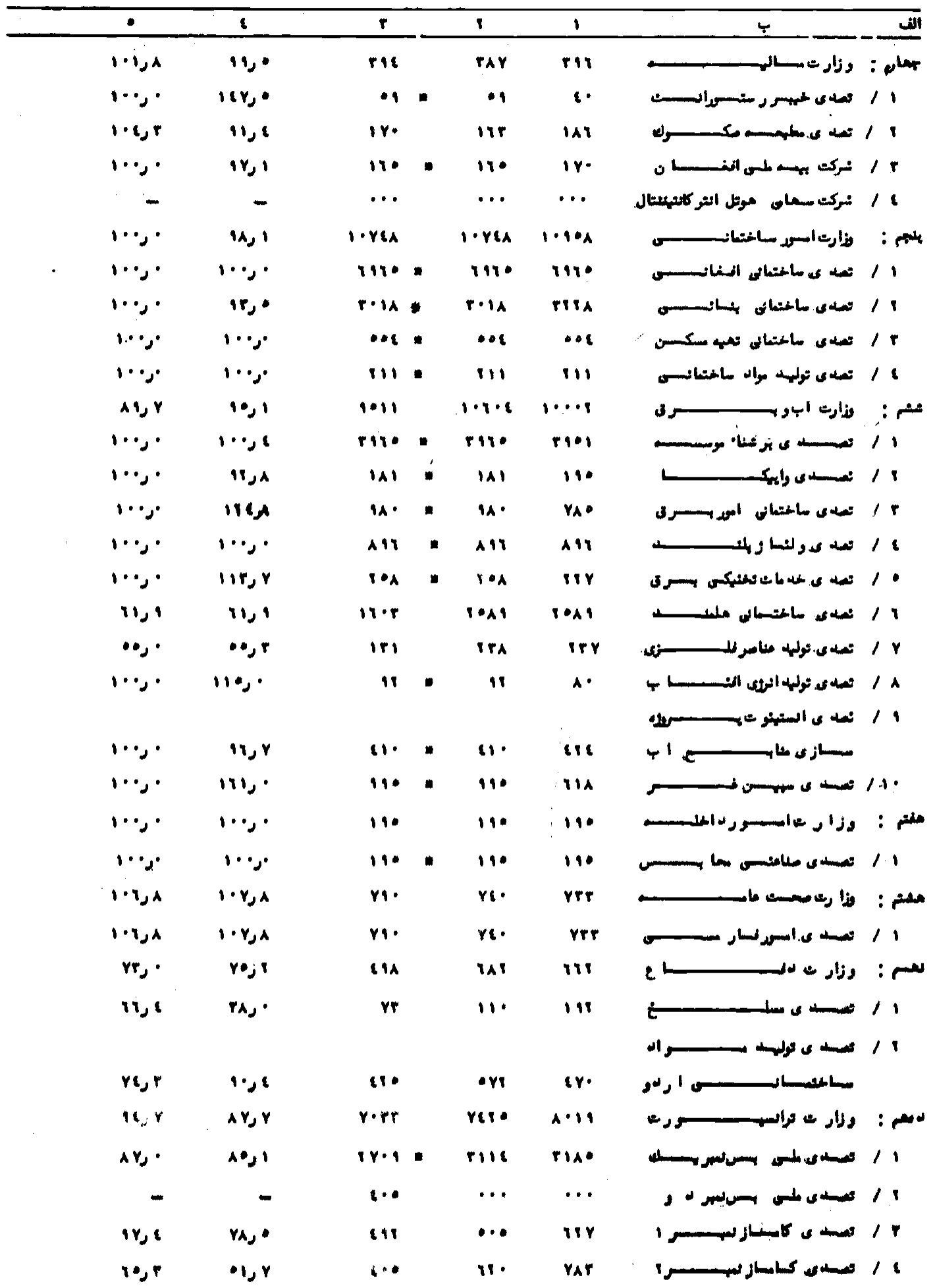


$r-r-r$

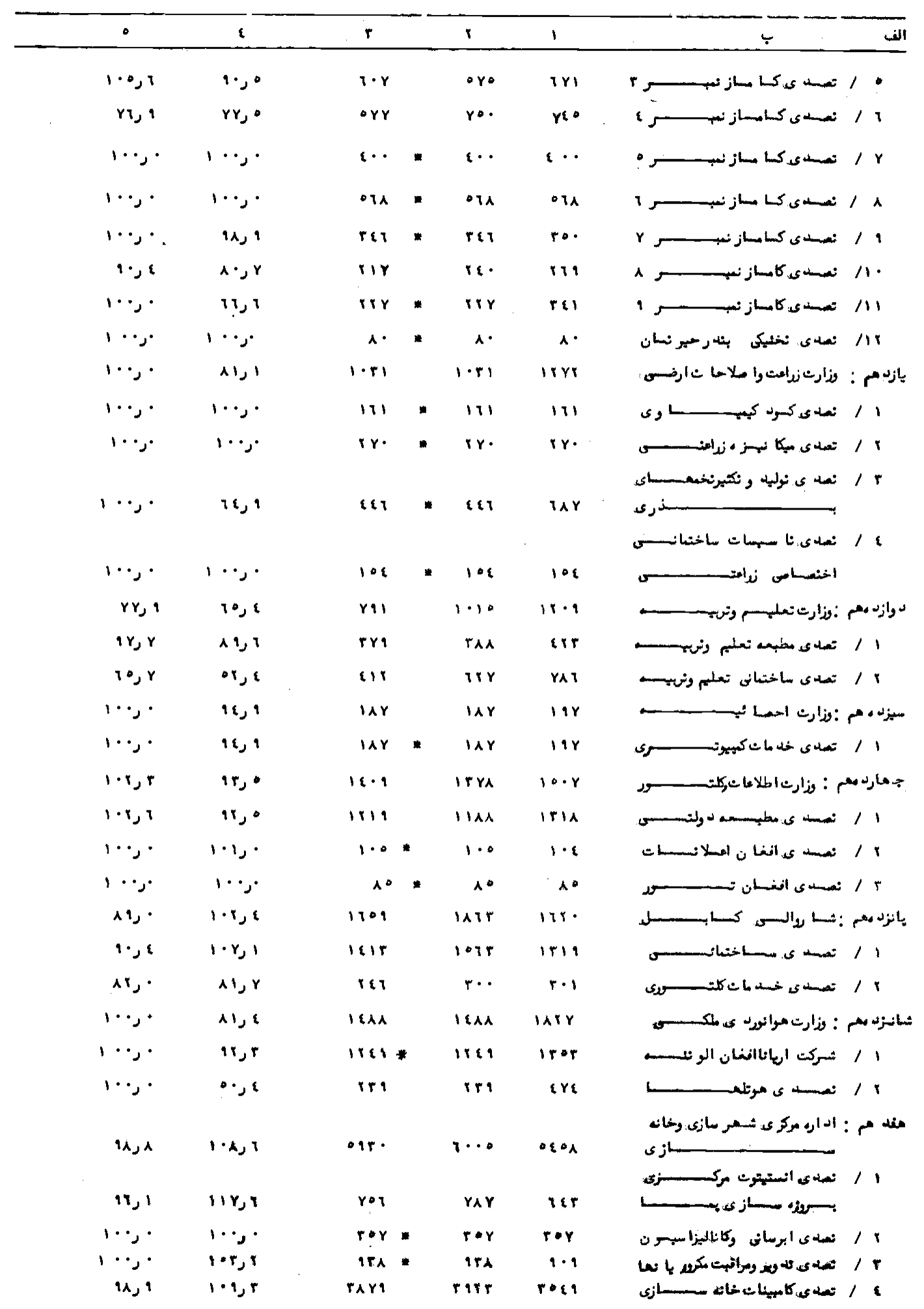




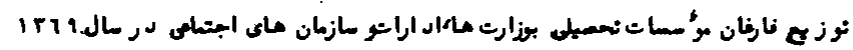

\begin{tabular}{|c|c|c|c|c|c|c|}
\hline \multicolumn{2}{|c|}{ 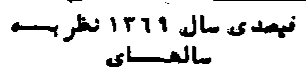 } & \multirow[t]{2}{*}{1819} & \multirow[t]{2}{*}{ Irra } & \multirow[t]{2}{*}{ irir } & \multirow[t]{2}{*}{1 دارات } & \multirow[t]{2}{*}{ تمساره } \\
\hline irdx & iris & & & & & \\
\hline - & $i$ & $r$ & $r$ & 1 & ب & الف \\
\hline $\begin{array}{l}11 r, y \\
1 \wedge y,\end{array}$ & 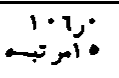 & $\begin{array}{l}11+8 \\
10\end{array}$ & $\begin{aligned} & \bullet \wedge-9 \\
& 1\end{aligned}$ & irti & 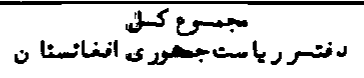 & 11 \\
\hline $1 r_{0} \cdot$ & $\bullet 9,1$ & ir & $r i$ & $n_{1}$ & رياسـت ثــــــــاكغز جــــــــان & 18 \\
\hline in, & $11 \cdot j \cdot$ & 11 & 11 & 1 & وزارت بــ & /r \\
\hline $1 \wedge, \lambda$ & $i \cdot r$ & 11 & 11 & ry & 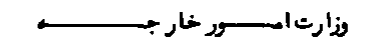 & 18 \\
\hline $9 r$ & $r \wedge, \lambda$ & וI & $r A$ & ir & 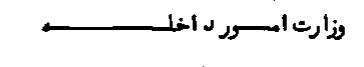 & 1 \\
\hline $1 \bullet r, r$ & $1 r 0,1$ & irr & 11 & $1 r \lambda$ & 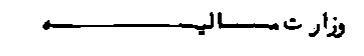 & 11 \\
\hline ا با مزتب & $16, x$ & ir & 19 & 19 & 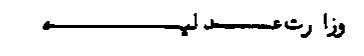 & / $r$ \\
\hline 19, & r & 11 & II & ir & 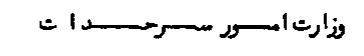 & $1 \wedge$ \\
\hline 110,0 & $101, \gamma$ & 198 & Irr & $M$ & 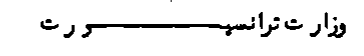 & 19 \\
\hline $\log 1$ & $1 r 2,1$ & ril & 11 & ror & ونارثا بو بسـ & 1. \\
\hline $\operatorname{lrog} r$ & $1 \cdots, r$ & 111 & 16 & Irr & وزارت معساد ن و منايـــــ & $M$ \\
\hline iris & $\operatorname{lrq}, q$ & $r$ & 101 & itr & وزارث صنايع خغينمو مواد غذائه & $1 \pi$ \\
\hline 191 & $r i, r$ & ro. & ry. & rry & وزارث تحميلاتعالى و مسلكسـى & / Ir \\
\hline$\| 1 x$ & $r i, r$ & $r \cdot r$ & iri & rar & 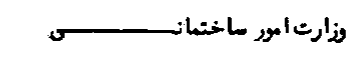 & 112 \\
\hline - & $9 \cdot, \cdot$ & ror & $r$ & IAL & وزا رت نداعست واملاحاتارضسى & 110 \\
\hline $1 \cdot 9, r$ & $r \cdot, r$ & ur & $r a$. & .98 & 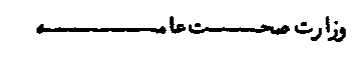 & 111 \\
\hline $1 \cdot 9,1$ & $11 \cdot, r$ & 11 & $|r|$ & ודו & 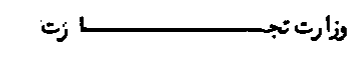 & / ir \\
\hline$r \cdot 1$ & 190,1 & $1 \cdot r$ & is & Ar & 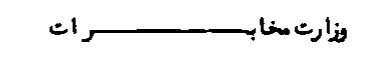 & 111 \\
\hline in $r$ & $\operatorname{lr} x$ & $r \cdot\{1$ & $Y \cdot Y E$ & $170 r$ & 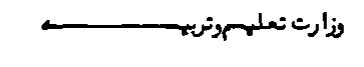 & 119 \\
\hline | & $1 \cdot r, r$ & ri & 16 & ir & زوارت ثئو ن اسلاه واوتســـــــ & 18 \\
\hline ira, $r$ & Iis & 11 & or & $r$ & وزارتدنف & 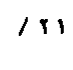 \\
\hline iris. & $1 \cdot 1,1$ & $u$ & Al & 11 & وزارت موانورلى ملكـــــــــ & / \\
\hline $\ln , 1$ & 141, & .6 & 11 & ry & وزارتامورعود تكند ه كــــــــن & /ir \\
\hline
\end{tabular}




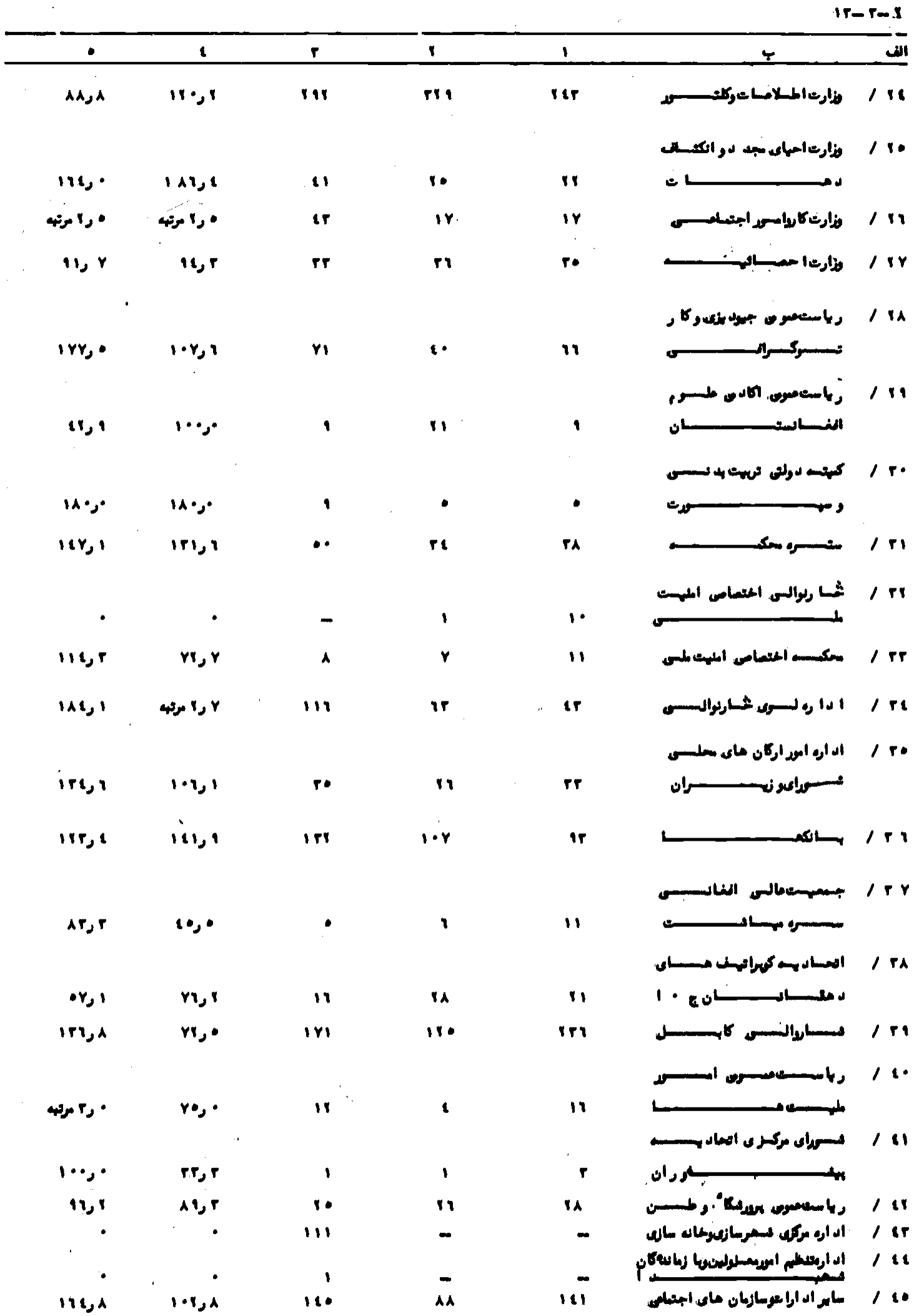




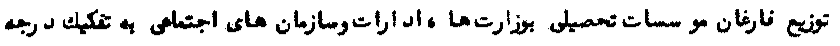

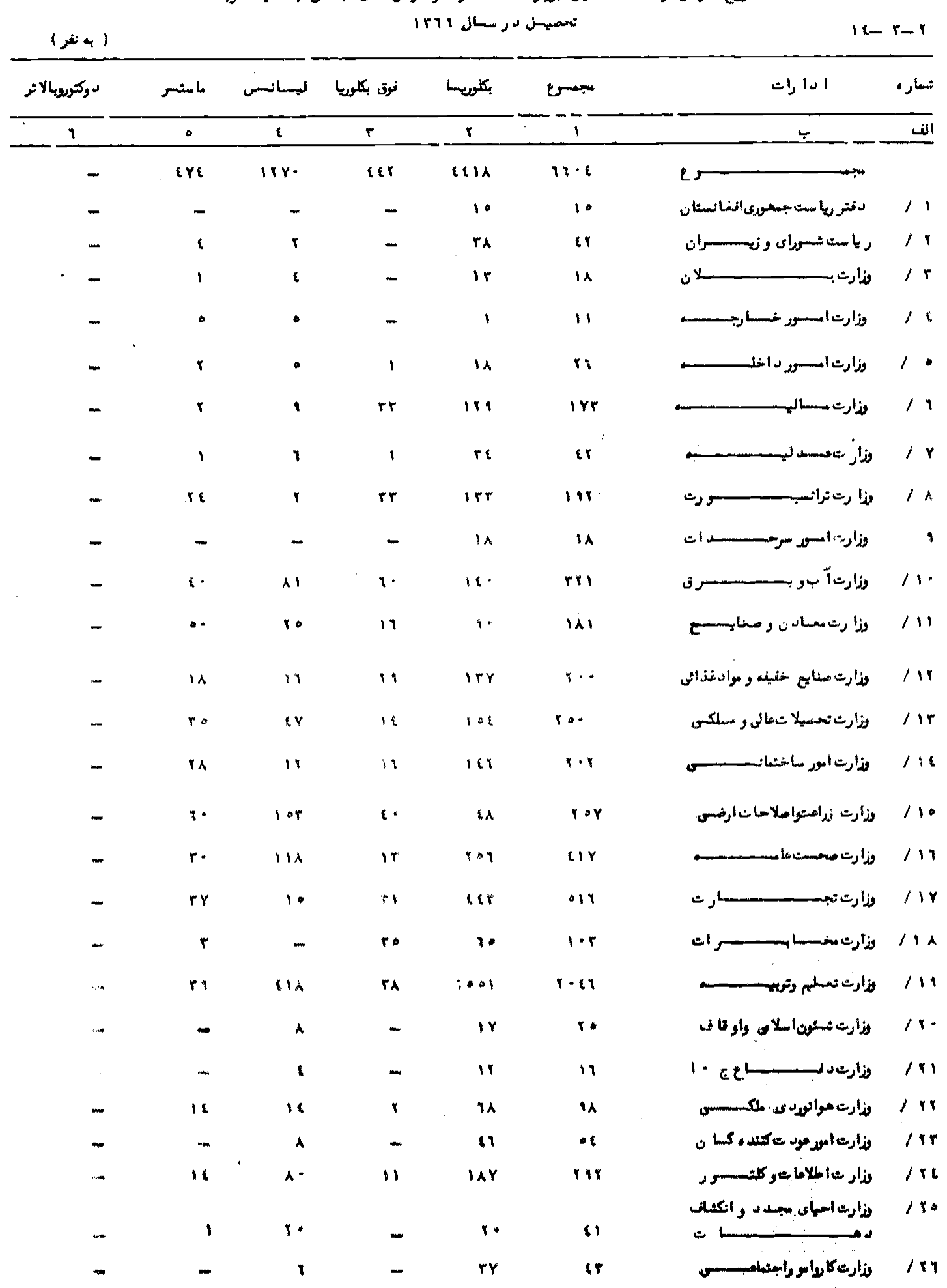


$18-r-r$

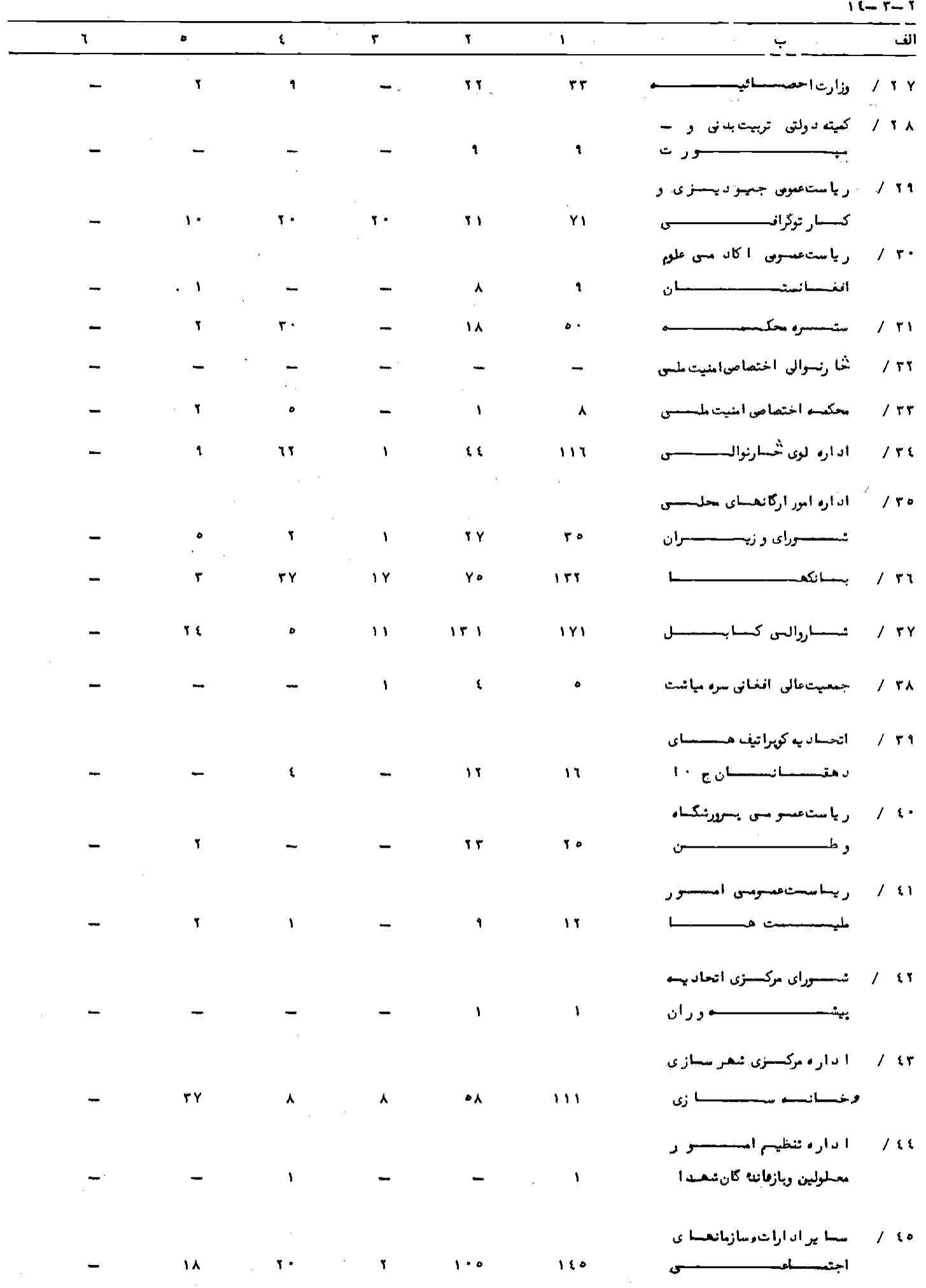




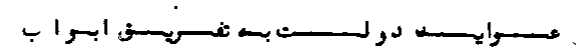

\begin{tabular}{|c|c|c|c|c|c|c|}
\hline ن افغانت & & & & & & $-\varepsilon-1$ \\
\hline كا ا نظر به سالعاى & فيعدى سال & Irt9 & iris & ITII & ثغصبــــــلات & |بحســــ 1 \\
\hline IrM & ITIY & & & & & \\
\hline$\cdot$ & \{ & $r$ & $r$ & 1 & 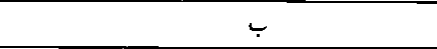 & الف \\
\hline 1A, : & 181 & irrots & irras, & $r \cdot 9 \cdot 1, \varepsilon$ & مجمس & \\
\hline 118,5 & $18 \gamma_{0}$ & $99 r \gamma, 0$ & novese & 0900,1 & 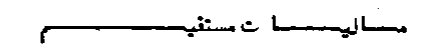 & $\cdots$ \\
\hline $1 \cdot r, \lambda$. & $10 \cdot, 8$ & q.१หر. & ra ra. & rrre, $r$ & ماليسات برعايهاث الشخامحفية & $11 \cdots$ \\
\hline & & & & & 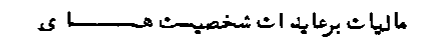 & $i r$ \\
\hline $1\{0,1$ & 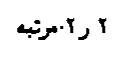 & $r T \cdot i_{j}$ & $10 \wedge \wedge,\{$ & $1 \cdot 10,2$ & 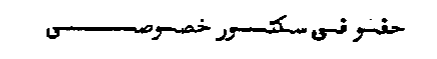 & \\
\hline - & - & - & - & - & ماليا ثبرعسابيه اثكويراتيف سكورخسو صى & ir. \\
\hline- & - & - & $18, \lambda$ & $r A, r$ & ماليات توعابها اثنشركث ماى يختلسـسط & $12 \cdots$ \\
\hline $1\{9,1$ & $1 r 1, r$ & $10 \cdot 9$, & $1 \cdot 11,0$ & $11\{x, 9$ & مالبات برعابد ان نمد يعأى دولتسى & 10. \\
\hline 170,9 & أ و را برنب & $1 k \cdot 1, r$ & isre, r & $M i \varepsilon, 0$ & 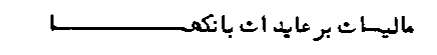 & $17 \%$ \\
\hline 10,0 & 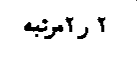 & $1 \varepsilon, 9$ & יני & i & ماليات برعابد اتكو براثب هاى د ولنسى & ir. \\
\hline$\{9,9$ & $1 \cdot 1,1$ & $r \cdot r, q$ & $\{15\}$, & $r \cdot r, r$ & 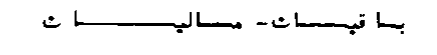 & $11 \cdots$ \\
\hline $11 r, r$ & $I r \varepsilon, T$ & inr $\cdots$ & $1870\{1$ & $10 \cdot\{r, Y$ & 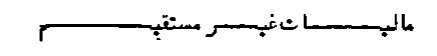 & $r \cdots$ \\
\hline$\|$ נוr & $\operatorname{irs} \mathrm{s}^{\circ}$ & |A rA\& & $|r \varepsilon| r \mid$ & 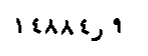 & مالبـا تسنتيم سكتر خصسـوصسيسى & $n \cdots$ \\
\hline$r \cdot r$ & " رب & $r T, q$ & $11 x, 1$ & $\{r, r$ & 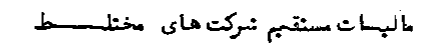 & 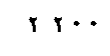 \\
\hline 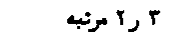 & | أمرنبه & rit, & $1 r 0, r$ & $11 \alpha, 1$ & مالياث ـسنتيم سكور دو لنــــــــــــ & rte \\
\hline & & & & & عوابد غير خالصفوشآلَ ن المــــــال & $r \cdots$ \\
\hline ir & $10, \gamma$ & $19 r \cdot, 1$ & $r \cdot \lambda \varepsilon, 0$ & $\mid r r \cdot q, r$ & 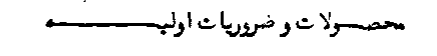 & \\
\hline 109 & 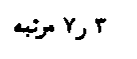 & $r 0$, & $\{r, 0$ & $\wedge, 9$ & عوابــ غير خالصنفرئ زمين وساخنطان & $r \cdots$ \\
\hline ا & 1,0 & $1 \pi, r$ & $r r, 0$ & $1 \cdot k \lambda T, 1$ & عوابه غبـر خالصفرش منابح طبيهــى & $r$ \\
\hline rit & $\bullet 9,1$ & $r \cdot{ }^{\prime}$ & $r r o, \lambda$ & $1 \cdots, r$ & عوابد غبـرخا لصفرونَمنابع نراعنى وحبواثن & rte \\
\hline $1 \cdot r \cdot 0$ & $1 \cdot 0$, & $90 \varepsilon, 9$ & $9 r, r$ & $9 \cdot 9, r$ & 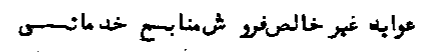 & $r q \cdots$ \\
\hline 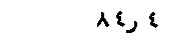 & $|r|, r$ & \&rT, : & $011, r$ & $r=4, t$ & عوايد ازمد رك فر شاموال لبلاه وضبطد & ro... \\
\hline $1, \lambda$ & $|\pi x|$ & $r o 0,9$ & $r i r, r$ & $10\{1$ & 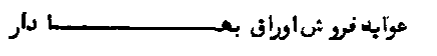 & ri.. \\
\hline $1 \cdot 9 \cdot$ & 118,1 & $\wedge \mu, \tau$ & $A \cdot r, q$ & $r \circ \varepsilon, 1$ & عوايبح لاهنسعا نبسعساوجسـرايســـ & ? $\cdots$ \\
\hline 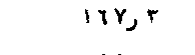 & $\{r, q$ & $1 \varepsilon \cdot$ & $A T, r$ & $\operatorname{rrat}$ & 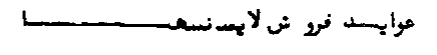 & \& $\cdots$ \\
\hline 9 & ا با برنب & ror, & $r \circ \varepsilon, 9$ & or,$r$ & 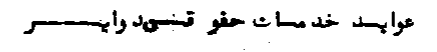 & $\{r \cdot$ \\
\hline 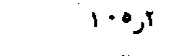 & 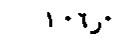 & rAA, & 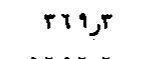 & Tוז & 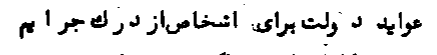 & $\varepsilon r \cdots$ \\
\hline ונזוזי & $1 \Gamma 1,1$ & $\hat{n \cdot A l, r}$ & זرזיוץ & rori, & 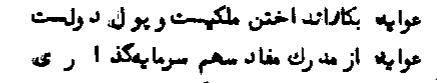 & $\cdots$ \\
\hline - & - & -- & - & - & 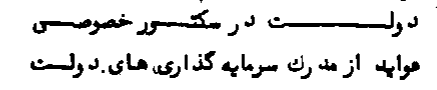 & or. \\
\hline$\overline{a r}$ & $\mid r r_{1}^{-}$ & (1) & $\operatorname{irrA,\lambda }$ & $\begin{aligned} \cdot r \\
1 \cdots,\end{aligned}$ & 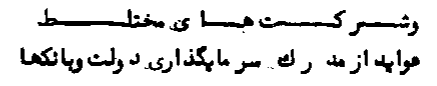 & or .. \\
\hline
\end{tabular}




\begin{tabular}{|c|c|c|c|c|c|c|}
\hline 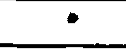 & 1 & $r$ & 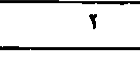 & 1 & ב- & الفي \\
\hline & & & & & 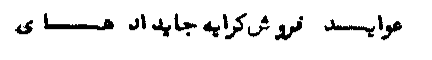 & . 4. \\
\hline$|r A| \mid$ & 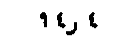 & 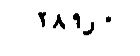 & $i r, r$ & $r \cdot r, 1$ & 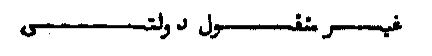 & \\
\hline $1 \cdot, \cdot$ & זי מי & $r, r$ & $r r_{j} \cdot$ & r & عوائ كرايسه جايج الد ماى منغول ل دولتي. & $\ldots$ \\
\hline lro, & " & - & rreja & $r r i r, r$ & موايه نمد ى ما ى دولنــــــــــــ & .9 \\
\hline- & - & - & - & $1, r$ & مو ابه كو يراتين ما ى دورلتـــــــــ & •r.. \\
\hline$r$. & • & $1 \wedge, \gamma$ & $\wedge \wedge, \gamma$ & $19 r \circ 1$ & 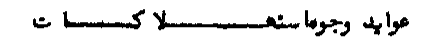 & ${ }^{\wedge} \cdots$ \\
\hline 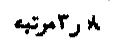 & 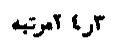 & $r r \cdot r, r$ & $10, r$ & $r_{\jmath} \cdot$ & سايرووائ بكارايد اختن ملكيتبول دولت & $\bullet .$. \\
\hline 19, & Ar, 1 & 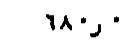 & $r(1 \cdot, r$ & $A Y A, r$ & 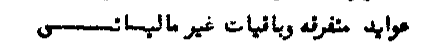 & $\cdots$ \\
\hline$r$, & 10,4 & • ניr & $\operatorname{irs} r$ & $r \cdot s$ & 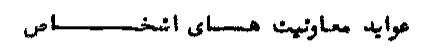 & $\eta \cdots$ \\
\hline- & - & - & - & - & موايه ازدر لغلو ش السنسادو فرضــ & $r \cdots$ \\
\hline 14,1 & iros. & 0.8 & $r \cdot\{1\}$, & $q \cdot q^{\prime} \mathfrak{q}$ & موايد اعاد ه ناديات الهانى وينسكى هـا & ir. \\
\hline $1 \cdot 1,0$ & י וניו & $1 \cdot 9 \cdot 0$ & $1 \cdot r, 1$ & $11 r, 6$ & 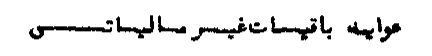 & $\mathfrak{n}$ \\
\hline 41 & 119 & $(r, y)$ & $\| r r \rho^{\circ}$ & LAr & 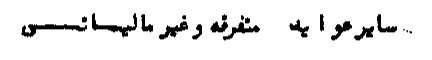 & $19 \cdots$ \\
\hline $\operatorname{lr} \lambda^{\prime}$ & $18^{\circ}$ & $r \circ y, r$ & $\circ r_{1}$, & $\cdot e \cdot, r$ & 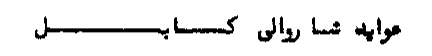 & r... \\
\hline 1198 & $198:$ & ritr & $\forall \wedge r \gamma^{\circ}$ & $\operatorname{lrr}, 9$ & 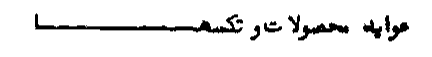 & ri.. \\
\hline ( & - & 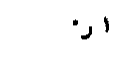 & - & - & 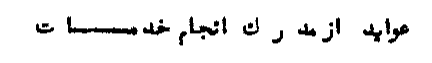 & $r r \cdots$ \\
\hline 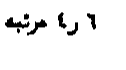 & - & 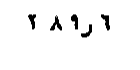 & irs & - & موايه فمد شاموال منتول وغير نفــل & rrw \\
\hline inr, & ir. & $p r$ & 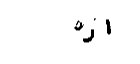 & $\because, y$ & 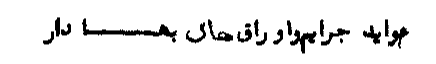 & ra. \\
\hline$n 1, r$ & ri, & $1 \cdot 1$. & $11 r, 9$ & rroph & 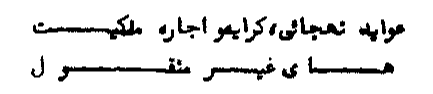 & ro.. \\
\hline- & - & - & - & - & 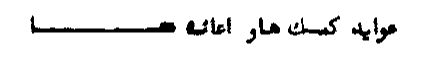 & rin \\
\hline riso & ا ل آمتثب & $r \cdot r$ & 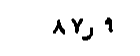 & 1 & 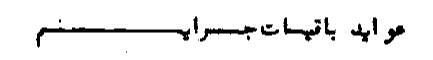 & $r r \cdots$ \\
\hline- & - & - & - & - & مواهيد نعسالهـت ماى نجارتى وصنمتى & $r_{A} \cdot \cdot$ \\
\hline 1.9. & $l i r, y$ & 4 & A० 1 & $1 \cdot i, 0$ & 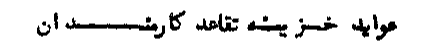 & ^ $\cdots$ \\
\hline $1 \cdot 00$ & $1 \varepsilon y, \gamma$ & 9 & a.rsi & $r \cdot 9 \cdot$ & 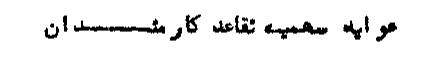 & $\wedge 1 \cdots$ \\
\hline $11 \cdot, 9$ & is & ara & rarros & $g r d a, d$ & 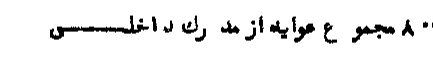 & $-1 \cdots$ \\
\hline $1 \cdot 0,1$ & $1 r 1, r$ & r.rrtas & $19+196$ & $\mid r \cdot A \lambda ر$ & 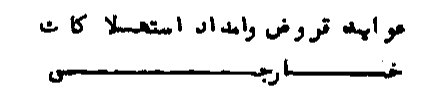 & $\cdots$ \\
\hline - & - & - & $r r \wedge, r$ & - & $\longrightarrow$ & \\
\hline $1 \wedge, \gamma$ & r., & riras & $x \cdot 1,5$ & Mitי & 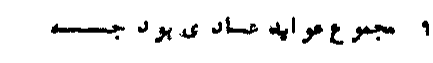 & $\cdots-1 \cdots$ \\
\hline 148 & 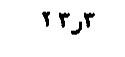 & ra. & stipe & $1 \cdot r 01,0$ & 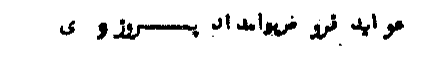 & $\cdots$ \\
\hline- & - & - & - & $9 \wedge_{\mu} \cdot$ & 1 مو ايه ازكانعاى سلحس & a.- $\cdots$ \\
\hline $1 \wedge, 6$ & 19 & rerragr & $\operatorname{Mras}$ & $r \cdot 9 \cdot \lambda, \&$ & لمبمع مو ايد & \\
\hline $1 \cdot 1,6$ & - & $1 \cdot 16$ & $1 \cdots$ & - & 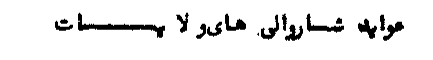 & \\
\hline iAs: & 161 & irrorer & irrats" & $r \cdot 9 \cdot A, t$ & هنزا نكلد & \\
\hline
\end{tabular}

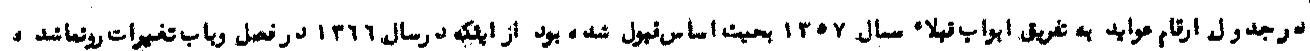

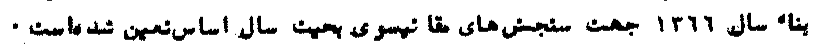




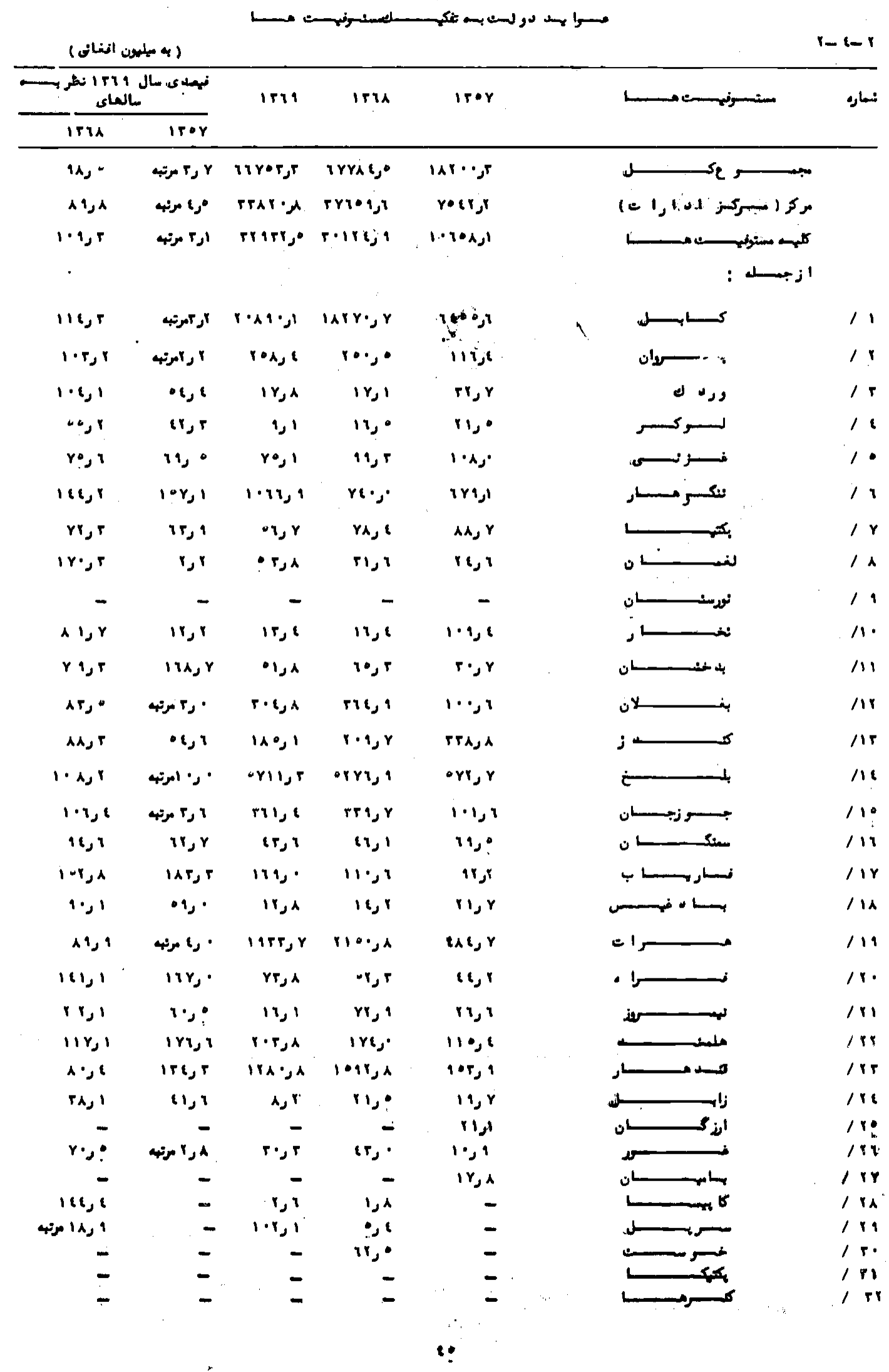



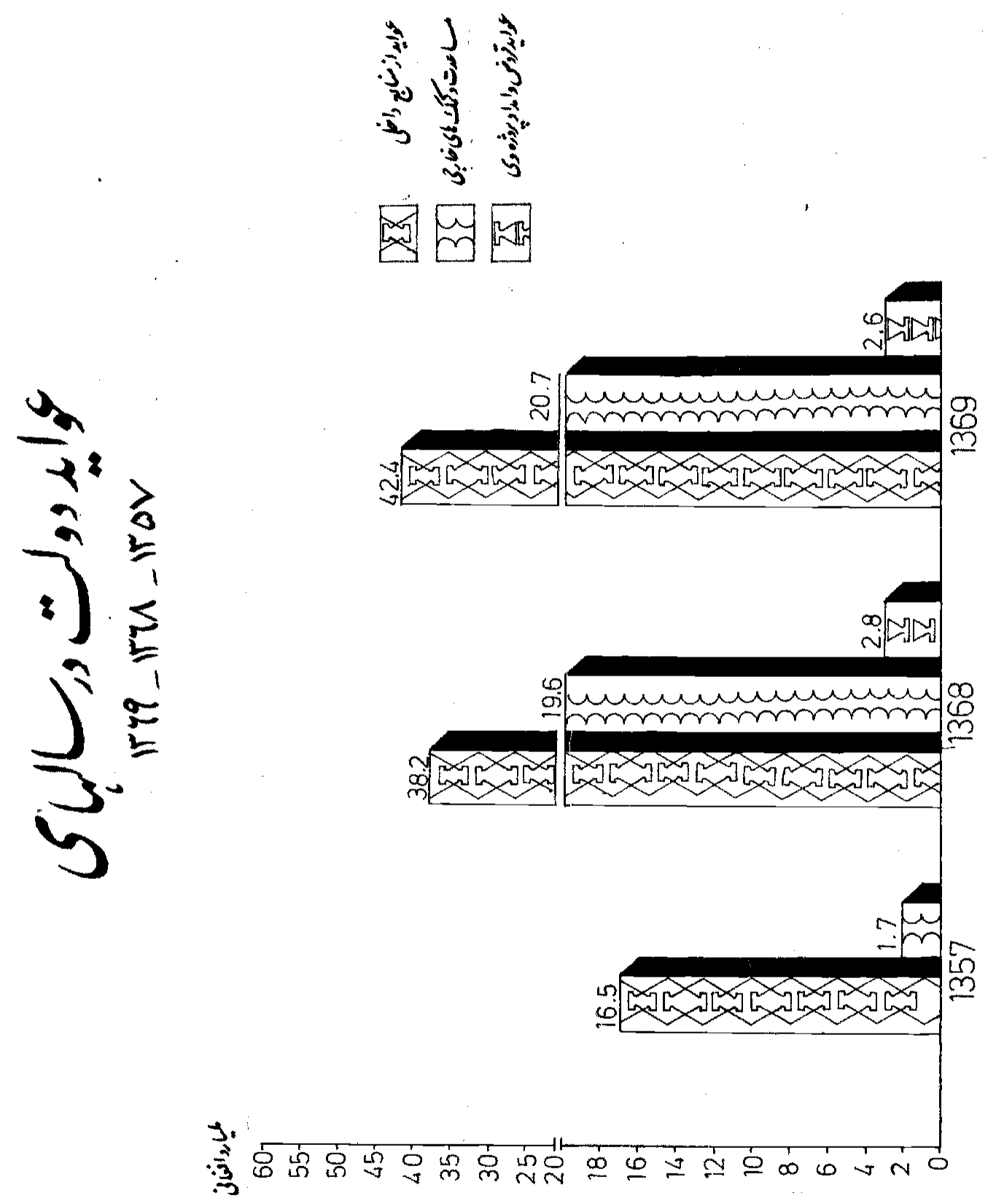

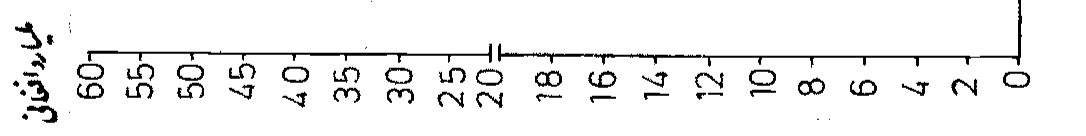




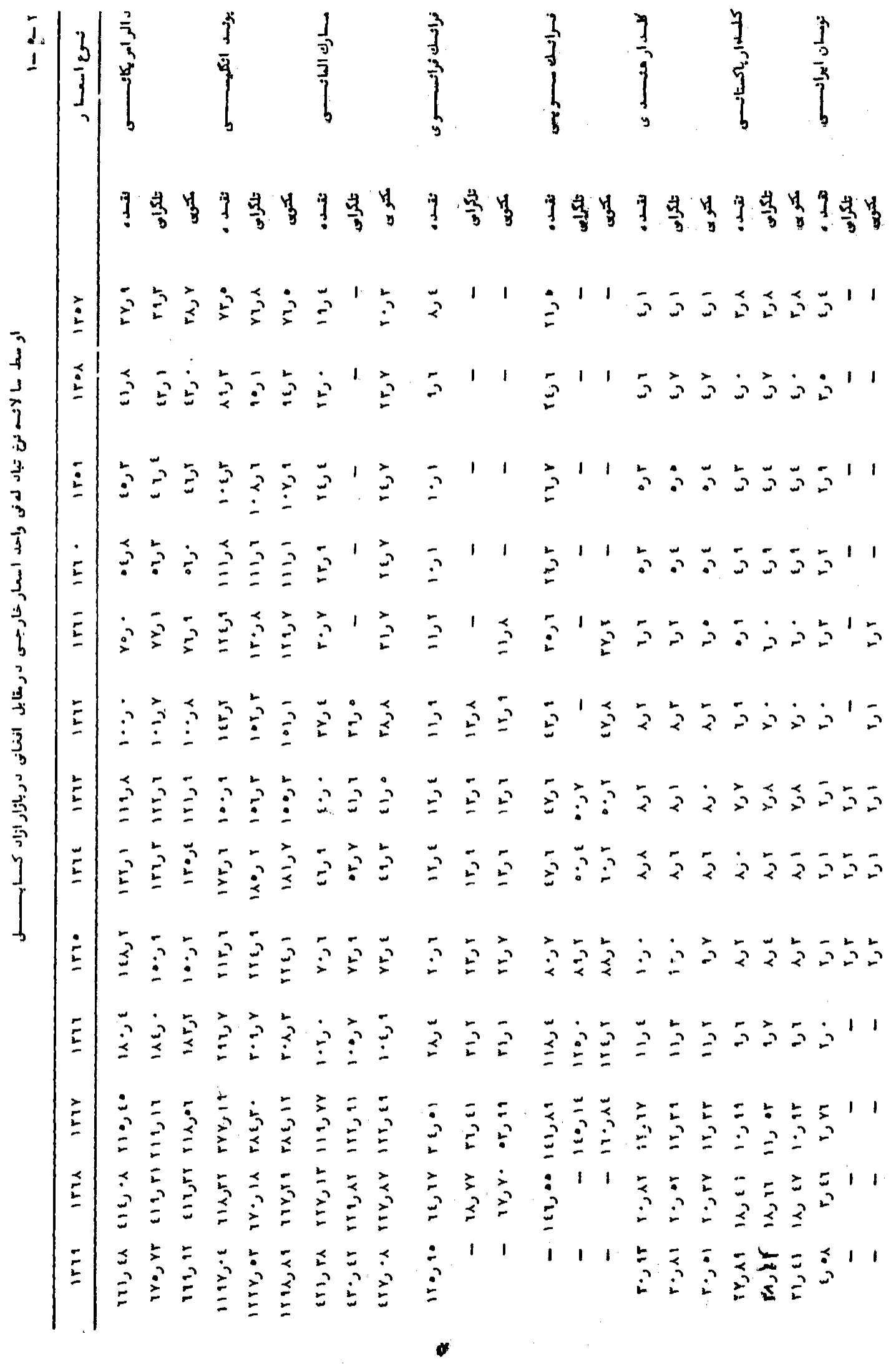




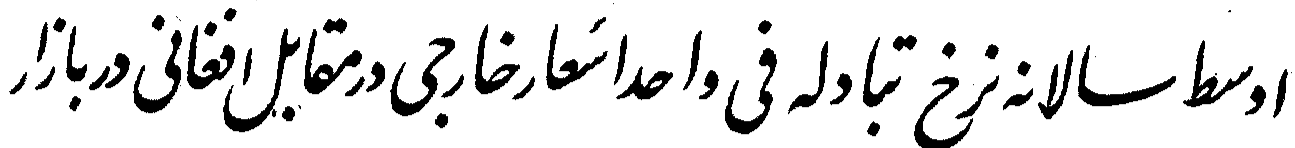

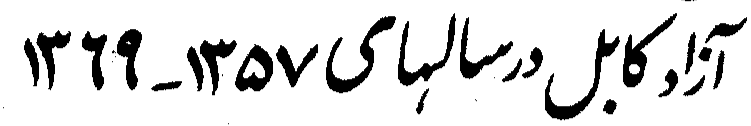

i).

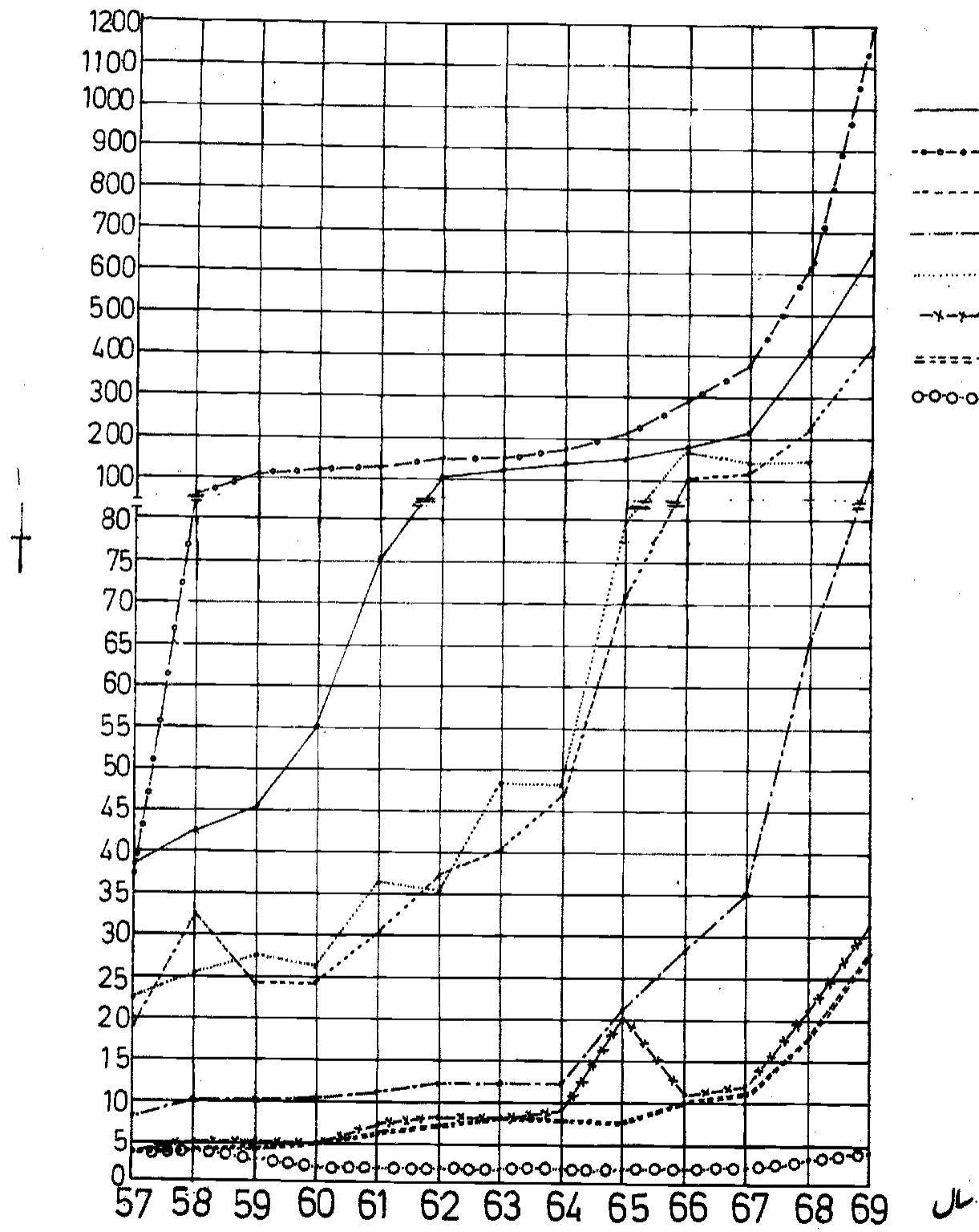




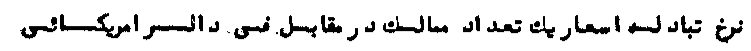

\begin{tabular}{|c|c|c|c|}
\hline \multicolumn{3}{|c|}{ 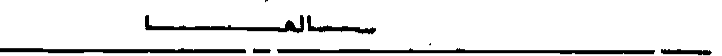 } & \multirow{2}{*}{ " } \\
\hline 1879 & Irin & irir & \\
\hline$\bullet, r$ & $\bullet, r$ & $\bullet, r$ & 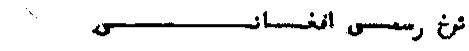 \\
\hline$\wedge \bullet \bullet \wedge r$ & - & $\operatorname{YE}, \wedge A$ & 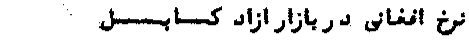 \\
\hline $1, r v \varepsilon$ & $1, Y \wedge A$ & 1,119 & 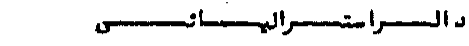 \\
\hline$\cdot$, rrt & •, rri & $\cdot$ erri & 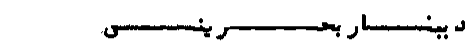 \\
\hline$r \cdot r q$. & ristre & $r y, r r \cdot$ & 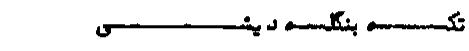 \\
\hline 1,178 & $1,1 \mathrm{rA}$ & $1,19 r$ & 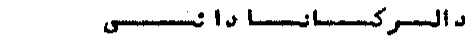 \\
\hline- & r, rrr & r, rrr & بهن- \\
\hline $10,1 \cdots$ & $1, \cdots$ & $\mathfrak{q} \mathfrak{\imath} \cdots$ & 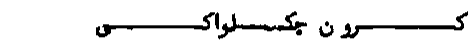 \\
\hline$\bullet 1 \cdot 1$ & $r_{\text {p }} q \cdot$ & I,AY\& & 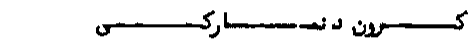 \\
\hline$\bullet \bullet \wedge \wedge$ & urro & $1, \cdot 01$ & نسمست \\
\hline 1,18 & 1,11 & $1, r A \cdot$ & 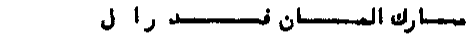 \\
\hline$r, r a$ & $r_{1} \wedge \cdots$ & $\checkmark, \wedge \cdot \wedge$ & 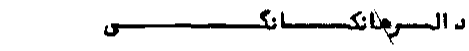 \\
\hline Tr, rA & •1, ० \& & $\Delta r \cdot r r$ & نس ندئد \\
\hline$|s,| \gamma \cdot$ & 17,780 & 18,189 & 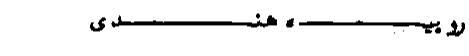 \\
\hline 11, Ү人 & $r r, r \cdot$ & $1 \wedge, \bullet i$ & $x^{\prime} J^{2}$ \\
\hline $11 r A, Y$ & irrogr & $\mid r \cdot a, \lambda$ & s \\
\hline $1 r q, r o$ & $i r q, r \cdots$ & $1 r \cdot, A 0$ & w \\
\hline 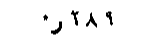 & P rqr & e rar & 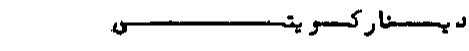 \\
\hline 1,100 & $r 1, r \cdot$ & $11,1 \cdots$ & سـاكستـستسانسستس \\
\hline$r, r \& 0$ & $r$ reo & $r, r \in$ & s. \\
\hline $1, r \cdot 0$ & 1,1 & $1, \mathfrak{x}$ & 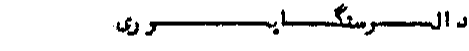 \\
\hline 1, rar & 1, Tוx & $1, \cdots \mathfrak{q}$ & \\
\hline$r *, \cdot q$ & $r o, r i$ & $r \bullet, r q$ & 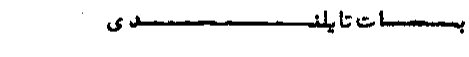 \\
\hline$\cdot 098$ & e $1 \mathfrak{a}$ & - & 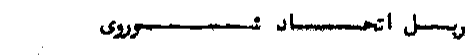 \\
\hline *رols & $\cdot \pi$ & $\cdot, \bullet r$ & بس بستسنس \\
\hline
\end{tabular}

نسوت

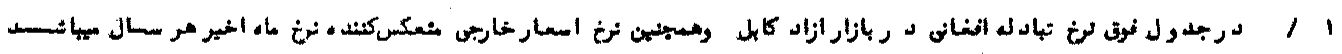

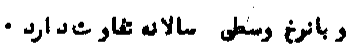

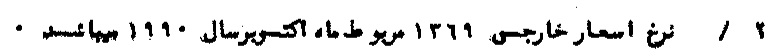

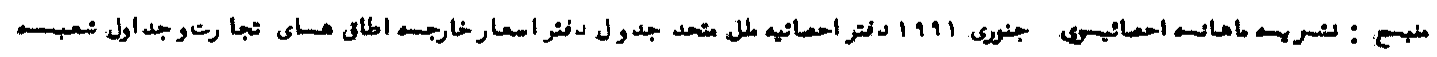

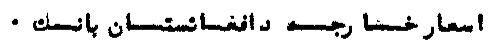




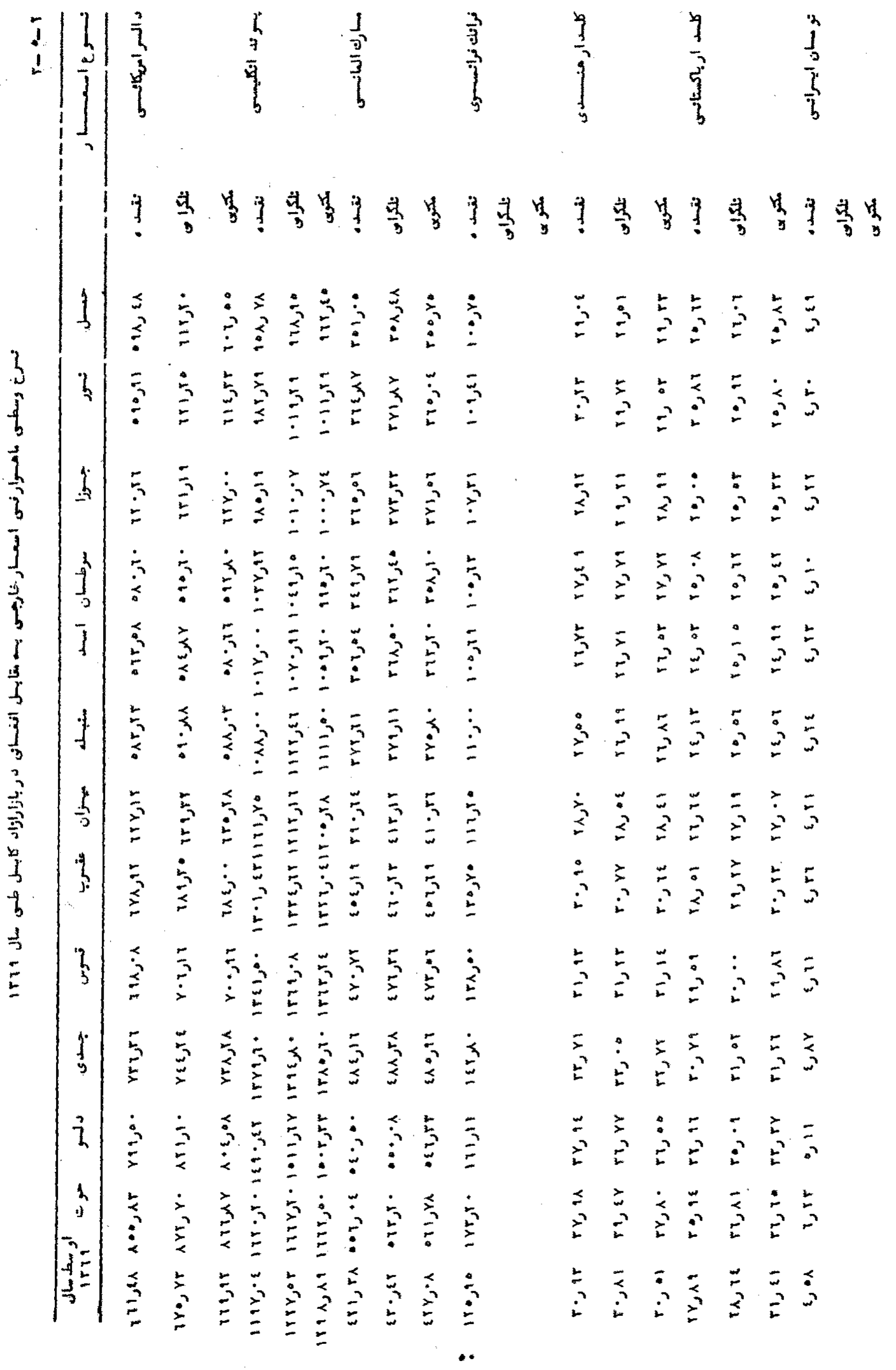




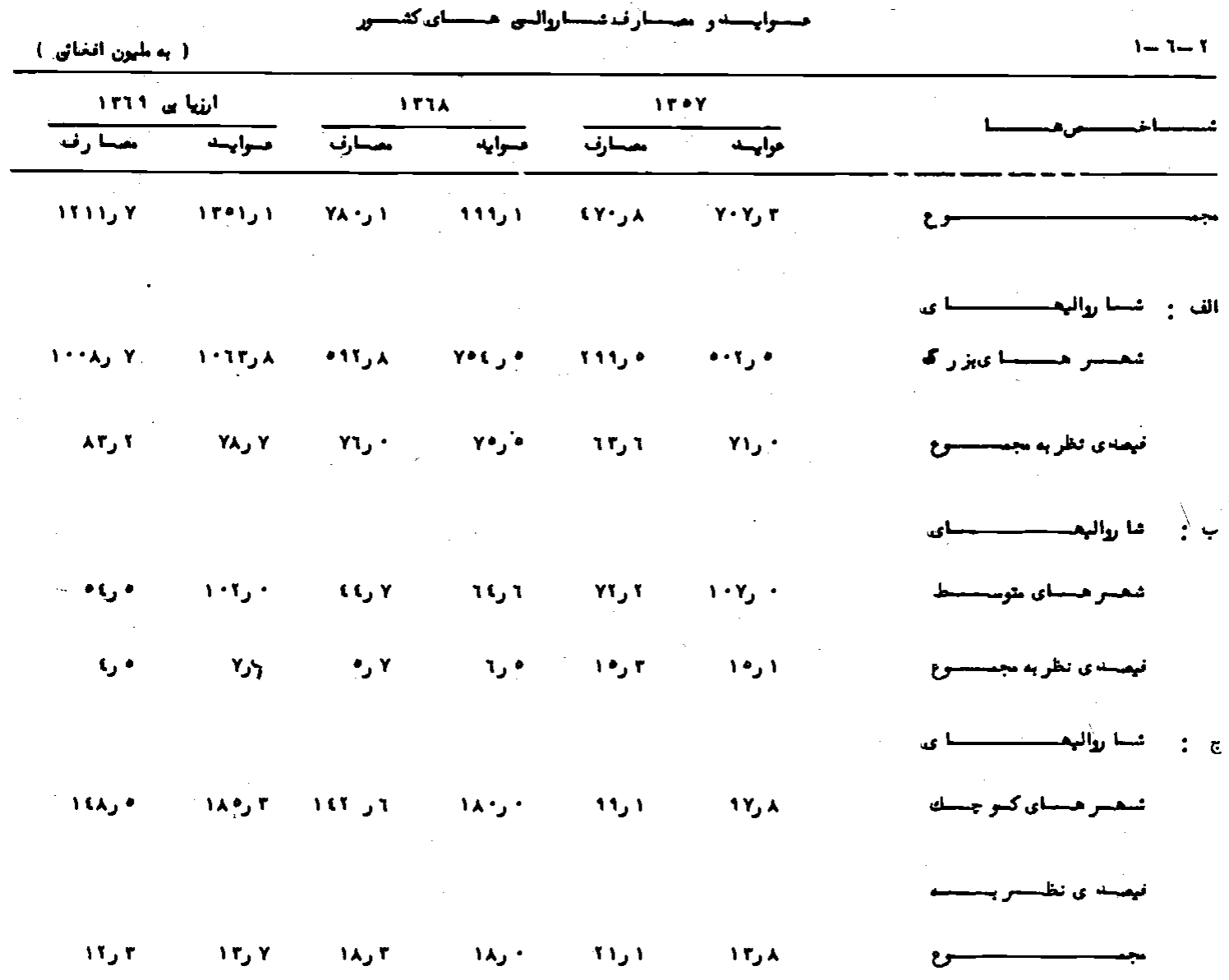

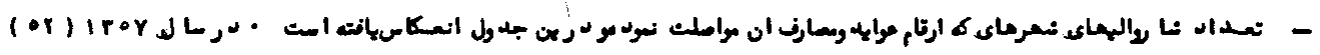

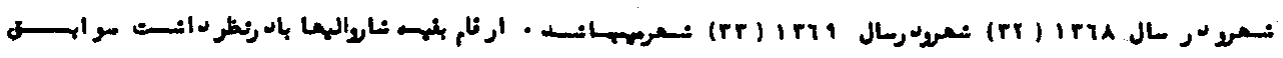

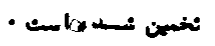

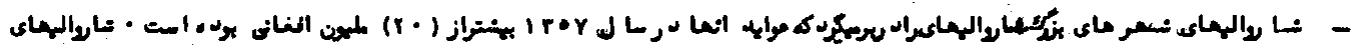

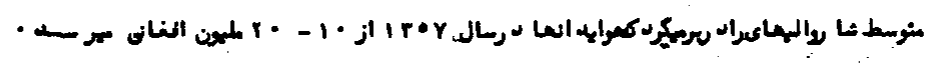

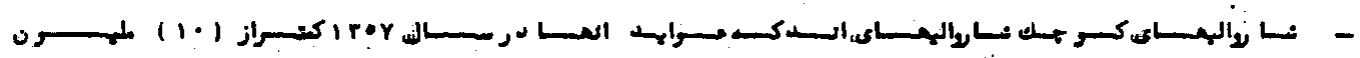
افغانسي مبادســــ 


\section{4. $\frac{3}{5}$ \\ 因迤}

')

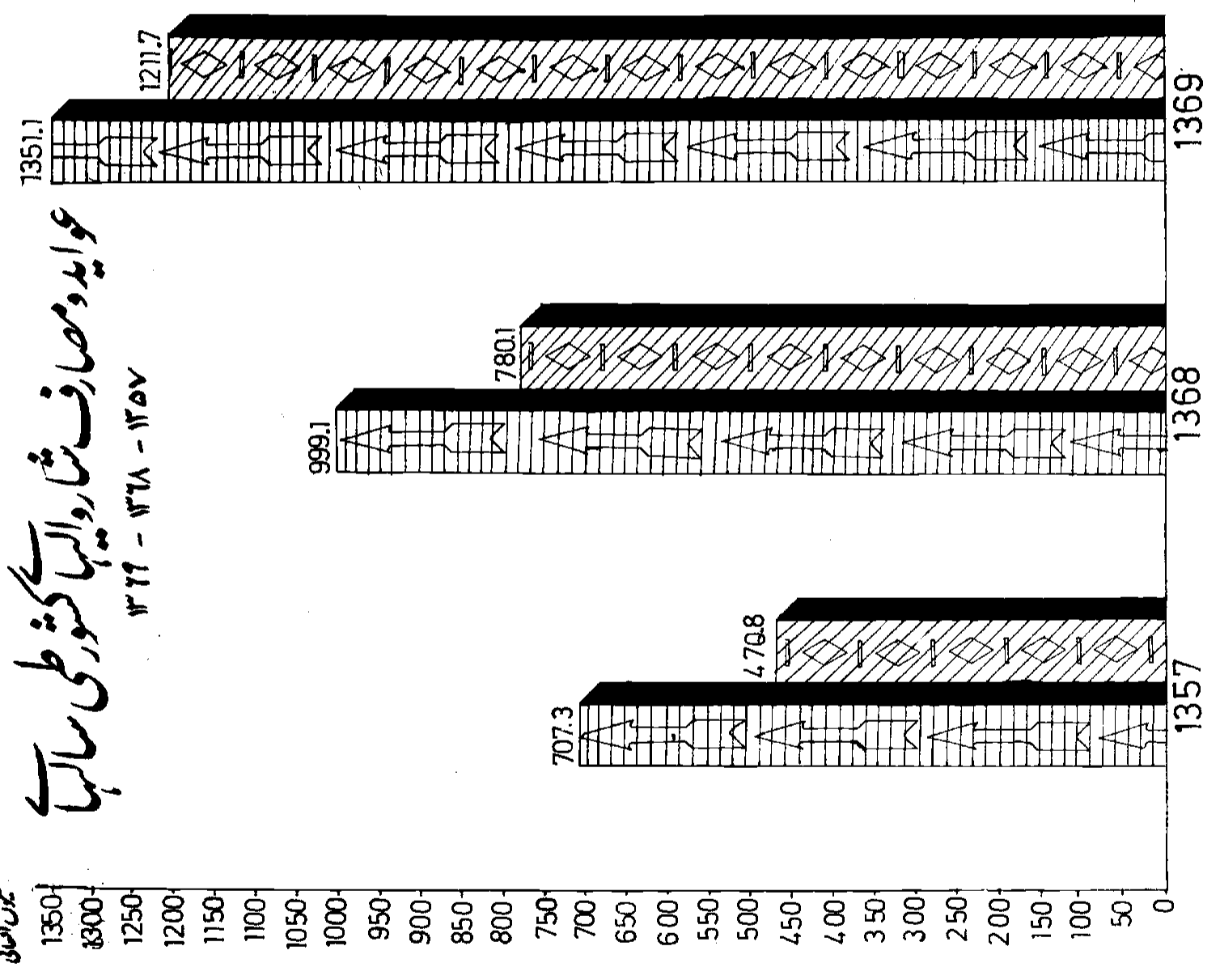




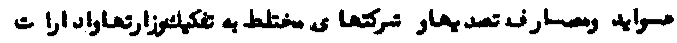

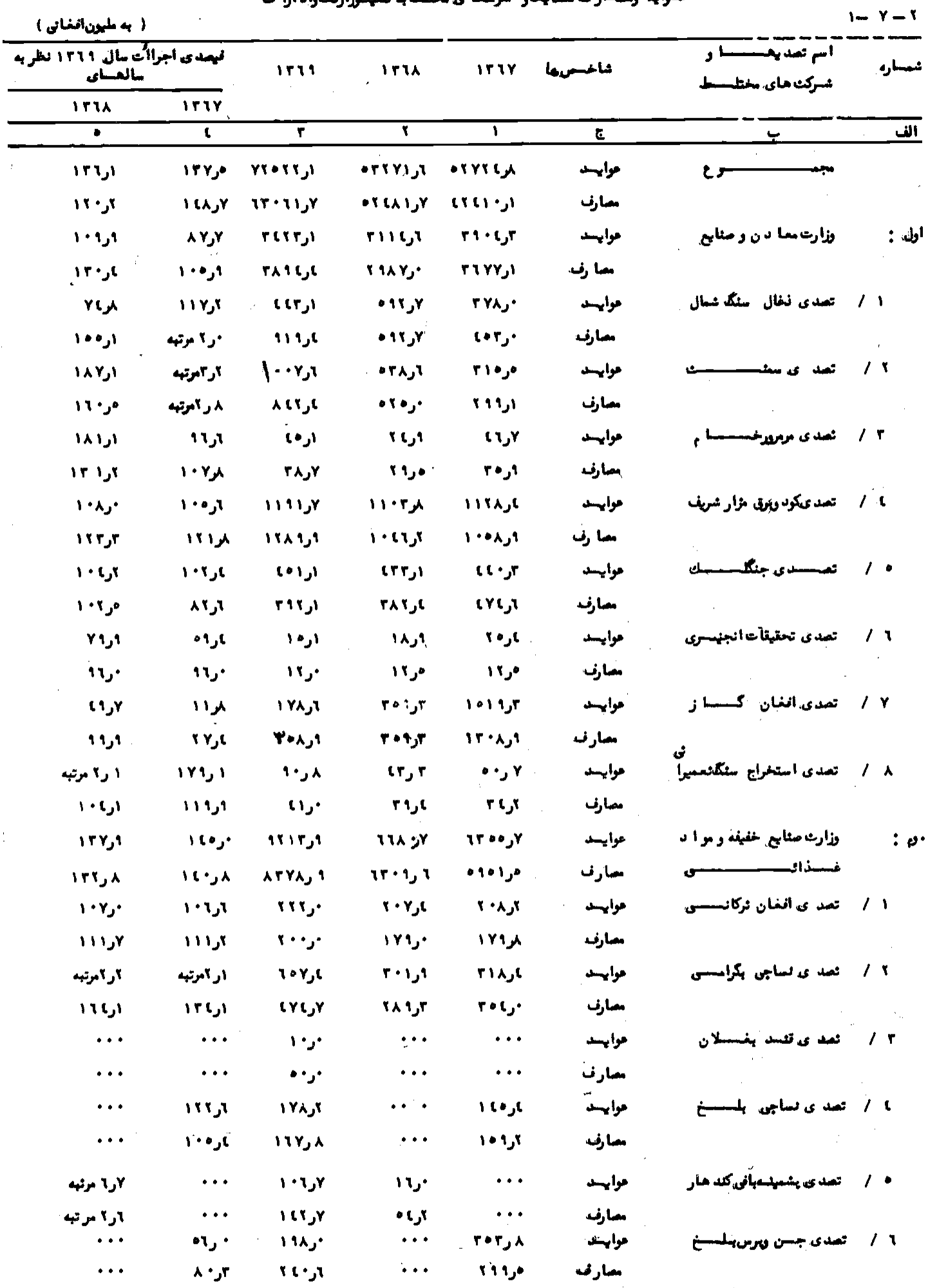




\begin{tabular}{|c|c|c|c|c|c|c|c|}
\hline$\cdot$ & 8 & $r$ & $r$ & 1 & $\varepsilon$ & 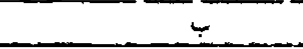 & الف \\
\hline$A Y, \varepsilon$ & $|r|, 1$ & ArY,Y & $98 \gamma$, & $\operatorname{irrg}$ & عوايسد & 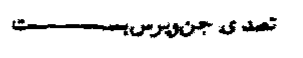 & / r \\
\hline $1 \cdot r, r$ & $1010^{\circ}$. & riv & ل & טגוי• & يمارنت & & \\
\hline$\cdots$ & $\cdots$ & $\cdots$ & • & $\cdots$ & عوايسد & تصد ى ميحوث كثد مستســـار & $1 A$ \\
\hline$\cdots$ & $\cdots$ & $\cdots$ & $\lambda^{\circ}$ & $\cdots$ & 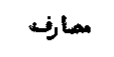 & & \\
\hline $\mid A r\}$ & ارها مرنبه & orr. & $r q u r$ & $r \circ 9, A$ & عوايست & تصدى كليمسد المغستسـا ن & 19 \\
\hline مرب مرنب & 111, & $11 \mu^{\circ}$ & $r i, r$ & 14,0 & مصارف. & & \\
\hline $1 \times \cdot 0$ & $\cdots$ & $\{\cdot 9$, & 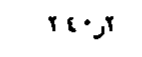 & $\cdots$ & عوايهـد & تصسل ى. سيـــــــن ند & $\Lambda$ \\
\hline $1 \cdot r_{j} \cdot$ & $\cdots$ & ع & $\left\{r \gamma_{j}\right.$ & $\cdots$ & مصارف & & \\
\hline 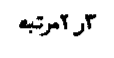 & $|r A|$ & \&7०, & r.s. & rrisr & عوأيس & 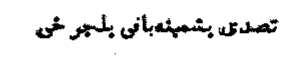 & আ \\
\hline$|7 \gamma|$, & Iria & $\{\cdot 1$, & $r \varepsilon \cdot e^{\circ}$ & $r i \cdot \lambda$ & مصارف & & \\
\hline$\wedge 9,1$ & 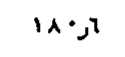 & $r \cdot r_{r} \cdot$ & rथा & $1 r \cdot 1, r$ & غوائسد & تصدى كامبينات نان كابسـل & Mr \\
\hline$\wedge 9, \wedge$ & $\mid r A, r$ & rares. & $r r \cdots, q$ & 1וזי & معسارف & & \\
\hline $1 \cdots, 1$ & $10, r$ & $\left\{A \& \mathcal{J}^{\circ}\right.$ & $\operatorname{Erq} \lambda$ & $0 \cdot r_{\lambda} A$ & عوايسد & تصد ى مبلـوى بهســـــلن & / ir \\
\hline $1 \cdot r, \cdot$ & $1 \cdot \lambda, 1$ & 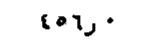 & (ะצ ) & $\sin , \lambda$ & مصارف & & \\
\hline$A: \mathcal{E}$ & $\varepsilon \cdot, \cdot$ & $r r y, \varepsilon$ & rAT,E & $\lambda \cdot r_{\jmath} \gamma$ & عوائسد & نمد ى سيلونى بلخمســرى & 118 \\
\hline$A \wedge, '$ & $r 9,1$ & $r \cdot A \nu \circ$ & rop. & $Y A A, \varepsilon$ & نصارن & & \\
\hline $17 x, 1$ & ناره مرتب & ris. & $19 \cdot 0$ & | & عوا بهد & تصد كي صنايحم انغسلن & 110 \\
\hline$i r \cdot s$ & عاكرتبه & rraj. & (178. & IIr & مصارف & & \\
\hline- & $\mid \& A, \varepsilon$ & $18 \cdot 8 \cdot$ & $\cdots$ & 180, & عوأيسيد & شركت نساجسى انغـــــــان & 117 \\
\hline - & |ران & " & $\cdots$ & $1 \cdot$ & مصارف & & \\
\hline $101, y$ & $\mid 1 x \cdot 1$ & zrristy & raم:A & $r \varepsilon \cdot Y_{0,8}$ & عوايسد & وزارت نجســـــــــــــ & سوم : \\
\hline $110,1$. & اره مرتب & rosors & $r \cdot A \mid \&, 8$ & דرع & 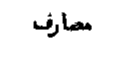 & & \\
\hline rAرl & 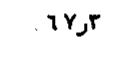 & ונידי & YYISE & $1 \cdots$ & عوايسم & تمدى تعلونى ، تجارتسـى & 11 \\
\hline ارها مرتب & 170,8 & 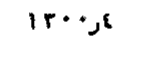 & r & YAP: & مصارف. & 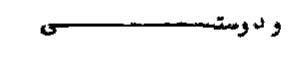 & \\
\hline$\cdots$ & $\cdots$ & $\cdots$ & $\left\{a^{\circ}\right.$ & 198 & عوائسد & نصس ى هسماد رات نباتات & Ir \\
\hline$\cdots$ & $\cdots$ & $\cdots$ & 19 & $r r^{\prime}$ & مصارفت & & \\
\hline$\cdots$ & $\cdots$ & $\cdots$ & $r y$ & or & عوايبهد & نيركست سعانى وصسا. & tr \\
\hline$\cdots$ & $\cdots$ & $\cdots$ & مر & r بر & ممارنـ & & \\
\hline $19 \cdot 8$ & $11, x$ & ratis. & $r \cdot \varepsilon r\}$ & ارثه•r & عوايسد & نمهى أفنطان كسمسـسارت & 18 \\
\hline $9 Y_{j}$ & (r) & (1) & $a r, r$ & تربr & 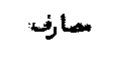 & & \\
\hline$|x| s \mid$ & ت برr مرتب & 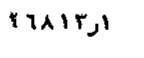 & 18180,18 & $\wedge \wedge 19,1$ & عوأيسد & نصدى ناسين أحنباجسات & 10 \\
\hline$\| r_{j}$ & ع عرب مرتبه & rritas & $r \cdot A r r_{\mu}$ & ( & 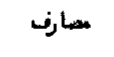 & than & \\
\hline 10,1 & ar & ori, 1 & $r \cdot 9,1$ & 91,1 & عوايسد & نمد ى، ميوه خثلك( سمون) & / 1 \\
\hline$\wedge \bullet, \lambda$ & م & orr. & ז & 180,1 & مصارفت & & \\
\hline$\cdots$ & ro, & $r i r$ & $\cdots$ & $r(A, 1$ & عوايهـ & تبد كي صساد راث بنـســـم & Ir \\
\hline$\cdots$ & $\{r, r$ & $0 \wedge$, & $\cdots$ & | & معارف & & \\
\hline$\cdots$ & $\cdots$ & $\cdots$ & $\cdots$ & $\cdots$ & عوايهد & تصدى نسيرغان بنســـــــر & $1 \wedge$ \\
\hline$\cdots$ & $\cdots$ & $\cdots$ & $\cdots$ & $\cdots$ & مارف & & \\
\hline
\end{tabular}


$1-Y-1$

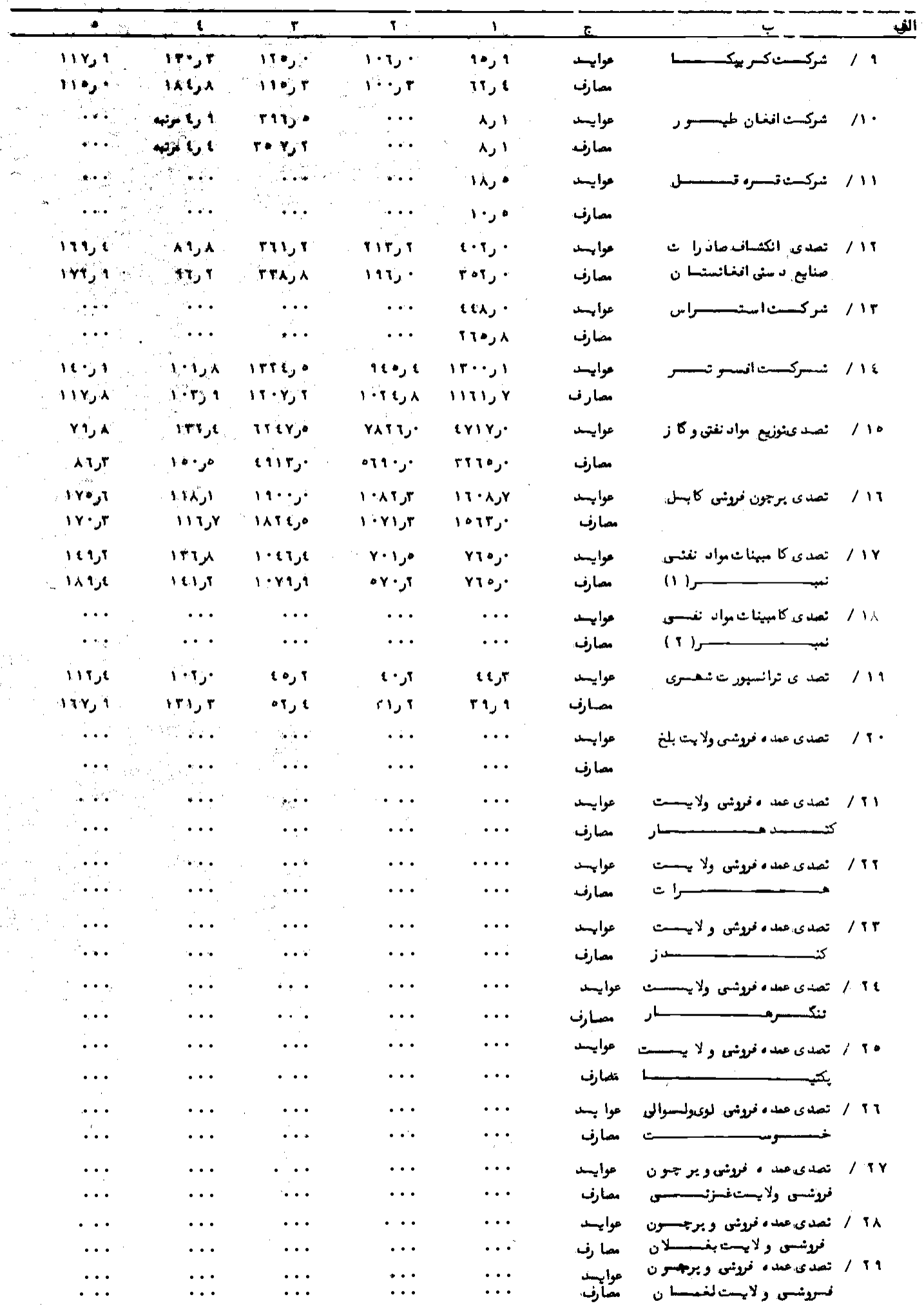


$1-Y-Y$

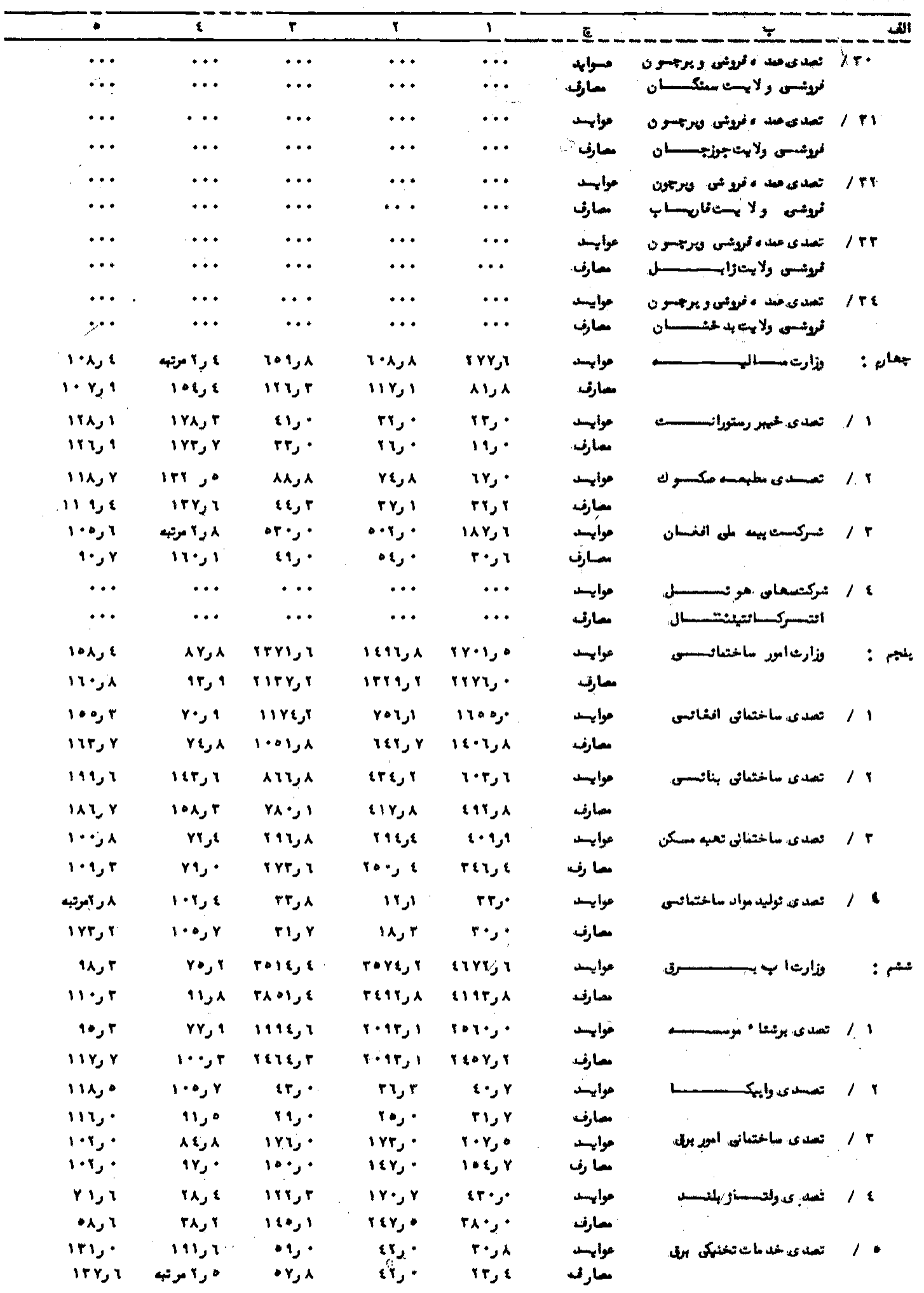




\begin{tabular}{|c|c|c|c|c|c|c|c|c|}
\hline$\cdot$ & $\varepsilon$ & $r$ & $r$ & 1 & $\bar{c}$ & ـــــ & & الن \\
\hline $1 \cdot \lambda, \gamma$ & اردצ & $7 Y \cdot \theta^{\circ}$ & י ניזי & ' זرר & عوايسـد & تصسن ى ساختمانـي هلمنــــــ & 11 & \\
\hline $1 \cdot Y, q$ & $\mathrm{YA}, \mathrm{I}$ & $r \cdot 0$, & $\bullet 1 \cdot, 1$ & rir, & مصارف & & & \\
\hline Ir 19 & $r r, \cdot$ & $r \cdot, \cdot$ & $\bullet r, A$ & $1 Y, r$ & عوايسـ & تصسئى توليد عنامرفلــــزى & 1 & r \\
\hline $101, Y$ & $q \cdot, \varepsilon$ & $u, Y$ & $\varepsilon s, r$ & $r$ • & معارف & & & \\
\hline 190,7 & ي ر ان مرتب & $Y, T$ & $r 7, r$ & $r 0, \lambda$ & عوايسـ & تهد ى توليد انمزى افتسا ب & $1 \mathrm{~A}$ & \\
\hline $1 \times 9,8$ & Y Y Yمرتب & קים & $r r$ & $r 0, x$ & مصارف & & & \\
\hline$\cdot 1 \cdot \gamma_{\mu} \cdot$ & $1 \cdot 1,1$ & r & $0 \wedge, 1$ & 09 & عوايسـ & تصدى انستيتوت يوزه سازى & / 9 & \\
\hline 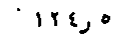 & $\mid \varepsilon 9,1$ & $\bullet$ & $\{\eta\}$, & $r A, 1$ & مصا رف & منسـابـابـا & & \\
\hline Ar, & ار & $r \varepsilon \cdot, \cdot$ & r., & $1 \wedge 0,8$ & عوايسد & تحسد ى سبيــــن غنســر & $11 \cdot$ & \\
\hline$r, r$ & א & $r \cdot \varepsilon, \cdot$ & $r i k, Y$ & וניזr & 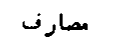 & & & \\
\hline$\cdots$ & $\cdots$ & $\cdots$ & $\cdots$ & $\varepsilon r$ & عوايسـ & 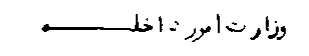 & & منتم : من \\
\hline$\cdots$ & $\cdots$ & $\cdots$ & $\cdots$ & $\{r, 0$ & 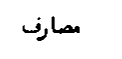 & & & \\
\hline$\cdots \cdot$ & $\cdots$ & $\cdots$ & $\cdots$ & $\{y$ & عوايسد & تصل ى صنانيتى حابسس & 11 & \\
\hline$\cdots$ & $\cdots$ & $\cdots$ & $\cdots$ & $(i, 0$ & 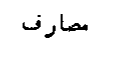 & 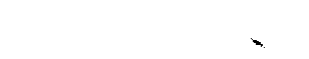 & & \\
\hline ار & ا رو مرتب & r.Y. & |AYY| & $1 \cdots$ & عوأيس & وزأر ت صحسـت عامس & & مشتهت \\
\hline$\| x_{j}$ & 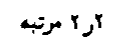 & IYxas & 1089 & $\wedge \cdot 1$, & مصارف & & & \\
\hline | & ارن مرتب & $r \cdot r t_{j} \cdot$ & $|A Y T|$ & $1 \cdots$, & عوايسـ & تصدى امورفارمسسـى & ' & 1 \\
\hline$\| x$, & 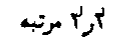 & $\operatorname{lva} 18$ & $10 \times 9, r$ & ה- & مصارف & & & \\
\hline (rs & 111,0 & $\mid 96$ & $1 \varepsilon r 0, r$ & $1 \cdot \wedge \vee, 7$ & عوايسـ & 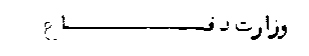 & & : re \\
\hline $1 \lambda \cdot \lambda$ & · مبr مرتبه & Y Y r & $1+n_{0}{ }^{\circ}$ & $n^{\circ} \operatorname{rog}^{\circ}$ & 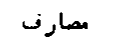 & & & \\
\hline $1 \Gamma q$ & (9ry & in $\mid \wedge$, & $i r \cdot \varepsilon \jmath$ & $9+91$ & عوايس & 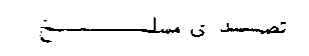 & 11 & \\
\hline $190, x$ & rارr متبه & גנודיז & $i r \cdot \gamma$, & vry, & مارث & & & \\
\hline $\mid r y, r$ & Wr, & $17 x, 9$ & Iris & $1 \varepsilon x_{2} 0$ & عوإبـ & تصدى تولبد مواد ساختعاني & $/ r$ & \\
\hline$Y 9, Y$ & 114,1 & $1\{1,9$ & $w_{n}$, & 14 & مصاري & 3 & & \\
\hline $101, r$ & $\| 1, x$ & $r \cdot \wedge^{9} \cdot$ & آمره & 1499,1 & عوائسم & وزارت ترانسبـــــــرت & : & دمبم \\
\hline $100, q$ & $A^{\vee}, A$ & IVHr, & $110\{x$ & 19YT & مصارف & & & \\
\hline $1+9$ & $1 \times \epsilon_{0}$ & $1 \cdot r a, r$ & $\operatorname{vr} 9,9$ & ונגזה & عو!يس & تصدى ملى بسنبسر ( ) & 11 & \\
\hline lor, r & $v E, r$ & (נזין & $\imath \cdots$ & Nry, & مصارف & & & \\
\hline$\cdots$ & $\cdots$ & $\cdots$ & $\cdots$ & $\cdots$ & عوا بسد & تصدى ملى بسنبسر | r & $1 \%$ & \\
\hline$\cdots$ & $\cdots$ & $\cdots$ & $\cdots$ & $\cdots$ & ميصا رف & & & \\
\hline r ر مرتب & ra, & $\operatorname{lrk} A$ & $7 \cdot 31$ & $91 \wedge$ & عوايسـ & تصحسى كامســازنمبر (1) & $\gamma r$ & r \\
\hline$I r r, y$ & irter & $10 x^{\prime}$ & $\mid 19,1$ & 119,8 & مصا رف & & & \\
\hline Ir & $1 \cdot 7,4$ & $r \cdot 1, r$ & 171,1 & $\ln x, y$ & عوايسد & تصدى كاماز نببـــر (r) & $1 \mathrm{t}$ & $i$ \\
\hline Ir & $1 \cdot Y, y$ & $r+1, r$ & II, & $\mid A x, y$ & 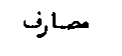 & & & \\
\hline ior 1 & $i r y, \lambda$ & $r(0,0$ & $17 \cdot, 1$ & $i r a, r$ & عوايهد & تصدى كاناز نبسرا (T) & 10 & • \\
\hline lor, 1 & $\mid r y, 1$ & $r(\bullet, \bullet$ & $\mid \gamma \cdot, \in$ & $i v \wedge, r$ & مصارف & & & \\
\hline • ر رت مرتب & $|r r|$ & $r \mid \varepsilon, r$ & $r \cdot, \cdot$ & $10 y, y$ & عوايد & تصسدى كامسازنمهر( \&) & 17 & \\
\hline iry, $r$ & $r_{j} \cdot$ & $x \sin x$ & 107,6 & $r r Y, E$ & مصا رف & & & \\
\hline
\end{tabular}




\begin{tabular}{|c|c|c|c|c|c|c|c|}
\hline- & $i$ & $r$ & $r$ & 1 & $\varepsilon$ & - & الف \\
\hline$i r \cdot r$ & II & $1<1$, & 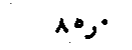 & $i r \cdot s$ & عسوايهد & نصدى كامســاز نبســــ ( م 1 & $/ \mathrm{Y}$ \\
\hline $10 i j \gamma$ & $119, r$ & $1 \& 9$. & ir, 9 & ires. & ممارف & - & \\
\hline$\cdots$ & $\cdots$ & $\cdots$ & $\cdots$ & or, 1 & موايهـ & تصدى كا مـاز نمبـــــــ ( ) & $/ A$ \\
\hline$\cdots$ & $\cdots$ & $\cdots$ & $\cdots$ & - & مصارف & & \\
\hline$\cdots$ & $\cdots$ & $\cdots$ & $\cdots$ & or $r$ & موايهد & 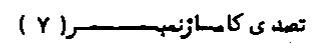 & 19 \\
\hline$\cdots$ & $\cdots$ & $\cdots$ & $\cdots$ & $\bullet \wedge, \wedge$ & مسكف & & \\
\hline A $i$, & 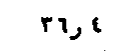 & $r \cdot, r$ & $a r$, & 11,9 & عوايهد & نصدى كاماز نعبــــــــ (A) & 110 \\
\hline$\| x, 8$ & $Y i, i$ & $r r, 1$ & 11,6 & 11,9 & 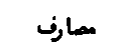 & & \\
\hline$\cdots$ & $1 \cdots, \mathrm{c}$ & $A \cdot, r$ & $\cdots$ & $\wedge \cdot, \cdot$ & عوايسد & نصدى كماز نمبــــــــ ( ) & 111 \\
\hline$\cdots$ & $r Y, \cdot$ & $\Lambda \cdot, \cdot$ & $\cdots$ & $A r, \bullet$ & 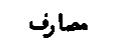 & & \\
\hline$\cdots$ & $\cdots$ & $\cdots$ & $\cdots$ & 18, & موايسد & تصدى نهنيكى بندوحهرنا ن & / ir \\
\hline$\cdots$ & $\cdots$ & $\cdots$ & $\cdots$ & 11,8 & مصارف & & \\
\hline$i r, r$ & $1 \cdot, 1$ & 1616,9 & $r r A, Y$ & 1001 & موايسد & وزارت نراعت راملاحسات أرضى & يازد • مثم : \\
\hline Ar, 1 & $7 t, r$ & $\|$ & $\operatorname{lrr} y, \pi$ & irir & مصارف & & \\
\hline$\| Y, Y$ & 11,1 & irre, a & $1 \cdot e r, r$ & ixe., & عوايهـ & نصد ى كود كيميـ__ـ_ــــاوى & 11 \\
\hline$Y \wedge, \lambda$ & $i 1$, & Are, & $1 \cdot 1 \cdot, \gamma$ & iries. & ممارف & & \\
\hline $9, Y$ & $\bullet, Y$ & $1 \cdot 1,1$ & $11 \%$ & 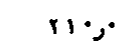 & موايجـ & نصدى مبكانيزه نداعنســـى & /r \\
\hline 10, & $1 \cdot, \cdot$ & 196,1 & $r \cdot \varepsilon, A$ & rios. & مصارف & & \\
\hline ri & $r r, c$ & $r r, 0$ & $i r, 1$ & in & عواهـ" & تصدى توليد رنكبرنخساي & $/ r$ \\
\hline $7 t, r$ & $11, r$ & $r i$ & ris, $q$ & iry,r & مصارف & بـ & \\
\hline $11 \cdot, r$ & - & $\cdot r$, & $r 9,8$ & $\cdots$ & عوايسـ & نصدى تاسيساء ساخنطانى & 18 \\
\hline IYo, & - & $(Y, Y$ & $r Y, r$ & $\cdots$ & 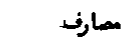 & اخنصاصس نداعتــــــــ & \\
\hline $1 \mathfrak{c}, 9$ & 11,1 & $i \circ \varepsilon, r$ & $(Y A, A$ & $\{90\}$, & عواهـ & : وزارث تعلبــ رنهريســــ & ندازدمث : \\
\hline $1 Y, 1$ & $\| r, A$ & $\varepsilon \cdot \varepsilon, 1$ & (1) & $r \circ 0, r$ & 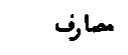 & & \\
\hline 99,8 & $i r \cdot, r$ & $r q, r$ & rqY, $q$ & $r(1, t$ & مواهسد & تصدى بطبعـه تعليم ونريه & 11 \\
\hline $1 \cdot 1, r$ & $1 Y 0, t$ & rit & $r \cdot, r$ & 100,1 & مارف & & \\
\hline$\wedge Y, \mathfrak{l}$ & ir, i & $10 \wedge, 1$ & $11 \cdot, 9$ & $r i x, y$ & موايسد & نصل ى ساخنعانى نعليه و & /r \\
\hline$n, r$ & $i \wedge, 0$ & $16 \cdot, \cdot$ & $1 \circ r, 1$ & $r \cdot \bullet \cdot$ & مصارف & 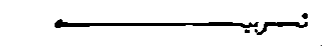 & \\
\hline $1 \cdots$, & $\Lambda \cdot, \cdot$ & (n): & in, & $1 \cdot$, & عوأيسد & 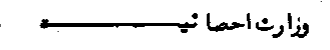 & سيزد • مـ : \\
\hline $1 \cdots$, & $1 \cdot, r$ & $r+$ & $r r$, & $r q, q$ & معارف & & \\
\hline $1 \cdot$, & $\wedge \cdot, \cdot$ & in, & $i \wedge$, & $i \cdot$, & موايسد & نصسى نحد ماتكهيرنسرى. & 11 \\
\hline $1 \cdot$, & $9 \cdot, r$ & r & r & $r q, q$ & 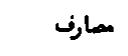 & & \\
\hline$|(x)|$ & $\operatorname{lr} x$ & 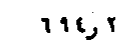 & $\{1 \wedge, \lambda$ & r r & موابسد & : وزارت اطلاعا تمكلتــــــرر & جمارد • مث : \\
\hline $160, r$ & $r r e, r$ & $\cdot r a, x$ & rYi,o & er $:, 9$ & 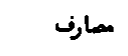 & & \\
\hline $10, y$ & $i r \cdot, r$ & irA, 9 & $\operatorname{crs}$ & oris. & عوايسد & تصدى ثطبعس د رلتسلى & 11 \\
\hline $161, r$ & iri, & $\therefore 9,0$ & $r\{1, r$ & 49, & مارف & & \\
\hline $1 r \cdot 0$ & $109, r$ & $c \cdot, r$ & $r r, 1$ & $r \cdot, r$ & موايسد & تصدى انغان املانســــات & Ir \\
\hline $\operatorname{lig}$ & $119, r$ & $19, r$ & $1 r, 8$ & 11,8 & ممارف & & \\
\hline$\| \wedge, \mid$ & $\cdots$ & 10, & $1 r, Y$ & $\cdot \cdots$ & عوا' يهد & نصدى انغنان نســــــور & $/ r$ \\
\hline 11,1 & $\cdots$ & 11, & 9,9 & $\cdots$ & مصارف & & \\
\hline
\end{tabular}


$1-\mathrm{r}-\mathrm{r}$

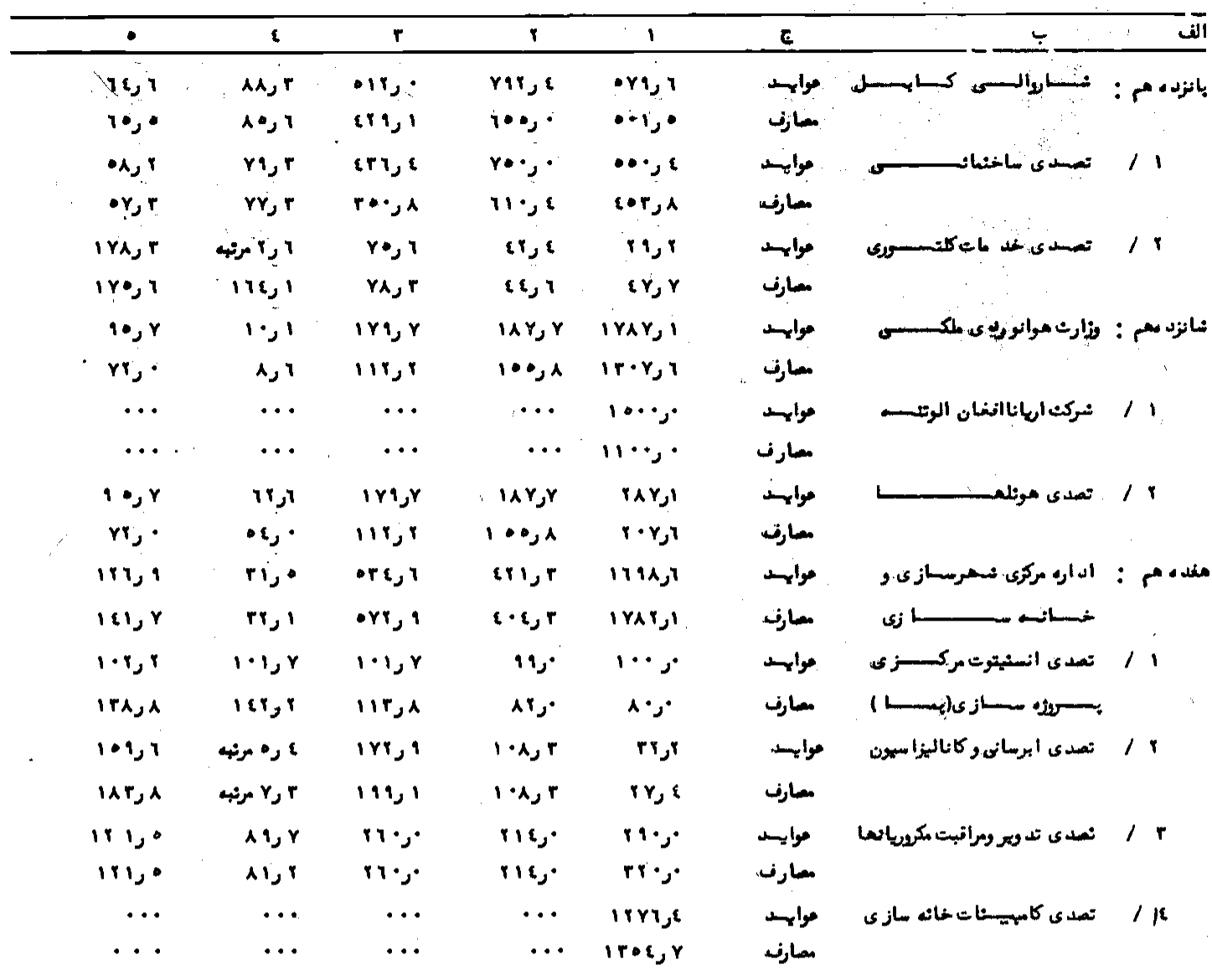

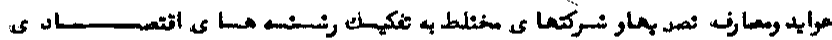

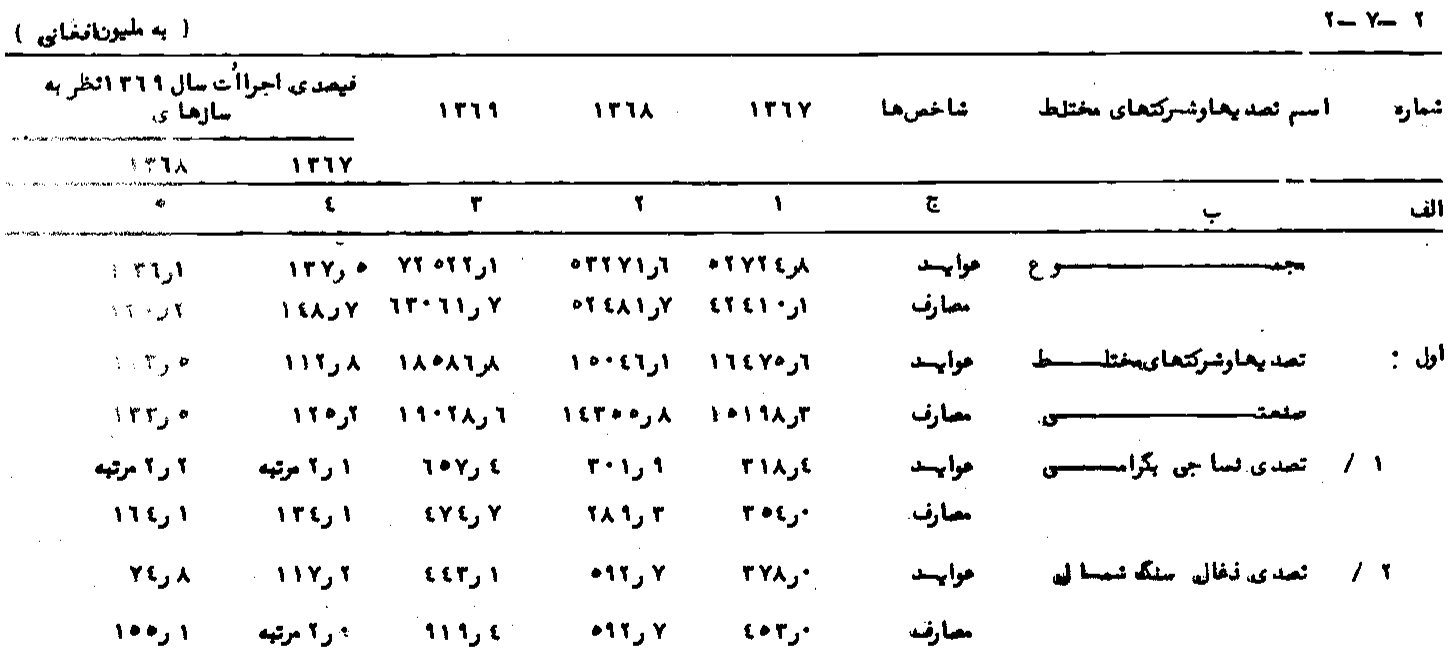




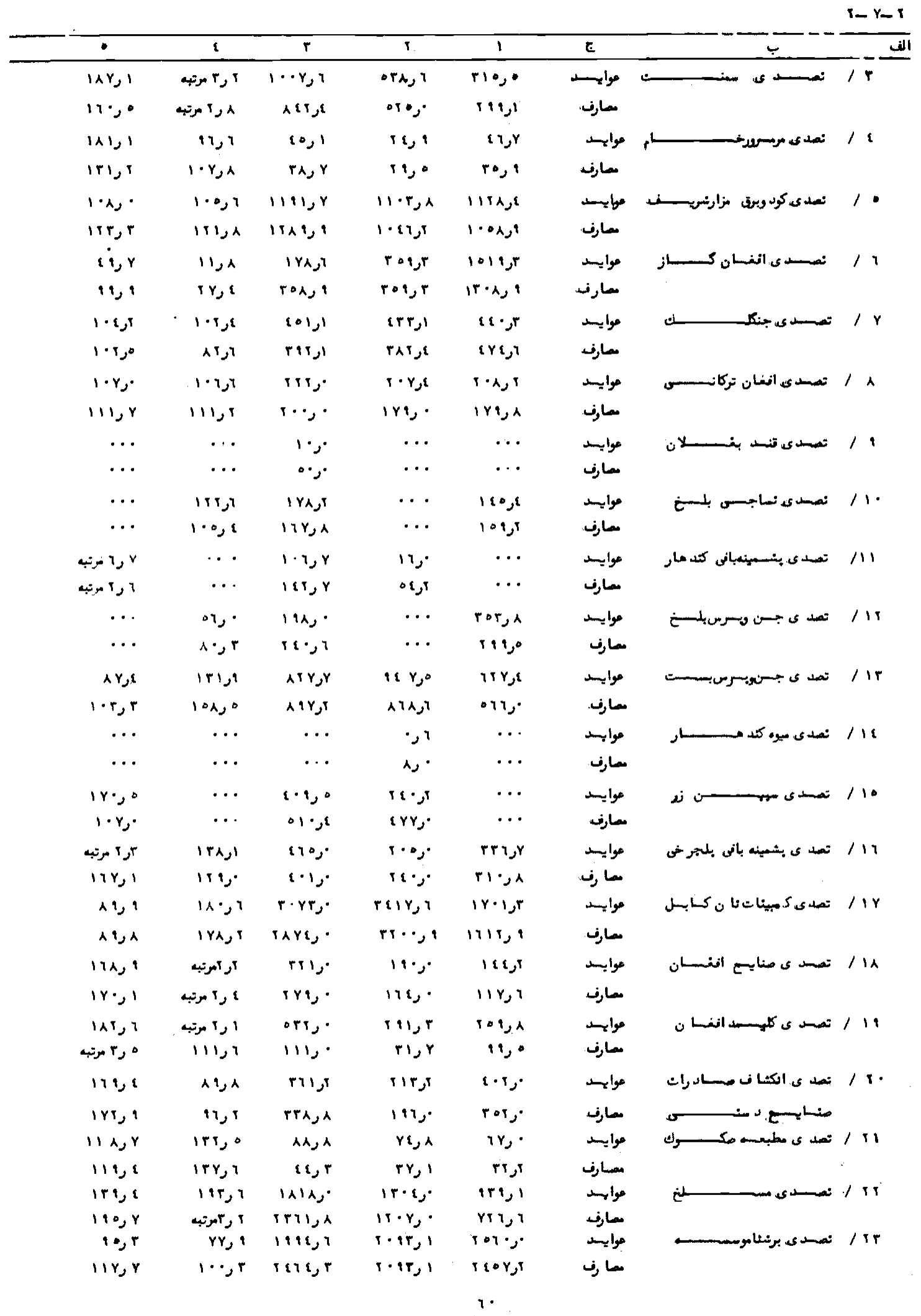


$Y-Y-T$

\begin{tabular}{|c|c|c|c|c|c|c|c|}
\hline$\cdot$ & 8 & $r$ & $i$ & 1 & $E$ & ب- & الف. \\
\hline$r i, r$ & iA, & $i r, r$ & $i r \cdot, r$ & $(r \cdot)^{\prime}$ & مواهـد & نصسدى ولنسـار بل & / 18 \\
\hline$\bullet \wedge, 1$ & rA, & $\mid(\bullet)$, & $r(y, 0$ & $r a \cdot, \cdot$ & مسارف. & & \\
\hline$\because$ & $\cdots$ & $\cdots$ & $\cdots$ & $(Y, r$ & موايسد & تصسدى منسلمتس سمابسس & / ro \\
\hline$\cdots$ & $\cdots$ & $\cdots$ & $\cdots$ & $(r, 0$ & 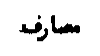 & & \\
\hline $10 \cdot, r$ & $i r \cdot, r$ & IrA, & (tis, & ori, & مواهد & نمدى بطيعسمه دوليتهـى & / ri \\
\hline $1(1, r$ & $1 \pi 1,6$ & $\bullet \cdot 1, \cdot$ & $r(A, r$ & (19, & مسارت & & \\
\hline $19, q$ & $\pi \cdot \pi$ & r & $r q Y, q$ & rater & مواهس & تصدى مطهبع تعليهرنvهי & / ir \\
\hline $.1 \cdot 1, r$ & $1 \times 0,8$ & ing & $r \cdot, r$ & $10 \cdot 1$ & مسارف & & \\
\hline $1 \cdots, 1$ & $10, r$ & (A) & $(Y, 1)$ & $\cdots r, \wedge$ & موايسد & نمسل ى سملحوكد بحسـلنغ & I IA \\
\hline (1) & $1 \cdot A, 1$ & (י) & (x), & $(1 \wedge, \wedge$ & سـارف & & \\
\hline$A \bullet, c$ & $i \cdot, \cdot$ & rir, i & rar, i & $A \cdot Y, Y$ & مواجسد & تمدى سعلسوى يلحسيسرى & 181 \\
\hline$\wedge \wedge, 1$ & $r q, 1$ & $r \cdot A, \cdot$ & $r \circ \cdot$, & YAA, $\mathrm{C}$ & مسارف & & \\
\hline$\cdots$ & 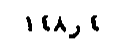 & $16 \cdot 1$, & $\cdots$ & $1(s) \cdot$ & موايهسد & نــركســت نساجــ & /r. \\
\hline$\cdots$ & $m, 1$ & ינוזיו & $\cdots$ & $1 \cdot 10,0$ & مسارف & & \\
\hline ا را مرت4 & $|r q|$, & $1 \cdot, \lambda$ & $i r, r$ & $\bullet, r$ & موايسد & تمدى استغرلة سنك نعميراتى & /ri \\
\hline $1 \cdot 1,1$ & 119,9 & 11, & $r q, r$ & $r q, r$ & مصارف & & \\
\hline irr, & $r r^{*}$ & $r \cdot, \cdot$ & 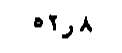 & $i r, r$ & موالسد & نصسيد عنامرنلــ- & / \\
\hline $101, r$ & $1 \cdot, 6$ & $i A, r$ & $10, r$ & ris. & 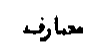 & & \\
\hline $11 \cdot, T$ & - & or, & 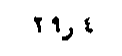 & $\cdots$ & عوايسد & تصد ى نا سيسات ساخنبانسـى & $/ r r$ \\
\hline $1 r 0,6$ & - & $(r, r$ & $r y, r$ & $\cdots$ & 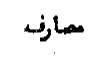 & 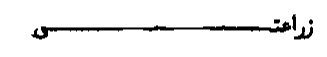 & \\
\hline$A 0,1$ & $01, y$ & ori, 1 & $r \cdot 1, \lambda$ & $1 r 1$ & مواجسد & نصدى ماد رات ميوه كا بســـل & /ri \\
\hline 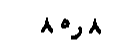 & $00, r$ & orr, & $r \cdot 9,1$ & 160,1 & 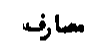 & 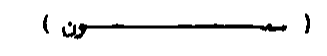 & \\
\hline 116,6 & Ar, & ינזוזו & . & yrri, & موابسد & تمد بهاونمركت ماى مختلسط & لدم : \\
\hline יוניו & $A r, \cdot$ & $\cdot q \cdot Y, q$ & $r q \bullet \wedge, 1$ & $\operatorname{lir}(x, y$ & 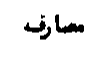 & حد مساتي ونرانسبــــرتســـى & \\
\hline iras. & iriso & $1 \cdot r a, r$ & rri, 1 & ונוזה & موايسد & تعد ى للس بسسنمبر (1) & 11 \\
\hline lor, $r$ & $Y i, r$ & " & $i \cdots$ & - & مسارن & & \\
\hline ا آر آمرتب & $i r q, r$ & $\operatorname{irc} A$ & $1 \cdot, 1$ & 11,1 & موايسـد & تمدى كامساز نبســـــــ (1) & 18 \\
\hline irt, Y & $i r r, r$ & $1 \bullet \wedge, \cdot$ & $\| 9,1$ & 119,8 & مسارف & & \\
\hline 176,1 & $1 \cdot 1,1$ & $r \cdot 1, r$ & 11,8 & $l \wedge A, Y$ & موإيسد & تمسلد كاسساز نعبســر ( T) & /r \\
\hline irs, & $1 \cdot 1,1$ & $r \cdot 1, r$ & $m, 6$ & $\| \wedge A, Y$ & مسارنس & & \\
\hline $10 r, 1$ & $\mid r Y, A$ & $r(0,0$ & $11 \cdot, 8$ & IYA,, & عواهس & تصدى كسامساز نبســر (r) & 18 \\
\hline lor, 1 & $i r r, A$ & $r(0,0$ & $11 \cdot, 8$ & IrA, & مسارف & & \\
\hline · ·ر مرتب & | & $r i s, r$ & $r \cdot, \cdot$ & $1 \bullet Y, Y$ & موأهس & 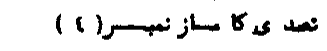 & $1:$ \\
\hline$i r y, r$ & ir & $\because 1, Y$ & $1 \cdot 1,6$ & irr, & عـارف & & \\
\hline$i r \cdot, r$ & 119,1 & 169, & $\wedge \circ, \cdot$ & $1 r \bullet \cdot$ & موإسد & تسدى كا كـــاز نههـر ( 1 & 11 \\
\hline$l \bullet A, Y$ & 119,1 & $1(9,0$ & ir, 1 & $\| r \cdot{ }^{\prime}$ & مسارف & & \\
\hline$\cdots$ & $\cdots$ & $\cdots$ & $\cdots$ & • & مواهس & تصسد مي كامساز نعســر ( I) & / $r$ \\
\hline$\cdots$ & $\cdots$ & $\cdots$ & $\cdots$ & or, 1 & مسارف & & \\
\hline$\cdots$ & $\cdots$ & $\cdots$ & $\cdots$ & $\bullet r, r$ & موأهس & 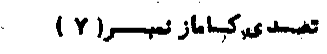 & 11 \\
\hline$\cdots$ & $\cdots$ & $\cdots$ & $\cdots$ & $\bullet \wedge, \lambda$ & سما رن & & \\
\hline 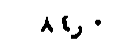 & ( & $r \bullet, r$ & $i r_{j} \cdot$ & 11 & مواجسد & تصسدك كساماز لسحسر (A) & 19 \\
\hline$\| Y_{\nu}$, & Yi, & ri, & 11,1 & 11 & مسارف & & \\
\hline
\end{tabular}


$1-Y-1$

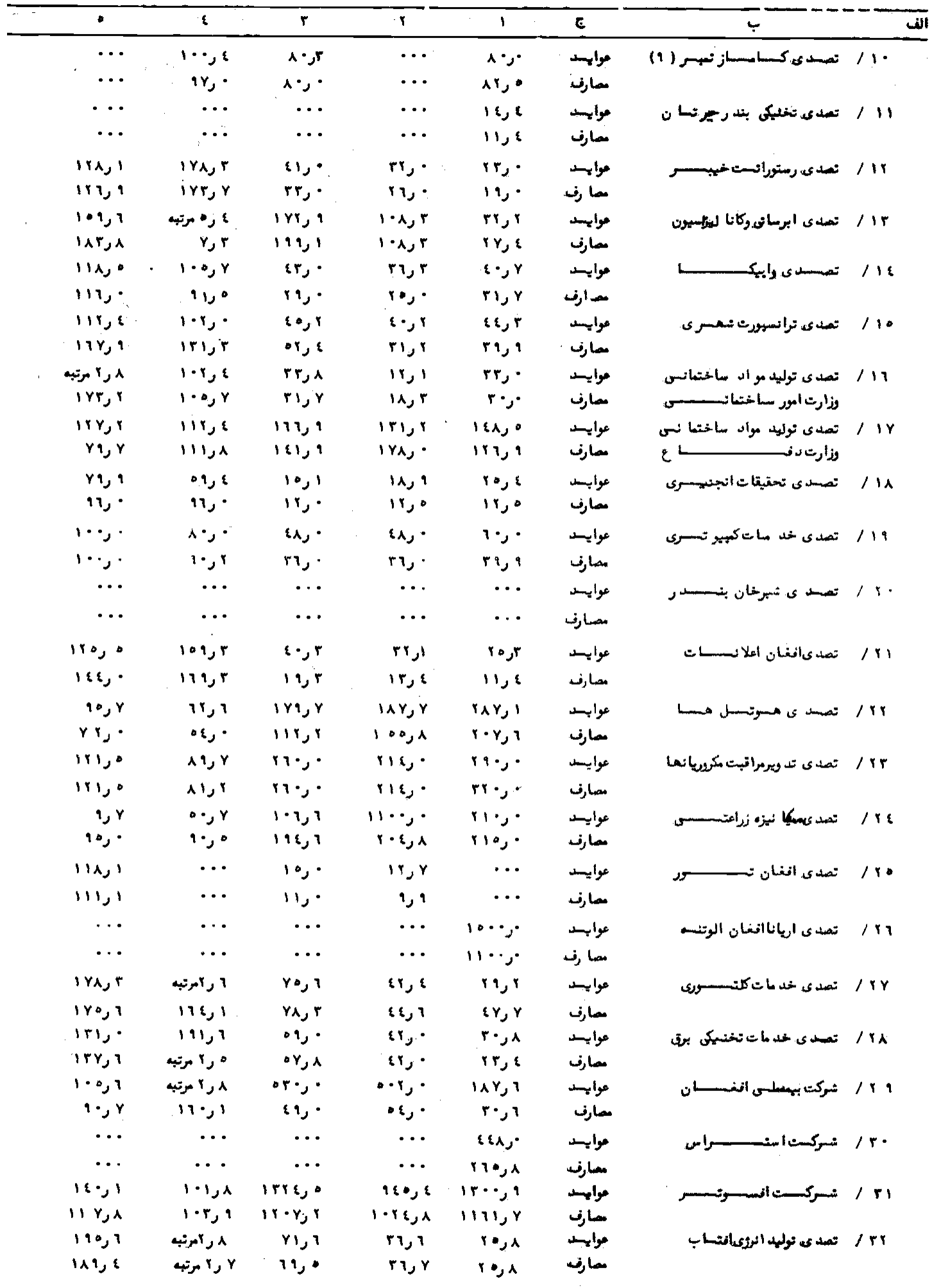


$r-Y-r$

\begin{tabular}{|c|c|c|c|c|c|c|c|}
\hline$\cdot$ & $i$ & $r$ & 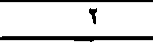 & 1 & E & $\overline{4}$ & النش \\
\hline $\begin{array}{l}169,1 \\
119,8\end{array}$ & $\begin{array}{l}1 r y, 1 \\
161, r\end{array}$ & $\begin{array}{l}1 \cdot\{1,6 \\
1 \cdot Y 9,9\end{array}$ & $\begin{array}{l}y \cdot 1, j 0 \\
\theta y \cdot j\end{array}$ & 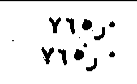 & مارفت & 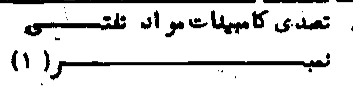 & / rt \\
\hline$\cdots$ & $\cdots$ & $\cdots$ & $\cdots$ & $\cdots \cdot$ & 1 & تصدى كامبينا تمواد ثغتــــى & / ri \\
\hline$\cdots$ & $\cdots$ & $\cdots$ & $\cdots$ & $\cdots$ & 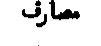 & نعبس (i) & \\
\hline$\cdots$ & $\ldots$ & $\cdots$ & $\cdots$ & $\cdots$ & إبلد & تصدم & /ro \\
\hline$\ddot{m}$ & $\cdots$ & $\cdots$ & $\ddot{\cdots}$ & $\cdots$ & مارفم & & $1 \% 1$ \\
\hline$\ldots$ & ... & $\ldots$ & $\ldots$ & $\cdots$ & موأبست & ماه موتلا:تتركا لتهيتال & fri \\
\hline $\begin{array}{l}1(9,0 \\
118 j^{\circ}\end{array}$ & 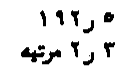 & 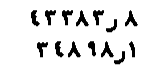 & $\begin{array}{l}r i \cdots r^{\prime} \\
r \cdots *\end{array}$ & $\begin{array}{l}Y Y \cap \cdot, y \\
1 \bullet 1.9 Y, 1\end{array}$ & موارفت & 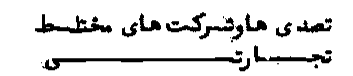 & مير" : \\
\hline $\begin{array}{l}r i j \hat{r} \\
\lambda i, r\end{array}$ & tit & $\begin{array}{l}\text { iris, } \\
\text { intros }\end{array}$ & 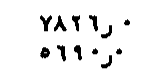 & 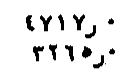 & موإِت & 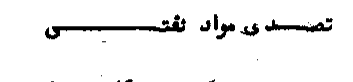 & 11 \\
\hline IYo, 1 & $\mid 11,1$ & $19 \cdots$ & $1 \cdot A r, r$ & $11 \cdot \lambda, Y$ & عواتهـ & 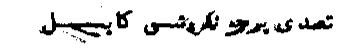 & / \\
\hline $1 Y \cdot{ }^{2}$ & 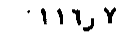 & IArtse & $1 \cdot r i, r$ & (1015. & مسارت & & \\
\hline - & - & $\cdots$ & $r, Y$ & $\circ r, t$ & عوابحت & ت نسركسـ & Ir \\
\hline$\overline{-}$ & ir & 而 & r & •ry & 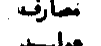 & & \\
\hline 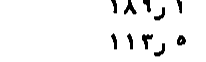 & أ آمرتبه & 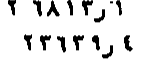 & 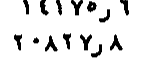 & $\begin{array}{l}A \wedge 9,9 \\
19 \cdot 1,0\end{array}$ & معارف & 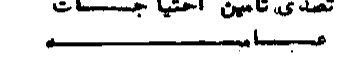 & 18 \\
\hline $\begin{array}{l}\| r{ }_{1} \mid \\
\| r ر .\end{array}$ & ارخا مرتبه & 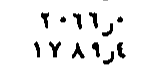 & 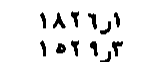 & 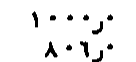 & موانتف & تعسدى امســرزفارمس & $1 \cdot$ \\
\hline$\| x, y$ & 91,1 & הנקוr' & $1 \cdot(r, r)$ & r & عوايسد & تصسد ى كود كيهح & 11 \\
\hline$Y \wedge, \lambda$ & 11, & Aros. & $1 \cdot \gamma \cdot \gamma$ & •ر• & 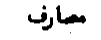 & & \\
\hline r & ( & • נקזי & ו & יניו & موأسـ & تمدى تولنهد وتكمير & / $Y$ \\
\hline 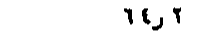 & r & ו ניו & $r e, 1$ & (rr & مارف & 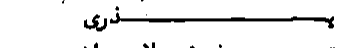 & \\
\hline- & - & $\cdots$ & $\cdots$ & $\cdots$ & عوايد & تصدى معد ه فونى ولا يت كليخ & $/ \lambda$ \\
\hline- & $\ldots$ & $\cdots$ & $\cdots$ & $\cdots$ & مهارت & & \\
\hline$\cdots$ & $\cdots$ & $\cdots$ & $\cdots$ & $\cdots$ & عوأيسد & تملد ى عدد ه فونه & 19 \\
\hline - & - & $\cdots$ & $\cdots$ & $\cdots$ & مارق & كتســـــــــ مـ & \\
\hline - & - & $\therefore$ & $\cdots$ & $\cdots$ & موارف & 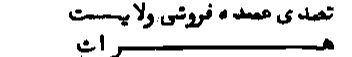 & $11 \cdot$ \\
\hline - & - & $\cdots$ & .. & $\ldots$ & موابهد & تصدلى عدد ه فور : & 111 \\
\hline - & - & $\cdots$ & $\cdots$ & $\cdots$ & مسارن & كـــ & \\
\hline - & - & $\cdots$ & $\cdots$ & $\cdots$ & عوأيسد & 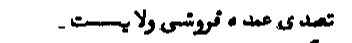 & / Ir \\
\hline- & - & $\cdots$ & $\cdots$ & $\cdots$ & معا رف & 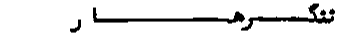 & \\
\hline- & - & $\cdots$ & $\cdots$ & $\cdots$ & موايسـد & تمدى معده فونى رلاحست & / ir \\
\hline - & - & $\cdots$ & $\cdots$ & $\cdots$ & مسارف & 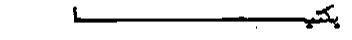 & \\
\hline - & - & $\cdots$ & $\cdots$ & $\cdots$ & عوايسد & تعدى عصدد • فوشى لســوى & 118 \\
\hline - & - & $\cdots$ & $\cdots$ & $\cdots$ & 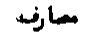 & 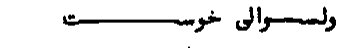 & \\
\hline$\cdots$ & $\cdots$ & $\cdots$ & $\cdots$ & $\cdots$ & موأبحد & 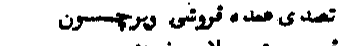 & 110 \\
\hline$\cdots$ & $\cdots$ & $\cdots$ & $\cdots$ & $\cdots$ & مسارت & 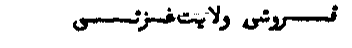 & \\
\hline$\cdots$ & $\cdots$ & $\cdots$ & $\cdots$ & $\cdots$ & عوأهـ & تصدى معد ه فوشىويسر بو ن & 111 \\
\hline$\cdots$ & $\cdots$ & $\cdots$ & $\cdots$ & $\cdots$ & مارن & نسسو شيى رلا يت ينسلان & \\
\hline$\cdots$ & $\cdots$ & $\cdots$ & $\cdots$ & $\cdots$ & عواجِح & تمد ى مدد ه فونسىو بـرهـــون & / Ir \\
\hline$\cdots$ & $\cdots$ & $\cdots$ & $\cdots$ & $\cdots$ & مبارف & 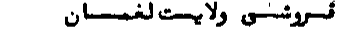 & \\
\hline$\cdots$ & $\cdots$ & $\cdots$ & $\cdots$ & $\cdots$ & موائسـ & نمبدى معد ه فو نى و ير جو ن & 111 \\
\hline$\cdots$ & $\cdots$ & $\cdots$ & $\cdots$ & $\cdots$ & ل مسارف & 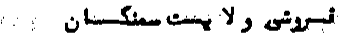 & \\
\hline$\cdots$ & $\cdots$ & $\cdots$ & $\cdots$ & $\cdots$ & موايسـد & تصدى عدد ه نوشى و ير يجبه ن & 119 \\
\hline$\cdots$ & $\cdots$ & $\cdots$ & $\cdots$ & $\cdots$ & مارن & 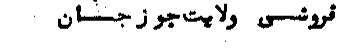 & \\
\hline$\cdots$ & $\cdots$ & $\cdots$ & $\cdots$ & $\cdots$ & عواءيـ & تعدى مدده فونىو ير جهسبون & $/ r$ \\
\hline$\cdots$ & $\cdots$ & $\cdots$ & $\cdots$ & $\cdots$ & مارف مار & فسرو مسنه رلايتثالحسـاب & . \\
\hline$\cdots$ & $\cdots$ & $\cdots$ & $\cdots$ & $\cdots$ & عرأهـ & تصدى:معدهنفونس فير هـوى & I 11 \\
\hline$\cdots$ & $\cdots$ & $\cdots$ & $\cdots$ & $\cdots$ & مارت & لسونس و.لا حست زأبســل & \\
\hline
\end{tabular}


$r-r-r$

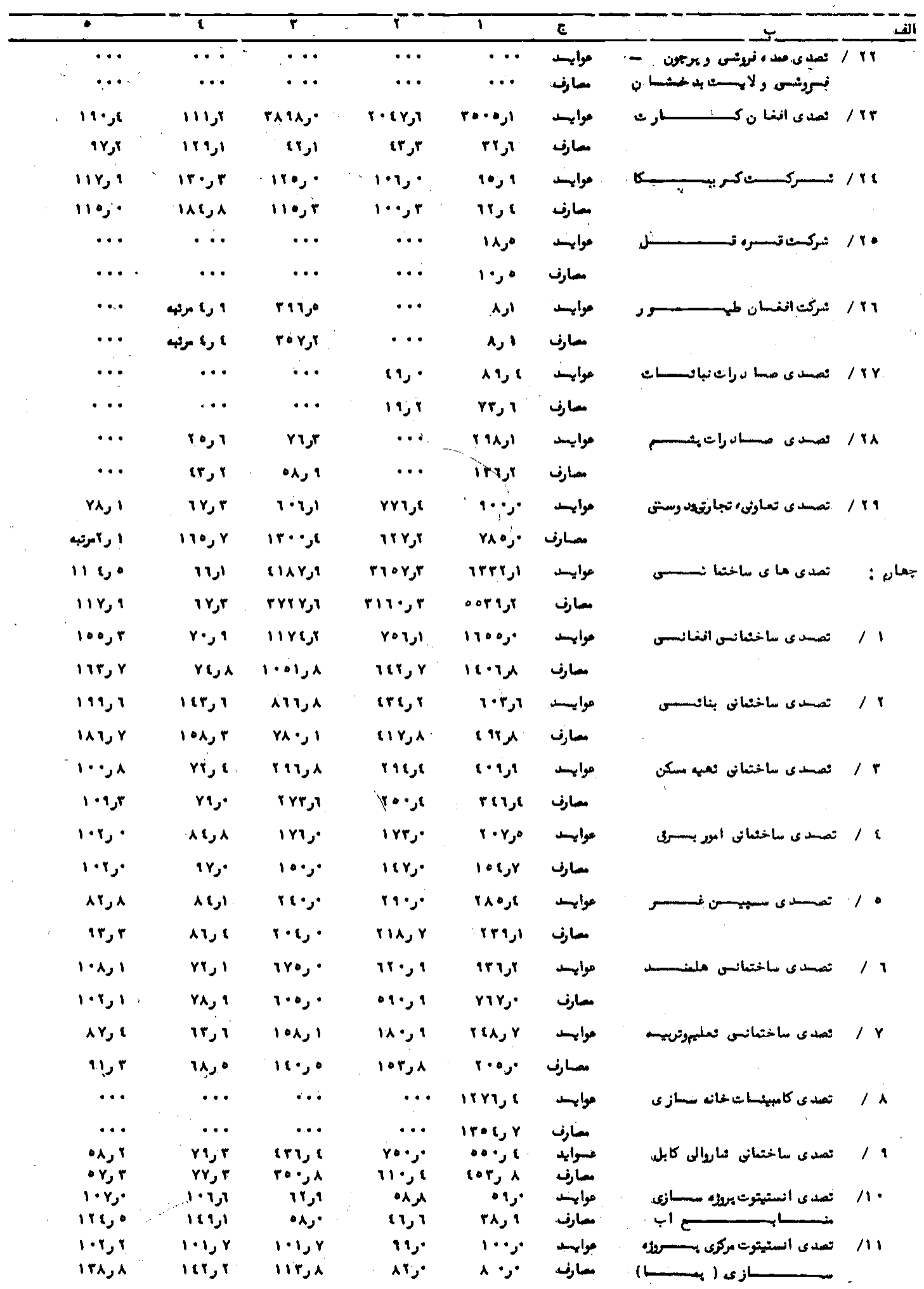



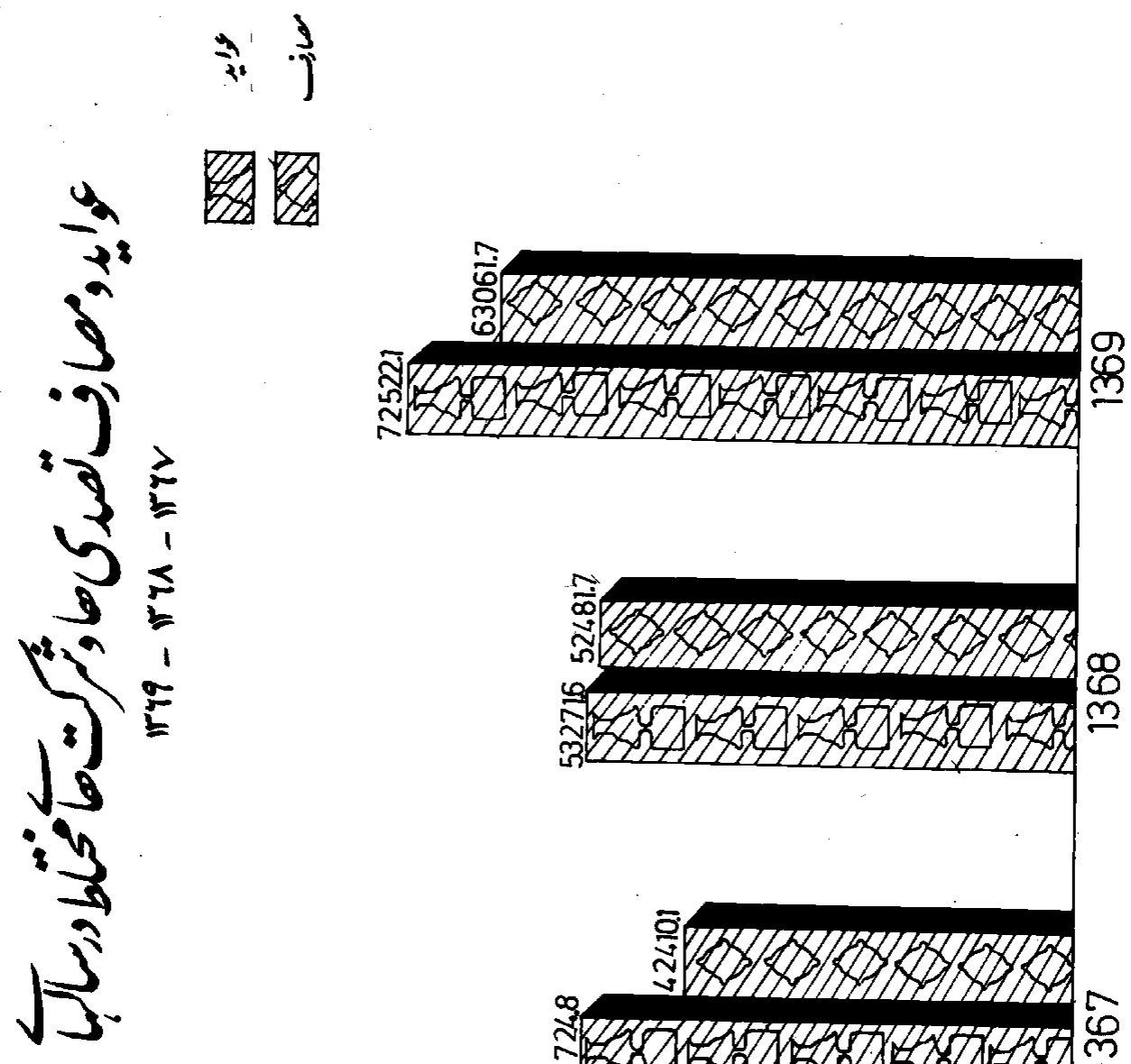

$\stackrel{5}{3.5}$

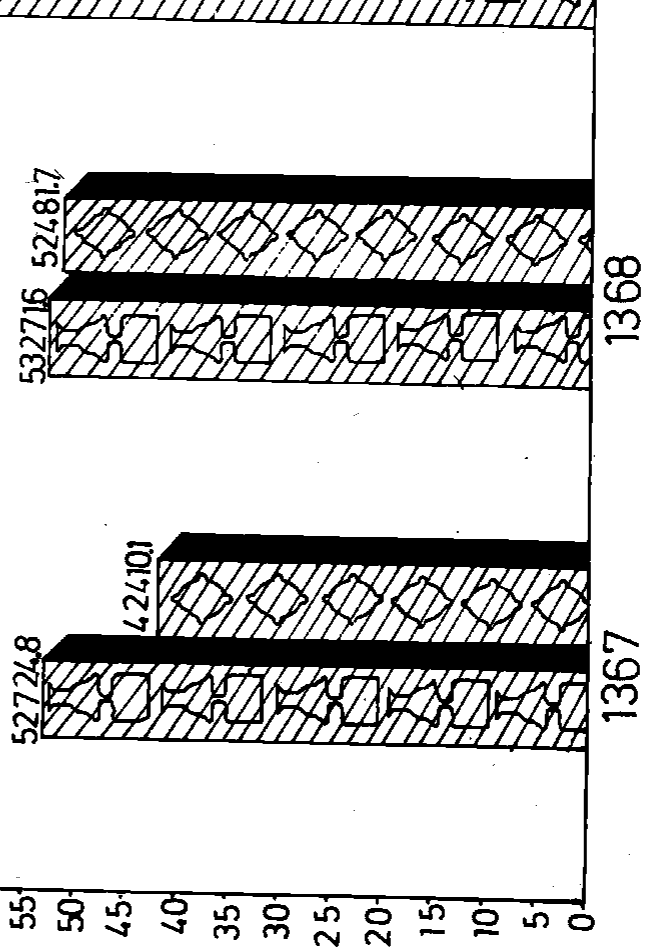




\begin{tabular}{|c|c|c|c|c|c|c|c|}
\hline دئابهس & 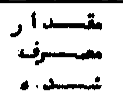 & مجسو 2 & تمبهنده دلرد & 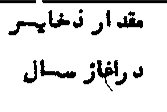 & وامسل & ــــاد . & منار. \\
\hline $1 \cdot, r$ & $99, r$ & $11 \cdot$, & $A \cdot, l$ & $r e, 1$ & مزارتهن & 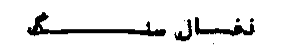 & 11 \\
\hline 1,1 & $a x, y$ & $1 \bullet, 1$ & $9 k$ & $1, i$ & لد & بط & Ir \\
\hline$\cdot 9$ & 176 & $170, r$ & 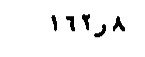 & $r$, & $\nu$ & 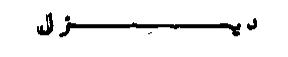 & Ir \\
\hline 1,8 & 116, & 110,9 & $11 \bullet, 8$ & • & $\nu$ & تهسـل نه بس بـــــن & 18 \\
\hline - & 1,1 & 1,1 & 1,1 & - & $\nu$ & تهسـسـل خــــــــاك & $1 \cdot$ \\
\hline- & $r, r$ & $r, r$ & $r, 0$ & r & $\nu$ & 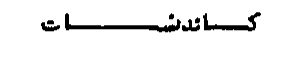 & 17 \\
\hline 17 & $1 \cdot A, r$ & Ires $r$ & $\operatorname{lrr}, \lambda$ & $r$ & ע & كود كيبــــــــــــاوى & / $Y$ \\
\hline 78,9 & $A r$. & $1 \& 1,6$ & 110, & $r r, t$ & ע & كسيسود هسوس ســــــــ & $1 i$ \\
\hline 1,0 & $r \varepsilon, A$ & ri, & $r$ r & $r \cdot$ & ע & كود فـاسفهـــــــــــ & 19 \\
\hline rir & $\bullet \wedge,:$ & $1 \cdot 1$ & 001 & t, & $\nu$ & سفـــــــ & 11. \\
\hline- & 1,1 & $1, \lambda$ & $0, \lambda$ & 1, & ע & 5 & 111 \\
\hline 1,1 & 11,2 & irs. & $1 \cdot, 9$ & r & $\nu$ & تهستر مستسـا: & / ir \\
\hline$\cdot r$ & irr, r & irr, 9 & irr, r & r & مزارمنرمكب & سيك تعميراتس & Iir \\
\hline- & 1, & $1, \cdot$ & 1, & - & مزار منرمبـى & سنستــــ مس & 118 \\
\hline$\cdots$ & $\cdots$ & $\cdots$ & $\cdots$ & $\cdots$ & $\nu$ & سنسك موز1 نهس & 110 \\
\hline$\cdots$ & $\cdots$ & $\cdots$ & $\cdots$ & $\cdots$ & $\nu$ & 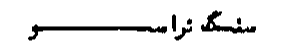 & 111 \\
\hline- & 11,0 & 11, & $1 \cdot, 1$ & 9 & $\nu$ & 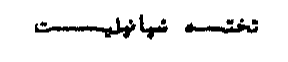 & $\operatorname{lir}$ \\
\hline$\cdot r$ & ra, & $r \cdot$, & $r y, r$ & $r$ & ميلس ن تالب & خ & 111 \\
\hline- & 0,1 & 0,1 & 0,1 & - & مزارمتركسب & جن تخن & 119 \\
\hline י & $\cdot \lambda$ & 1,8 & r & $\cdot \lambda$ & مزارتسنّ & 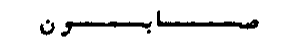 & /re \\
\hline , & is & \& 1 & $r$ & • & $\nu$ & 4 & 18 \\
\hline 1 & r ג & $r, q$ & $r$ & $\bullet r$ & $\nu$ & 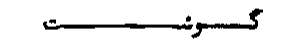 & /rr \\
\hline r r & 0,1 & 1 & 1 & - & $\nu$ & 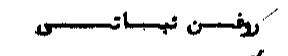 & /rr \\
\hline$r_{j} \cdot$ & $\bullet 9, r$ & יו יו & $1 \cdot$, & י וי & $\nu$ & أرد كــــــــــــــم & /re \\
\hline- & $1 \cdot, r$ & $1 \cdot, r$ & $1 \cdot, r$ & - & $\nu$ & سعو لات نا نوانــــــــ & ro \\
\hline r r & s. & is & \& 1 & i & $\nu$ & :S & / \\
\hline - & is. & is. & $r, \cdot$ & , & $\nu$ & 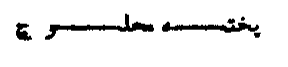 & jerr \\
\hline$\cdots$ & $\cdots$ & $\cdots$ & $\cdots$ & $\cdots$ & $\nu$ & بسرنـ & I RA \\
\hline- & $r \cdot c_{n} \cdot$ & $r \cdot k$, & $r \cdot r$ & 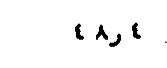 & $\nu$ & 8 & 189 \\
\hline$\cdots$ & $\cdots$ & $\cdots$ & $\cdots$ & $\cdots$ & $\nu$ & 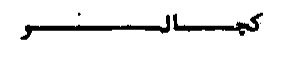 & $1 r$ \\
\hline , 9 & r r & $r, r$ & $r, q$ & $i, r$ & مهلعون متسر & 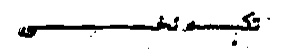 & /ri \\
\hline- & $\cdot, 9$ & 9 & • & $\cdot r$ & $\nu$ & 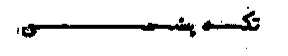 & Irr \\
\hline- & e & $\dot{\imath}$ & $\cdot r$ & $\cdot 1$ & $\nu$ & - & / rr \\
\hline- & 1, & $1, \cdot$ & $1, \cdot$ & $11-$ & مزارشترمع & كالين يا & /re \\
\hline
\end{tabular}




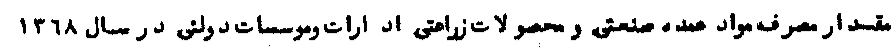

$1-1-1$

\begin{tabular}{|c|c|c|c|c|c|c|c|}
\hline درخايسم & مستسفر & مجمسو & 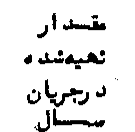 & 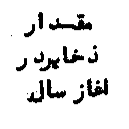 & مقهـاس & اسســ مسراد & نهاره \\
\hline$r r, r$ & $1 \cdots, 1$ & $|r a|$, & $18, q$ & $q r, r$ & مزارنــن & ذ غســـــال سنـــــــ & 11 \\
\hline$r$ & AT, & $1 \cdot, 0$ & $x ?, q$ & 1,1 & עد & 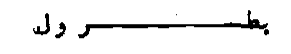 & 18 \\
\hline 1, & \& & Ir. & $|r r|$ & , & עد & 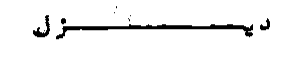 & Ir \\
\hline $1, \lambda$ & אוז' & $\operatorname{Irq} t$ & irr, & 1,8 & ע & 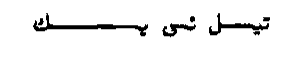 & $/ q$ \\
\hline- & 1,0 & 1,0 & 1,0 & - & لد & 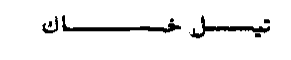 & $1 \cdot$ \\
\hline$\cdots$ & $\cdots$ & $\cdots$ & $\cdots$ & $\cdots$ & لد & 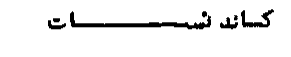 & 11 \\
\hline $0 \wedge, y$ & $\operatorname{lr} \lambda$ & 101,0 & $1 \cdot$, & r & لد & كـود كيميــــــــــــــ & I r \\
\hline c小, Y & $a \gamma, \varepsilon$ & $\mid\{1, \mid$ & A1, : & 1 & لد & كـود يسـوبيحسـ & 10 \\
\hline- & $1 \cdot 1$ & $1 \cdot, q$ & ני & $1, q$ & لد & 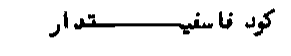 & 19 \\
\hline 'ו & $r \cdot, r$ & $r r, r$ & $r \cdot, r$ & • & لد & سنــــــ & 110 \\
\hline r & q & ' & $\{\mathfrak{q}$ & 11,7 & لد & 3 & 111 \\
\hline$\cdots$ & $\cdots$ & $\cdots$ & $\cdots$ & $\cdots$ & لد & تيسمريسـايـ & / \\
\hline . ر. & $\{\wedge, \gamma$ & r & or $r$ & - & مزارمنرمكسب & سنســ تعميراتس- & / ir \\
\hline - & $\cdot \lambda$ & $\cdot \lambda$ & $\cdot \wedge$ & - & مزارمترمبع & سئـــ & 118 \\
\hline$\cdots$ & $\cdots$ & $\cdots$ & $\cdots$ & $\cdots$ & لد & سنسك مسو زانيــــ & 110 \\
\hline$\cdots$ & $\cdots$ & $\cdots$ & $\cdots$ & $\cdots$ & עد & سفســــك تسراسـ & 117 \\
\hline • & 150 & $1 \varepsilon 1$ & $1 \varepsilon, 0$ & 1 & ע & 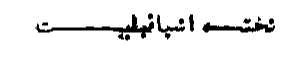 & Ir \\
\hline- & 10,8 & $10, r$ & if 9 & $\cdot 1$ & ميليو نقالب & خت & 111 \\
\hline$\cdots$ & $\cdots$ & $\cdots$ & $\cdots$ & $\cdots$ & مزارنترمكسب & اكسهبجسن تنفنبكسـ & 119 \\
\hline- & $\cdot \rho$ & ر." & $\cdot \circ$ & - & مزارتسن & صسا بـ & 18 \\
\hline er & ו & $r, \lambda$ & ו & $\cdot r$ & لد & & 181 \\
\hline ا & r & $r, r$ & $r$ & ا & ע & كسـرنسـ & $\operatorname{lit}$ \\
\hline r & is & 0,1 & $\varepsilon$ & • & لد & 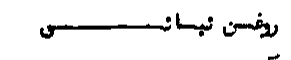 & /rt \\
\hline i & $r \cdot, r$ & $7 \varepsilon$ & or $r$ & $r, r$ & لد & 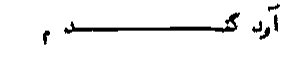 & $/ 18$ \\
\hline- & 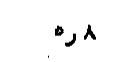 & A & $\bullet \wedge$ & - & لد & مس مسسولات نانوائسس & 10 \\
\hline ا ر & $r$ & $\ldots t \boldsymbol{t} \cdot$ & $r, r$ & er & ע & ئ & 114 \\
\hline- & r & r & 0 & - & لد & 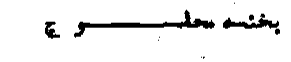 & I IY \\
\hline$\cdots$ & $\cdots$ & $\cdots$ & $\cdots$ & $\cdots$ & لد & & $1 \mathrm{ra}$ \\
\hline$\cdot r$ & $P+q, q$ & $r \cdot \varepsilon, r$ & $r \cdot q, \gamma$ & - & لد & & 189 \\
\hline$\cdots$ & $\cdots$ & $\cdots$ & $\cdots$ & $\cdots$ & 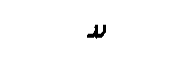 & 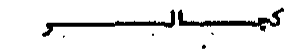 & $/ r$ \\
\hline r & $\bullet r$ & 01 & $r_{j}$ & $i$ & مهلون متسر & تكســـ نشيست & $1 \mathrm{rI}$ \\
\hline 1 & וر• & r & 1 & ارن & ע & 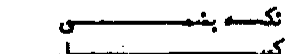 & $\begin{array}{l}\text { /rr } \\
\text { /rr }\end{array}$ \\
\hline$\stackrel{0}{0}$ & r & is & r & $=$ & مزارينديسه & كالهن & \\
\hline
\end{tabular}




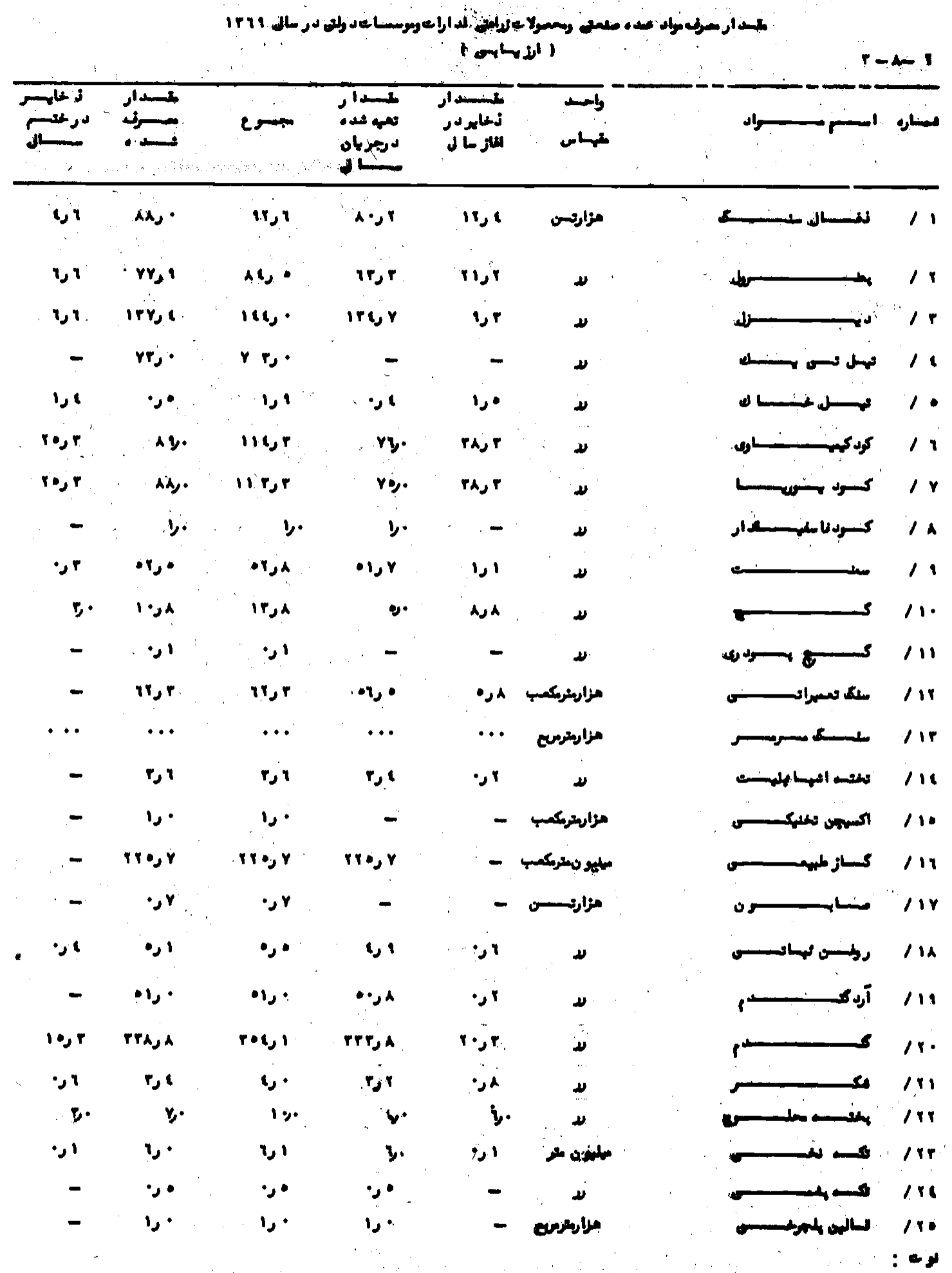

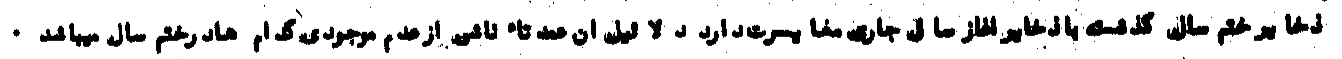




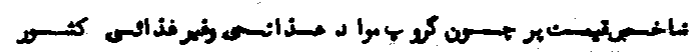

$1 \ldots=1$ 1

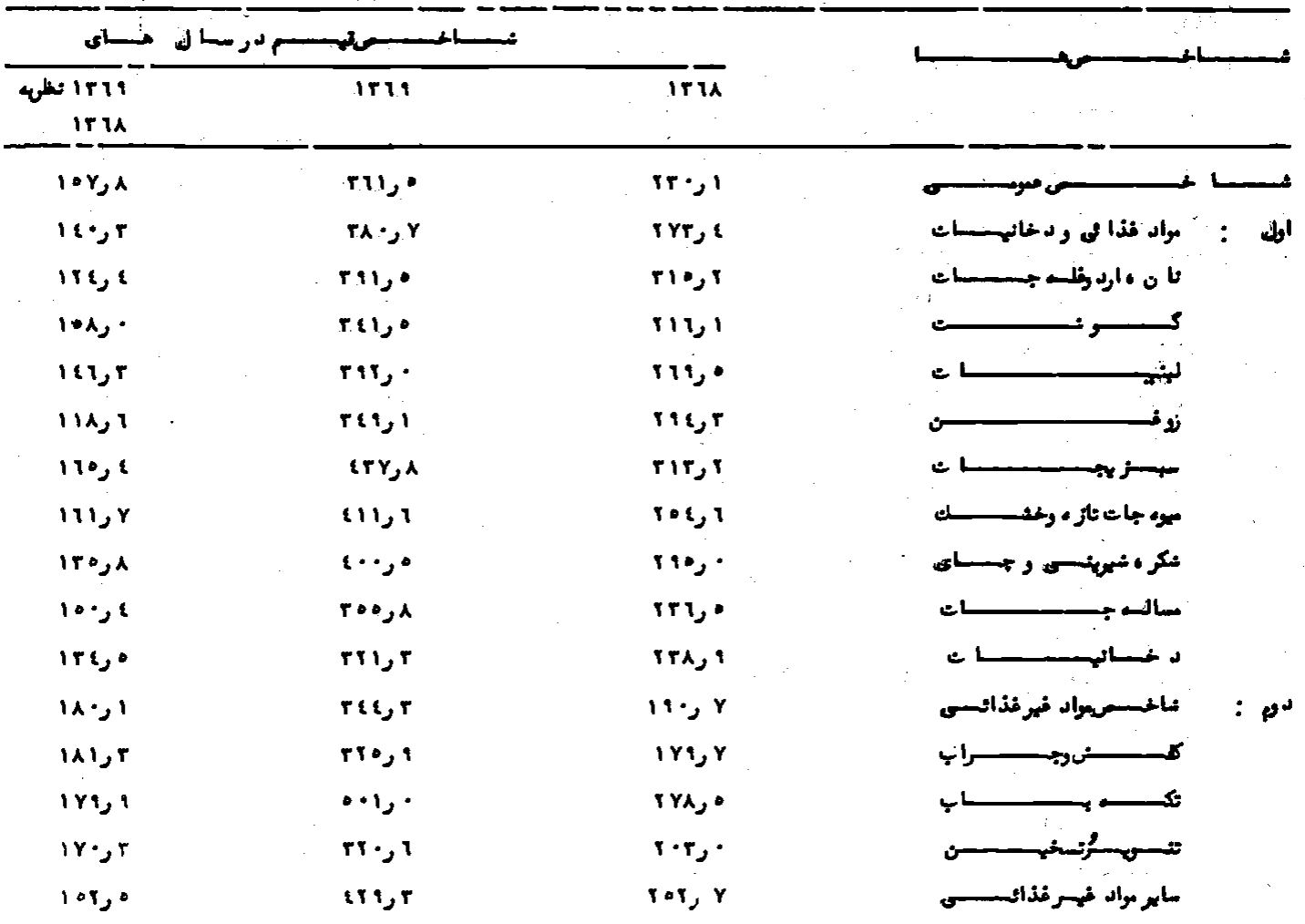

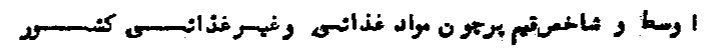

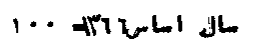

\begin{tabular}{|c|c|c|c|c|c|c|c|}
\hline \multirow{2}{*}{ ال } & \multicolumn{2}{|c|}{ نماشسمقيعست در ريال } & \multicolumn{3}{|c|}{ اروسط تهبــند روالزماى } & \multirow{2}{*}{ وَاحسـ } & \multirow{2}{*}{ w } \\
\hline & 1819 & $\operatorname{lru}$ & $\operatorname{lr19}$ & $\operatorname{lr} 11$ & 1rit & & \\
\hline 1 & - & 8 & $r$ & 1 & 1 & 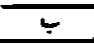 & जा \\
\hline $1 \circ \gamma, 1$ & ril, & $r r \cdot$, & & & & & الث : م \\
\hline$i \varepsilon \cdot, r$ & $r \lambda \cdot, r$ & 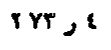 & & & & & ـ د خسطالهــات \\
\hline $\operatorname{lr} \varepsilon$, & $r \because, \cdot$ & $r 10, r$ & & & & & نان ، اردروظلـه جســا ت \\
\hline$|r|, \lambda$ & $r \cdot 2,0$ & $i n, r$ & $r r, q$ & $\mid r, \cdot$ & $\lambda, \lambda$ & تس م & لســـان ليد \\
\hline $\operatorname{lry}$ & $\varepsilon \cdot r, q$ & $r \cdot$, & 180,9 & 110,1 & $r 1,9$ & كمليو & \\
\hline irre. & ras ${ }^{\circ}$ & $r i \bullet, 1$ & $r r \cdot, r$ & ris, & $A r, r$ & H & 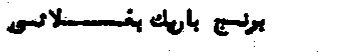 \\
\hline $181,:$ & $q \cdot 1, p$ & $r r r, r$ & $V \wedge \varepsilon, \lambda$ & 111,9 & $r \cdot, 1$ & $\nu$ & 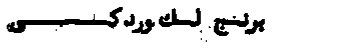 \\
\hline $1 \cdot r, r$ & $r l \cdot r$ & $. r i, r$ & rYa, \& & $r \cdot r, q$ & $\operatorname{irr} \cdot$ & لـ & \\
\hline$m y, 1$ & $r i s, \cdot$ & $\operatorname{rrx}, \hat{\imath}$ & $r \varepsilon 0, x$ & $y \cdot 9,1$ & $i r, r$ & ע & set \\
\hline 118,1 & $1 \cdot 1,6$ & Irro. & $r r y, 1$ & $1=1,1$ & $1 \cdot 1,1$ & ע & S \\
\hline
\end{tabular}




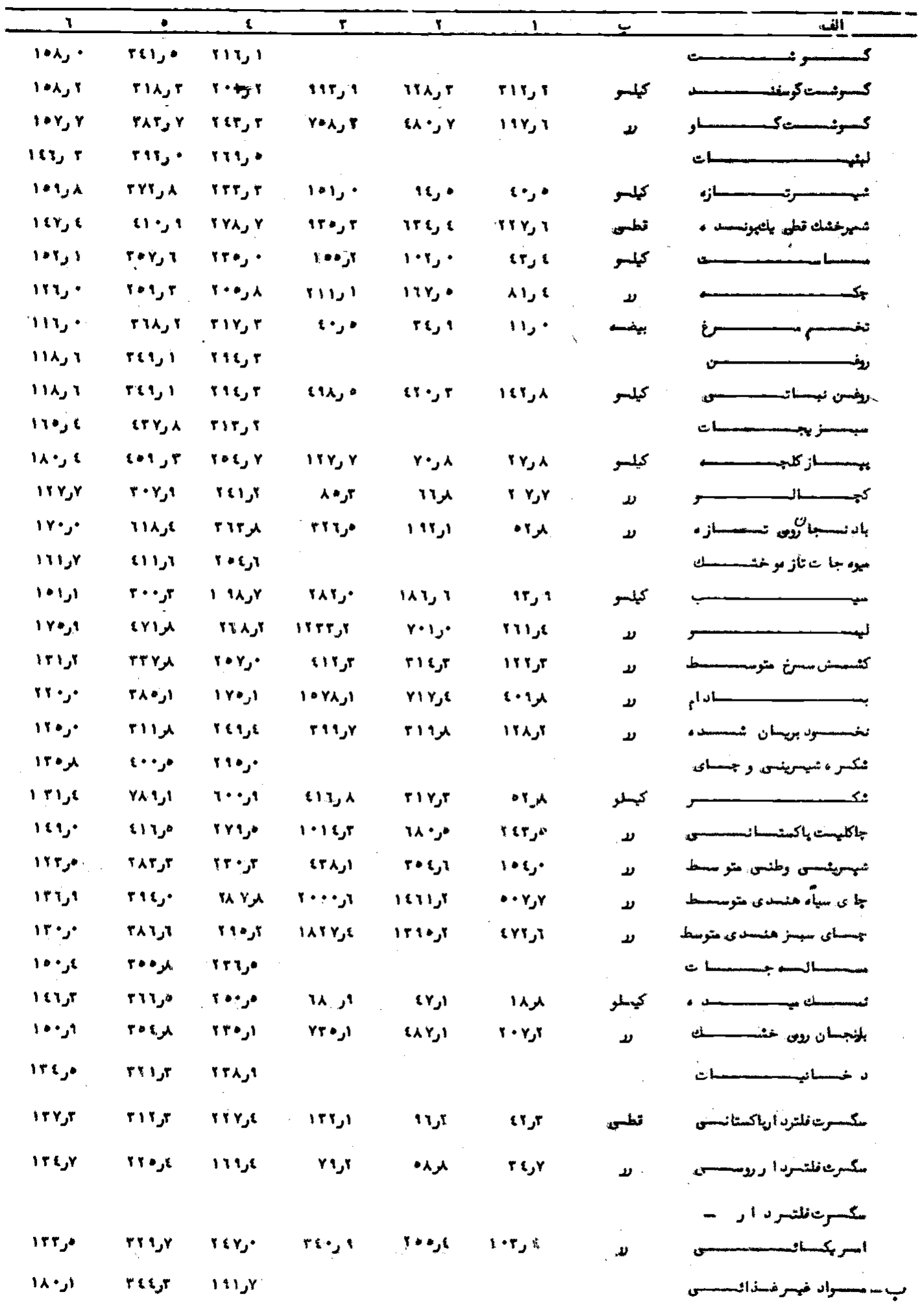




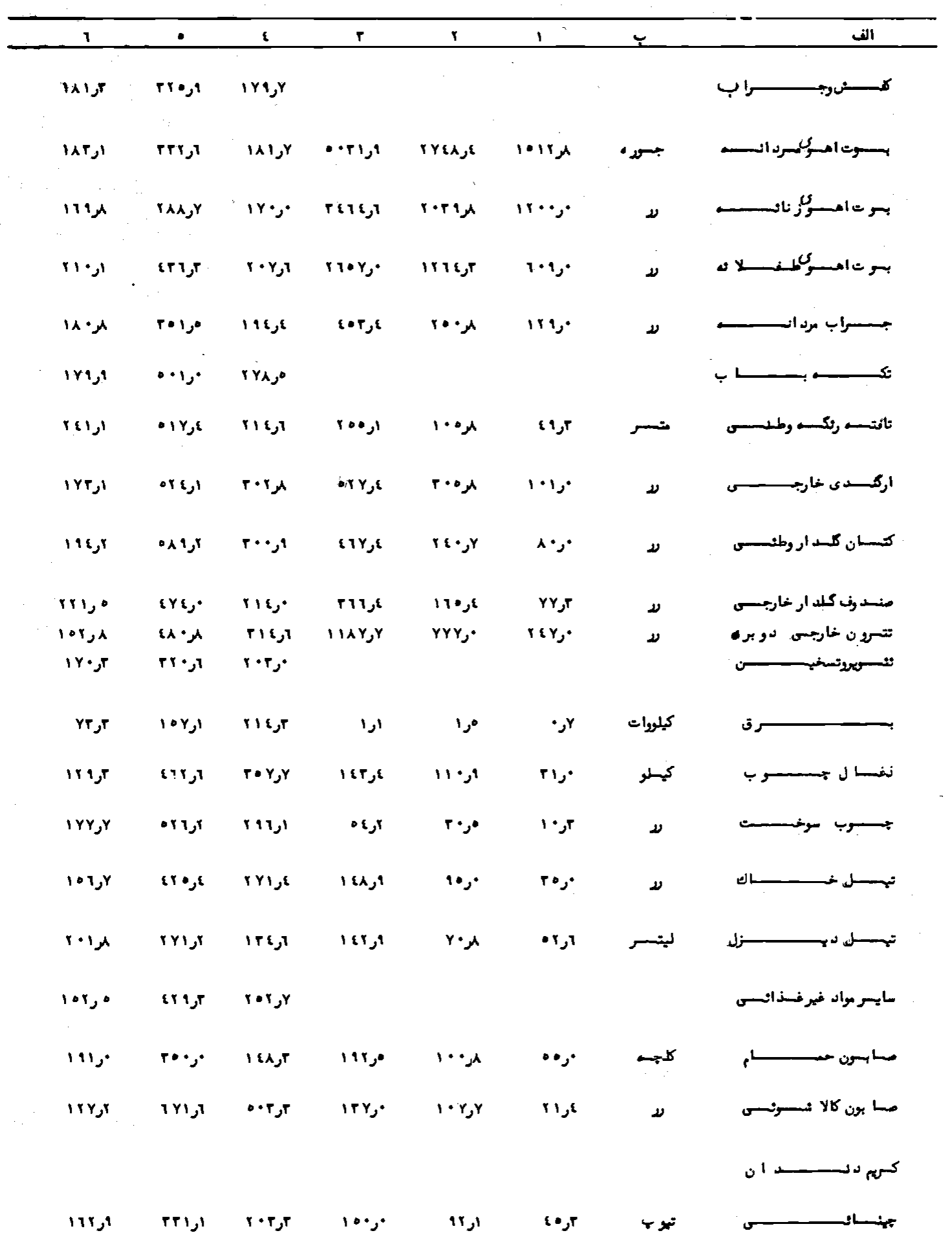




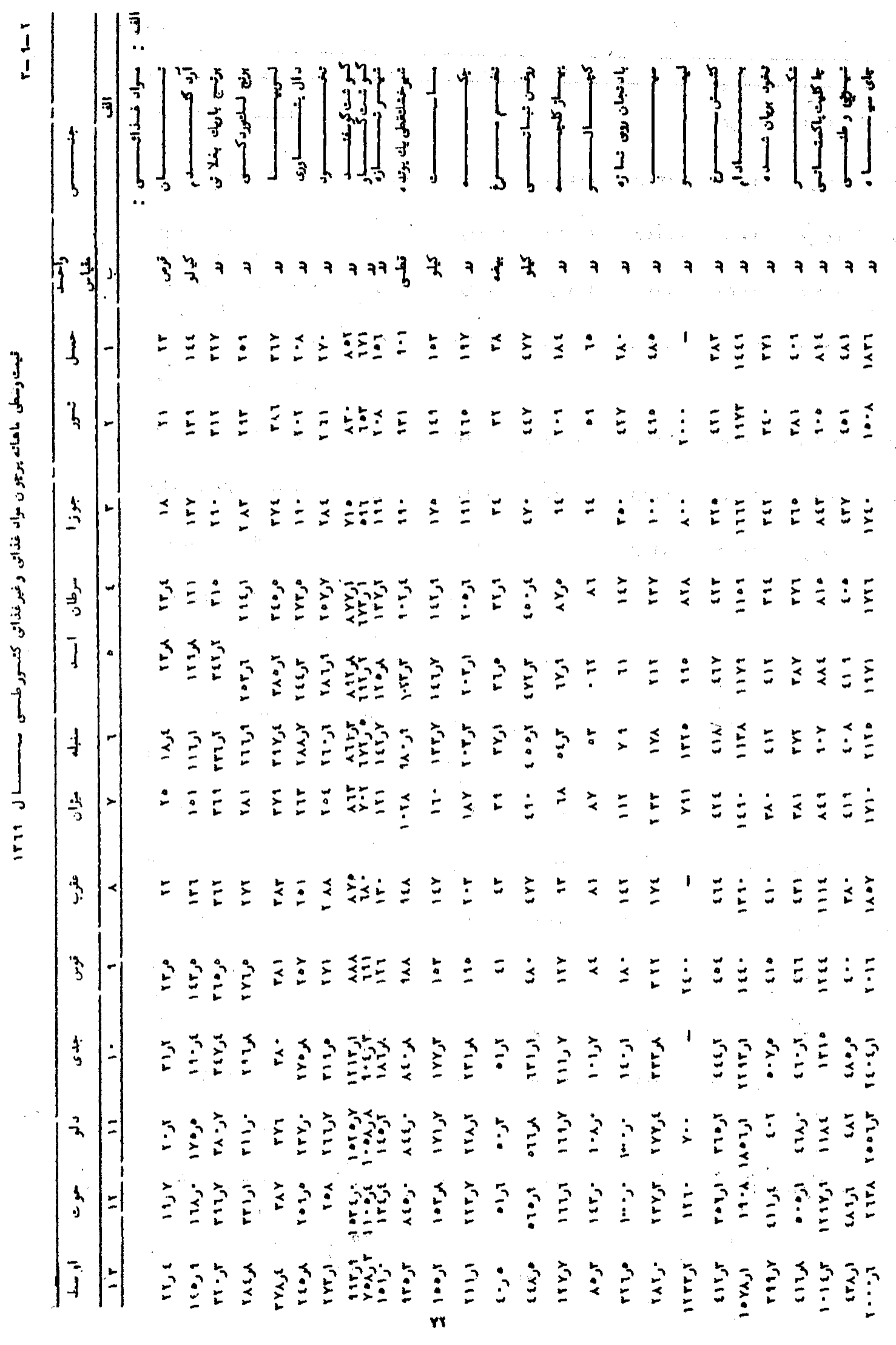




\section{1}

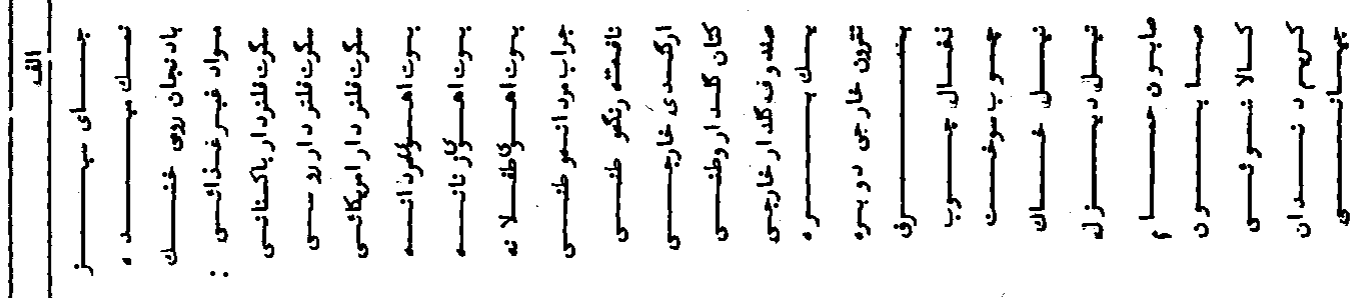
ง

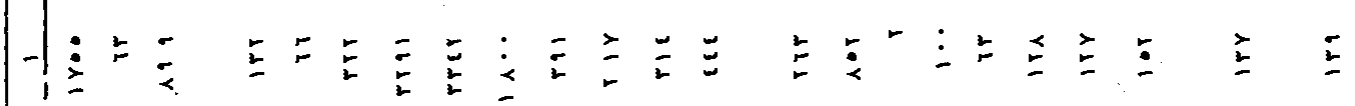
H: - - 旁京

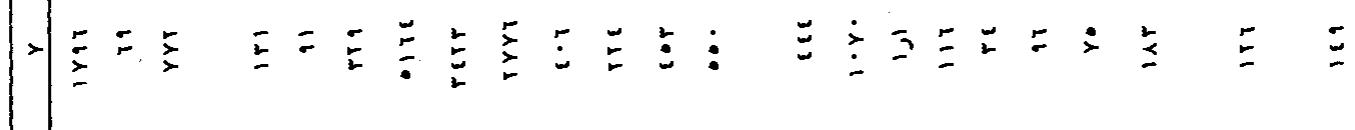

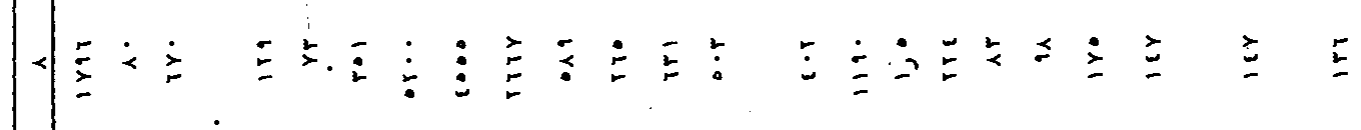

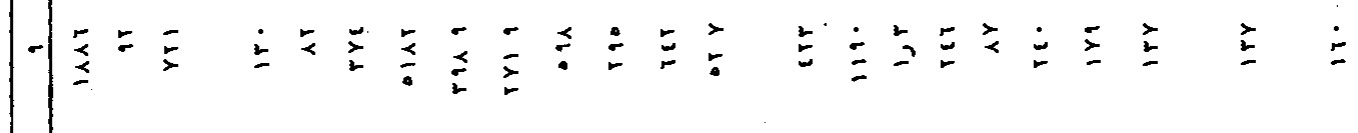

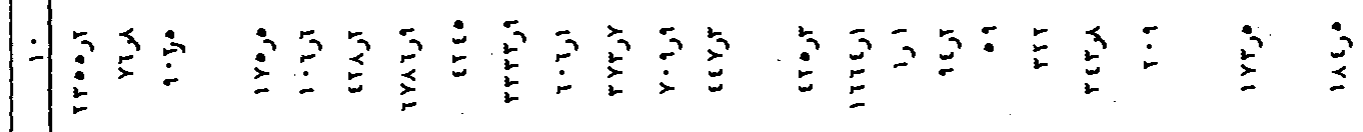

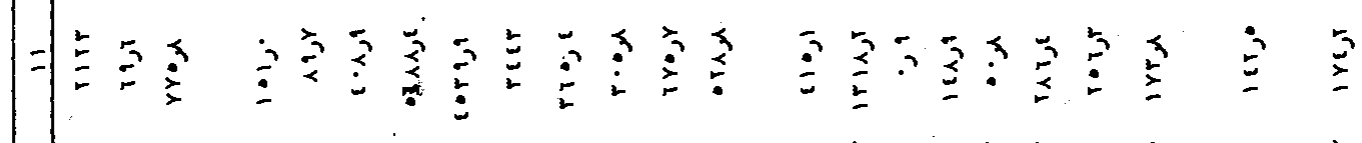

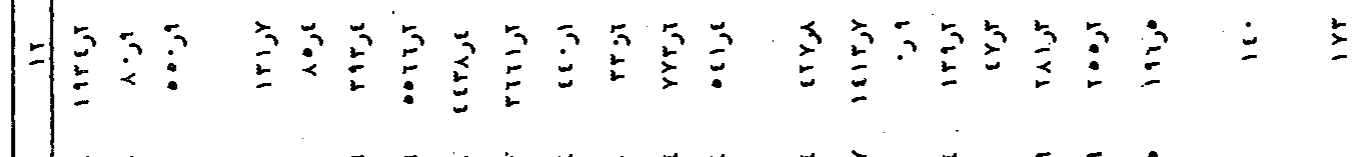

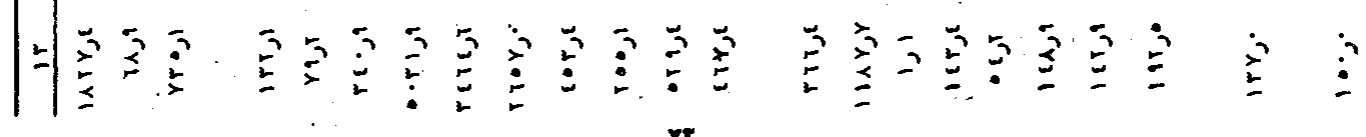




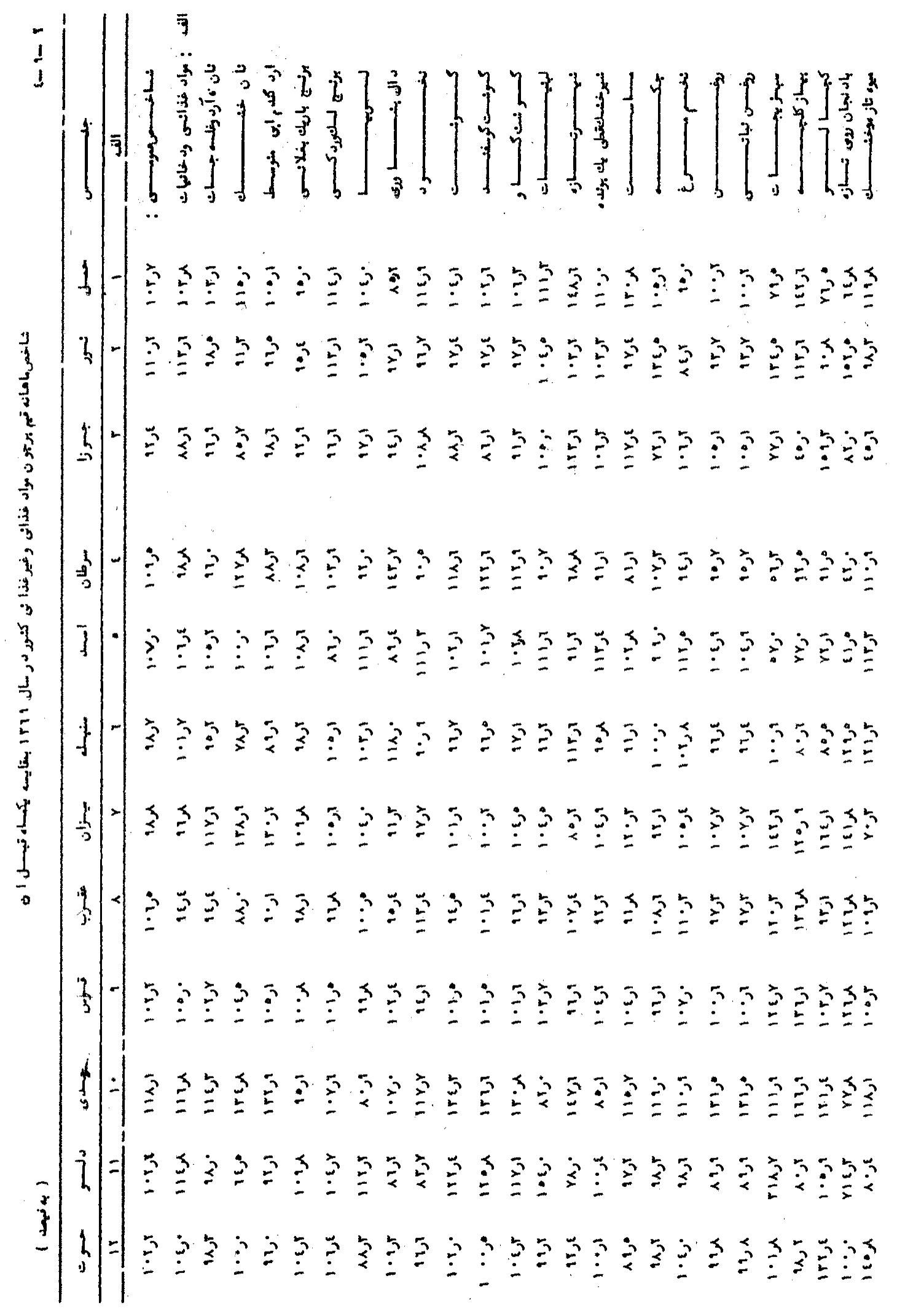




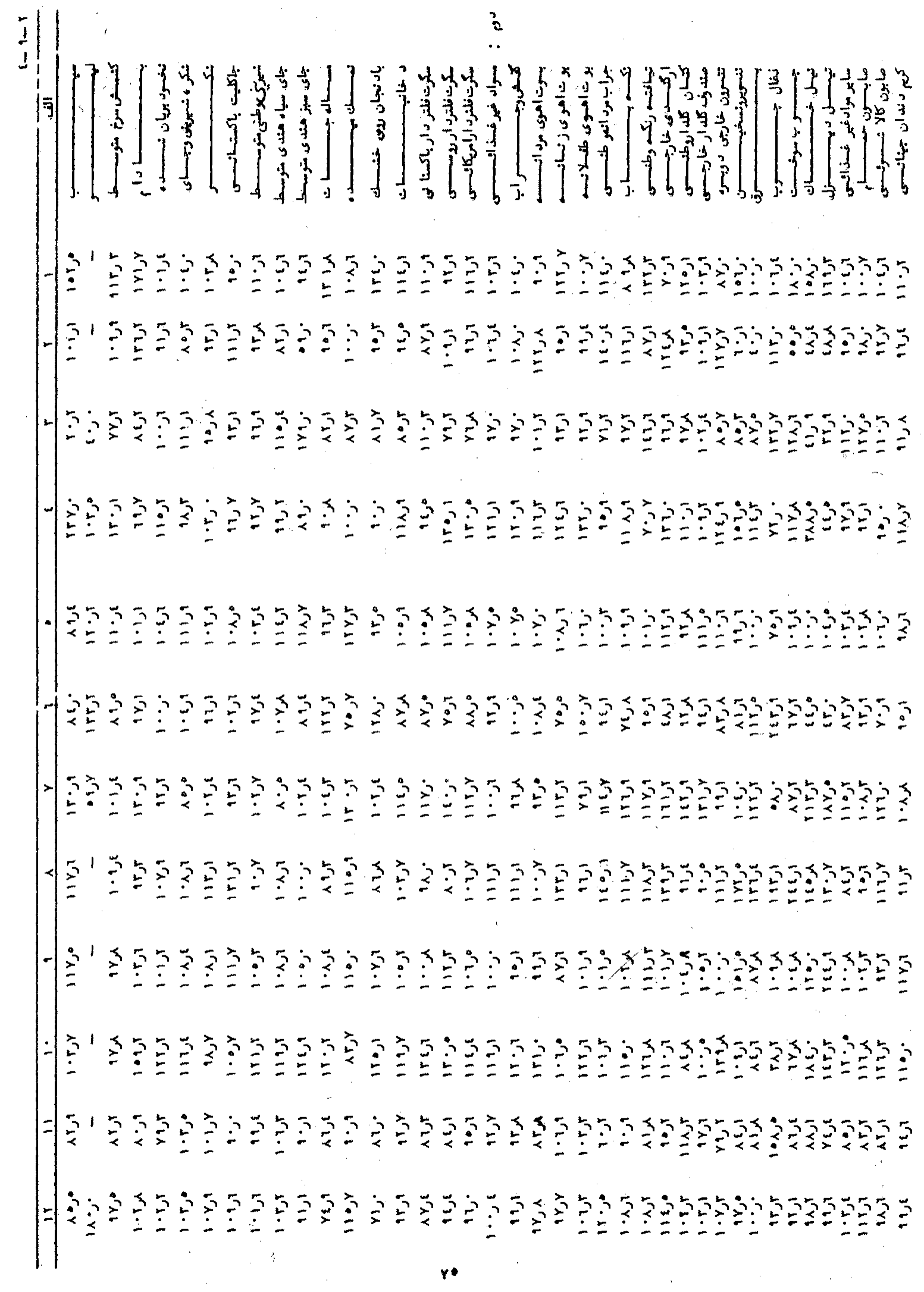




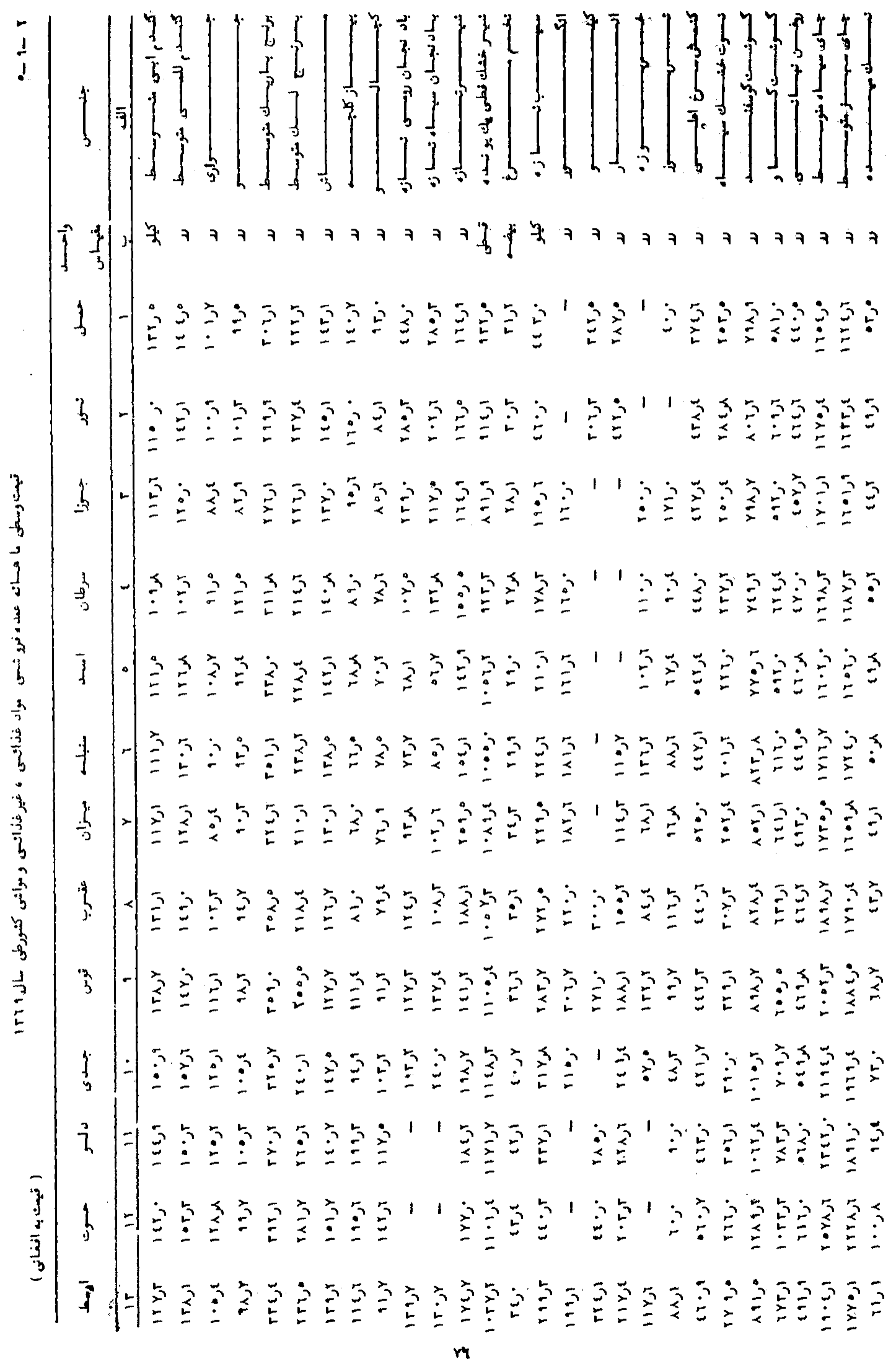




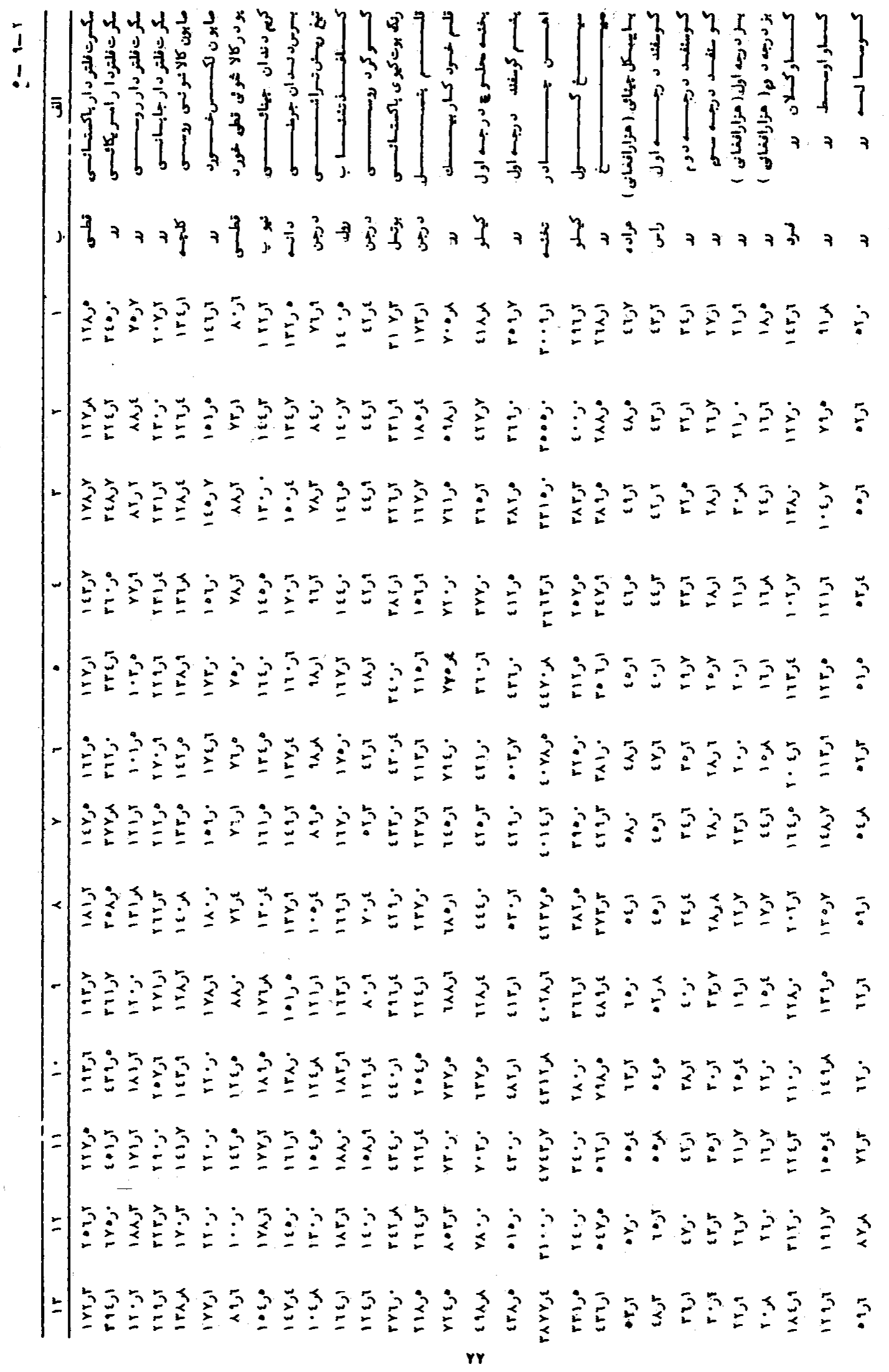




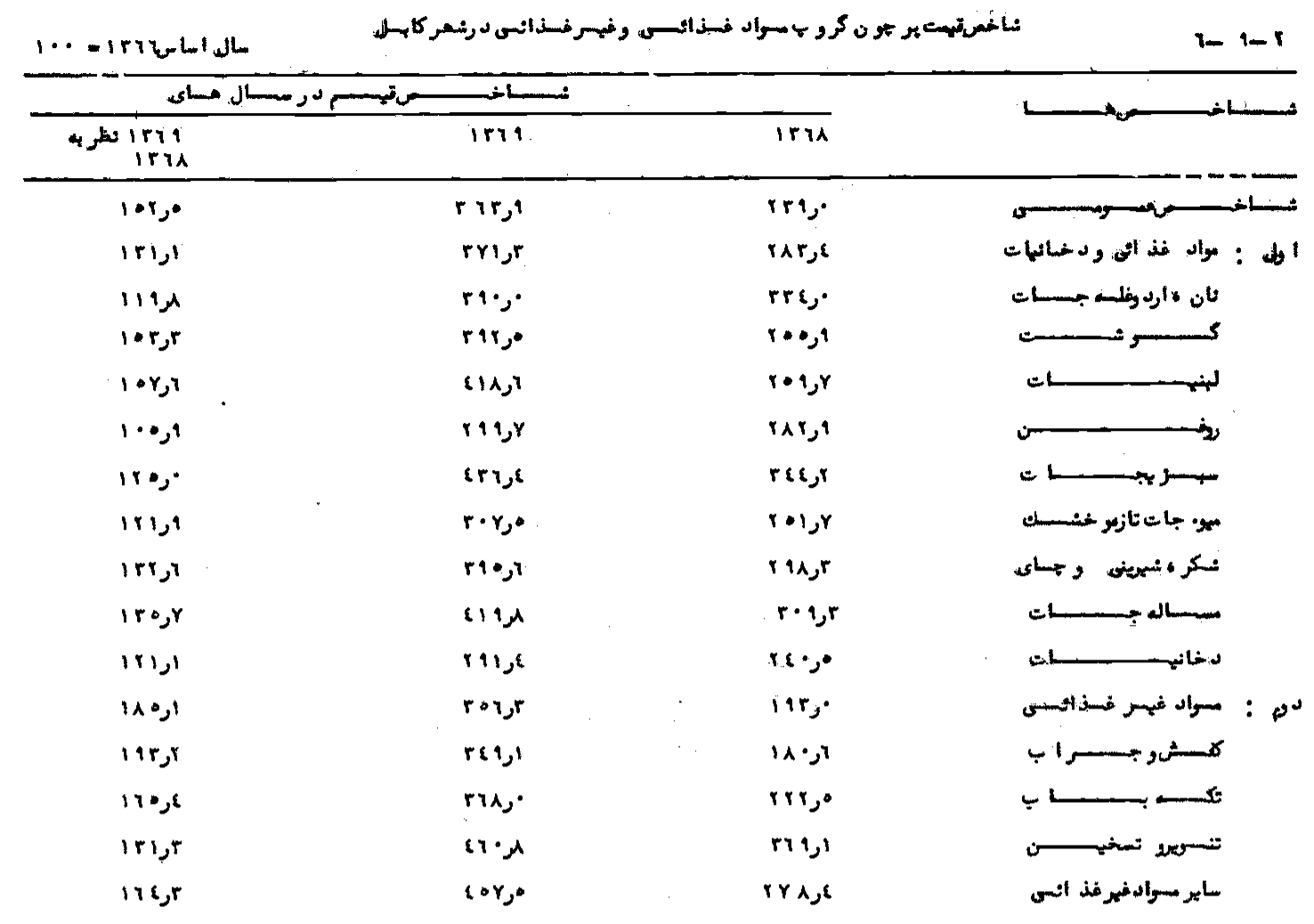

\begin{tabular}{|c|c|c|c|c|c|c|c|}
\hline \multirow{2}{*}{\multicolumn{3}{|c|}{ 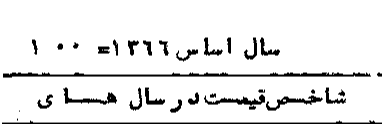 }} & \multicolumn{4}{|c|}{ 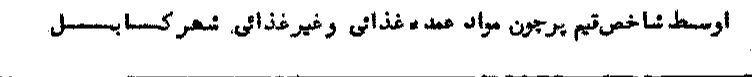 } & $r-1-r$ \\
\hline & & & & لي لدرمسال & & واحسد & \\
\hline $\begin{array}{l}\text { Iry } \\
\text { IryA }\end{array}$ & 1819 & $\operatorname{lrud}$ & 1879 & $\operatorname{lrra}$ & $\operatorname{lr} 71$ & مقيساس & \\
\hline 1 & 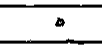 & $\varepsilon$ & $r$ & $r$ & 1 & + & 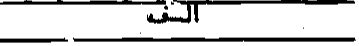 \\
\hline 1080 & $r i r, q$ & $r r \varepsilon \cdot$ & & & & & ماخسمسمور \\
\hline | & $r r i, r$ & rarge & & & & & الو : مواد نذاثن ود خانها = \\
\hline$\| 1 \mu$ & $r q \cdot, \cdot$ & rris. & & & & & 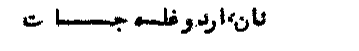 \\
\hline$i r i, y$ & $r \cdot \bullet \cdot$ & 10.0 & $i r, r$ & $\varepsilon$ & יני & تموس & 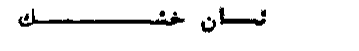 \\
\hline $11 r, 9$ & \&ะห) & $r q 1,0$ & إ & $\mid r \lambda, \varepsilon$ & $r$ ri & 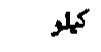 & 'اد كدم ابسى متوسسيسط \\
\hline $1 \times 1,9$ & $r q \varepsilon, \varepsilon$ & $r \cdot \mu$ & $r \varepsilon \cdot, \varepsilon$ & $r u r$ & $\alpha r$ & لد & يرنهج بار كبكبلانى متوسط \\
\hline | ارrri & $r r \cdot, t$ & $r+0, Y$ & $r r a, r$ & $r \cdot r \cdot$ & $19, r$ & עد & 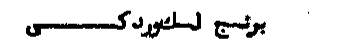 \\
\hline $1 \cdot r, 9$ & rir. & $r a 1, r$ & $\varepsilon \cdot \cdot$ & $r r \cdot, r$ & $18 \Lambda_{,}, 1$ & עد & \\
\hline $1 \cdots$ & $\varepsilon \cdot r, \varepsilon$ & $\varepsilon * r, \varepsilon$ & IA1 & | & $11, r$ & $\nu$ & 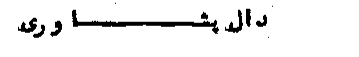 \\
\hline irre & $r A 1 ;$ & $r r r$ & r r r r & 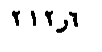 & 18,2 & עد & وود \\
\hline ror & rir, & r०⿻, & & & & & \\
\hline
\end{tabular}




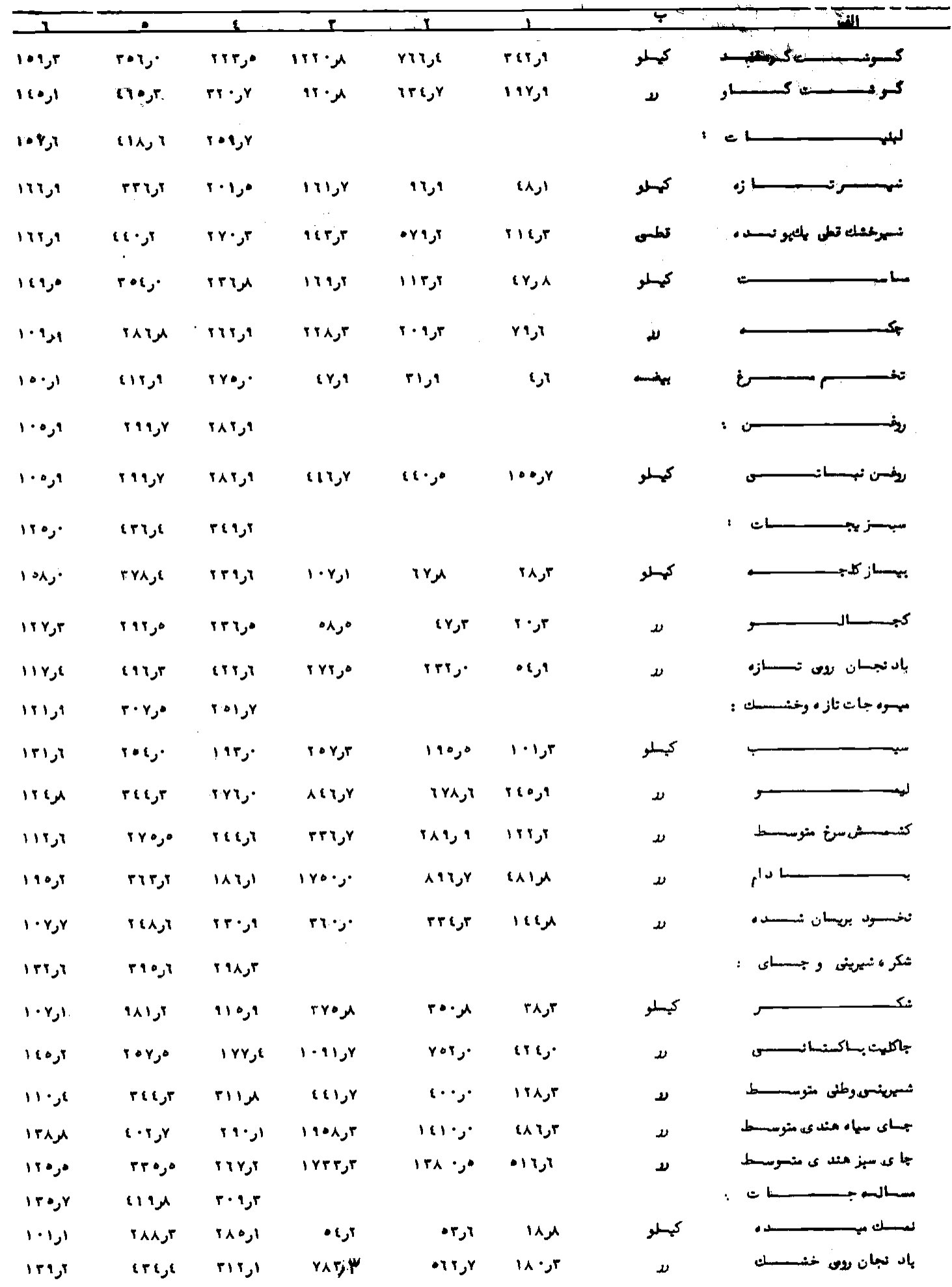




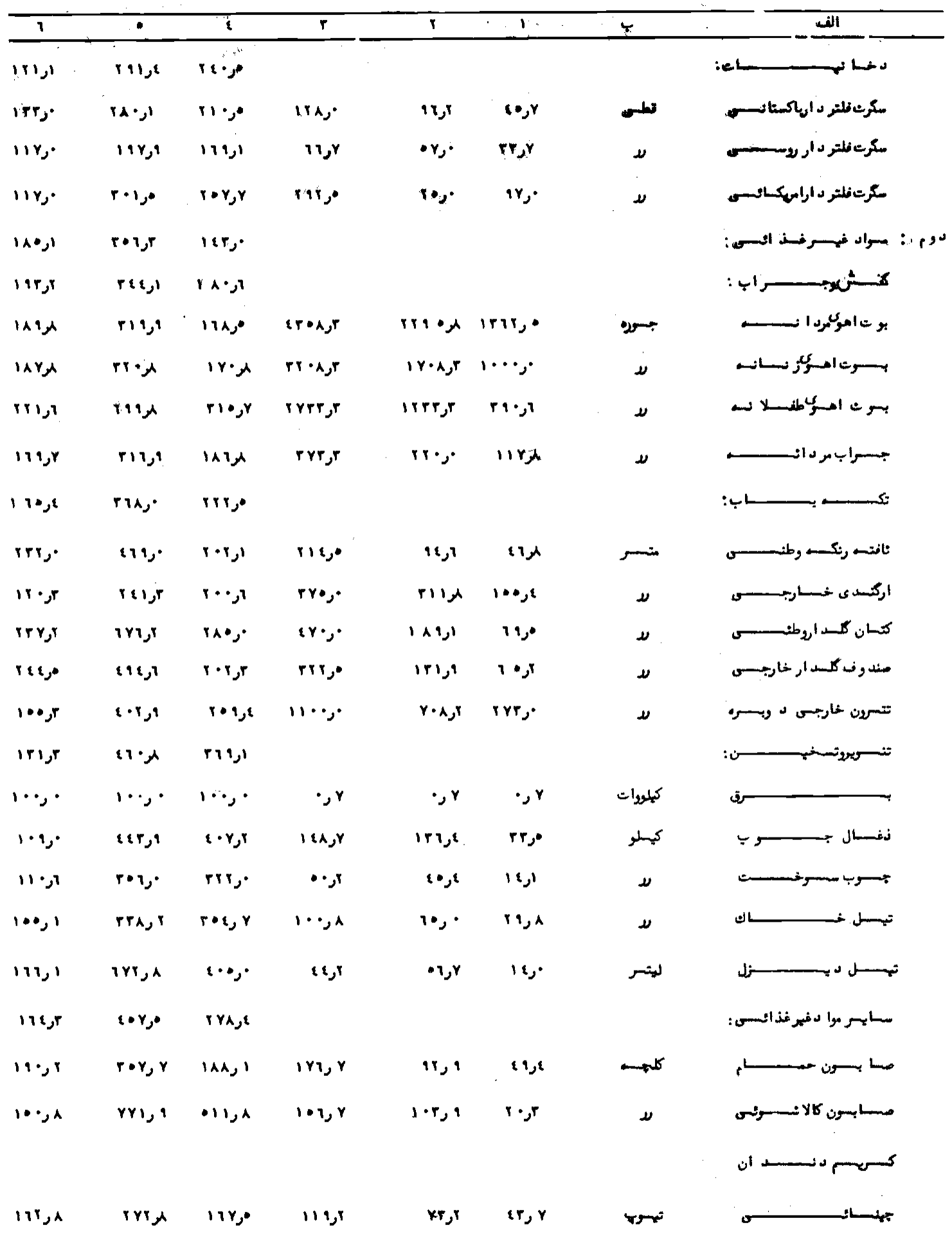




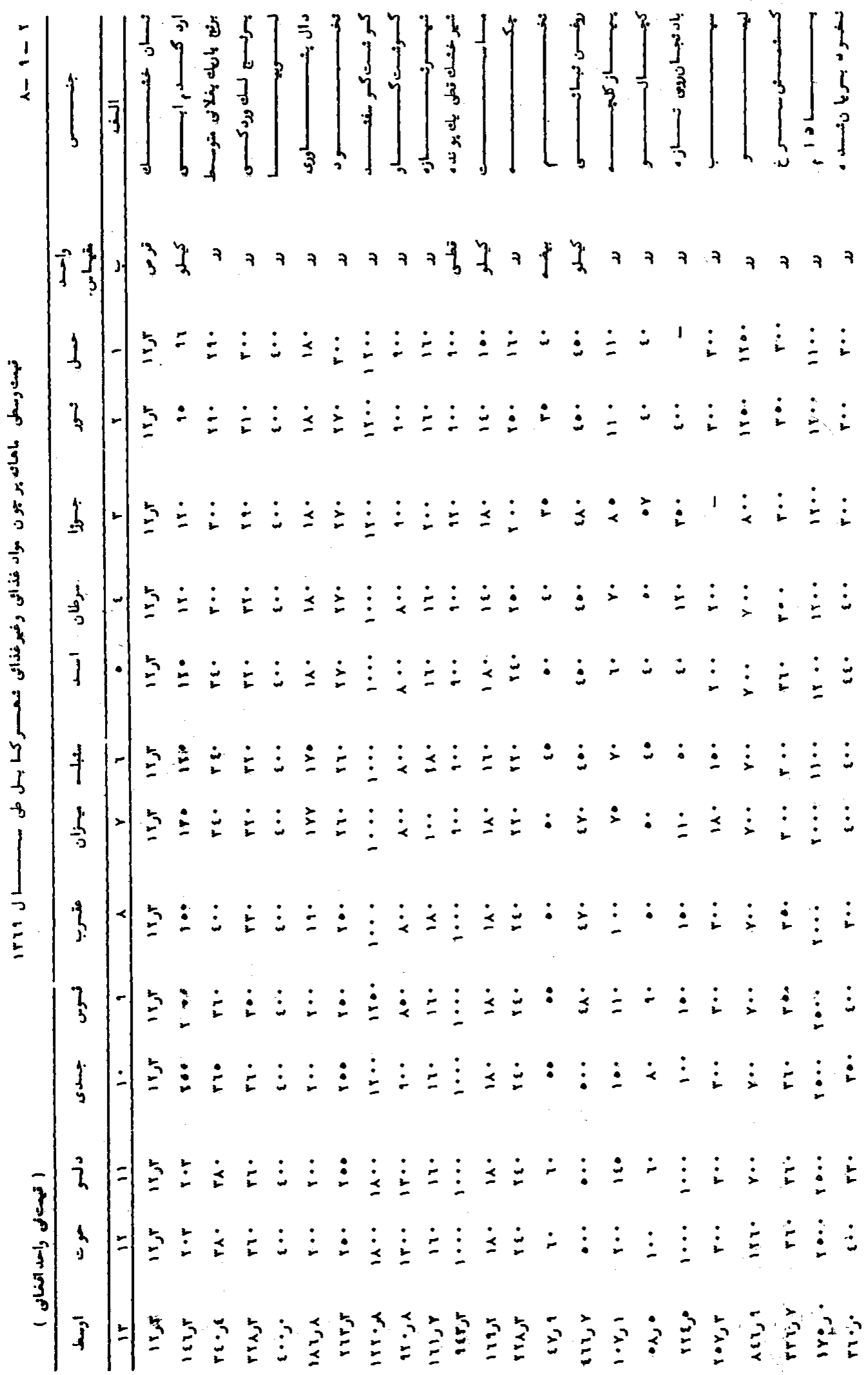




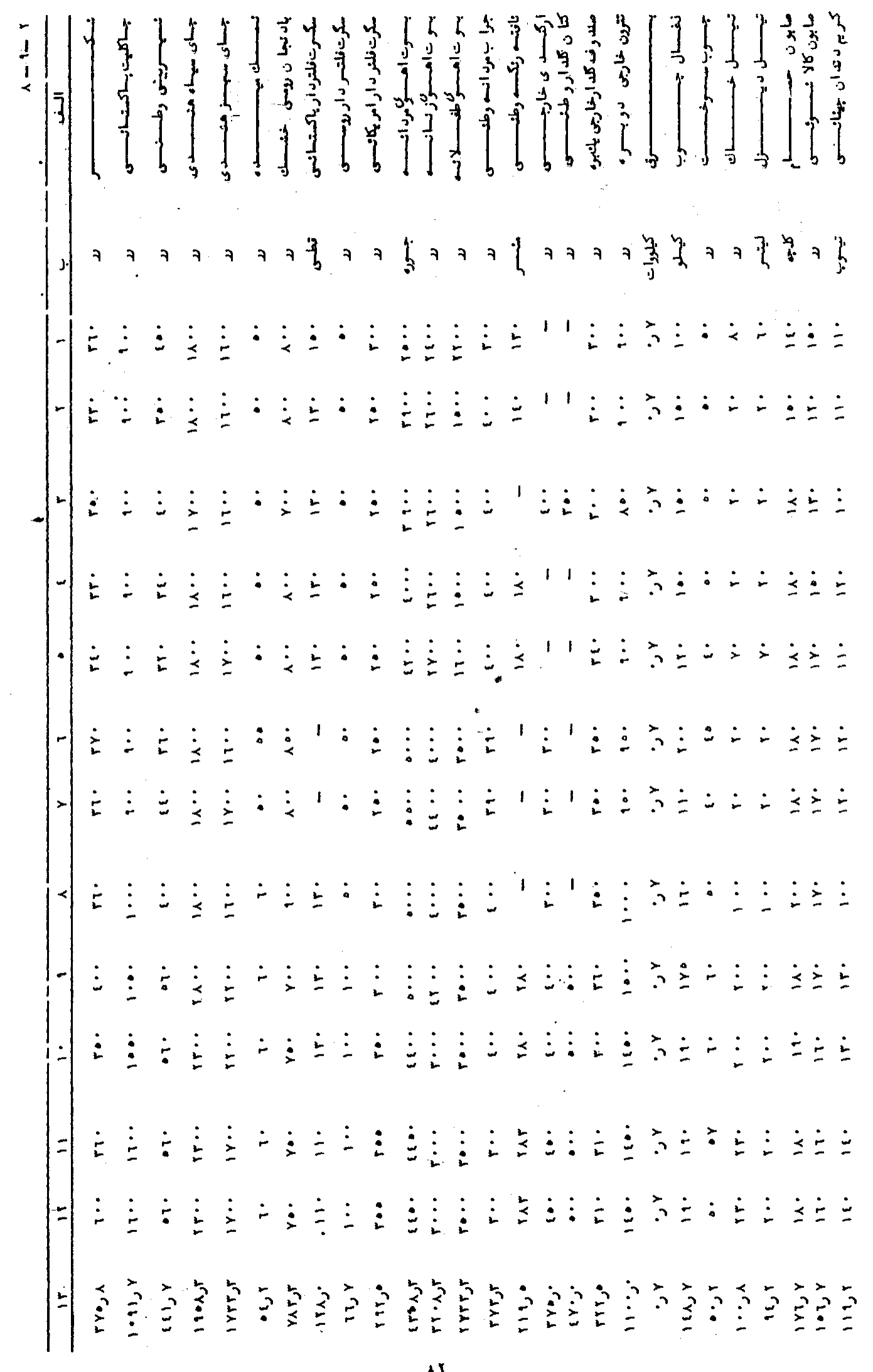




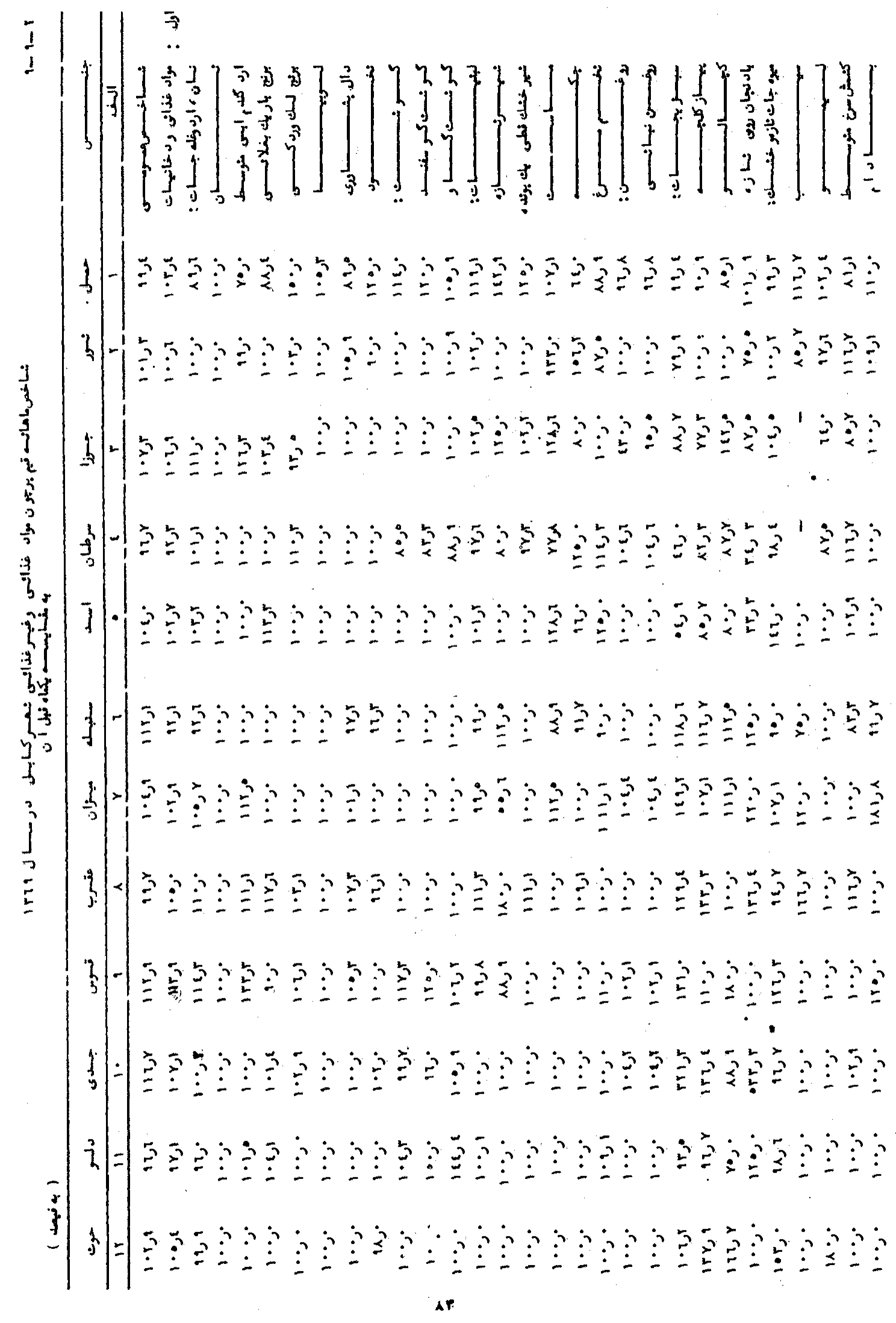




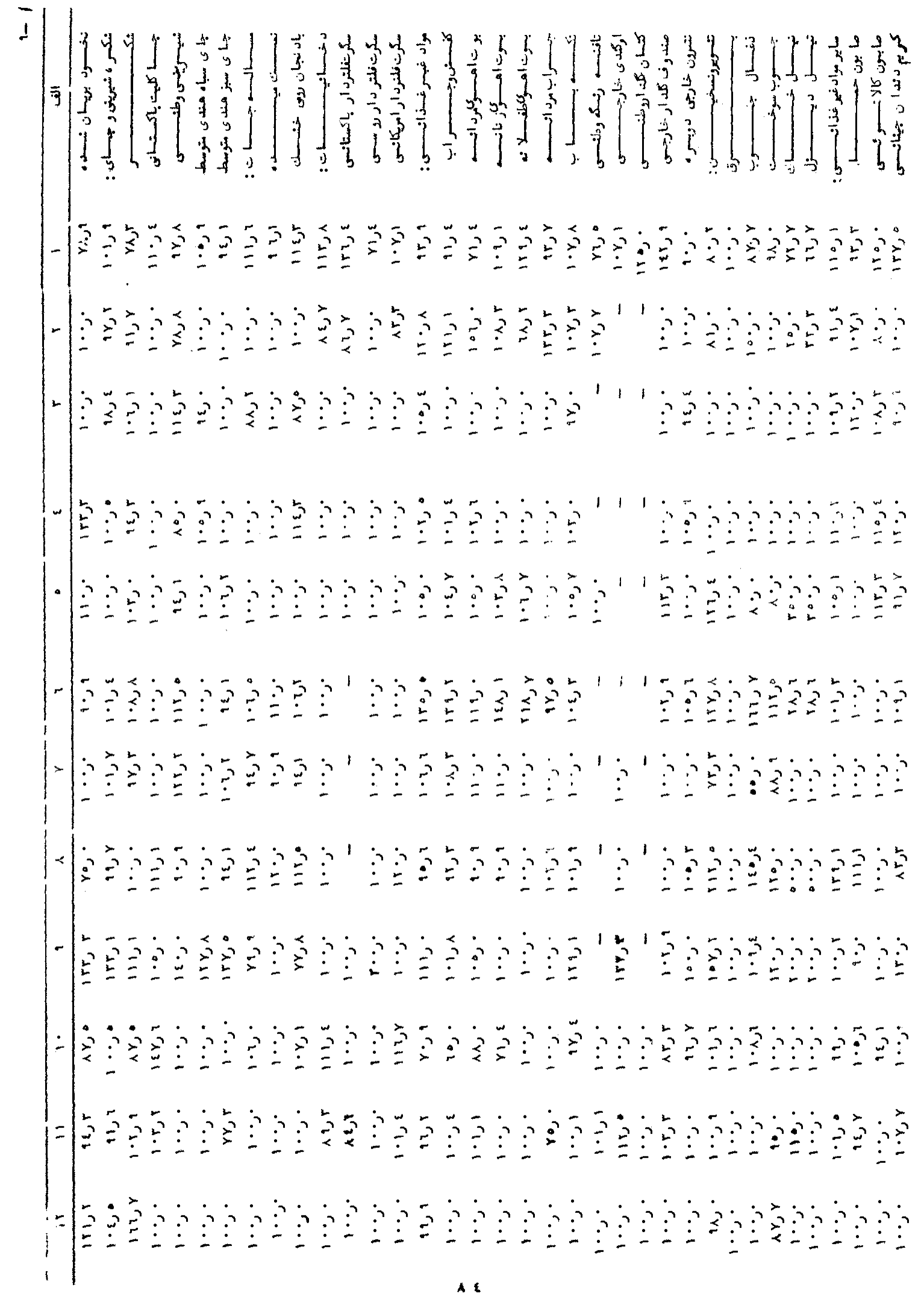




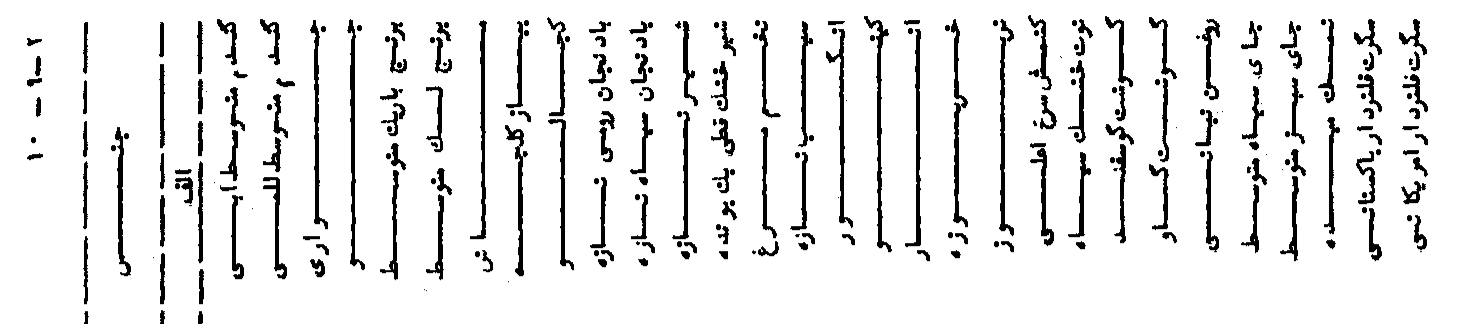

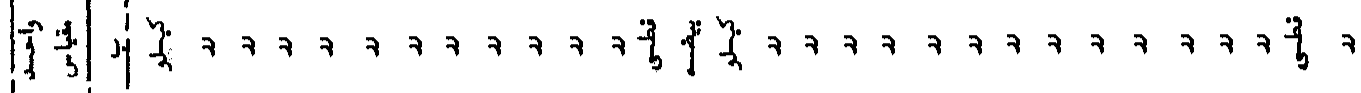

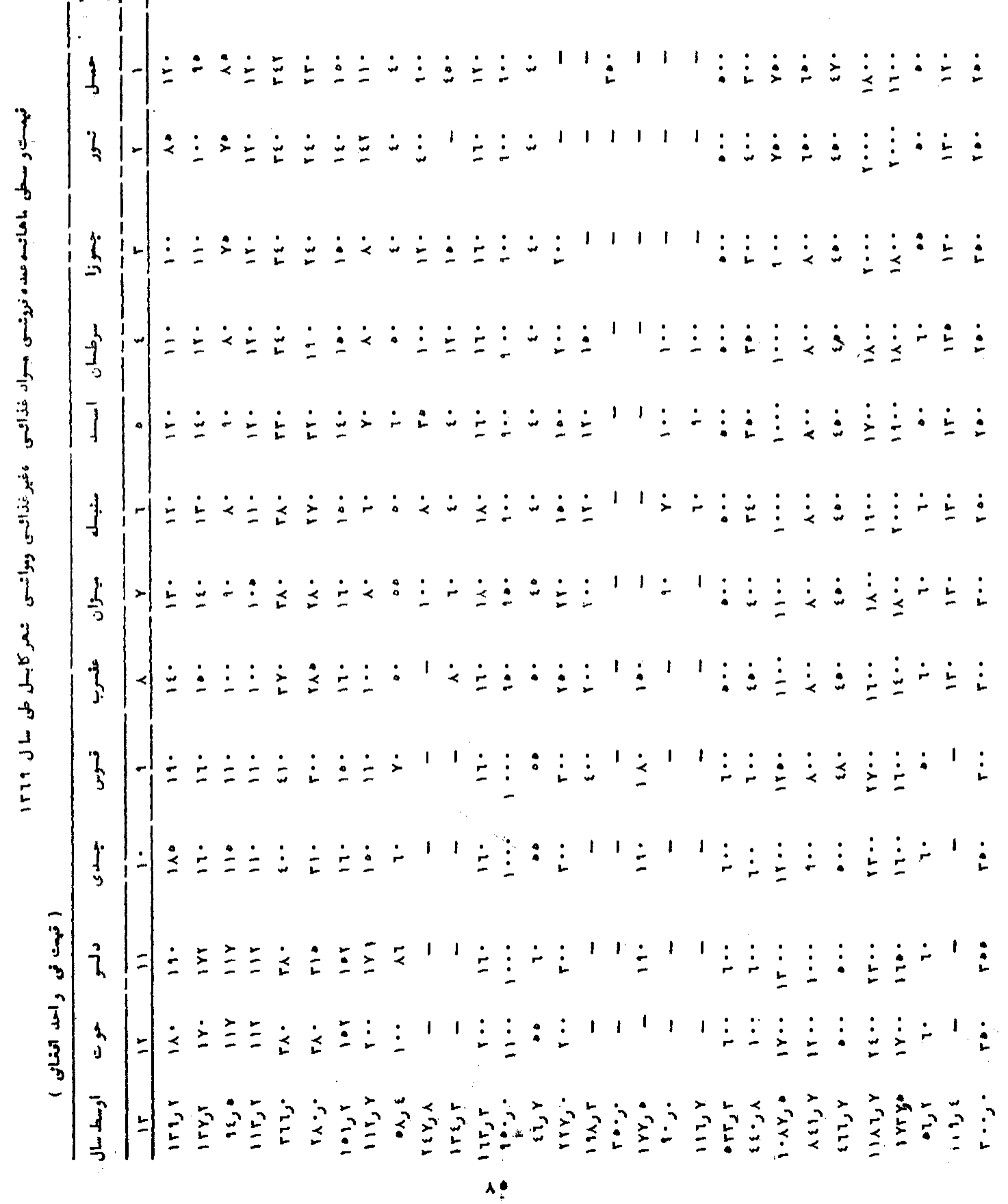




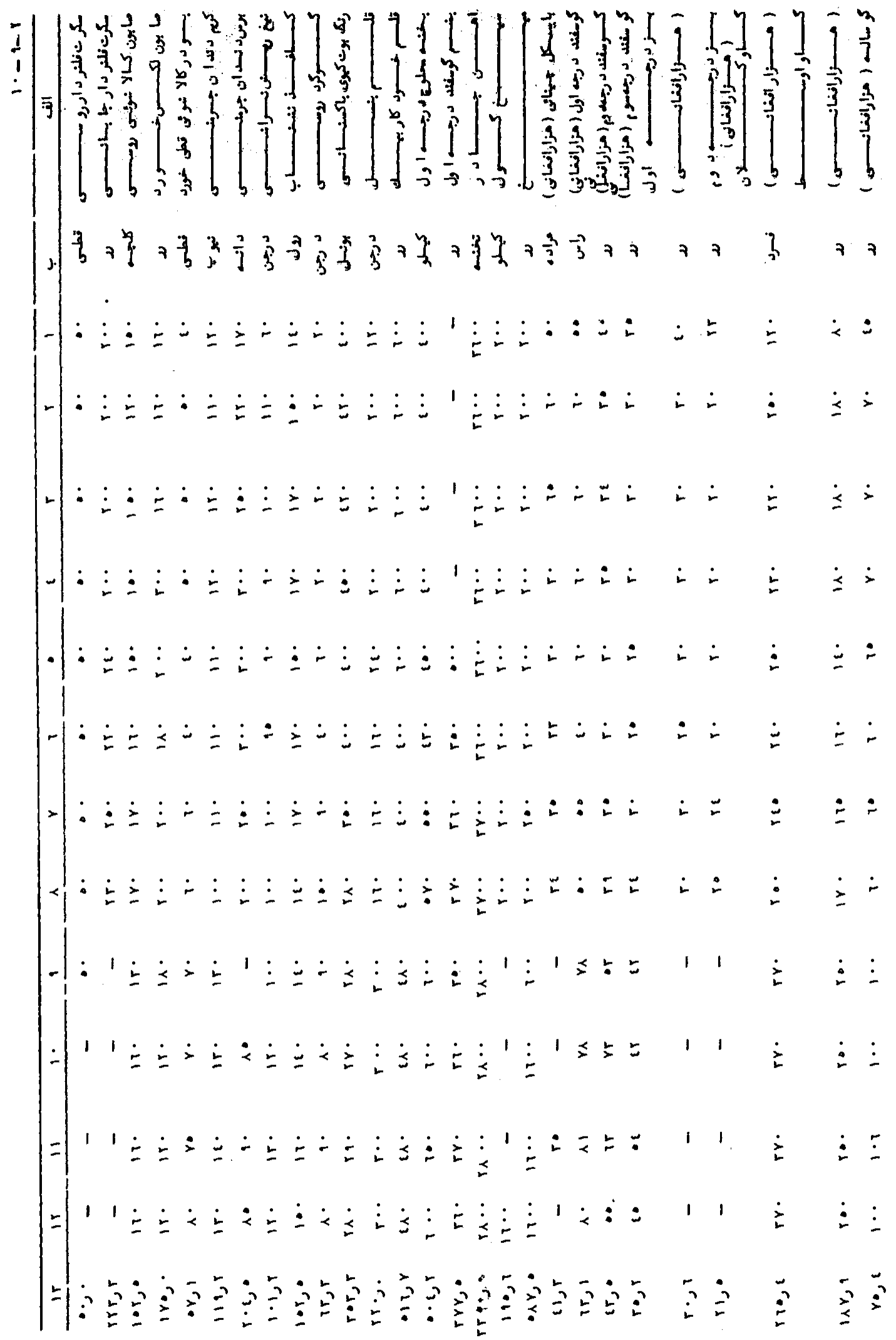




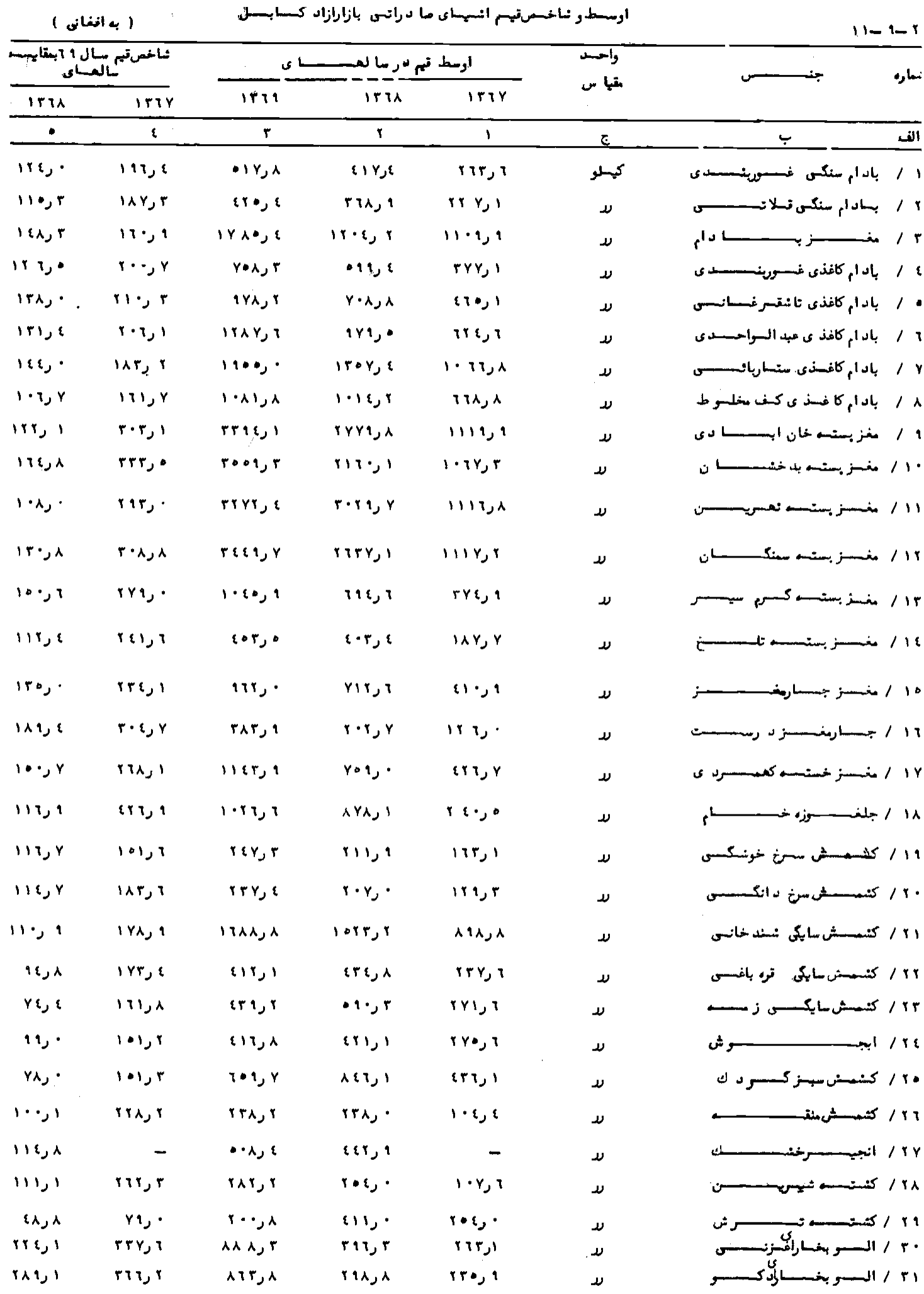




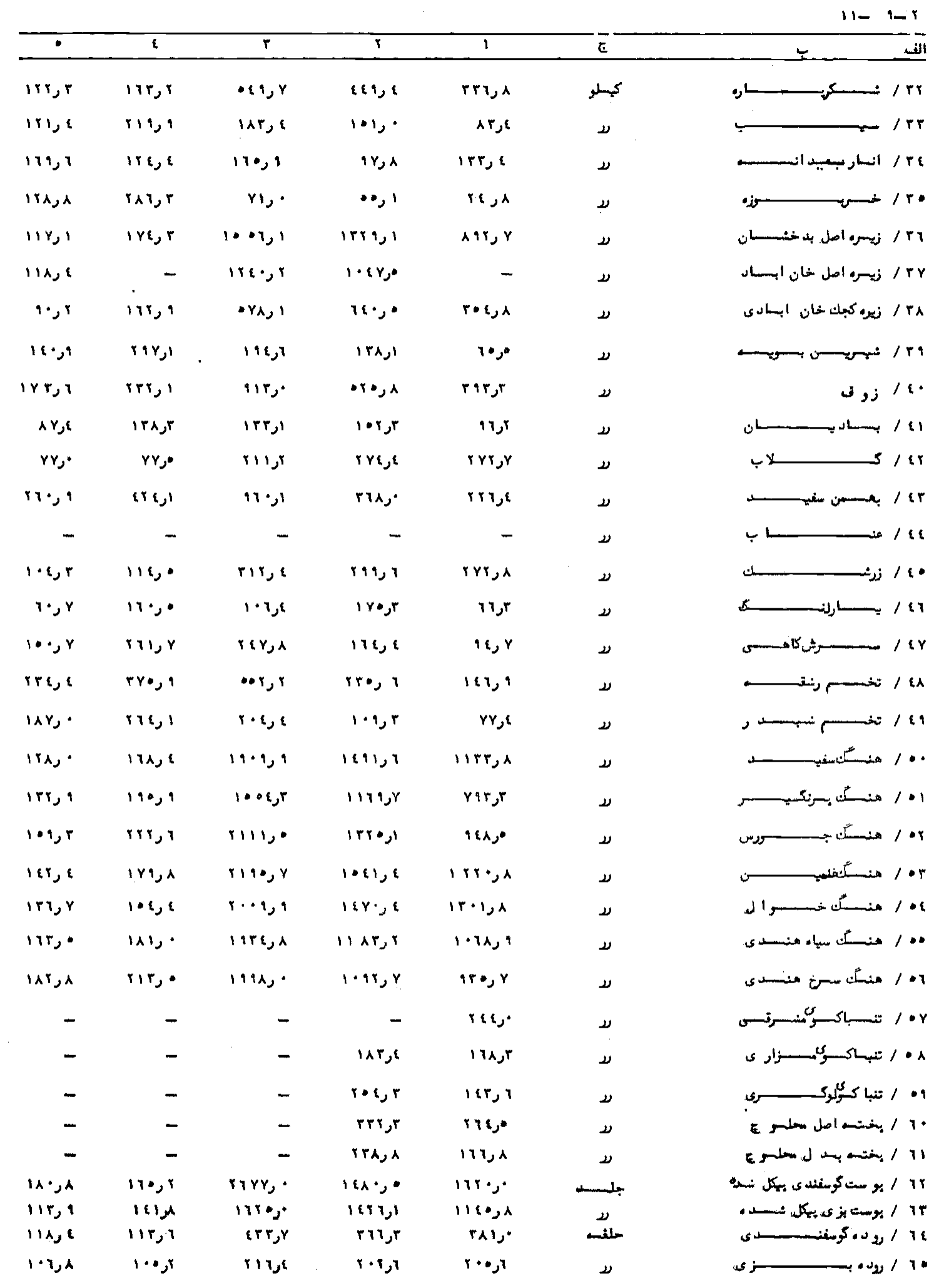




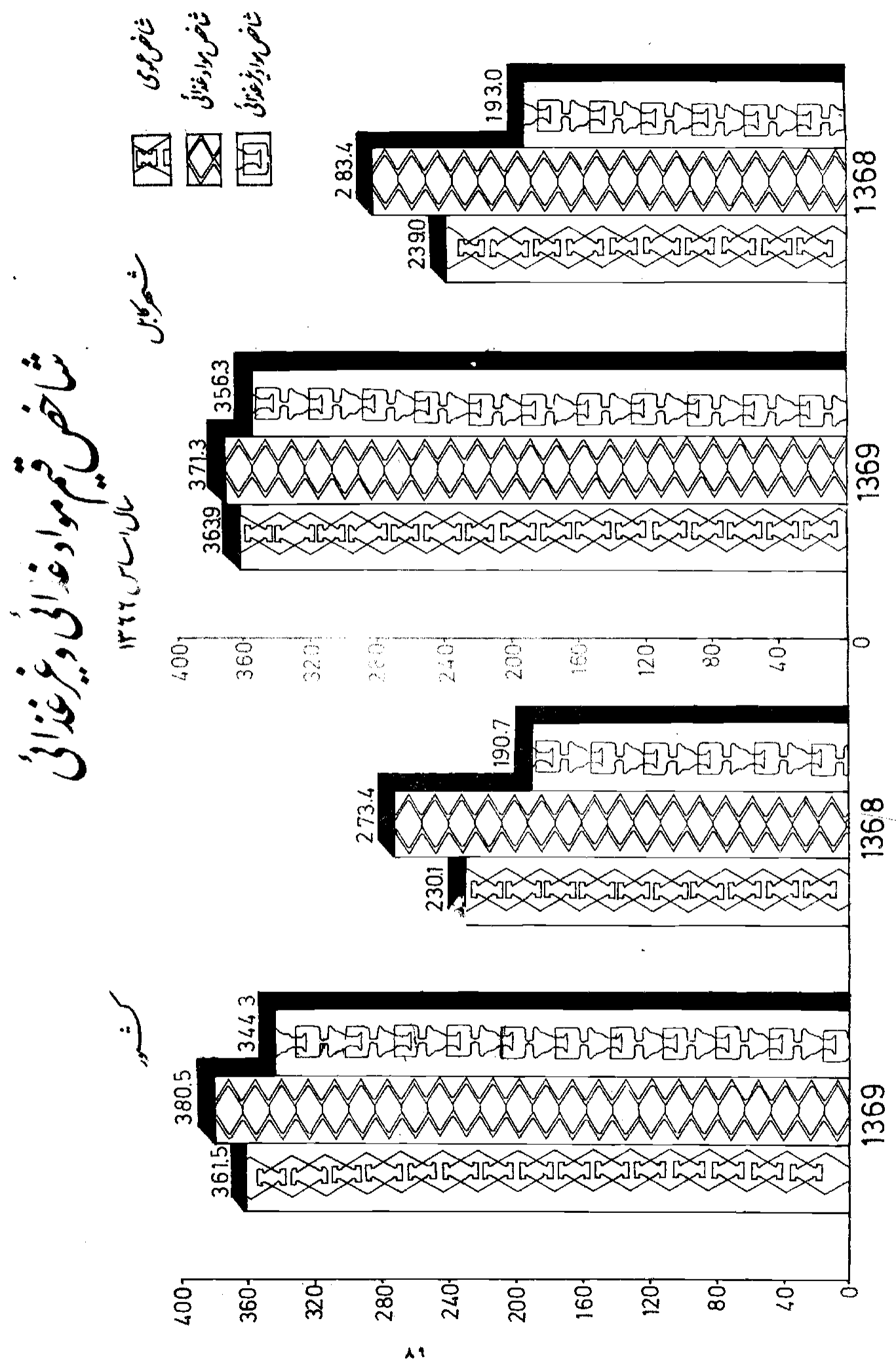




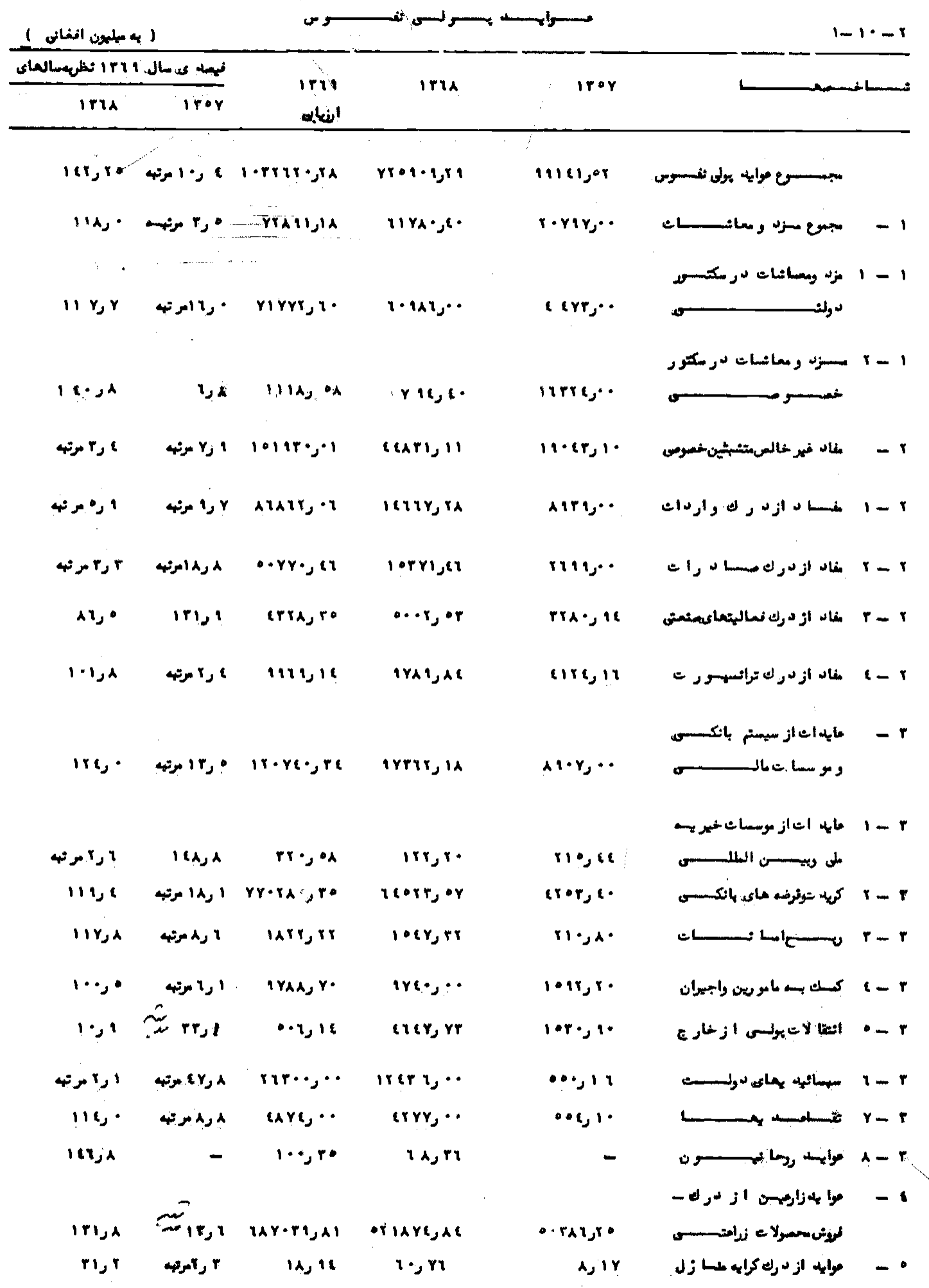




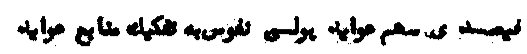

$r-1 \cdot-r$

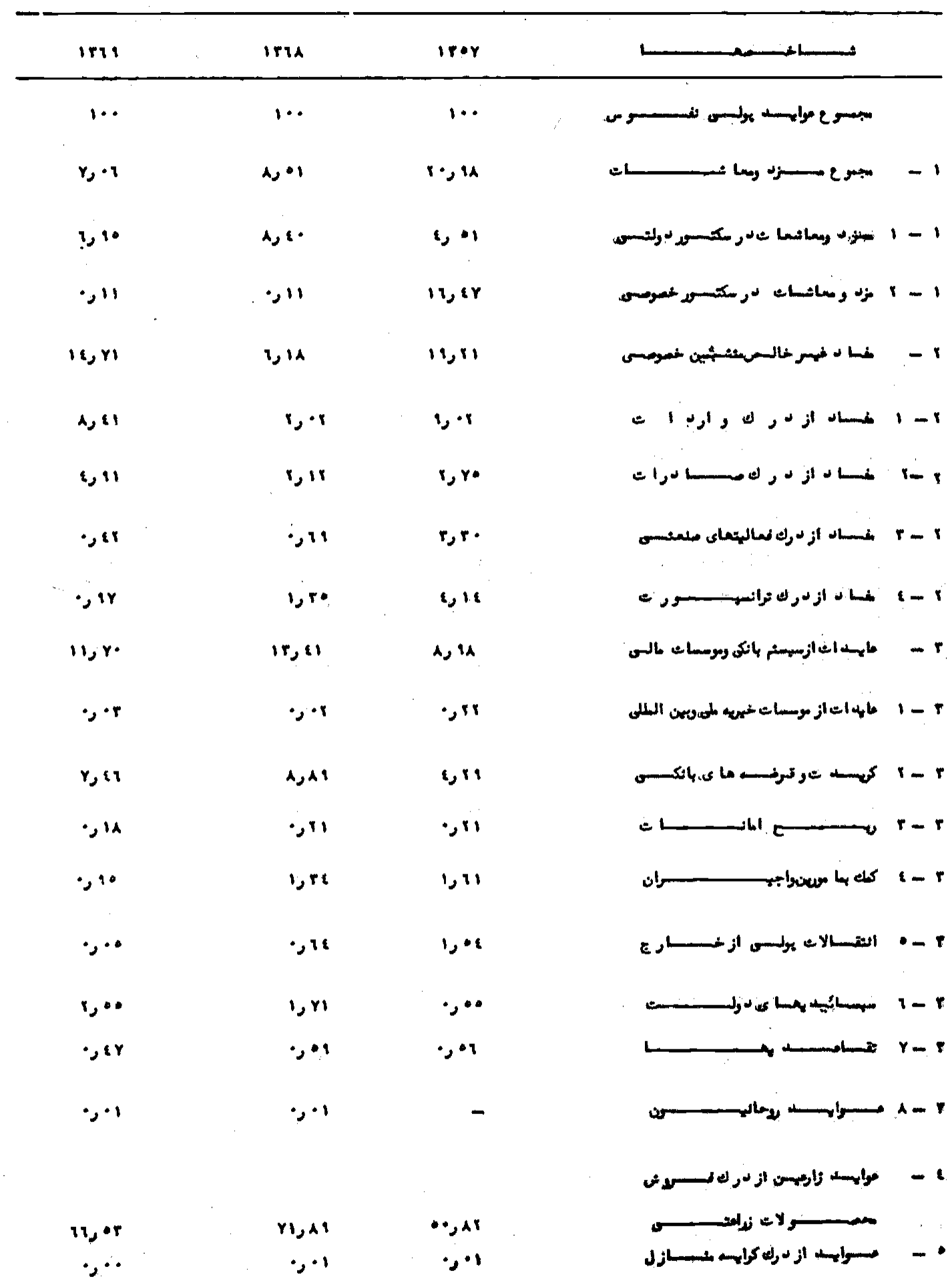



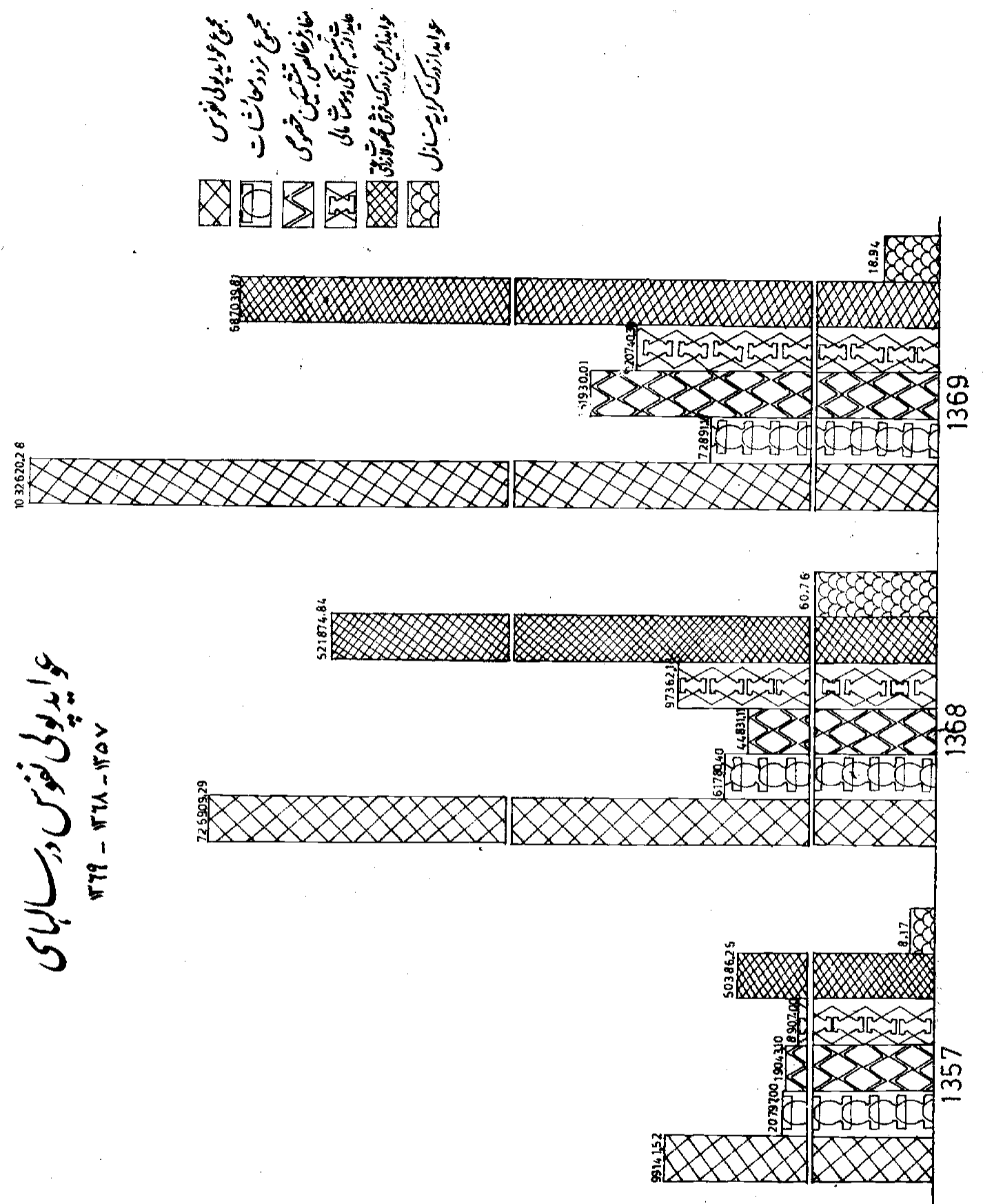

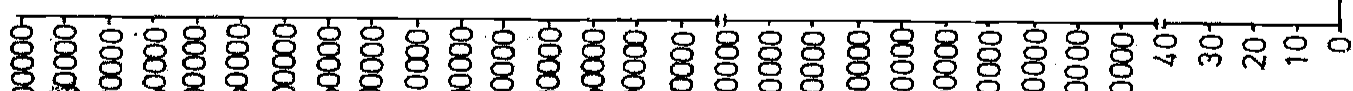

兽勇务 


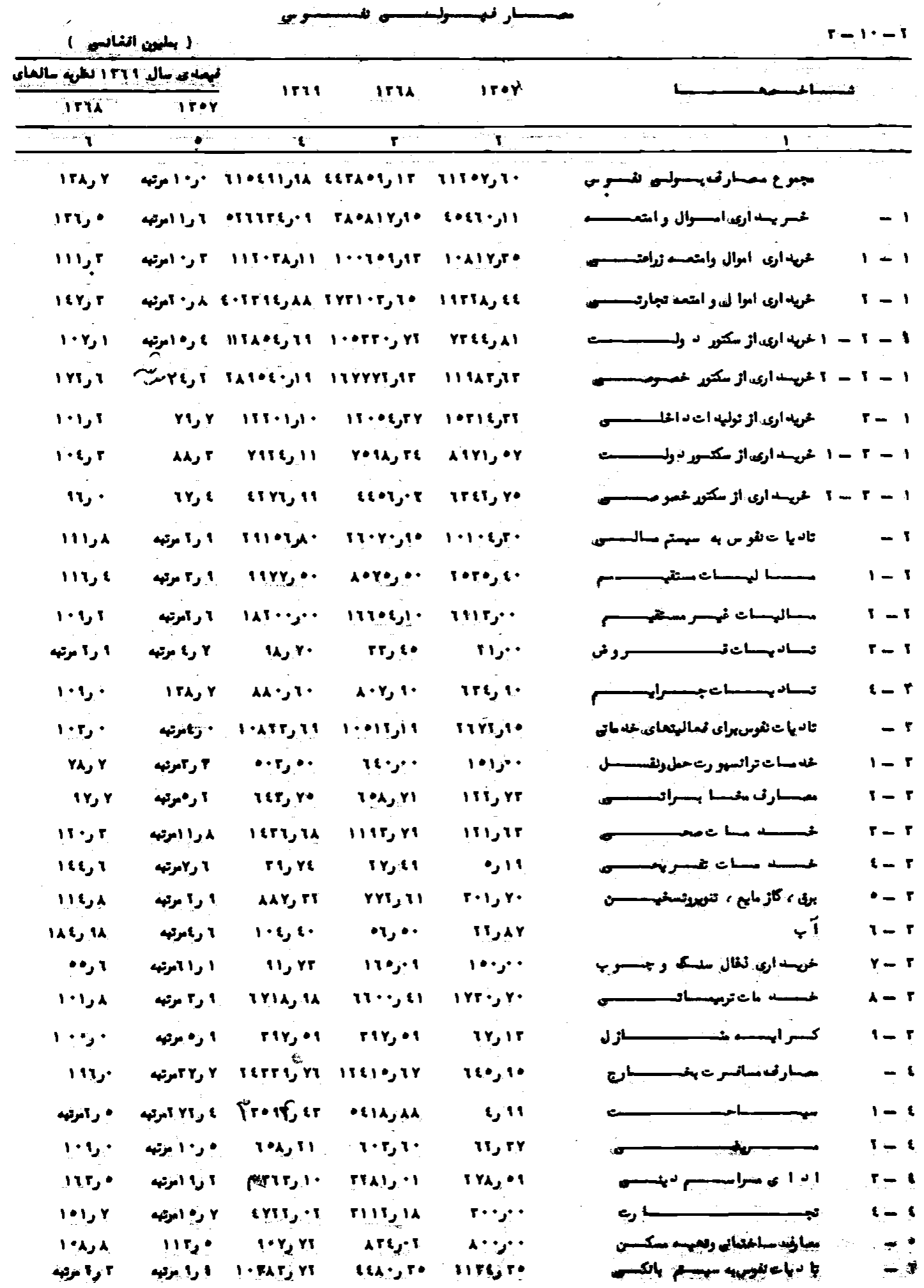


$\boldsymbol{r}-1 \cdot \boldsymbol{r}$

\begin{tabular}{|c|c|c|c|c|c|c|}
\hline 7 & - & 1 & $t$ & $r$ & 1 & \\
\hline ا & 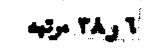 & $\because \cdots r_{j} \mid Y$ & $r \cdot 1, r \cdot$ & $r Y, i r$ & 나 & $-r$ \\
\hline • رr مرنه & 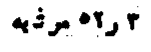 & $1 \cdot(I Y, \mid Y$ & $r \cdots r, A C$ & IIA,AY & . & $1-r$ \\
\hline$|A|, \mid$ & 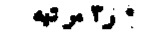 & 19 & $(r, \bullet)$ & $r \cdot, \cdot$ & מ & $r-r$ \\
\hline - & - & - & - & $(r, 10$ & & $r-r$ \\
\hline ا رث مور4 & r را متثه & $r \bullet \bullet, \cdot 1$ & 190,07 & $I r r, r A$ & & -1 \\
\hline irit & | 17, & 011,21 & $r i t, r r$ & $13, r$ & هن & $1-1$ \\
\hline Hin $11, r$ & וניו & r.rute & 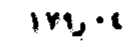 & $1 \cdot r_{2} \cdot 1$ & & $r-1$ \\
\hline $1 \cdot 8,8$ & 1 & 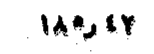 & $|A|, \mid A$ & $r \bullet, \bullet$ & & -1 \\
\hline$\because \cdot 0$ & 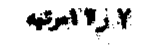 & $\mid x_{2}, v_{1}$ & won & : & كابث & $1-1$ \\
\hline${ }^{18}$, & i & $r r_{\mu} \cdot r$ & - Y , 1A & $r y$ & المسلا & $r-1$ \\
\hline irt, $r$ & ا & $r A_{2}=1$ & $r \cdot A^{\prime}$ & $\bullet, 1$ & 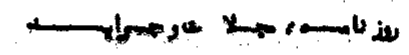 & $r-1$ \\
\hline$i r r, r$ & • راكالمونه & or & $r e, r$ & $i_{\alpha} \cdots$ & حسى المضو بتكرياثلمس & $1-1$ \\
\hline
\end{tabular}

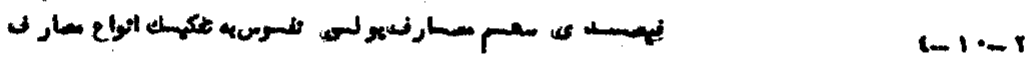

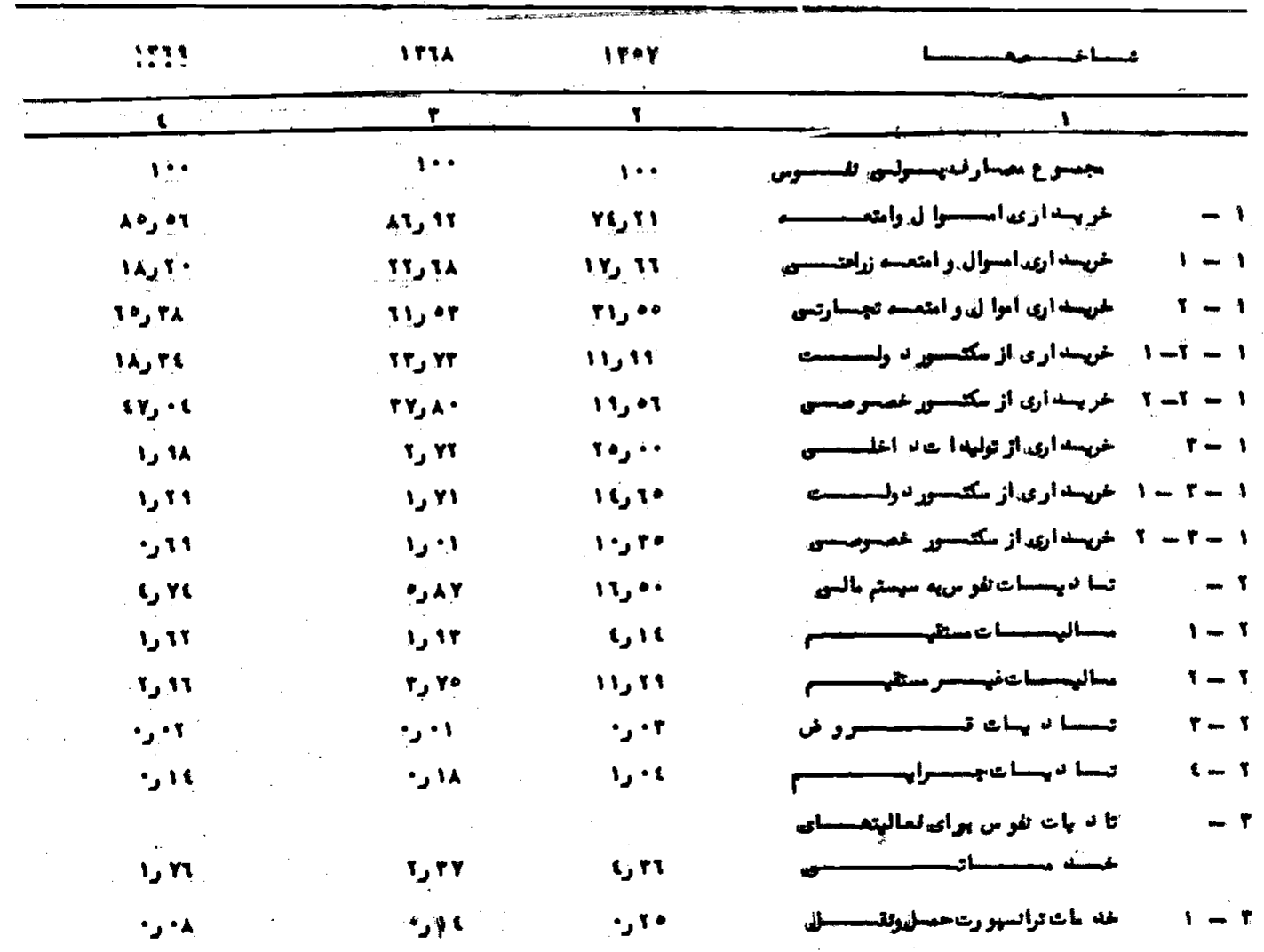




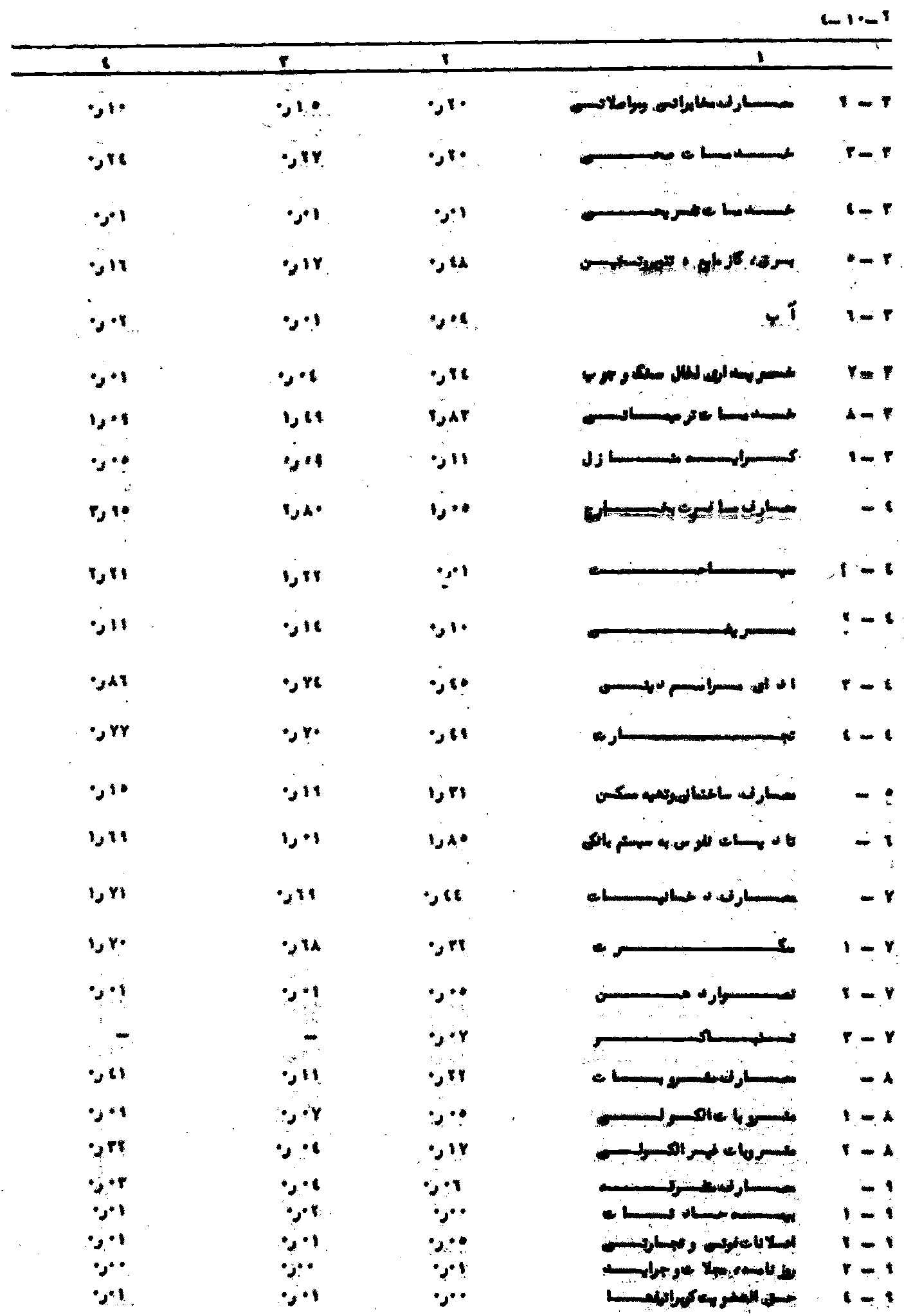




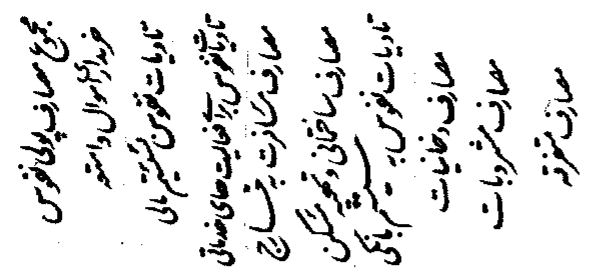

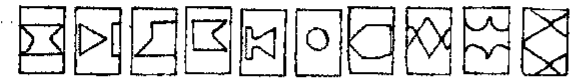

185.47

3

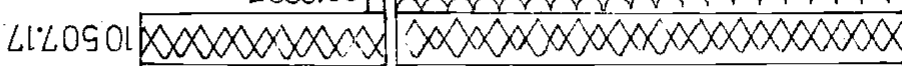

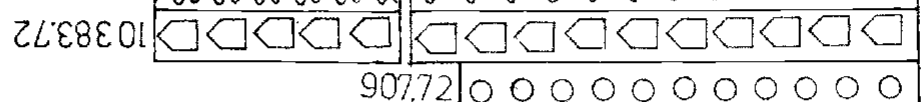

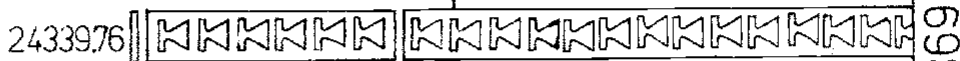

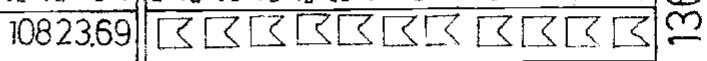

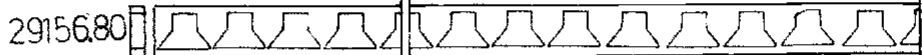

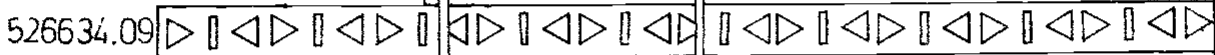

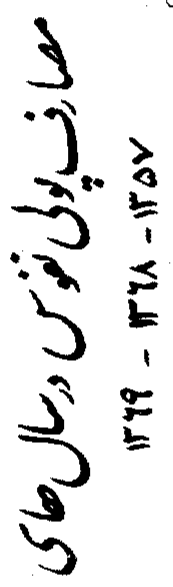

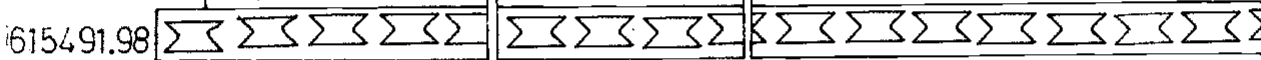

$$
\begin{aligned}
& 181.28 \\
& 49537 \mathrm{unun}
\end{aligned}
$$

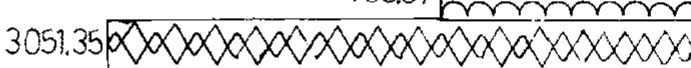

$$
\begin{aligned}
& 4480.35 \square \square \square \square \square 0 \square \square \square \square \square \square \\
& 834.020000000000
\end{aligned}
$$

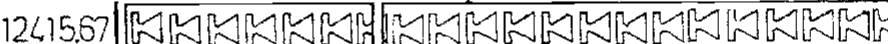

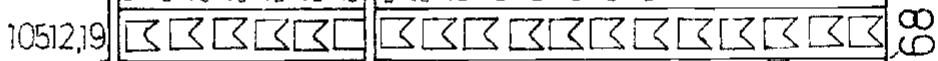

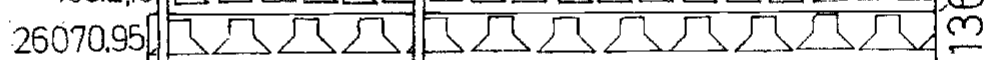

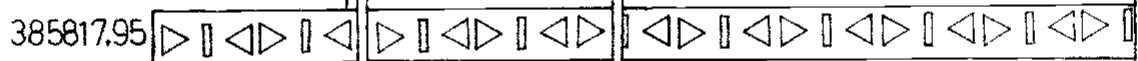

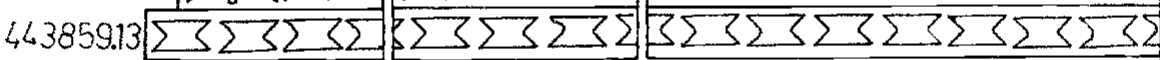

$$
\begin{aligned}
& 35.59 \\
& 1 3 2 . 3 8 \longdiv { \mathrm { m } } \\
& 2 7 1 . 9 7 \longdiv { \times \times \times 1 0 0 }
\end{aligned}
$$

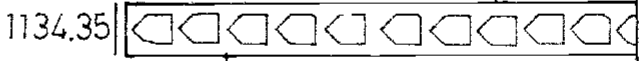

$$
\begin{aligned}
& 800.0010000000000
\end{aligned}
$$

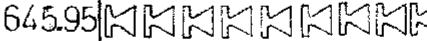

$$
\begin{aligned}
& 26 \% 2.95 \text { G } \\
& 10104.30 \square \Omega \Omega \Omega \sqrt{\Omega \Omega \Omega \Omega \Omega \Omega \Omega \Omega i n ~}
\end{aligned}
$$

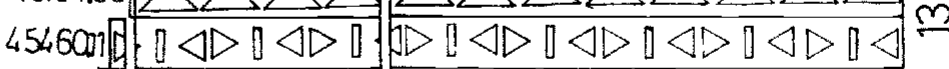

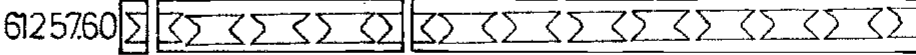

ง 


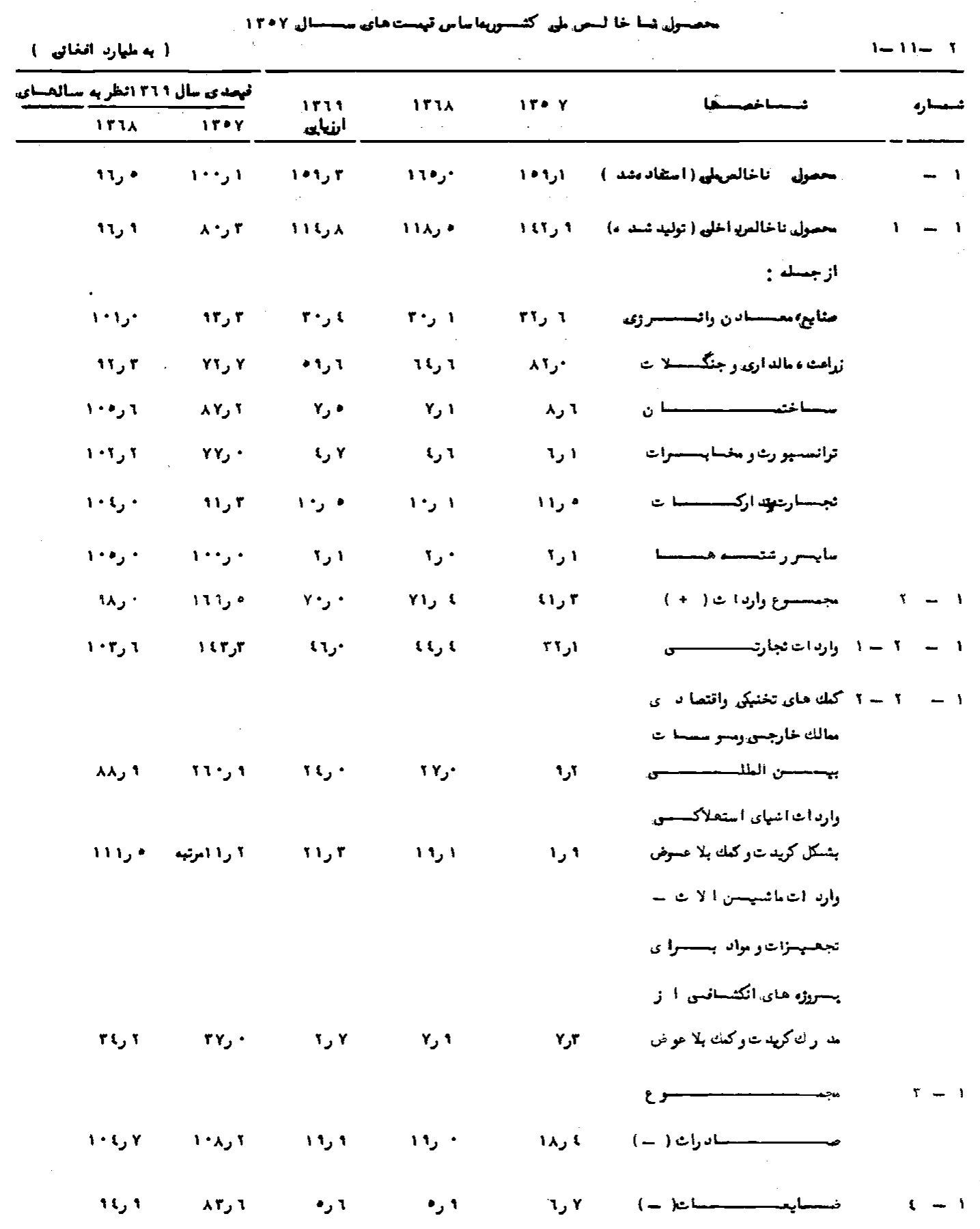




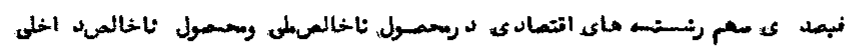

$r-11-r$

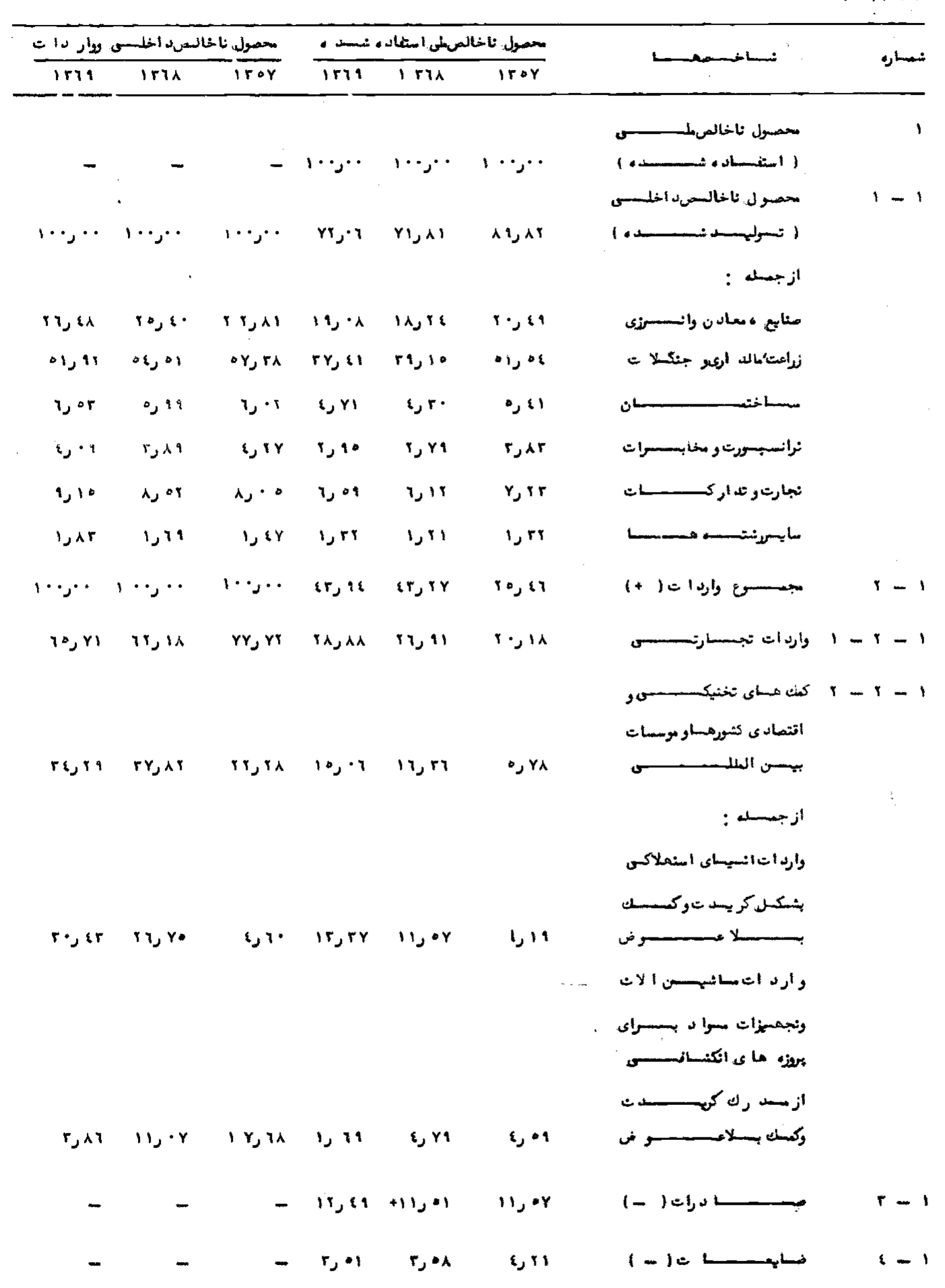




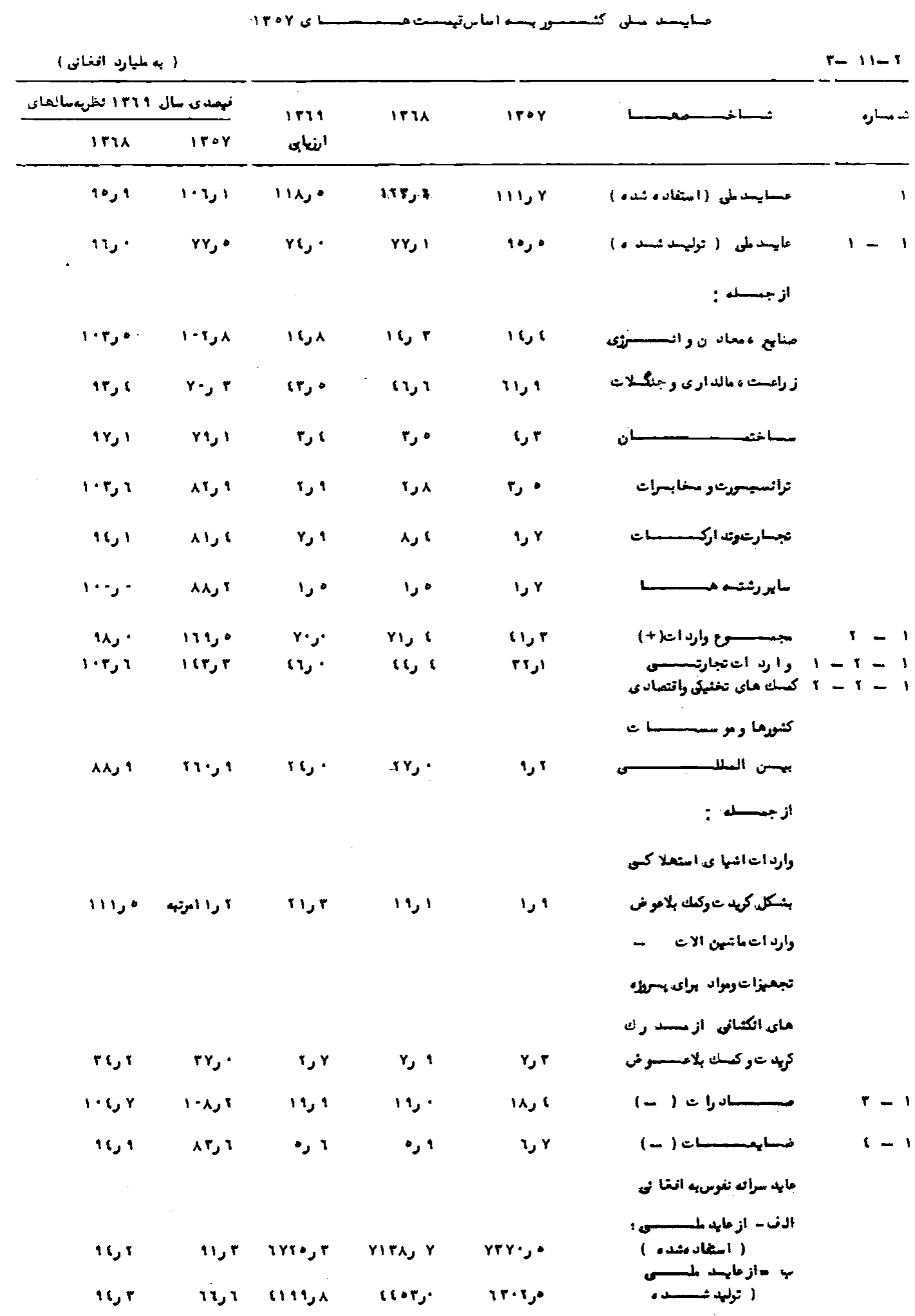




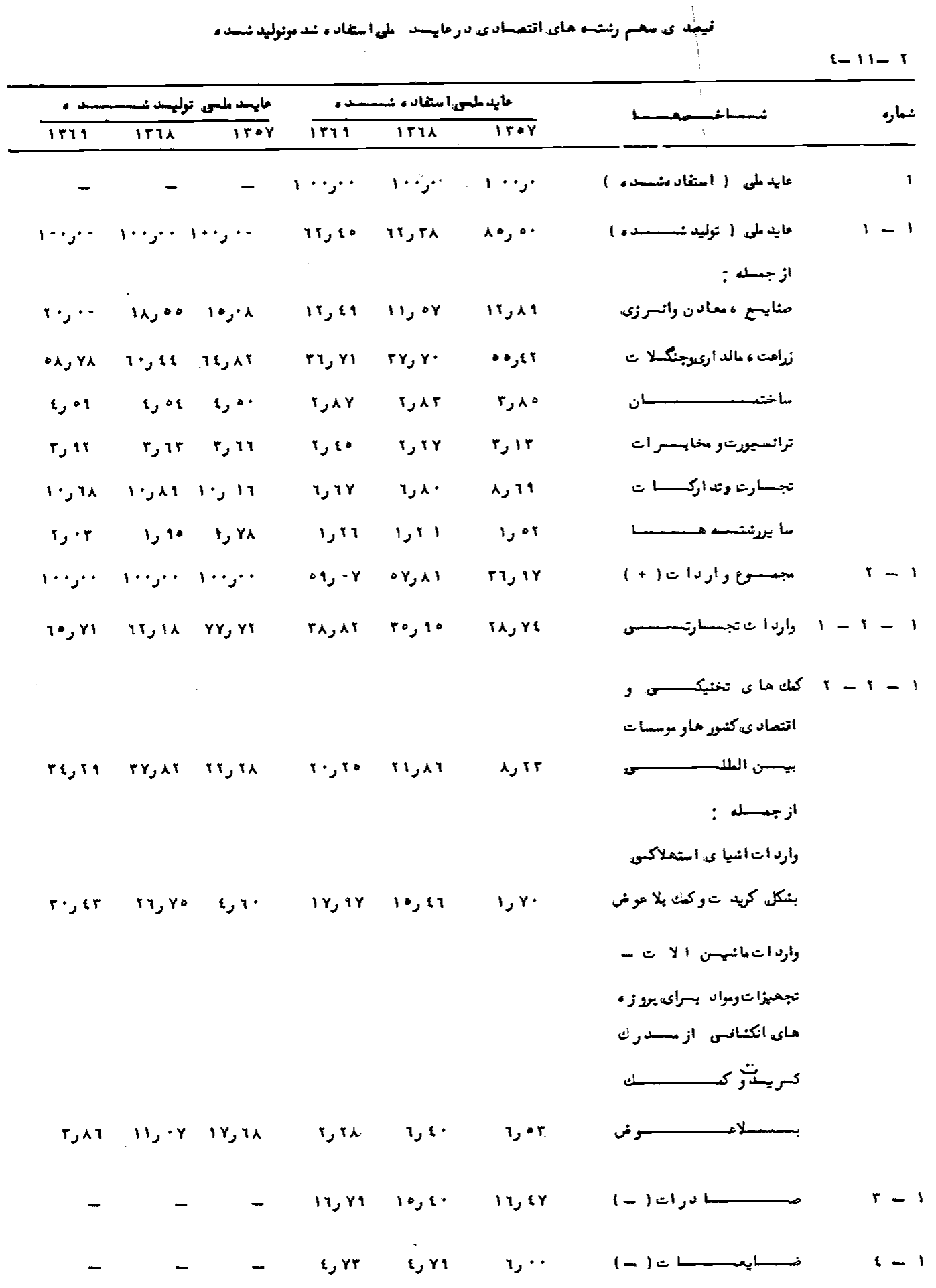




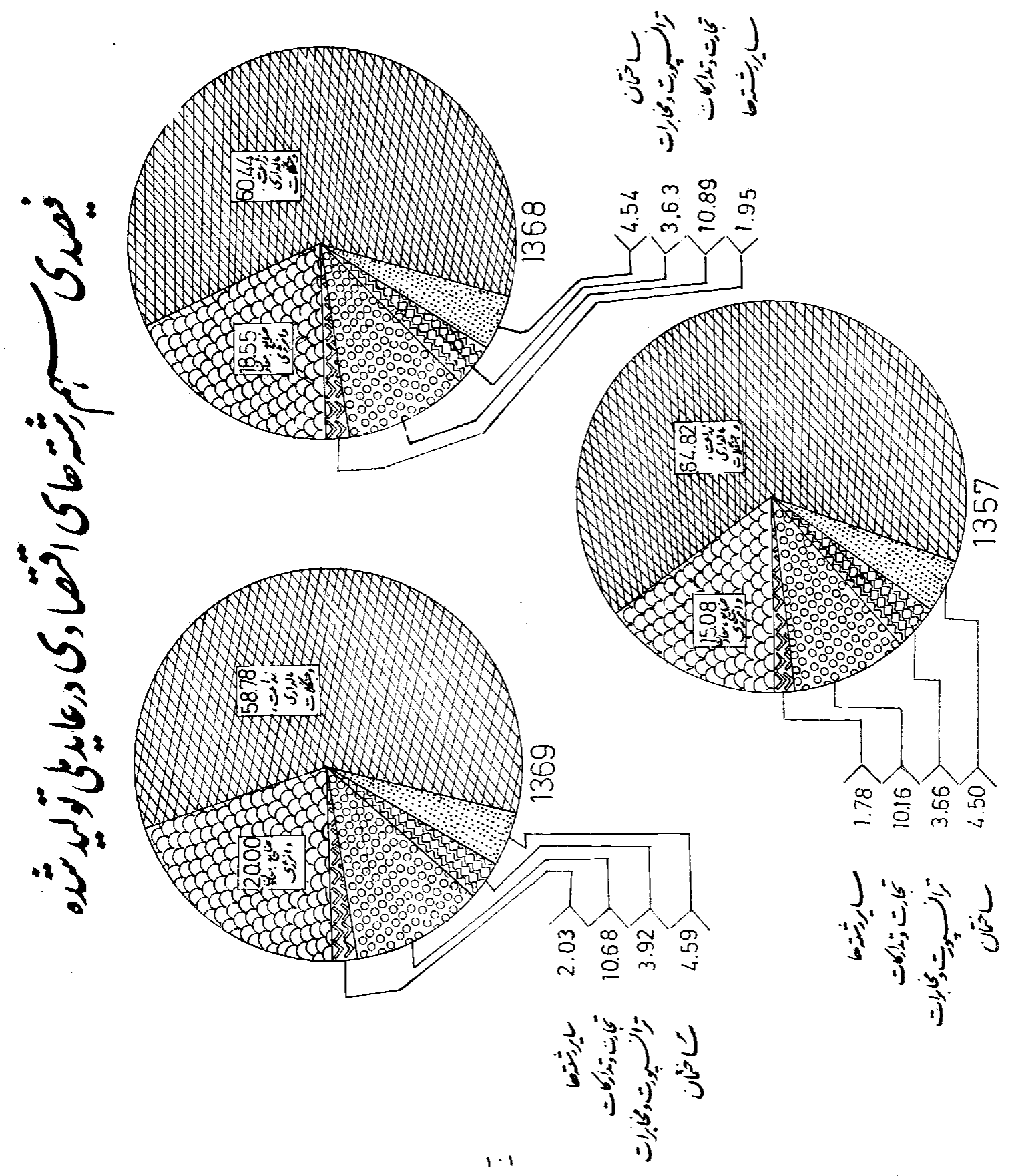




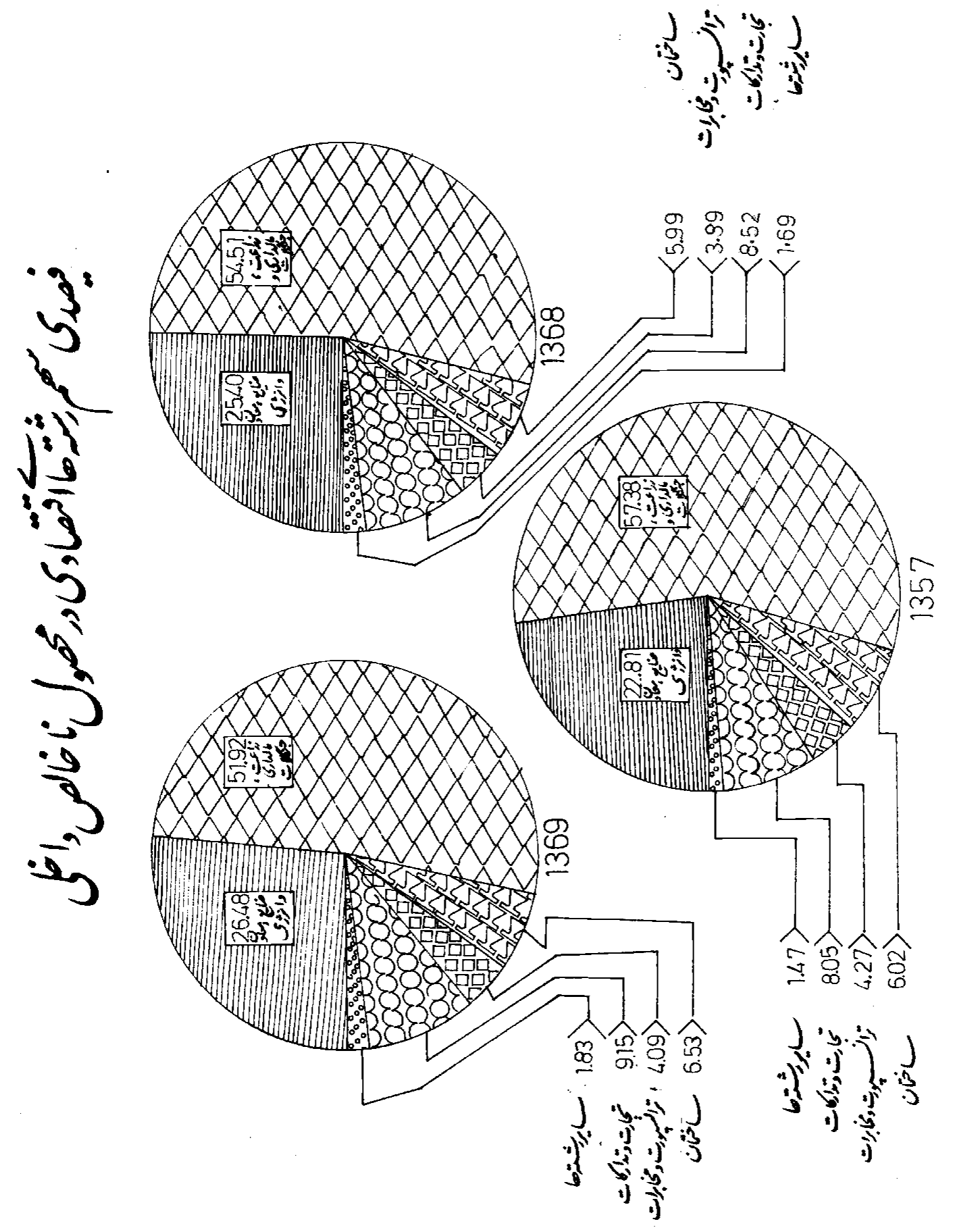




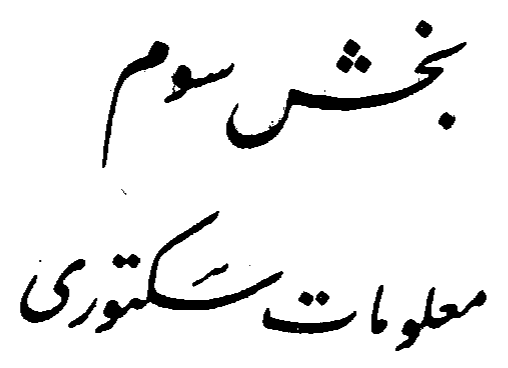




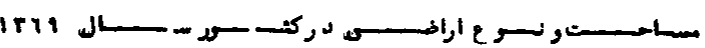

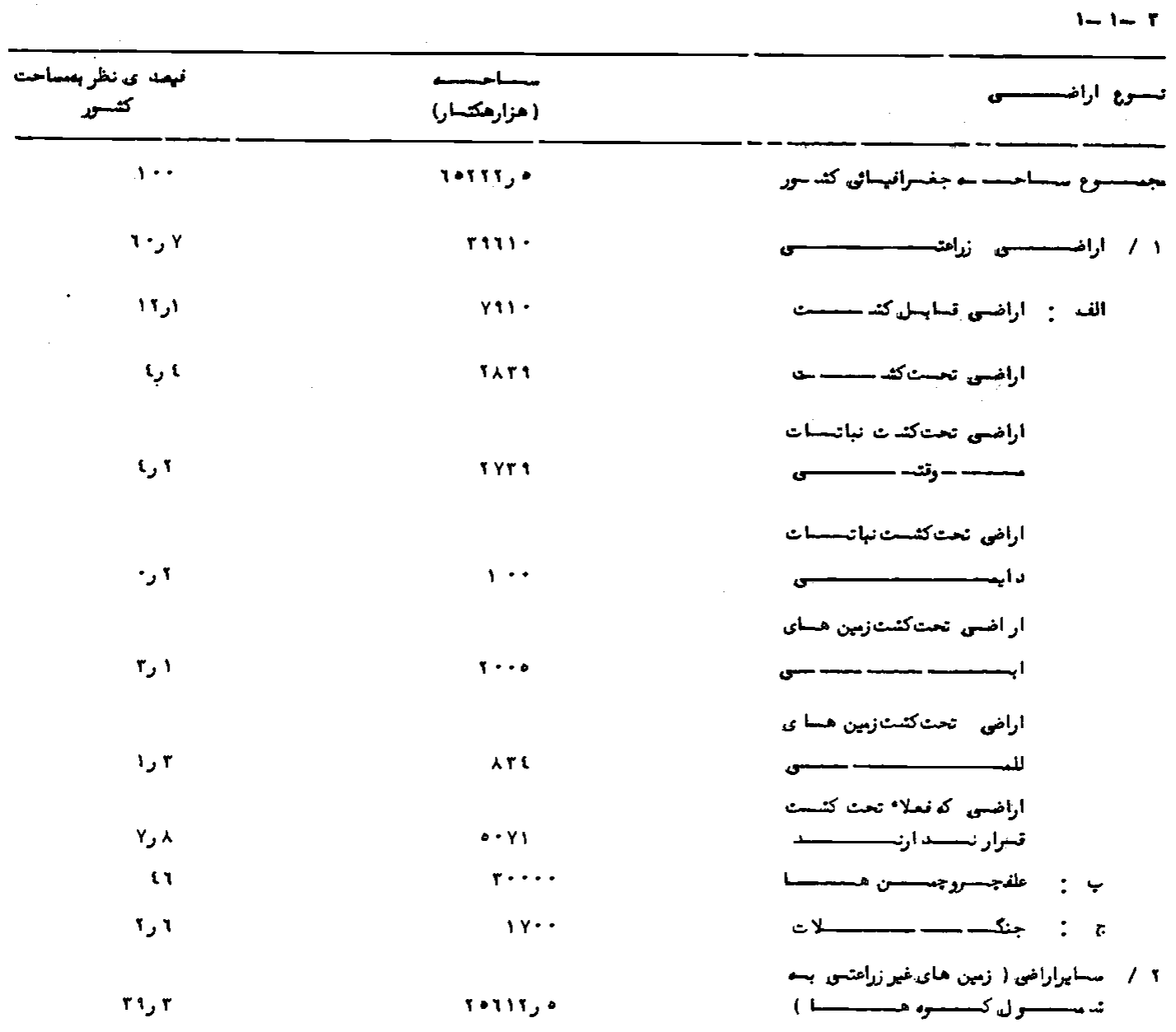

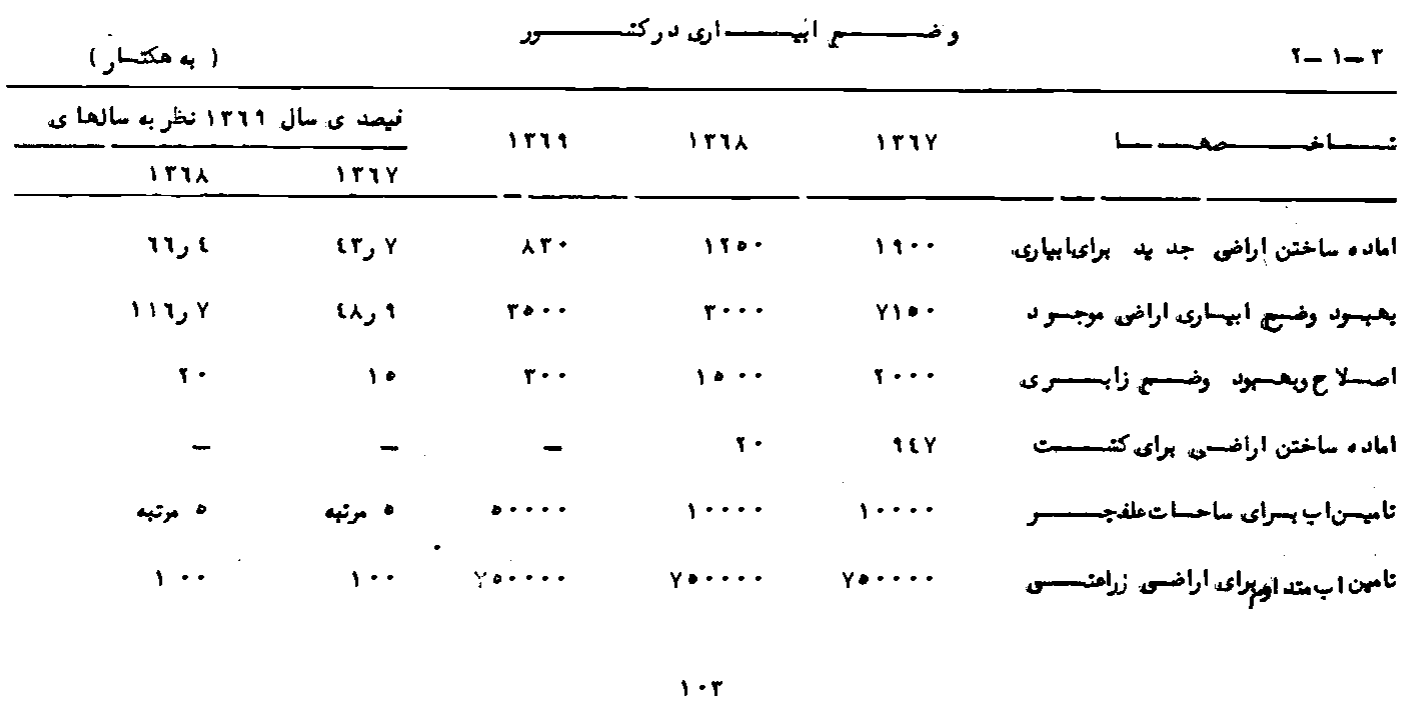




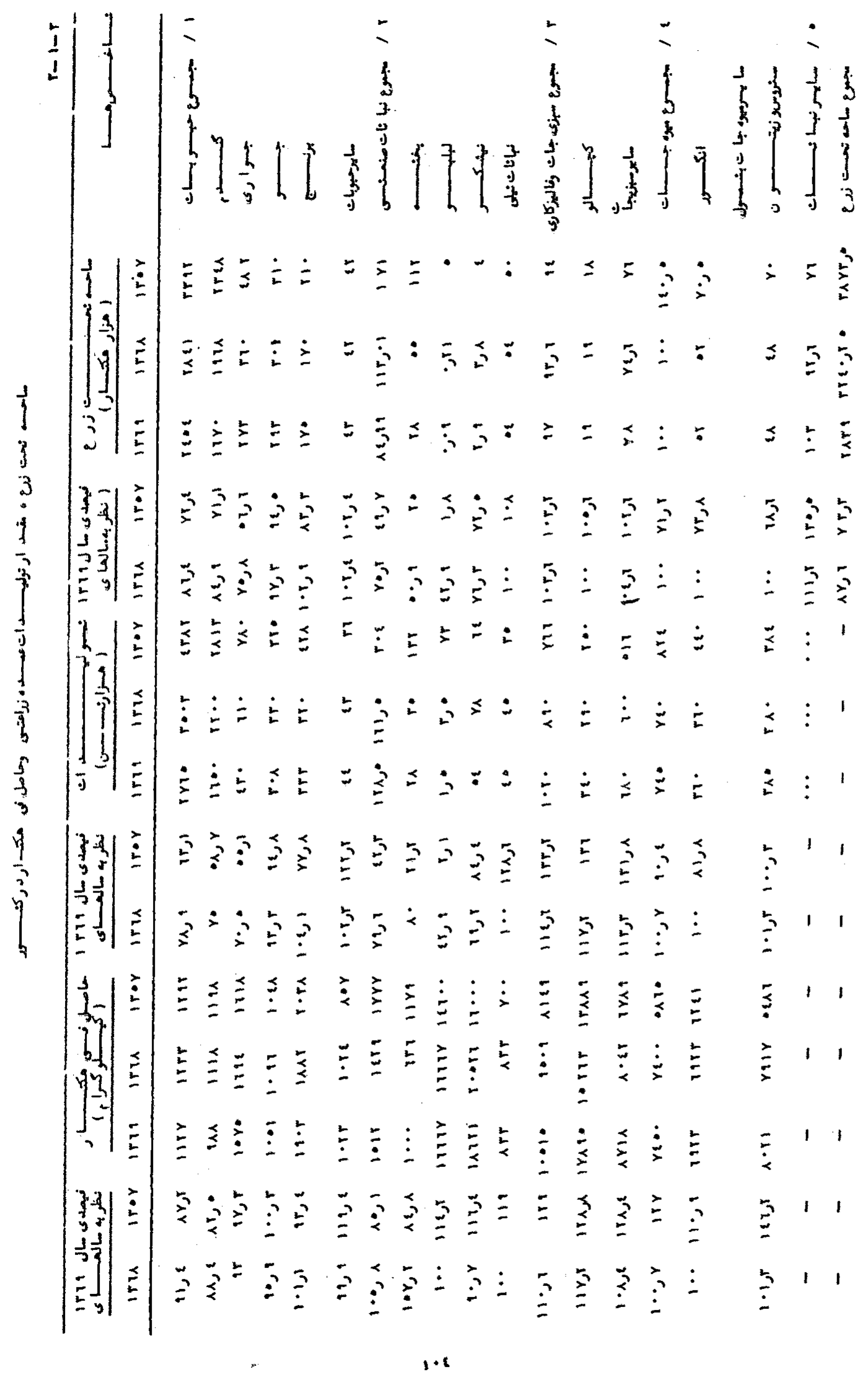




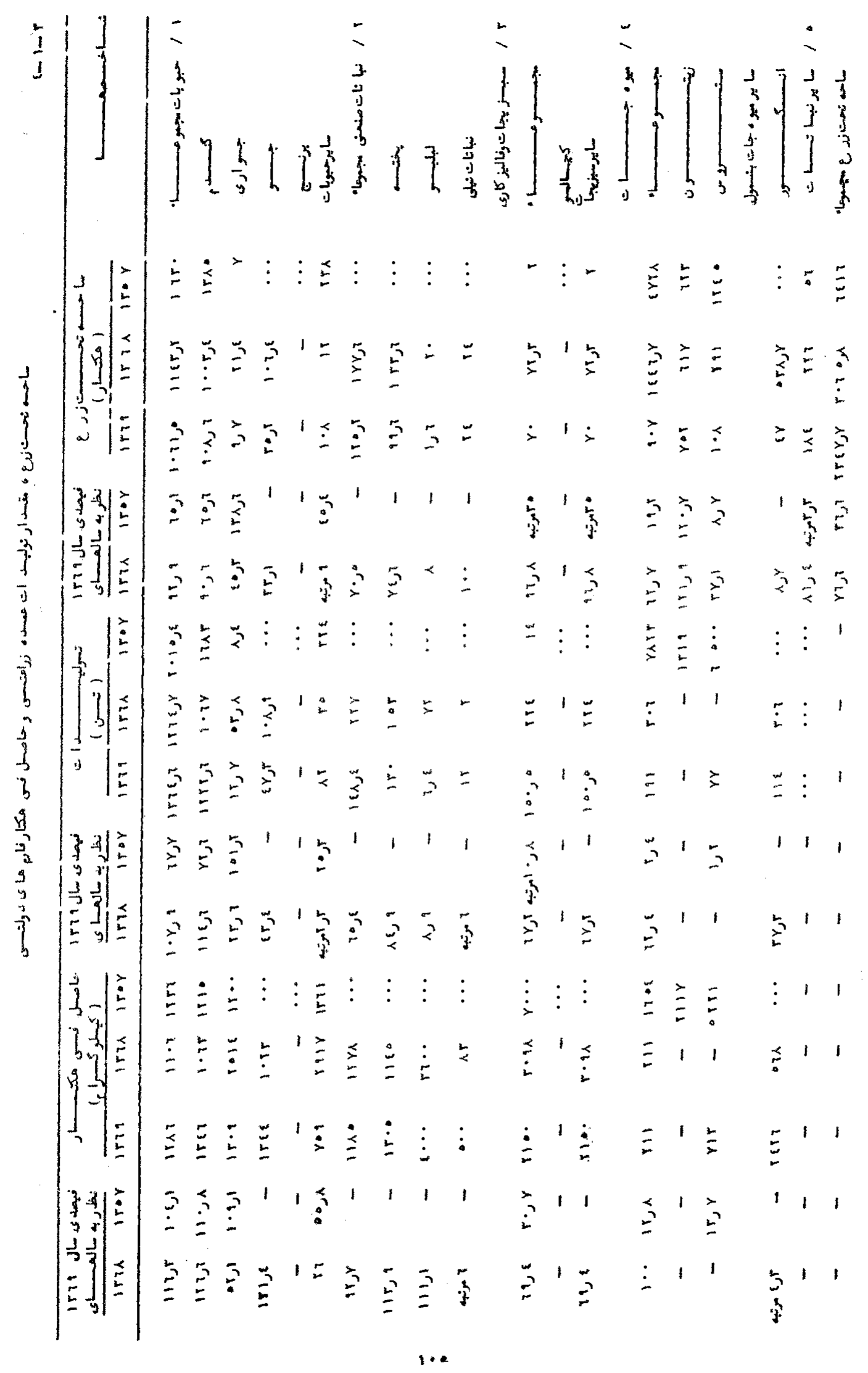




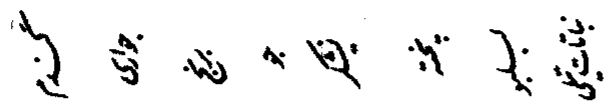 因四四四回四}
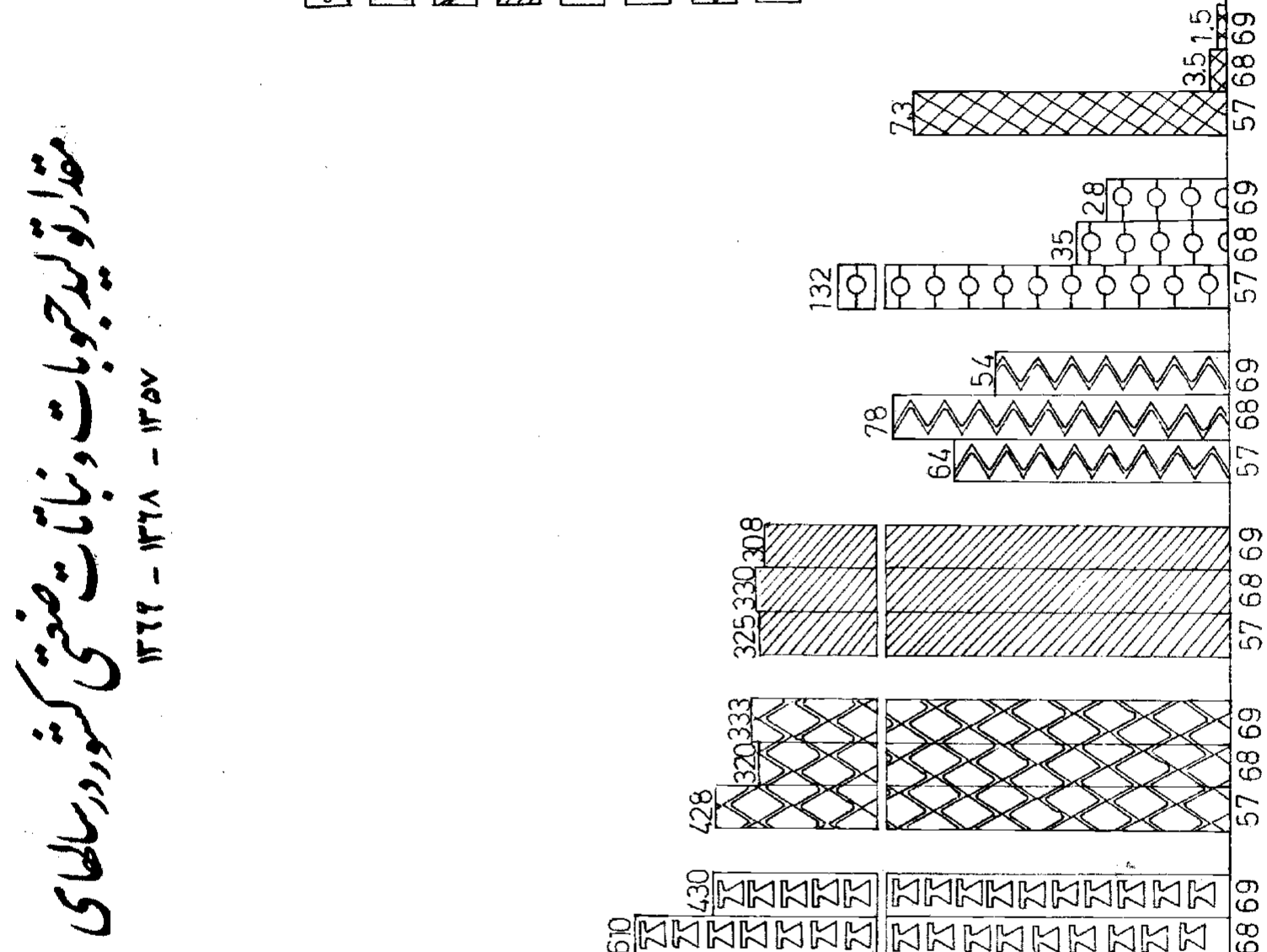

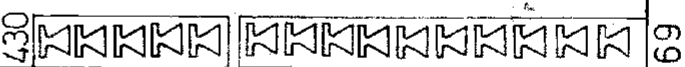

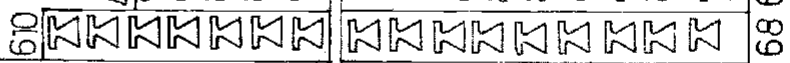

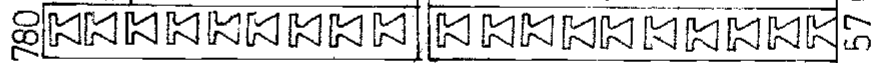

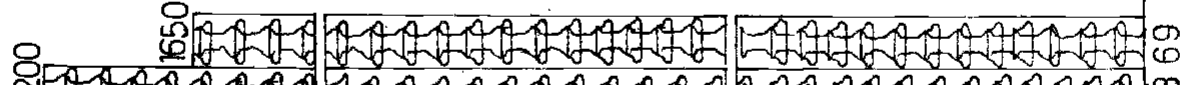

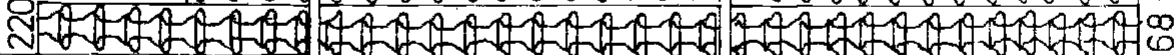

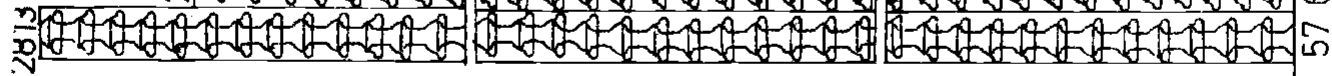

3

ఛ帝 


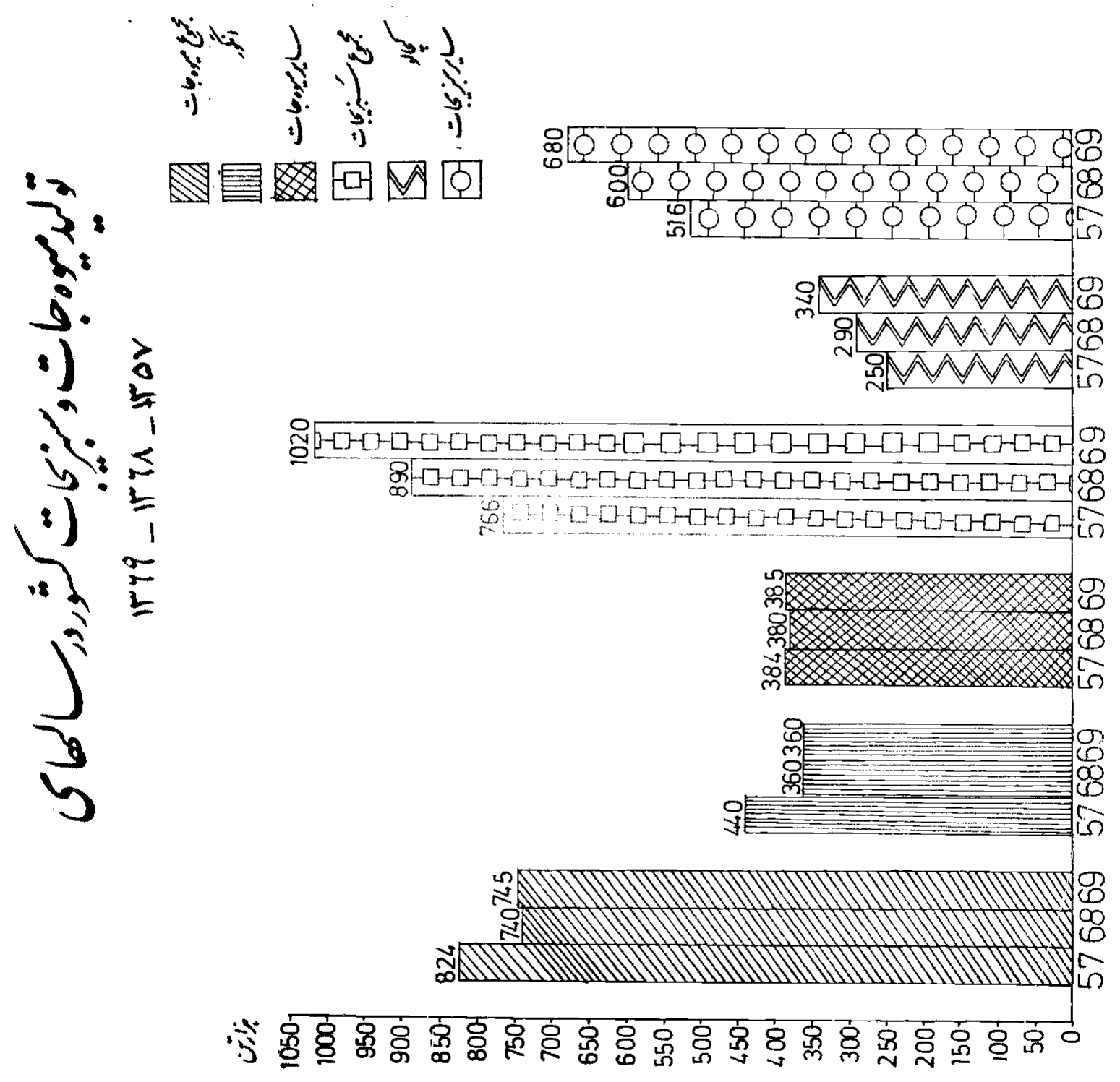




\begin{tabular}{|c|c|c|c|c|c|c|c|}
\hline \multicolumn{8}{|c|}{ 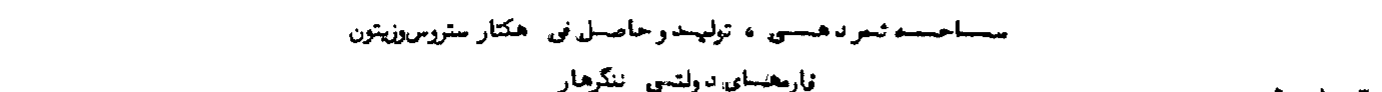 } \\
\hline \multicolumn{2}{|c|}{ 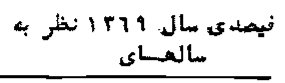 } & \multirow[t]{2}{*}{1719} & \multirow[t]{2}{*}{$\operatorname{lru}$} & \multirow[t]{2}{*}{$I T \circ Y$} & \multirow[t]{2}{*}{ واحس } & \multirow[t]{2}{*}{ 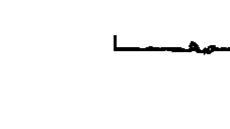 } & ند سمســاخـــ \\
\hline iru & $I r \bullet Y$ & & & & & & \\
\hline$r y$, & $\wedge, Y$ & $1 \cdot 1$ & र१ & Ir\&* & مكتـار & سـاحســـ & ستــــروس \\
\hline- & $.1 r, y$ & pir & - & ort & كبلوكرا & سال مل نى مكتســـار & \\
\hline - & $1, r$ & $Y Y$ & - & $1 \cdots$ & تستسـن & 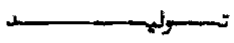 & \\
\hline$|r|, \mid$ & $1 r \cdot, v$ & vor & MY & irt & مكسطر & مسط & تون \\
\hline - & - & - & - & Mr & كيلوكرام & عاصلل نى مكتســــار & \\
\hline- & - & - & - & $1 \mathrm{rIq}$ & تســـن & 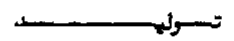 & \\
\hline
\end{tabular}

ו




\begin{tabular}{|c|c|c|c|c|c|c|}
\hline \multicolumn{2}{|c|}{ 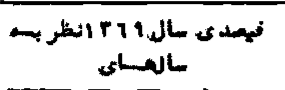 } & \multirow[t]{2}{*}{ IrI9 } & \multirow[t]{2}{*}{ irix } & \multirow[t]{2}{*}{ ir $\bullet r$} & \multirow[t]{2}{*}{ ماس } & \multirow[t]{2}{*}{ 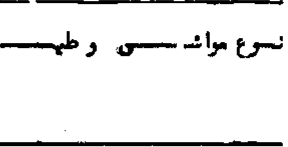 } \\
\hline ir 11 & Iror & & & & & \\
\hline $1 \cdots, r$ & 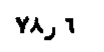 & rirr & rir. & rrr. & 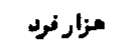 & 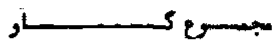 \\
\hline$\cdots, r$ & $r \wedge, r$ & Arr & AYs & 118. & $\nu$ & منجطل : كساونبيستسـرى \\
\hline $1 \cdots, 1$ & res r & ing. & 161 & $19 \cdot r \cdot$ & عزالداس & 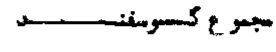 \\
\hline $1 \cdots, c$ & $r i, r$ & rext & rey. & (1) & ע & منجطل :كو سفيد قره تسـلـ \\
\hline $1 \cdots$, & $r i, r$ & $r r \cdots$ & $r r \cdots$ & $r \cdots$ & $\nu$ & \\
\hline $1 \cdots$, & $r Y, i$ & iro & iro. & ire. & ע & 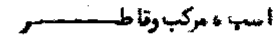 \\
\hline $1 \cdots$, & $r i j r$ & $r r \cdot$ & $r r \cdot$ & $r \cdot$ & مزارنغس & اشنس \\
\hline $1 \cdot 1$, & $\wedge 1$, & $\cdots$ & $\cdots$ & $i r$ & مزارثطعـ & - ســــوز \\
\hline
\end{tabular}

\begin{tabular}{|c|c|c|c|c|c|c|}
\hline \multirow{2}{*}{\multicolumn{2}{|c|}{ 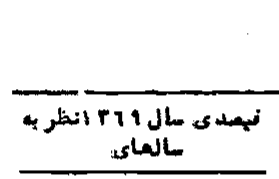 }} & \multicolumn{5}{|c|}{ 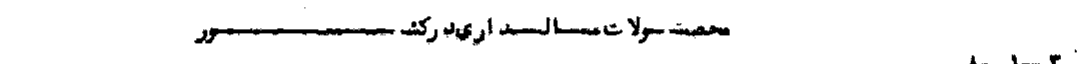 } \\
\hline & & \multirow[t]{2}{*}{ ir in } & \multirow[t]{2}{*}{$\operatorname{IrTh}$} & \multirow[t]{2}{*}{ Iror } & \multirow{2}{*}{ مأهساس } & \multirow[t]{2}{*}{ ثبسـانيســـ } \\
\hline iru & Iror & & & & & \\
\hline$\cdots$, & $r a, \cdot$ & $1 \cdots$ & $1 \cdots$ & 19. & 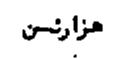 & كونست بوز ن كنبنـــــــــار مجموعاء \\
\hline ( ) & $1 \cdot 1$, & 11 & $u$ & ir & $\nu$ & منجمل : كسو نســـكسيسا و, \\
\hline 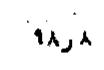 & $11, i$ & Ar & At & $i r \cdot$ & $\nu$ & كسو ند سعكوسفنسد و ب- ســـز \\
\hline$i r \cdot \theta^{\prime}$ & 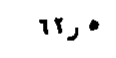 & - & 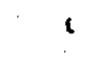 & $\wedge$ & $\nu$ & 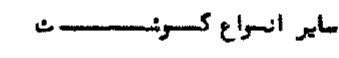 \\
\hline$\cdots, r$ & • 1 & in & \&\& & yar & $\nu$ & -4 \\
\hline 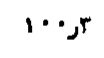 & $\cdot 1$ & $r \cdot 1$ & $r \cdot$ & irr & $\nu$ & 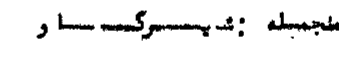 \\
\hline $1 \cdots$, & .01, & 14 & $1 \varepsilon Y$ & $r$ & ע & 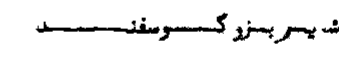 \\
\hline$\cdots, 1$ & $1 \cdot 1, r$ & $\varepsilon+\varepsilon$ & $\& \bullet$ & 84,8 & مليونبيض & تغستس ســـ بـ \\
\hline$\cdots$ & $A 1,1$ & $\cdots$ & $1 \cdots$ & irat & مزاربلد & 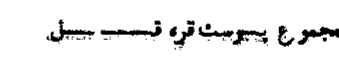 \\
\hline י נזיו & r & 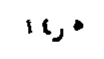 & 14 & 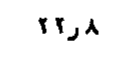 & 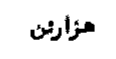 & 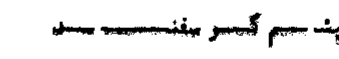 \\
\hline 99,8 & $11 \cdot 2$ & ut & $1 \times 1$ & $r$ & 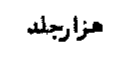 & 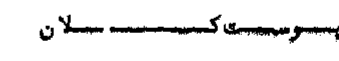 \\
\hline יני & $0 i, 1$ & rar. & rar. & y... & ע & 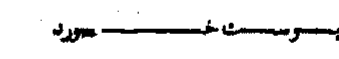 \\
\hline $1 \cdot r, 1$ & $178, x$ & rr.. & ri.. & $\operatorname{lrts}$ & مزإرحلت & لإند \\
\hline $1 \cdots$ & $1 \cdot y_{j}$ & $\bullet 1$ & 11 & ire & كي لركرام & ارسط سالاث نسيرنه، فرد كسـار \\
\hline$n \pi, r$ & Ir $x$ & $r$ & 1,6 & 1,1 & $\nu$ & اوسط سالانه بثدم فن رأُكاكسلد \\
\hline $1 \cdot \lambda, 1$ & $\mid r r$ & 11 & $1 \cdot$ & $A \cdot$ & min & أوسط سالانمنه فه تطله سر غ \\
\hline
\end{tabular}




\begin{tabular}{|c|c|c|c|c|c|c|c|c|}
\hline \multirow{2}{*}{ 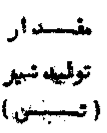 } & \multicolumn{3}{|c|}{ تعد اد كوسالسه ( نسمرد ) } & \multicolumn{3}{|c|}{ نعد اد كاو مسلسا (مسرد 1} & \multirow{2}{*}{ تجمس } & \multirow{2}{*}{ 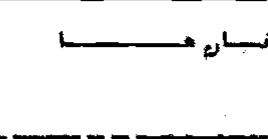 } \\
\hline & بكسبا ل لنساز & كئسراز & مبور & نركساو & فيرنسيرد ه أ و & 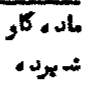 & & \\
\hline 17. & $\bullet 1$ & $\wedge$ & iry & - & $\mathrm{r} \cdot$ & $8 \cdot$ & ire & كسانسال ننكرهــــــــــر \\
\hline$\wedge r$ \&. & $1 \cdot 9$ & $\wedge \wedge$ & 198 & $\checkmark$ & $1 \cdot Y$ & Ar & 11 & بنستى عصستس \\
\hline 11,99 & 18 & $r r$ & \&Y & 11 & \& & $r r$ & $\wedge \bullet$ & ملعنـــــ \\
\hline- & - & - & - & 11 & - & - & 18 & التســاح مصنسر عس \\
\hline$r r \bullet, \mathbb{E}$ & IY9 & $\gamma \cdot \gamma$ & rAl & $r \varepsilon$ & ris & Ire & ery & و \\
\hline
\end{tabular}

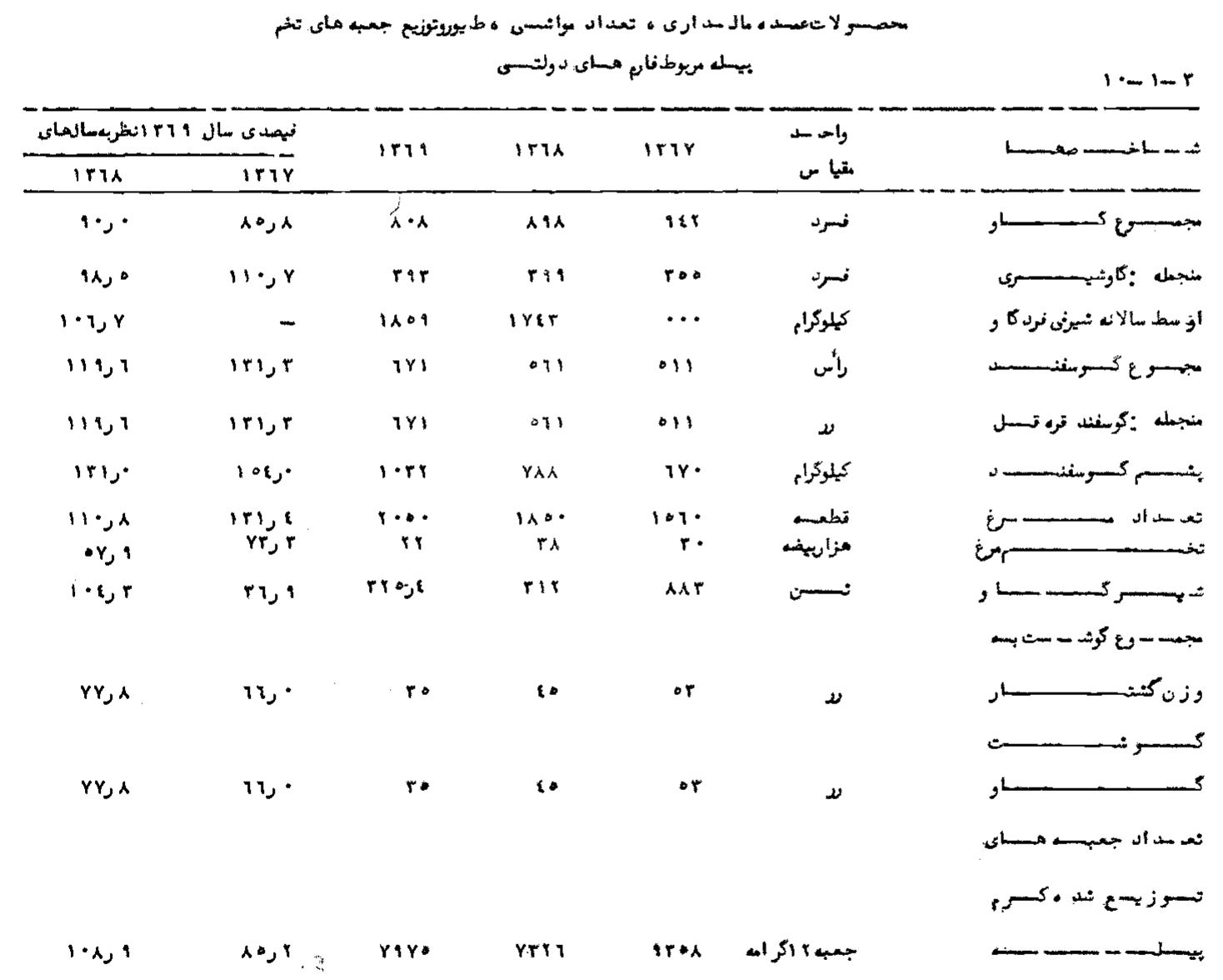




\begin{tabular}{|c|c|c|c|c|c|}
\hline \multicolumn{5}{|c|}{ 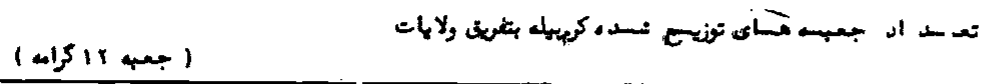 } & \multirow[t]{2}{*}{$11-1-r$} \\
\hline \multicolumn{2}{|c|}{ 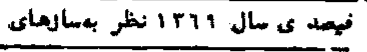 } & \multirow{2}{*}{ יורי } & \multirow{2}{*}{$\operatorname{lru}$} & \multirow{2}{*}{$\operatorname{lrir}$} & \\
\hline irin & $\overline{1 r i r}$ & & & & , ע بــــــــــ \\
\hline $1 \cdot 1,1$ & $\lambda \bullet, r$ & rive & reti & $1 t \cdot 1$ & مجعــــــــــــ \\
\hline- & - & - & 1721 & rytr & مسركسزكســــــ بلد \\
\hline$I r A, r$ & ا ران مرنه & $r \cdot r \cdot$ & $1 \cdots$ & $1 \cdots$ & 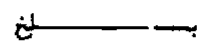 \\
\hline ل أمرتبه. & ا رامرتبه & rre. & $\cdots$ & $1 \cdots$ & جـ سوزجســـــان \\
\hline ire, & $\wedge \wedge, r$ & $r \cdots$ & $r \cdots$ & $r \varepsilon \cdot r$ & $=1,-$ \\
\hline 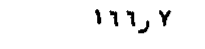 & اري متبه & $\bullet$ & $r \cdot$ & r & 0 \\
\hline$\cdots$, & ا & $\cdots$ & $\cdots$ & $1 \cdots$ & كي \\
\hline - & - & - & - & ir & 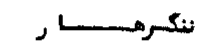 \\
\hline 1יני & - & $1 \cdots$ & $1 \cdots$ & - & فساريســسـا ب \\
\hline - & - & - & - & $\bullet \mathfrak{q}$ & 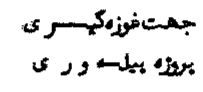 \\
\hline
\end{tabular}

\begin{tabular}{|c|c|c|c|c|c|c|}
\hline \multicolumn{7}{|c|}{ 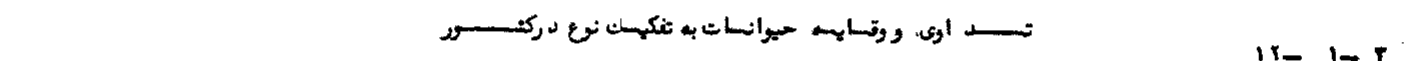 } \\
\hline \multicolumn{2}{|c|}{ نيصد ى سال 1 ר ז1 نظر به سالهساى } & \multirow{2}{*}{ iris } & \multirow{2}{*}{ irix } & \multirow{2}{*}{$I T \cdot Y$} & \multirow{2}{*}{ مقيساس } & \multirow{2}{*}{ 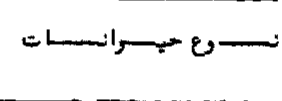 } \\
\hline $1+11$ & $1 \mathrm{irar}$ & & & & & \\
\hline $1 \cdots$, & iratr & $12\{19,1$ & $120 \ldots$. & $1 \cdot\{\wedge \gamma, 1$ & & \\
\hline $1 \cdot 1,1$ & 1998 & $r \cdot r$ ז & $r \cdot \cdots, r$ & 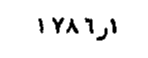 & 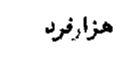 & 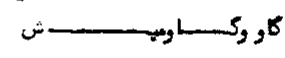 \\
\hline 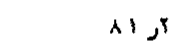 & اركرتبه & $r \cdot \varepsilon, \varepsilon$ & $r\{Y \cdot s$ & $\wedge \wedge \mathrm{r}, \mathrm{Y}$ & هزاسأس & \\
\hline $1 \cdot 1$ & (1) & $\{\cdot \circ \varepsilon \circ$ & $\{\cdots 9, r$ & $r a r i s$ & لد & S S S S \\
\hline$r r, y$ & $r i, r$ & ש ני & $\bullet r$ & $r$ & هزارنغر & \\
\hline $1 r, q$ & Irr, & $0, r$ & ו ני & $\varepsilon, r$ & هزالساس & \\
\hline$A \varepsilon \varepsilon^{\circ}$ & $1 \cdot 1,1$ & $\varepsilon$ & • & $r, q$ & ע & نســاطســـــــ \\
\hline $1 \cdot 1 \cdot$ & |رעr|| & $\{1 \cdot 9,1$ & $\{0 \cdot 1, r$ & $r A \cdot 0, r$ & هزأرتطس ـ & 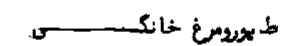 \\
\hline$\wedge \wedge, 1$ & $11 \varepsilon, 1$ & $r, \varepsilon$ & $r, r$ & $i, r$ & 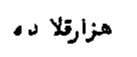 & و بـ \\
\hline
\end{tabular}

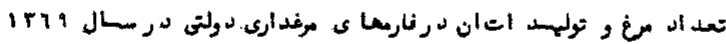

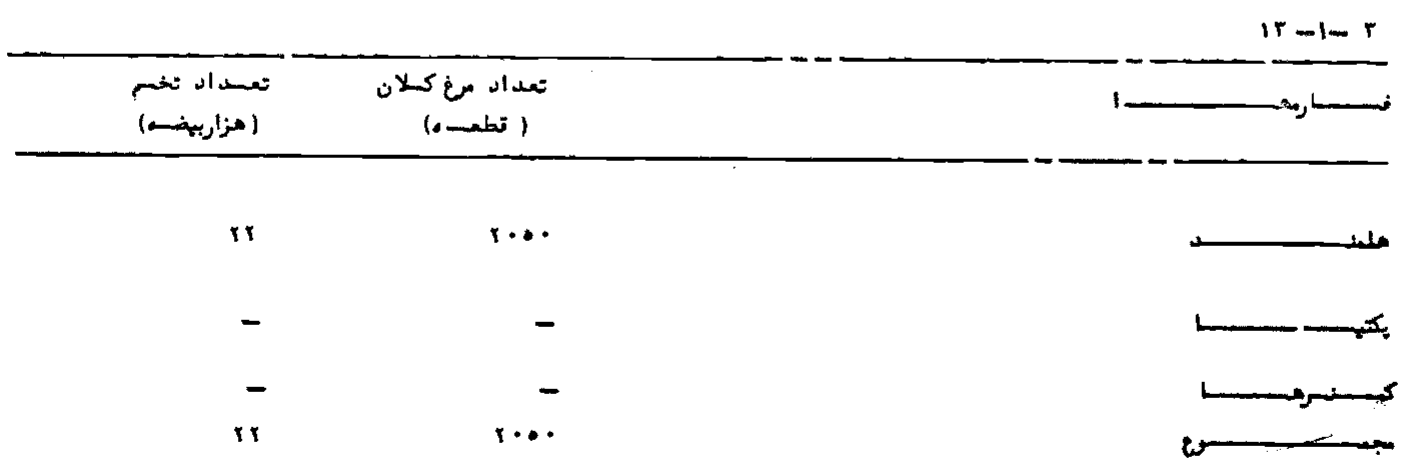




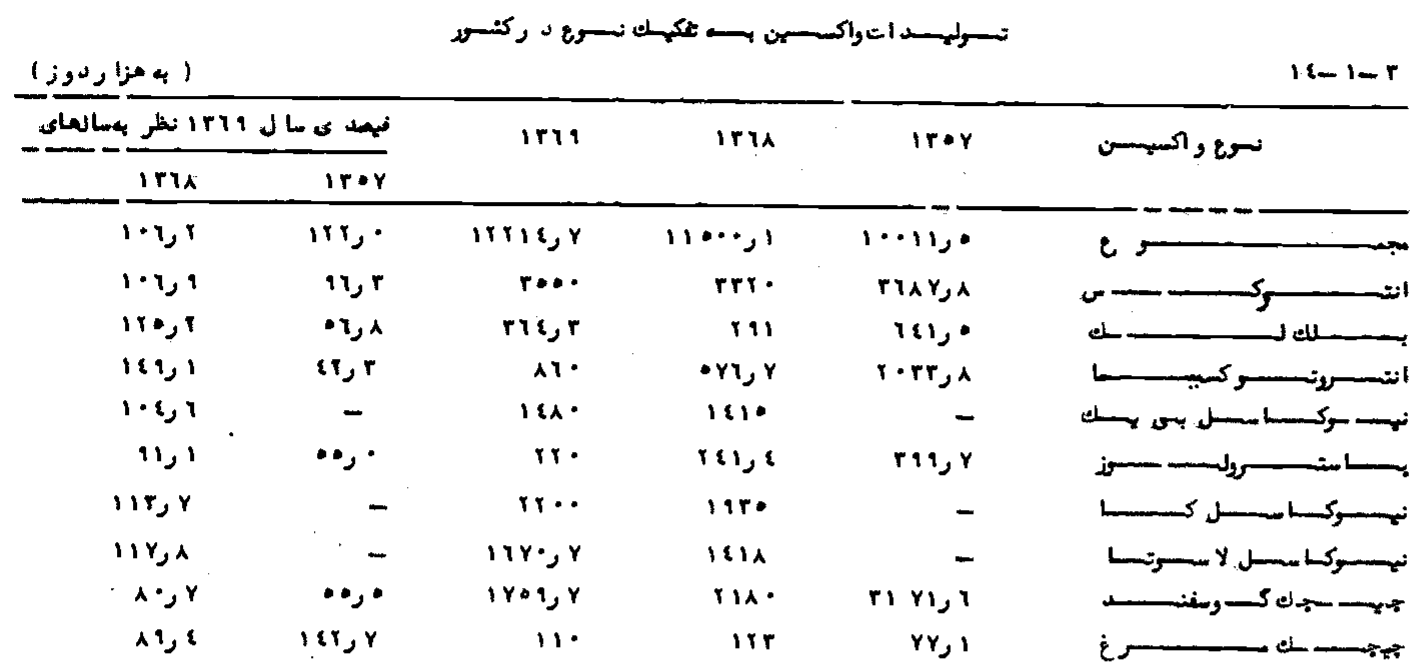

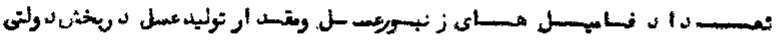
$1:-1-r$

\begin{tabular}{|c|c|c|c|c|c|c|}
\hline \multicolumn{2}{|c|}{ 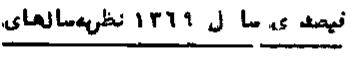 } & \multirow[t]{2}{*}{179} & \multirow[t]{2}{*}{ Irin } & \multirow[t]{2}{*}{ iriy } & \multirow{2}{*}{ مقياس } & \multirow[t]{2}{*}{ 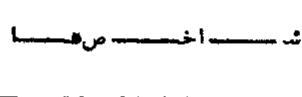 } \\
\hline $\operatorname{lru}$ & iryy & & & & & \\
\hline $1+2 *$ & $1+1,1$ & 87. & 21. & $\varepsilon \cdot r$ & 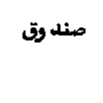 & 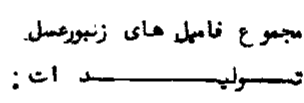 \\
\hline$r A, \lambda$ & $r i, r$ & १^ג & $r \& r y$ & rir. & كيليركار', & مسله : \\
\hline 19,1 & $r y$ & $\wedge$ & \& & $*$ & ע & 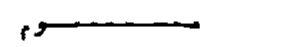 \\
\hline
\end{tabular}

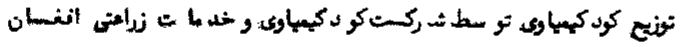

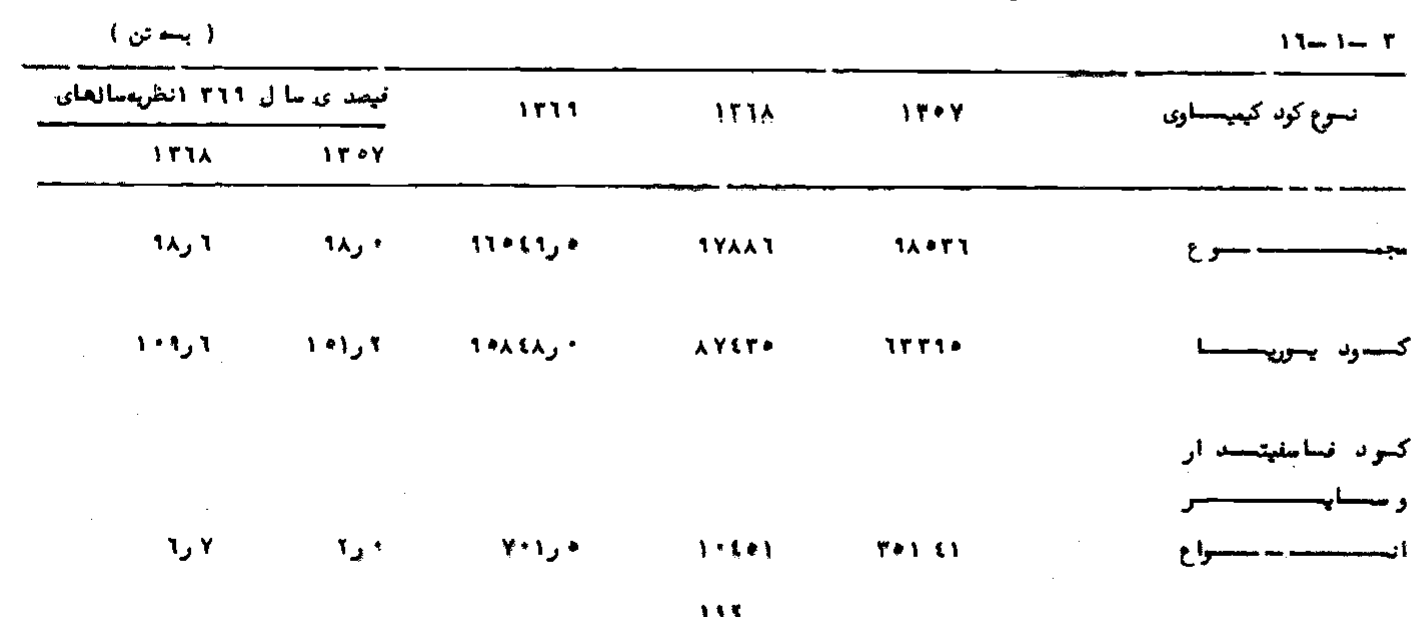




\begin{tabular}{|c|c|c|c|c|c|c|}
\hline \multicolumn{7}{|c|}{ 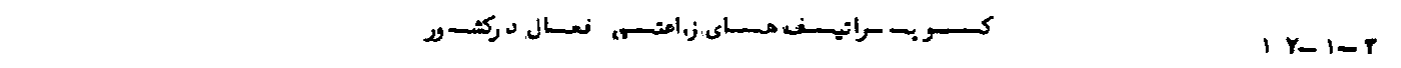 } \\
\hline \multicolumn{2}{|c|}{ 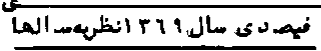 } & \multicolumn{3}{|c|}{ الس ختر سال } & \multirow{2}{*}{ مغ واحس س } & \multirow{2}{*}{ 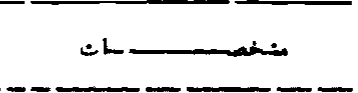 } \\
\hline ir 11 & ITYY & iryis & $1+11$ & 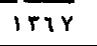 & & \\
\hline $1 \cdot 1, r$ & $1 \cdot{ }^{\prime}$ & १Y & $|Y|$ & $y \leqslant Y$ & بساي & تعد اد كوراتهـف مساى زرامتسسـه \\
\hline $1 \cdots$ & $1 \cdot \xi, r$ & $19, r$ & $M, Y$ & $1 \bullet, r$ & 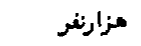 & تعد د اد العضائكوراتيف مائى نس الل \\
\hline $1 \cdot r, 1$ & $1 \cdot 1,1$ & $\cdot 1$ & $\cdot \varepsilon$ & ارا & مليونانغانى & 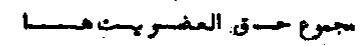 \\
\hline $1 \cdots, 1$ & $1 \cdot \varepsilon \varepsilon$ & $\operatorname{lor} 1$ & 101 & $1 \varepsilon y$ & مزارمكتار & سجمع ساسعنحت نظارتكيراتهنسا \\
\hline- & rr & נر & - & r & مزارنسن & فروش سحمرلا ت در بازارعاى خسارة \\
\hline- & $\{r, r$ & $\wedge_{\jmath} \cdot$ & - & $i i_{j} \cdot$ & مزارجلد & فرث:يوست فرتللد نازارعاى خارج \\
\hline r & $i r 9, r$ & $r \cdot, \varepsilon$ & $\infty 1$ & $\{y$ & مليونانغانى & تمهسب و تسونيحم تسـسـرو ض \\
\hline
\end{tabular}

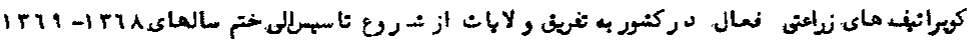

\begin{tabular}{|c|c|c|c|c|c|c|c|c|c|c|}
\hline \multicolumn{2}{|c|}{ 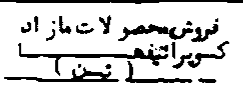 } & \multicolumn{2}{|c|}{ 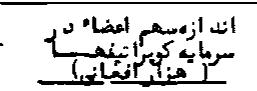 } & \multicolumn{2}{|c|}{ 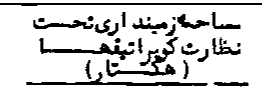 } & \multicolumn{2}{|c|}{ أهضl } & \multicolumn{2}{|c|}{ 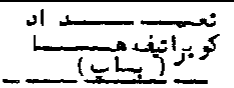 } & \multirow[t]{2}{*}{ 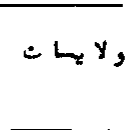 } \\
\hline 1519 & iris & 1519 & 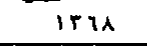 & 1719 & irix & 1519 & 1511 & 1519 & $1 \pi \overline{11}$ & \\
\hline YIYIs, & $A r A \cdot Y \cdot$ & H & זر• זצז & loryel & lareqg. & $m r \cdot r$ & MYSY & $1 Y 9$ & $|Y|$ & مبس سر و \\
\hline itro. & TYTT. & $1 \cdots\{r, \varepsilon$ & $1 \cdots 1,\{$ & $y \cdot r t$ & IIY & $\cdots 1 \varepsilon$ & - 1 & YY & Yr & كــــا بـــلـ \\
\hline$i .04$ & IAs. & •ر" & Tritri & ortr & - \{१Y & $\varepsilon \&: 4$ & $\{\eta \cdot T$ & ri & $r \varepsilon$ & روا ن \\
\hline 10r & 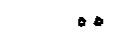 & $|Y|, \mid$ & $|Y|, \lambda$ & $Y Y$. & r r & $r \cdot q$ & $r \cdot r$ & $\wedge$ & $\wedge$ & \\
\hline - & - & $r \varepsilon$ & $\lambda$ & - 1 & - ر. & 19 & 19 & 1 & 1 & Sــ \\
\hline - & - & $0 x \cdot 9$ & - $A 0,9$ & $17 Y$. & IIY & rirt & ritr & 11 & 11 & غــــنــــ \\
\hline IYT & 110 & $18 \varepsilon \cdot 1$ & $1 \varepsilon \varepsilon \cdot ر$ & Ditr & - נrre & ינוזים & • & or & -r & بكتيــ \\
\hline REItr & $1 \varepsilon \cdot r \cdot$ & 1AपY & $r \varepsilon \varepsilon r$ & $r \cdot 11 \cdot$ & VI: & 1114 & MY & IY & 19 & ننكر ها ر \\
\hline - & $r$ & $r Y A, r$ & $r Y A j$ & 1AY & AAI & $18 \varepsilon 8$ & lहs & 9 & 9 & لغنهيا ن \\
\hline - & - & - & - & - & - & - & - & - & - & نورسنا ن \\
\hline$\cdots$ & $r Y$ & VATYA & RATYH & $A \varepsilon I Y$ & $A\{1 Y, r$ & \& & \&IT० & 01 & 01 & بد ختــان \\
\hline - & - & $1: 1 Y$ & 1 & rita & riाis & ris. & Vis. & 10 & 10 & نحستســـار \\
\hline$q \cdots r$ & $\gamma Y \cdot \varepsilon$ & $r q \circ Y_{j}$ & $r q \circ Y\}$ & rqYs & $r q Y\{r$ & rale & ralo & ri & ri & بغـلا ن \\
\hline YYY. & olrt & $\{A \mid \varepsilon\}$, & צ & r\&१. & rधा & $n A$ & 1149 & rq & $r \varepsilon$ & \\
\hline$r \cdot \varepsilon \cdot$ & rit. & $r Y Y, T$ & $r Y Y, Y$ & 9ix & $\{1 Y, 1$ & ur & IAT & - & - & سمنكـان ن \\
\hline$\lambda \cdot i \cdot$ & IETrt & - & $11 \varepsilon \cdot 5$ & $|\cdot| \varepsilon \lambda \mid$ & $1 \cdot 9 \cdot 9,1$ & $11 \cdot 11$ & $11 \cdot 1 r$ & \& & $\varepsilon Y$ & بلـــــــن \\
\hline 148 & $1 \cdot 1$ & Yqur, & $Y \| Y Y^{\prime}$ & $1908 \varepsilon$ & Mrrs & I $\varepsilon 8 \%$ & itio & $\{\varepsilon$ & $\&$ & جوزجان \\
\hline - & - & $\| r, A$ & $\| r, \lambda$ & $r \cdot q$ & $r \cdot \wedge \mu$ & $19 \cdot r$ & $19 \cdot 8$ & $Y$ & $Y$ & سمريل \\
\hline Y $\{T$ & $Y \cdot \xi$ & Trqu & rrqu & $1 \cdot r+8$ & 1. & ir & iris & $\{q$ & $\{9$ & فاريساب \\
\hline- & - & 100,4 & 100,1 & sAt & $\{\lambda r, \lambda$ & Yrr & YIT & $Y$ & $Y$ & بادغيسـس \\
\hline 111. & xy & $r Y \cdot r$ & $r Y \cdot 1$ & IYIY & IYY & YTM & YTM & $\varepsilon q$ & ₹ & هـرا ث \\
\hline$A r$. & - & זرy & r r & $r \cdot r o$ & Rر & 110 & 111. & IY & IY & نسـرا \\
\hline DYo & $r \cdot Y$ & 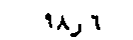 & $1 A_{j} 0$ & 11. & $11 \cdot 8$ & rit & rit & $\wedge$ & $\lambda$ & نيمر وز \\
\hline $1 \cdot \varepsilon \cdot$ & IIAA & rรษ·ภ & $r \varepsilon q \cdot{ }^{\prime}$ & $M \cdot r A$ & 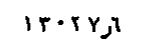 & $\varepsilon r \cdot Y$ & $\varepsilon r \cdot Y$ & ri & $r$ & ملحنـــ \\
\hline - & $r T \cdot Y$ & $1 \times 193^{\circ}$ & $17 \times 90^{\circ}$ & MiYo & river & $r \cdot 10$ & $r \cdot 1$. & 10 & 10 & كد ما ر \\
\hline - & - & $\{4,1$ & $\{1\}$, & irr & Irrs & Yr & Yr & $r$ & $r$ & زابـ- ـل \\
\hline- & - & - & - & - & - & - & - & - & - & 'اעنسان \\
\hline- & - & $\mid r \cdot s$ & 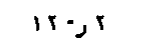 & roo & $r \bullet \cdot$ & rit & rit & $r$ & $r$ & غسـورد \\
\hline - & - & $\mid 9 A, 1$ & $|n|$, & .9. & \& & $1 \varepsilon r$. & ist. & $r$ & $r$ & \\
\hline- & - & 1ر. & - & $\circ$ & - & 1. & - & $r$ & - & \\
\hline- & - & 090,8 & - & E & - & 11.1 & - & rT & - & كترهــL \\
\hline- & - & - & - & - & - & - & - & - & - & خوستس \\
\hline \multirow[t]{2}{*}{-} & - & - & - & - & - & - & - & - & - & \\
\hline & & & & & 115 & & & & & \\
\hline
\end{tabular}




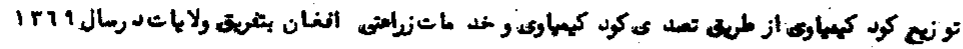

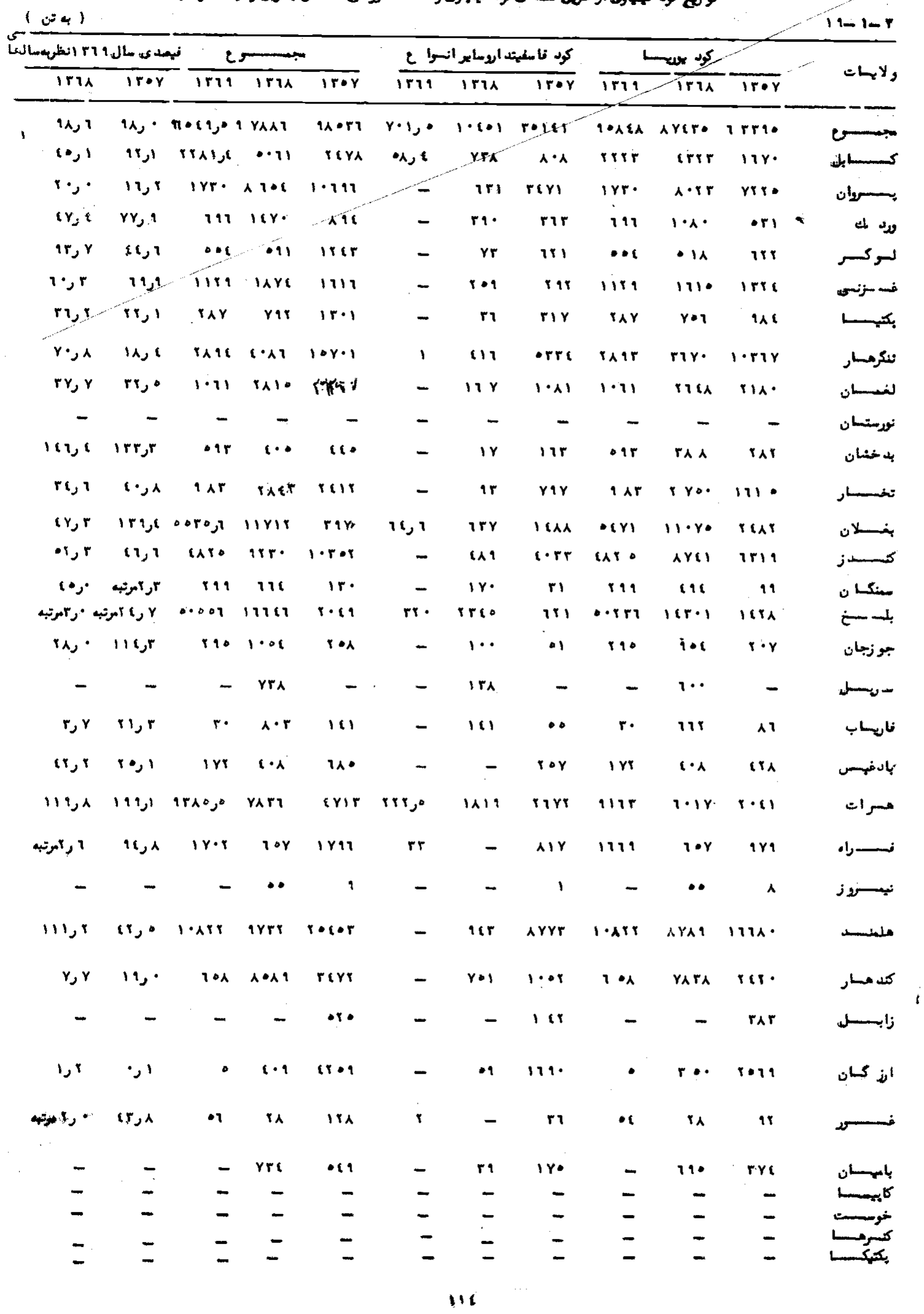




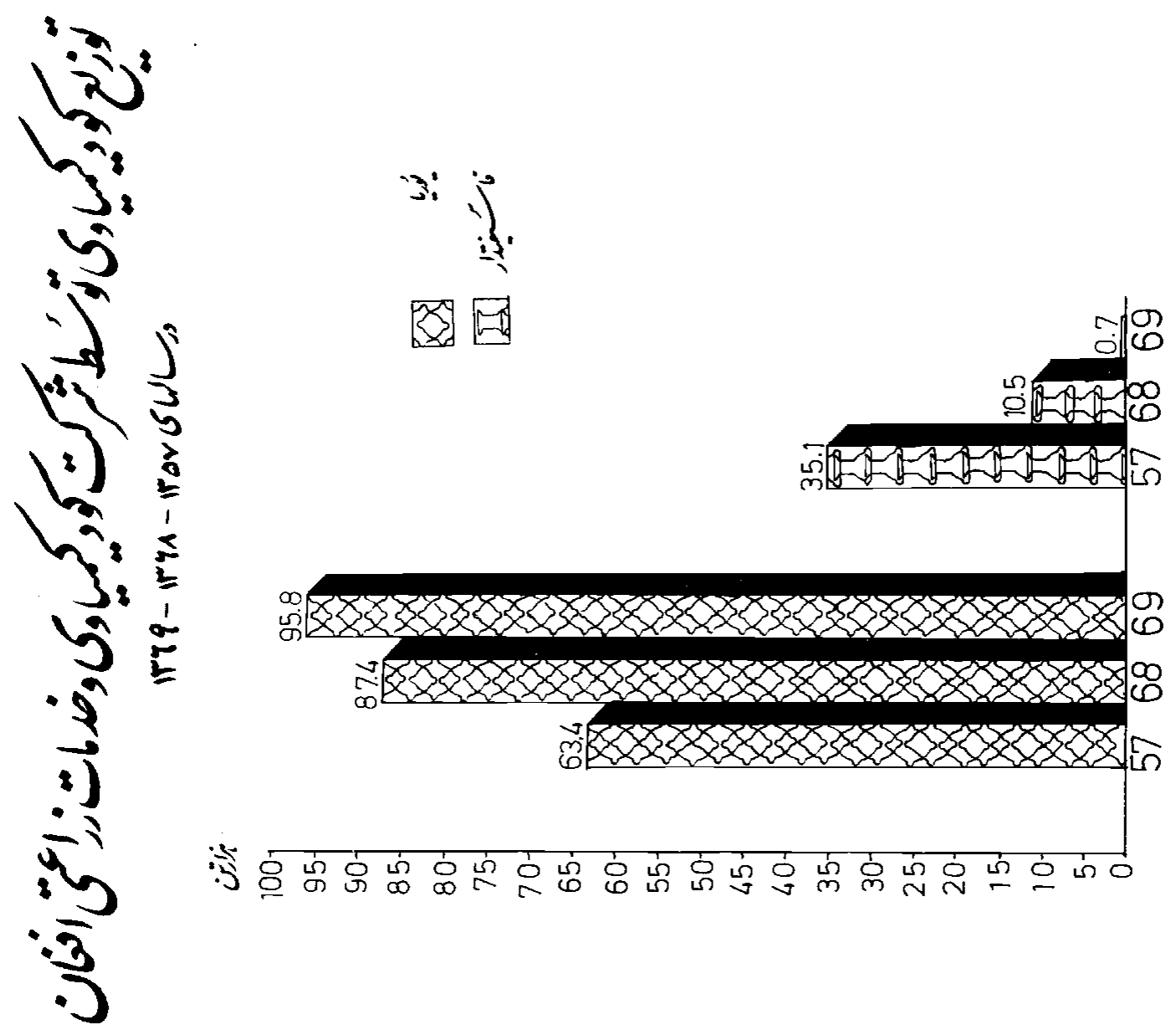

11 


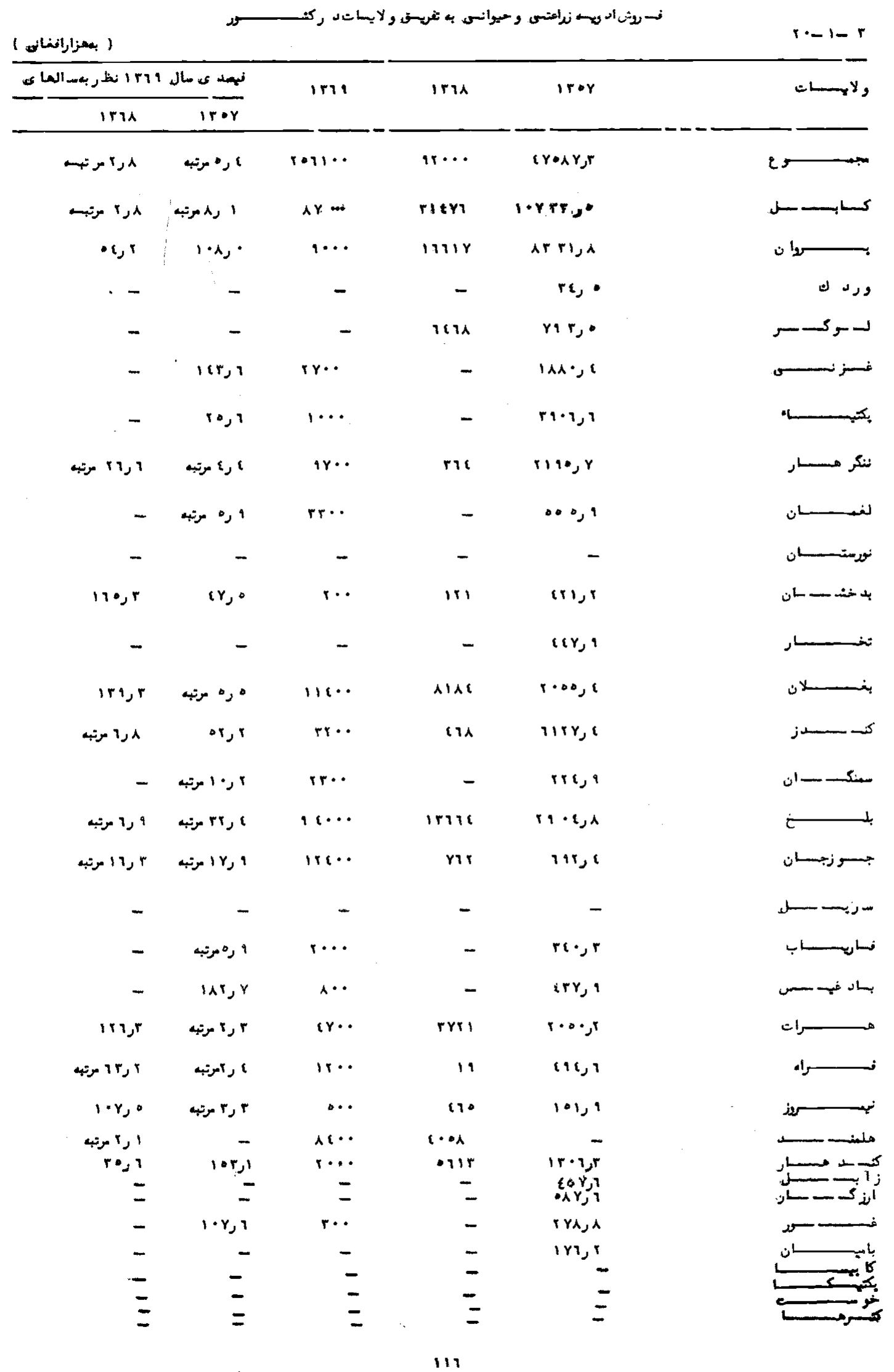




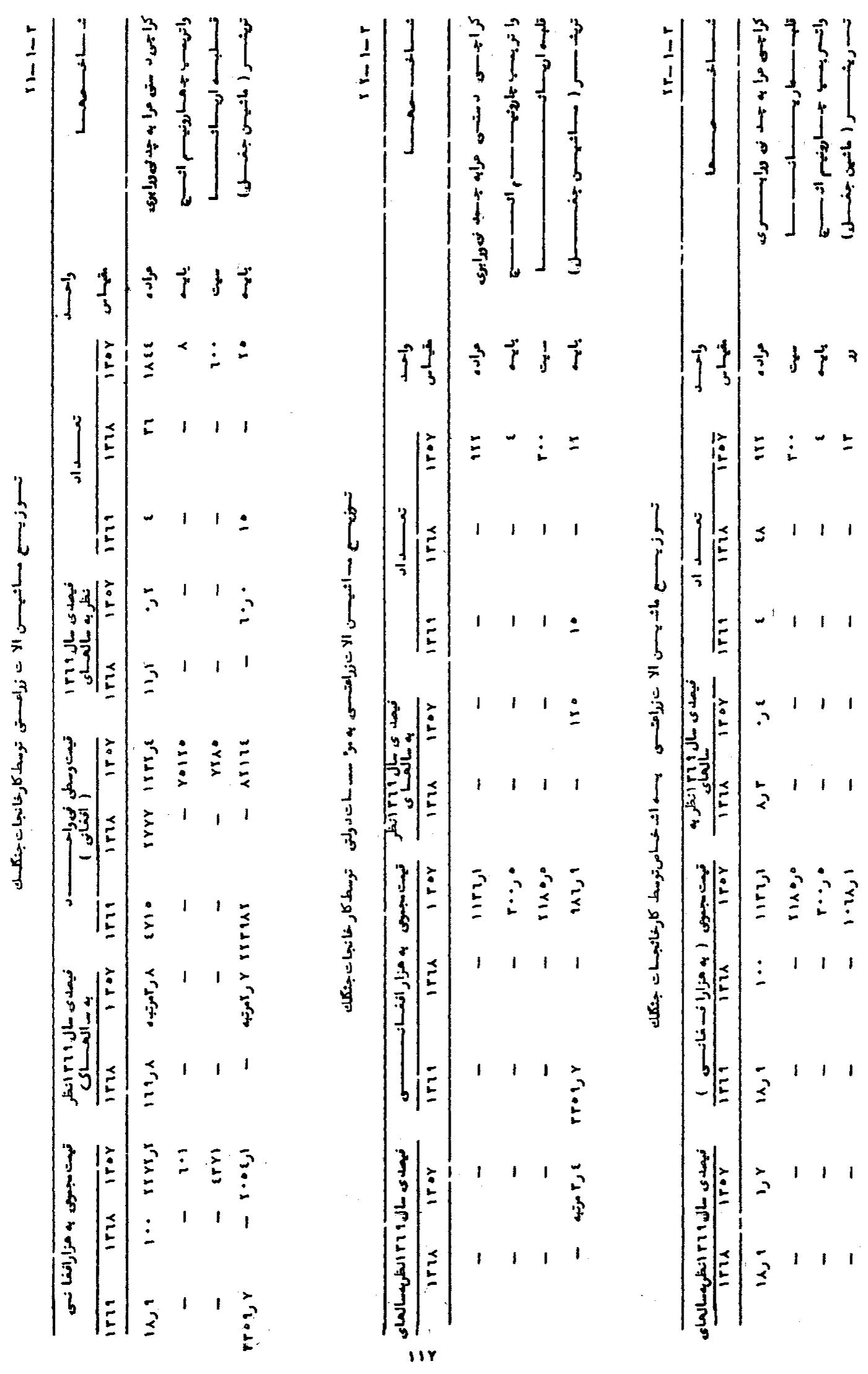




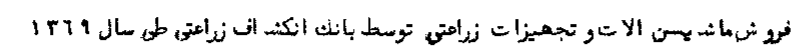

$1 \varepsilon-1-t$

\begin{tabular}{|c|c|c|c|c|c|c|c|}
\hline \multicolumn{2}{|c|}{ فيصدى سال 19 النظره سالعأى } & \multirow[t]{2}{*}{ irtq } & \multirow[t]{2}{*}{$1+11$} & \multirow[t]{2}{*}{$I T \cdot Y$} & \multirow{2}{*}{ 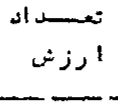 } & \multirow{2}{*}{ واحيساس } & \multirow{2}{*}{ مند خصساث ترضـ ســــ ، } \\
\hline irth & $I r \circ y$ & & & & & & \\
\hline$r \cdot r$ & ع أمرتبه & $\wedge 9,1$ & $\mid \varepsilon A, \cdot$ & $r Y, Y$ & النش & ميليونافغاني & $\varepsilon g$ \\
\hline$r i, r$ & 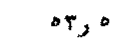 & rt & $1 \cdot 1$ & $\{r$ & تعداث & عراد ، & 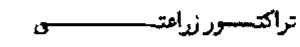 \\
\hline$r r_{0}$ & $1 \cdot r, r$ & $r r, 1$ & ris 1 & $r i$ & | & ملي ون الفغلا & \\
\hline$r \varepsilon, \lambda$. & $19 ., 0$ & $\varepsilon \cdot$ & 17 & M & تعداد & عهد & ملحنتسات ( تريلرجيه كني ) \\
\hline$\forall \wedge, \lambda$ & | & 93 & $r i, t$ & 1,0 & النشث & مليون انغناً & \\
\hline $110 \% 9$ & r r r r r r & $\lambda \cdot$ & 19 & 11 & تعداد & عسـد د & واتيعب بعمارسبالر مائيختلف \\
\hline $1 \circ r, y$ & Y ربry & rr & $r$ & $\cdot 9$ & النث & ميليون افغانه & \\
\hline - & - & - & - & $r$ & تعـ د اد & عستسدد & 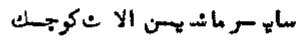 \\
\hline $1+21$ & or & $\cdot \gamma$ & T & $1, r$ & الذش & ميليونافغانغ & \\
\hline $15 \varepsilon 1$ & • لر مرتبه & $M, \lambda$ & ix & 11,5 & النئن & ميليونأفخ اني & 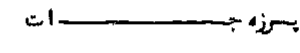 \\
\hline - & - & - & - & $\circ$ & ت تعداث & ع د & 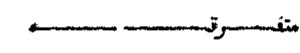 \\
\hline - & - & - & - & $\cdot r$ & ا ارنن & ميليونأفغانى & \\
\hline
\end{tabular}

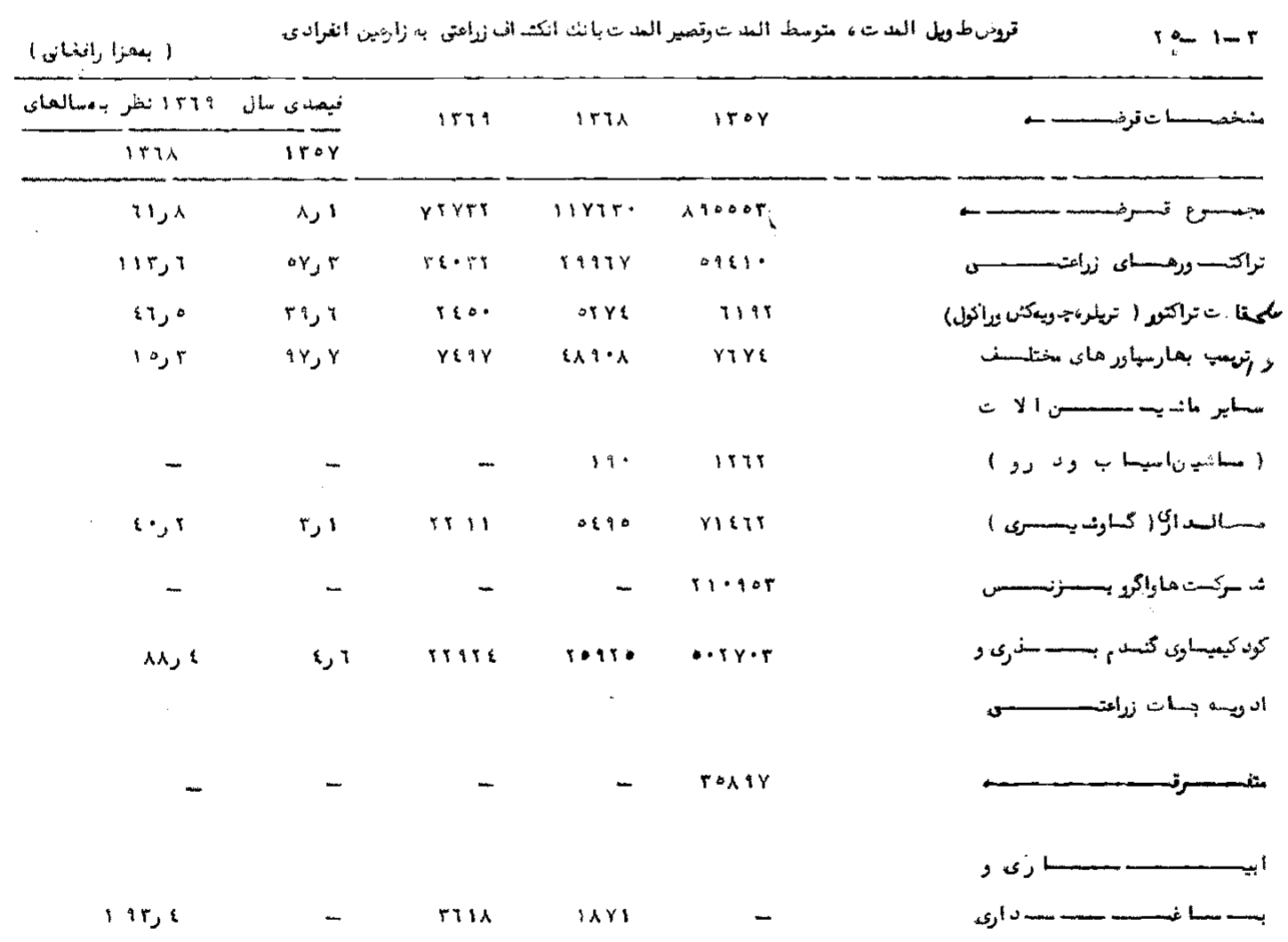




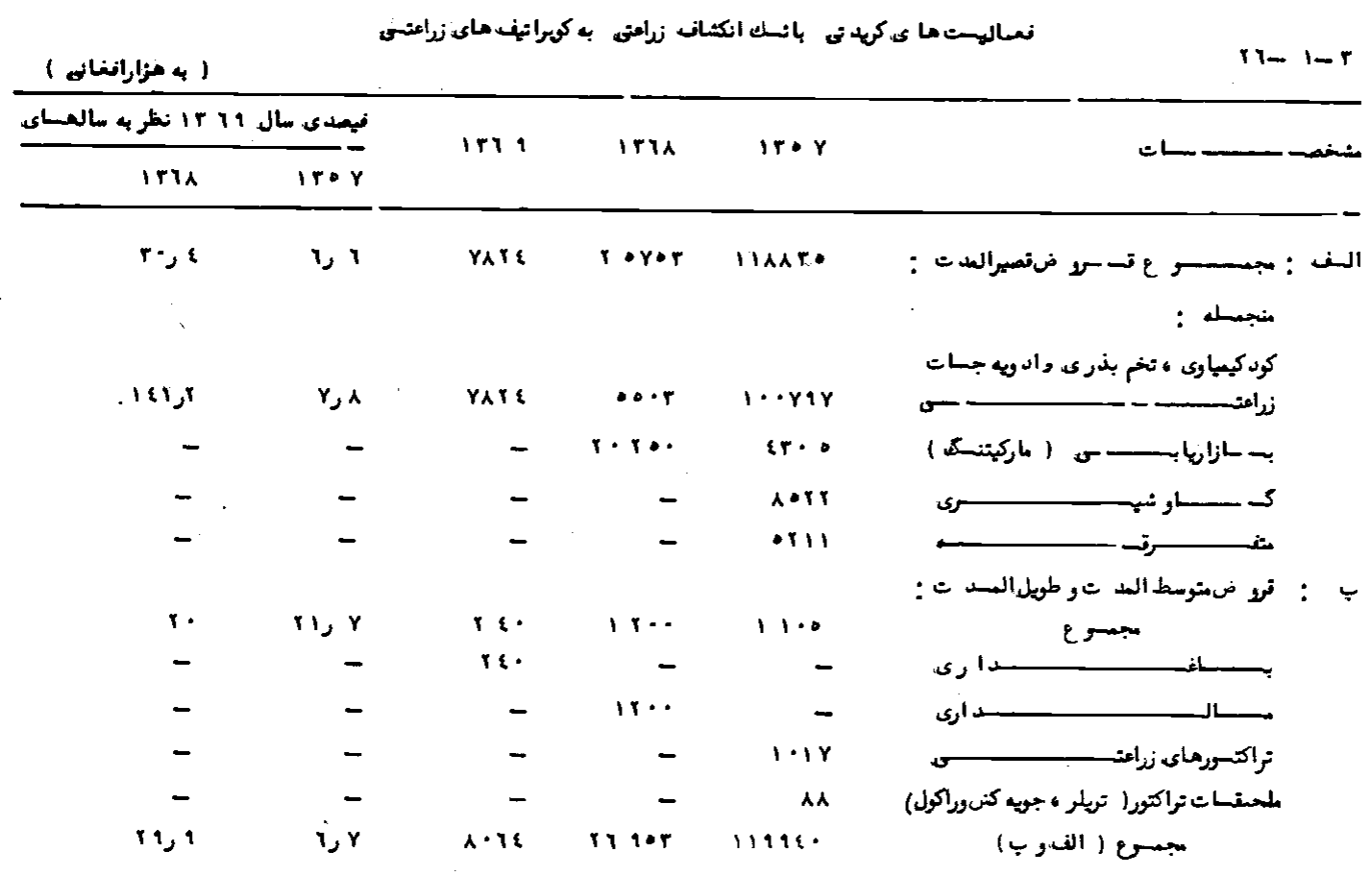

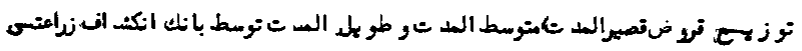

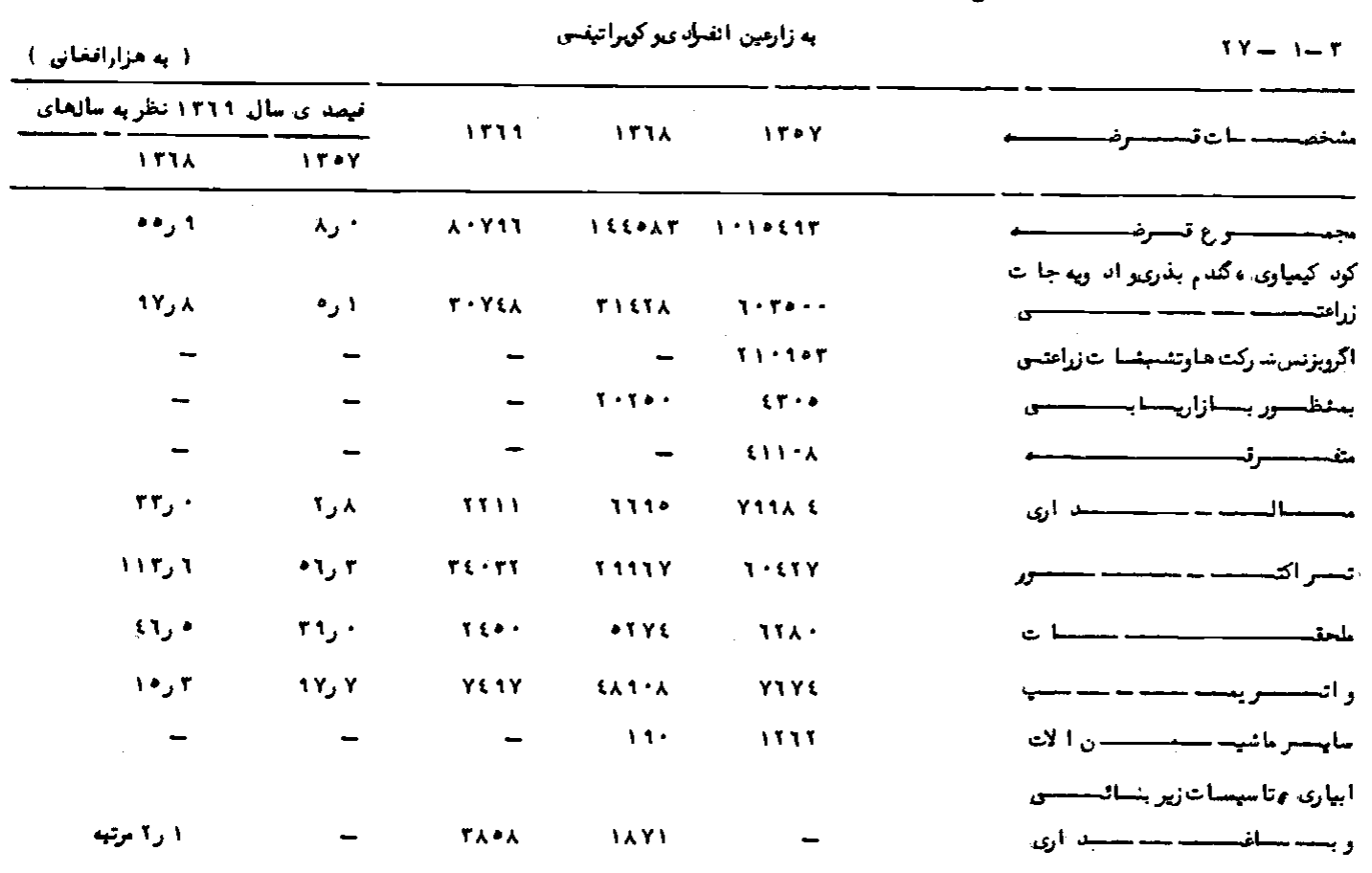




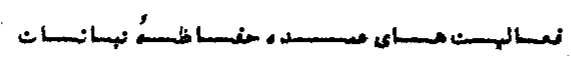

$r A-1-r$

\begin{tabular}{|c|c|c|c|c|c|c|c|}
\hline \multicolumn{2}{|c|}{ 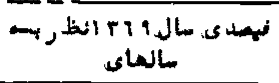 } & \multirow[t]{2}{*}{ iris } & \multirow[t]{2}{*}{ irix } & \multirow[t]{2}{*}{ iriy } & \multirow{2}{*}{ واسستس } & \multirow[t]{2}{*}{ 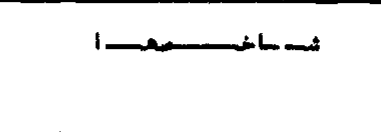 } & \multirow[t]{2}{*}{ مد مس اره } \\
\hline וrin & ITIY & & & & & & \\
\hline & & & & & & بياد له علهسه أمسرافروأنان انبا ر & 11 \\
\hline Ai, $\mathrm{E}$ & 1 & $\gamma \cdots$ & $\wedge 1 \cdots$ & $r_{1} \cdots$ & مزارامل & 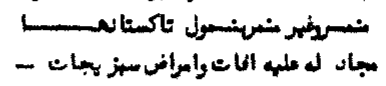 & 18 \\
\hline$\wedge \wedge, r$ & $r$ & ri, & $r \cdot$ & $\mathfrak{\imath}$ & مزارمكار & 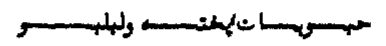 & \\
\hline ir & $\cdot 1, r$ & $\bullet$ & •r & 11 & مزاريتريكعب & 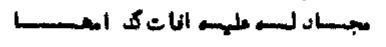 & /r \\
\hline$Y Y, 1$ & 109 & rY & ro & $\because$ & مزارمكا ر & 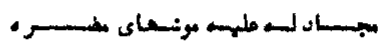 & 14 \\
\hline & & & & & & تد أرى تخم ماى خذرى خله بات رنبانات & $1 \cdot$ \\
\hline $9 \cdot$ & $r \cdot, r$ & 60 & $\Delta \cdots$ & $18 \cdots$ & نستسن & صنعنسيس & \\
\hline Vr. & rr & $1 \&$ & 191 & IYs & هزارمكار & 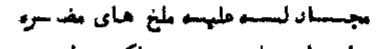 & 11 \\
\hline$I r r, r$ & $Y \wedge, 1$ & $r \cdots$ & $1 \cdots$ & $r \circ r^{\circ}$ & مزاراتفغانى & موايد از د رن نونيع مرنيفكيت نياتسلى & / Y \\
\hline
\end{tabular}

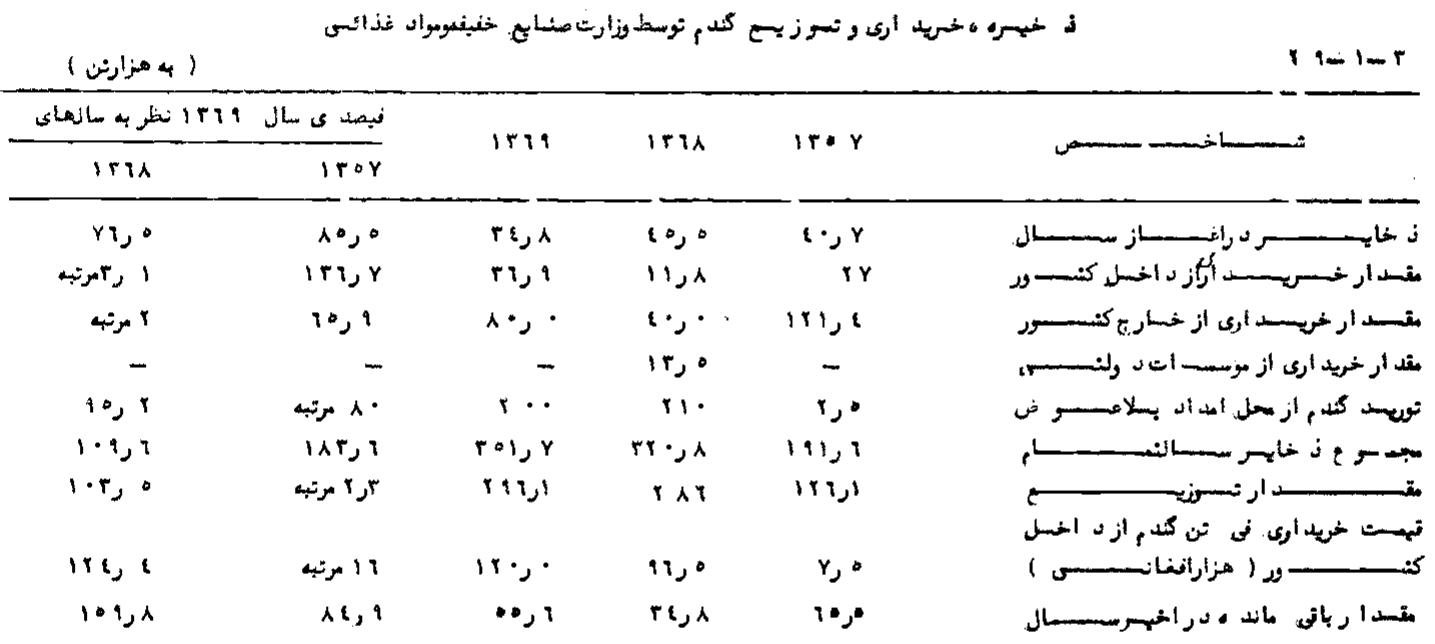

\begin{tabular}{|c|c|c|c|c|c|c|}
\hline \multicolumn{2}{|c|}{ فيصع س سال 9 المباى انظر به } & \multirow[t]{2}{*}{ Iris } & \multirow[t]{2}{*}{ Irin } & \multirow[t]{2}{*}{ iris } & \multirow[t]{2}{*}{ مقيساس } & \multirow[t]{2}{*}{ 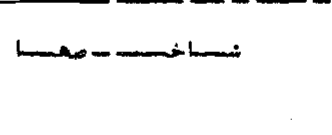 } \\
\hline וגו ואו & iris & & & & & \\
\hline - & - & - & $n \cdot Y$ & $n \cdot 1$ & نسسن & $s^{2}$ \\
\hline$r$ & in, 9 & rite & $.1 \%$ & eyet & تسـن & 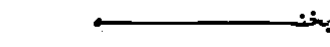 \\
\hline ir, 9 & ir 9 & 1,1 & $\varepsilon$ & $\varepsilon$ & نسسن & 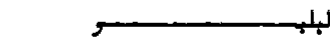 \\
\hline Y ر Y Y Y Y Y & $1 \cdot 1,9$ & YAY & $1 \cdot r$ & Yo. & كيلوكاן & $=\longleftarrow$ \\
\hline
\end{tabular}




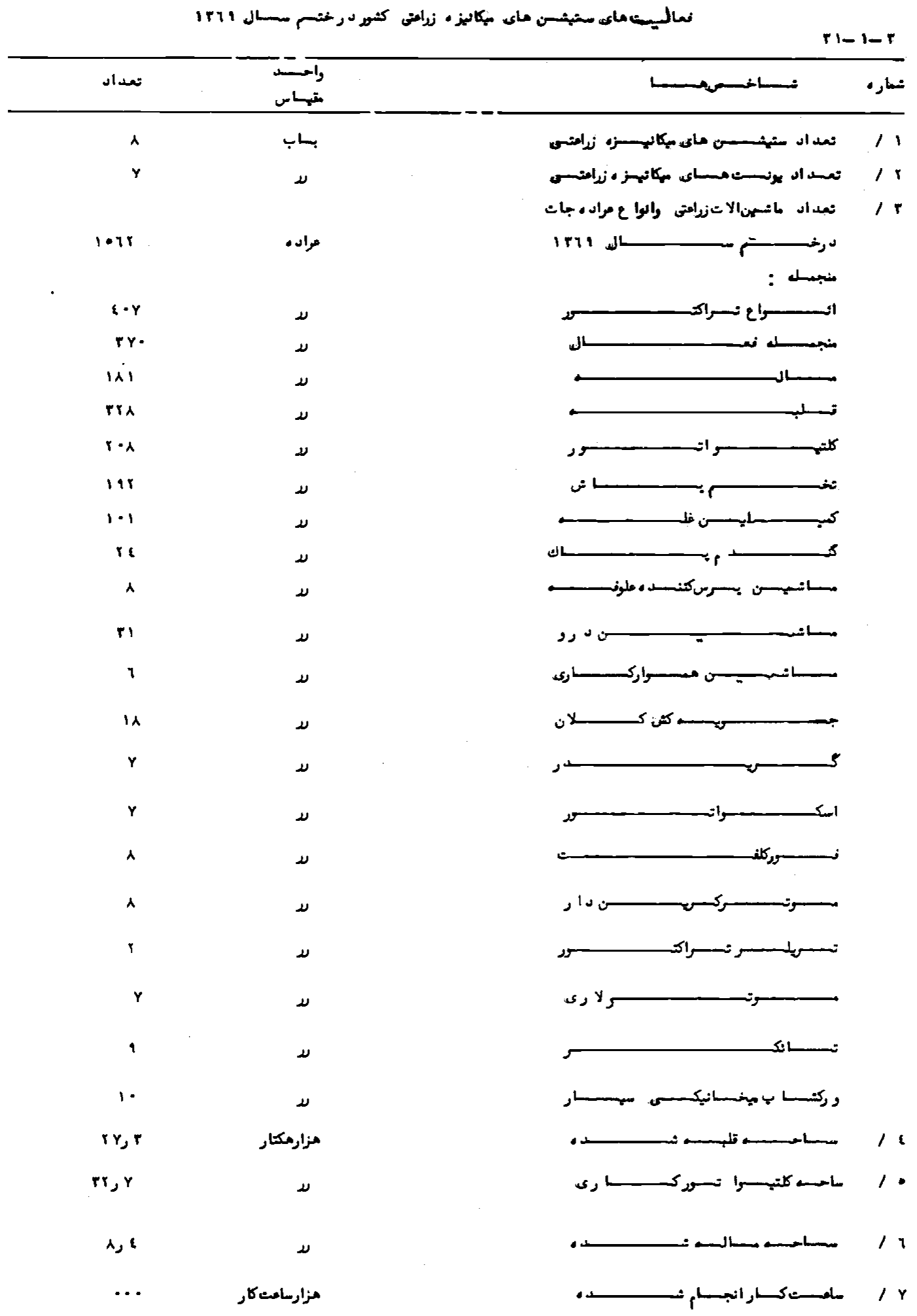




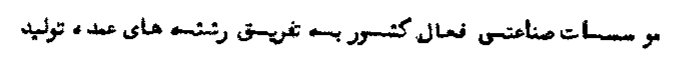

\begin{tabular}{|c|c|c|c|c|c|c|c|}
\hline \multicolumn{3}{|c|}{ ازجمــله دولتى روختلط } & \multicolumn{3}{|c|}{ مجستس عوستسات كثنسور } & \multirow{2}{*}{ ثـانسيسم ثمستسا } & \multirow{2}{*}{ نسيسار، } \\
\hline 148 & Irหג & Iror & 1479 & irix & $I r \cdot r$ & & \\
\hline$\S$ & $\varepsilon \varepsilon$ & rr & 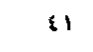 & $\varepsilon \varepsilon$ & rr & 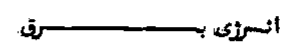 & 11 \\
\hline 1 & $r$ & $r$ & 1 & $r$ & $r$ & 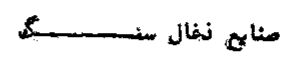 & /r \\
\hline$r$ & $r$ & $r$ & $r$ & $r$ & $r$ & 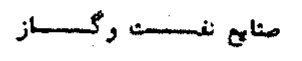 & /r \\
\hline 1 & 1 & $r$ & Ar & Ar & $r \cdot$ & 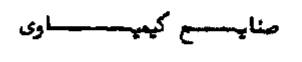 & $1 \mathrm{e}$ \\
\hline ir & ir & $r$ & 11 & 19 & ir & صنائكع ساختهانســــــ & I \\
\hline - & - & r & $\cdots$ & \{\} & ir & صنايع مانينسازيو نلز كَ رى & 14 \\
\hline 1 & 1 & $r$ & $r$ & $r$ & $\cdot$ & صنايع ثولسهـد ادربستســــ & / $r$ \\
\hline$r \varepsilon$ & $r r$ & $1 \lambda$ & $r$ & $r \cdot$ & $r \varepsilon$ & 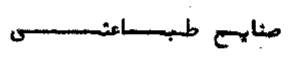 & / $x$ \\
\hline 1 & 1 & $r$ & 17 & 10 & 1 & صنايهم نجاركيو كافذ سمازى & 19 \\
\hline ir & ir & $\wedge$ & $|\varepsilon|$ & $\operatorname{ir\varepsilon }$ & $\varepsilon Y$ & 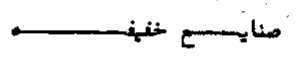 & 110 \\
\hline $1 \cdot$ & 1. & 15 & $\operatorname{lr\varepsilon }$ & $18 \cdot$ & ir & صنايع. مواد ارتــزاتســــــى & 111 \\
\hline- & - & - & 19 & 70 & 1 & مسايحسر صنسـسايسمس & / ir \\
\hline 11 & $11 \varepsilon$ & $\wedge 9$ & ors & 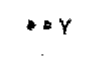 & $r \varepsilon r$ & كجمست & \\
\hline
\end{tabular}

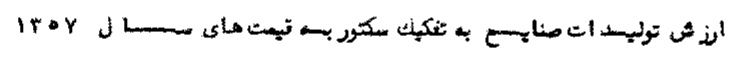

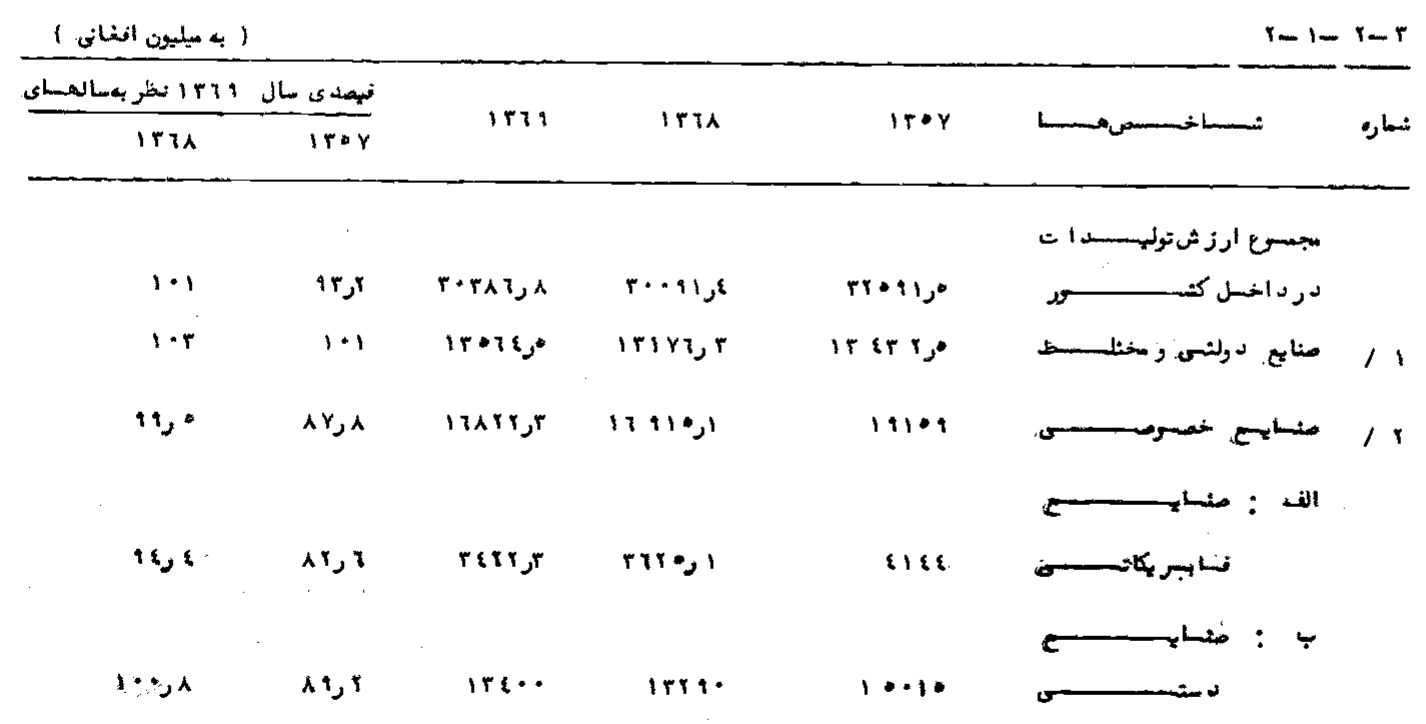



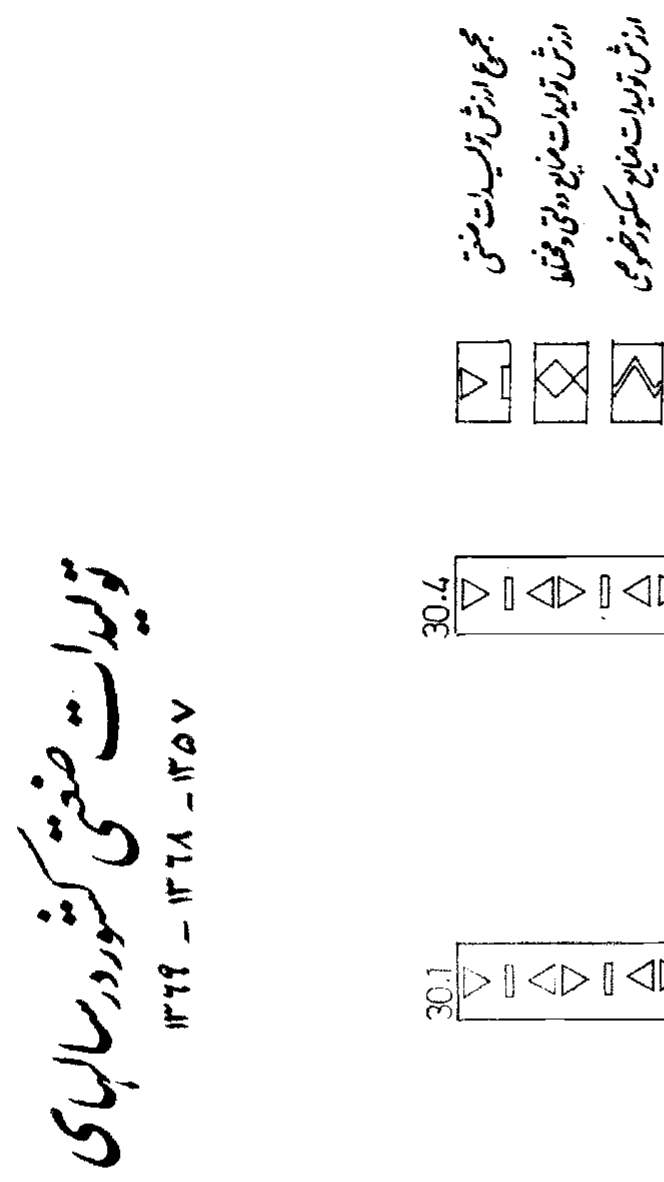

曰国因

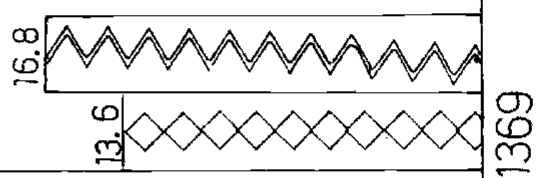

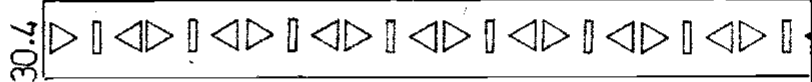
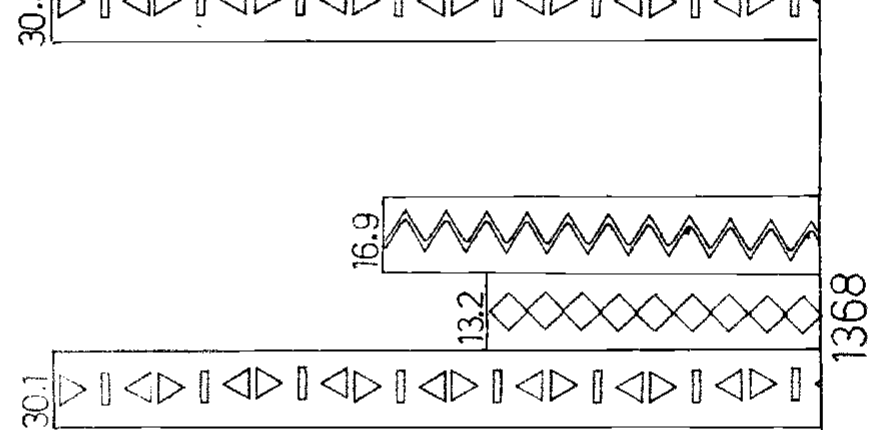

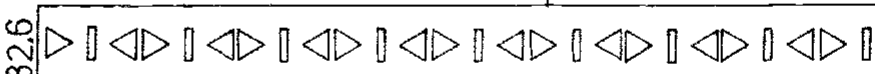

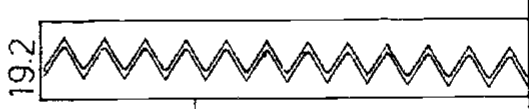

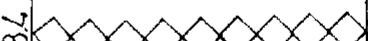

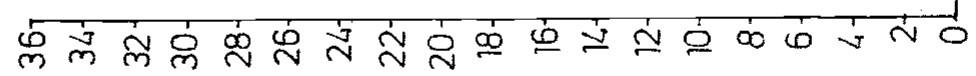




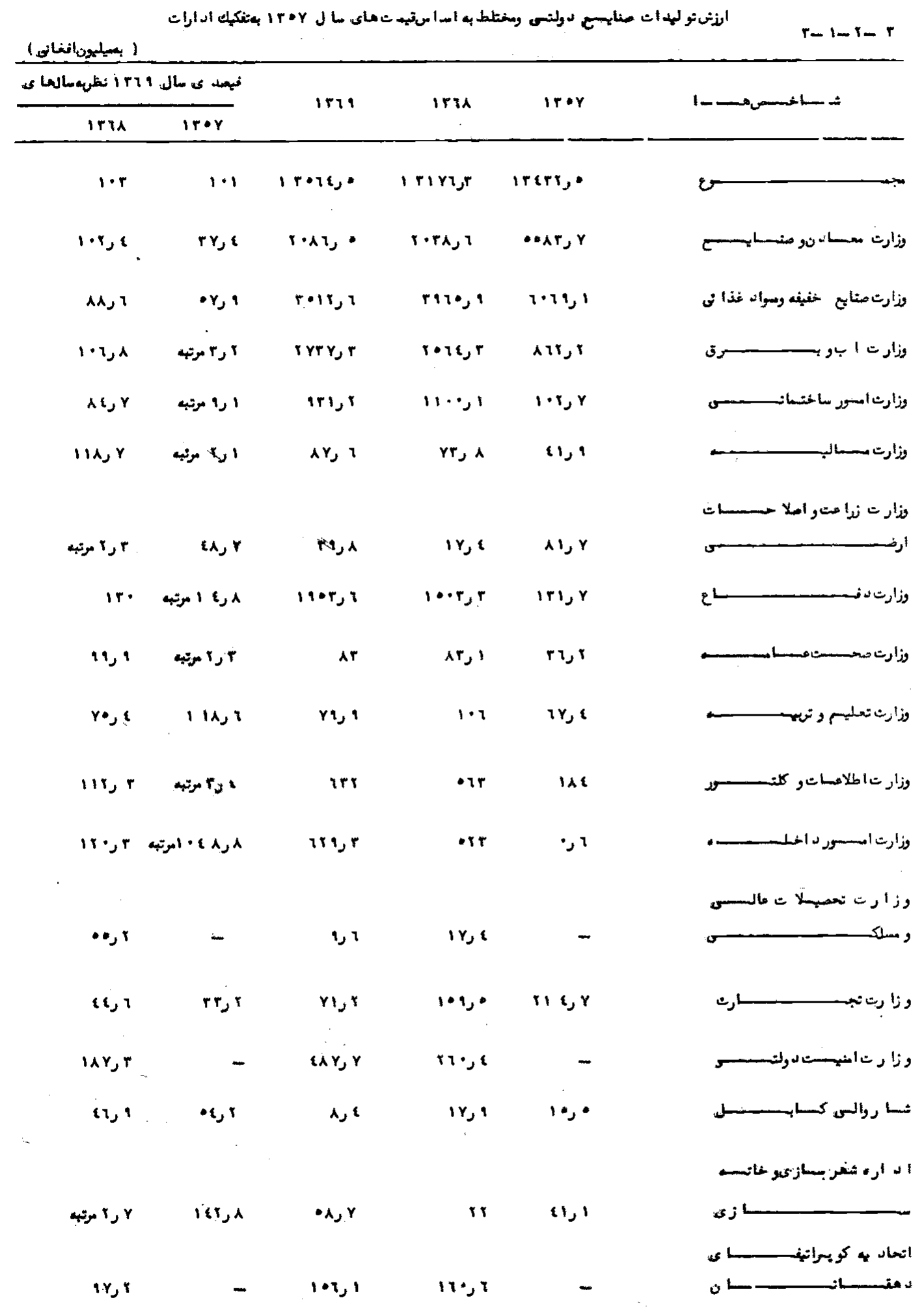




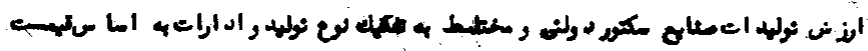

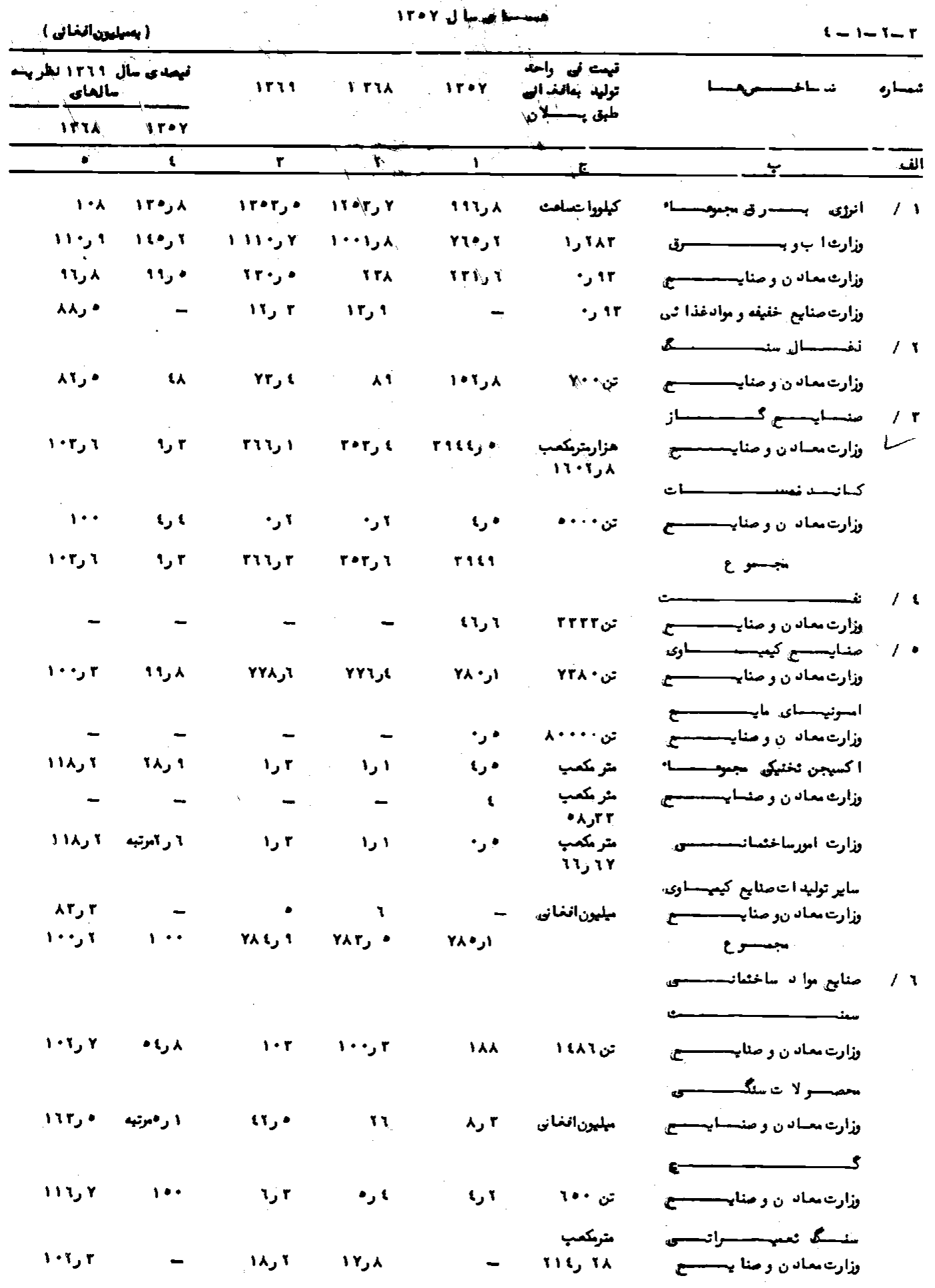


$1-1-r-r$

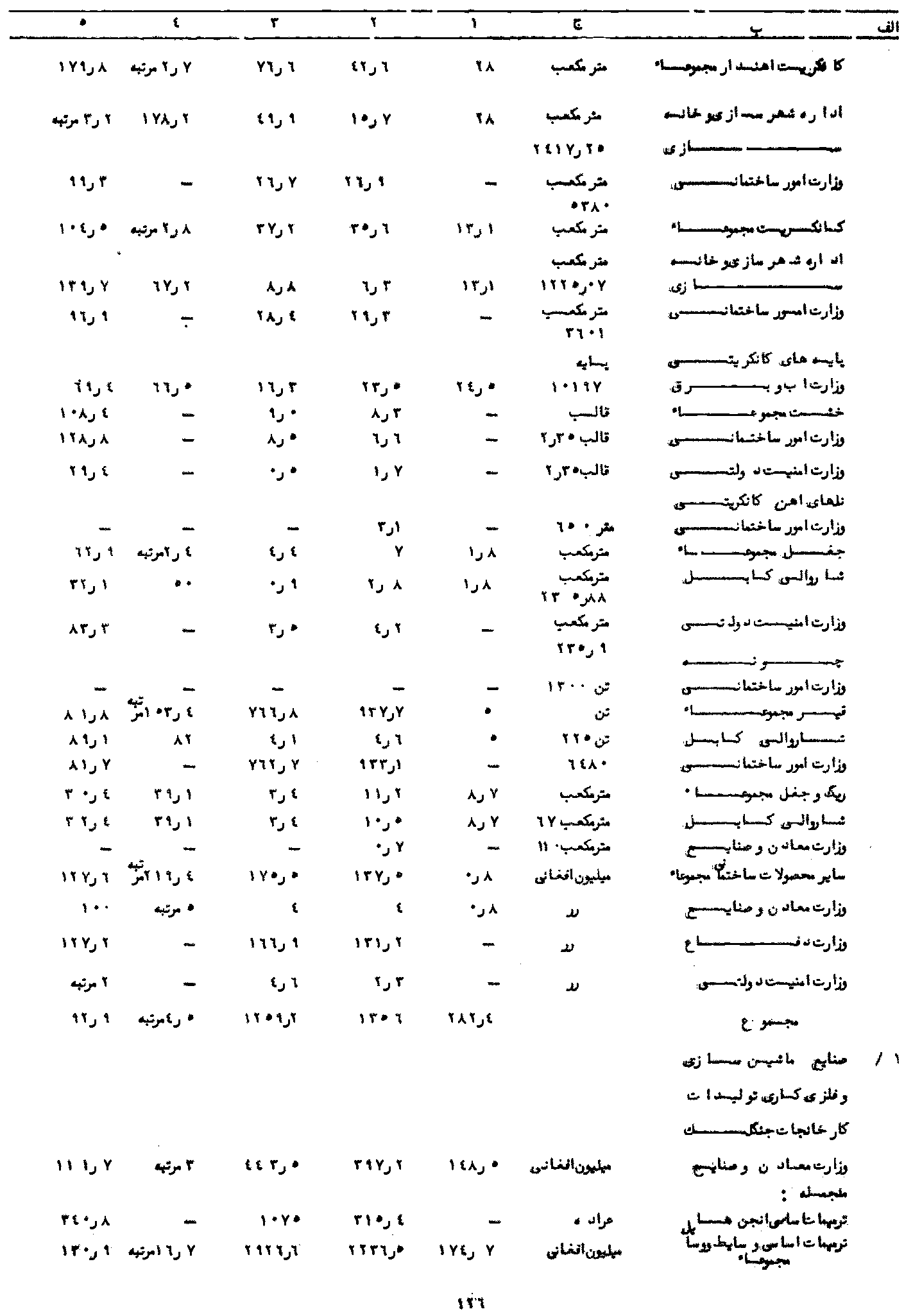


$\{-1-r-r$

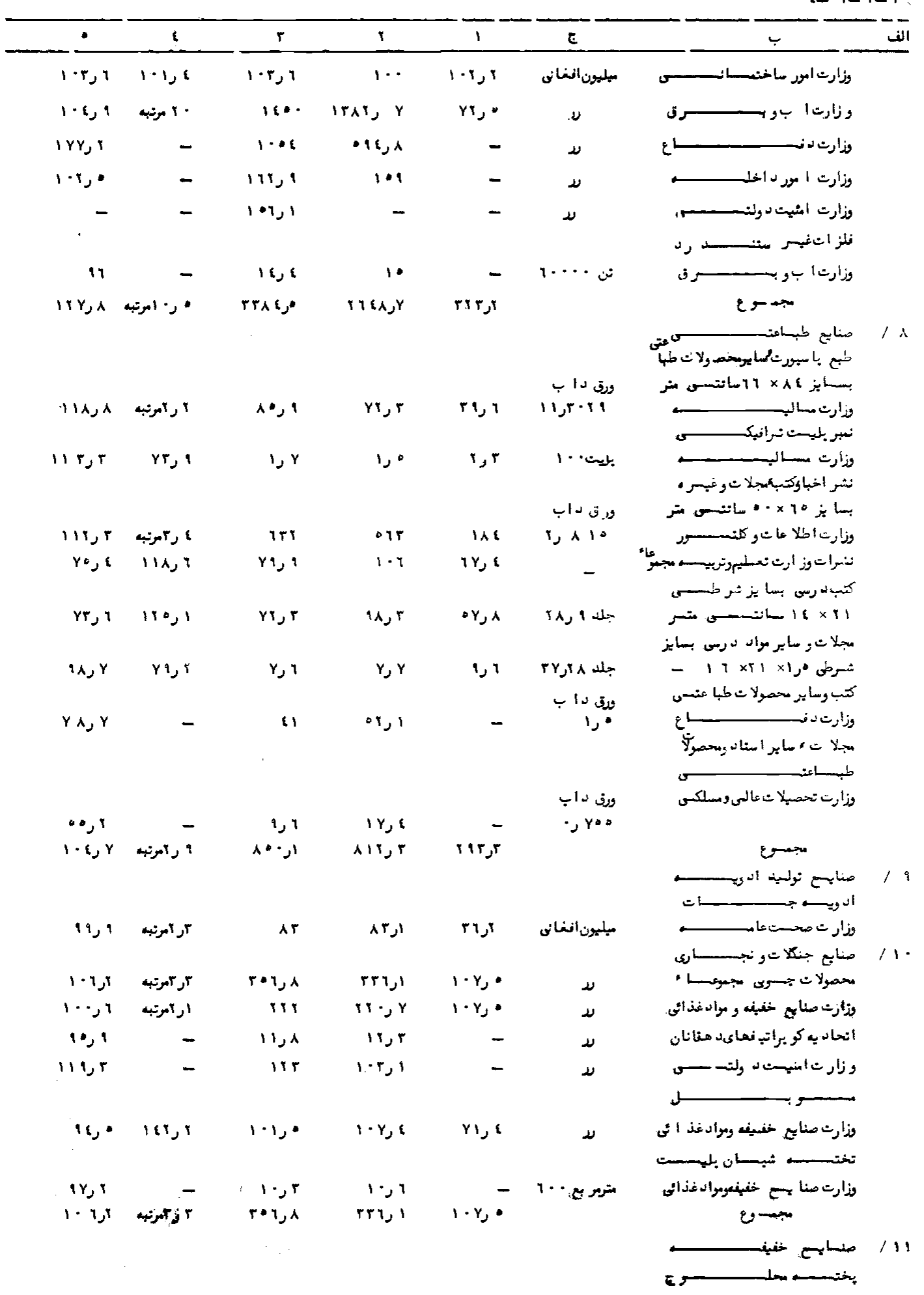


$2-1-1-1$

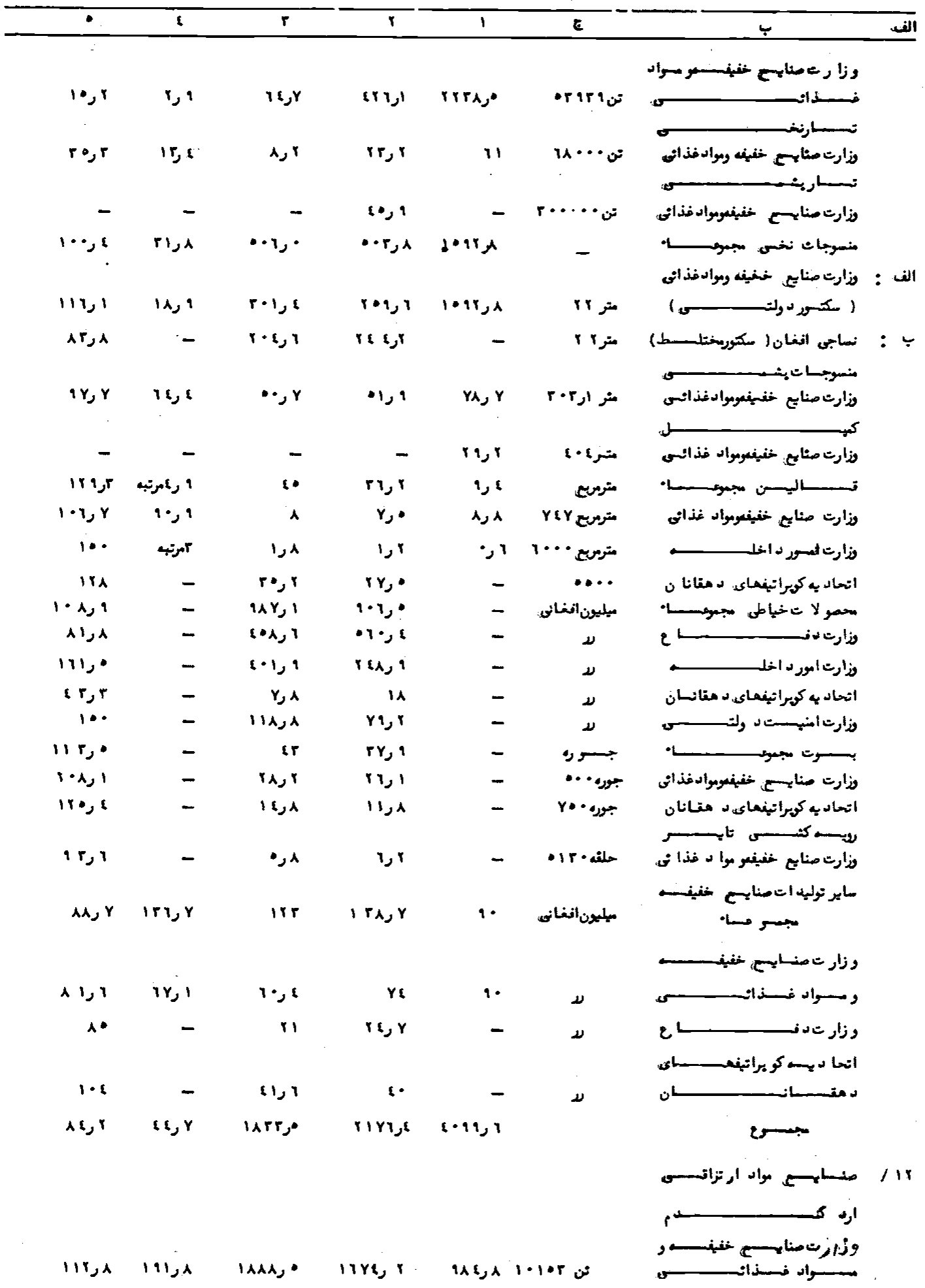




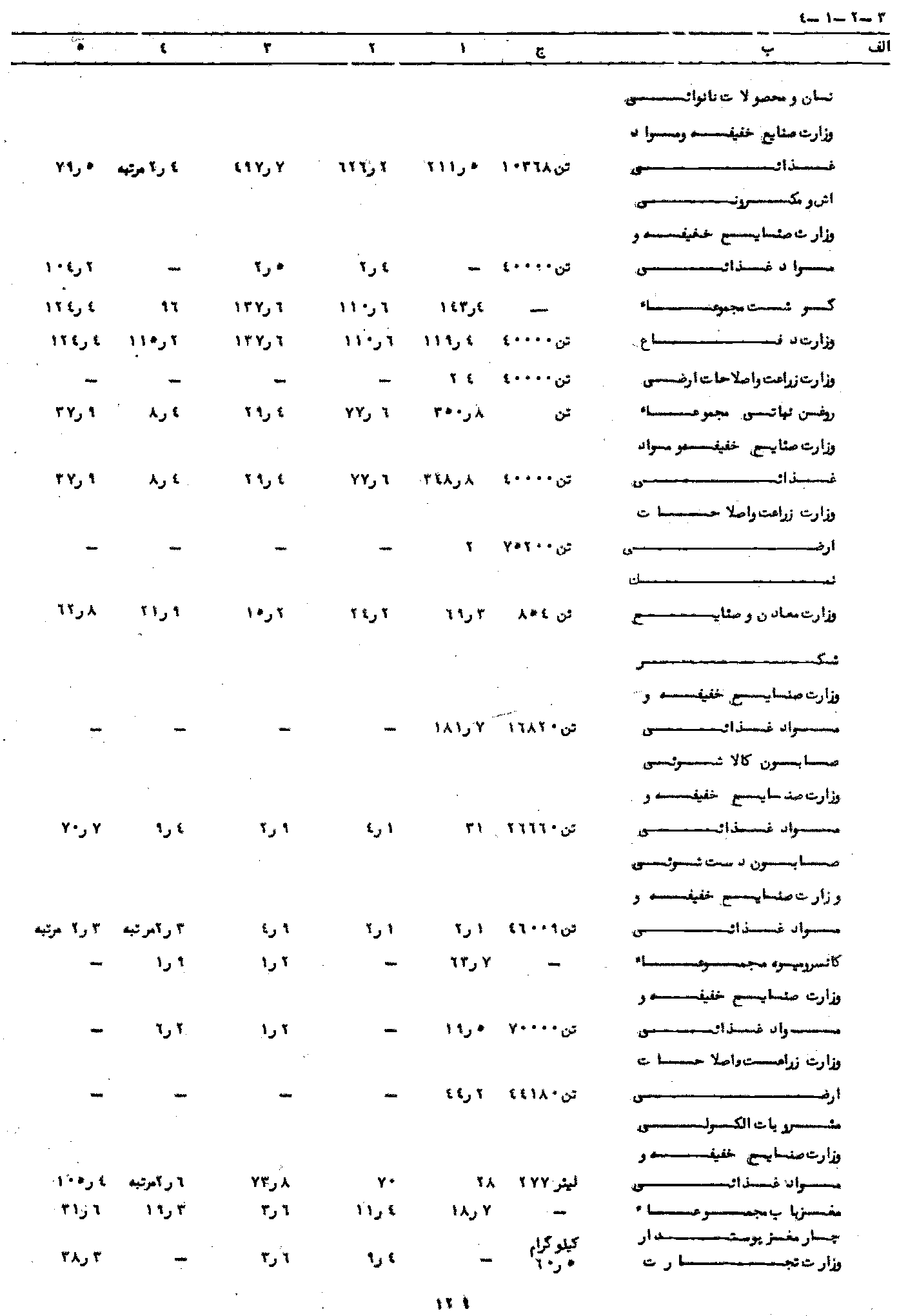


$\varepsilon-1-r-r$

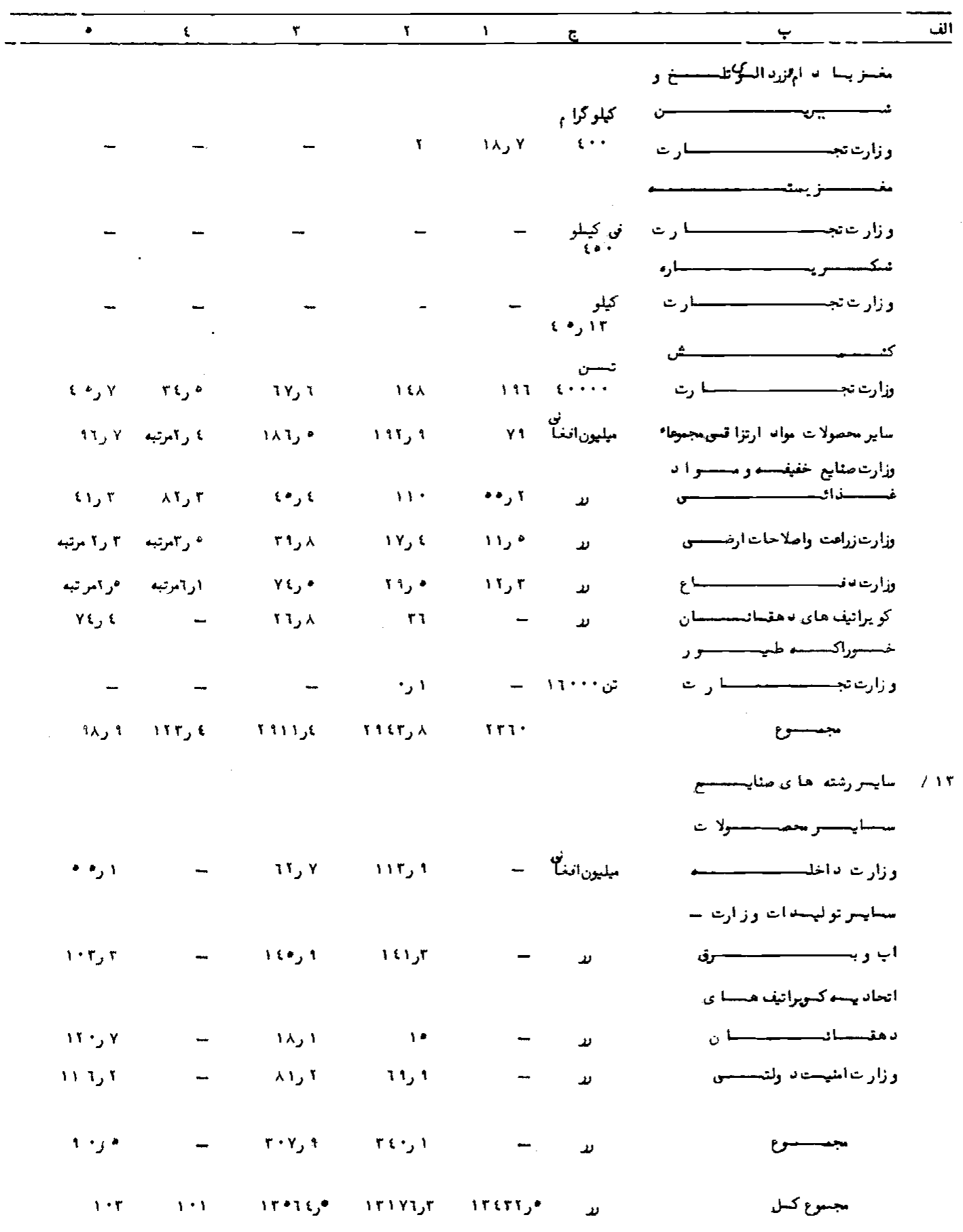




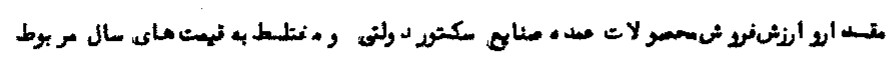

- in r-r

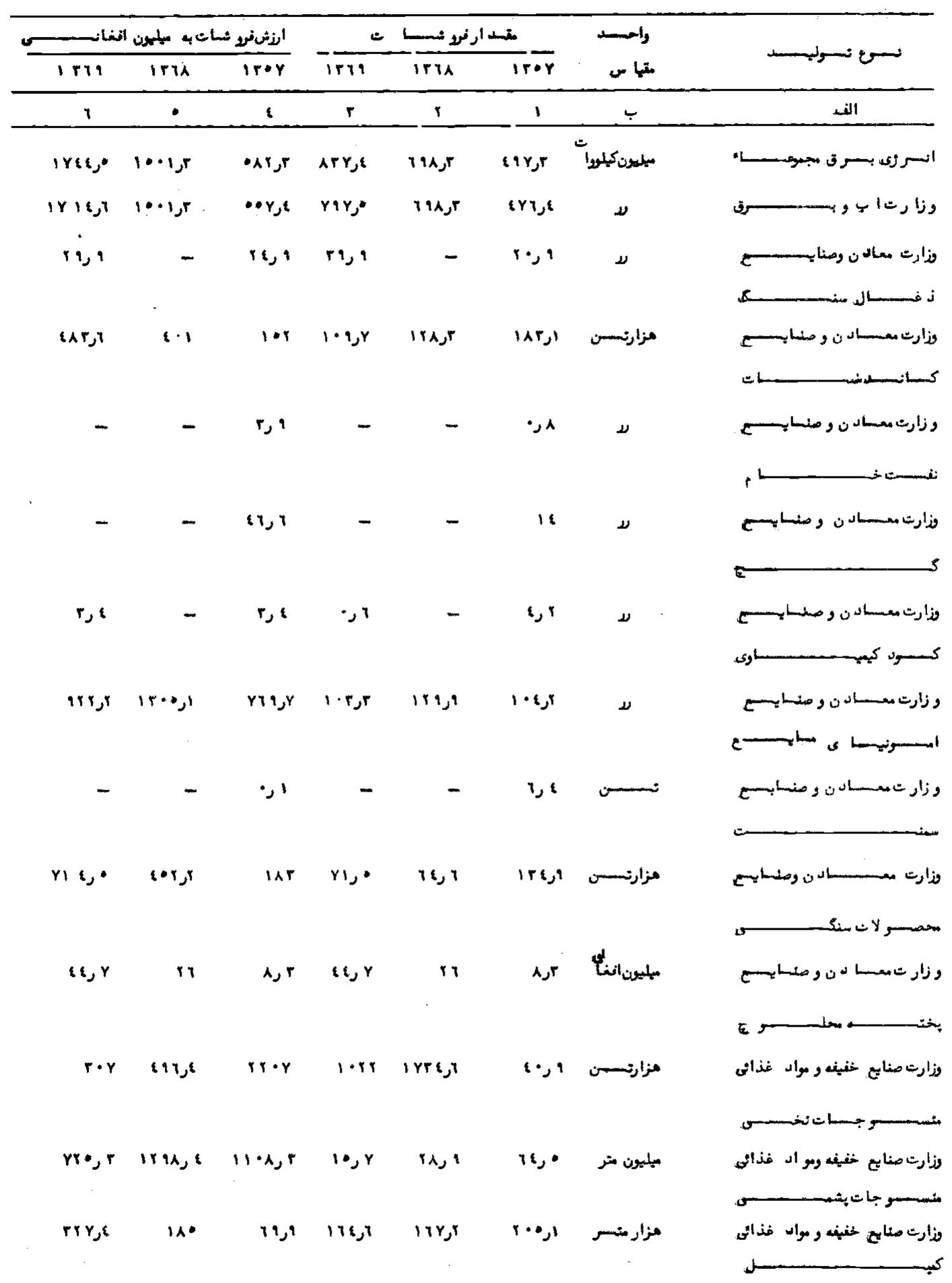


$\begin{array}{lllll}1 & 1 & r & 1 & 1\end{array}$

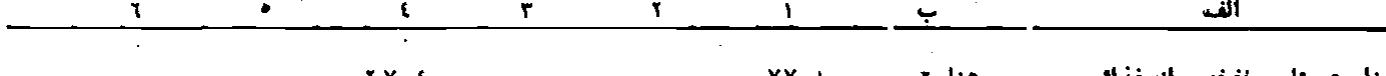

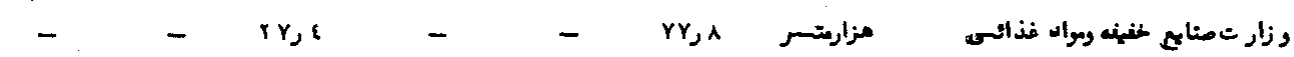

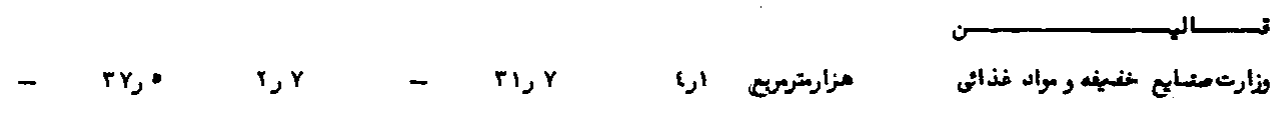

\begin{tabular}{|c|c|c|c|c|c|c|c|}
\hline$r i \lambda_{2} \mid$ & $\operatorname{lr} 4, \lambda$ & - & $\cdot \varepsilon, r$ & $r \lambda_{2} r$ & - & مزارجور & أرت صنايه خنيفه ومواد غذائس \\
\hline $1 \cdot, r$ & 0,8 & - & 1111 & $Y i r, A$ & - & حلتس & لر خنيفه ومواد غذائسى \\
\hline
\end{tabular}

اروم

نذارت صنايع خغيفه ومواد غذائس

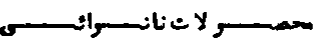

وزار تصنايع: خغينه وماد غذائس

.

وزار

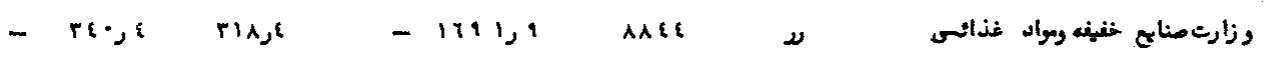

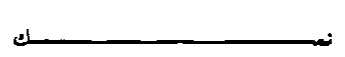

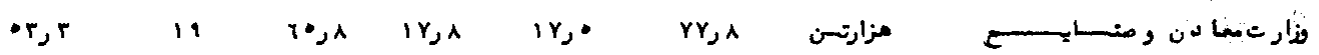

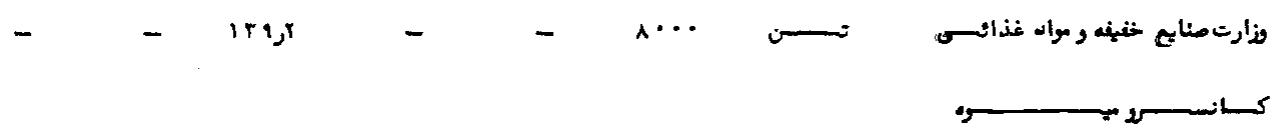

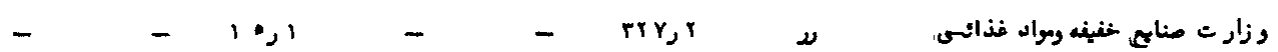

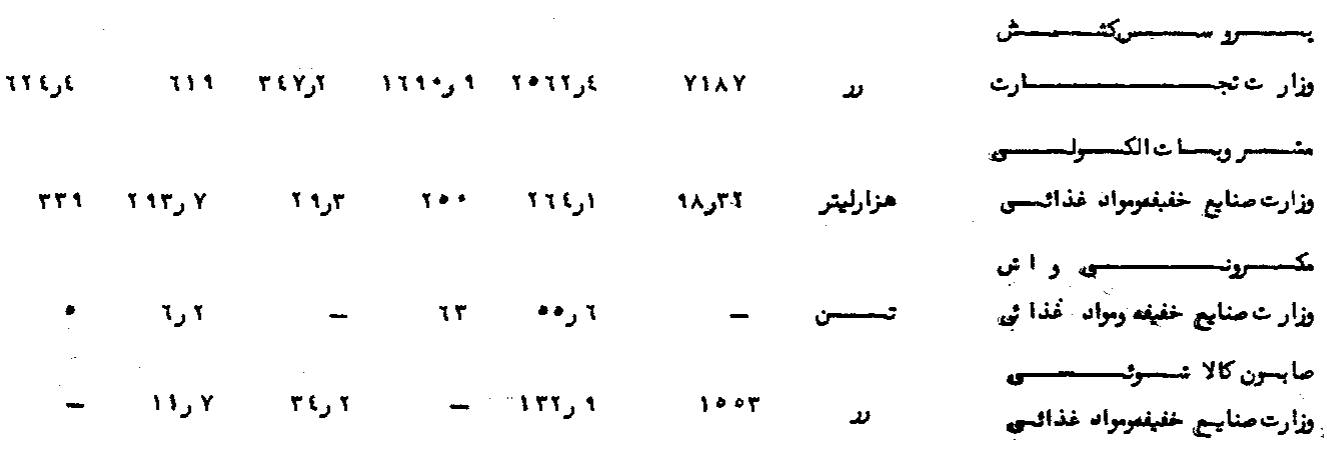

IrY 


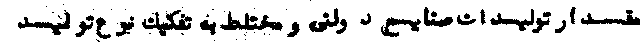

$1-1-r-r$

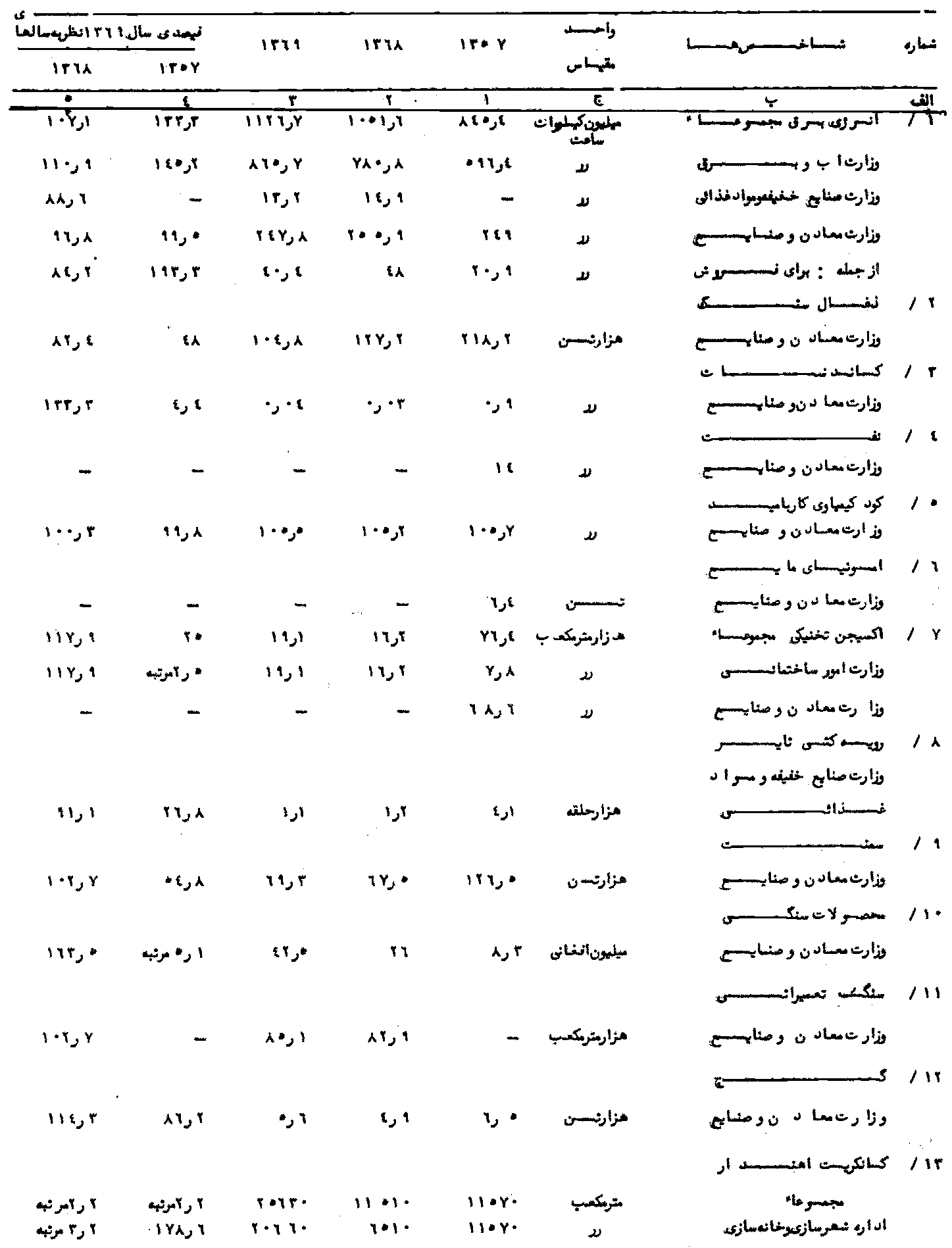


$1-1-r-r$

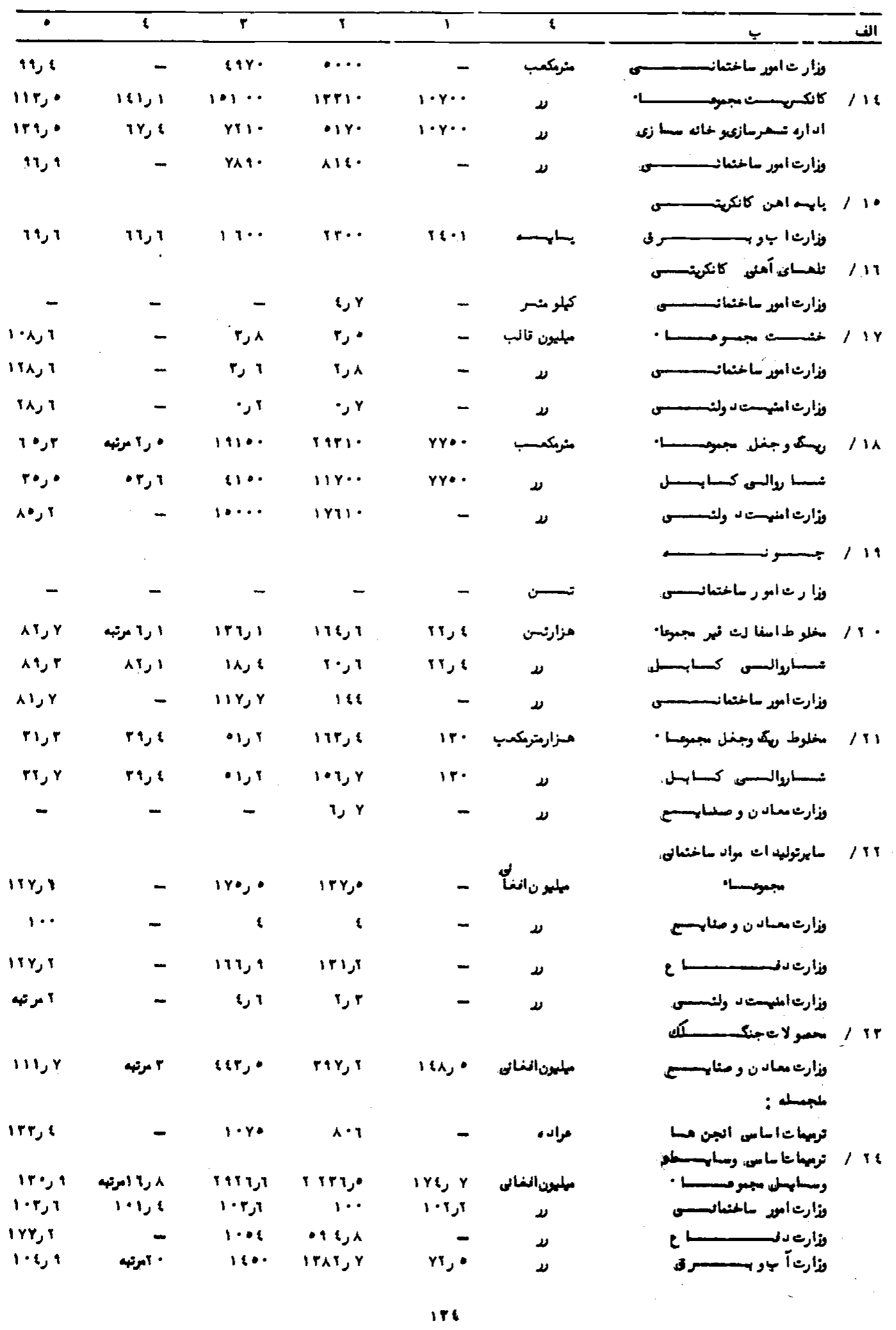


$1-1-1-7$

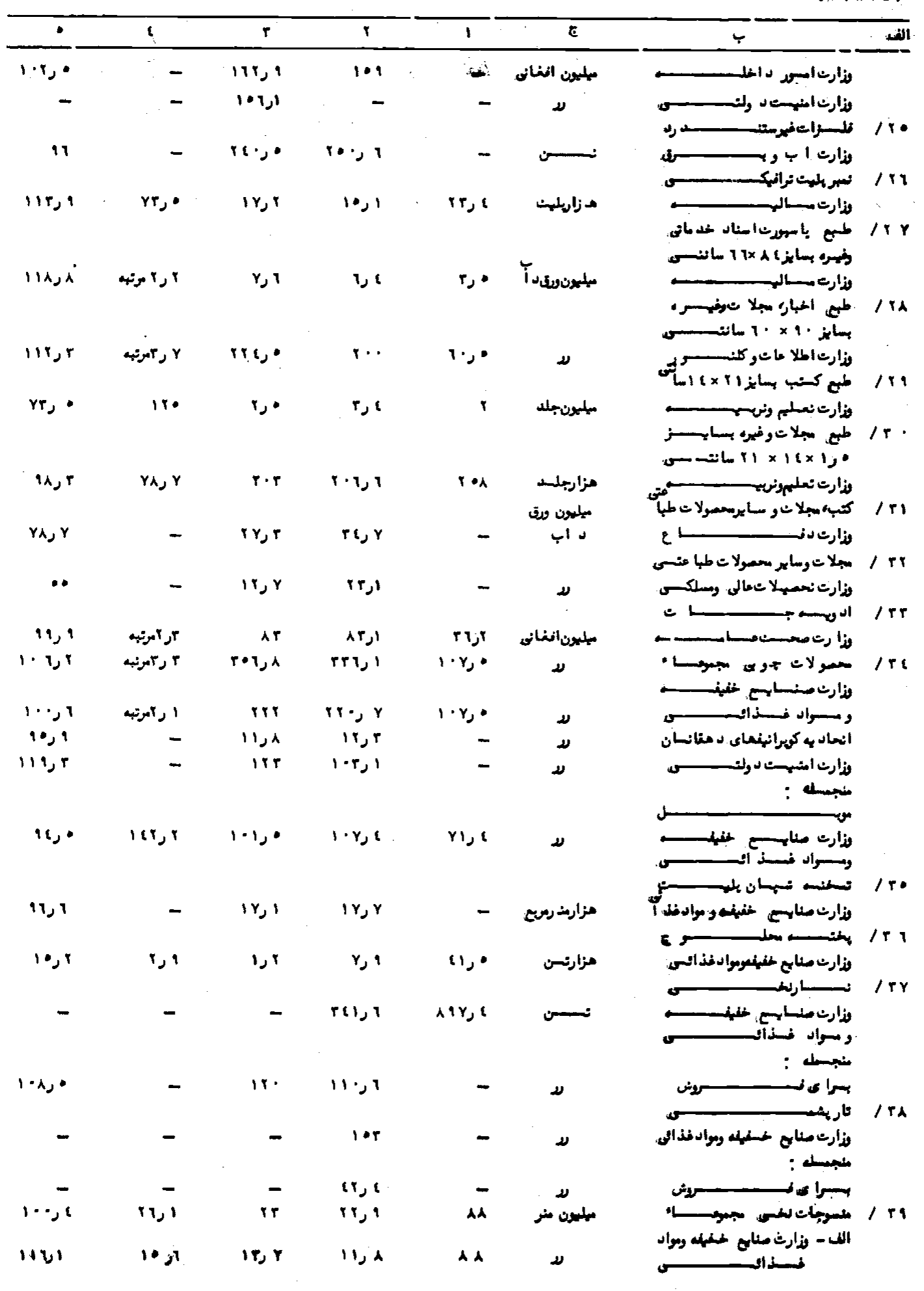


$1-1-r-r$

\begin{tabular}{|c|c|c|c|c|c|c|c|}
\hline$\cdot$ & $\mathrm{i}$ & $r$ & $r$ & 1 & $\tau$ & $\bar{Y}$ & المن. \\
\hline$A r, \lambda$ & - & $9, r$ & 11,1 & - & مهلعن شتر & بـ - نساجـ انغانه ( سكوربغتلط ) & 18 \\
\hline $9 Y, 1$ & 76 & $\operatorname{li} Y, Y$ & $\mid Y i, r$ & $r \cdot 9, \cdot$ & مزار متسر & 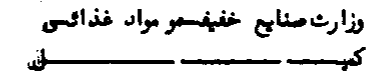 & \\
\hline- & - & - & - & Yr, $r$ & ע & وزارت صناي خن ينه و مواد غذانسه & \\
\hline$\| r, Y$ & 14,1 & $\mid Y, i$ & $1 \bullet$, & 11,9 & مزارمنرميع & 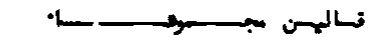 & / \\
\hline $7 \cdot \bullet, 9$ & $q \cdot, Y$ & $1 \cdot, \mathrm{Y}$ & $1 \cdot 1$ & $11, \lambda$ & $\nu$ & وزار ث صنسايي خغينمو موانفذذانس & \\
\hline $1 \cdots$ & ا مرنب · & $\cdot r$ & $\cdot r$ & - & $\nu$ & وزارت أمســـر د اخـلـــــــــــــ & \\
\hline $1 \times 1$ & - & , & • & - & $\nu$ & أتحاد يه كوراتيفعاي د مهنانسا ن & \\
\hline $1 \cdot \lambda, 1$ & - & $1 \wedge Y, 1$ & $9 \cdot 1 \cdot$ & - & ميلبونافغانه. & 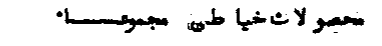 & / ir \\
\hline$A 1, \lambda$ & - & $(\bullet A)$, & $\bullet$ & - & $\nu$ & 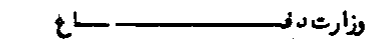 & \\
\hline $1 \cdot \cdot$ & - & $11 \lambda, \lambda$ & $Y q, r$ & - & ע & وزارت المنــــد ولتهـــــــــ & \\
\hline 111, & - & $c \cdot 1,9$ & $r(A, q$ & - & ע & 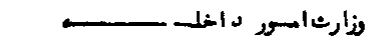 & \\
\hline$(r, r$ & - & $Y, \lambda$ & 11 & - & $\nu$ & اتحاد بكوبراتيفعاكى د متانسا ن & \\
\hline$\lambda \wedge, Y$ & Iru & irr & $I r A, Y$ & $१ \cdot$ & $\nu$ & ساير توليد اتصندايج خنيغســـــ & $1 \mathrm{k}$ \\
\hline$A 1,1$ & $\mid Y, 1$ & $1 \cdot, \mathrm{l}$ & Ye & $१ \cdot$ & $\nu$ & وزارت صنا يع خغبنمومواد غذانس & \\
\hline$\Lambda \cdot$ & - & Y & $r e, r$ & - & ע & 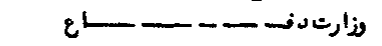 & \\
\hline $1 \cdot \mathfrak{l}$ & - & $(1,1$ & \&. & - & $\nu$ & اتحاد يه كوراتيفساى د مثانسا ن & \\
\hline 111,9 & - & $r u \cdot$ & ir & - & مزار جسمص. & 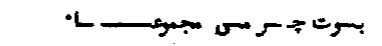 & 16 \\
\hline $1 \cdot Y, 9$ & - & $\bullet$ & $\cdot r$ & - & $\nu$ & وزارتصنايع خغهغو موادغذانهى & \\
\hline $1 r \cdot \theta^{\circ}$ & - & $19, Y$ & $1 \bullet, y$ & - & $\nu$ & انه أد ي كويرانينصاى د منانسان & \\
\hline$\| 18,1$ & 191,1 & $1 \wedge 1$ & 1789 & १Y & مزارتســن ن & 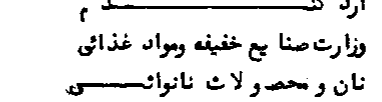 & $/ \mathrm{EY}$ \\
\hline$Y q \cdot$ & ا ع مرتبه & 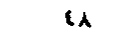 & $7 \cdot, 8$ & $r \cdot, r$ & $\nu$ & وزارت صنايع خففه ومو الدغذانى & \\
\hline$r i e^{\circ}$ & $1 \cdot 1,9$ & res. & ryis & ris & ن & 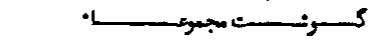 & 14 \\
\hline 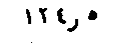 & $11 \cdot, r$ & res. & ryis & rac & $\nu$ & 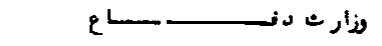 & \\
\hline - & - & - & - & rrr & $\nu$ & وزارثنراعت وأهلانحاثا أرخ هى & \\
\hline$r_{\lambda}$ & 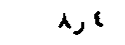 & Yri & IIrA, & A YeY & $\nu$ & 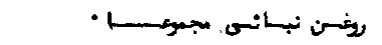 & 189 \\
\hline ra & 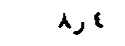 & Yri & IIra, & AYr. & ע & وزأرث حسنايع خنيغ وموانغنذانى & \\
\hline- & - & - & - & $r Y$ & $\nu$ & نزارتنراعت واهلاهـات ارضـى & \\
\hline$r$ & rr & $\mid Y, \lambda$ & $r A, r$ & 11,1 & مزارتســن & وزارث معاد ن و صنايســـــ & \\
\hline- & - & - & - & $1 \cdot \lambda$ & $\nu$ & وزأرتصنايع. خفنبنه وموادغذانق & \\
\hline- & $1, r$ & 11 & - & IrY9 & تـــــــن & 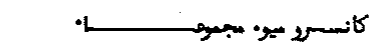 & f \\
\hline- & - & - & - & $1 \cdots$ & $\nu$ & وزارت زراعت را صلاحات أرضهى & \\
\hline- & $1, Y$ & 11 & - & $r Y q$ & $\nu$ & 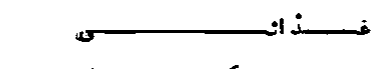 & \\
\hline$(\bullet)$, & $r e, r$ & $1, Y$ & $r, r$ & is 9 & $\nu$ & 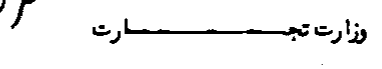 & \\
\hline - & - & - & $i$ & - & تســـــن & 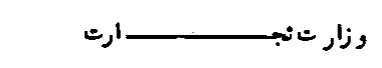 & \\
\hline & & & & 1) & & & \\
\hline
\end{tabular}


$1-1-r-r$

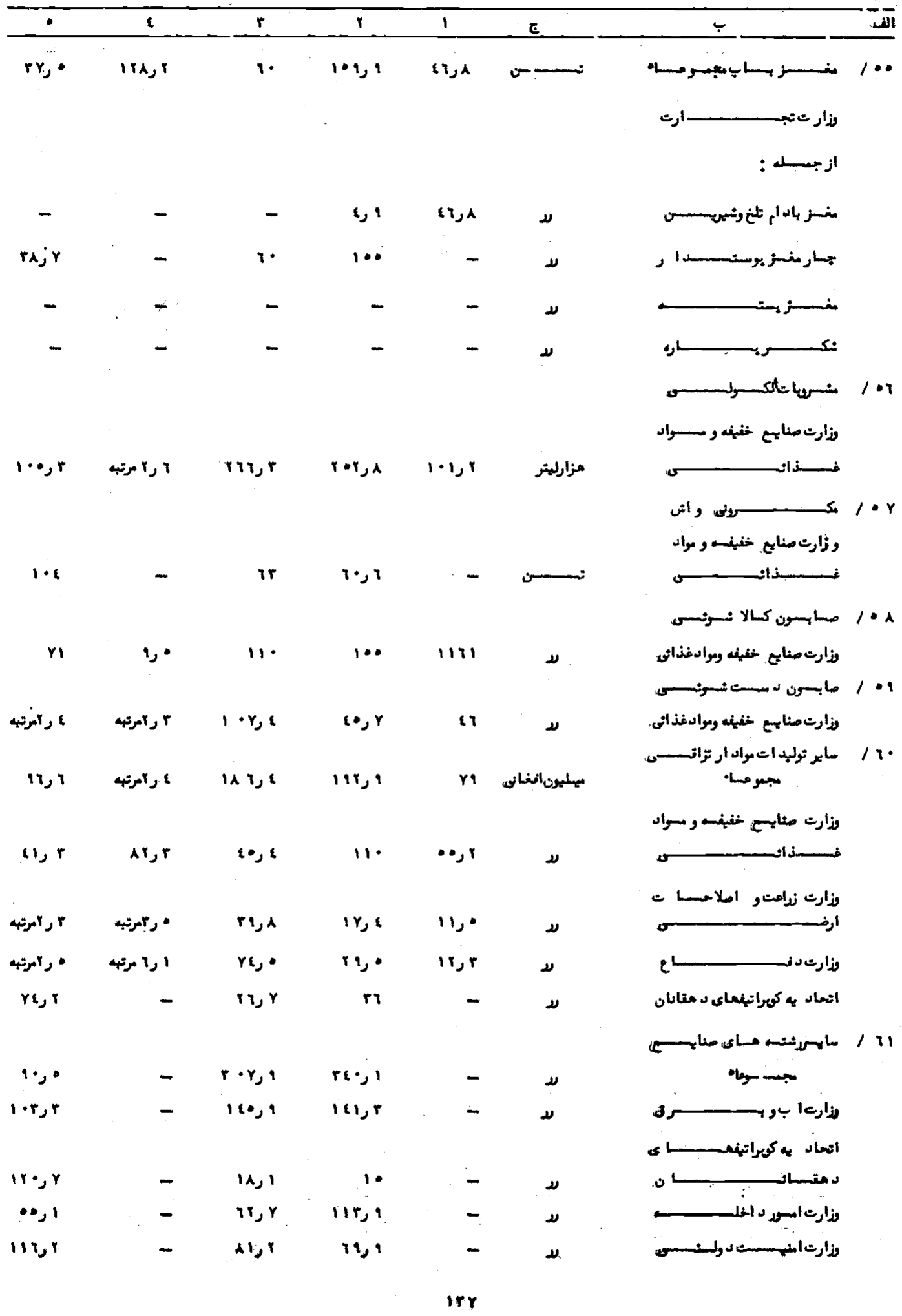




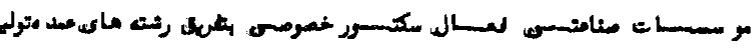

\begin{tabular}{|c|c|c|c|c|}
\hline IF1 & $\operatorname{lrm}$ & Iror & كسـامس سـس & بسار، \\
\hline AI & Al & r & 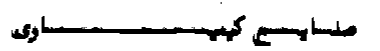 & 11 \\
\hline 1 & 1 & 11 & و اد ستساطعسمسالسستس & 11 \\
\hline $6 \cdot$ & 4 & $1 \cdot$ & ملاه مانهسن ساز سوللزكسـارس. & $/ r$ \\
\hline 1 & 1 & 1 & 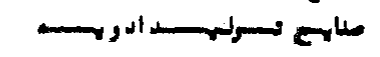 & 11 \\
\hline $1 \cdot$ & 1 & 1 & 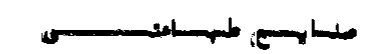 & 1 \\
\hline $1 \cdot$ & 14 & 1 & 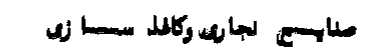 & 11 \\
\hline 119 & int & $r$ & 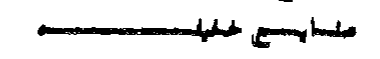 & $/ Y$ \\
\hline 118 & 11. & 01 & سك مواد اروسرإ:لسسيس & $1 \wedge$ \\
\hline 19 & 1. & 1 & $c$ & 11 \\
\hline 174 & ter & 108 & ed & \\
\hline
\end{tabular}

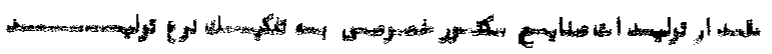

Ios I- Y. Y r

\begin{tabular}{|c|c|c|c|c|c|c|c|}
\hline \multicolumn{2}{|c|}{ لهيد } & \multirow{2}{*}{ 1Р99 } & \multirow{2}{*}{ IrIA } & \multirow{2}{*}{$I r: Y$} & \multirow{2}{*}{ واهيا سي } & \multirow{2}{*}{ Lat } & \multirow{2}{*}{ ond } \\
\hline Irin & IreY & & & & & & \\
\hline$=\quad$ & 1 & $F$ & 1 & I: & 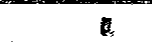 & & 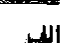 \\
\hline $11 *, y$ & $Y 0,1$ & 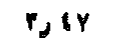 & $r$ & 4 & 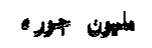 & 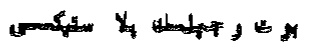 & 11 \\
\hline 111,1 & נינו & $Y Y Y, Y$ & $91 \cdot, 7$ & $11 Y$. & س & t & 11 \\
\hline$=$ & $=$ & $=$ & 1216 & 11,1 & 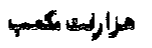 & رإه- & 1 \\
\hline$Y 1,1$ & 111,1 & $=1,1$ & Y9 & $\left|y_{y}\right|$ & un & ظظير & 11 \\
\hline$A T, P$ & $=$ & 1 & 1,1 & $\cdots$ & 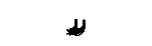 & سائمر & 1 \\
\hline 118,1 & $10, \lambda$ & $11, \lambda$ & $\gamma_{\lambda} \lambda$ & Al & ע & رئ. & 11 \\
\hline 100 & 12 & 1 & 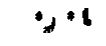 & 1 & مراريطر e & & $1 v$ \\
\hline 181,1 & $Y, Y$ & 1 & 1,6 & 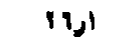 & 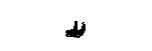 & $m$ & $1 \mathrm{~A}$ \\
\hline 10,1 & $A 1,1$ & irit & $1 P A^{\circ}$ & 1111 & ת & & 11 \\
\hline - & - & $=$ & 16, & $\because 4,1$ & cons & & 110 \\
\hline- & $=$ & - & bo & 48 & لـ & اليـــ & \\
\hline- & - & - & 1, & $16 \% 1$ & עل & 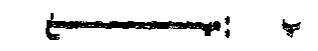 & \\
\hline$(A, \mid$ & $4 \mu$ & $\| h_{j} r$ & 180,9 & $\boldsymbol{r}$, & مليمسالنياد & ate ent & 111 \\
\hline$r q, 1$ & ارب مرب4 & 11,1 & $\| y_{j} \mid$ & $p, r$ & $y$ & الف : & \\
\hline 106,1 & " & $\left|r_{j}\right|$ & $\mid Y, Y$ & 1 & ע & 4 & \\
\hline $111, y$ & - & 1,1 & 1,1 & $=$ & 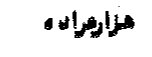 & 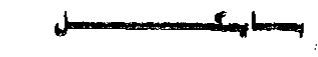 & 111 \\
\hline 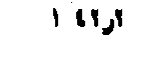 & $Y P_{j}$ & $1\left|1 Y_{j}\right|$ & $1 \cdot p 1,1$ & $\eta \cdots$ & $v=-d$ & sist & 117 \\
\hline
\end{tabular}


Y-Y-Y

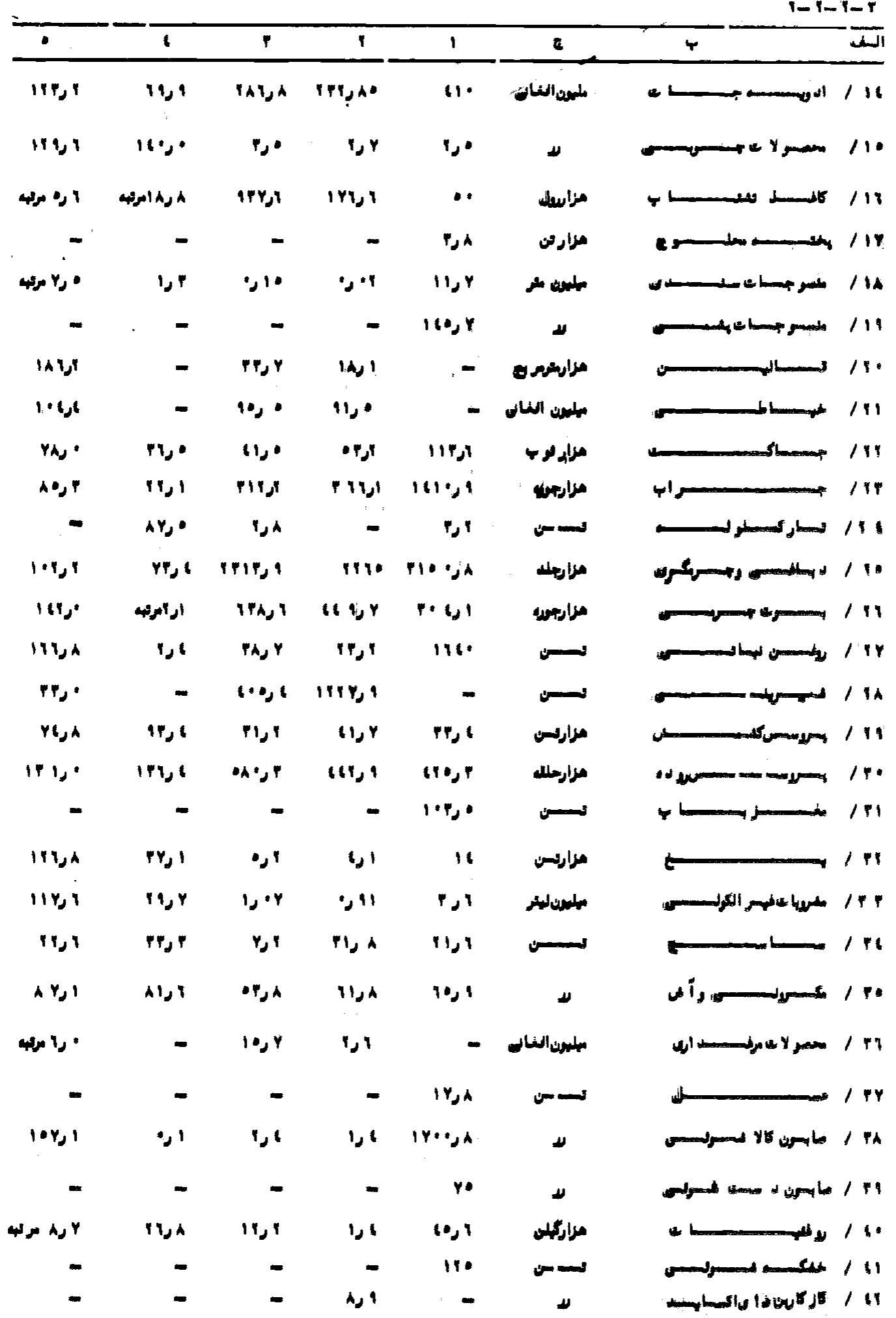




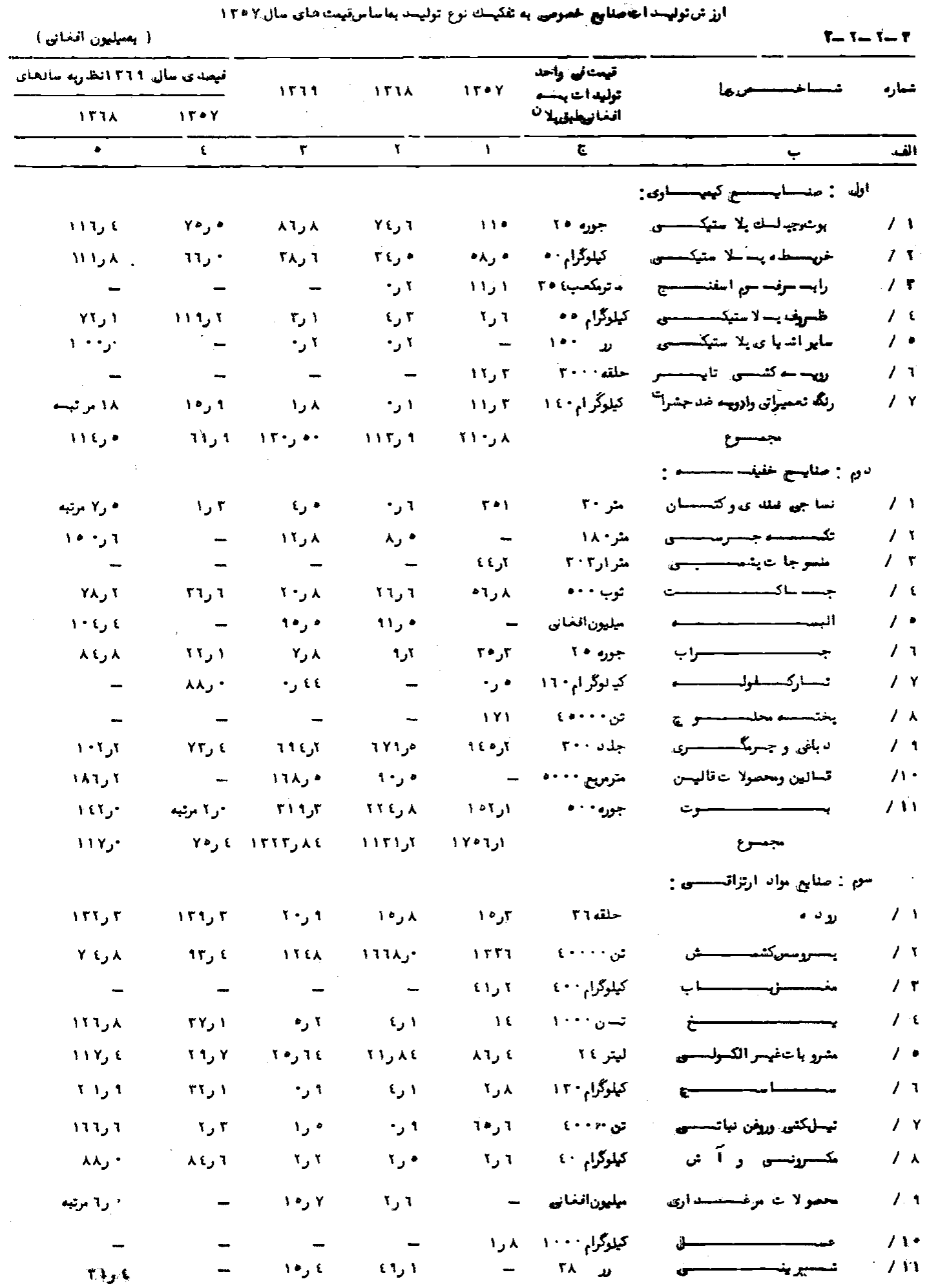


P-1- I-

\begin{tabular}{|c|c|c|c|c|c|c|c|}
\hline - & 1 & $r$ & 1 & 1 & 8 & 4 & الستض \\
\hline A גנ مرته & • & •, & كוبر & $\bullet 1$, & كيلركار r & صساتحن كالا نسسرولس- & 111 \\
\hline - & - & - & - & P. & 11 & كا هن د سـت فـرئس & / Ir \\
\hline$y \cdot J \cdot$ & Ar, $t$ & Irro, $A *$ & IrISJAT & 111 & & نجمس & \\
\hline
\end{tabular}

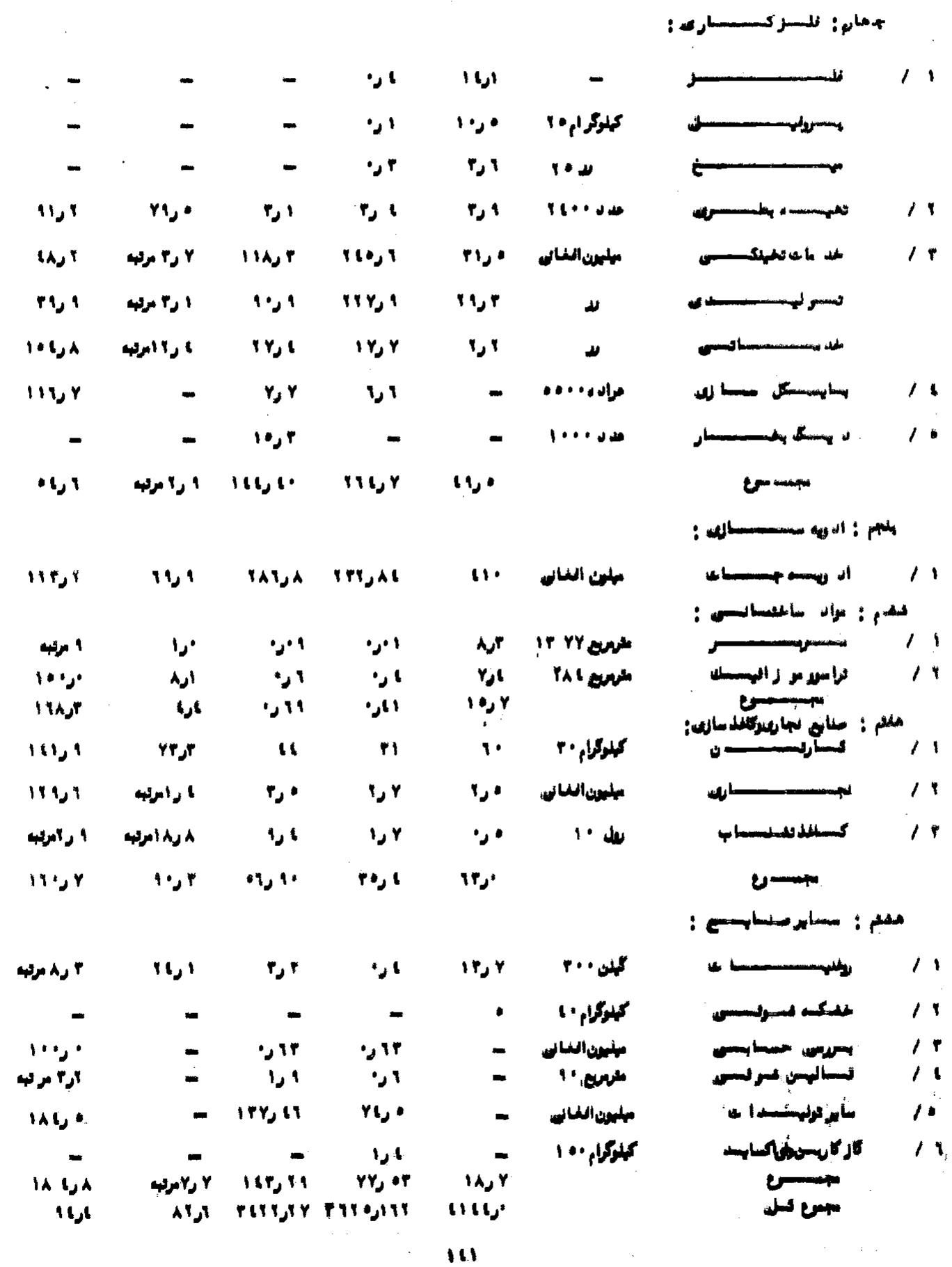




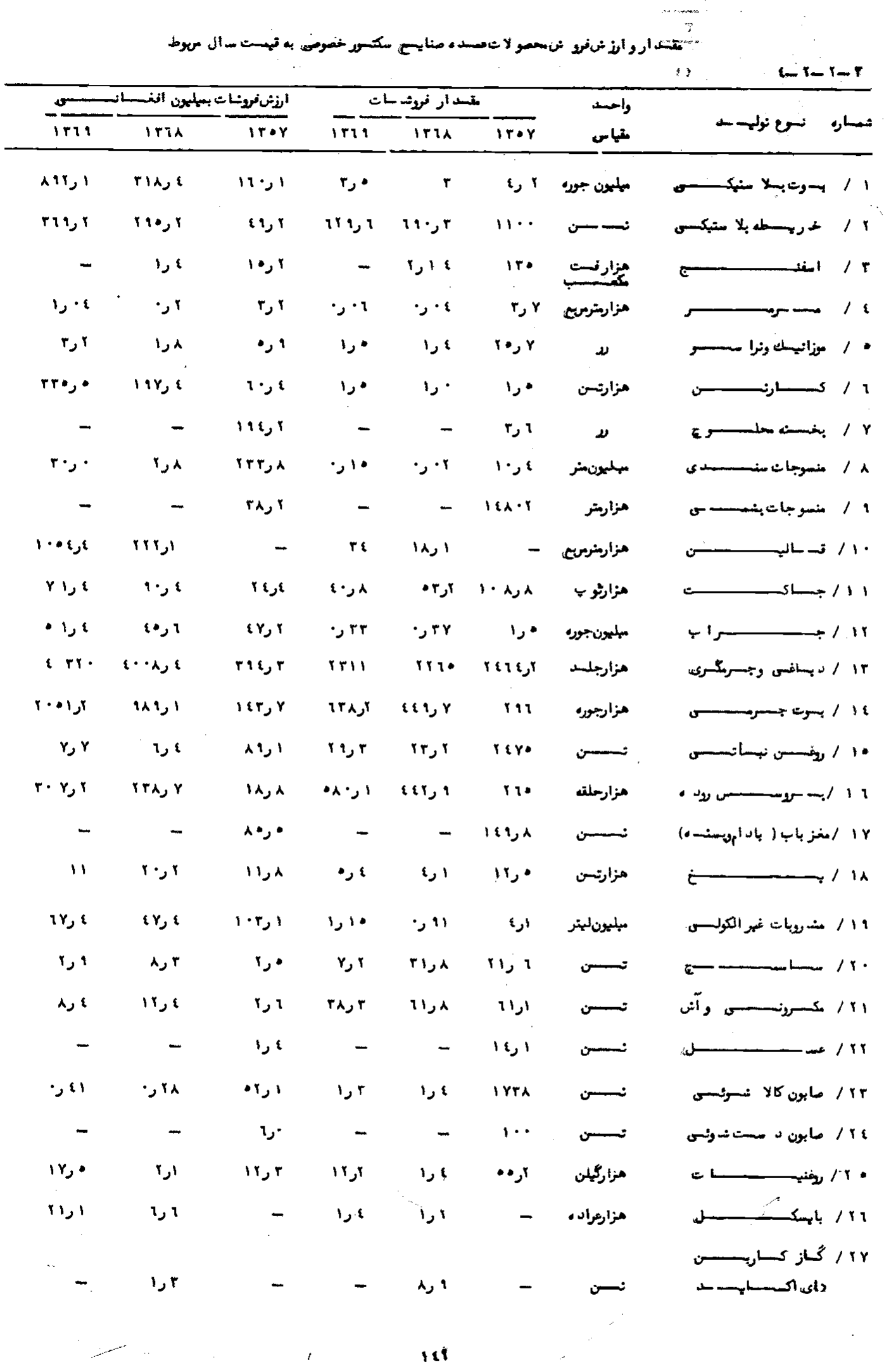




\begin{tabular}{|c|c|c|c|c|c|c|}
\hline \multicolumn{7}{|c|}{ 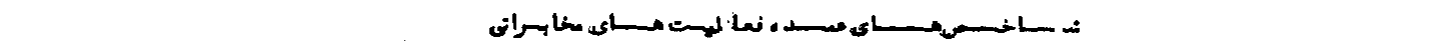 } \\
\hline \multicolumn{2}{|c|}{ 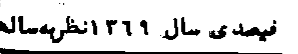 } & \multicolumn{3}{|c|}{ سالعهـا ي } & \multirow{2}{*}{ واحس } & \multirow{2}{*}{ 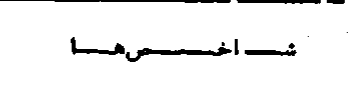 } \\
\hline iris & $\overline{I r \cdot Y}$ & 1819 & iris & $1 T \cdot Y$ & & \\
\hline $1 \cdots$ & $A \cdot, Y$ & หq & rq & raq & بسب & بستسه خانسه د ر اخهر ســالد \\
\hline 1,1 & $18, y$ & rerto & $r \wedge r \cdot r$ & YYIYT & مزارنطس & 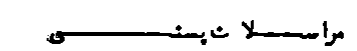 \\
\hline$\cdot 1,1$ & $|Y|, \cdot$ & -rqry, & $1 \cdot(111, \lambda$ & $\operatorname{ritag}$ & مزارهخابره & مخســابـره تيلفسـو نـ \\
\hline $1 \cdots, 2$ & $10\{1$ & rrrie & rriye & $\operatorname{ring}$ & بايحس & 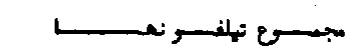 \\
\hline & & & & & & م جموع د سنكاه مائ سخابره بيى \\
\hline $1 \cdots$ & - & $r \cdot \lambda$ & $r \bullet \lambda$ & - & $\nu$ & سيح \\
\hline $1 \cdots$ & - & $r$ & r• & - & $\nu$ & مجمع د ستكاه مايبرد كاست راد يو \\
\hline $1 \cdots$ & - & 19 & 19 & - & $\nu$ & سجمو د سنكامهايفرستند هتلوغنون \\
\hline $11, x$ & كروتمرتب & $\cdot[\lambda$, & $(19,1$ & $r \bullet \bullet r$ & مزارفطس & 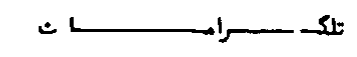 \\
\hline$\cdots$ & • مان مرتب & $I Y Y$ & IYY & $Y \cdot, \cdot$ & 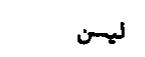 & تلكs_ \\
\hline IY, & كرب مرنبه & $A \because, r$ & $11 \cdot, \mathrm{a}$ & $r n, r$ & ل ليون افغاني، & موايد خد مات مخابسراتحـــــ \\
\hline $9 \cdot, \mathrm{l}$ & $\| A, Y$ & $A T, q$ & 11,1 & Yr & $\nu$ & بَسبـ \\
\hline $11 \cdot, \cdot$ & 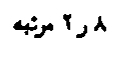 & $\cdot[a, i$ & $q 9, Y$ & 198 & $\nu$ & 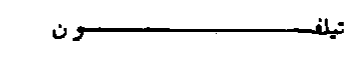 \\
\hline $18 r, 1$ & r r r مرتب & $r \bullet \bullet, q$ & $r \cdot A, \lambda$ & $Y Y, Y$ & $\nu$ & 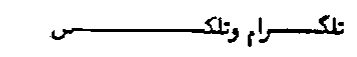 \\
\hline$r, \cdot$ & 1,9 & 1,1 & $\| Y, \lambda$ & $(1, r$ & $\nu$ & عوايد اسع ســ اريد \\
\hline
\end{tabular}

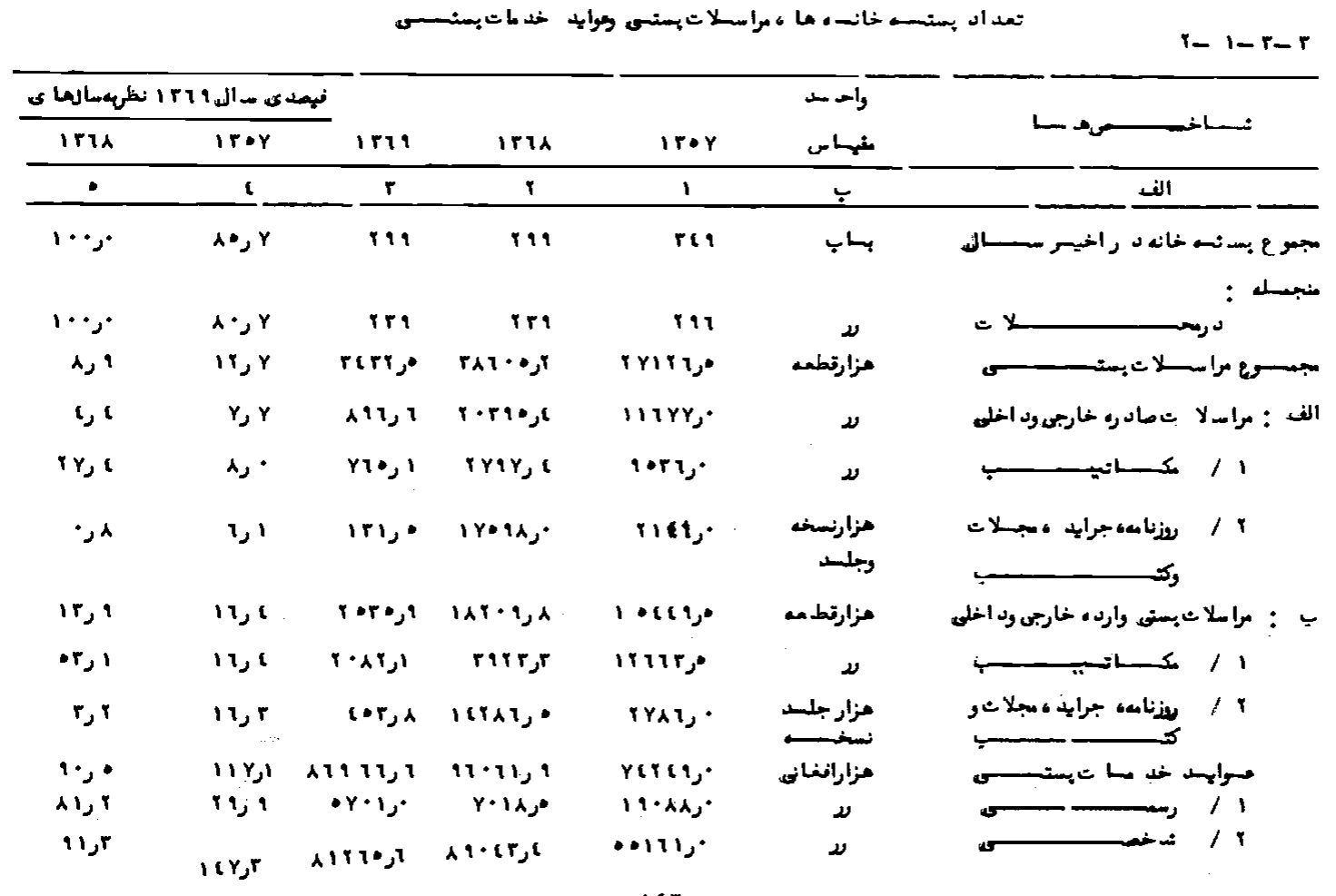




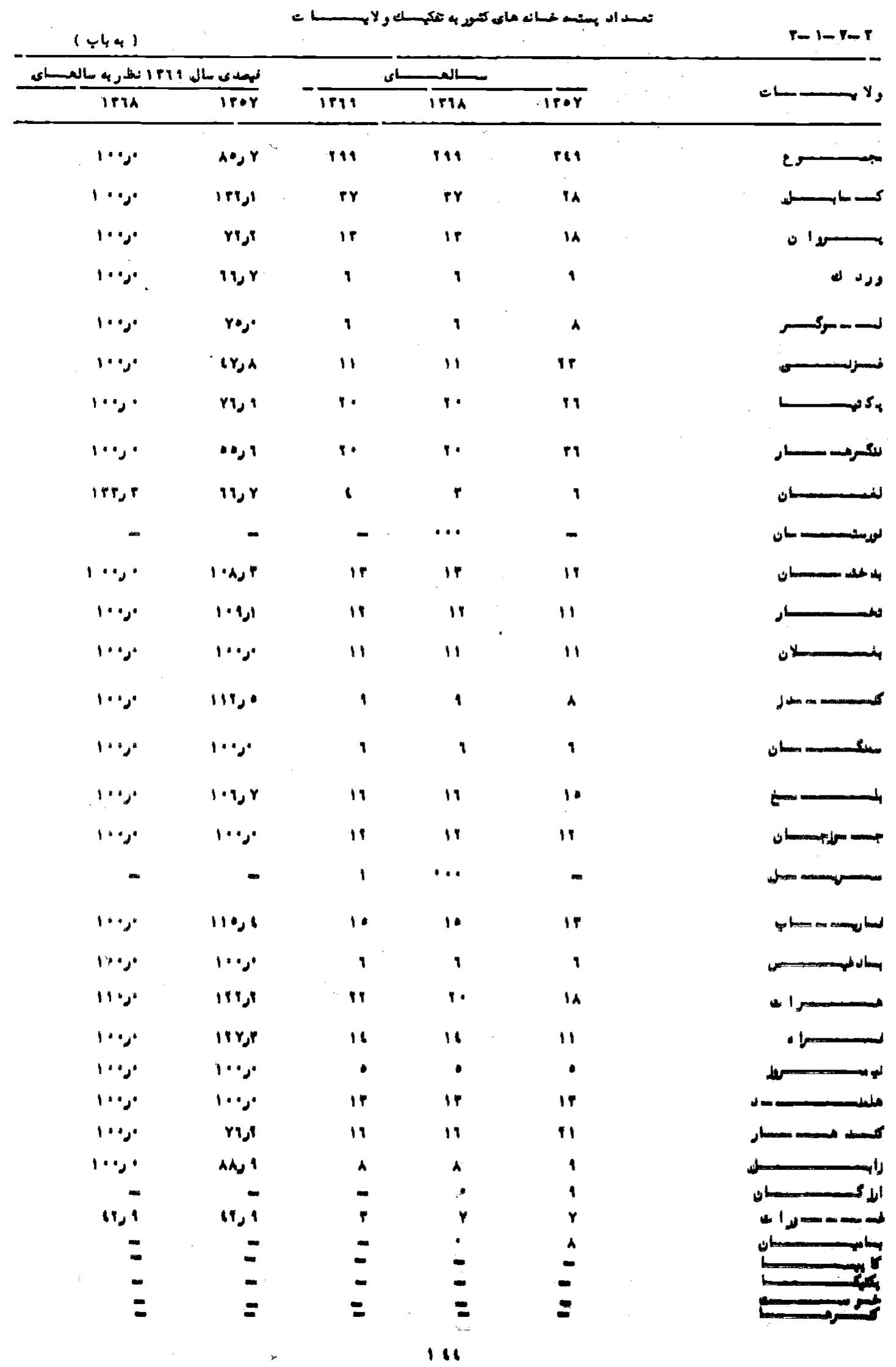




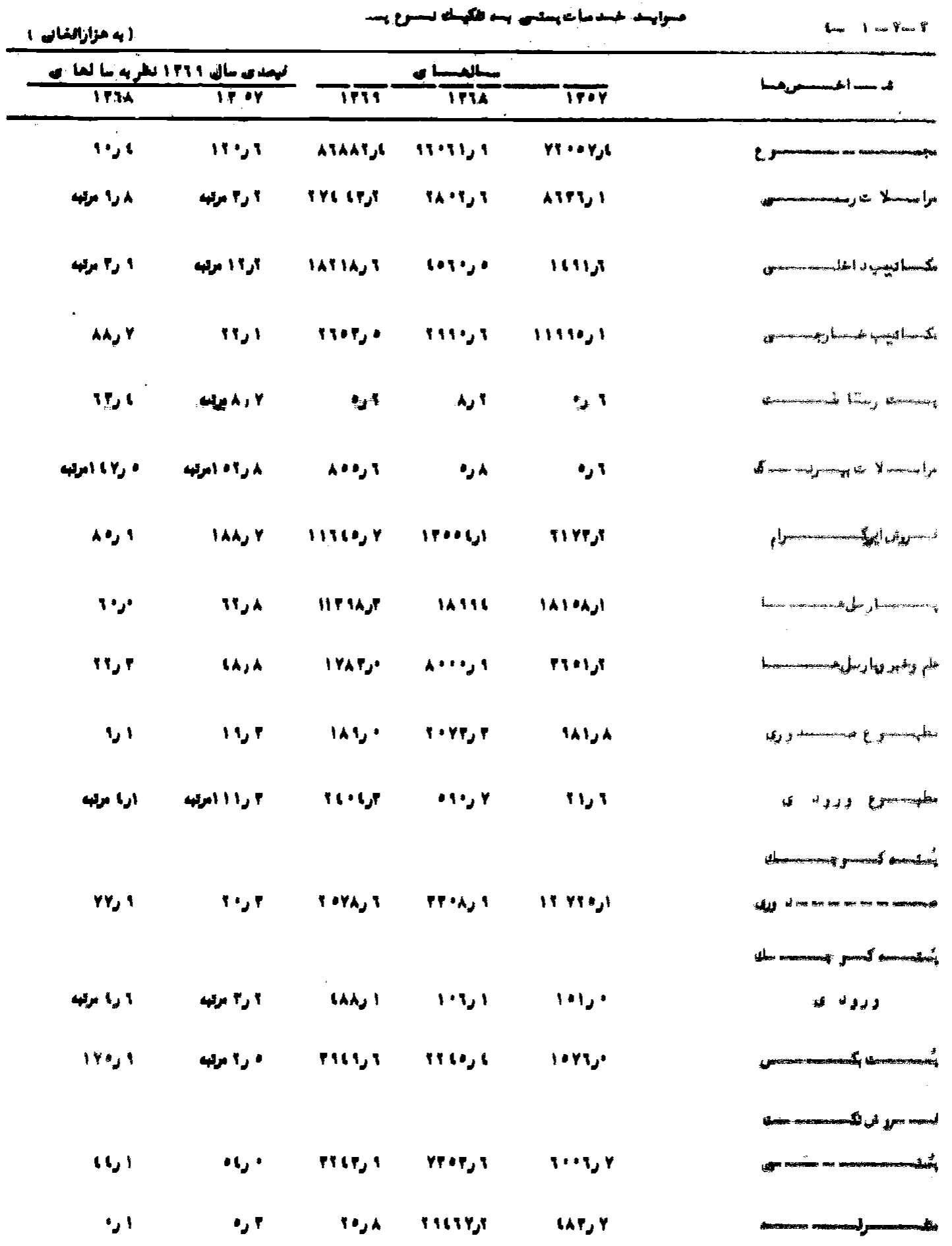




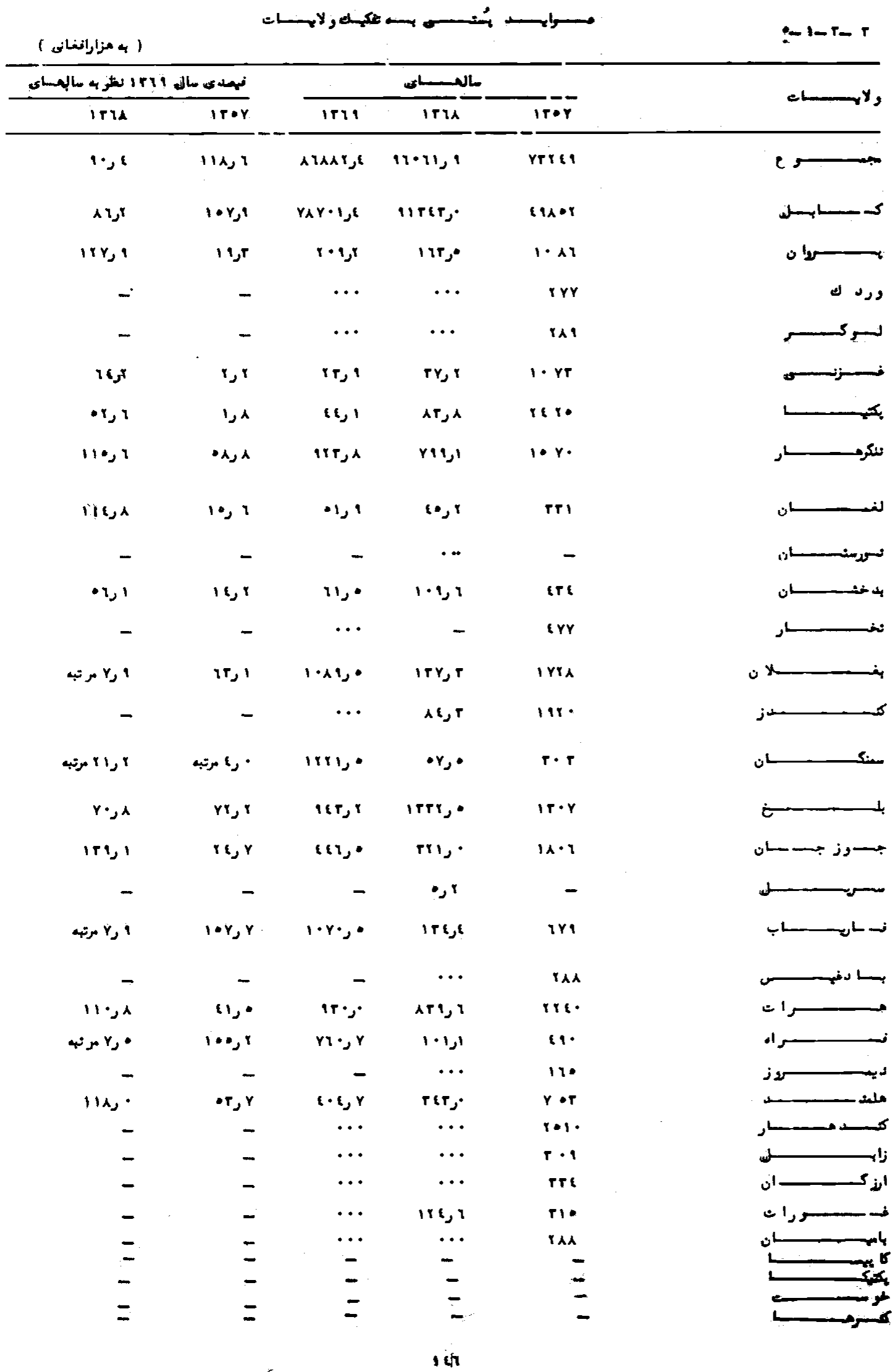




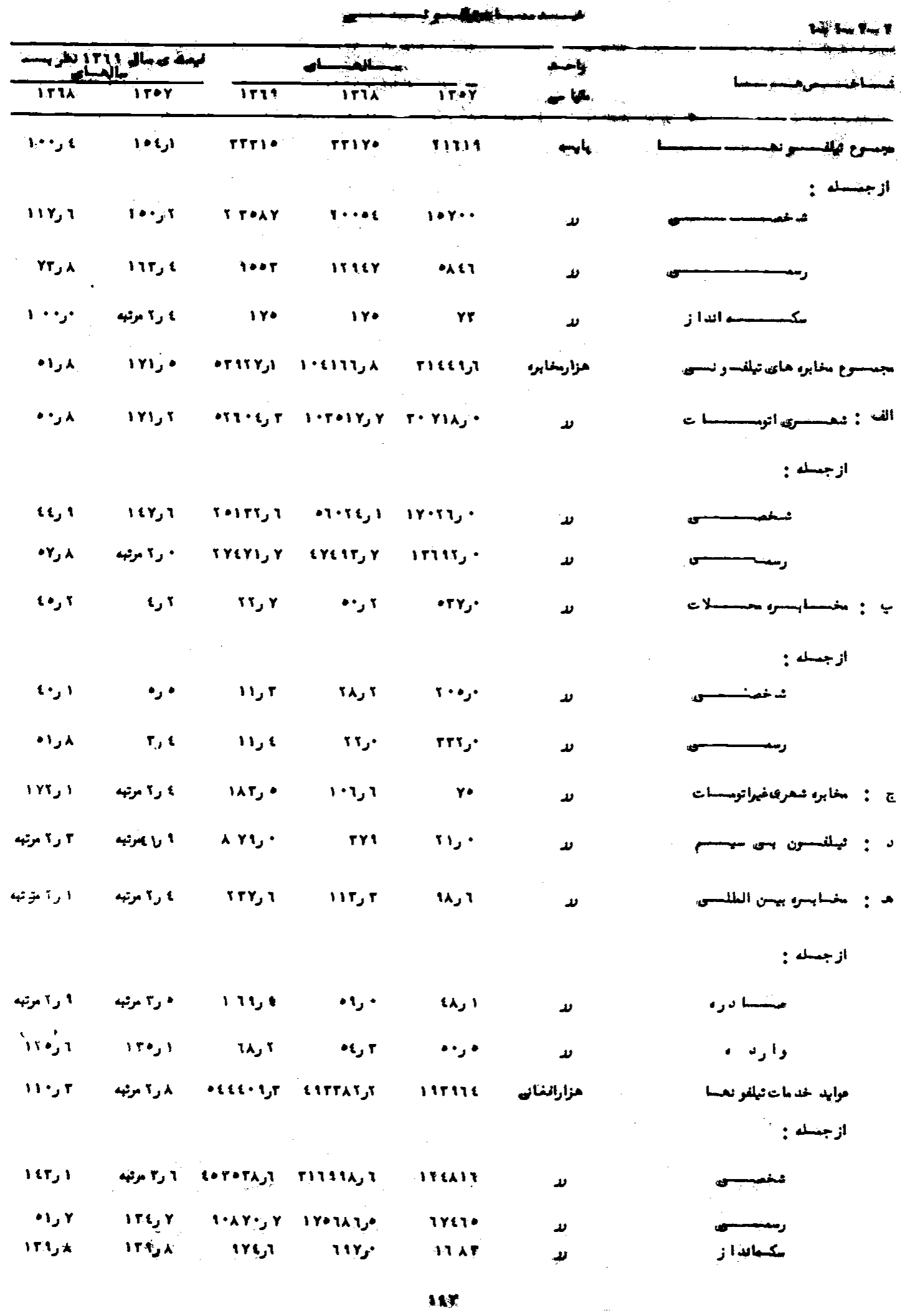




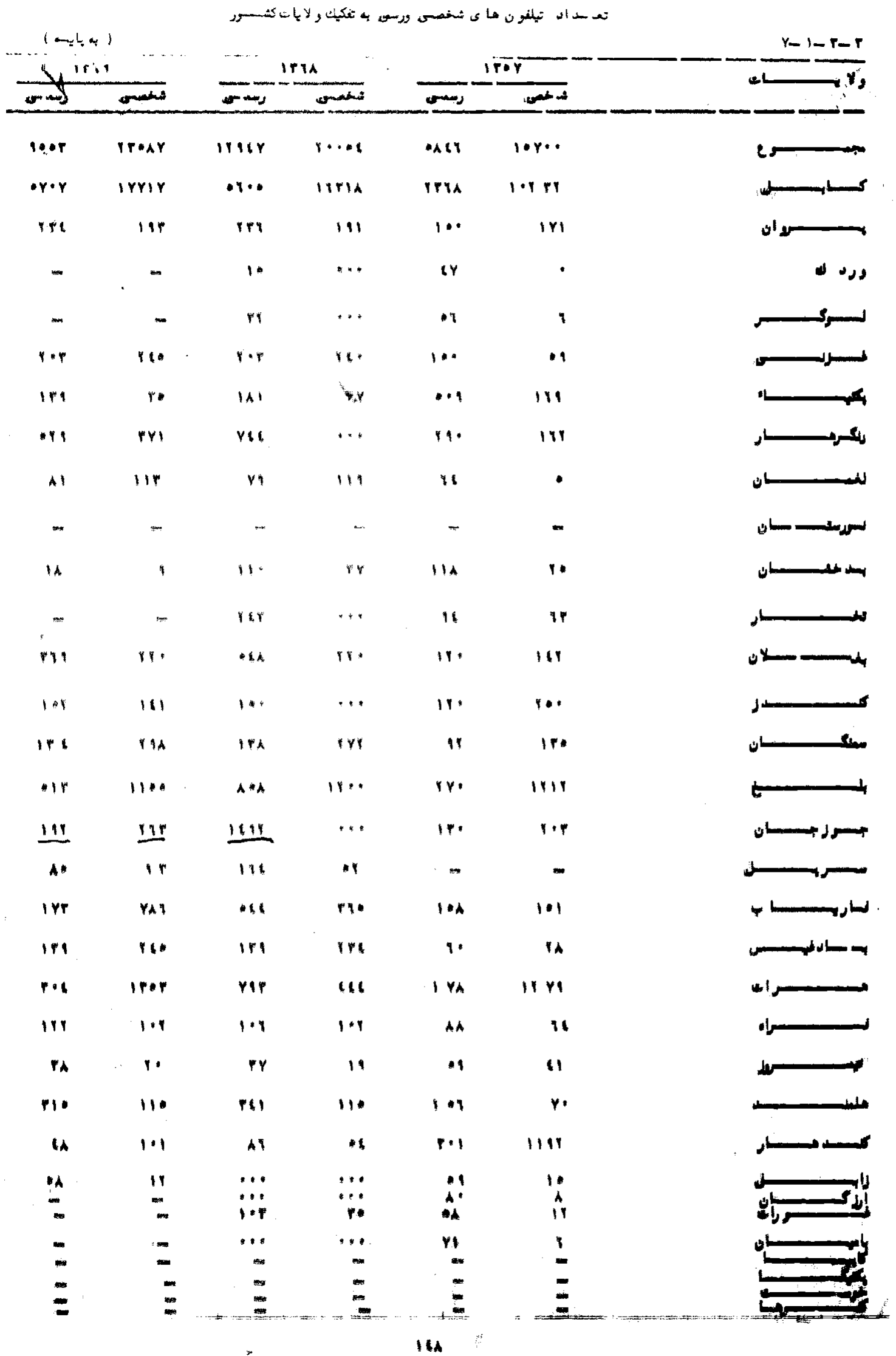




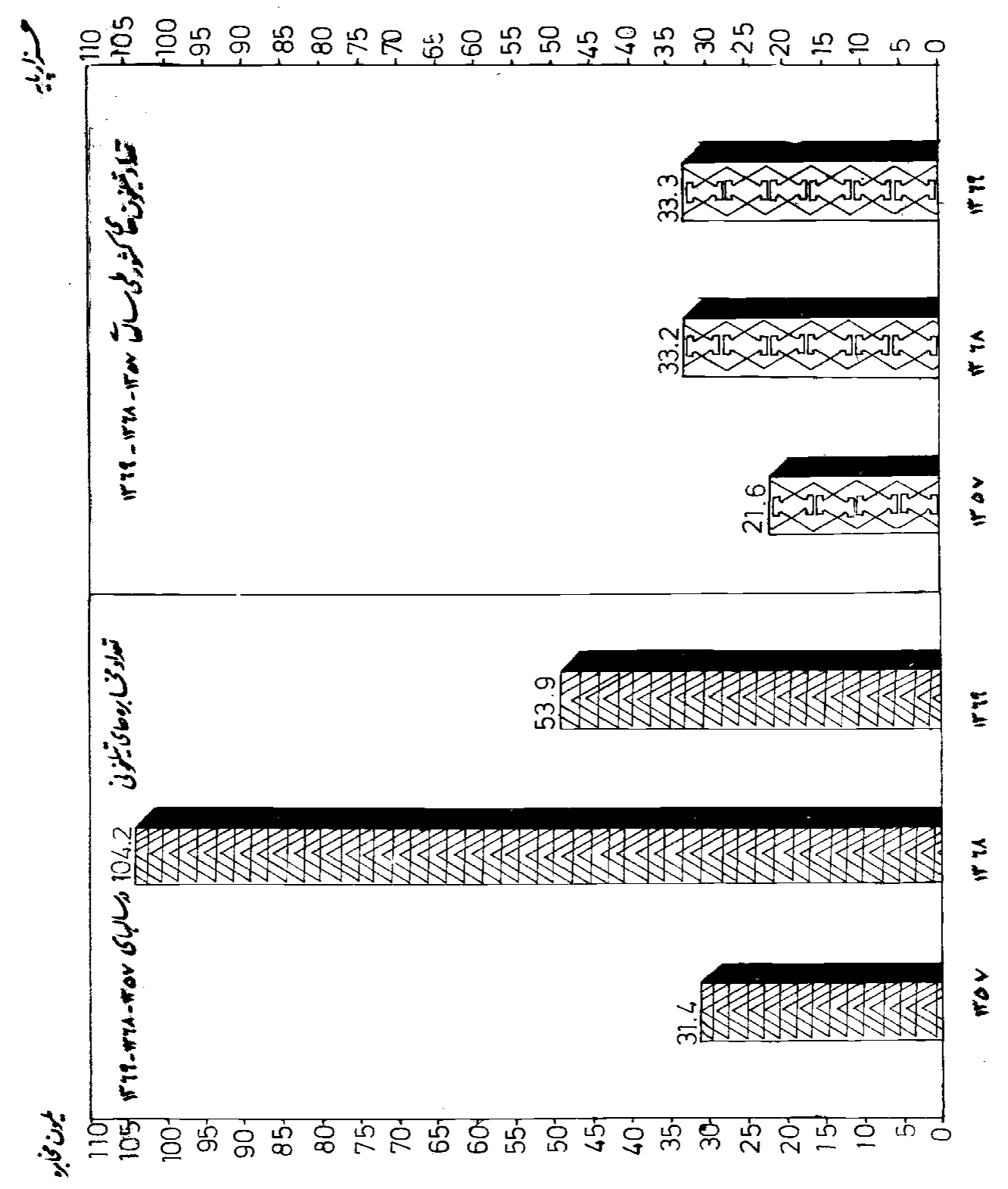




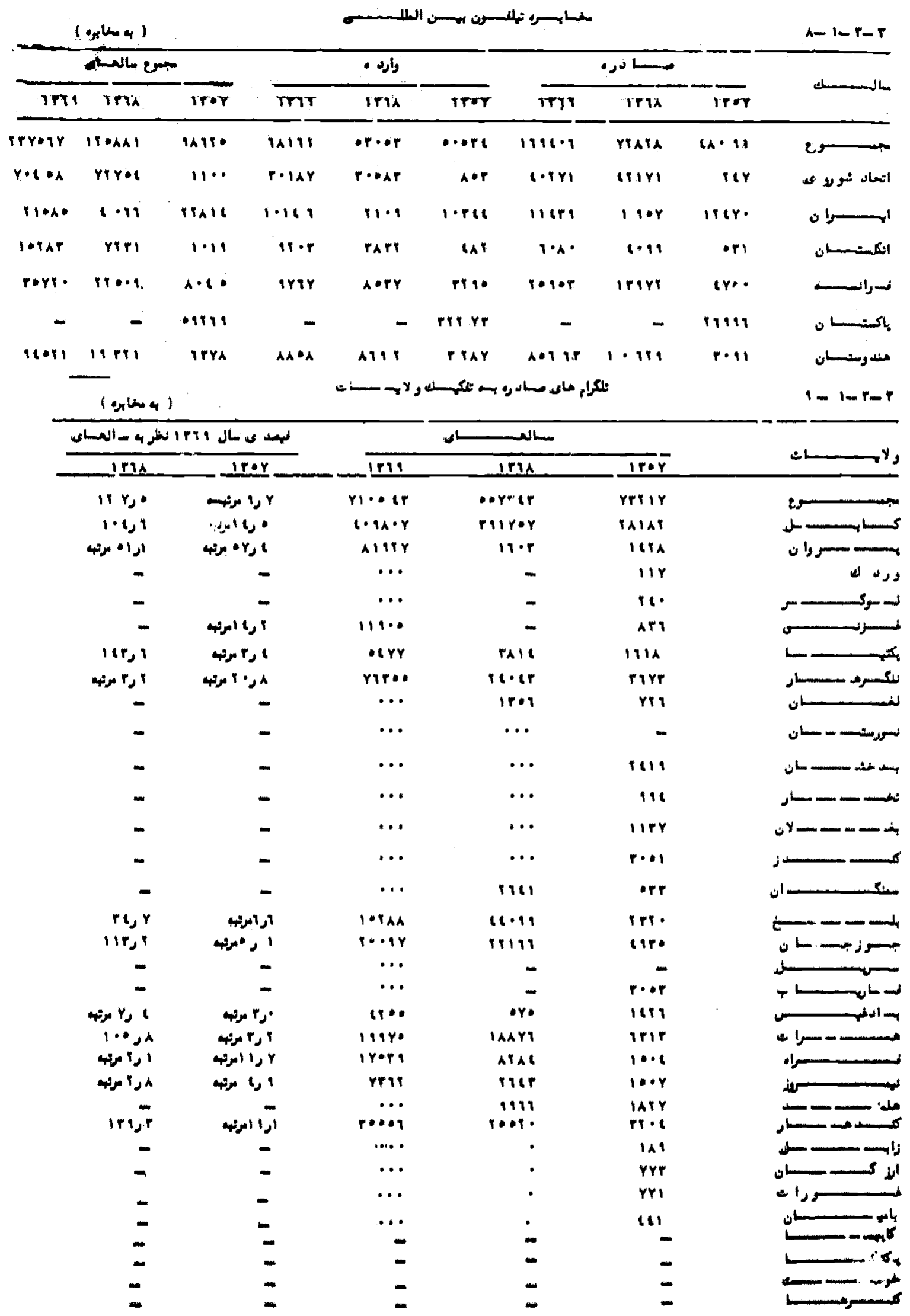




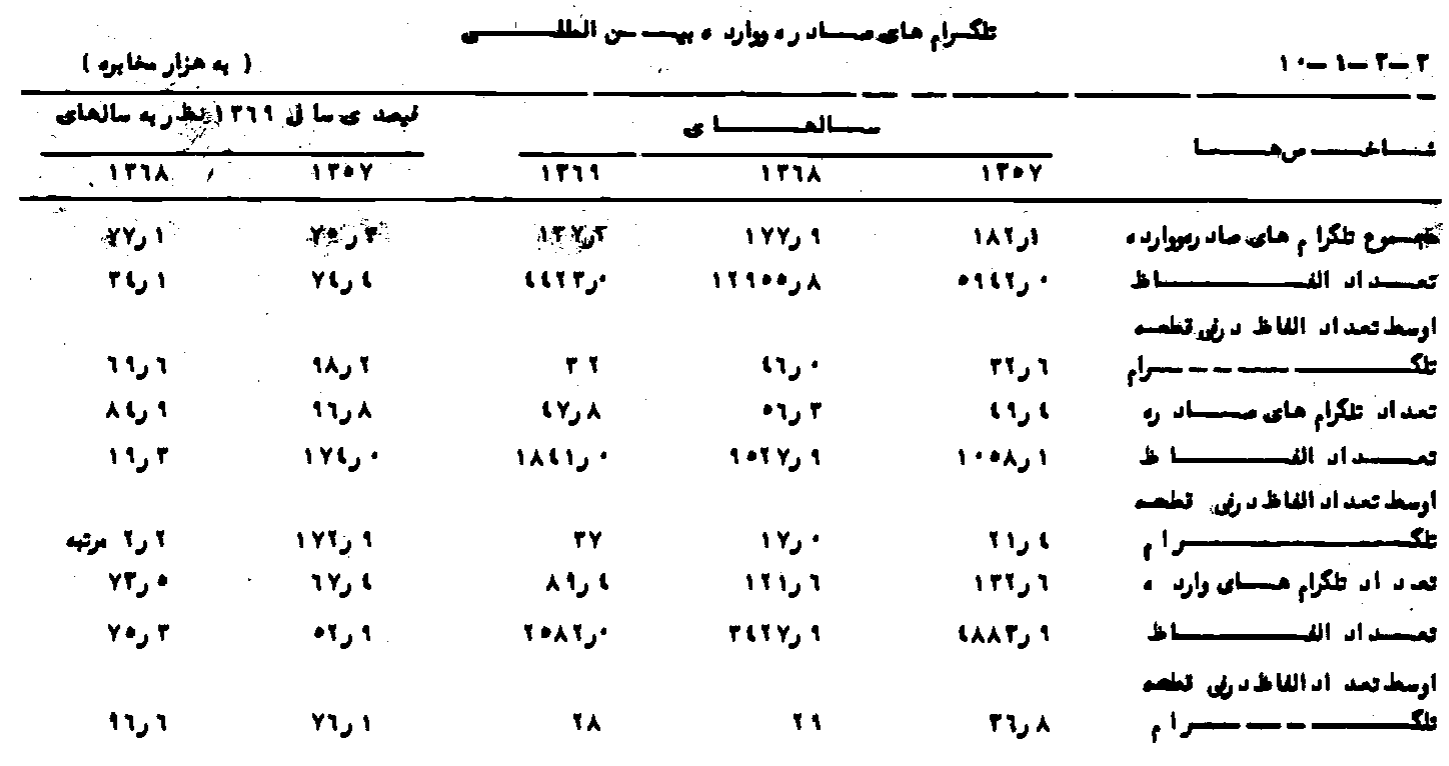

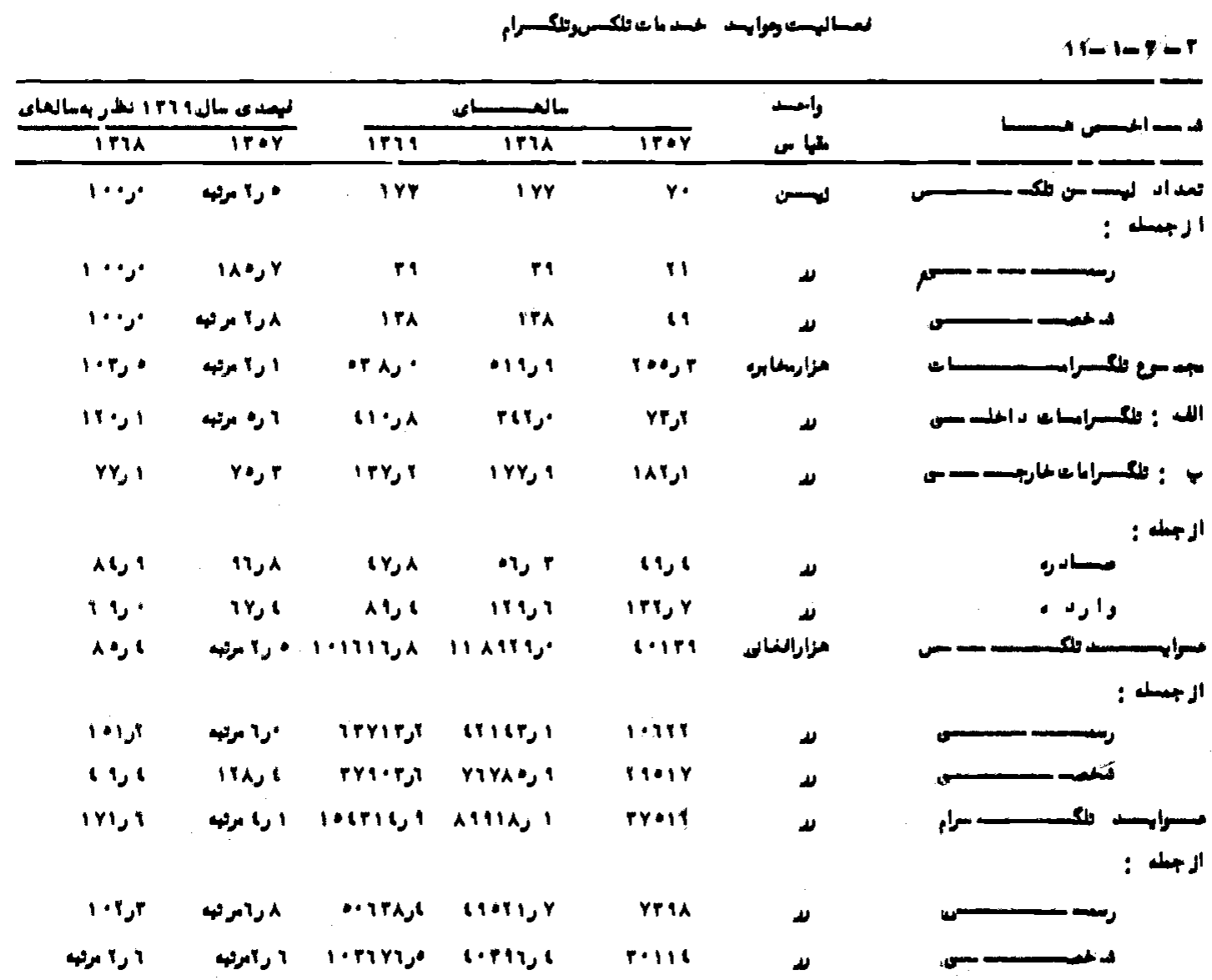




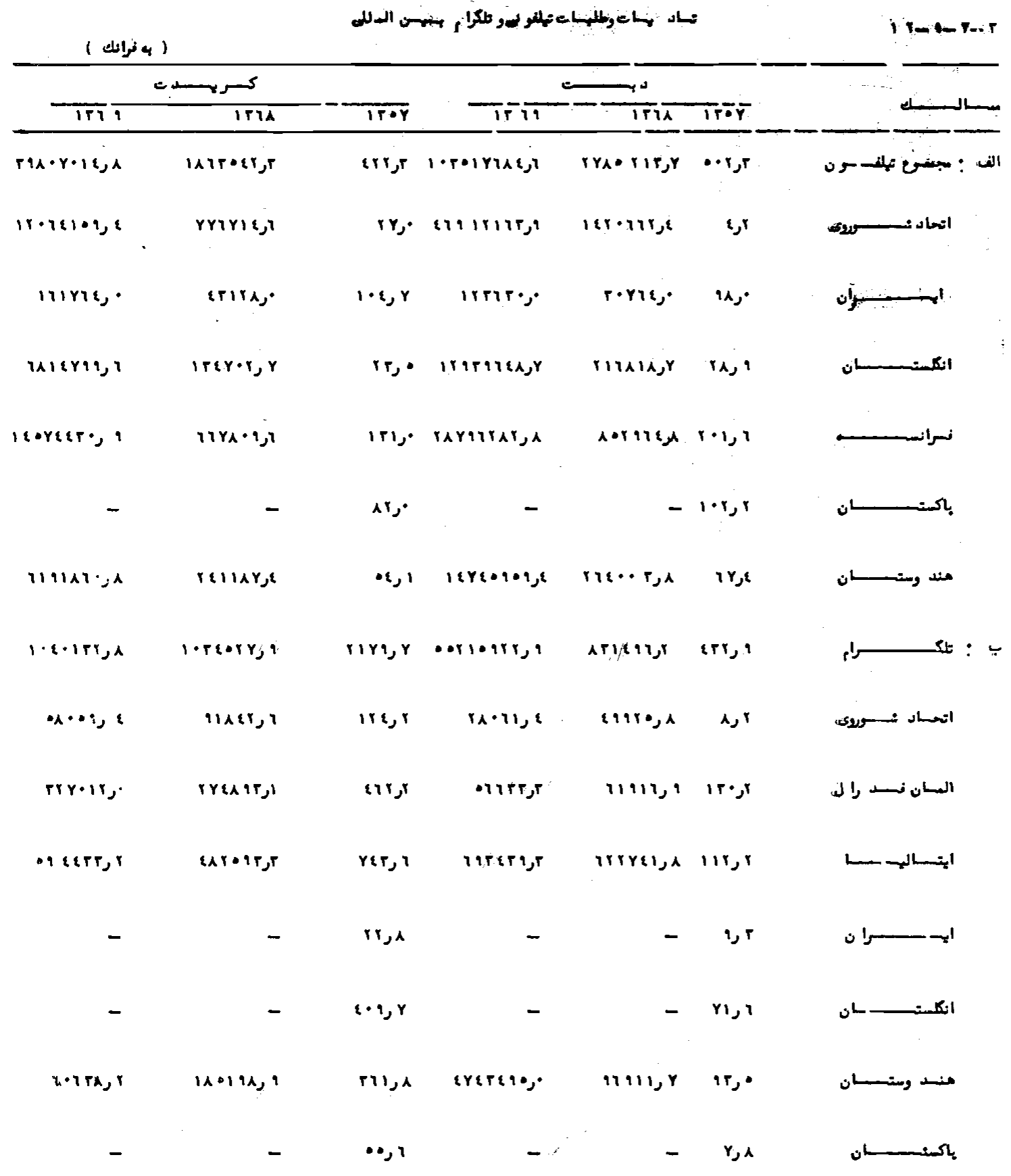



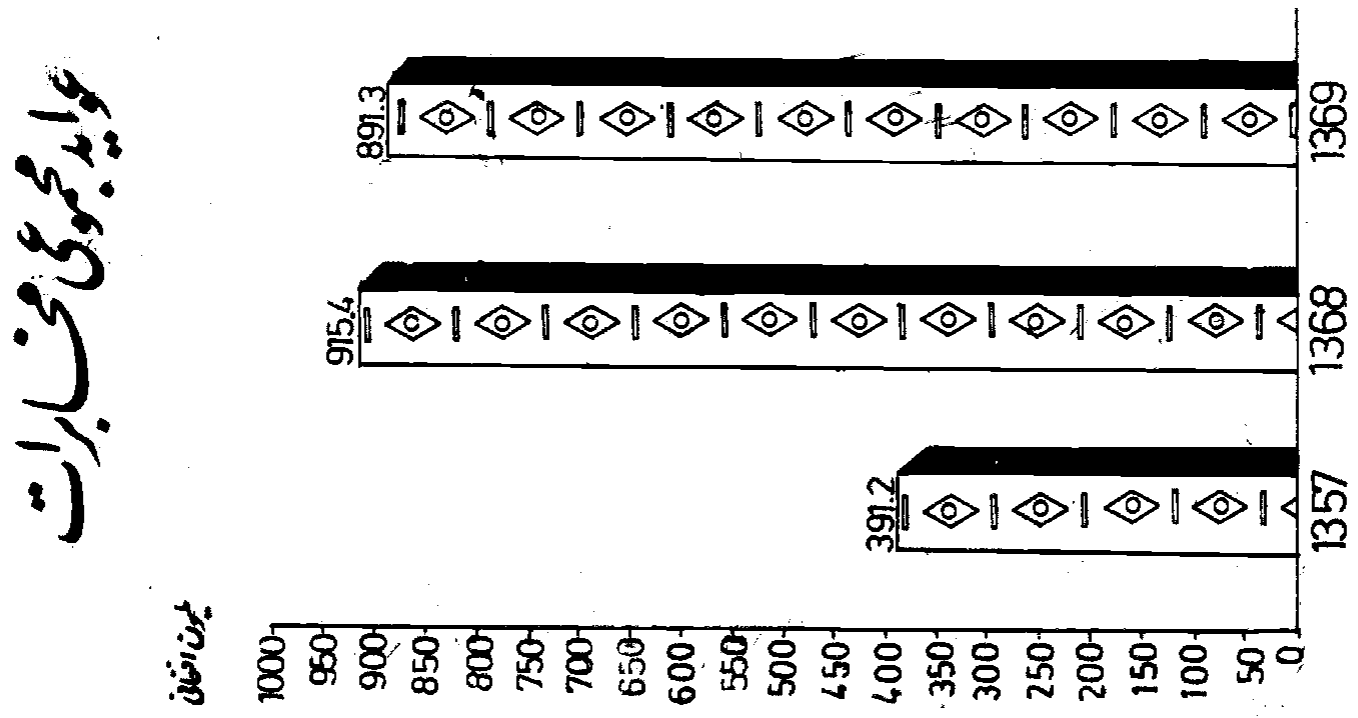


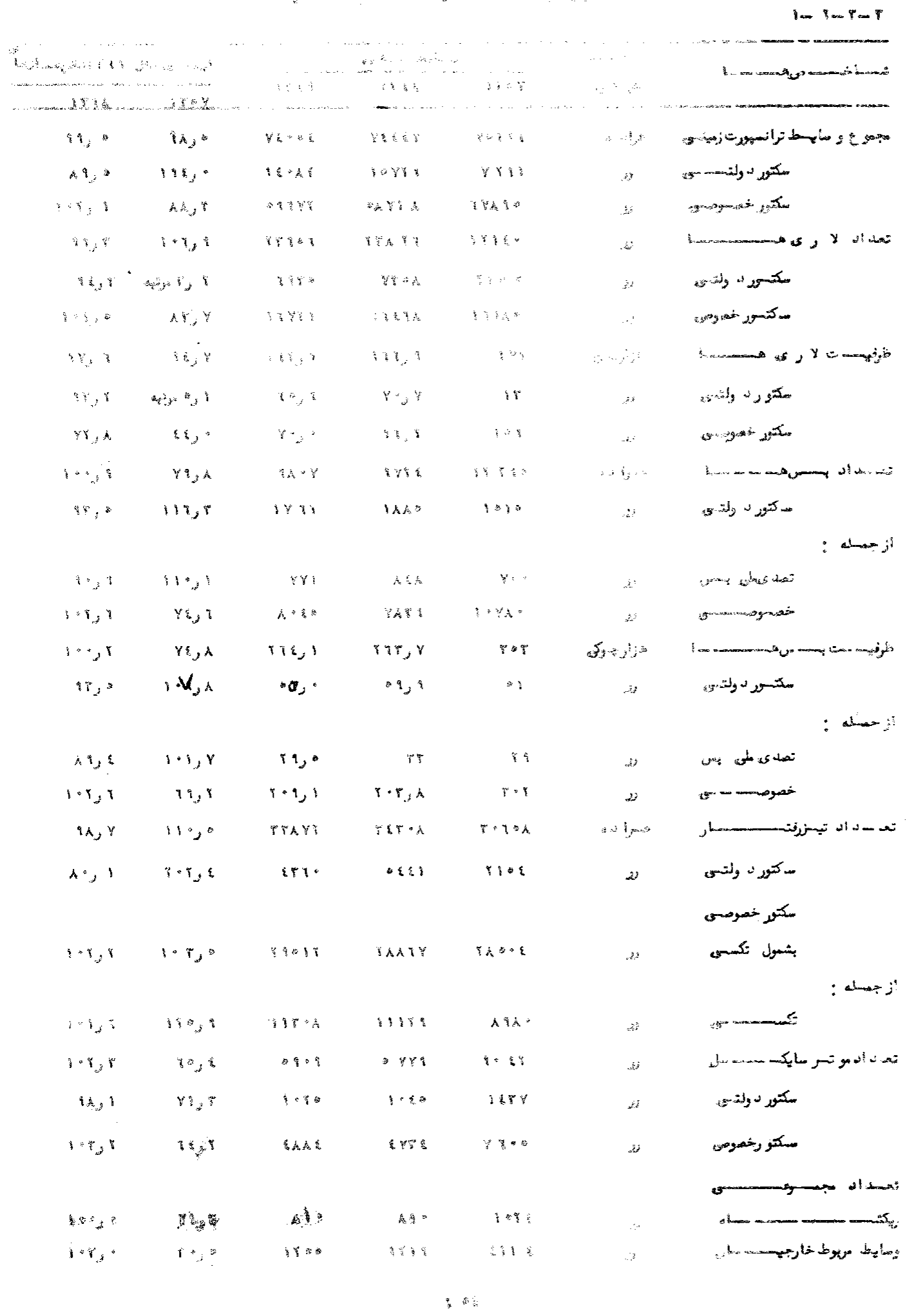




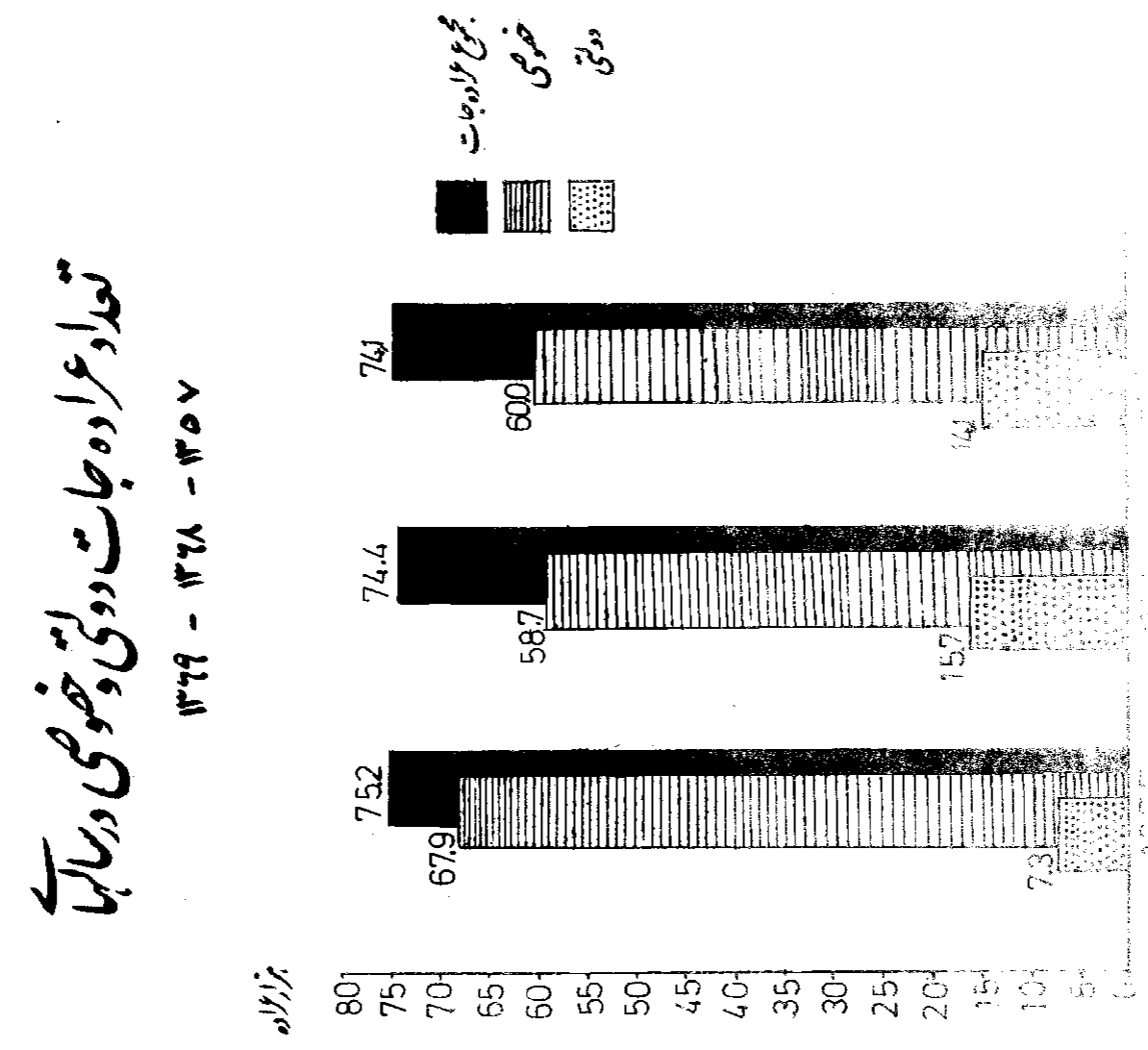

$1 * 0$ 


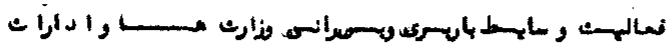

r-I-r-T

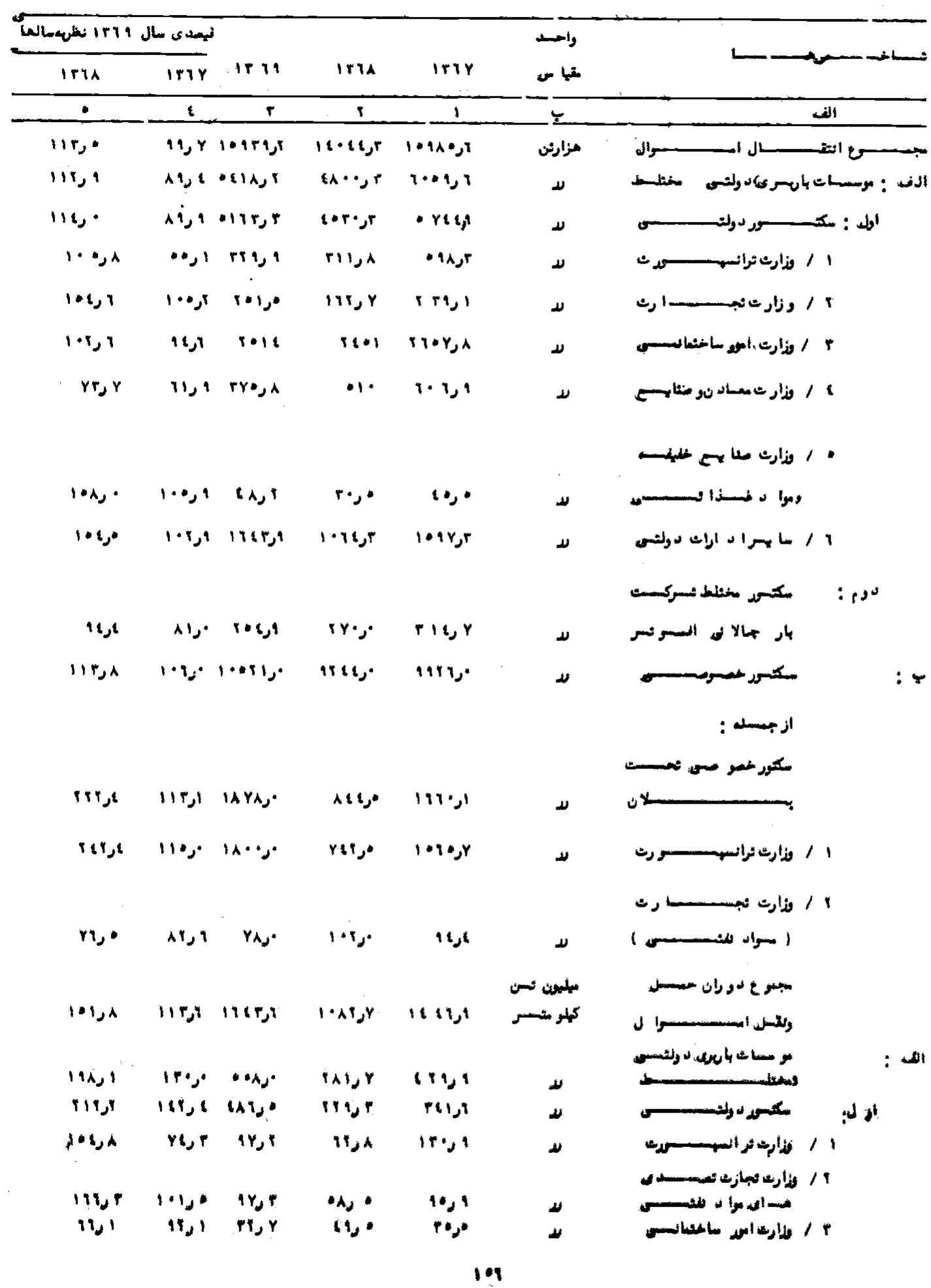




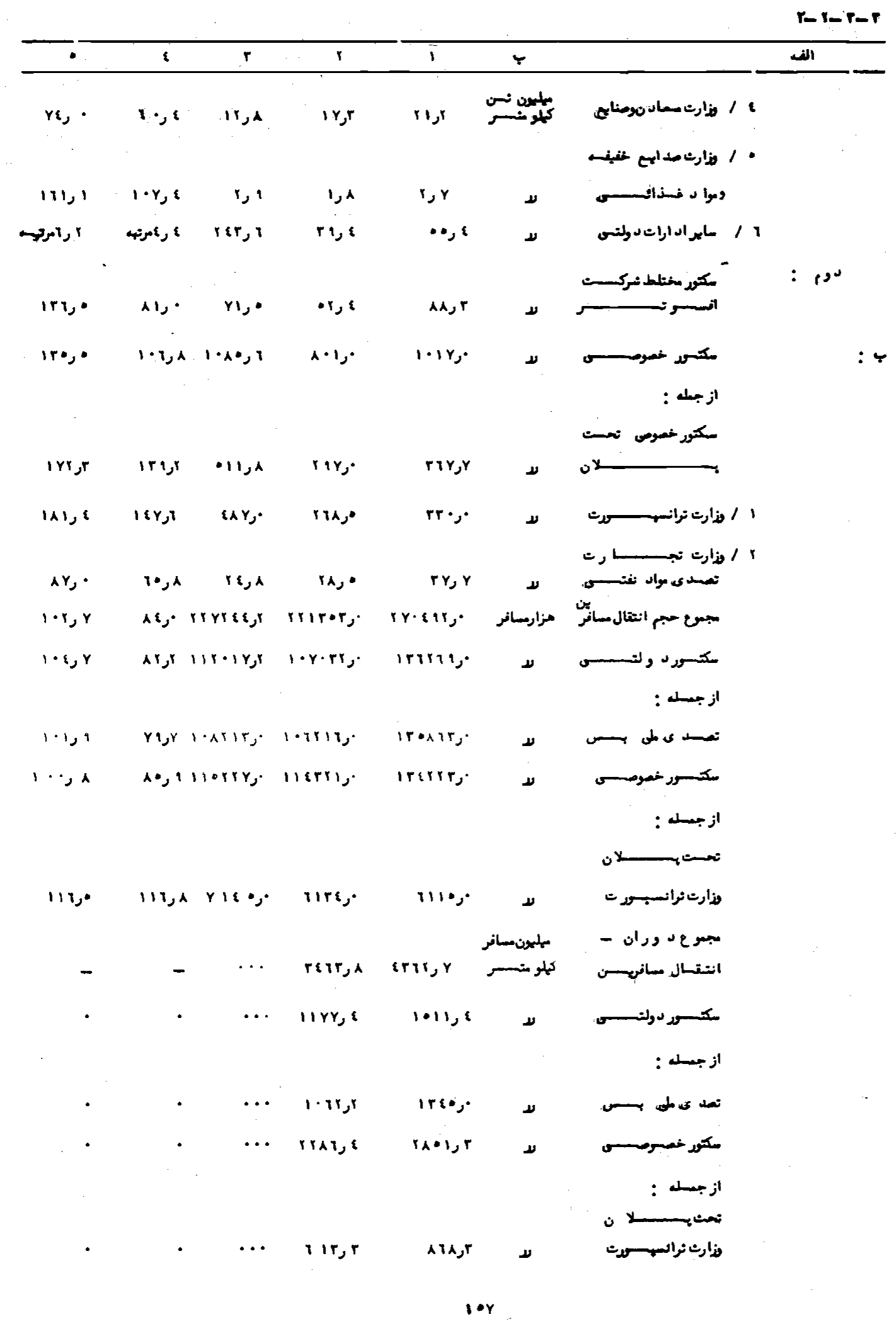




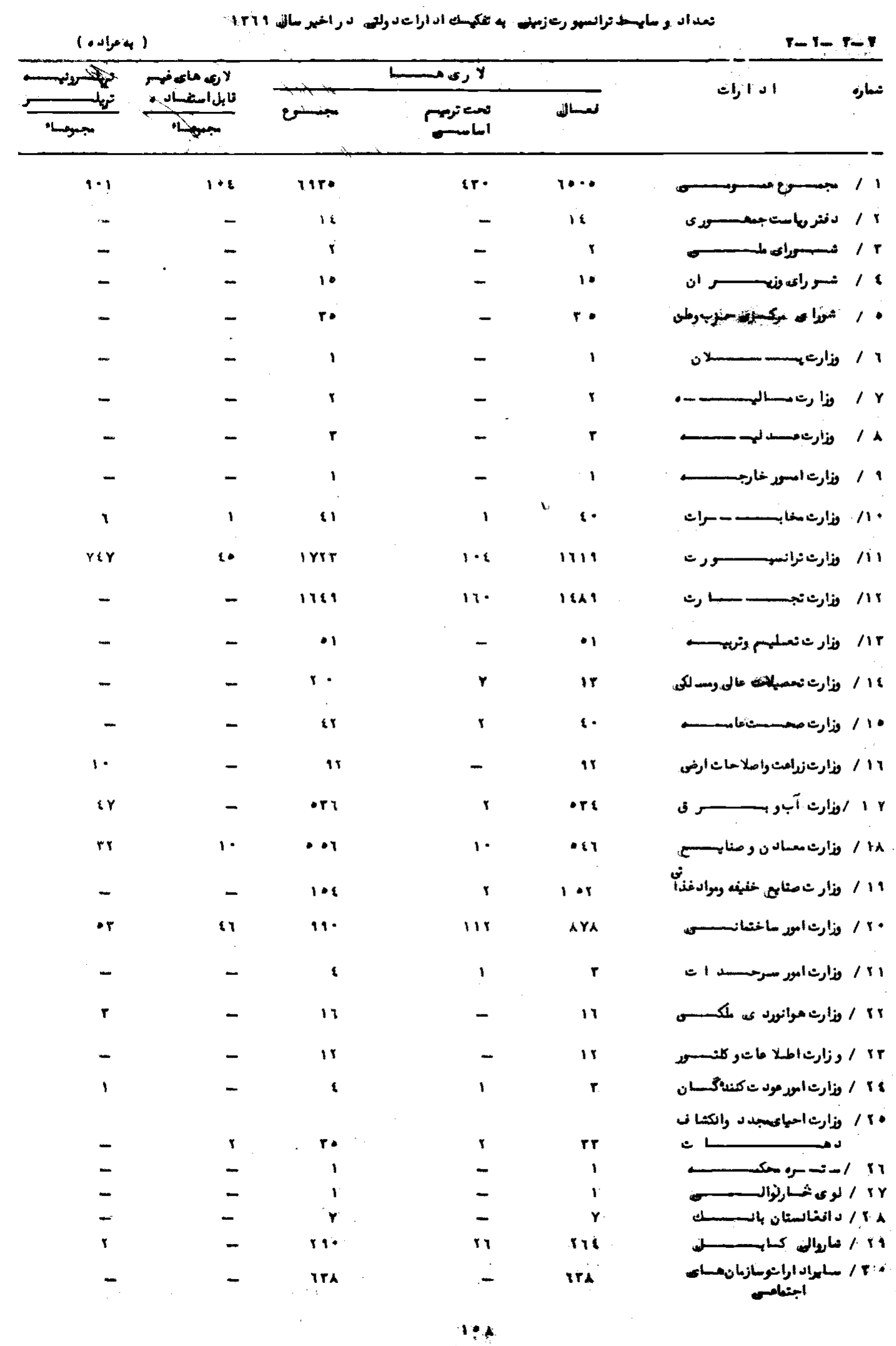




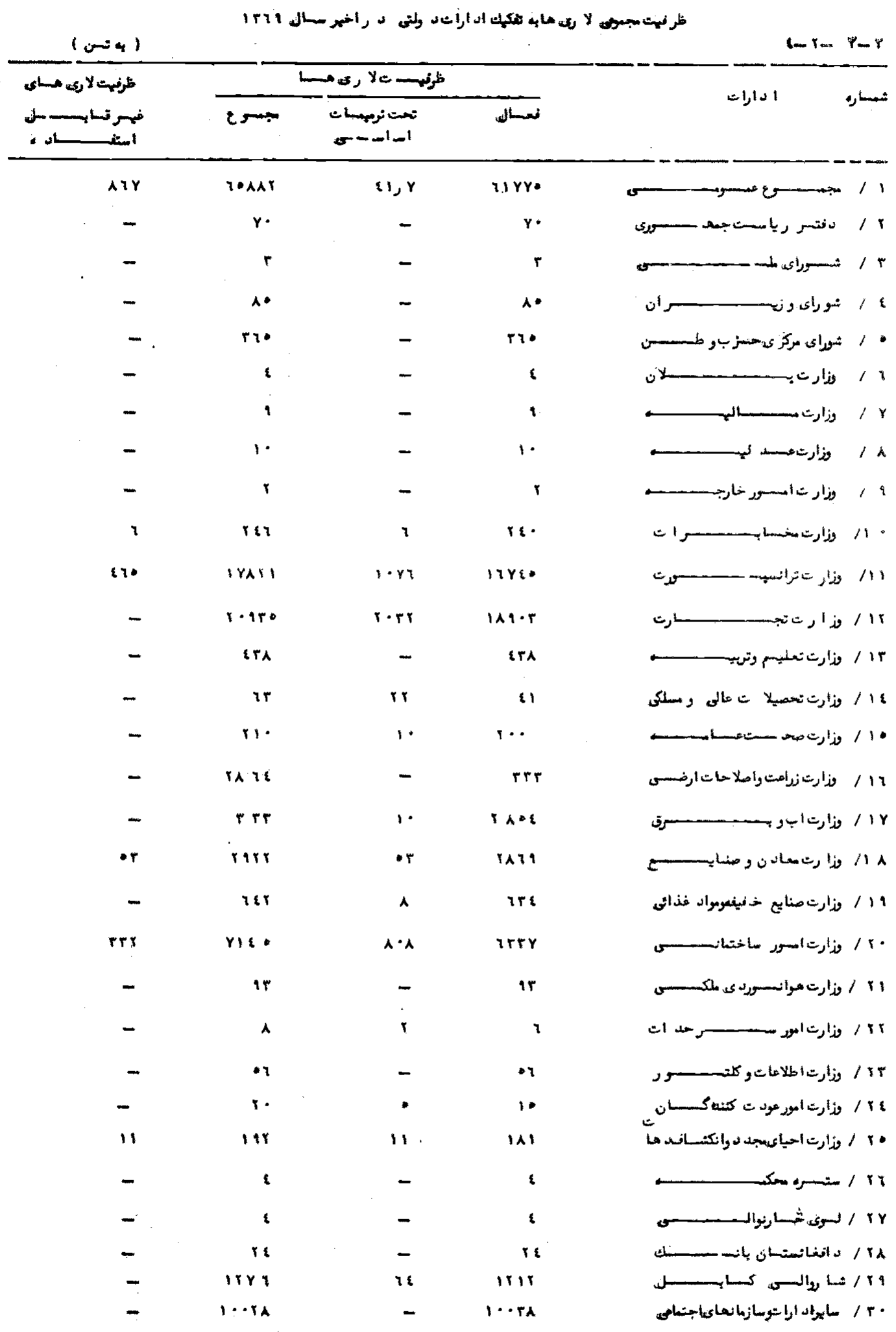




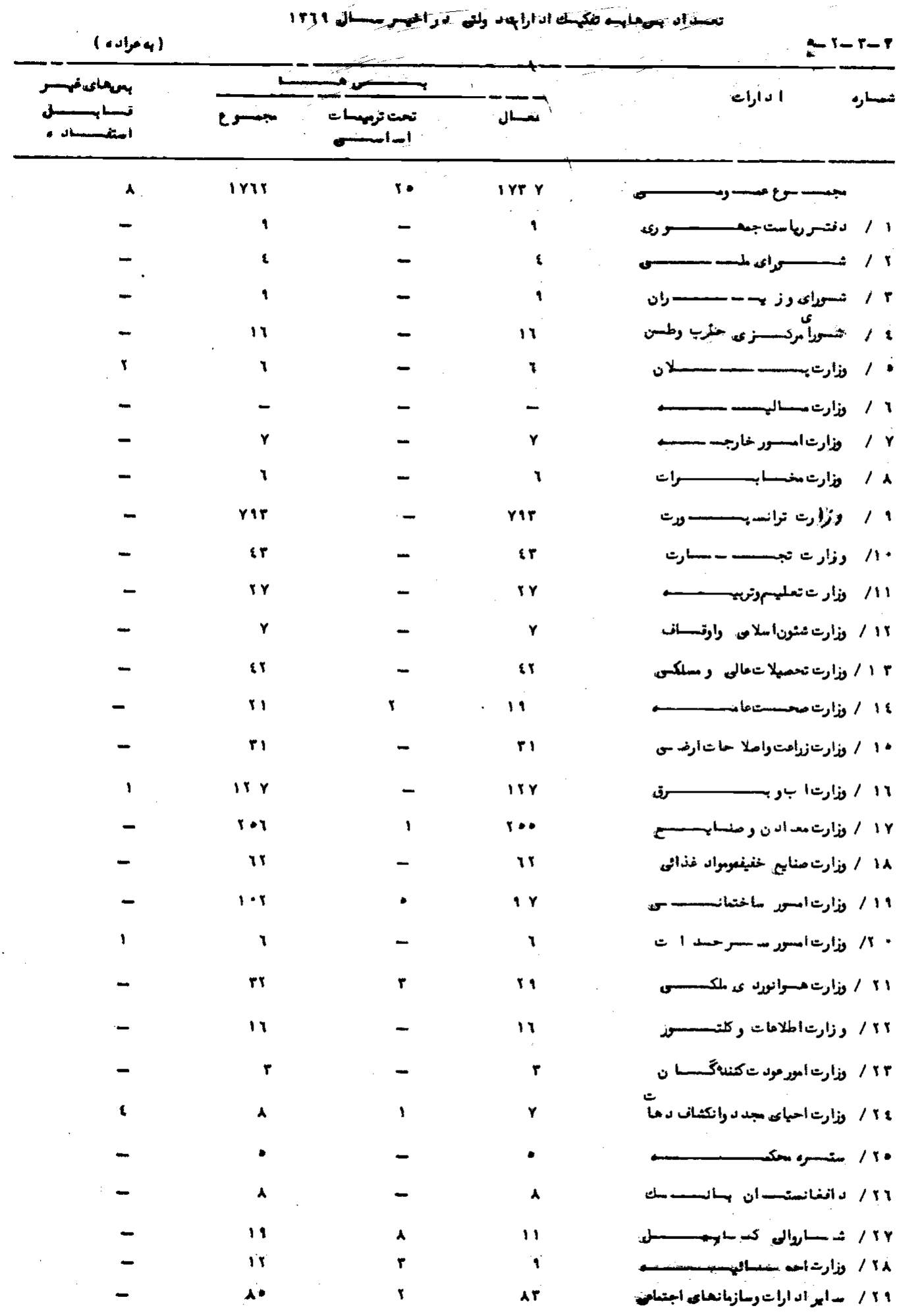




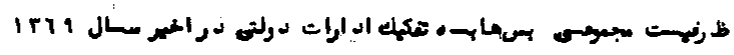

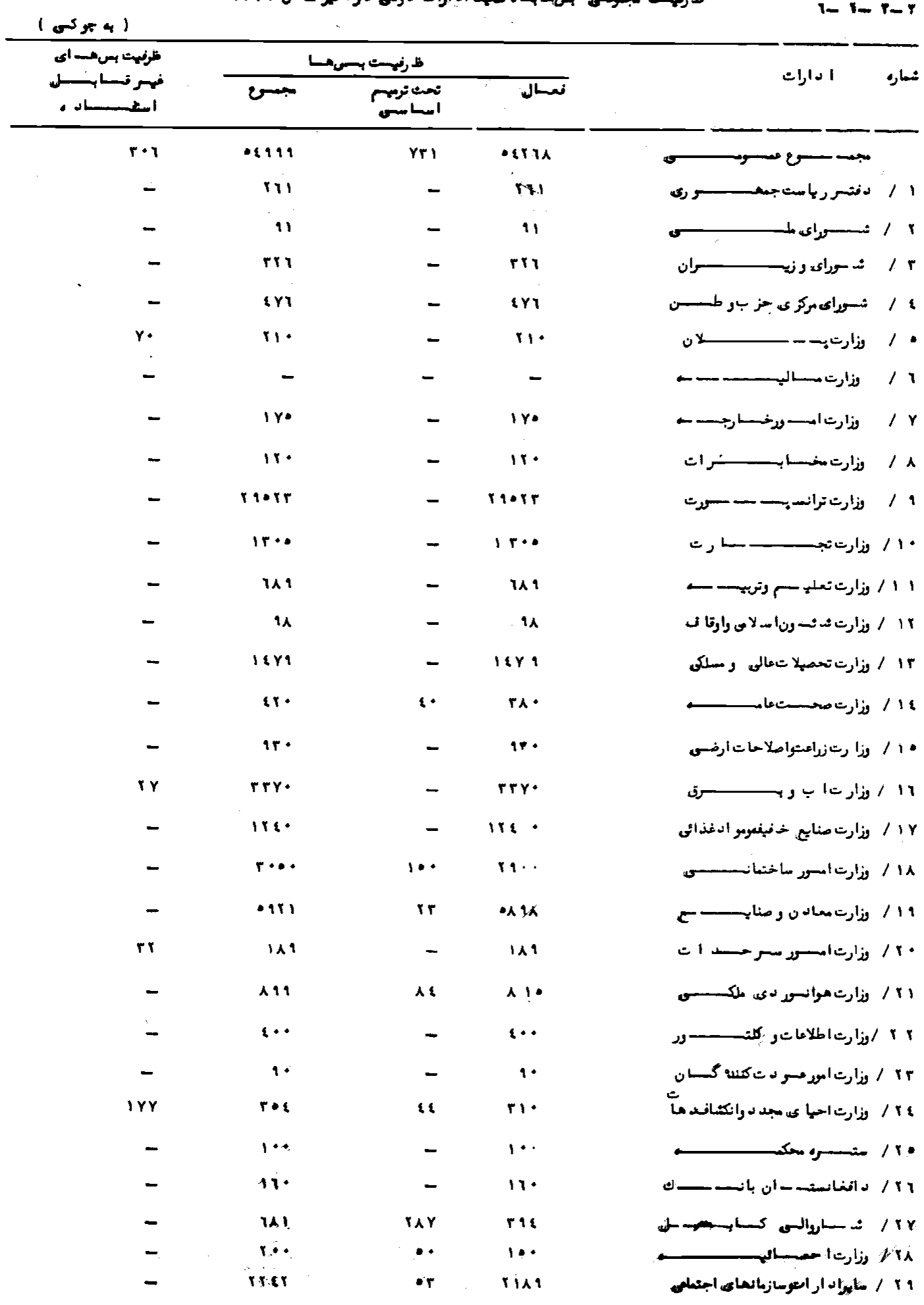




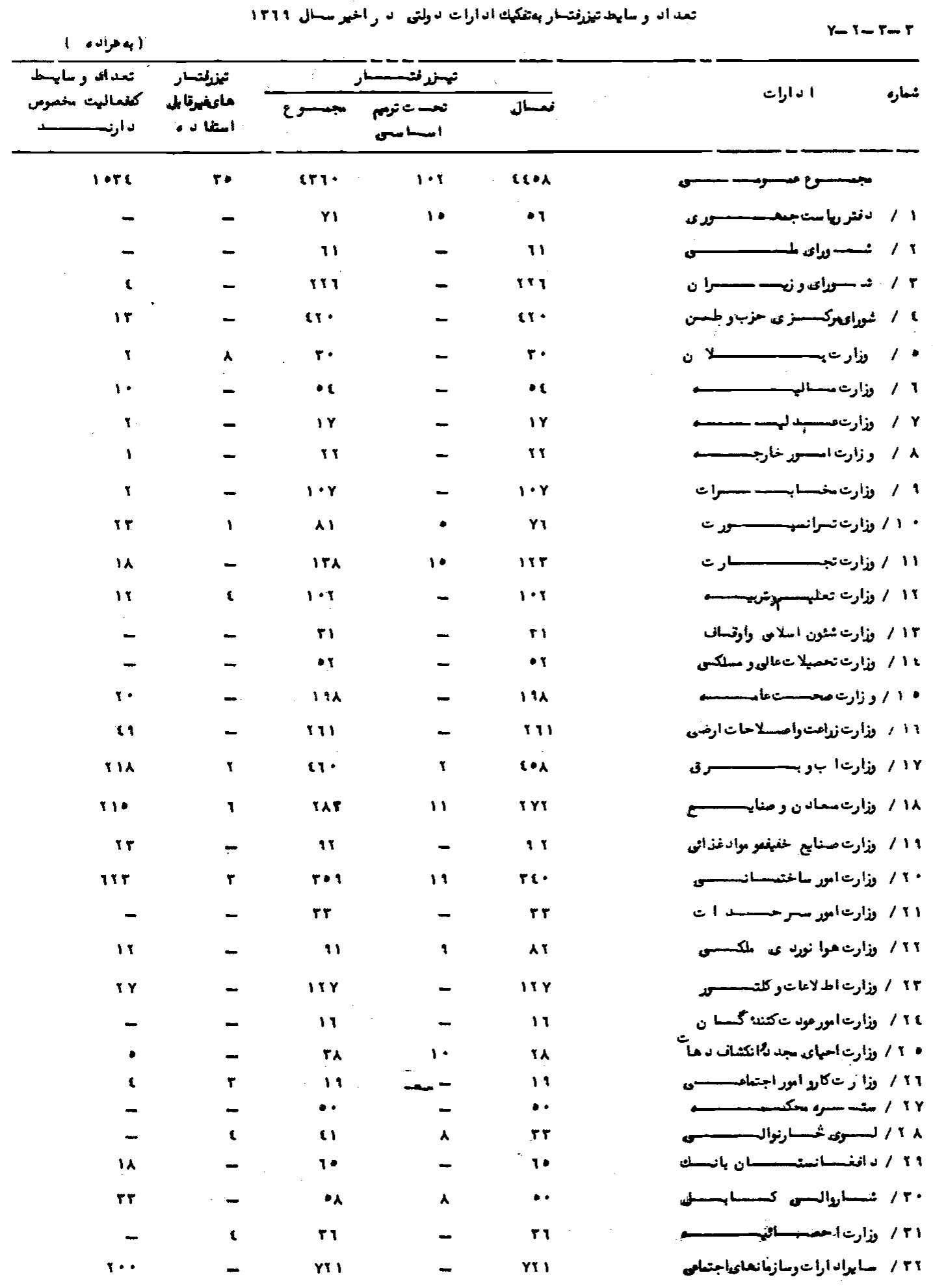




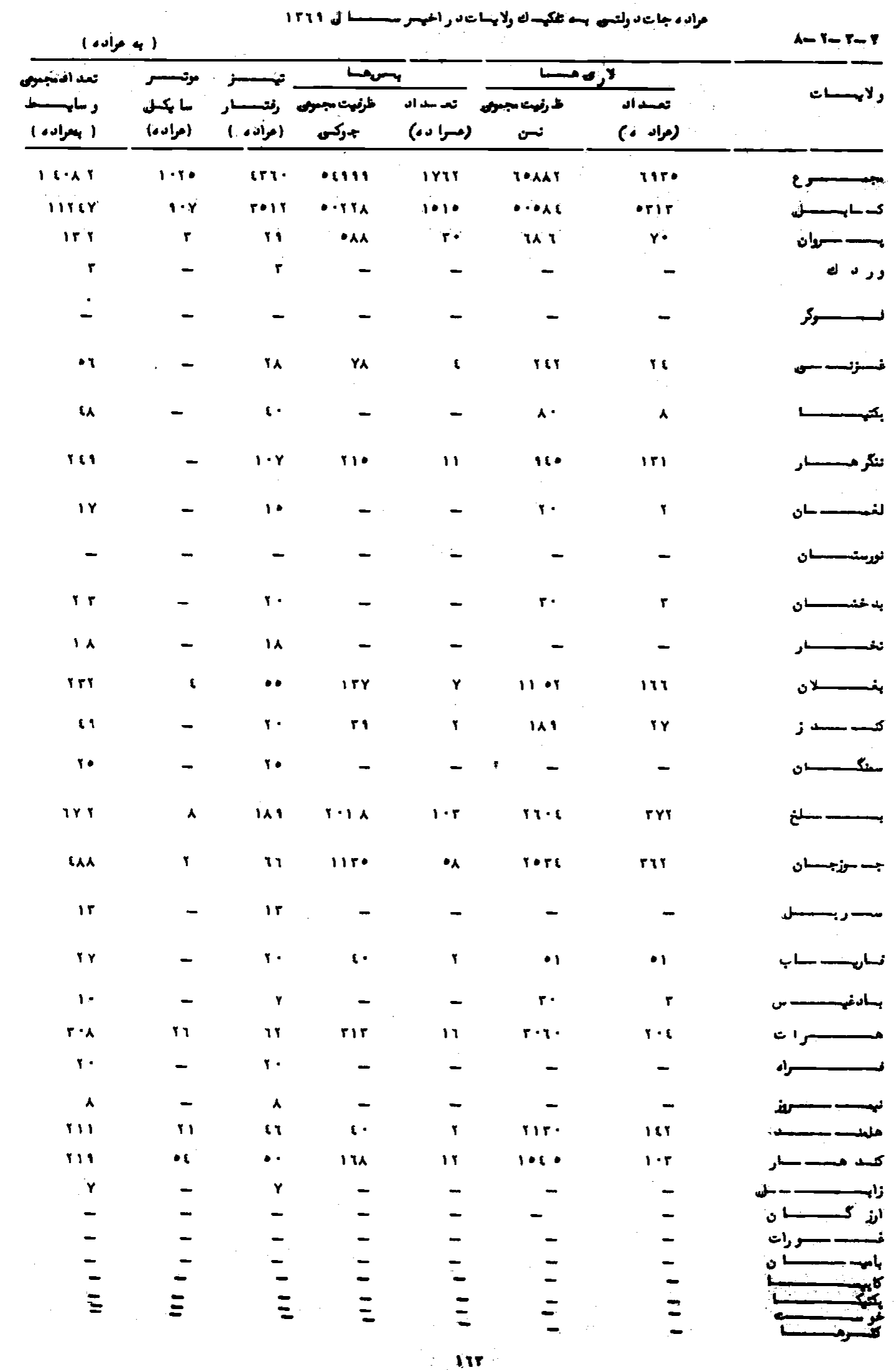




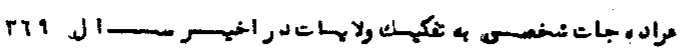

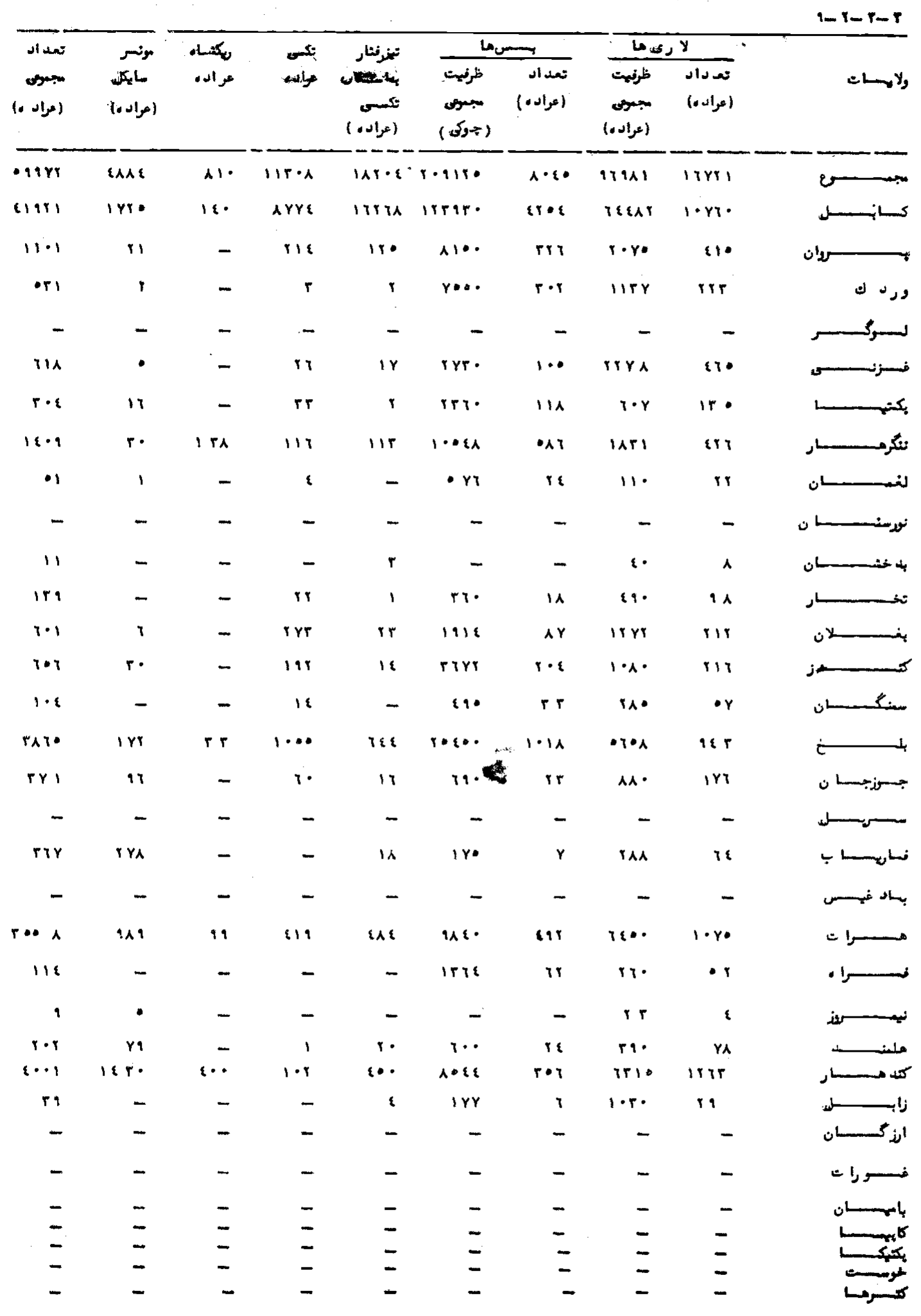




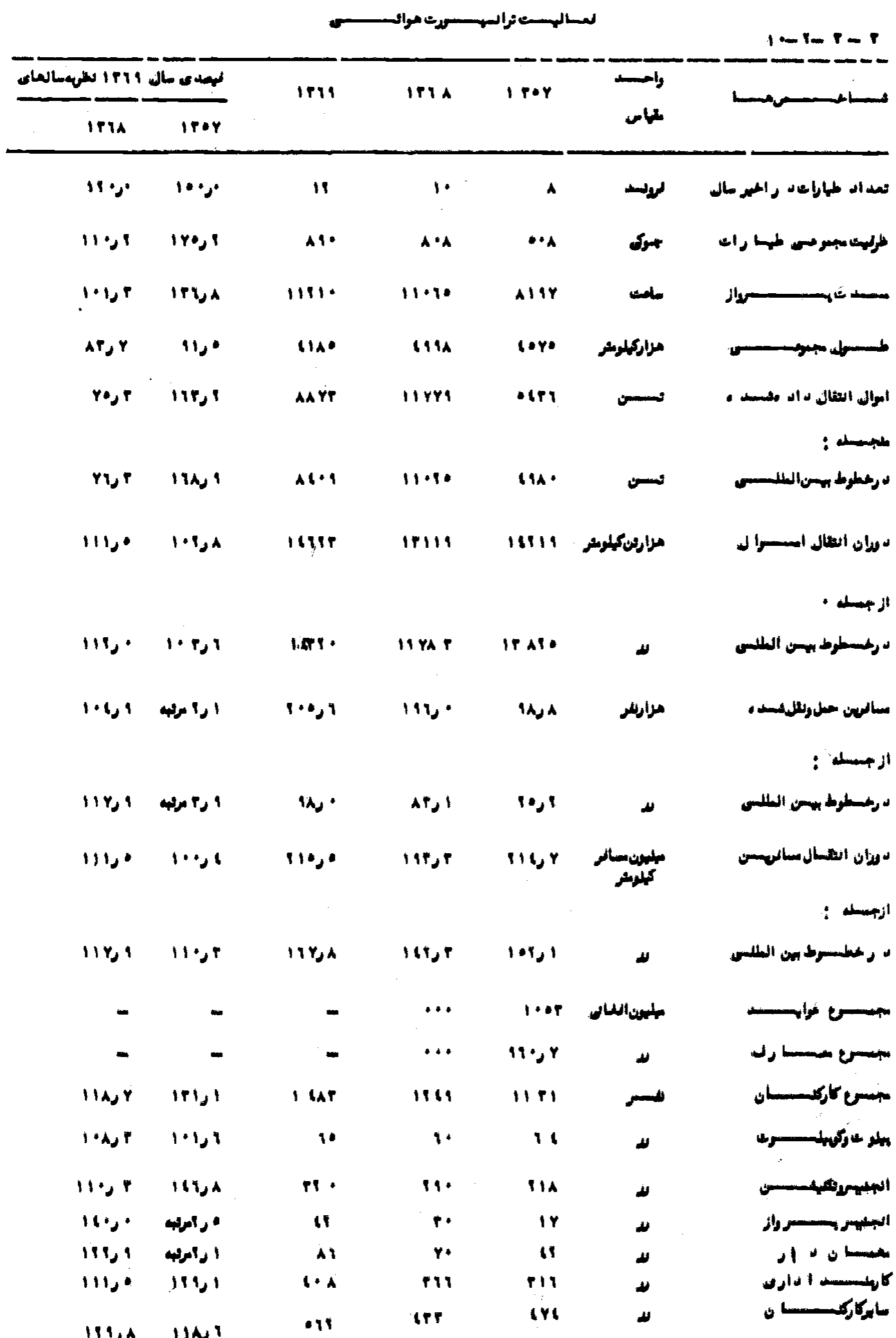




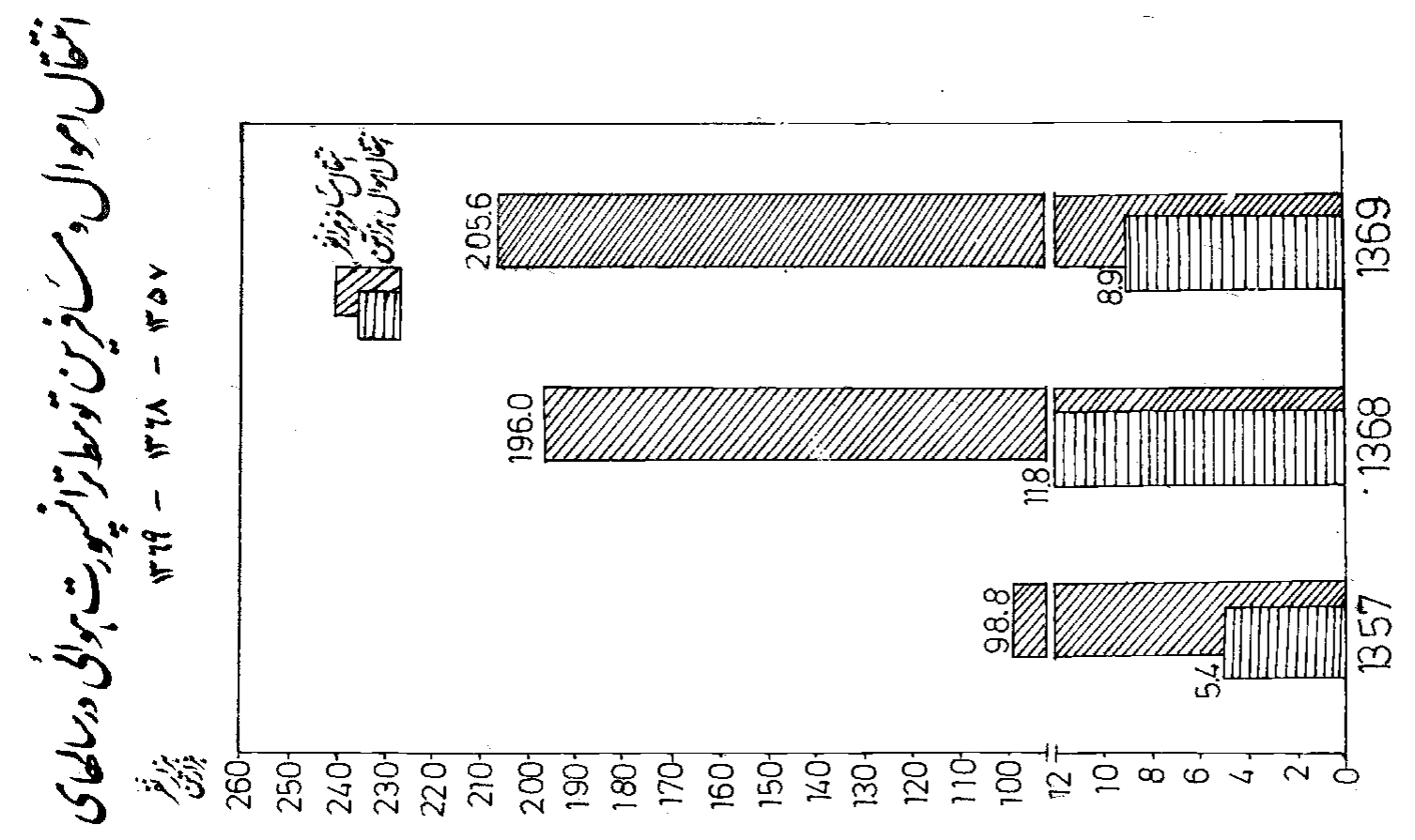




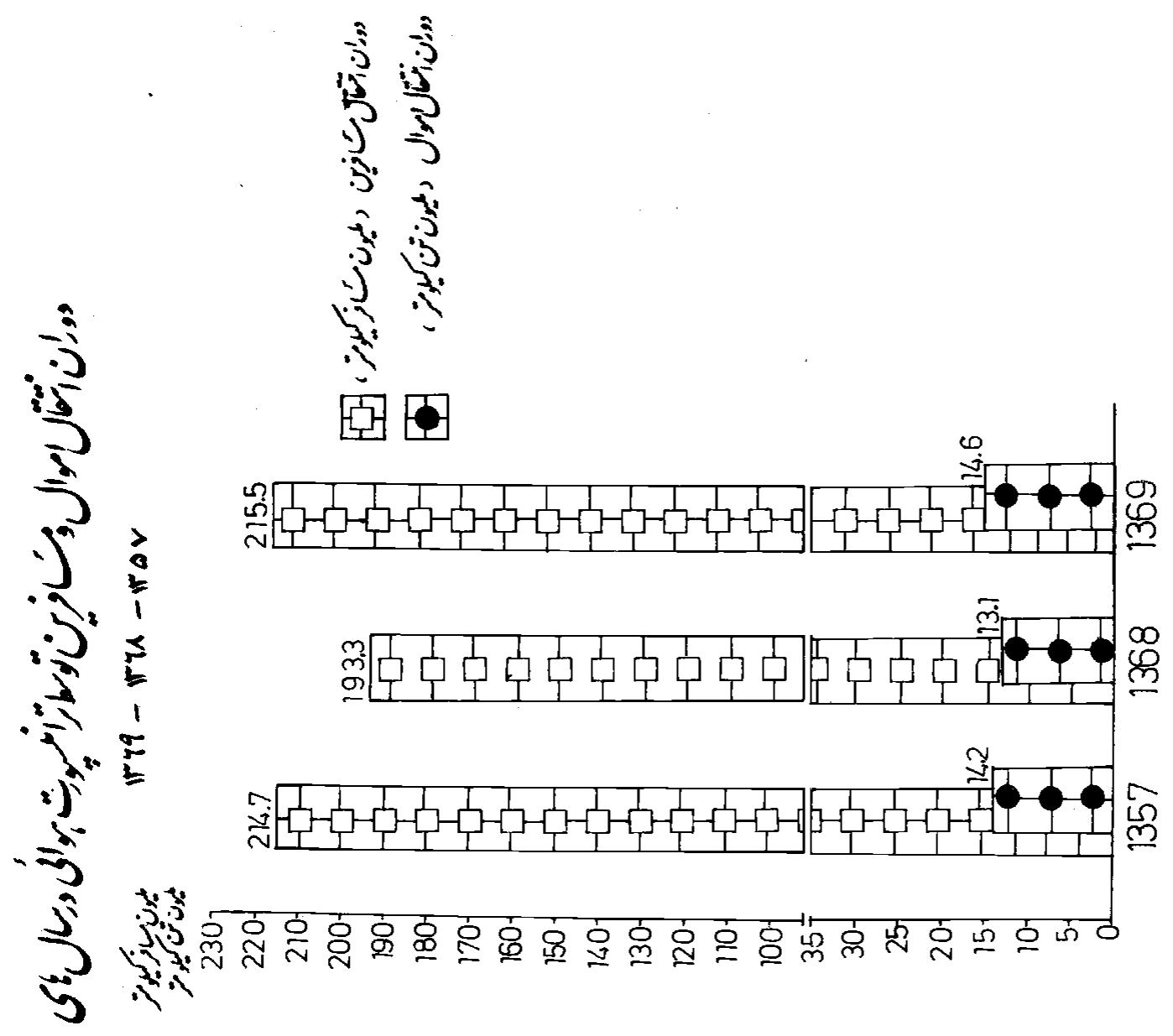




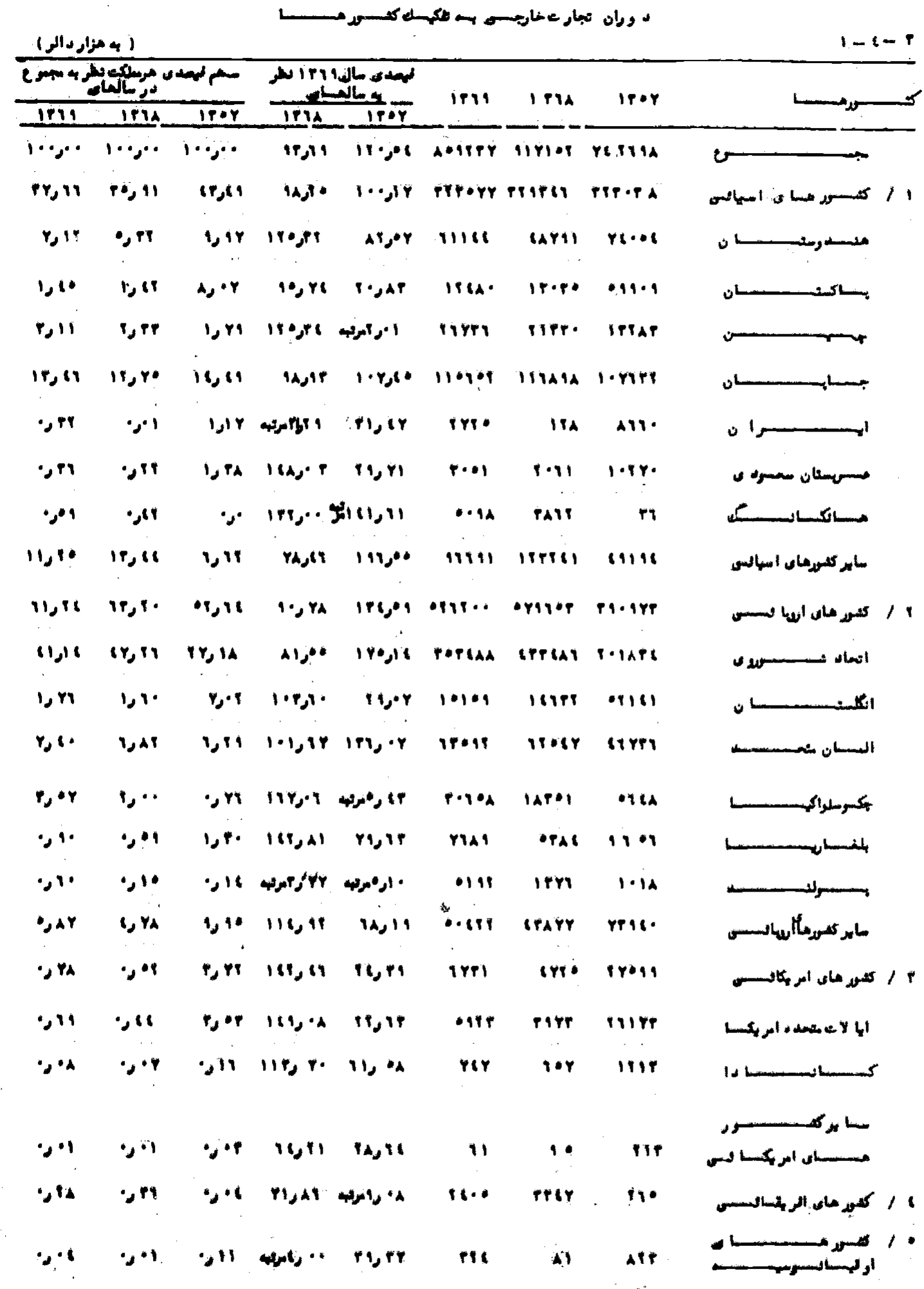




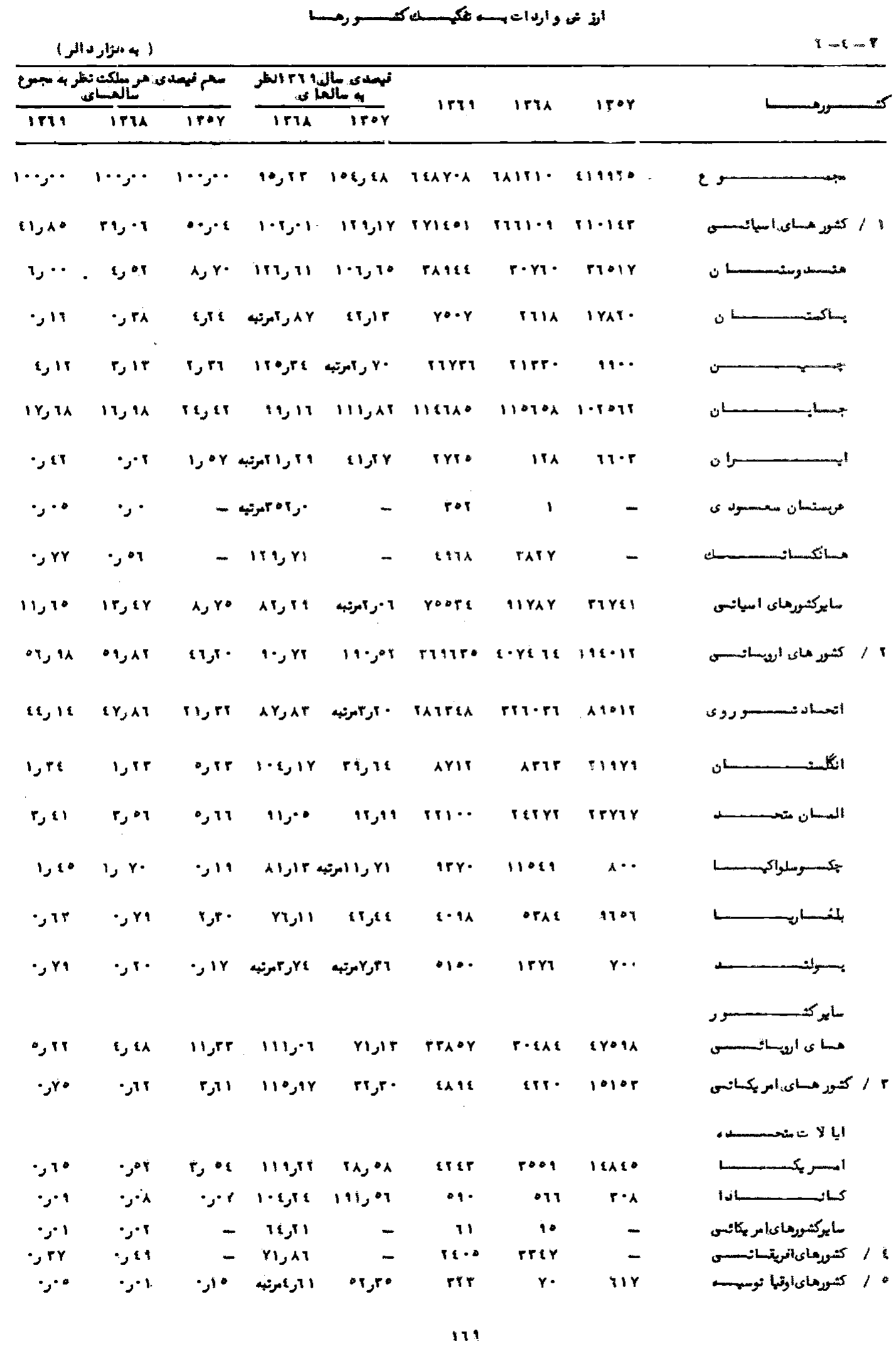




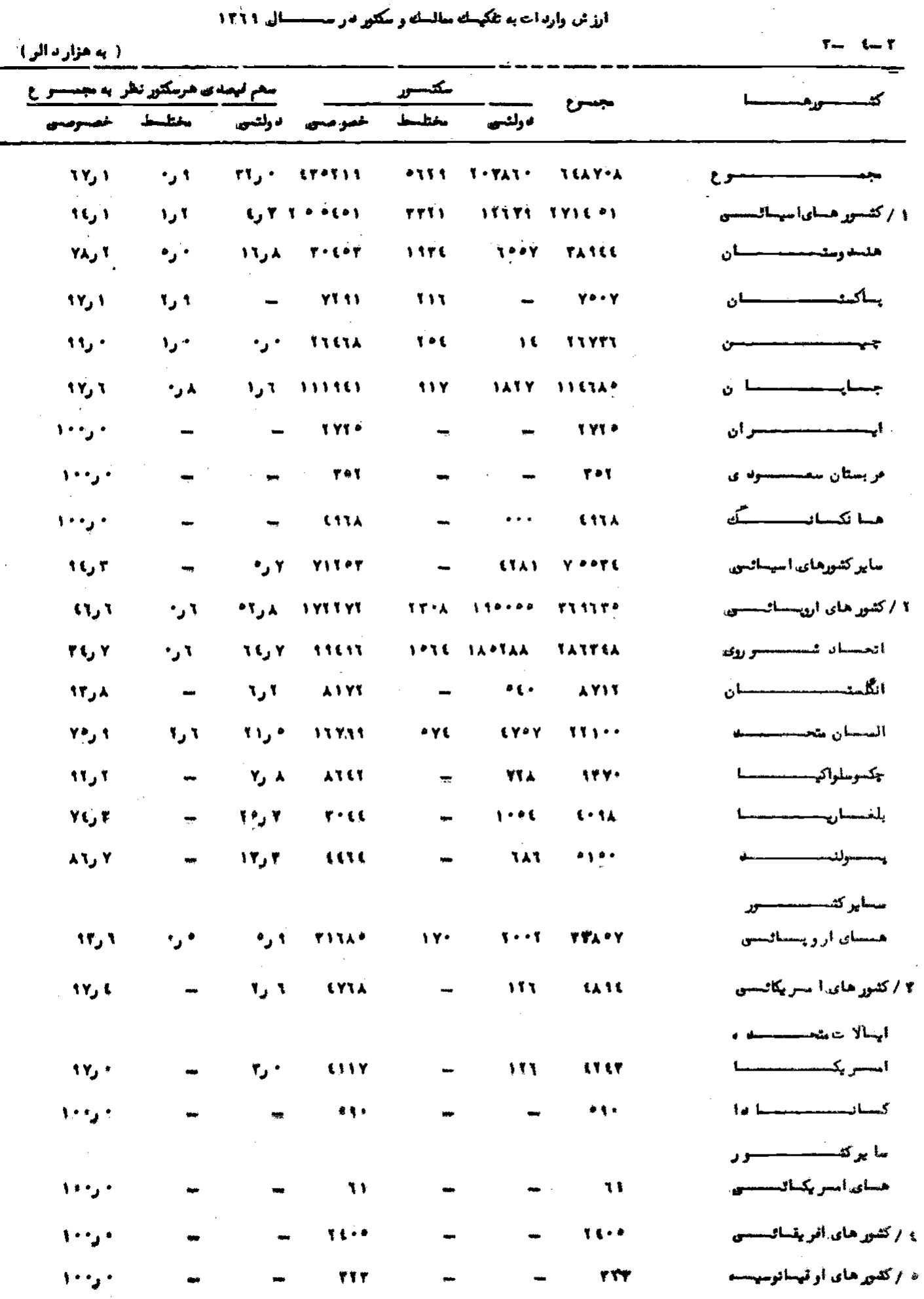




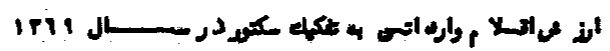

$4-1$

\begin{tabular}{|c|c|c|c|c|c|c|c|c|}
\hline \multicolumn{3}{|c|}{ 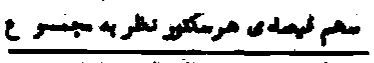 } & \multicolumn{3}{|c|}{ مكس } & \multirow{2}{*}{ (4) } & \multirow{2}{*}{ والمسا } & \multirow{2}{*}{ ابهلسـساس } \\
\hline غلمبرم- & معله & دولبه & thene & همتلسط & رل & & & \\
\hline \& 1 & - & 101 & tire & - & $A \cdots$ & Alire & & $r^{2}$ \\
\hline " & - & 1.4 & iple & - & $r e$. & rotric & & \\
\hline- & - & • ניני & - & - & $11 A \cdot 1$ & $r u \cdot 1$ & & \\
\hline- & - & $\cdots, \cdot$ & - & - & $H \cdot 1$ & $A 1 \cdot 1$ & 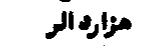 & \\
\hline Yis. & וני & $\mid A_{J}:$ & IXAY & 11 & \&YYY & IIx. & & 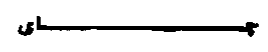 \\
\hline$r, Y$ & t & $r 0,1$ & VIVAT & 180 & $1 Y+1 r$ & rett & & \\
\hline $\begin{array}{l}A t, i \\
Y i, r\end{array}$ & $\begin{array}{l}1,1 \\
r, 1\end{array}$ & $\begin{array}{l}i r_{j} \cdot \\
|r,|\end{array}$ & $\begin{array}{l}\text { repir } \\
\text { ireer }\end{array}$ & $\begin{array}{l}\text { ir. } \\
\text { ini }\end{array}$ & $\begin{array}{l}\text { PAAY } \\
\text { PATE }\end{array}$ & 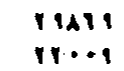 & & \\
\hline$A \bullet j$ & ני & $|8|$ & 1118 & 11 & ent & $r i \cdot r$ & & \\
\hline$r *, 1$ & ' ני & $r r \mid$ & YYYY & 11 & rry. & $1 \cdot r e 4$ & & \\
\hline 19 & - & 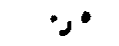 & vert & - & ir & ISTA & لمعن داد & \\
\hline 198 & - & 1 & $A \cdot 1 Y$ & - & 11 & AIIA & & \\
\hline 19. & r & r & $1 \cdot 1 \cdots$ & ir & 11 & $1 \cdot 64$ & & \\
\hline 11,1 & نرن & اد & Alit & 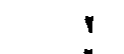 & 11 & AEY & & \\
\hline IAJ $Y$ & ז קי & ise & $n \cdot$ & 1 & $\wedge$ & $Y Y \cdot$ & & \\
\hline $1 \cdot 5 \cdot$ & וני & $r, P$ & Prate & IPA & 1011 & pirer & & \\
\hline 11,1 & - & es & tops & - & 11 & $1 \ldots$ & v & -1 \\
\hline- & - & - & 1111 & - & $\bullet \bullet$ & IIre & & \\
\hline $\begin{array}{l}11,1 \\
11,1\end{array}$ & 1' ני & r ر & $\begin{array}{l}\text { reter } \\
\text { riyos }\end{array}$ & ir. & $m$ & 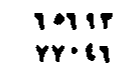 & & \\
\hline$I r_{\mu}$ & , 1 & 0, & $A \cdot A$ & $A 1$ & $\ln$ & Ality & & 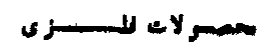 \\
\hline 19 & e & $r \cdot, l$ & Iro. & $|r|$ & $\ln 1 A A$ & riris & & \\
\hline 1,1 & - & $\mid y, 1$ & $\bullet 1$ & - & rep. & $r(A)$ & 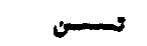 & \\
\hline $\mid r, 1$ & - & rise & ry & - & $(1)$ & ine & & \\
\hline $\mid t, 1$ & - & es 1 & 180 & - & 101 & $r \cdot 0 v$ & & \\
\hline 10, & - & t. & $A \cdot Y$ & - & $e \cdot Y$ & AMA & & \\
\hline$r Y_{J}:$ & $\mid 1 / \boldsymbol{H}$ & 1,7 & 19t & rMA & IrI & $1 \cdot 11$ & & \\
\hline 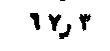 & is & ive & 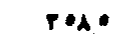 & err & irre & epry & & \\
\hline $1 r_{2} \cdot$ & - & $r_{\jmath} \cdot$ & 118 & - & $\Delta r$ & IVIA & الم الر & \\
\hline$\cdots$ & - & - & $v \bullet 11$ & - & - & $r \cdot 1 A$ & مراره السر & \\
\hline 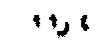 & - & וני & irre & - & $A$ & irre & مراd بקد & \\
\hline 19,1 & - & $2 A$ & I epr & - & 11 & 1048 & & \\
\hline$A A_{J} C$ & - & 11,1 & 16r & - & ive & $1 \cdot 17$ & & \\
\hline$A Y_{2}$ & - & $\mid r_{2} e$ & ryer & - & YAT & $e+1)$ & & \\
\hline$r y, r$ & 108 & - & 1111 & rI. & - & 11111 & & \\
\hline$A \mid, 1$ & $1 A, 1$ & - & IIY & 100 & - & AYY & & \\
\hline 1・י & - & - & PIAOA & - & - & PIACA & & \\
\hline$\because \cdots$ & - & - & 101 & $\infty$ & - & rovi & & \\
\hline 11,1 & $P_{\mathbf{N}} \mathbf{r}$ & 45 & $1 A \cdot C$ & 111 & Itr & $7 \cdot 46$ & & \\
\hline 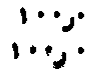 & $=$ & $=$ & $\begin{array}{l}\text { rife } \\
\text { ryy }\end{array}$ & 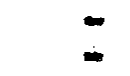 & $=$ & Irm & & \\
\hline $10 !$ & 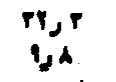 & 10 & $\begin{array}{r}100 y \\
8, x\end{array}$ & $\begin{array}{l}1.198 \\
\text { ret }\end{array}$ & $\begin{array}{l}\text { A1: } \\
7 \%:\end{array}$ & $\begin{array}{r}\text { Pot } \\
\text { row }\end{array}$ & & \\
\hline $\begin{array}{l}111 \\
17,1\end{array}$ & $\begin{array}{l}21 \\
+1\end{array}$ & $m$ & $\begin{array}{l}\text { H.ro? } \\
\text { sforil }\end{array}$ & $\begin{array}{l}\text { Iri } \\
\text { ori }\end{array}$ & $\begin{array}{r}17 \\
1.748+\end{array}$ & $\begin{array}{l}\text { nose } \\
\text { repts }\end{array}$ & & \\
\hline
\end{tabular}




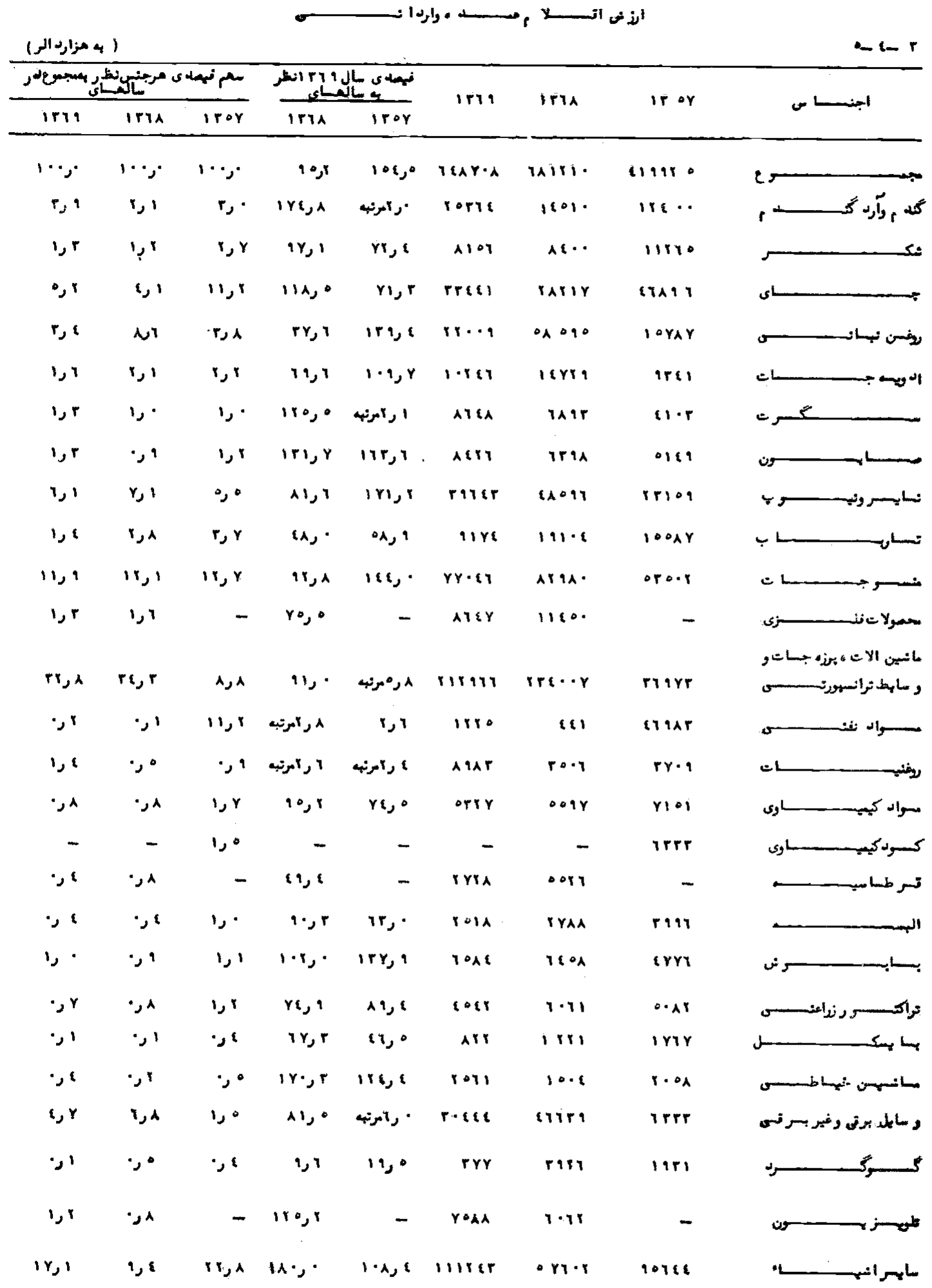




\begin{tabular}{|c|c|c|c|c|c|c|}
\hline \multicolumn{2}{|c|}{ 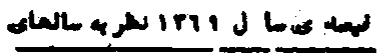 } & \multirow{2}{*}{ irn } & \multirow{2}{*}{ iria } & \multirow{2}{*}{ iror } & \multirow{2}{*}{ رأسساس } & \multirow{2}{*}{ ابلســا - } \\
\hline $\operatorname{lna}$ & iror & & & & & \\
\hline$|r|, \mid$ & $A Y, P$ & Acite & atio & ITPAA & تهسن & أر رأرب كسـدم, \\
\hline $1 \cdot A_{0} \cdot$ & $i s \cdot$ & $n x \cdot 1$ & rer. & rotis & تسن & r \\
\hline lite. & $A \bullet$, & ina. & IIIPAA & nori & تسـن & لــــان \\
\hline$(x, y$ & $1 \cdot r, 1$ & mais & iaria & $11 \ldots 1$ & نسمن & \\
\hline$A 1,8$ & Ire, & $r i \bullet r$ & $r \cdot c \cdot$ & irst & تهن: & CL \\
\hline 18,1 & 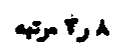 & reta & 114 & $m$ & لمعن دانه & \\
\hline $1 \cdot r, 1$ & $118 \cdot$ & $1 \cdot 24$ & $n \wedge \cdot$ & irri & تسنى & \\
\hline$\because, 1$ & $\| r$, & $r r e$ & $1 \cdot 10$ & 'A & مزارملك مزلك & \\
\hline יוני: & $r$, & $2 \cdots$ & $A \cdot e r$ & ler.. & تهس & ㄴ \\
\hline $1 \cdot \bullet, 1$ & $\mid r i$ & ion & inst & orry & مزارعو & $=L$ \\
\hline " & ا & $r(x)$ & i & iAt & مزارئسن & \\
\hline ri,s & ' קי متنه & $r \cdots r$ & $r+1$ & $11 A 1$ & ow & \\
\hline וj: & $r \gamma, \gamma$ & $r+1$ & $(016)$ & irer & تسـن & لكاوى \\
\hline- & - & - & - & it & نسـن & L \\
\hline$\bullet 1,1$ & 1 & irre & irry & Bry & مزارجده & \\
\hline 11 & $1 \cdot i, 1$ & $1 \cdot 1 r$ & inr & $1 \cdot 1 r$ & مراد. & \\
\hline$(\alpha)$, & $r, i$ & ir & ir & $r r$ & مزارواد. & \\
\hline irr, $r$ & (i) & $r$ & in & " & مزاساهـ & - \\
\hline is & 116,1 & mre & ..rs & la. or & مزاردربن & \\
\hline Itrse & - & $r r \cdot r$ & ireri & - & كان- & \\
\hline
\end{tabular}




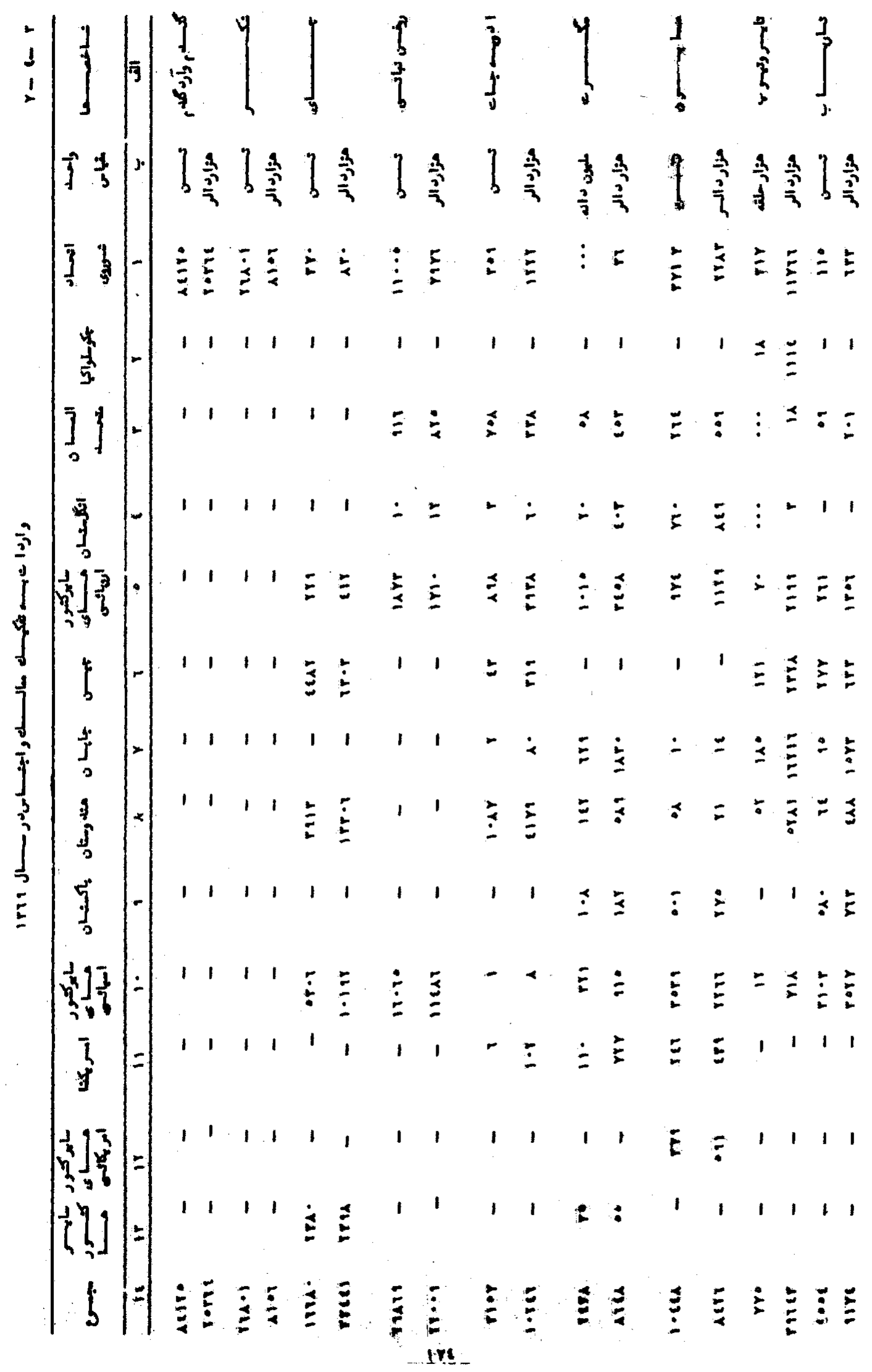




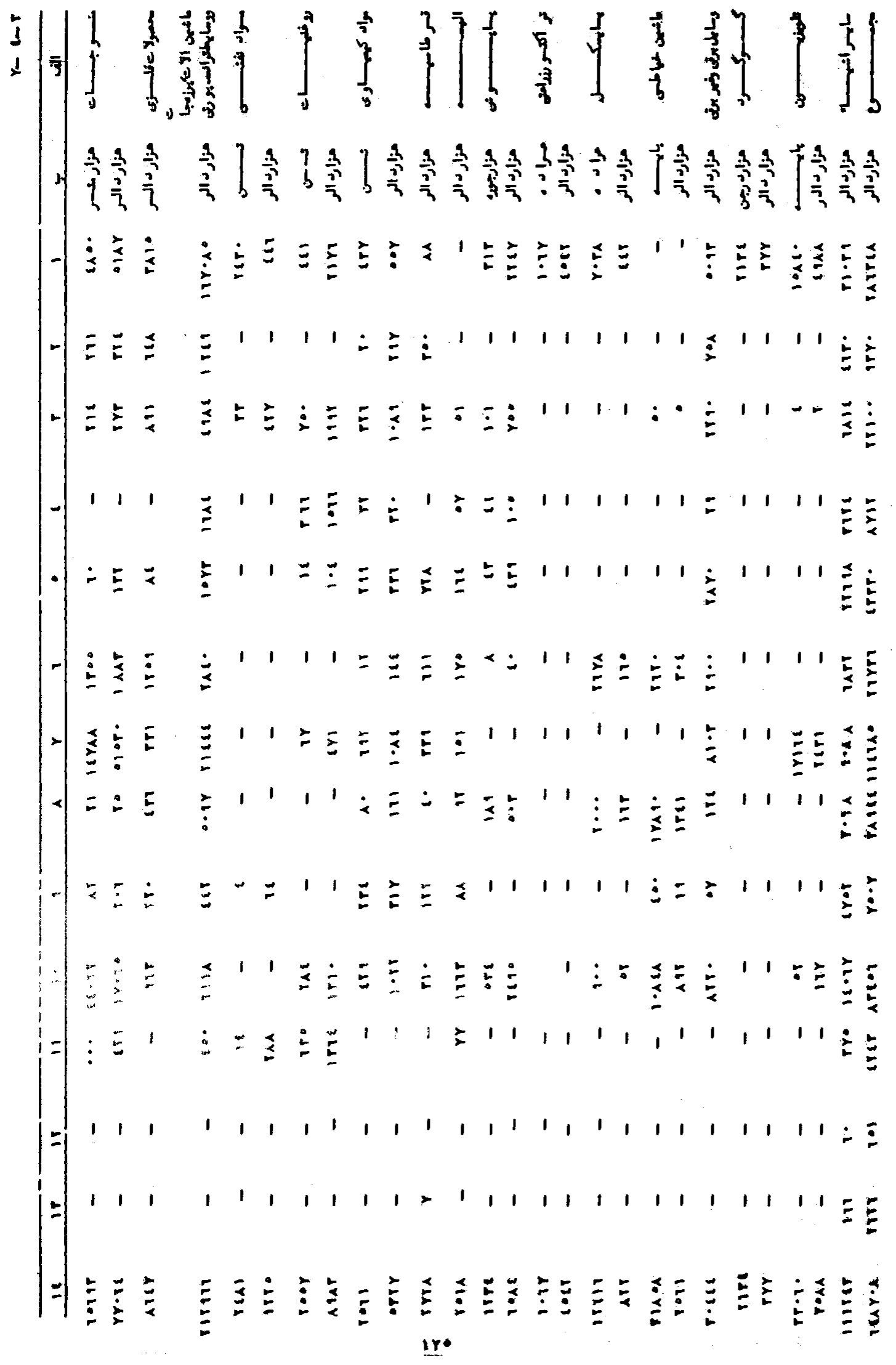




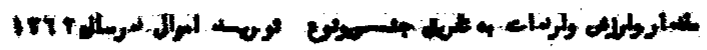

1-2 -

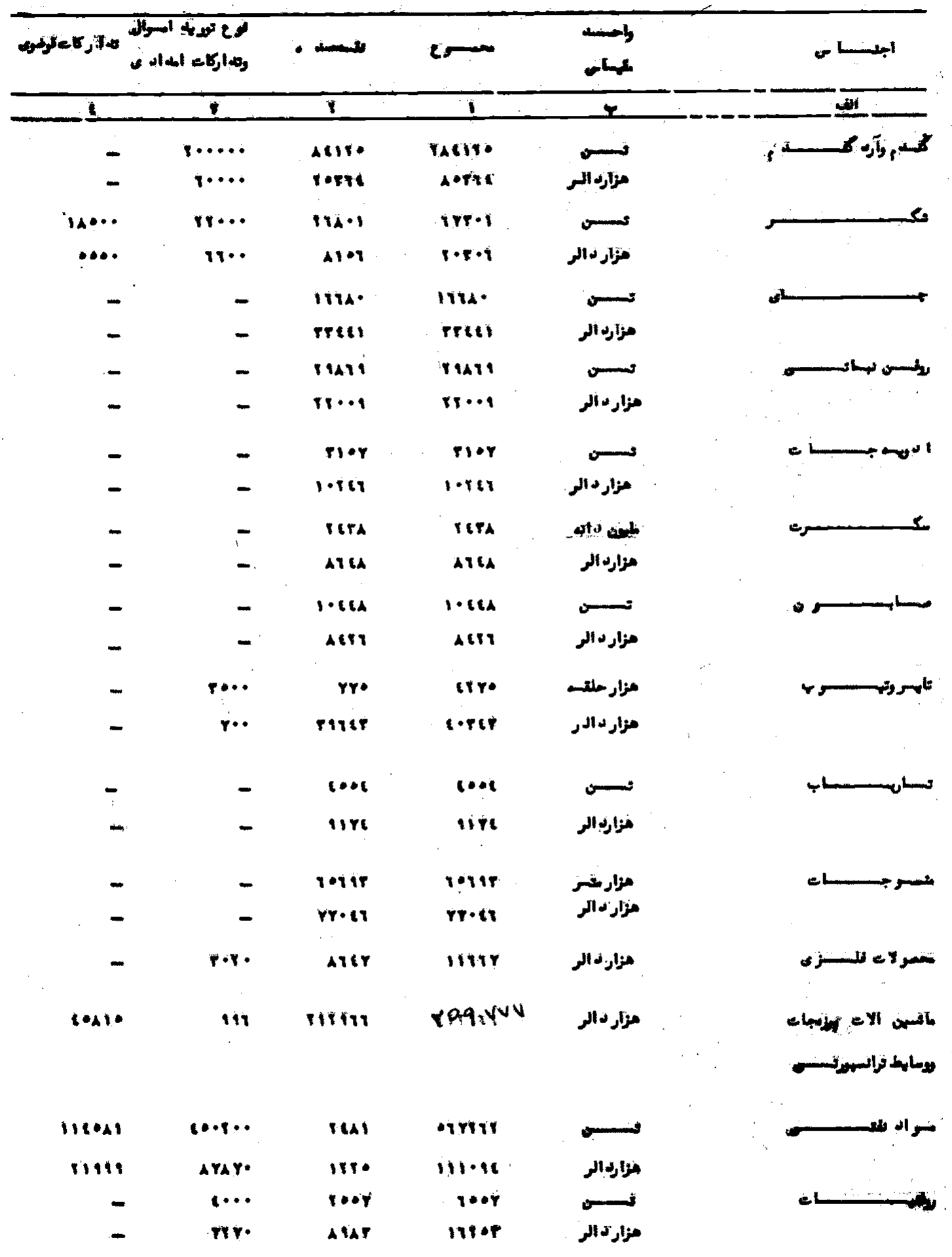




\begin{tabular}{|c|c|c|c|c|c|}
\hline & & & & & $a-2-r$ \\
\hline 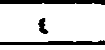 & $r$ & 1 & 1 & 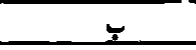 & الف \\
\hline- & $1.9 r \cdots$ & - & I.tr. & 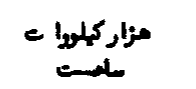 & 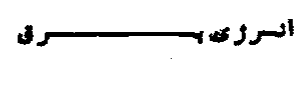 \\
\hline- & $\because r$. & - & esr. & مزارد الر & \\
\hline - & - & ren & $r \cdot 1$ & تسمت & برواد كميهـ \\
\hline- & - & or ir & •rry & مزار دالر & \\
\hline- & $r \cdot A \cdots$ & - & $r \cdot A \cdot \cdot$ & نسـن & كســرد كهيــــــــــ \\
\hline- & $m$. & - & $\pi$ & مزارد الر & \\
\hline- & - & $r g r \cdot r$ & ret?r & تسنسن & سع \\
\hline- & - & mis & mi & مزارد الر & \\
\hline- & $\cdots$ & iria & rata & مزار د الر & كسر طـــاسد \\
\hline- & - & $r \cdot 14$ & 8014 & مزار د الر & 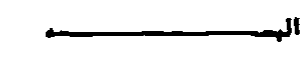 \\
\hline- & - & irrs & irrs & هزارجدو & بك بــــ \\
\hline- & - & YoAs & reat & مزأرد الر & \\
\hline- & - & $1 \cdot 2 r$ & $1.1 Y$ & مسا د. & تر اكتســــــ نوامت \\
\hline- & - & $\cos 1$ & sost & مزارد الر & \\
\hline - & - & in & inn & عرا د. & r \\
\hline- & - & AIr & AIr & مزار د الر & \\
\hline - & - & riaen & PIA An & باهس & ماشهسمن اله \\
\hline - & - & $r \cdot n$ & $r \cdot 1$ & مزار د الر & \\
\hline - & - & $r \cdot s e s$ & $r \cdot s t 8$ & مزارد الر & 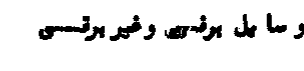 \\
\hline - & - & rire & rirs & مزارد رجن & -3 \\
\hline - & - & $r r r$ & rry & مزارد الر & \\
\hline - & - & $r r \cdot r$. & $r r \cdot r$. & بطيس & كلهو هسز \\
\hline - & - & YoAA & YOAA & مزار د الر & \\
\hline - & $m \cdot A$ & $11 \cdot(A)$ & $\mid r r \cdot n$ & مزارئا لو & بـاعتِرافه \\
\hline rrits & retrat & IsAY:A & iretes & مزار دالر & Cr \\
\hline
\end{tabular}




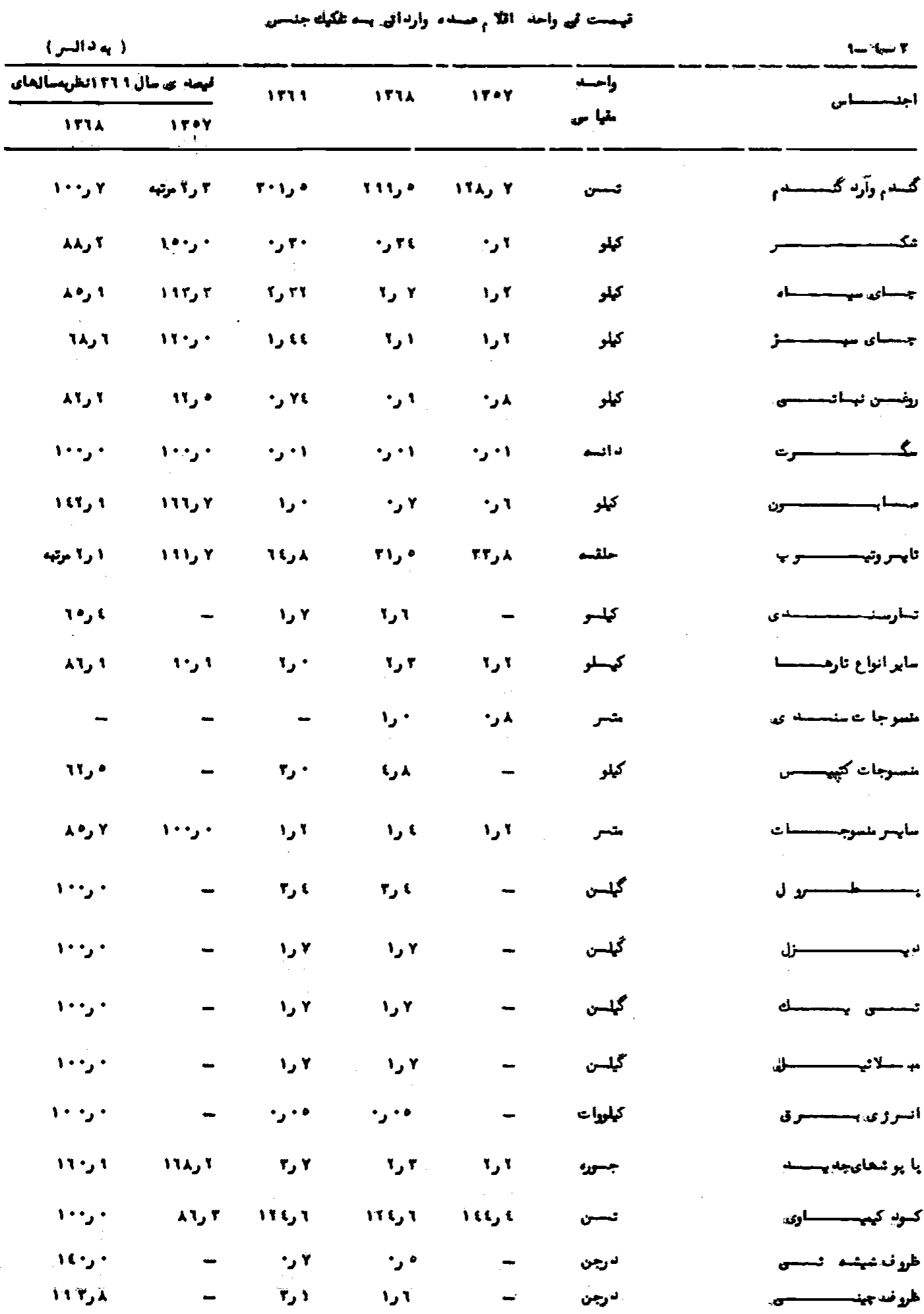




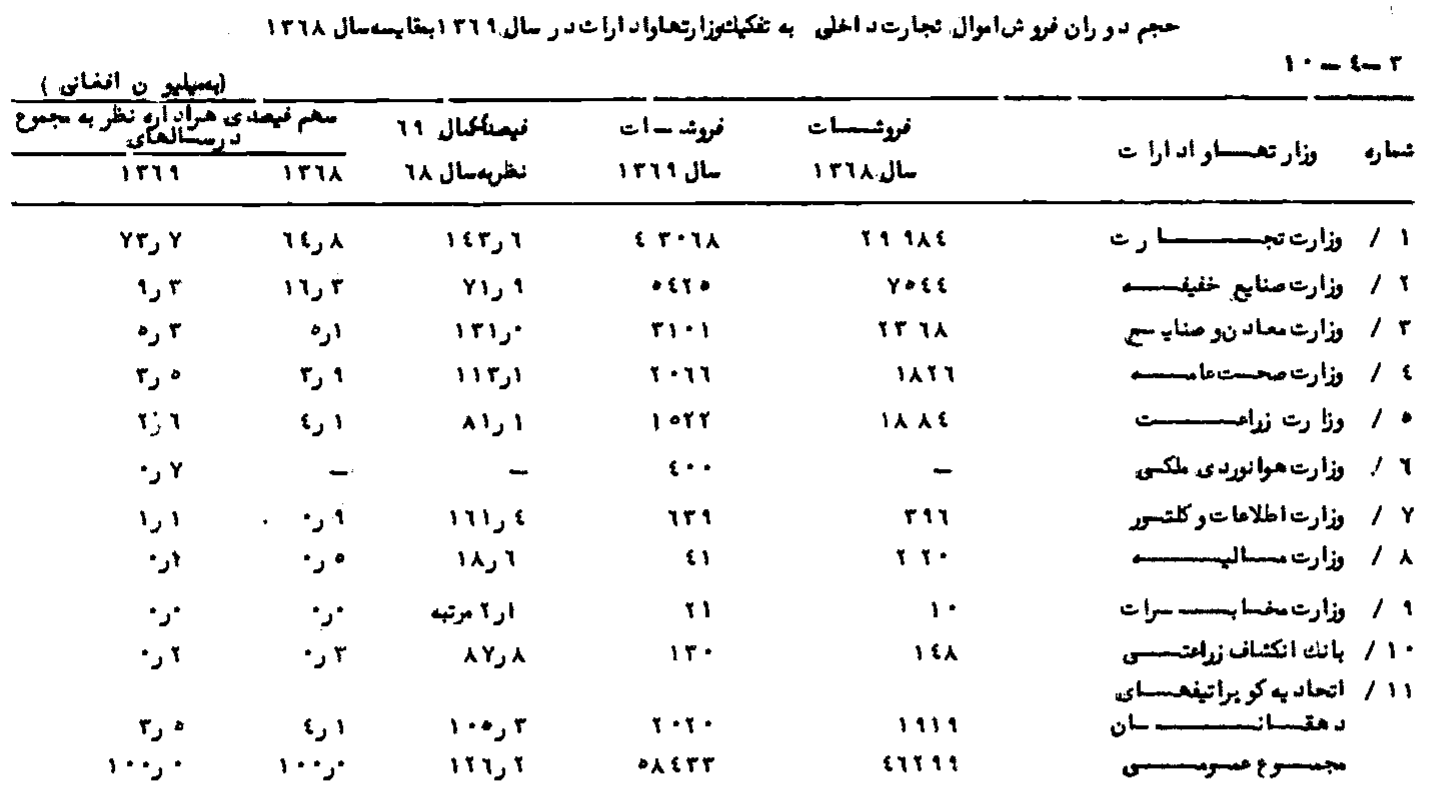

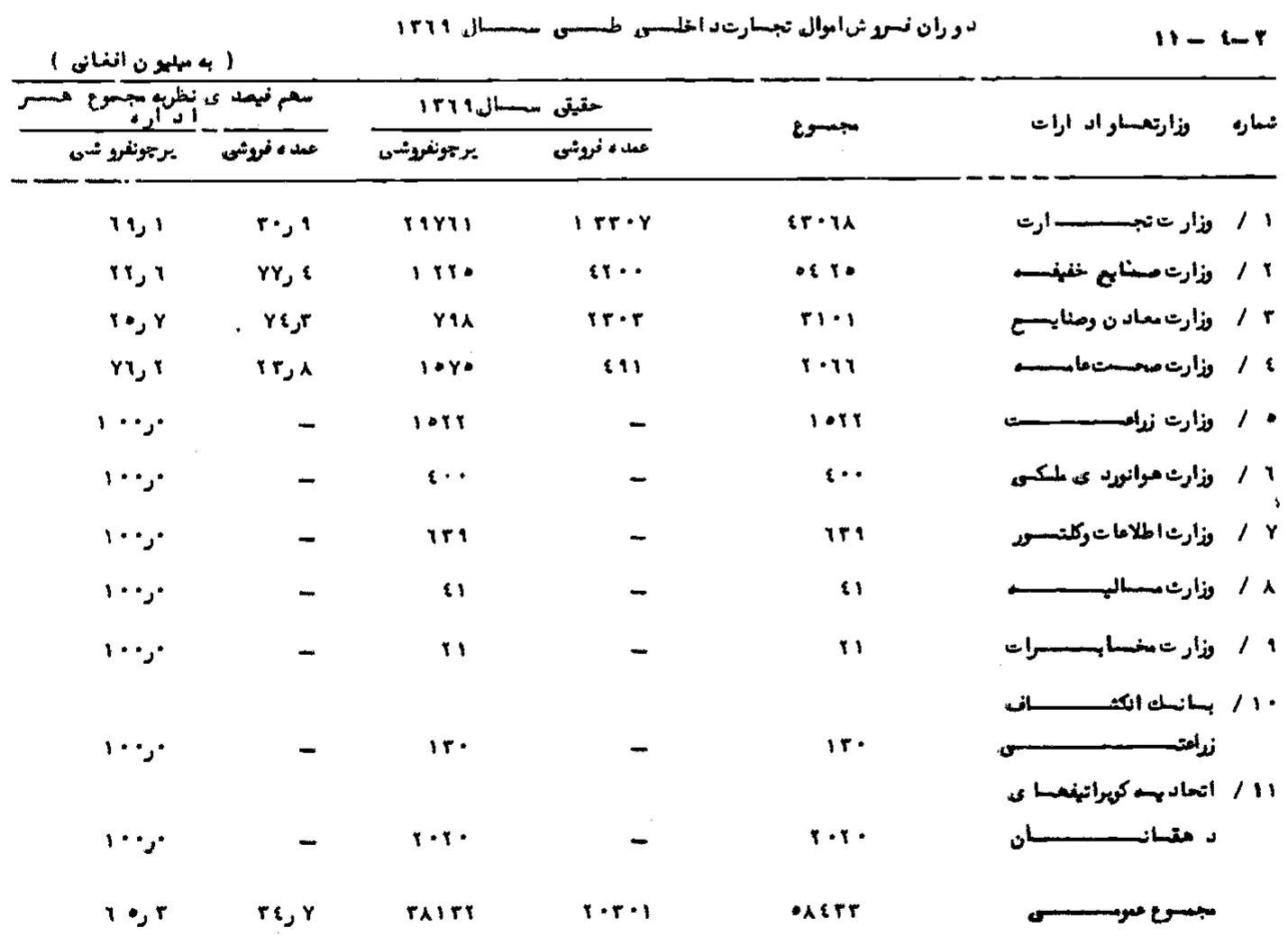




\begin{tabular}{|c|c|c|c|c|c|c|c|c|}
\hline 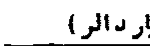 & 21 & & & & & & & $11-2-1$ \\
\hline \multicolumn{3}{|c|}{ 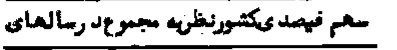 } & \multicolumn{2}{|c|}{ فبمدى سال 1 ר آ انظرب } & \multirow{2}{*}{ 1 } & \multirow{2}{*}{1711} & \multirow{2}{*}{$1 T \cdot Y$} & \multirow{2}{*}{ 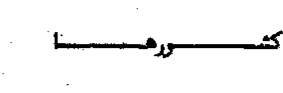 } \\
\hline 1511 & 1511 & $I T \cdot Y$ & rin & $I T \cdot Y$ & & & & \\
\hline $1 \cdot$, & $1 \cdots$, & $1 \cdots$, & A,$r$ & $r \cdot r$ & rיer & rteigr & TrYYYT & c. \\
\hline$r \varepsilon, \lambda$ & $r$ r & $r \varepsilon, 1$ & Ar, $\mathrm{g}$ & \& & - & itry & lirk10 & 1 / كثورمائ، أسطانسـسـ \\
\hline 19 & $r, Y$ & 11,7 & $\left|r r_{2}\right|$ & $\cdot 1,1$ & $r r r$ & $|A \cdot T|$ & 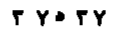 & مثلد وسمتـــــــــان \\
\hline$r, \imath$ & 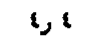 & ir & $\varepsilon, Y$ & 11,1 & \& & $1 \cdot 21 Y$ & \& 149 & هاكستــــــــــــن \\
\hline - & - & $1, \cdot$ & - & - & - & - & tTAT & جيســـ \\
\hline 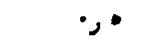 & 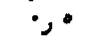 & 1 & $r_{\wedge} j^{\cdot}$ & $\mid 19$ & 11.Y & $\operatorname{lrg}$ & $\cdots Y \cdot$ & جســابيستســـــــ ن \\
\hline- & - & ו & - & - & - & - & $r \cdot r r$ & 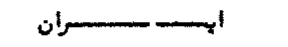 \\
\hline $1, r$ & , 1 & r r & $\mid r i{ }^{\circ}$ & $r$ & 111 & $r \cdot r \cdot$ & rerye & عريسنان سـ سود ى \\
\hline ارن & $\dot{\theta}$ & $\cdot \cdot$ & 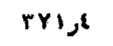 & זו1 & $15 \cdot$ & $r \cdot$ & וז & 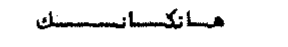 \\
\hline $1 \cdot, \cdot$ & $i r, r$ & $r, r$ & $T Y, \Gamma$ & 179 & $r H \cdot r$ & rises & IrEOT & سايركتورماىاسيانس \\
\hline$Y \&, \varepsilon$ & Yr, & 11, & ارن & $r_{i}, \cdot$ & $1 \cdot 7 \cdot 7 \cdot$ & IYrIAT & ויודו1 & r /كثورماى الويسـانسـى \\
\hline$r i, 1$ & $(\bullet, \bullet$ & $r \varepsilon, \lambda$ & $r$ ro & $\bullet 9,1$ & IYIs. & $1 \cdot Y 2 \cdots$ & IIrTr & 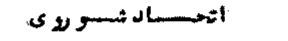 \\
\hline r & $r, r$ & $1, r$ & $1 \cdot r, \lambda$ & ri, & 188 & צוד & $r \cdot 11 r$ & انهستـــــــــن \\
\hline 19,8 & $17, r$ & $r_{2} 1$ & $1 \cdot \hat{A} \jmath^{2}$ & $11 \cdot, 2$ & \&18 ir & rAYY. & rrit & البـــان متهــــــــــ \\
\hline $1 \cdot 1$ & $r$ & $1, \cdot$ & litי & $\{r q\}$, & rirak & $7 x \cdot r$ & \&s\& & بكسوملراكي ســــــــا \\
\hline $1, r$ & - & - & - & - & $r \bullet 1$ & - & - & 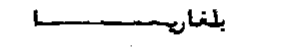 \\
\hline$\dot{\bullet}$ & - & ار• & - & $\mid r, r$ & ir & - & ris & بستــــلينستــــــــــد \\
\hline$r, 1$ & $0, r$ & $\Lambda, r$ & $1 r T, 0$ & וr & $17 \cdot 7 \cdot$ & itgit & titer & سا يركت ورماي. الروانه. \\
\hline , 1 & rار• & $r, 1$ & ג & 18,1 & IATY & $\cdots$ & ir:st & r / كثورماى امريكانســـي \\
\hline$\cdot 1$ & $\varphi r$ & r. & 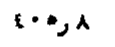 & 18,1 & $171^{\circ}$ & 118 & nTra & اليالا تع متعدمامريكا \\
\hline$\cdot, \cdot 1$ & $\cdot$ & ت ار & $|r|$, & $I Y, T$ & $1 \bullet r$ & 11 & $1 \cdots$ & 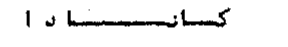 \\
\hline - & - & ارن & - & - & - & - & Mit & سايركتورماى الريكا ثي \\
\hline- & - & ارن & - & - & - & - & $r i$ & 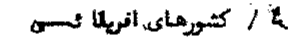 \\
\hline$\varphi \cdot$ & $\cdot \cdot$ & 0,1 & 1 & $\bullet \cdot$ & 1 & 11 & $r \cdot r$ & • ركثور ماي ارتيانوسيه \\
\hline
\end{tabular}

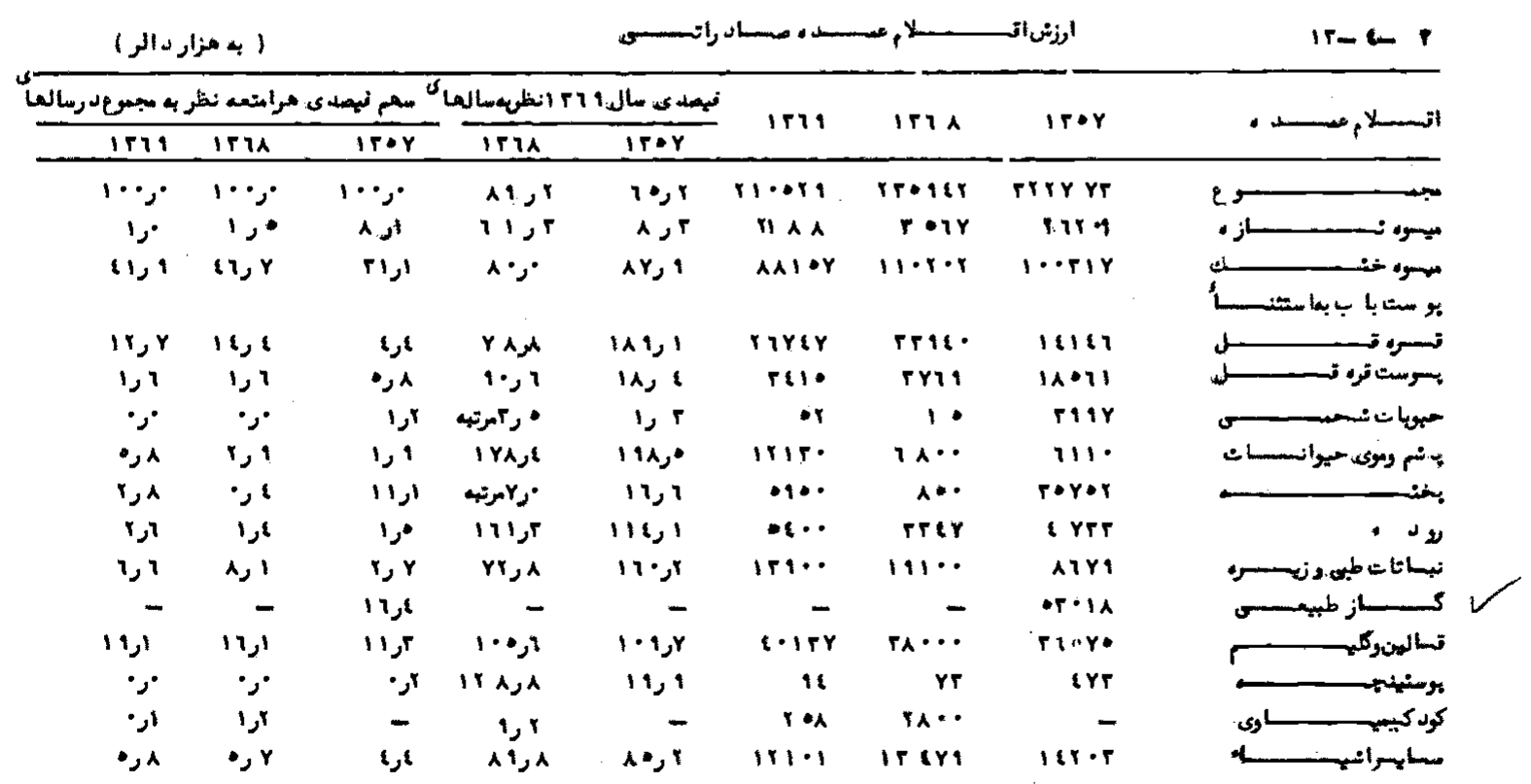




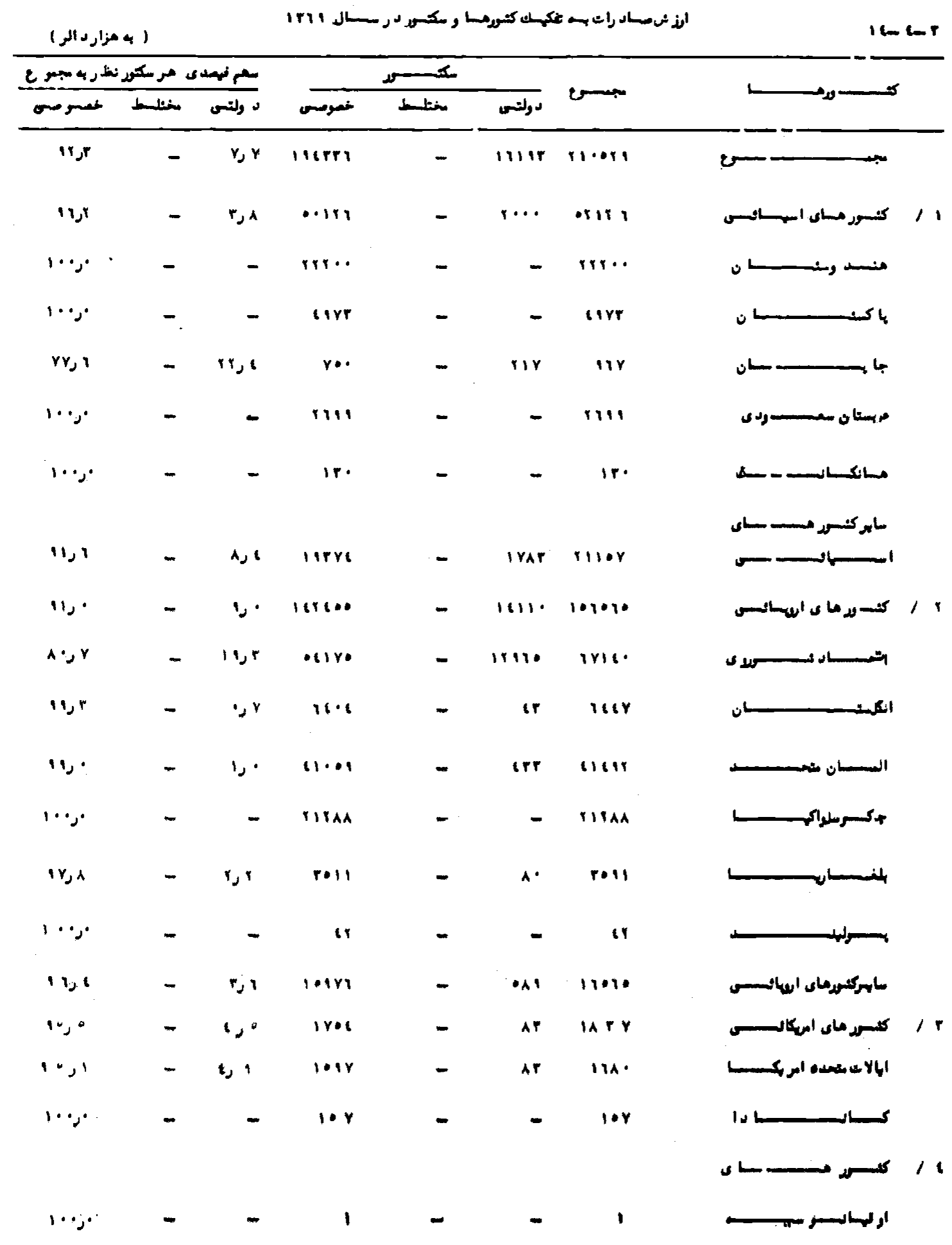




\begin{tabular}{|c|c|c|c|c|c|c|c|}
\hline \multicolumn{2}{|c|}{ 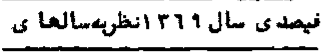 } & \multirow{2}{*}{1819} & \multirow{2}{*}{ iris } & \multirow{2}{*}{ Iroy } & \multirow{2}{*}{ مقيساس } & & \multirow{2}{*}{ 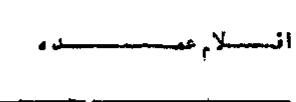 } \\
\hline $\operatorname{lru}$ & Iror & & & & & & \\
\hline ir $q$ & ت ارr & rals & rq1 & AA१Y & نسسن & & 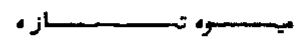 \\
\hline$A \cdot, r$ & $\cdot a, r$ & $\cdots$ & $i r \cdots$ & $A \cdot \mid A r$ & نستسن & & 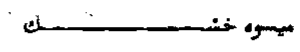 \\
\hline$r i, r$ & $Y Y, \Lambda$ & $r q \varepsilon$ & \&ry & ryat & مزارجلد & & بوست باب به أستثناء قره تسلم \\
\hline i० & ו ניו & ויו & $\varepsilon \cdot 1$ & $1: 1$ & هزار جلد & & 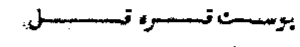 \\
\hline $\mid \wedge, 1$ & $\cdot \gamma$ & 01 & $1 \cdot$ & $Y \& 99$ & نس & & 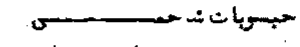 \\
\hline $1 x \cdot 1$ & ' & riYq & $|Y| \mid$ & rair & تسسن & & ينّ مـ وموى سيرانسســـــات \\
\hline Y را امتبب & $i r$ & ro. & $r \cdot$ & YYYYY & تسسن & & بخنس بـ \\
\hline $1 \cdot 9,1$ & $i y, r$. & 10 & ונומו & rita & هزأ,حلته & & 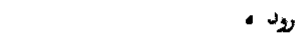 \\
\hline $1 \cdots$, & אוצ & $111 \cdots$ & 1118. & וזו & نسمسن & & نباتات طبسى ونيـــــــــــ \\
\hline $1 \cdot 1,0$ & $111, r$ & $\wedge 9$ & ATt & -r & مزأرمنرميب. & ; & 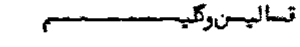 \\
\hline 1" & r & 1 & 1 & ra & مزارنوب & & 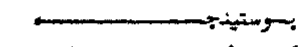 \\
\hline 11,1 & - & Mri & irye. & - & نســن ن & $\therefore$ & كسـود كيمه \\
\hline
\end{tabular}

\begin{tabular}{|c|c|c|c|c|c|c|}
\hline \multirow{2}{*}{\multicolumn{2}{|c|}{ 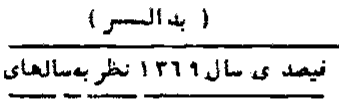 }} & \multicolumn{4}{|c|}{ 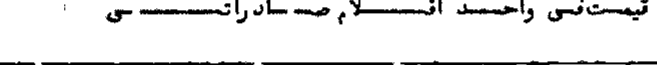 } & \multirow{2}{*}{$11-\varepsilon$} \\
\hline & & \multirow{2}{*}{1519} & \multirow{2}{*}{ iris } & \multirow{2}{*}{ iroy } & \multirow{2}{*}{ واس } & \\
\hline iris & $15 \cdot Y$ & & & & & \\
\hline $111, y$ & irø. & بور & ارن & \& & 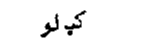 & انســـواع انكـــــــورد \\
\hline- & 1•., & rار & - & rر• & $\nu$ & 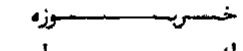 \\
\hline $1 \cdot \lambda, r$ & " بر بمرتبه & זرن & rار & $\cdot{ }^{8}$ & $\nu$ & 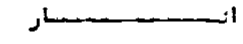 \\
\hline $1 \cdot r, 1$ & $1 \times 90^{\circ}$ & יני & r & 'ו & ע & 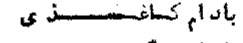 \\
\hline $1 \cdot 0,1$ & $11 r, 1$ & 1,1 & $1, y$ & 1 & $\nu$ & باد الر سنكـــــ5 \\
\hline $1 \cdot r, r$ & $1 r 1,4$ & $\varepsilon$ & $\varepsilon$ & $r, Y$ & $\nu$ & 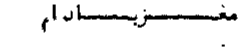 \\
\hline ש \& & $11 \%, 8$ & 8 & $\gamma_{j}$ & $\Lambda ر$ & $\nu$ & 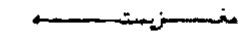 \\
\hline$i r \cdot 0$ & ارץ مرتبه & 1,1 & $10^{\circ}$ & • ب & $\nu$ & 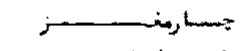 \\
\hline 1 r r r r r r r & - & $r \jmath^{*}$ & וرי & - & $\nu$ & هنــز جارمنــــــــز \\
\hline $1 \cdots$, & $i r Y \mu$ & נו & נرו & יני & ע & 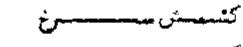 \\
\hline $1 \cdot r, 1$ & •رامتبه & مرr & r & 1,8 & $\nu$ & كشتمش سبـــــــز \\
\hline $1 \cdots$ & $\mid r Y, 1$ & ינו & יני & יני & עد & كتــــن سي \\
\hline $1 \cdot \gamma, \gamma$ & 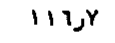 & \& & r & r & $\nu$ & 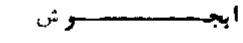 \\
\hline $18, y$ & ا & 1,1 & 1, & بر• & $\nu$ & شكسيكر بســــاره \\
\hline 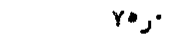 & ار آهرنب & $r$ & יני & $r$ & جلسد & بو سث كوسنفنســــن \\
\hline AY Y & كربت مرتبه & $1 \cdot 1$ & • & $r, \varepsilon$ & جلس & 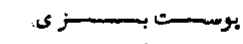 \\
\hline$r_{0,1}$ & יار آهرته & 11,1 & $r r$ & ינו & جملد & بسوستكت كســــــا وs \\
\hline 159,1 & $1 \wedge, \wedge$ & $i r, 1$ & 9,1 & 1Aر & 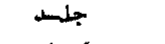 & 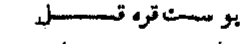 \\
\hline - & 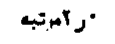 & 'ر & - & •ر• & كهلو & 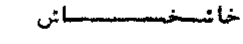 \\
\hline $1 \cdot 80^{\circ}$ & 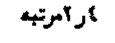 & ارغ & "ر\& & Yرا & ע & 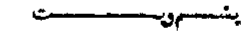 \\
\hline $1 \cdot, y$ & $15 \cdot 21$ & $1, y$ & $1, A$ & iر & $\nu$ & 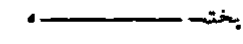 \\
\hline ira, 1 & iris: & ונז & i & ارن & $\nu$ & 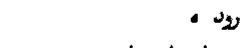 \\
\hline$r \cdot r^{r}$ & $r i, r$ & $1, r$ & $1, Y$ & ارؤ & $\nu$ & نبساتساتطبستسمى \\
\hline $1 \cdot 1,5$ & יז & ارע & "נ• & rer & 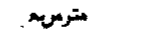 & تس اليسن وكليســــ \\
\hline - $\{$ ر & - & ir & $r r \cdot$ & - & ت & كود كيهي_ــــــــاوى \\
\hline
\end{tabular}




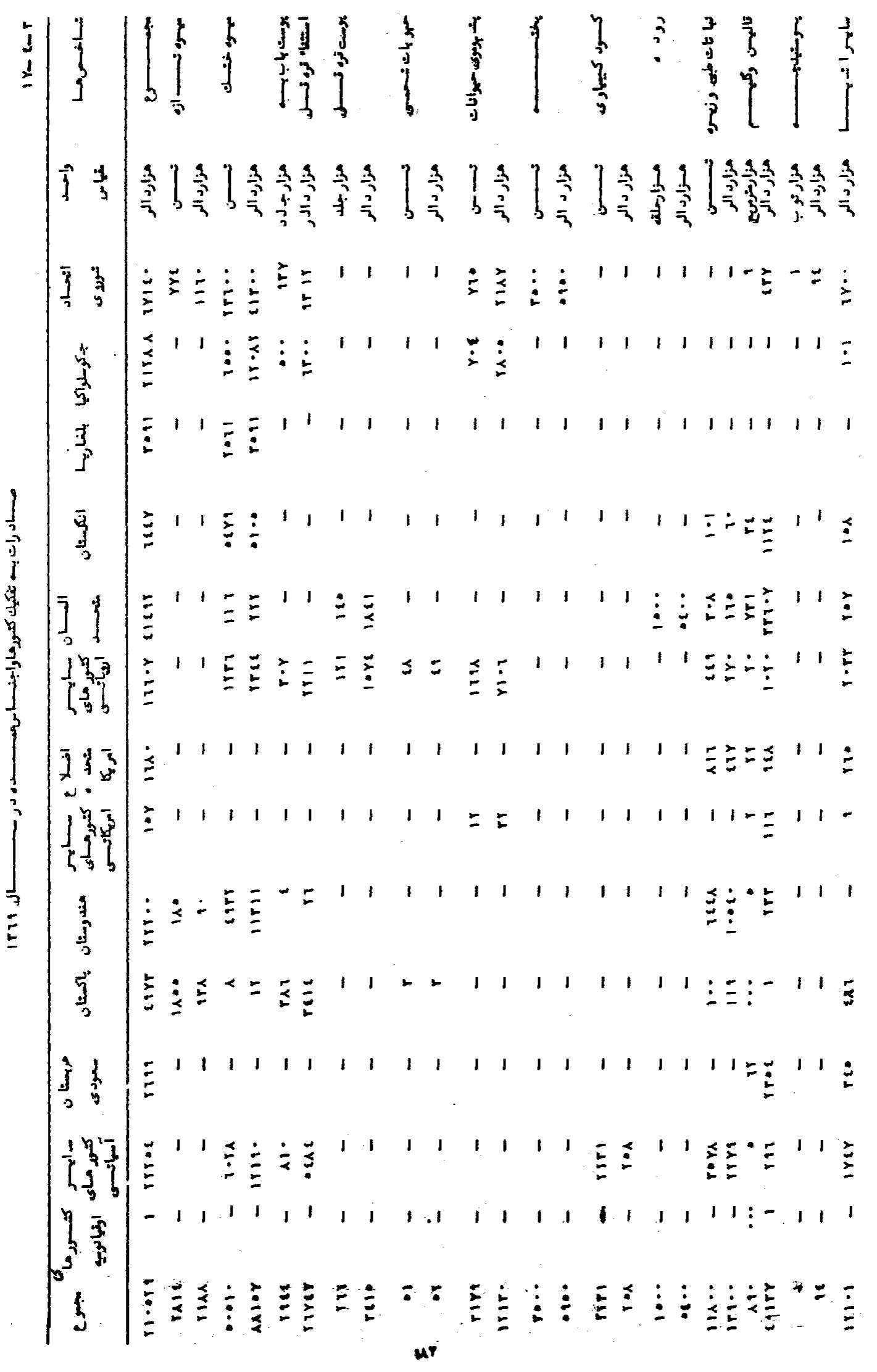




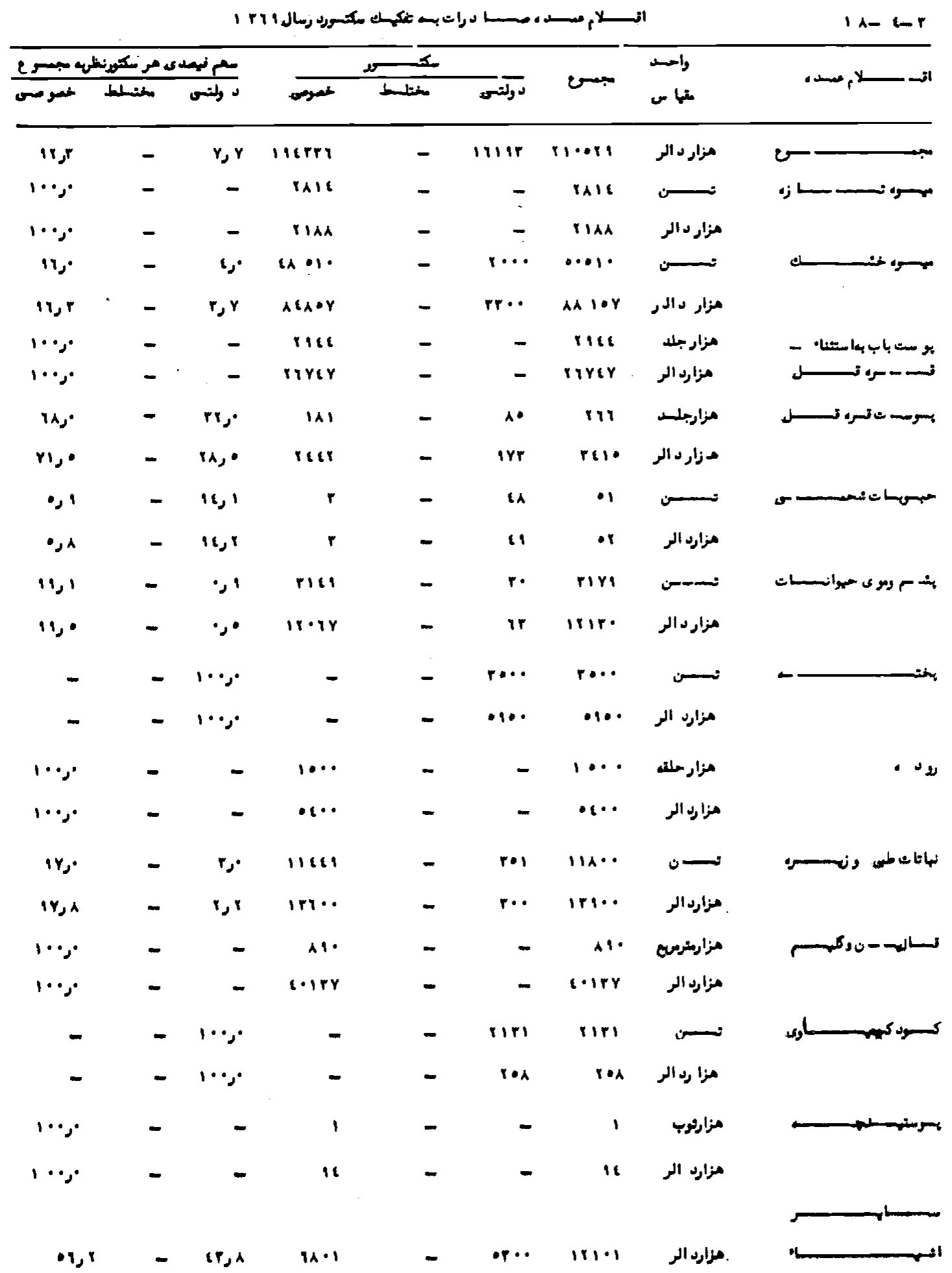




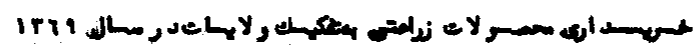

\begin{tabular}{|c|c|c|c|c|c|}
\hline كسنس & نحســـود & لسשس & بسرنهب & كسدم & ولاعسـات \\
\hline 10 & $\boldsymbol{\lambda} \cdot$ & ire & rear & Miry & $\downarrow$ \\
\hline 18 & 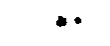 & תו & I IYY & 119 & 0 \\
\hline - & $* 1$ & 2 & 811 & IYIT &, \\
\hline$\cdot 4$ & $r \cdot$ & $7 !$ & $A Y Y$ & Ar ro & لم \\
\hline • & $\bullet A$ & YA & irf & TYET & سان \\
\hline 1 & $n$ & is & rry & $1 \cdot Y 11$ & - \\
\hline$r$ & $r$ & rY & $r \cdot \lambda$ & וזr & \\
\hline 1 & IrA & rr & $r \cdot \lambda$ & rATI & $\sigma$ \\
\hline$r$ & $1 \cdot$ & ir & iri & ir re & \\
\hline ir & $m$ & $2 \lambda$ & ive & $11 \cdot 9$ & $=1$ \\
\hline - & ir & IY & 101 & lirya & سـار \\
\hline - & - & - & ire & $r \cdot s t$ & $L$ \\
\hline$r$ & 10 & ir & 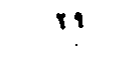 & Iro. & كرن \\
\hline in & $\varepsilon$ & 1 & $\cdots$ & rrri & - راه \\
\hline$\wedge$ & 1 & 1 & $\varepsilon \varepsilon$ & 1998 & 0ᄂ \\
\hline$r$ & $r r$ & • & $r \mid r$ & $r \cdot r r$ & oL \\
\hline- & ro & $r \lambda$ & rer & rrat & \\
\hline $\mathbf{Y}$ & re & ir & rYr & $i r \cdot r$ & o \\
\hline $\mathbf{r}$ & $1 \cdot$ & $r$ & $1 \cdot 1$ & rrt. & \\
\hline- & - & - & 1 & ry & \\
\hline- & - & - & ir & 180 & $=1$, \\
\hline 8* & $r \cdot$ & $r^{i r}$ & IYA & - & - هواט \\
\hline 1 & $1 \cdot 1$ & 11 & - & rele & \\
\hline - & - & 18 & $r \varepsilon$ & $\boldsymbol{A \lambda} \boldsymbol{A}^{\circ}$ & \\
\hline- & - & - & - & ir & \\
\hline$r \cdot r$ & iry & YAI & 1.8r & irre $q$. & \\
\hline
\end{tabular}




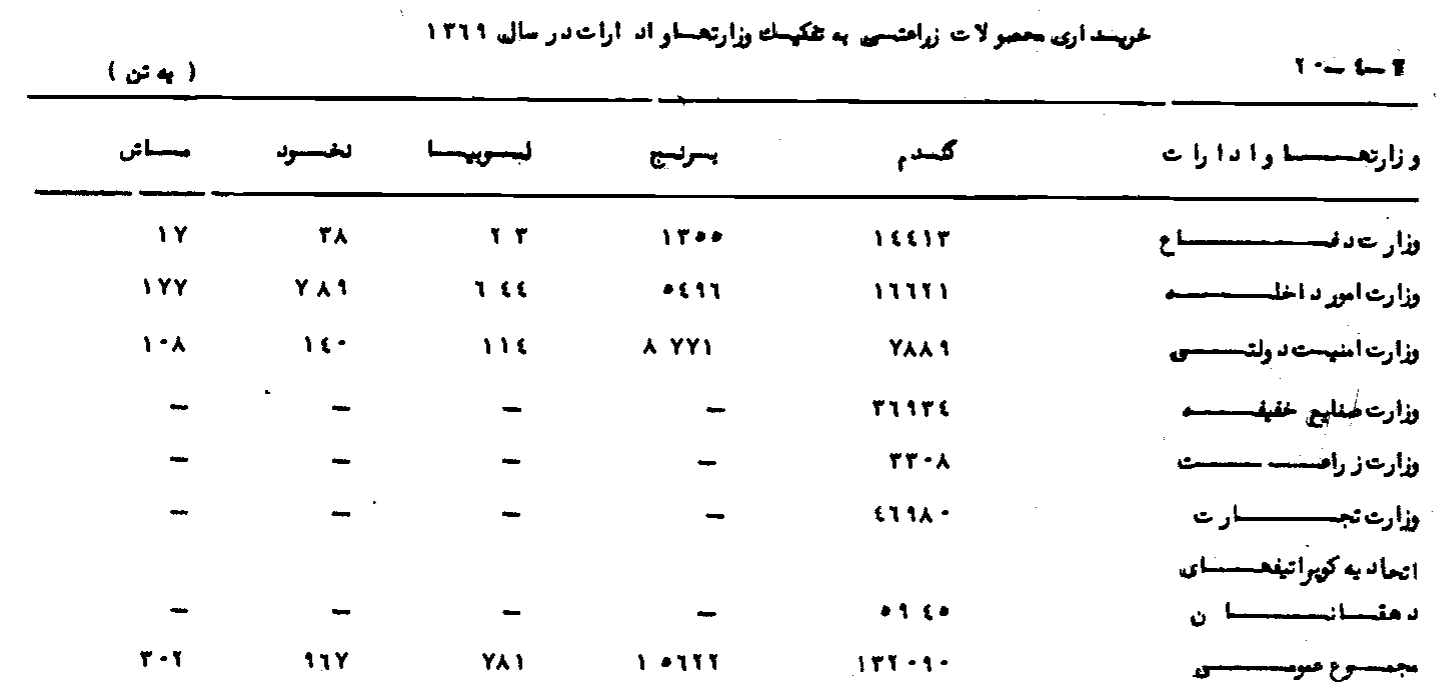

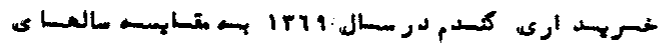

iru, irge

(i)

$V 1-2-T$

\begin{tabular}{|c|c|c|c|c|c|}
\hline \multicolumn{2}{|c|}{ 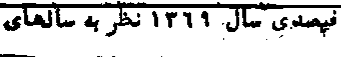 } & \multicolumn{3}{|c|}{ 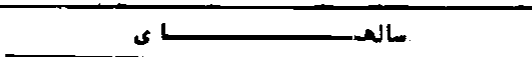 } & \multirow{2}{*}{ وزا رتعســــــاد ارا = } \\
\hline IruA & irye & IrI9 & iruA & irye & \\
\hline Y رז مونهـ & •رr متتب & 18617 & rAY\& & $\leqslant \ll$ & 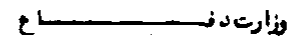 \\
\hline $1 \bullet \wedge, \gamma$ & 1 & III1 & $1 \cdots$ & $r \bullet \wedge y$ & 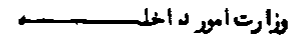 \\
\hline $1 \& 1,8$ & - & YAA & $\bullet \wedge \cdot$ & - & 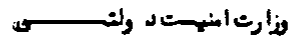 \\
\hline ارت مرت4 & • ر" مزت4 & ryirs & IArI & II YY & نأرت منايع خغبغســـــــ \\
\hline $\mid r q, 1$ & $\{9,1$ & $r r \cdot A$ & YrYq & IYIY & ار ث نرامسـ \\
\hline 1 رح مرتب & Y رو مرت4 & 874. & $1 r \cdot i r$ & 1919 & ل فأرث نجس \\
\hline $1 \cdot, *$ & $118, x$ & -18 & $11 \cdot 1$ & $\cdot \mathrm{HA}^{\circ}$ & 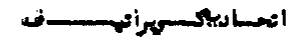 \\
\hline • ر مرلهم & • رع مرته. & iry-9. & -rase & $r Y \cdot Y Y$ & \\
\hline
\end{tabular}




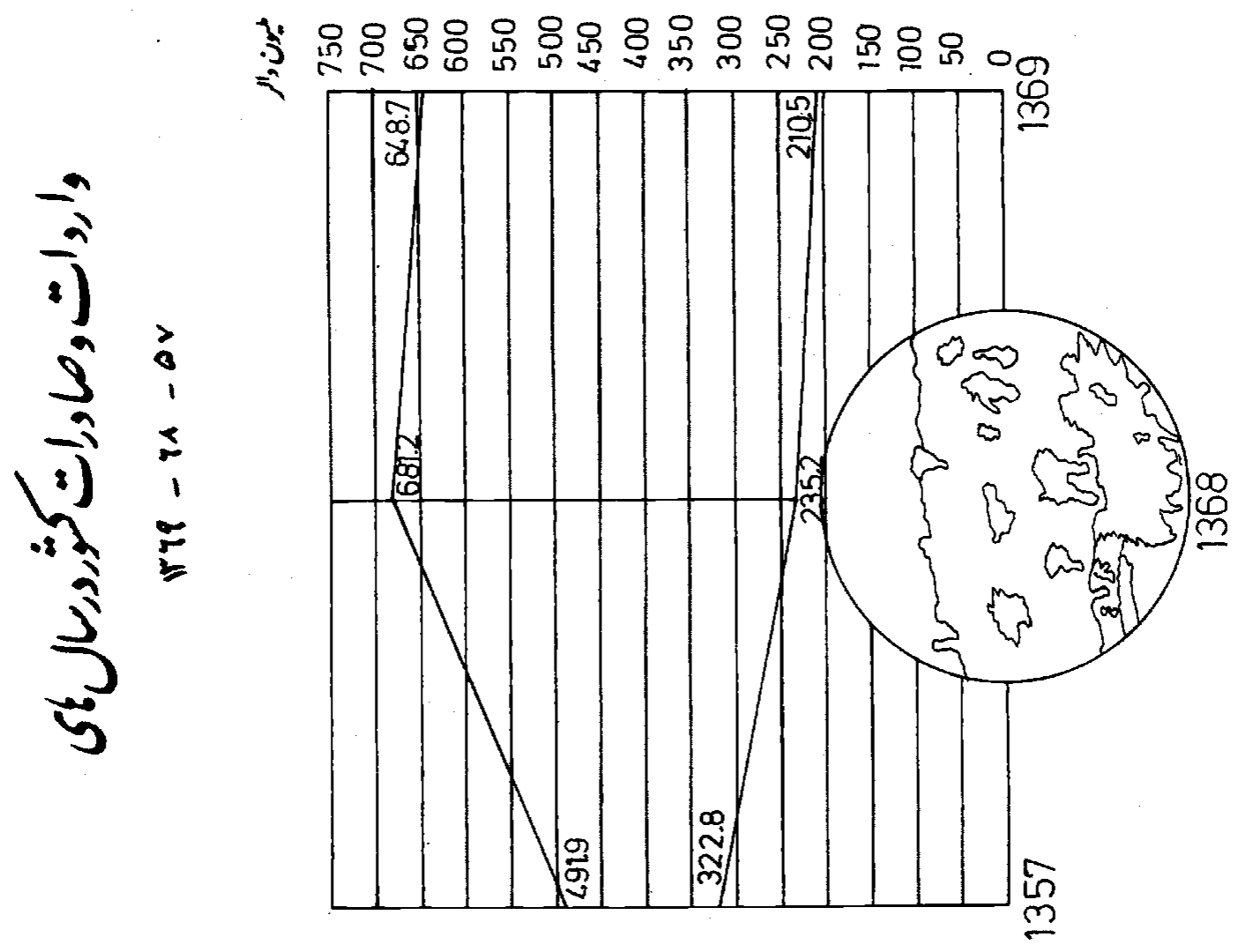




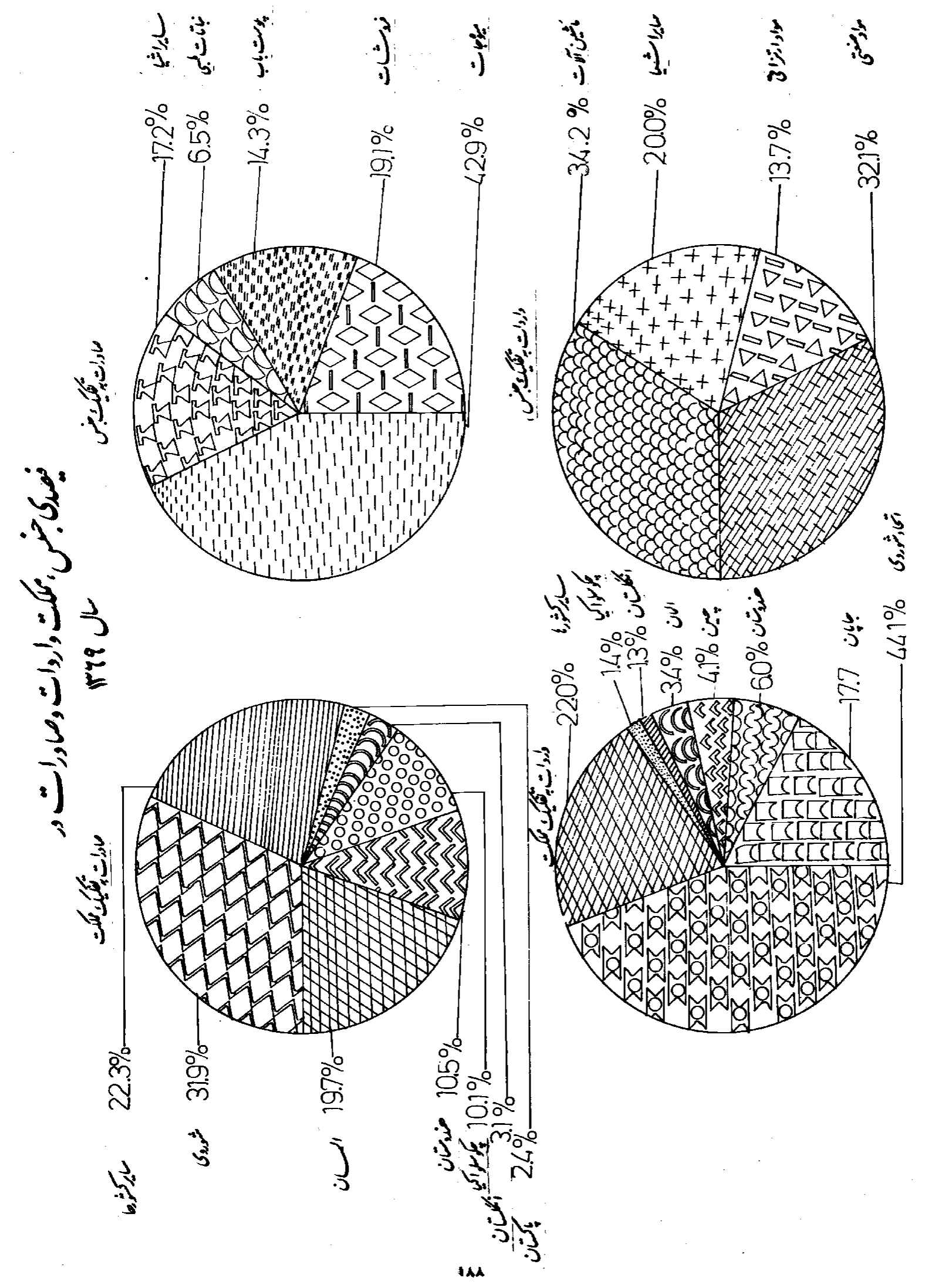




\begin{tabular}{|c|c|c|c|c|c|c|c|c|c|}
\hline \multicolumn{2}{|c|}{ سبمستر } & \multicolumn{2}{|c|}{ امستسداد } & \multicolumn{2}{|c|}{ 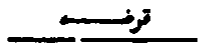 } & \multicolumn{2}{|c|}{ - Ier تصد اد } & \multirow[b]{2}{*}{ كث سر، ماروستس سلـــان } & \multirow[b]{2}{*}{ يماره } \\
\hline ir19 & Tris & 1819 & $\overline{1 r u}$ & Tा1 & 179 & Trit & $\pi \pi$ & & \\
\hline$\hat{\Lambda}$ & $\mathbf{Y}$ & 1 & - & $\mathbf{t}$ & $r$ & 1 & 1 & ب & التـ \\
\hline$(r, r$ & $r \cdot, 1$ & - & 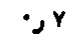 & ir & $r i, l$ & 11 & ri & 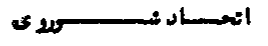 & 11 \\
\hline 1,1 & $1, Y$ & - & - & 1,1 & $1, Y$ & 1 & 1 & 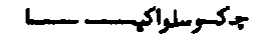 & 11 \\
\hline - & 1 & - & - & - & 1 & - & - & L & Ir \\
\hline 'י & $1, r$ & 1, & $1, r$ & - & - & ' & ' & 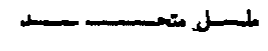 & 12 \\
\hline $11, \lambda$ & $(\cdot, 1$ & 1, & יני & $(\bullet, \lambda$ & $(r, r$ & IA & 11 & "بمستسـس & \\
\hline
\end{tabular}

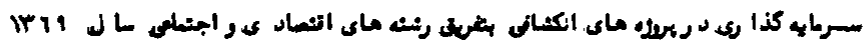

\begin{tabular}{|c|c|c|c|c|c|c|c|c|c|}
\hline \multicolumn{10}{|c|}{ 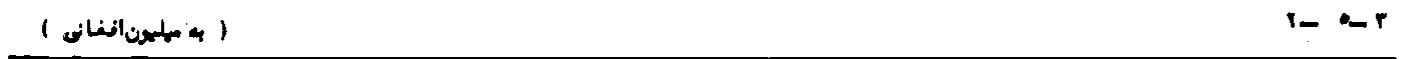 } \\
\hline \multicolumn{2}{|c|}{ مبمر عسلد مار رن } & \multicolumn{2}{|c|}{ مارنسازماه لهارجسى } & \multicolumn{2}{|c|}{ مارف ازمنابعد الطلى } & \multicolumn{2}{|c|}{ تعد اد مئده مســ } & \multirow{2}{*}{ 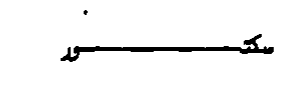 } & \multirow{2}{*}{ نهار. } \\
\hline 1811 & $\sqrt{181 A}$ & 1819 & 1811 & 1791 & $\sqrt{171}$ & 179 & 1811 & & \\
\hline$\Lambda$ & $Y$ & 1 & - & 6 & $r$ & 1 & 1 & ب & الف \\
\hline$i r \cdot 1, y$ & $11 r, y$ & r נr & ונוויו & $1+1, y$ & Mrita & $\wedge$ & •r & نداعسبـ وابسـ - & 11 \\
\hline$r \cdot q, 1$ & $r * r, \lambda$ & $1, r$ & ر & $r \cdot r, y$ & $r \cdot r$ & ' & - & اسياك حجد د بكلده & \\
\hline$A t r, r$ & $T r r, 1$ & $n, r$ & 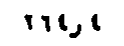 & $\cdots 1$, & $l \cdot \lambda, \lambda$ & 11 & IY & 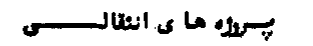 & \\
\hline$i r, r$ & $(1, Y$ & - & - & $i r, r$ & $(1, y$ & 11 & 11 & 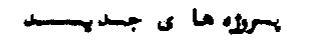 & \\
\hline$r y, r$ & $r \cdot$ & - & - & $r y, r$ & $r \cdot e^{\prime}$ & $\wedge$ & $\bullet$ & 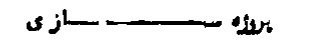 & \\
\hline$r r i, r$ & riY, & r r & $Y \wedge J$ & rrajl & 14,1 & 19 & it & ب : & 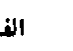 \\
\hline$r(t,$. & $11, \lambda$ & $r r, r$ & $Y \lambda_{\lambda} \cdot$ & $r i \cdot, A$ & rr & 11 & 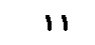 & كلا وه مسكاي ا نتلالســيس & \\
\hline$I Y, T$ & $r \cdot, r$ & - & - & $\mid r, r$ & $r \cdot, r$ & ir & 11 & 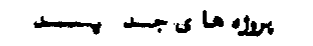 & \\
\hline - & • & - & - & - & $\bullet$ & 1 & 1 & 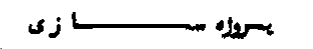 & \\
\hline$A \wedge||$, & $r i, r$ & $1 \bullet 9,1$ & $|\lambda A|$, & $i n, r$ & $(Y Y, 1$ & $\bullet$ & 19 & 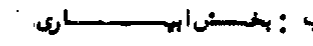 & \\
\hline$r \cdot 1,2$ & $r \cdot r, i$ & $1, Y$ & r. & $r \cdot Y, Y$ & $r \cdot 1, r$ & $\mathbf{l}$ & - & اسيا ى سبدد دي كعذ & \\
\hline$(1 \lambda, r$ & PAl, & $r \cdot 1,1$ & $1 x \cdot 1$ & $r \cdot, r$ & 110, & ri & 11 & كعثه ماى التهـــ1 & \\
\hline$r \bullet, Y$ & 11,1 & - & - & $r \bullet, Y$ & $\mid$ & 1 & $\bullet$ & 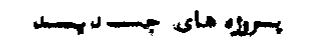 & \\
\hline$r y, y$ & $r \cdot{ }^{\prime}$ & - & - & $r Y, Y$ & $r \cdot$ & 1 & $r$ & كسبط سـ & \\
\hline$r r \cdot r$ & $r \cdot \bullet 1$, & (1114 & "וr & 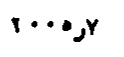 & 1111, & 11 & Yr & معاد نمساه و السرل & 11 \\
\hline$(1 r, r$ & $(11)$ & $1 \cdot 1$ & 116,1 & $r \cdot r, r$ & $111, r$ & 1 & 1 & 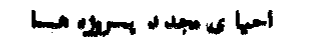 & \\
\hline $\mid x \cdot Y^{\prime}$ & $r \cdot(x, n$ & $\| 1 \cdot, \lambda$ & AYr. & A & $\operatorname{lir},{ }_{1}$ & i. & $1 \cdot$ & 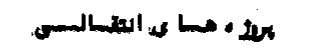 & \\
\hline $1 \cdot, 1$ & 11,1 & - & - & $1 \cdot, 1$ & 1,1 & $\mathbf{r}$ & - & 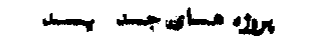 & \\
\hline 11,1 & $\cdot 1$ & - & $r \cdot, 1$ & 1,1 & $r \cdot, \lambda$ & 16 & il & 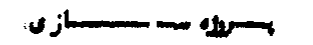 & \\
\hline
\end{tabular}


$r-r$

\begin{tabular}{|c|c|c|c|c|c|c|c|c|c|}
\hline A & $r$ & 1 & - & $\varepsilon$ & $r$ & $r$ & 1 & 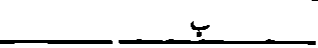 & الثي \\
\hline IIIYY & Irraj: & Ir & rY०, & إرع & $9 Y \varepsilon, \varepsilon$ & 11 & 19 & 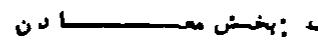 & الغ \\
\hline$r \varepsilon$ r & $r q r, q$ & ו & irs? & נית. & $11 \cdot 5$ & - & $r$ & احيا ك مجدد بدوله مســـ & \\
\hline |ר•• & וر• וrr & \|•r. & •・1 & 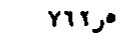 & YI & $r$ & 11 & 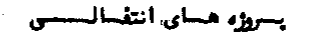 & \\
\hline$r \cdot{ }^{\prime}$ & $x \cdot, \varepsilon$ & - & - & $r \cdot r^{\prime}$ & $r \cdot, \varepsilon$ & 1 & $r$ & 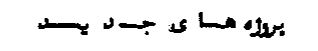 & \\
\hline ו & (ر) & - & - & I & $\varepsilon \cdot$ & $r$ & $r$ & بسونه سحس سـازs & \\
\hline$\{\wedge q\}$, & $r \cdot \wedge, *$ & $r Y_{j}$ & •^ر & \{rर, & $r \cdots, r$ & ir & $r \cdot$ & بخستصصنايح & ب \\
\hline $1 \cdot 1, \gamma$ & 10,8 & ' & ? & $I r \bullet, r$ & $1 \varepsilon r$ & $r$ & - & احيا ى مجدد بهزه مســا & \\
\hline$r \cdot r, r$ & $r q r, r$ & 11,1 & $r i, q$ & 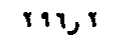 & $r H, r$ & 11 & $1 \cdot$ & بسمةه مســاى انتخسالى & \\
\hline$r \cdot r$ & - & - & - & $r \cdot r$ & - & $r$ & 1 & 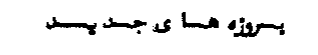 & \\
\hline - & $\varepsilon q, \gamma$ & - & $x \bullet \varepsilon$ & - & $r \varepsilon, r$ & $\mathbf{r}$ & 9 & 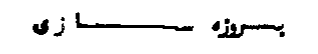 & \\
\hline$\| \bullet \wedge$ & ותו1ו & $r$ & Y & • \१ו & $|Y| r$ & ir & 19 & 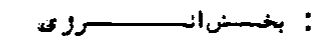 & $\varepsilon$ \\
\hline 19. & $\bullet \cdot$ & - & - & | & $\bullet \cdot$ & 1 & 1 & ا حسا ى مجدد بتزذه مسـسا & \\
\hline$\bullet \wedge \varepsilon \wedge$ & $9 r r, r$ & $r$ & Y ניק & ••人ر & 1 וرזr & it & Y & بعزه ما ى انتخــــــالسـى & \\
\hline- & וני & - & - & - & 'י & - & $r$ & بسمونه هـاى جسـد بـســ & \\
\hline (18. & ק' & - & - & | & ני & $\varepsilon$ & $\mathbf{r}$ & بـسنزه سحس زى & \\
\hline $1 \cdots 1$ & צניט & $r r_{1}$ & צ & 11র•ر & $11 Y \cdot, 9$ & ir & $\circ \varepsilon$ & مشأبرأت و مواصســــلات & $1 r$ \\
\hline$r r \cdot, r$ & $r\{0, r$ & - & $1 \cdot 1$, & $r y \cdot r$ & $r \varepsilon r, Y$ & $1 \cdot$ & $1 \cdot$ & 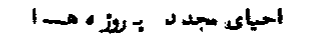 & \\
\hline$\| r r_{j}$ & $\|$ Ira, & 111,8 & riri & $\eta \bullet, \gamma$ & $Y \varepsilon 1, \varepsilon$ & ry & $\mathbf{r}_{\mathrm{A}}$ & 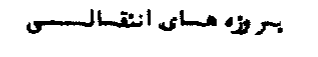 & \\
\hline$r \bullet, 9$ & $\| r, \lambda$ & - & - & $r \cdot, q$ & $\operatorname{lir}, 1$ & 11 & 1 & بح سله ماى جد يســــ & \\
\hline $1 \wedge, \cdot$ & 11,0 & - & - & $i n$, & $i n^{\prime} \cdot$ & $\wedge$ & • & 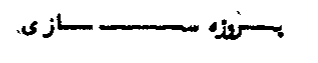 & \\
\hline$r \varepsilon, r$ & $\cdot \varepsilon, \varepsilon$ & $r$ & - & $r i, r$ & $\bullet \varepsilon$ & 11 & 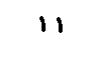 & 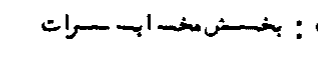 & 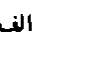 \\
\hline- & י & - & - & - & r · & - & 1 & احيا ى مبدد بيزذ مســا & \\
\hline$i r, r$ & $\varepsilon Y, q$ & Y 9 & - & $r r$ & $\varepsilon Y, q$ & - & r & يسلاف مســاى انتــالسـى & \\
\hline$\wedge, \varepsilon$ & $r$ & - & - & A, $\varepsilon$ & re & $r$ & 1 & بسرون مساى جسد هلـ & \\
\hline- & ני & - & - & - & 1, & $r$ & $\boldsymbol{r}$ & 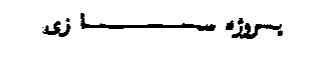 & \\
\hline $1 \& r x, r$ & $\| 1 \bullet, 1$ & rik, & צ צ & irir, & 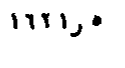 & $\cdot 1$ & $\varepsilon r$ & : بغستصمواصحسـا & ب \\
\hline $\begin{array}{l}r r \bullet, r \\
r \cdot r=j\end{array}$ & $\begin{array}{l}r\{r, r \\
r \cdot q \cdot r\end{array}$ & Iis. & $\begin{array}{l}i \cdot 1, \bullet \\
r q r, 1\end{array}$ & $\begin{array}{l}r y \bullet, r \\
A \bullet r, z\end{array}$ & $\begin{array}{l}Y \varepsilon \cdot, Y \\
Y q A, \cdot\end{array}$ & $\ddot{11}$ & i & 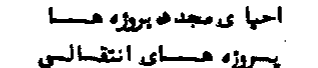 & \\
\hline 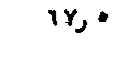 & $r r \cdot r$ & - & - & 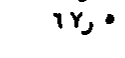 & $M$ & $1 \cdot$ & $1 \cdot$ & 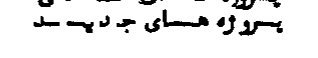 & \\
\hline $11, \cdot$ & $\mid r$. & - & - & $11, \cdot$ & $\mid \gamma_{j} \cdot$ & - & $r$ & 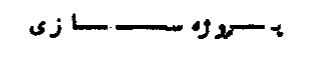 & \\
\hline rAY & $r \cdots$ & $\{r \cdot \gamma$ & $r \cdot r$, & rraq, & IY\&ม & $r \cdot \lambda$ & rir & 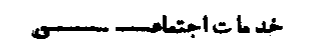 & 18 \\
\hline
\end{tabular}




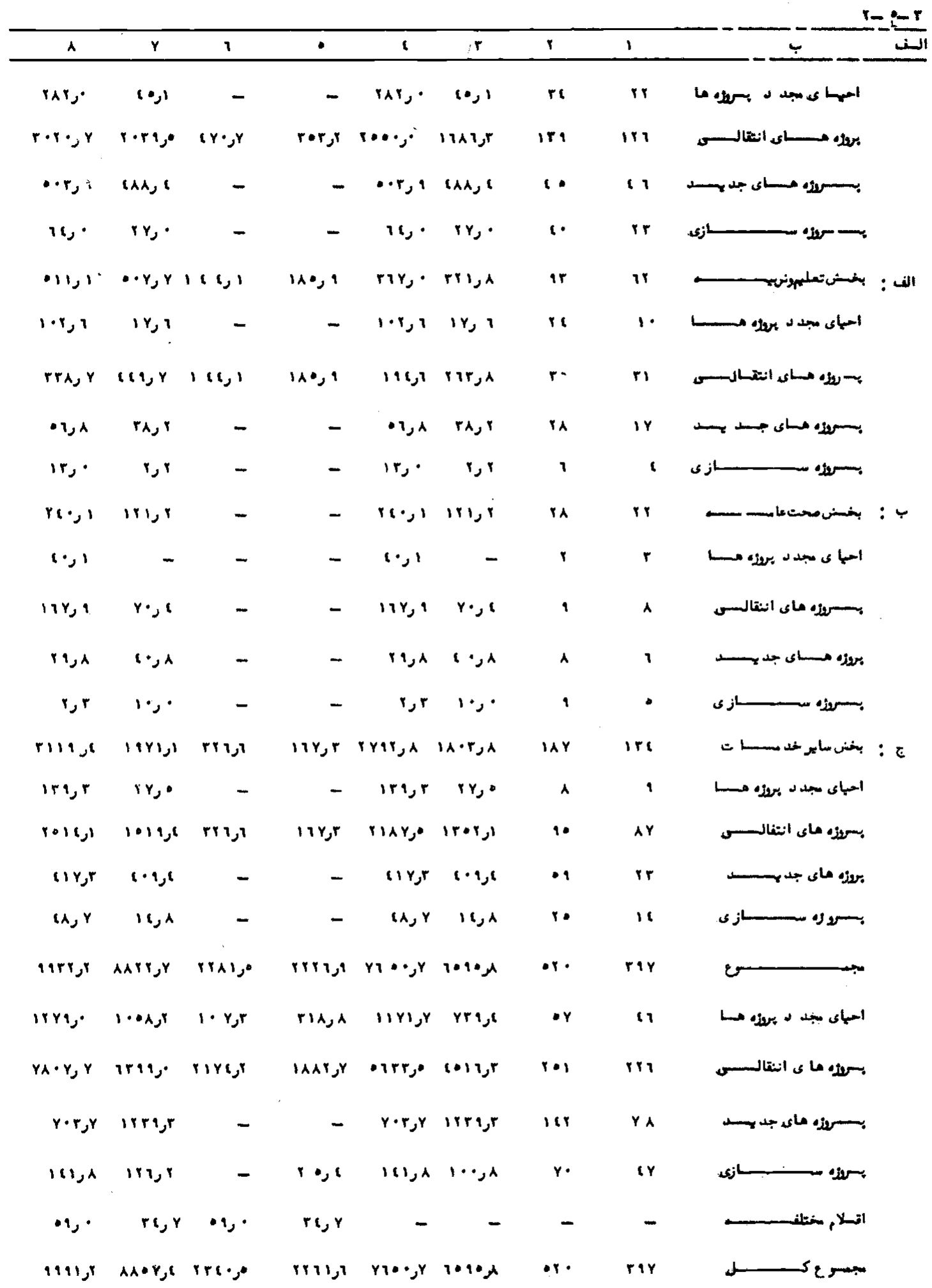




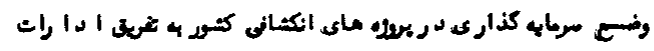

\begin{tabular}{|c|c|c|c|c|c|c|c|c|}
\hline \multicolumn{2}{|c|}{ مجمر عكل معسرن } & \multicolumn{2}{|c|}{ مارن أزماه شاربه } & \multicolumn{2}{|c|}{ مسارنعززمنابع د الحلى } & \multicolumn{2}{|c|}{ تعد اد يونه محس } & \multirow{2}{*}{ أد ارا } \\
\hline 1819 & IrIA & 179 & IFIA & 179 & IFIA & 1719 & IriA & \\
\hline A & $r$ & 1 & $\cdot$ & 1 & $r$ & $r$ & 1 & الدف. \\
\hline PA & $T(\cdot)$, & $r r r$ & $r A, 0$ & $r \cdot r$ & $r 11$ & r9 & $r \cdot$ & وذارت نرامت واملامات ارطسسه : \\
\hline rir, & $r \cdot 1, \lambda$ & $r T, r$ & $r A, \cdot$ & ryas & r & 11 & ir & 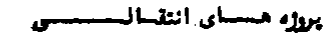 \\
\hline$r r_{2} \cdot$ & $r \cdot, r$ & - & - & $r r_{2} \cdot$ & $r \cdot, r$ & 11 & $1 \cdot$ & بعله ميسا ى جد بحس \\
\hline- & $\bullet$ & - & - & - & $\bullet \cdot$ & r & $r$ & 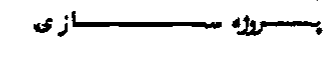 \\
\hline $11, r$ & $A 1, Y$ & - & - & $11, r$ & $A 1, r$ & eA & $r$ & 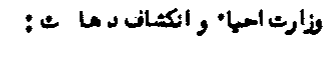 \\
\hline$r 1, r$ & $r A, r$ & - & - & $r 1, r$ & $r A, Y$ & $\wedge$ & ir & احيا ى مجدد د بعلد مســـــا \\
\hline$r \cdot, r$ & - & - & - & $r \cdot, r$ & - & 18 & - & 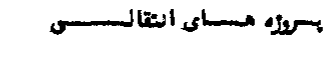 \\
\hline $16, t$ & $|r|$ & - & - & 61,6 & Ir. & it & 1 & 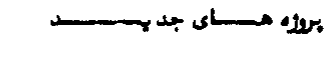 \\
\hline 96 & - & - & - & is & - & - & $r$ & 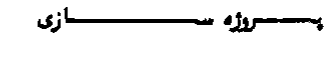 \\
\hline$|6(A)|$, & $1 \cdot A Y, 1$ & $r A Y, Y$ & $(r A, l$ & 1111,1 & $11 \cdot 6$, & 6 & 6 & 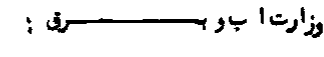 \\
\hline$r A_{\lambda} \cdot$ & $r(r)$, & $1, \lambda$ & קر & rry & $r t, 1$ & 6 & 6 & احبا ك مجدد بملذه مـ \\
\hline $1 \cdot 16,1$ & $|r A|, \mid$ & YAl, 1 & $(r \cdot)$, & $r r \cdot s \cdot$ & $A \cdot \bullet$ & $r t$ & $r r$ & 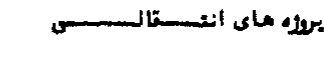 \\
\hline$\bullet r, A$ & $r \cdot j \cdot$ & - & - & $\bullet r, A$ & $r \cdot, \cdot$ & 6 & $\mathbf{r}$ & 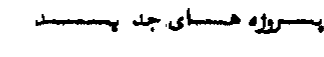 \\
\hline$\bullet r$ & $r 9, r$ & - & - & $\bullet r$ & $r 9, Y$ & $r$ & 1 & 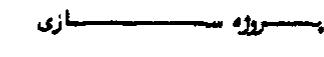 \\
\hline$Y Y I Y, Y$ & $\operatorname{lrrq} 1$ & $18+1,1$ & rres. & $\mid r(j)$ & irtel & ir & $r \cdot$ & وذارت معادن ن ومناهجـــ \\
\hline$r u, r$ & $P 11$, & ונקיA & 11, & $1 \cdot 9,1$ & $1 A \cdot 2 \cdot$ & - & ! & اعبا ى سبد د ب بحسلده مستس \\
\hline 197••• & IrY & $110 \mathrm{rg}$. & $0 \cdot 1,:$ & YAY & ris. & $\wedge$ & $1 \cdot$ & بسمدزه هاى التستسمالس \\
\hline$r \cdot \mu^{*}$ & $r \cdot, t$ & - & - & $r \cdot r^{\prime}$ & $r \cdot, t$ & 1 & $r$ & بعلده مساى جسـد بح \\
\hline $1, \cdot$ & t, & - & - & $9 \cdot$ & 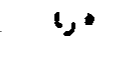 & $\mathbf{r}$ & 1 & 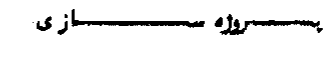 \\
\hline$r \cdot r, \cdot$ & $1 \cdot r, 9$ & $1 \cdot 9$ & ris & דוניו & 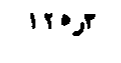 & ir & 11 & 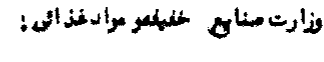 \\
\hline $1 \cdots, t$ & 1,1 & $1 \cdot, 6$ & $\dot{\lambda}$ & $\mid r t$, & •s & $r$ & $r$ & أحباى مجدد ديعاه مــ \\
\hline $\mid r, 1$ & $1 \cdot 1,1$ & - & 1,1 & $|r Y|$ & r & 1 & $r$ & بعلك مســاى انتئسـا \\
\hline$r \cdot, \cdot$ & - & - & - & $r \cdot s$ & - & 1 & 1 & كسول مسـاي بهـد \\
\hline - & $(1, r$ & - & $r \cdot, t$ & - & $r, r$ & - & 1 & 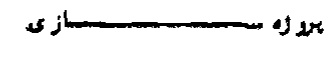 \\
\hline$r$ w $r$ & •rr & $\mid Y Y_{j} \cdot$ & $r \bullet 9, r$ & $116, y$ & 176,6 & Y & $M$ & 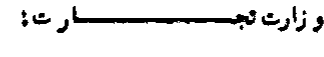 \\
\hline$r \cdot A, r$ & $\mid r Y, 1$ & $\mid r \gamma_{j} \cdot$ & $r \cdot 9, r$ & $|r|, Y$ & $r Y, A$ & ir & ir & بعلد مسيا ى انبلسيالس \\
\hline$r r_{j} \cdot$ & $A Y, i$ & - & - & $r r_{2} \cdot$ & $A Y, P$ & 6 & 1 & سمل ره مبسى بـد \\
\hline - & $r, r$ & - & - & - & $r, r$ & 6 & $r$ & س \\
\hline 10,5 & $r^{*}$ & - & - & $r \cdot r$ & $r$, & 11 & $i$ & نسه : \\
\hline$\cdot r, r$ & $\cdot 1$, & - & - & $\cdot r, r$ & $\cdot 9$, & $\wedge$ & 1 & or \\
\hline 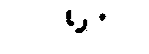 & 1, & - & - & $t_{j} \cdot$ & 1, & 1 & 1 & 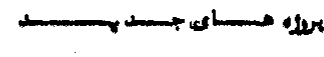 \\
\hline
\end{tabular}




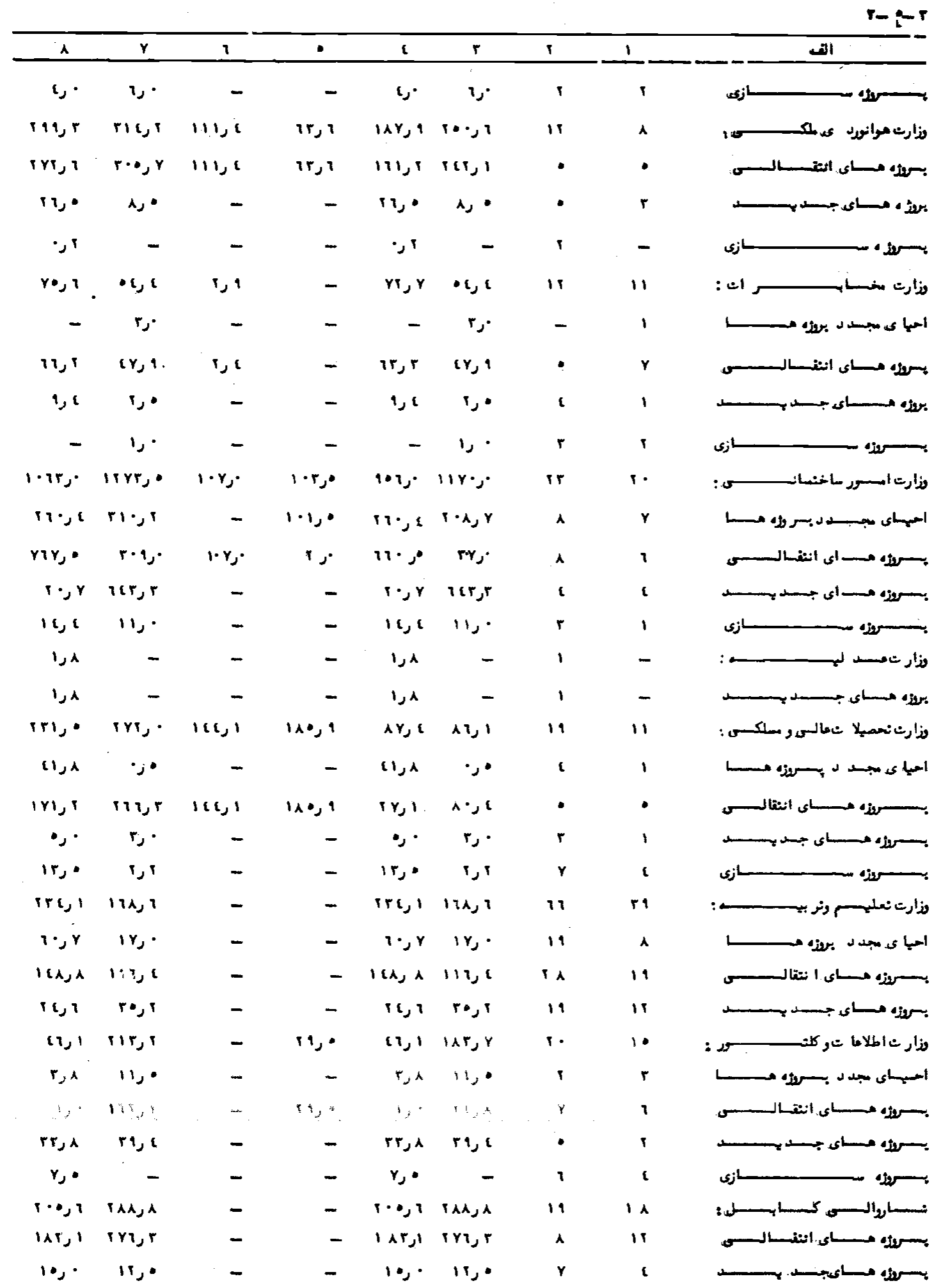




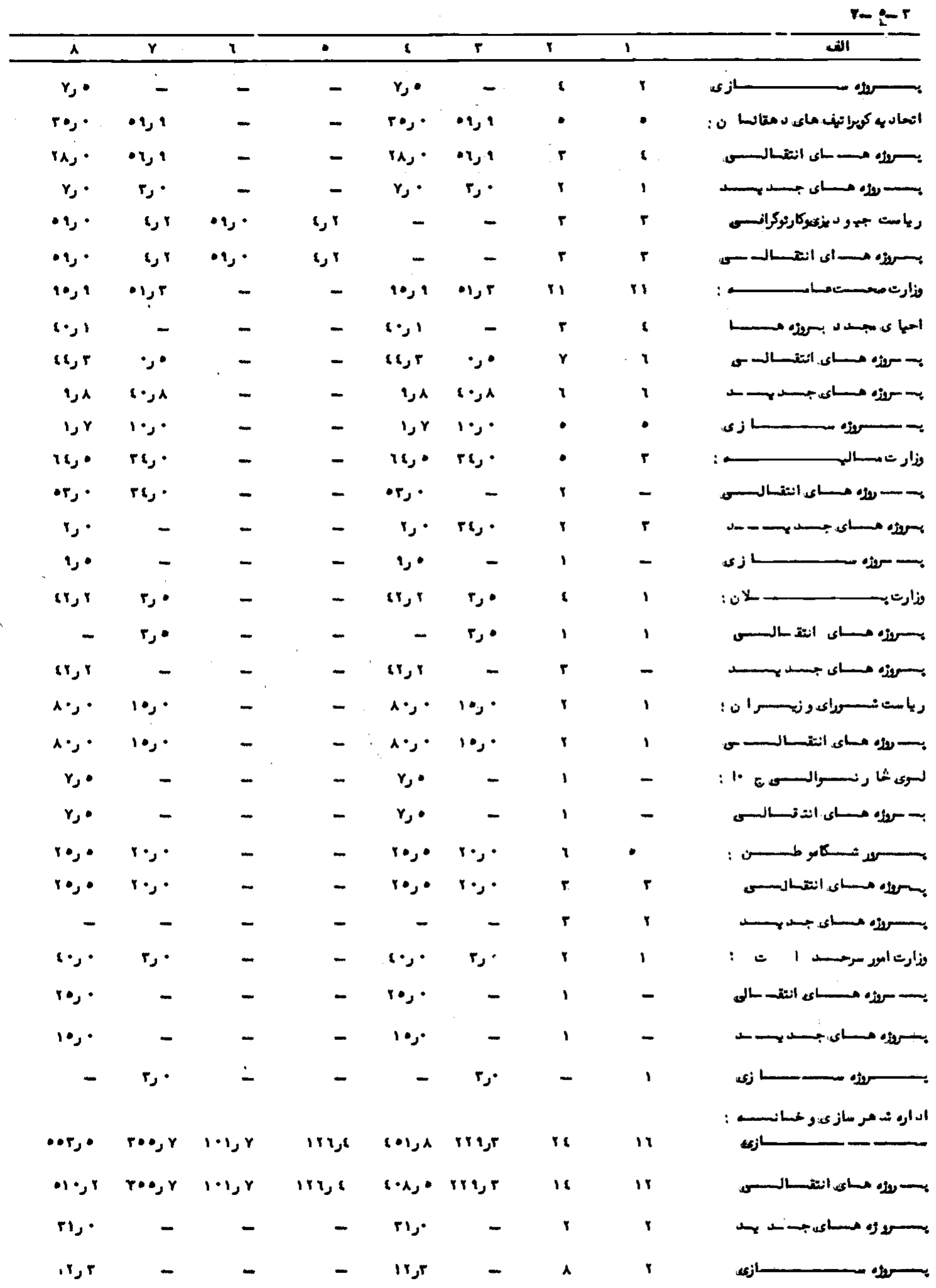




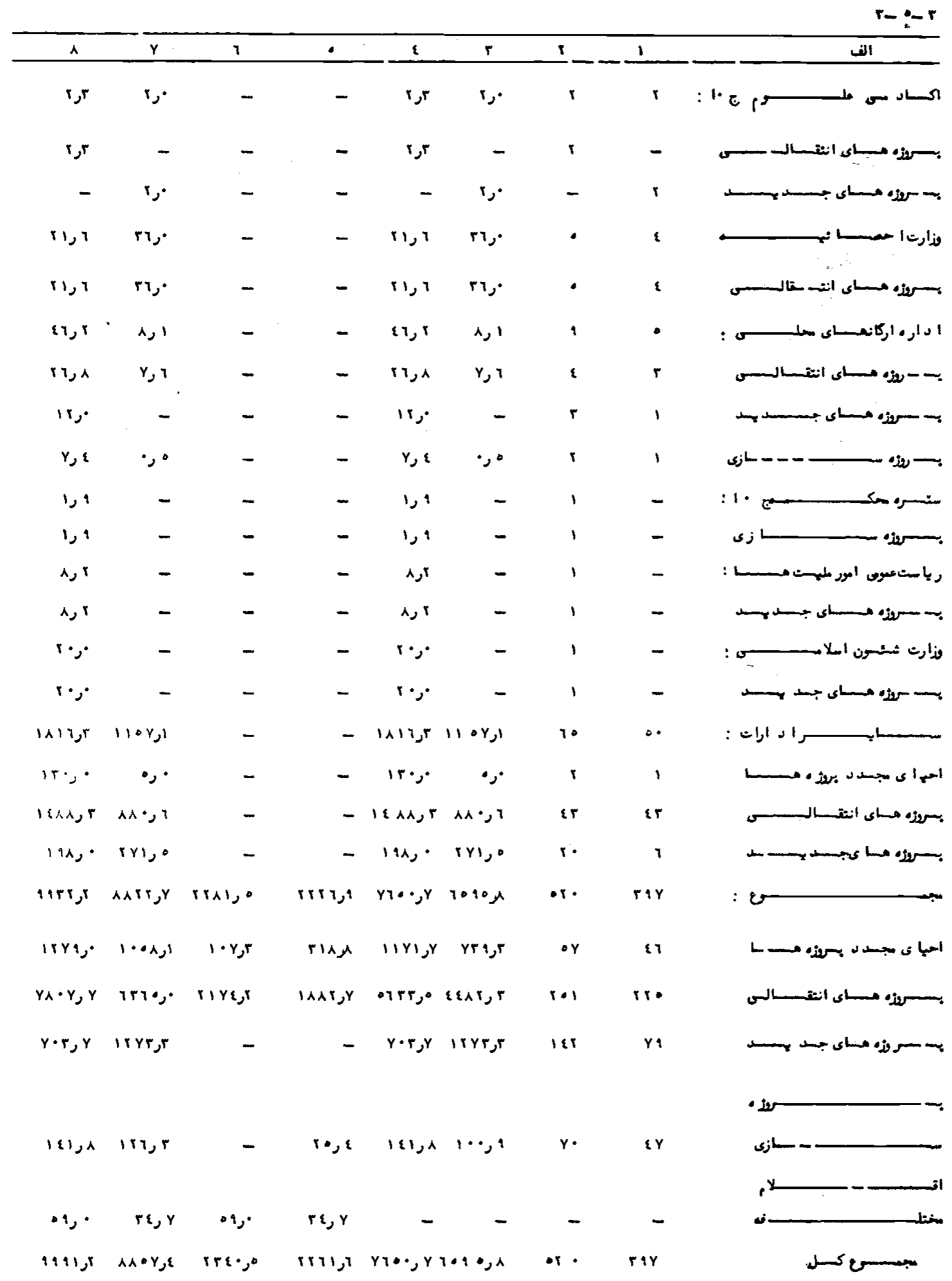




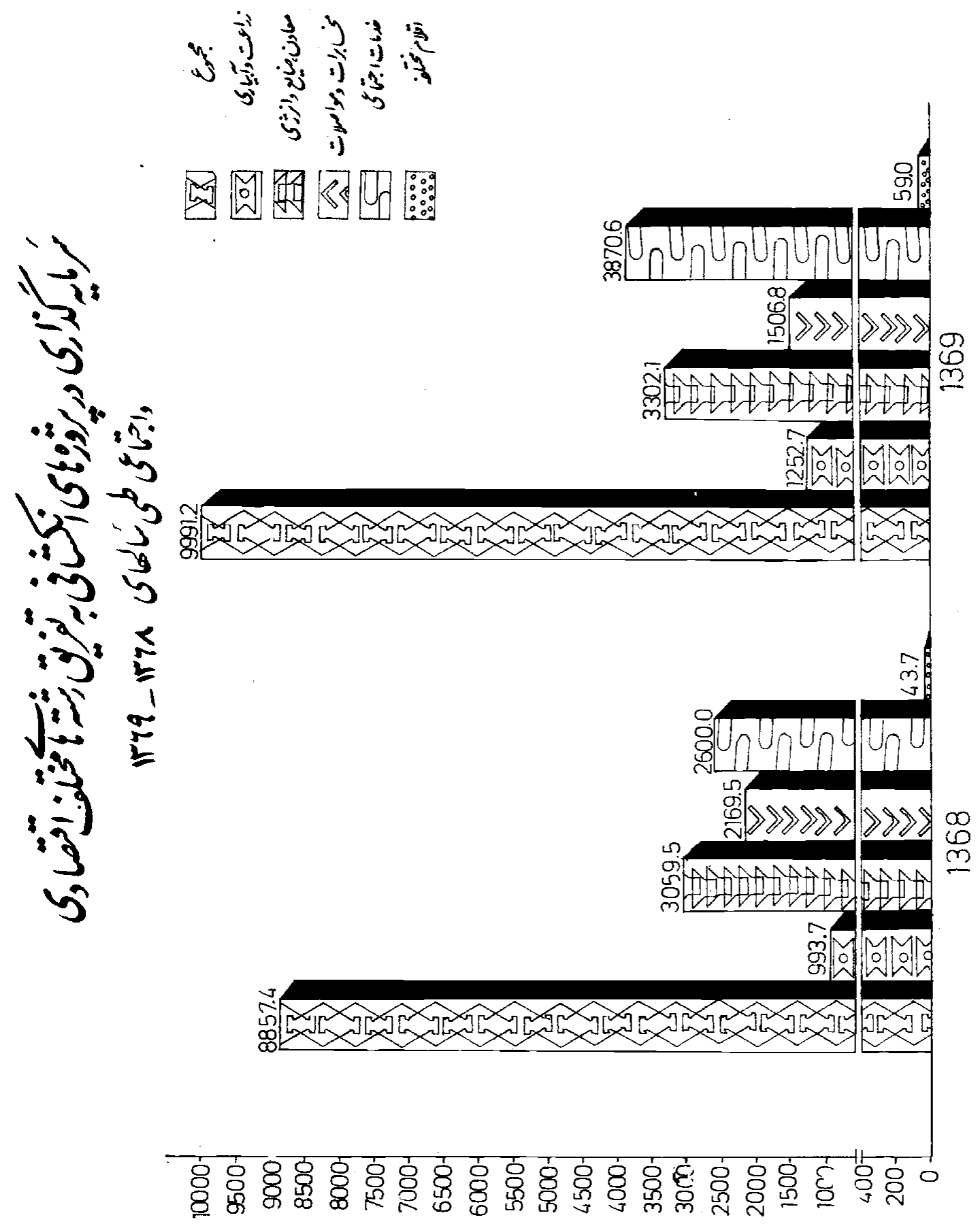

117 


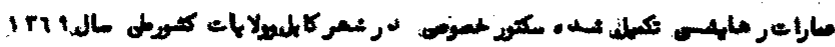

\begin{tabular}{|c|c|c|c|c|c|c|}
\hline \multirow{2}{*}{ ا منرمستمبه ) } & \multicolumn{3}{|c|}{ 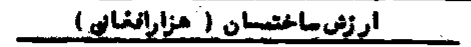 } & \multirow{2}{*}{ كسدأد } & \multirow{2}{*}{ 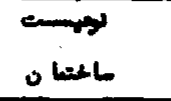 } & \multirow{2}{*}{ • } \\
\hline & لهe & تهمe سالطتان & تهم:زمن & & & \\
\hline Irrei & AACA & Arrry & $11 * 9$ & 11 & مازات رماهثن & 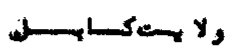 \\
\hline$\bullet \cdot$ & 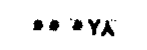 & יח & rive & $r \cdot$ & كالكرتهـس & عالעالسه كدياكسل \\
\hline rrus & $r r \cdot 1 t$ & rni & rer. & ri & Shenth & \\
\hline $\mathbf{Y A} \bullet \boldsymbol{H}$ & Iril & $\wedge \bullet \bullet$ & rœ & « & هـثت طسام & \\
\hline$\wedge \cdots$ & $1 \mathrm{n} \cdots$ & $16 \cdots$ & $s \cdots$ & 1 & هاركجستـــت & \\
\hline Air. & $10 \mathrm{Yr} 4$ & rir. & $\operatorname{lrr}$ & A & لدوكسطا ن & \\
\hline 111 & ATRA & $111 \cdot 8$ & orte & ir & كعتب بغته & \\
\hline $\begin{array}{l}Y A \cdot A \\
\cdot Y r \cdot r\end{array}$ & $\begin{array}{c}\text { iril } \\
\text { iryit }\end{array}$ & 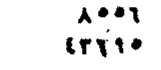 & $r \cdots r$ & $r$ & 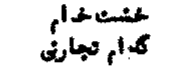 & \\
\hline$r \cdots$ & $18 \cdots$ & $1 \cdots$ & $1 \cdots$ & 3 & حعستسـار, & \\
\hline$r r \cdots$ & rre... & $1 \cdots \cdots$ & $\operatorname{lr} 6 \cdots$ & $\cdots$ & مارت رمايهن & 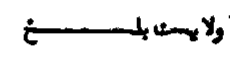 \\
\hline c.... & - & - & $r+\cdots$, & $\cdots$ & كانكرينستسن & نا لاله مزار نسمـت \\
\hline$\leftrightarrow \cdots$ & - & - & $r i r \cdot$ & irt & خفـث بكنس & \\
\hline $111 \ldots$ & - & - & Arro. & ry. & عeستطدار & \\
\hline$\cdots$ & $r \cdots$ & $r \cdots$ & $1 \cdots$ & $\mathbf{r}$ & كأر تهارتى & \\
\hline $\operatorname{lr} \cdots$ & rio.. & $r \cdots$ & $1 \cdots$ & $r$ & مرنستسـل & \\
\hline- & irat. & $m \cdots$ & ren & $\mathbf{Y A}_{\boldsymbol{A}} \cdot$ & ماراث رمايخى & ولاهي- بسـاد \\
\hline- & - & - & - & - & 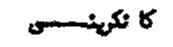 & ثا עالى ظلمه نسســر \\
\hline - & $n \cdots$ & $r \cdots$ & $11 \cdots$ & $1 \cdots$ & لشتث بمثه & \\
\hline- & erroe & 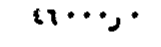 & Irep. & $u \cdot$ & عنستحسام & \\
\hline- & 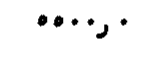 & $\cdots \cdot \cdot$ & $\cdots$ & $r$ & & \\
\hline$r \cdots$ & Etry & a.. & ery & 1. & مخنست خساترماهن & نسا لألسى غسسز نسى \\
\hline
\end{tabular}

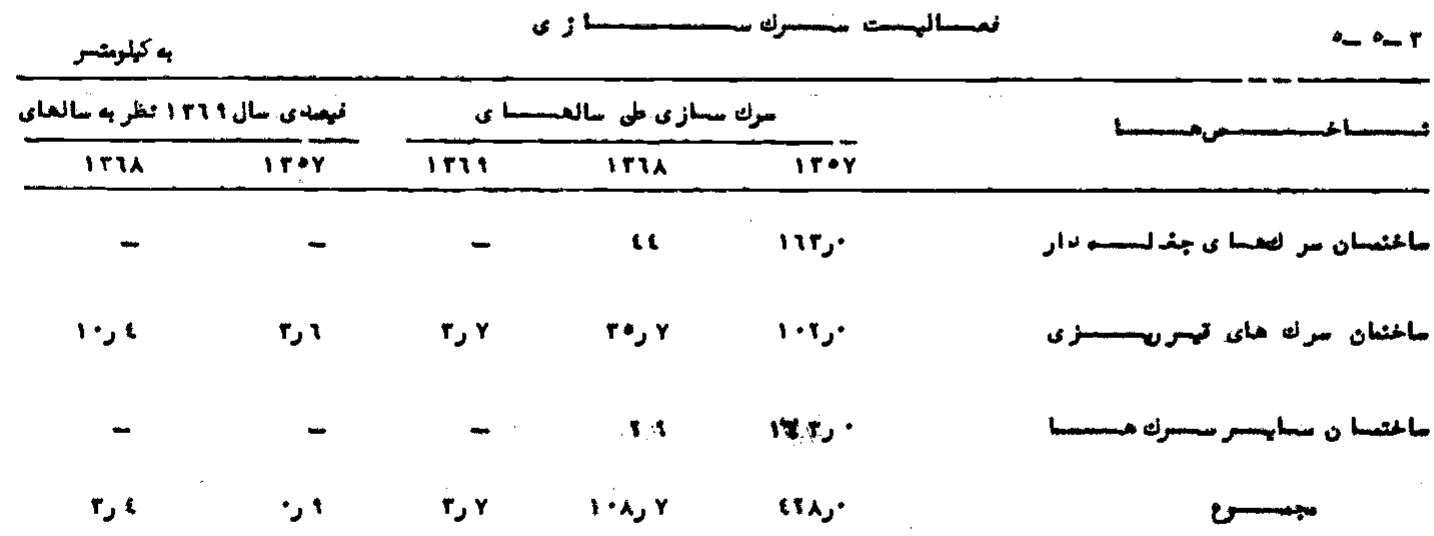




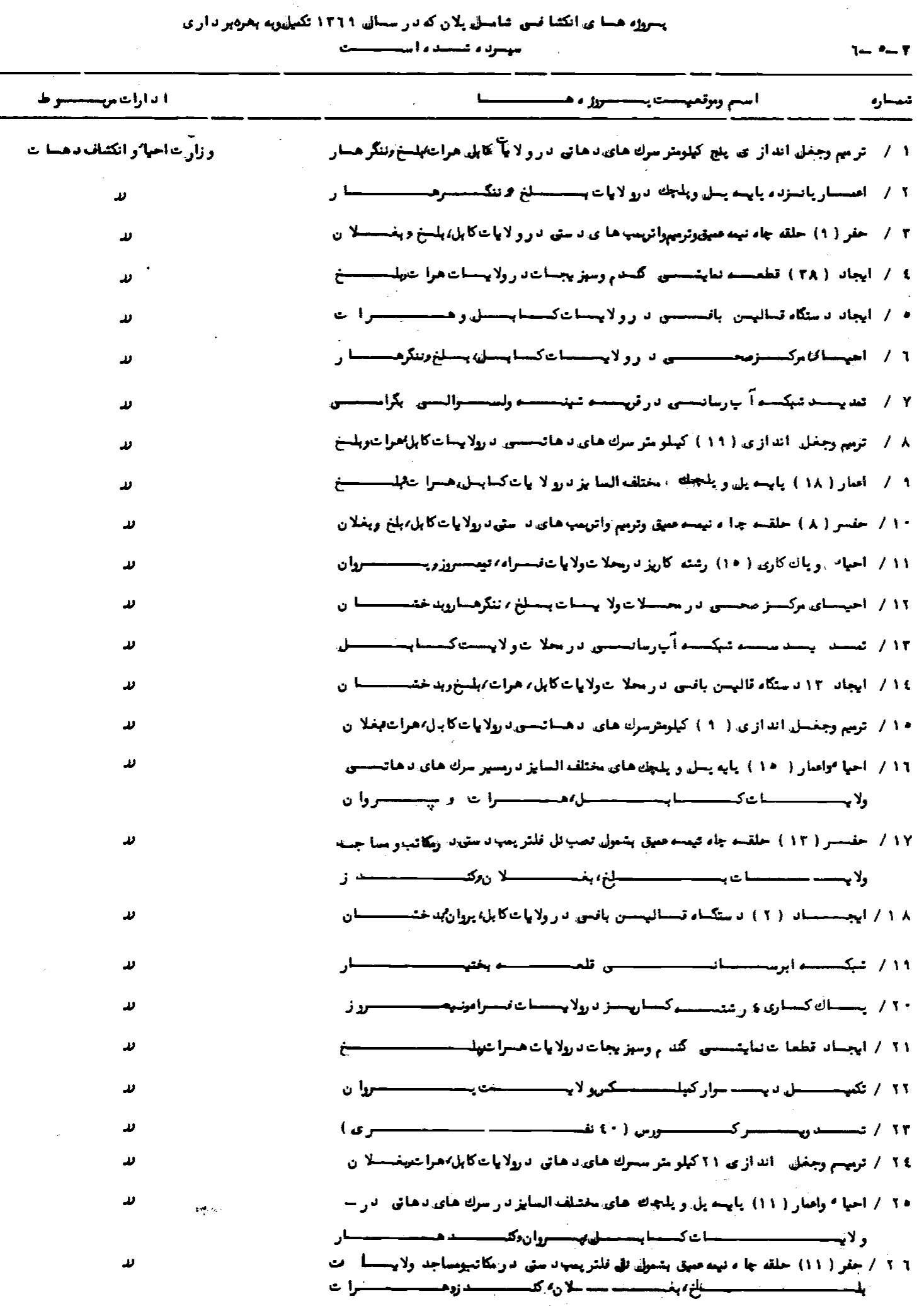




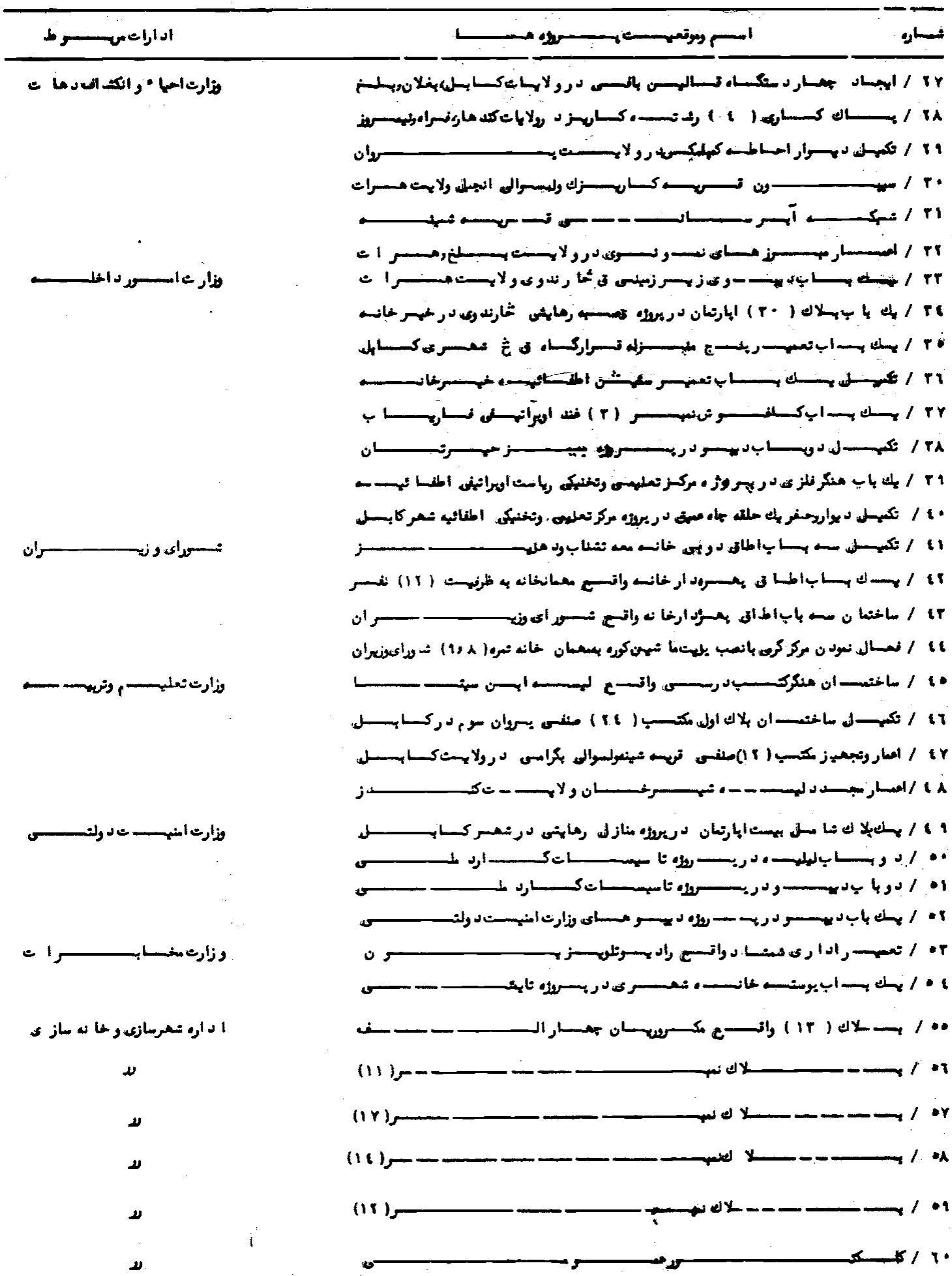




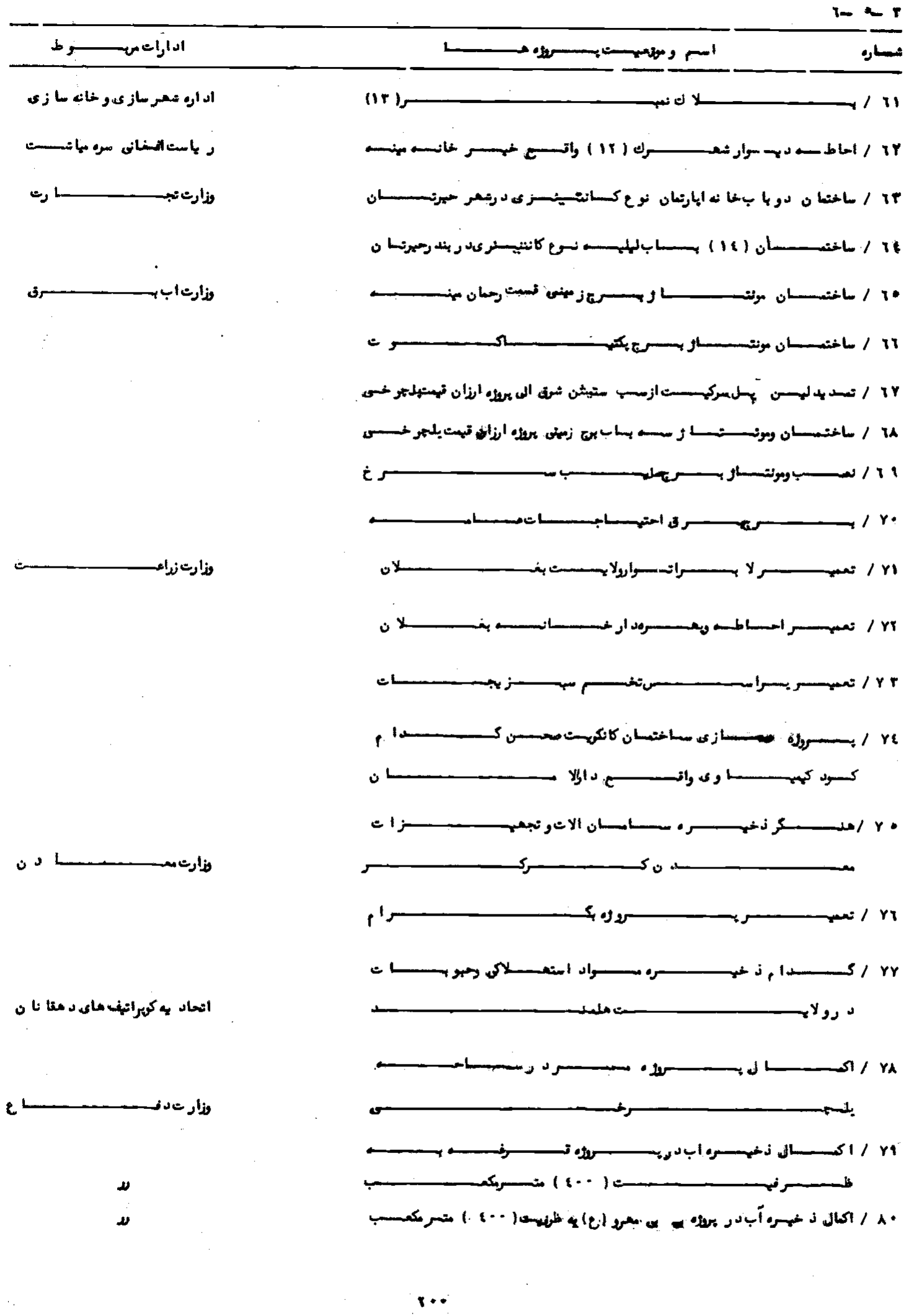




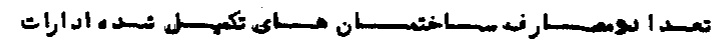

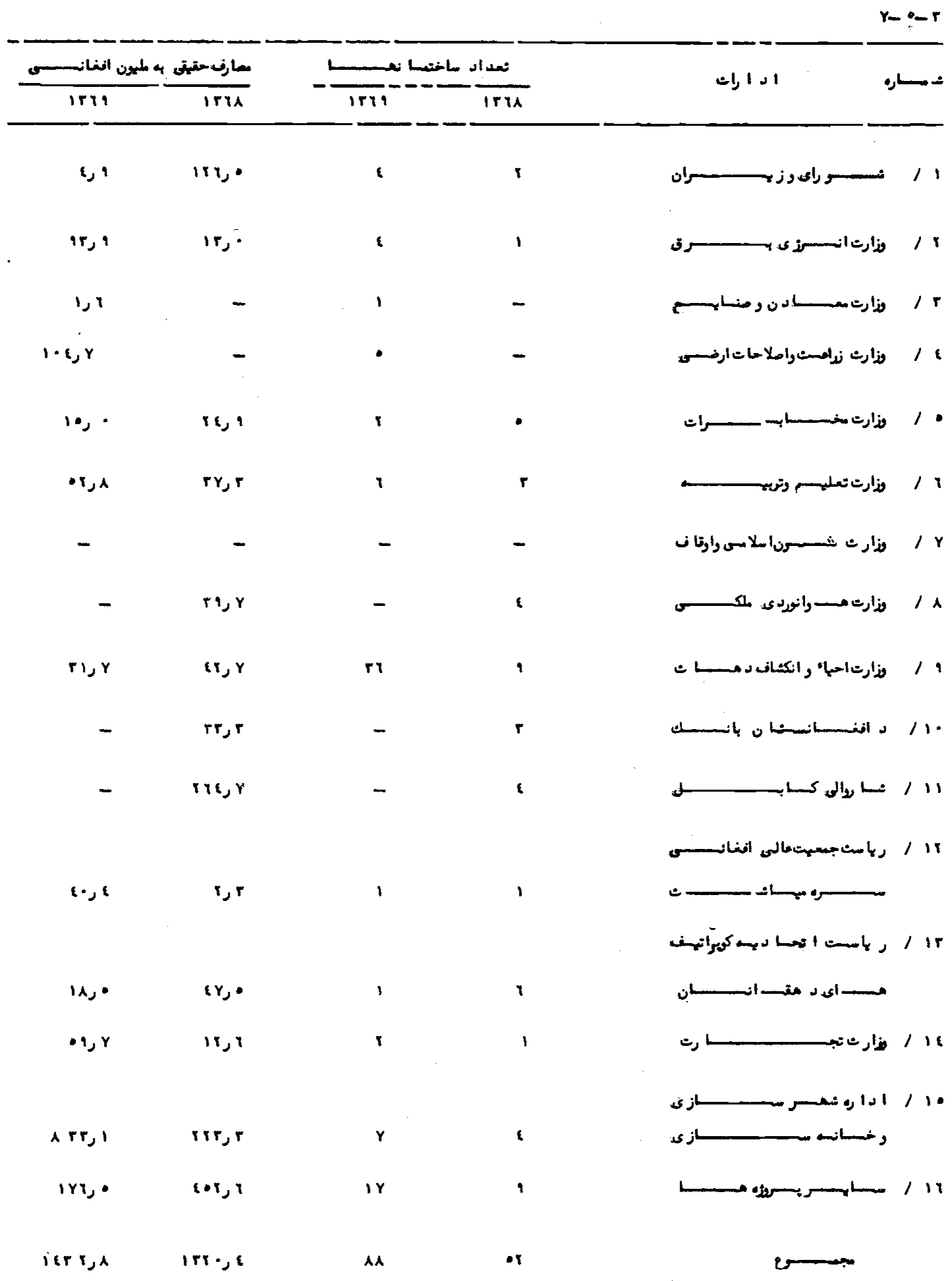




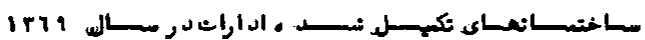

$A-0$

\begin{tabular}{|c|c|c|c|c|c|}
\hline 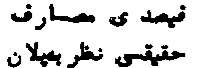 & 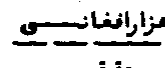 & مسارف مجمع & & & ا أدا راث \\
\hline 1 & $\bullet$ & $\varepsilon$ & $r$ & 1 & 1 \\
\hline ri, r & $\bullet \|$ & irirs & 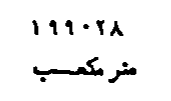 & 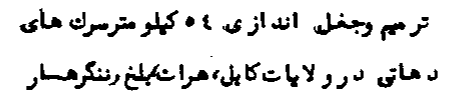 & 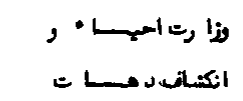 \\
\hline $1 \cdots, \gamma$ & $\lim \varepsilon$ & IArki & تصن & 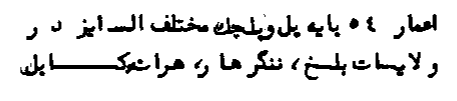 & \\
\hline 11 & $r \cdot \bullet, r$ & $\bullet \bullet r, \bullet$ & حلتسه & 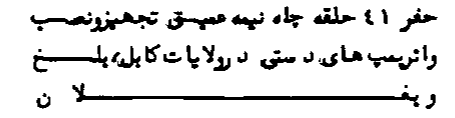 & \\
\hline $1 \varepsilon \theta, 1$ & 89. & rris & ( & 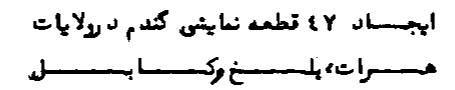 & \\
\hline$r \cdot, r$ & Irrr, $Y$ & $r \cdot Y r$ & $\begin{array}{l}19 \\
19 \\
156\end{array}$ & 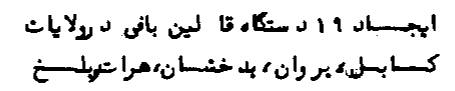 & \\
\hline $111, r$ & rrir, & $r \cdot \boldsymbol{A}$ & $\begin{array}{l}\hat{1} \\
\mathbf{l}\end{array}$ & 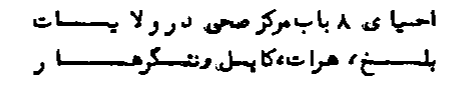 & \\
\hline$\cdot 1,1$ & $1 \cdot 1 \varepsilon, r$ & rir. & - & تعديد بنج نسبك ابر مانى د لالاهتكابل & \\
\hline$r \cdot, r$ & $r \varepsilon q$ & 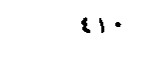 & - & اعطارمسر ز ها ى نمونوى د رولايات بلخرومرات & \\
\hline$i r, r$ & $\{1, \cdot$ & $\cdots$ & - & 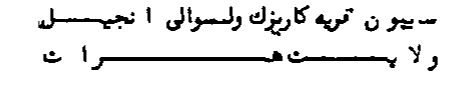 & \\
\hline $1 r i, 9$ & IArt & $1 \cdots$ & - & تكيل د دوار احاطس كبكسر لا يثنبو' ن ن & \\
\hline$\{9,1$ & $r q u, r$ & $\wedge^{\cdots}$ & 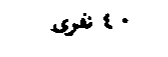 & ابجساد كسـوس · ع نغســــــــــ & \\
\hline$r r, r$ & $r \cdots, \cdot$ & $\operatorname{lrq}$ & ا & 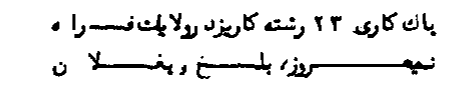 & \\
\hline ir, & $r \lambda q 1, r$ & $\operatorname{trix}$ & & مجمســ & \\
\hline $1 \cdots$, & $1 \cdots$ & $1 \cdots$ & 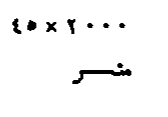 & 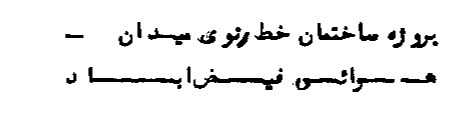 & وز ارت مرانسو رد ى ملكي \\
\hline $1 \cdots$, & $1 \cdots$ & $1 \cdots$ & & مجمستــ 2 & - \\
\hline $1 \cdots$, & $r \cdots$ & $r \cdots$ & مترمبع & 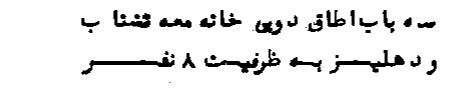 & نـــراى هجتر ونيران \\
\hline $1 \cdots$, & $\boldsymbol{\Lambda} \cdots$ & $\boldsymbol{\lambda} \cdots$ & r r r r r & 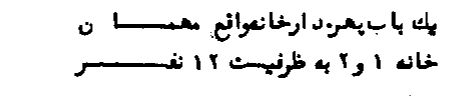 & \\
\hline $1 \cdots$, & $11 \cdots$ & $11 \cdots$ & 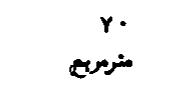 & 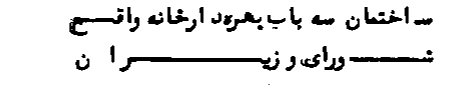 & \\
\hline $1 \cdots$ & $\cdots$ & $\cdots$ & - & 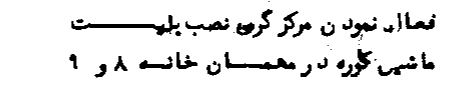 & \\
\hline $1 \cdots$ & 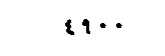 & $29 \cdots$ & & مبمسـ- م-وץ & \\
\hline
\end{tabular}




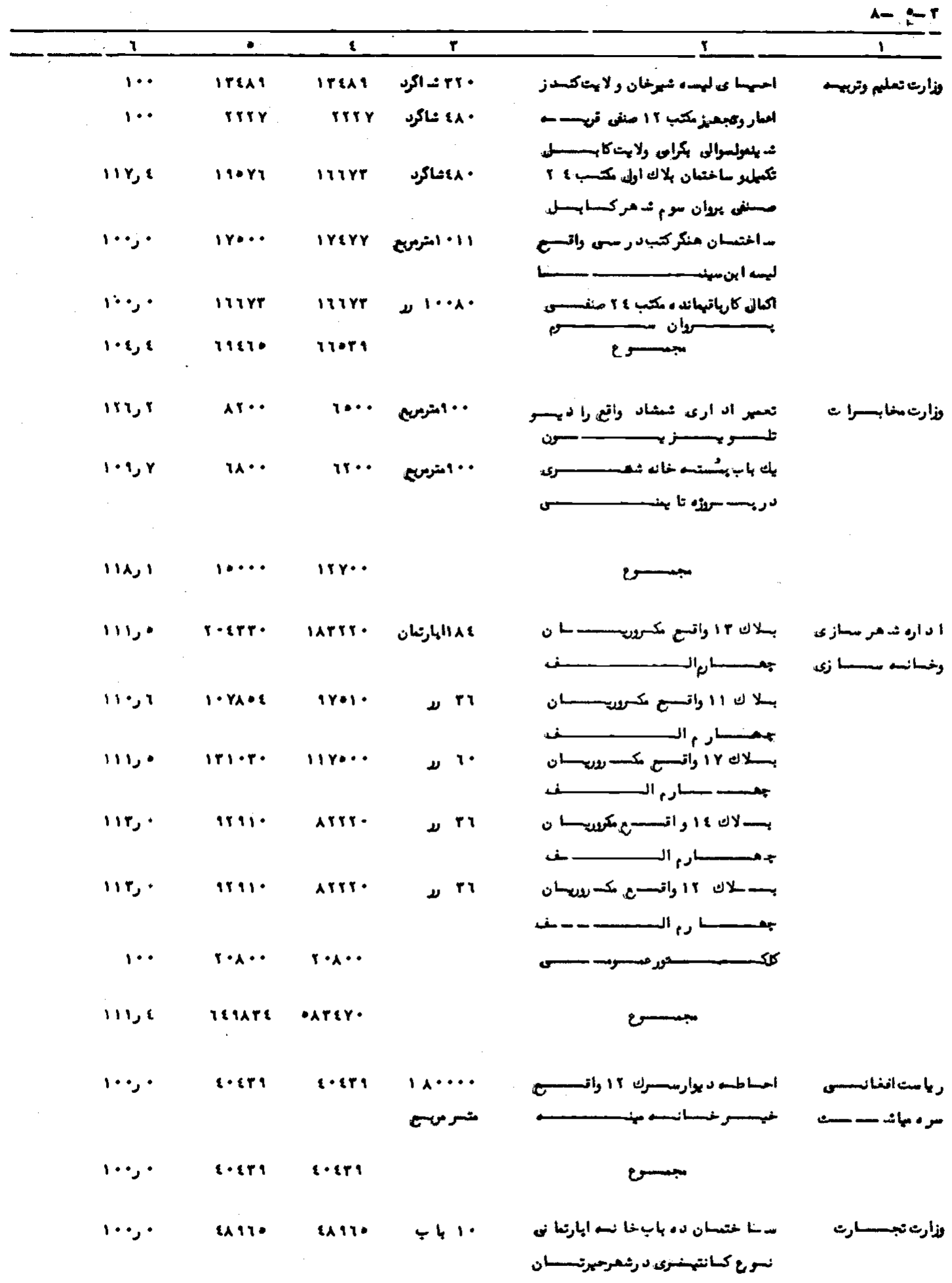




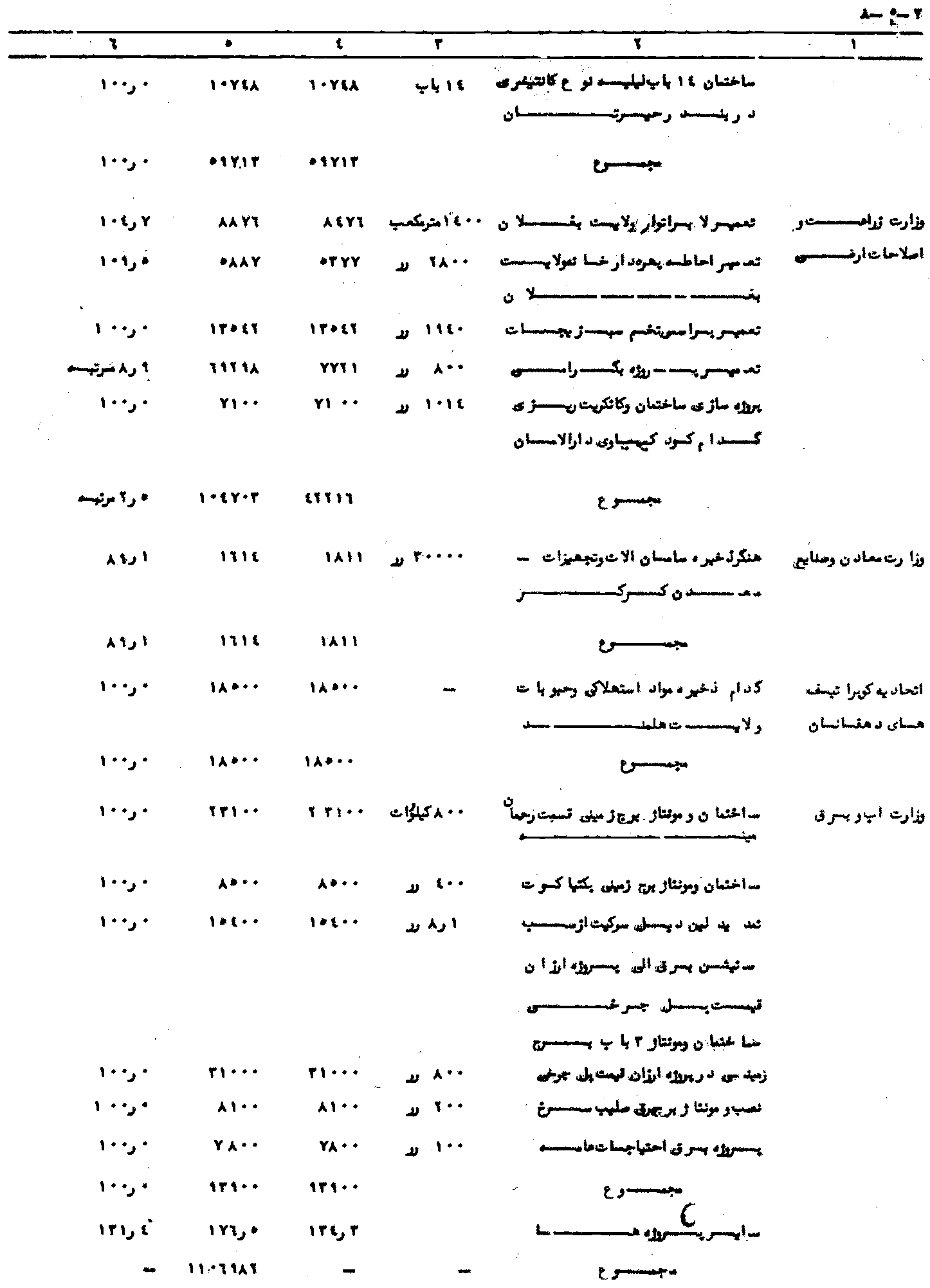




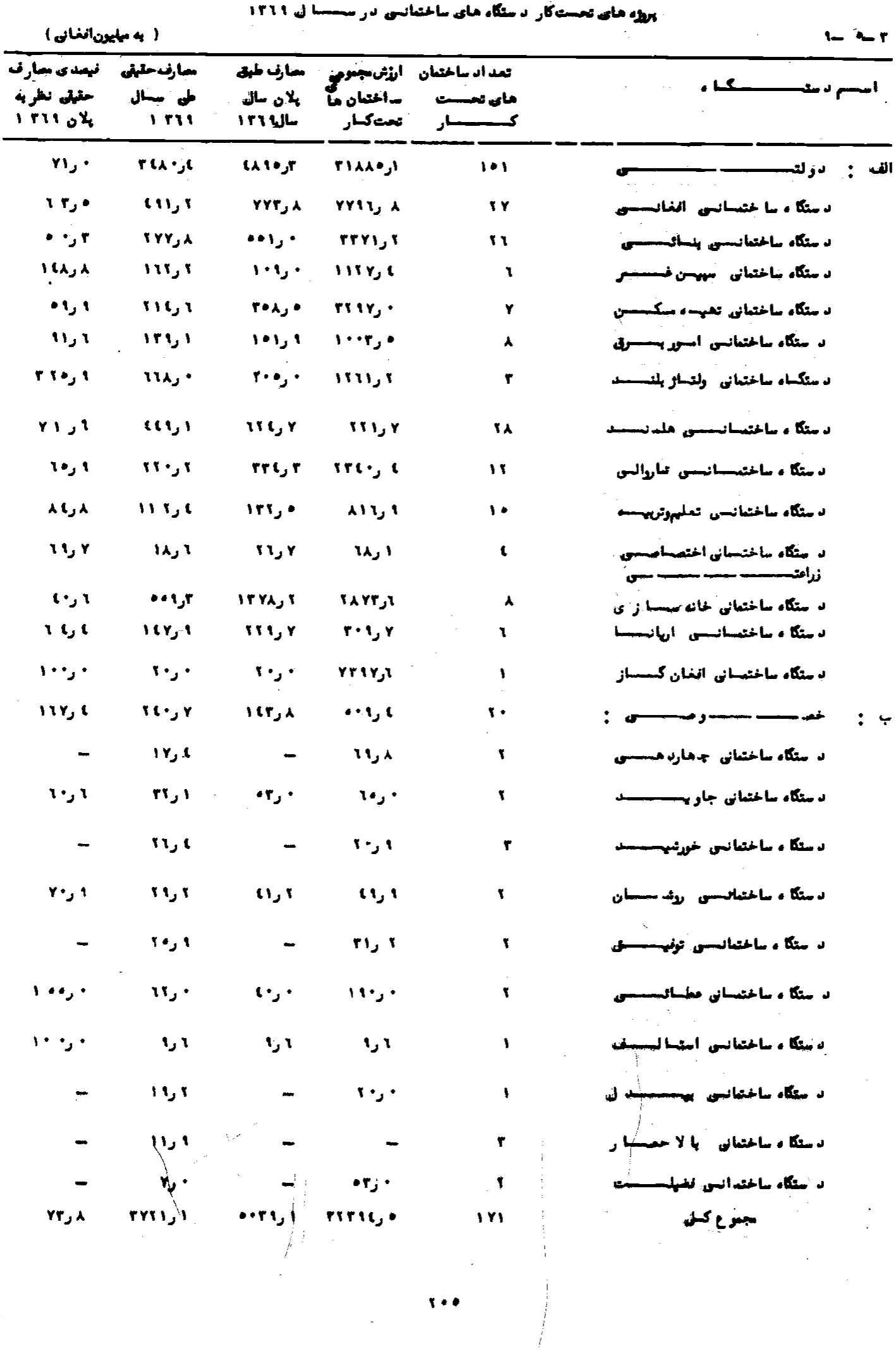




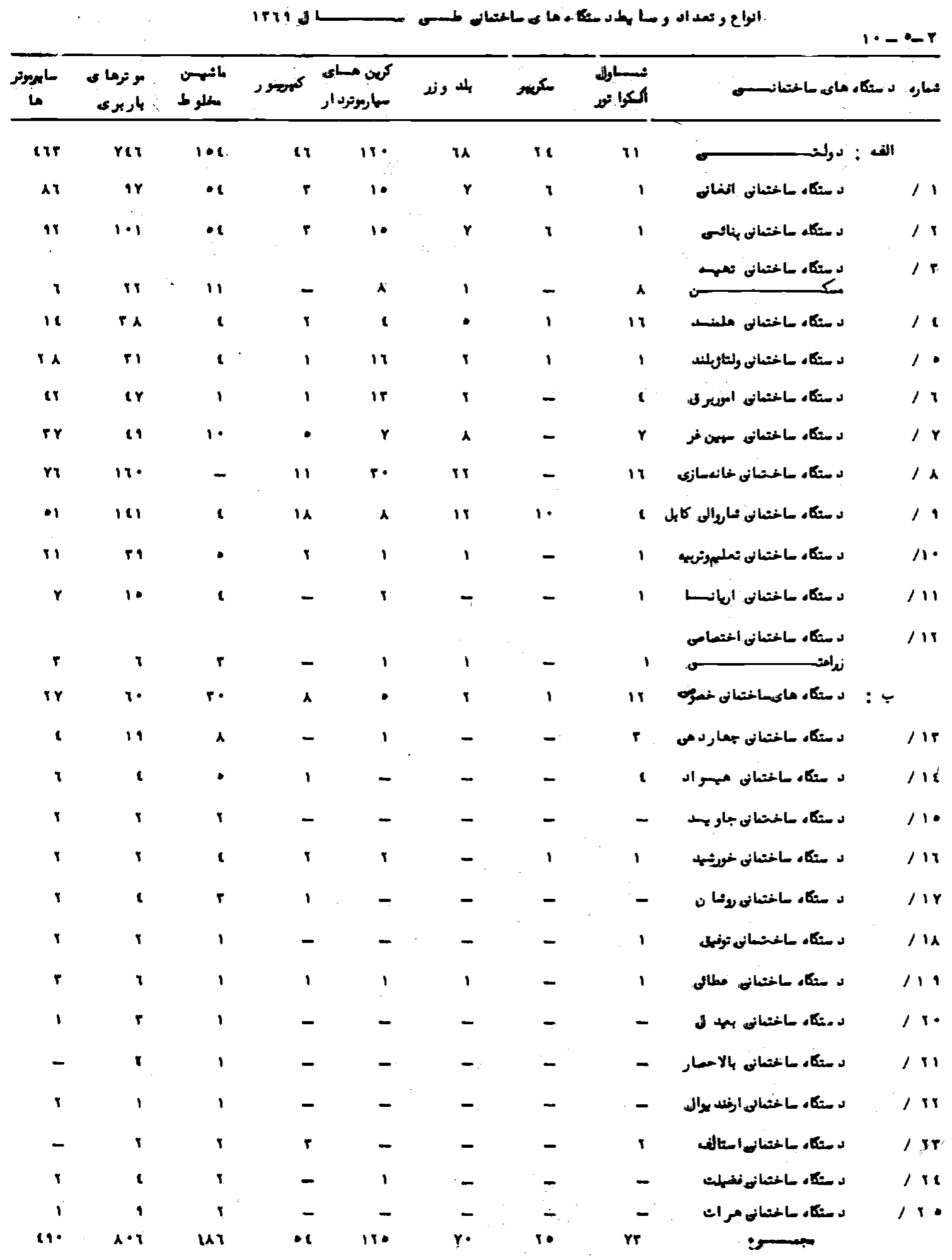




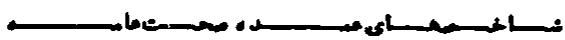

$1-1-1-r$

\begin{tabular}{|c|c|c|c|c|c|c|}
\hline \multicolumn{2}{|c|}{ فيملى سال 1 7 1 ا نطه سالحاى } & \multicolumn{3}{|c|}{ 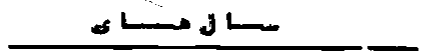 } & \multirow{2}{*}{ مقساس } & \multirow{2}{*}{ 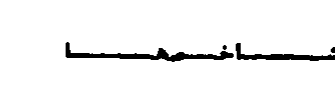 } \\
\hline $\operatorname{lr} 11$ & iror & $\operatorname{lrq}$ & $\operatorname{lrm}$ & $1 r \cdot r$ & & \\
\hline $1 \cdot 1, r$ & $16 t, r$ & 11 & $1 \cdot 8$ & $r Y$ & باب & 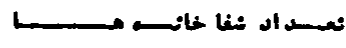 \\
\hline $1 \cdots, \cdot$ & 11,8 & $\cdot 8$ & - $\mathbb{R}$ & $\bullet 1$ & $\nu$ & 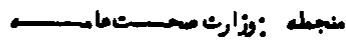 \\
\hline $1 \cdot r, r$ & أ آ مرنب & $1 \cdot r \mathrm{rr}$ & $1 \cdots: 1$ & $\operatorname{trt}$ & بنسـر & 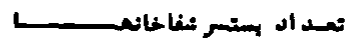 \\
\hline $1 \cdots, r$ & ا r r مرتب & .118 & - iar & $r \varepsilon \cdot 1$ & $\nu$ & 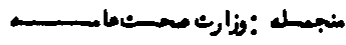 \\
\hline $1 \cdot 1,1$ & r r r r r r r & 1,8 & $1, r$ & $r, \lambda$ & ע & نعد اد بستسر برایهرد ـ مزارنغـر \\
\hline $1 \cdot Y, \lambda$ & r r r مرته & $r \cdot r \cdot$ & rira & $1 \cdot 70$ & نغسر & 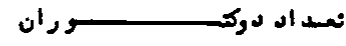 \\
\hline$\| r, \mid$ & 1 مرا مرنب & $r \cdot x$ & rin & $1 \cdot 1$ & ע & ملجمل : وذارث مسحــهاه \\
\hline $1 \cdot \varepsilon, 1$ & 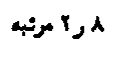 & $r, r$ & $r$ & • & $\nu$ & دـ \\
\hline $1 \cdots, r$ & $i r r, \cdot$ & TIYr & $110 r$ & expo & $\nu$ & نمسل اد هر سونسل شترسط \\
\hline$i r, \cdot$ & iros. & rete & $\operatorname{rin} r$ & $r a \cdot r$ & ע & معجلهـ : وزارث مسمسن.مامســــ \\
\hline 19,1 & $\operatorname{lrr}, 1$ & ir & 118 & 10 & بساب & نعـد اد د ــنكاه اكســـ \\
\hline $1 \cdot 1,1$ & ixr, $Y$ & $1 \cdot$ & 19 & 19 & $\nu$ & منجطل : نذارثمســـــــاء \\
\hline$I r A, r$ & ا & 11 & $\wedge \cdot$ & ry & $\nu$ & تعد اد در ملورماى د رلتسـ \\
\hline $1 \cdot \bullet, r$ & ا & 178 & 1080 & Mr & $\nu$ & تعد اد د رطتو لعساى هـ \\
\hline $11 r, 4$ & ا رهمتبه & $\wedge \cdot \wedge$ & rir & ire & لd & 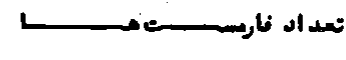 \\
\hline$i r r, r$ & $r \cdot, 1$ & $1 \cdot r$ & re & ler & بطاب & LL \\
\hline$i r$, & $1 \cdot, \cdot$ & $\boldsymbol{\lambda}$ & ir & ri & $\nu$ & هاد مراك \\
\hline
\end{tabular}




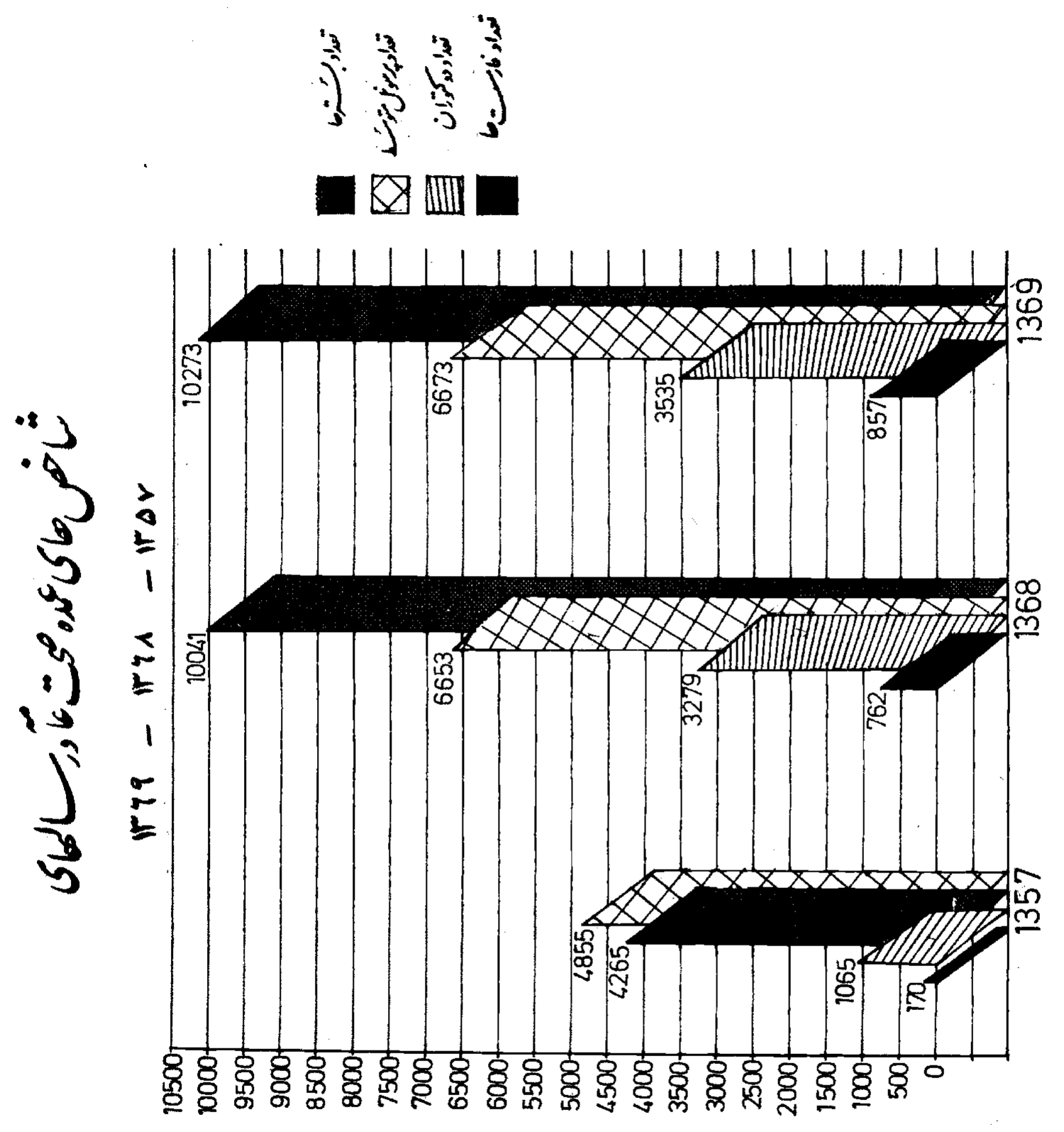

$r \cdot A$ 


\begin{tabular}{|c|c|c|c|c|c|c|c|c|c|c|c|c|c|c|c|}
\hline \multicolumn{3}{|c|}{ 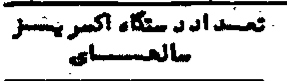 } & \multicolumn{3}{|c|}{ 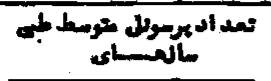 } & \multicolumn{3}{|c|}{ 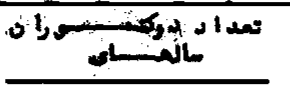 } & \multicolumn{3}{|c|}{ 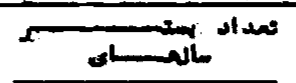 } & \multicolumn{3}{|c|}{ 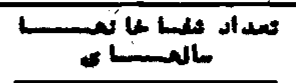 } & \multirow{2}{*}{ رلابساء } \\
\hline irrt & IrT & $I T \bullet Y$ & IrIS & IrTA & $I T \bullet Y$ & irts & IT & Ir०r & 1819 & IrIA & Ir०Y & IrII & Ir & $I T \cdot Y$ & \\
\hline 10 & AI & 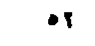 & PAEA & ritr & 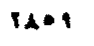 & 10.1 & IM & $1 \cdot 1$ & Hitr & olar & $18 \cdot 1$ & -1 & - $\mathrm{E}$ & ד & \\
\hline$\therefore$ & 11 & 10 & I.: T & $i r \cdot s$ & irti & IATT & ITYA & or. & inity & rur & IIr & 18 & 18 & ir & كسمساش \\
\hline 1 & 1 & 1 & -1 & $r y$ & 1.1 & 1 & 11 & it & $r$ & 1. & 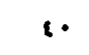 & 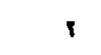 & $i$ & 1 & old \\
\hline- & - & - & ir & 18 & - & 8 & 1 & - & 1. & 1. & - & 1 & 1 & - & $\infty$ \\
\hline- & - & - & 1. & $r$ & 1 & $i$ & $i$ & - & $r$ & $r$ & - & 1 & 1 & - & وكر \\
\hline 1 & 1 & i & ir & 11 & $\bullet$ & ir & 11 & is & $\cdots$ & •. & 8 & 1 & 1 & I & \\
\hline 1 & 1 & i & 1 & $r$ & זו & $r$ & 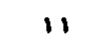 & $\mathbf{M}$ & ro & 10 & irs & 1 & $r$ & 1 & $\longleftarrow$ \\
\hline$r$ & $r$ & 2 & $1 \ldots$ & $1 \cdot 2$ & Iro & Mr & AT & $r \cdot$ & 11 & $\because$ & 10 & 8 & i & $r$ & \\
\hline 1 & 1 & 1 & $\mathrm{M}$ & r. & re & $r$ & 11 & 1 & 1 & 1. & $r$ & 1 & 1 & 1 & لغد \\
\hline 1 & - & - & $\wedge$ & 1 & - & 1 & - & - & - & - & - & - & - & - & نورستان \\
\hline- & 1 & 1 & $r$ & $r \cdot$ & $r \cdot$ & 11 & 17 & $1 \cdot$ & $\cdots$ & $\bullet$ & $r \cdot$ & 1 & 1 & 1 & بد خشان \\
\hline 1 & 1 & 1 & it & ri & re & 11 & 1 & 18 & $8 \cdot$ & 8 & 10 & 1 & 1 & I & \\
\hline 1 & i & 1 & 18 & ro & AI & $\bullet \wedge$ & ir & $n$ & 10 & 10 & ro & 1 & $r$ & $r$ & بغــــلان \\
\hline 1 & 1 & - & $A T$ & ri & rI & it & ri & $1 \cdot$ & $r \cdot$ & $r \cdot$ & 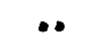 & 1 & 1 & $r$ & سـدز \\
\hline 1 & 1 & 1 & $r$ & rr & it & 1. & 1. & 1 & 10 & $r$ & $r \cdot$ & 1 & 1 & 1 & نك \\
\hline$r$ & $r$ & $r$ & 119 & 180 & $\bullet \wedge$ & 116 & $r_{\lambda}$ & 11 & 10 & 10 & ro & 1 & 1 & 1 & \\
\hline$r$ & $r$ & 1 & $r$ & re & 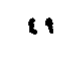 & rq & in & 11 & 8 & 10 & $\varepsilon$ & $r$ & $r$ & 1 & جسان \\
\hline- & - & - & $\wedge$ & 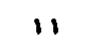 & - & $r$ & $\wedge$ & - & $r \cdot$ & $r \cdot$ & - & 1 & 1 & - & مسسرل \\
\hline$r$ & 1 & 1 & 11 & $r T$ & $\{r$ & $T \xi$ & $r Y$ & 18 & $\lambda \cdot$ & $\Lambda \cdot$ & \&o & 1 & $i$ & 1 & مسارب \\
\hline 1 & 1 & 1 & 18 & 10 & ir & $r$ & 1 & 11 & $r$ & $r$ & 8 & $r$ & $i$ & $r$ & بمادغهس \\
\hline$r$ & $r$ & 1 & 190 & 11 & 11 & $\Lambda 0$ & ro & $r$ & $r \cdots$ & $r \cdots$ & $\Lambda \cdot$ & \& & 8 & 1 & \\
\hline 1 & 1 & 1 & $r A$ & or & $r$ & 1. & $r$ & ir & $r$ & •. & 8 & 1 & 1 & 1 & نسـراه \\
\hline 1 & 1 & $\begin{array}{l}1 \\
.\end{array}$ & 17 & 18 & ir & $r$ & $r$ & $\wedge$ & 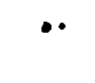 & 1. & 10 & 1 & 1 & 1 & \\
\hline 1 & 1 & 1 & $r$ & $r i$ & rE & 11 & II & 18 & 17 & 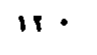 & 10 & 1 & 1 & 1 & ملعسد \\
\hline$r$ & $r$ & 2 & ro & י & ro & 1. & 1 & ri & 17 & $\mathrm{rr}$ & 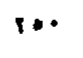 & I & 1 & 1 & \\
\hline 1 & 1 & - & $r$ & $r$ & 11 & 8 & 2 & $\lambda$ & $r$ & 1 & $r \cdot$ & 1 & 1 & 1 & \\
\hline 1 & 1 & 1 & 10 & 18 & 14 & 1 & $\lambda$ & 11 & 1 & 1 & 1 & $i$ & 1 & 1 & ان كسان \\
\hline 1 & 1 & 1 & $i$ & $r$ & 10 & 1 & $r$ & 10 & 1 & $r$ & $r$ & 1 & 1 & 1 & غســــد \\
\hline 1 & 1 & 1 & 8 & 8 & 10 & - & - & 11 & - & - & $r=$ & - & - & 1 & يامهان \\
\hline$=$ & - & - & $=$ & $=$ & $=$ & $=$ & $\overline{-}$ & $\overline{-}$ & $\overline{-}$ & $\overline{-}$ & - & $=$ & $=$ & $=$ & \\
\hline- & $\overline{-}$ & - & - & $=$ & $\bar{I}$ & - & $=$ & - & - & - & - & - & - & - & \\
\hline- & - & - & - & - & - & - & - & - & - & - & - & - & - & & \\
\hline
\end{tabular}




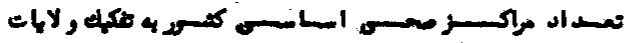

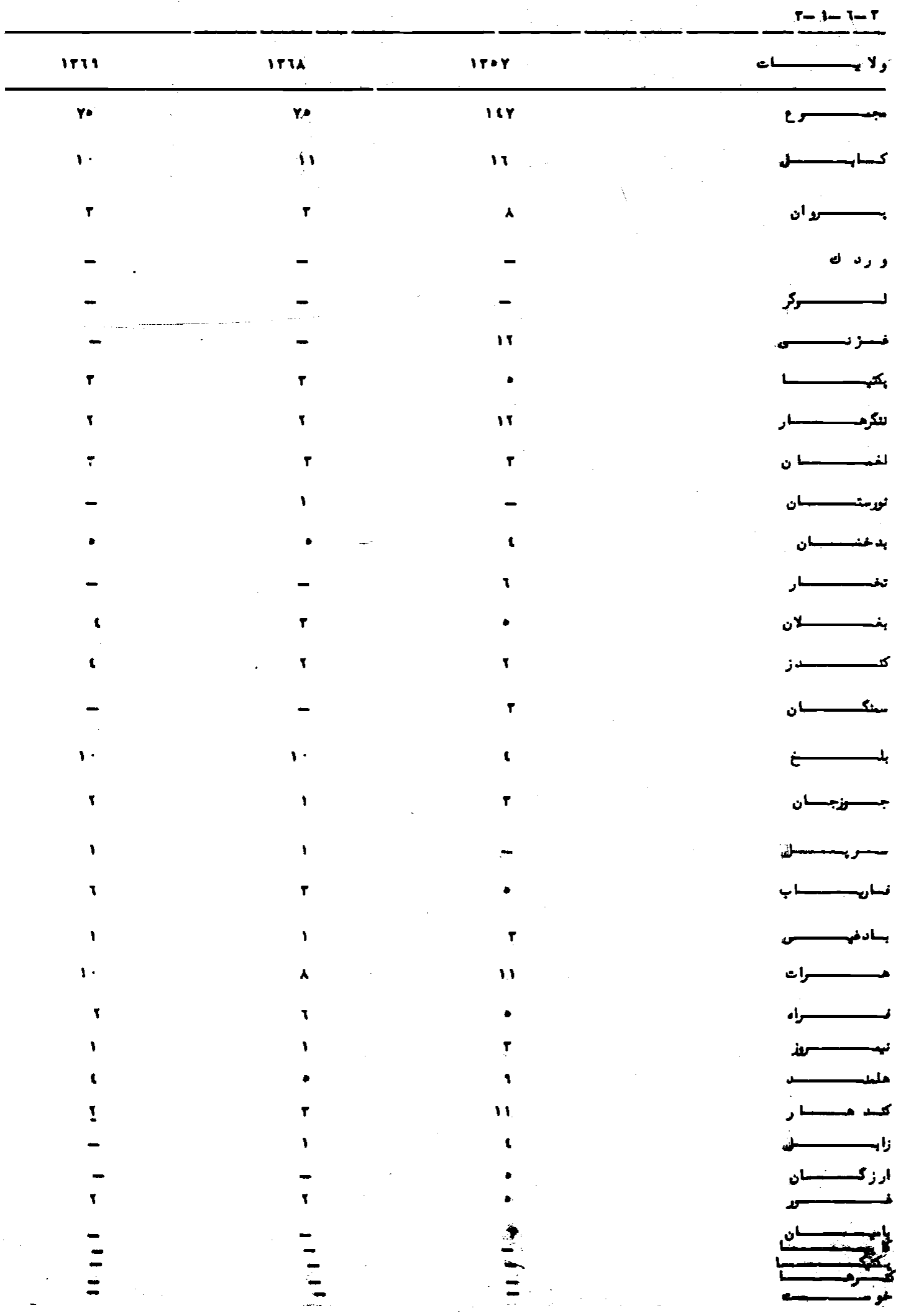




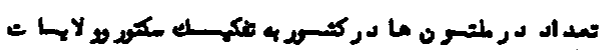

$-1-1-r$

\begin{tabular}{|c|c|c|c|c|c|c|c|c|c|}
\hline \multicolumn{3}{|c|}{ بمس عالعسليطائ } & \multicolumn{3}{|c|}{ نسمسكى } & \multicolumn{3}{|c|}{ دولتهـــــ } & \multirow[b]{2}{*}{ = $\mathbf{Y}}$, \\
\hline Irq1 & Iru & $T r \cdot Y$ & 1ז9 & TrMa & $1 T \cdot r$ & irm & Tris & $1 T \cdot Y$ & \\
\hline rir & $\pi$. & ira & UAY & $\bullet \wedge$ & 111 & re & ro & 1 & كسبا كــــ \\
\hline$u$ & - $r$ & $r$ & $1 \bullet$ & - & $r$ & $r$ & $r$ & $r$ & - كوان \\
\hline - & - & - & 8 & 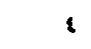 & - & 1 & 1 & - & ورد ه \\
\hline ir & 19 & - & ir & 19 & - & - & - & - & لســـــــــــــــ \\
\hline - $r$ & it & :• & $\bullet$ & 21 & $r 9$ & r & $r$ & 1 & كســـ \\
\hline A1 & u & ir & $r_{1}$ & $r r$ & $\imath$ & $\mathbf{r}$ & 1 & $r$ & 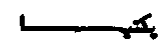 \\
\hline $1 \cdot 1$ & 1.9 & \&A & 1.1 & $1 \cdot 8$ & ir & $r$ & $r$ & 1 & سكرمــــــار \\
\hline ir & $n$ & $\wedge$ & r & $r \cdot$ & $r$ & 1 & 1 & 1 & لــــان \\
\hline - & - & - & - & - & - & - & - & - & كـان كان \\
\hline 11 & 11 & 1 & ir & 18 & - & 1 & r & 1 & ســان \\
\hline \&r & re & 10 & ir & re & 10 & - & - & - & كسـار \\
\hline 11 & ir & is & $r r$ & ir & ir & 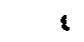 & $\varepsilon$ & 1 & wh \\
\hline .9 & :. & $\$ 1$ & . & $r$ & : & r & 1 & 1 & حــ \\
\hline 18 & 1. & $r$ & ir & ir & $r$ & r & $r$ & - & ن \\
\hline A. & $r \cdot$ & $r \cdot$ & $r r$ & ir & r & $\wedge$ & $\wedge$ & 1 & $i$ \\
\hline$\bullet$ & $\bullet \wedge$ & ir & •r & . $r$ & 11 & - & - & 1 & كان \\
\hline ir & ir & - & ir & ir & - & 1 & 1 & - & \\
\hline - $r$ & ir & $r \cdot$ & - $r$ & $2 r$ & 19 & $\varepsilon$ & 8 & 1 & \\
\hline rr & $r$ & 11 & r & 11 & 11 & 1 & 1 & - & \\
\hline 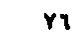 & $1: 8$ & \&r & irr & 182 & $\because$ & $r$ & $r$ & 1 & \\
\hline 11 & $1 \cdot$ & 18 & 11 & 18 & 18 & - & 1 & - & مراه (مراه \\
\hline$\wedge$ & 1 & 1 & $r$ & - & 1 & 1 & 1 & - & in \\
\hline 19 & ir & ir & ir & $r \bullet$ & 1. & $r$ & $r$ & $r$ & 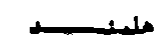 \\
\hline$n$ & ro & 21 & $n$ & $r_{0}$ & \&. & - & - & 1 & 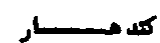 \\
\hline ir & ir & $\wedge$ & ir & ir & $r$ & - & - & 1 & 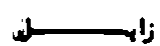 \\
\hline 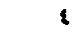 & 8 & $\varepsilon$ & $\varepsilon$ & 2 & 8 & - & - & - & از كــــــان \\
\hline$r$ & $r$ & $r$ & $r$ & $r$ & 1 & - & - & 1 & \\
\hline$r$ & $r$ & $r$ & r & $r$ & $r$ & - & - & 1 & سـان \\
\hline $11 \cdot 1$ & 1787 & $1: 2$ & irri & $1 \cdot 10$ & nr & $\wedge \cdot$ & A1 & ir & م- \\
\hline- & - & . & $=$ & - & $=$ & - & 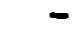 & 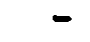 & \\
\hline - & - & - & - & - & - & - & $=$ & $=$ & \\
\hline- & - & - & - & - & - & - & - & - & 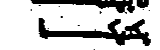 \\
\hline
\end{tabular}




\begin{tabular}{|c|c|c|c|c|c|}
\hline \multicolumn{6}{|c|}{ 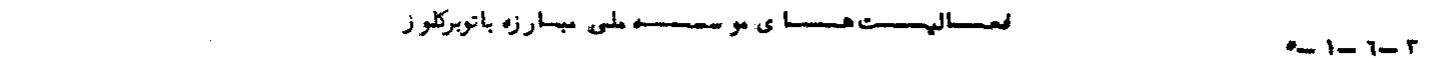 } \\
\hline \multicolumn{2}{|c|}{ 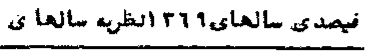 } & \multicolumn{3}{|c|}{ ستسنالعســـا } & \multirow{2}{*}{ 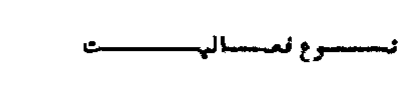 } \\
\hline irth & $I T \circ Y$ & $1+19$ & $1+14$ & $I T \bullet Y$ & \\
\hline 118,9 & $i r, r$ & irti. & A\&ItY & $Y १ \& 11$. & 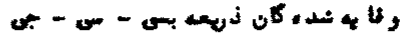 \\
\hline $1 \cdot \varepsilon, r$ & $Y \& \wedge, r$ & rotor & retrt & trye & 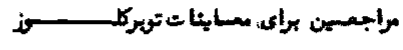 \\
\hline $1 \cdot 9,0$ & $Y Y, Y$ & $\operatorname{lrark}$ & יודיו & tr.AY & 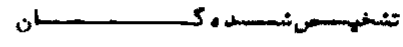 \\
\hline $11 \cdot 1$ & $r i, q$ & $\cdots r$ & gogtt & rrosu & 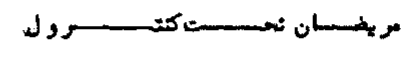 \\
\hline $1 \varepsilon \cdot, y$ & $r \cdot j \cdot$ & 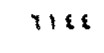 & \&Tו & 011 & 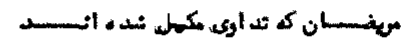 \\
\hline $111, r$ & rA, $Y$ & trots & $r \cdot r \& Y$ & anir & معا ينــــات لا يرانواريكنغنس \\
\hline
\end{tabular}

ن




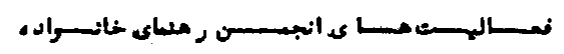

$Y-1-1-r$

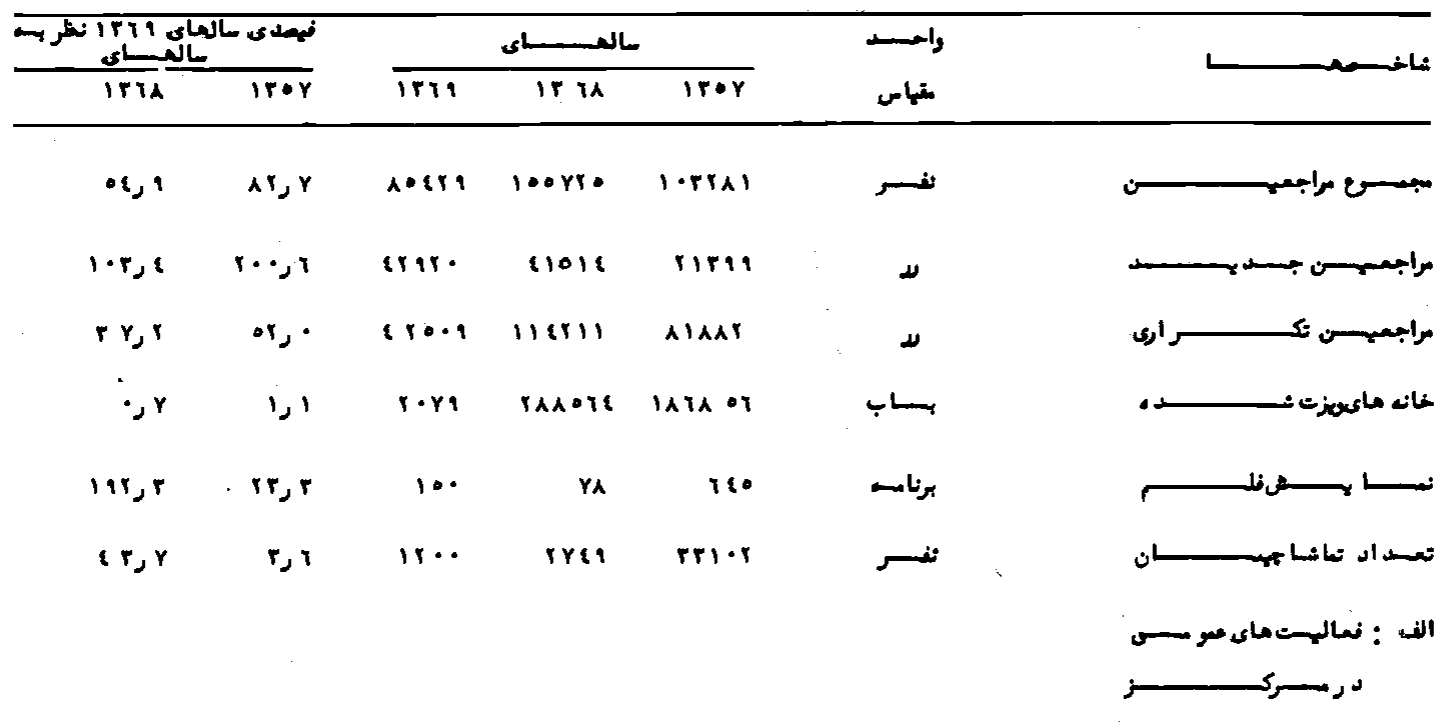

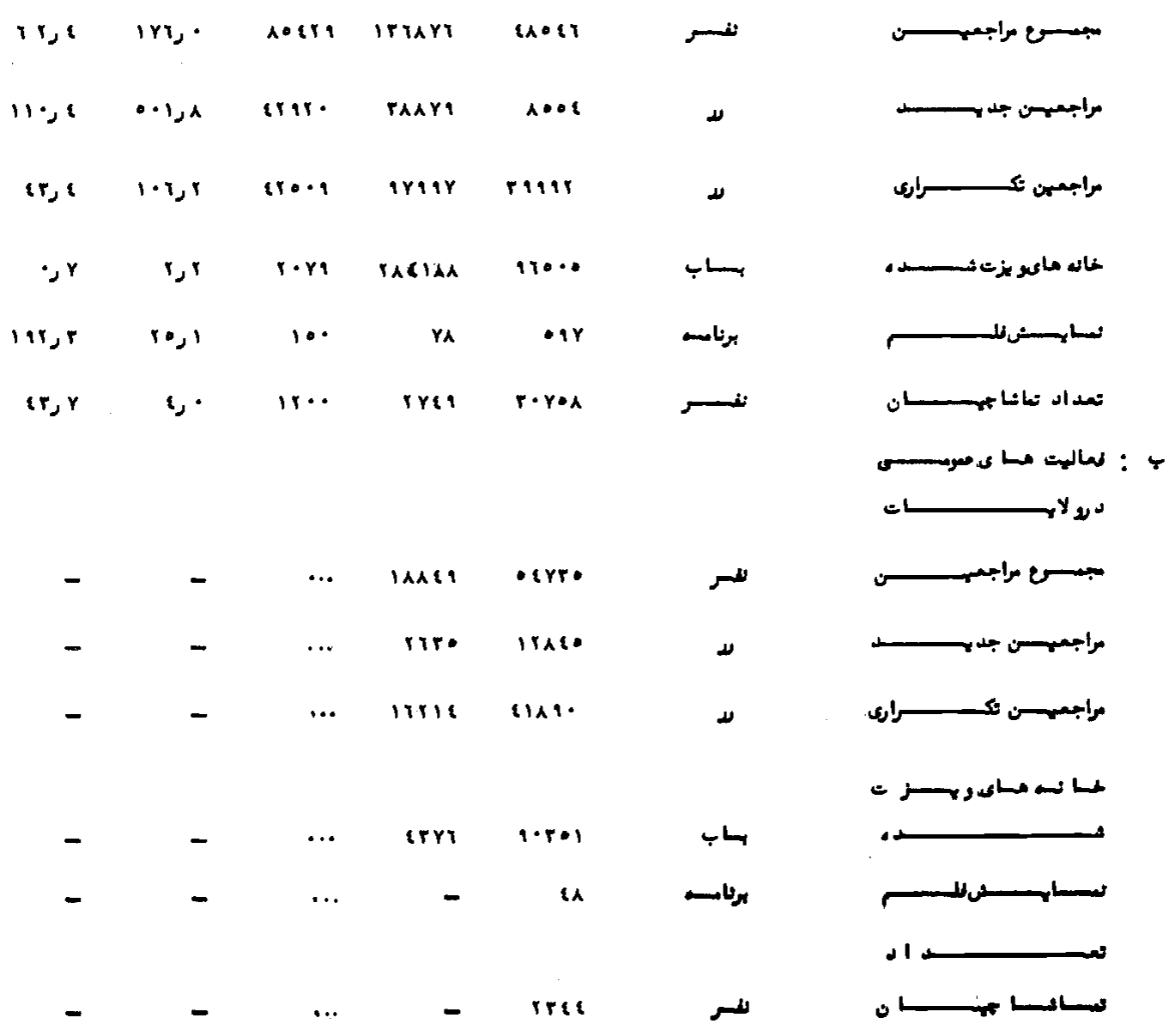




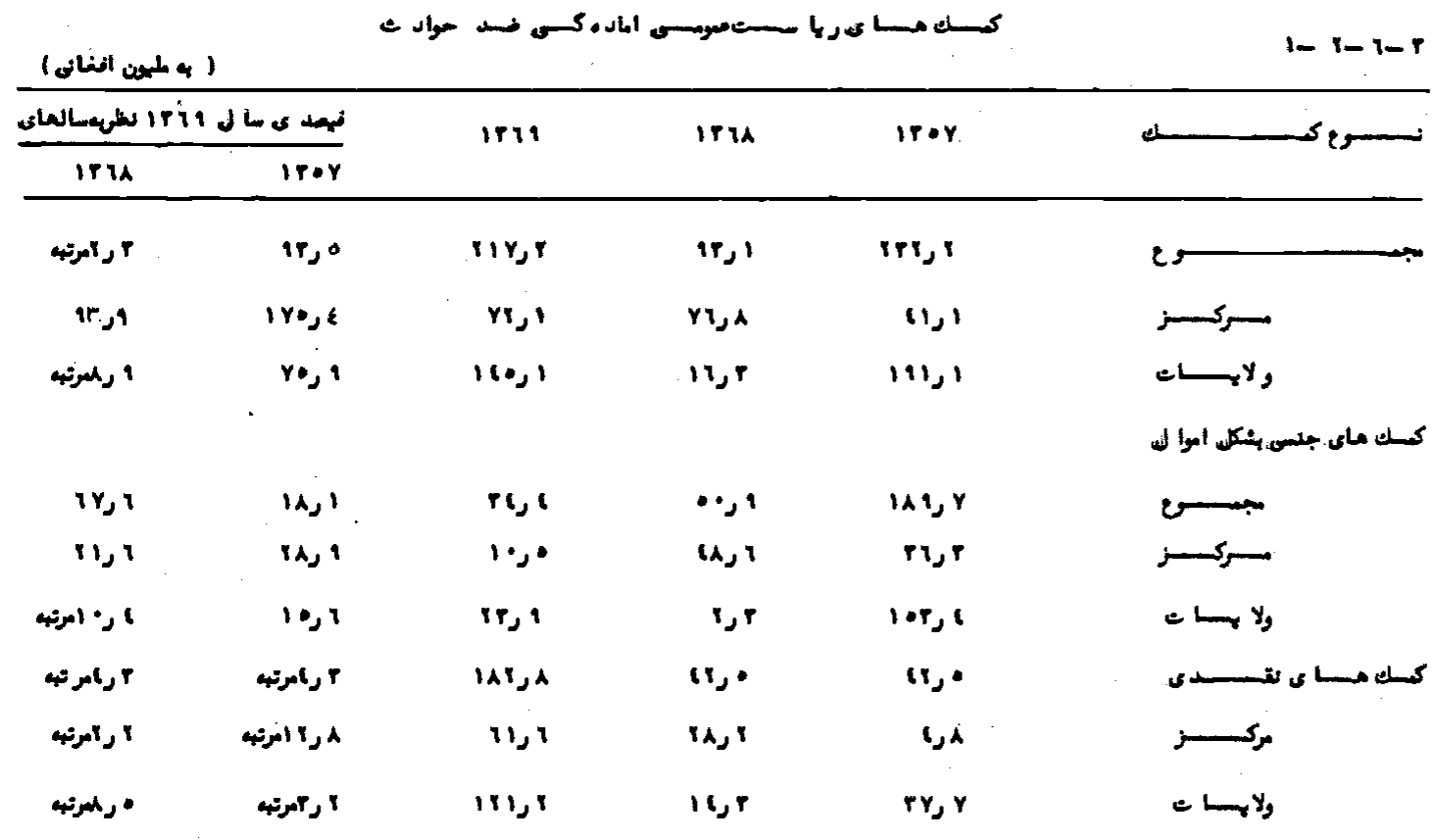

\begin{tabular}{|c|c|c|c|c|c|}
\hline لغانه 1 & & & & & $1-r-i-r$ \\
\hline \multicolumn{2}{|c|}{ 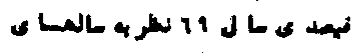 } & \multirow{2}{*}{ irn } & \multirow{2}{*}{ iris } & \multirow{2}{*}{ irer } & \multirow{2}{*}{ SUS } \\
\hline iruA & Iror & & & & \\
\hline 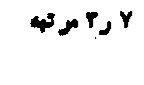 & $11 r, 1$ & 10, 6 & $r o, r$ & Al, & er \\
\hline \multirow[t]{2}{*}{ ارب مرنه } & $1 \cdot r, p$ & $\wedge \wedge, \cdot$ & $n$ & Ax, & وال \\
\hline & ז ر مر & ז. & 6,1 & 1.7 & \\
\hline Ira• & & & & & \\
\hline 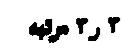 & " تري مرله & • & er & זر & \\
\hline
\end{tabular}




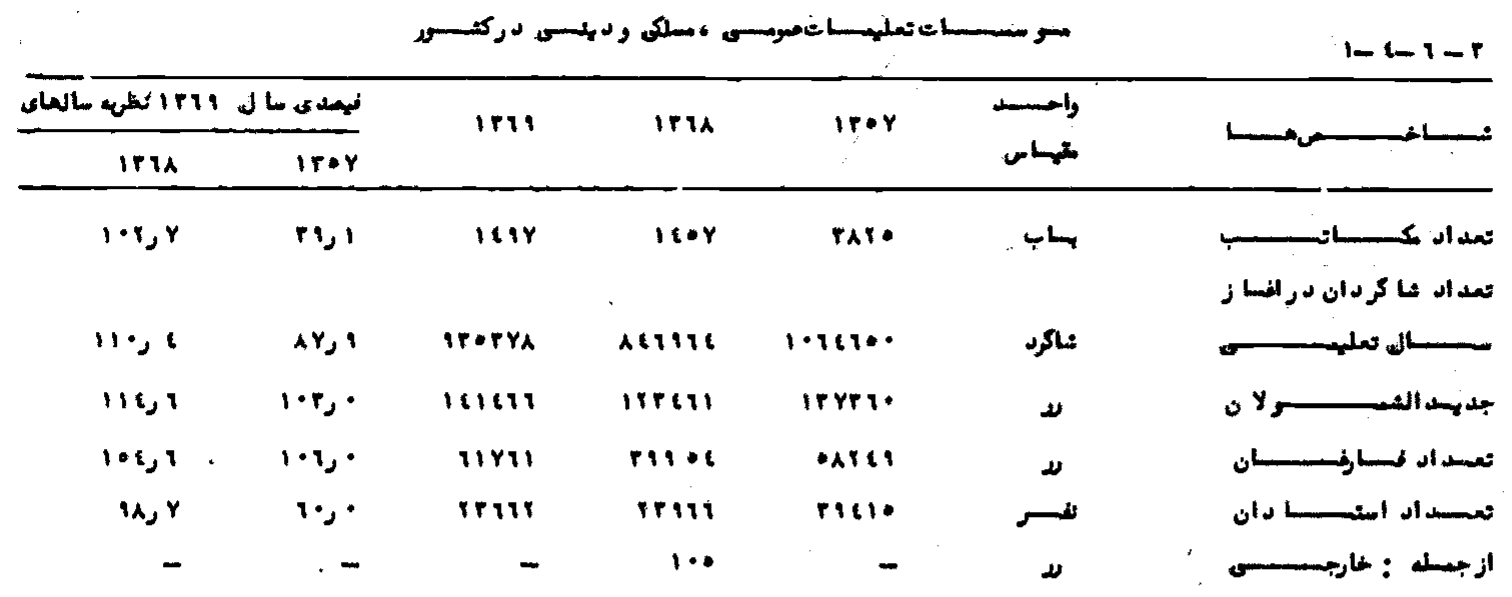

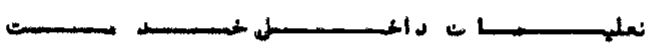
$r-1-1-r$

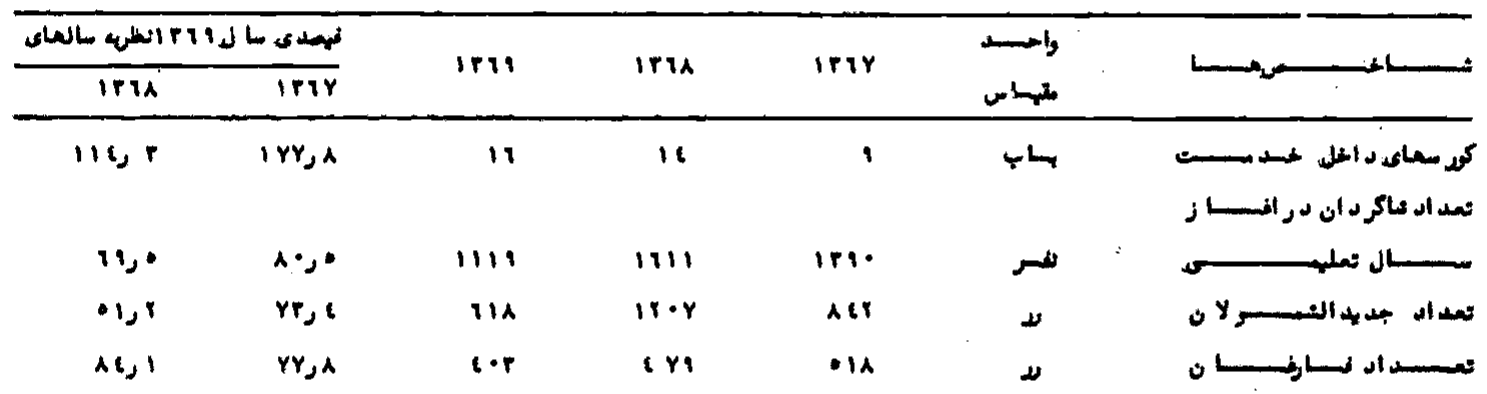

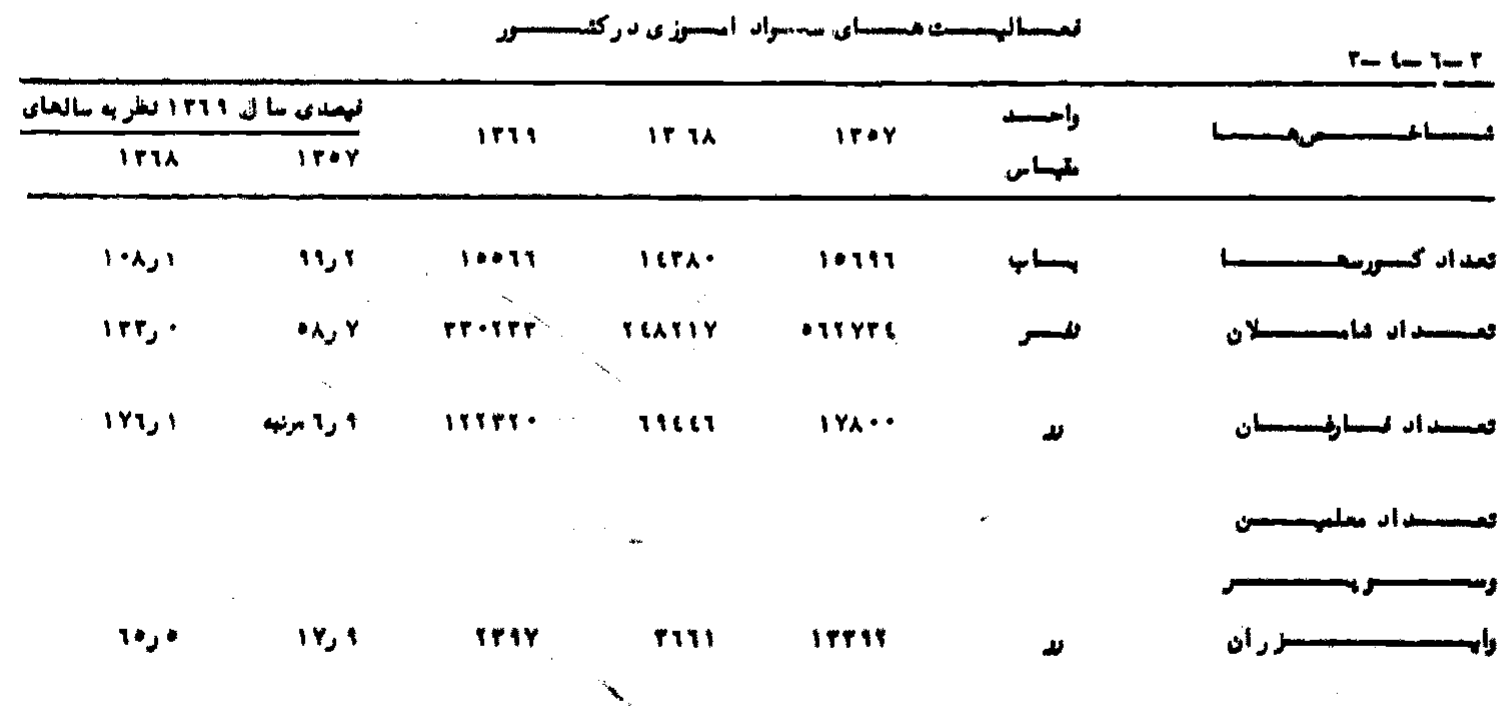




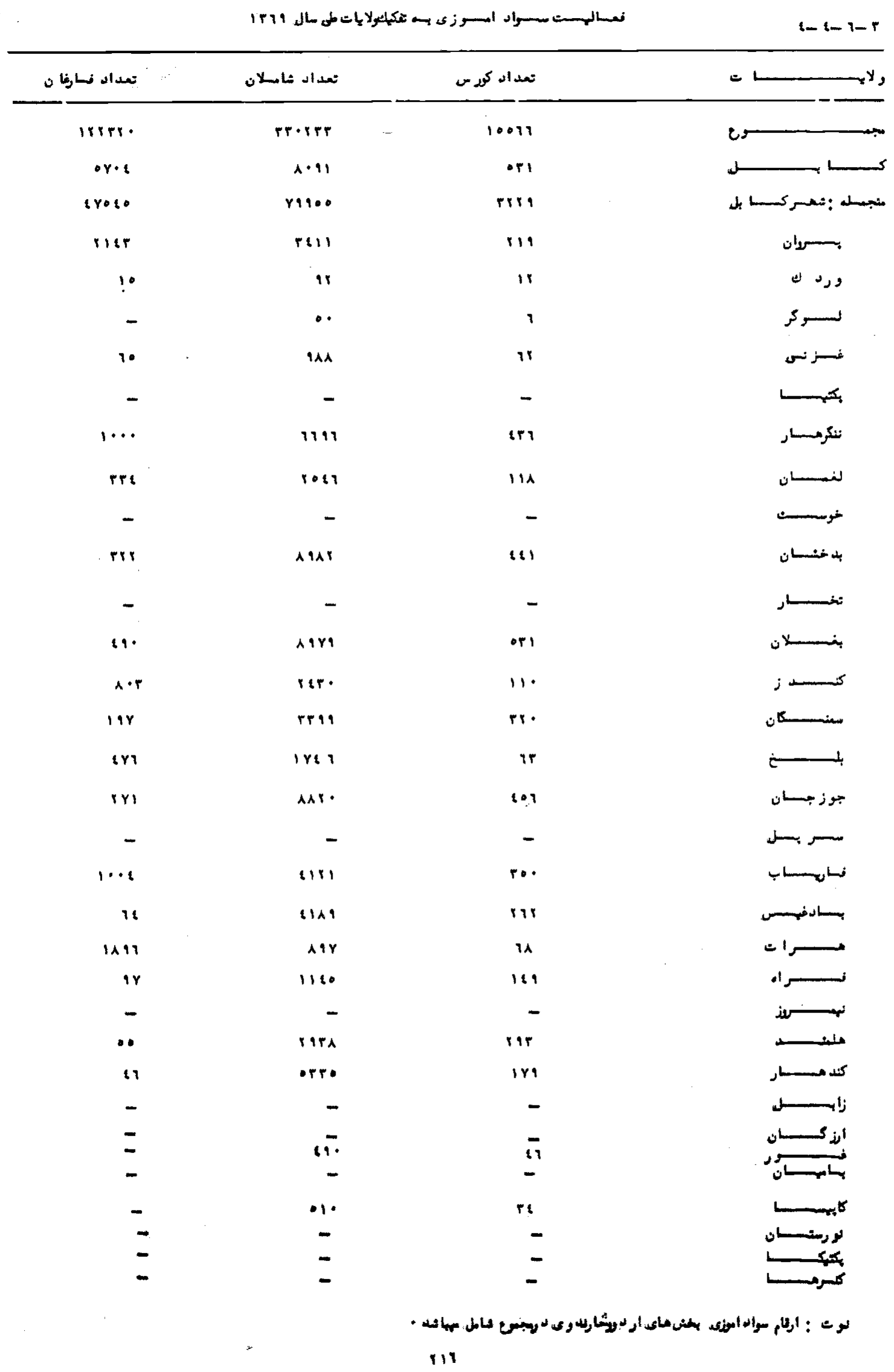




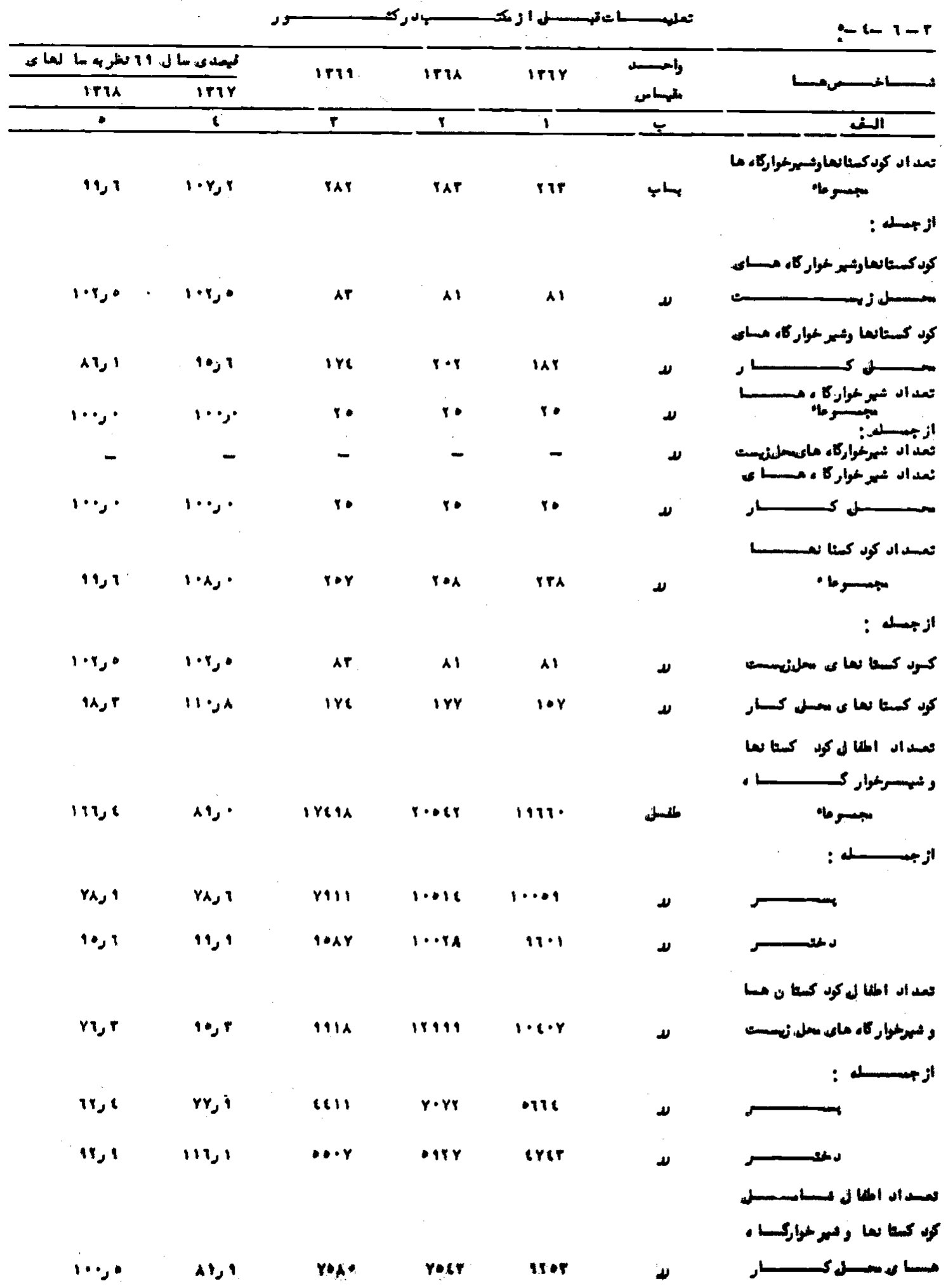




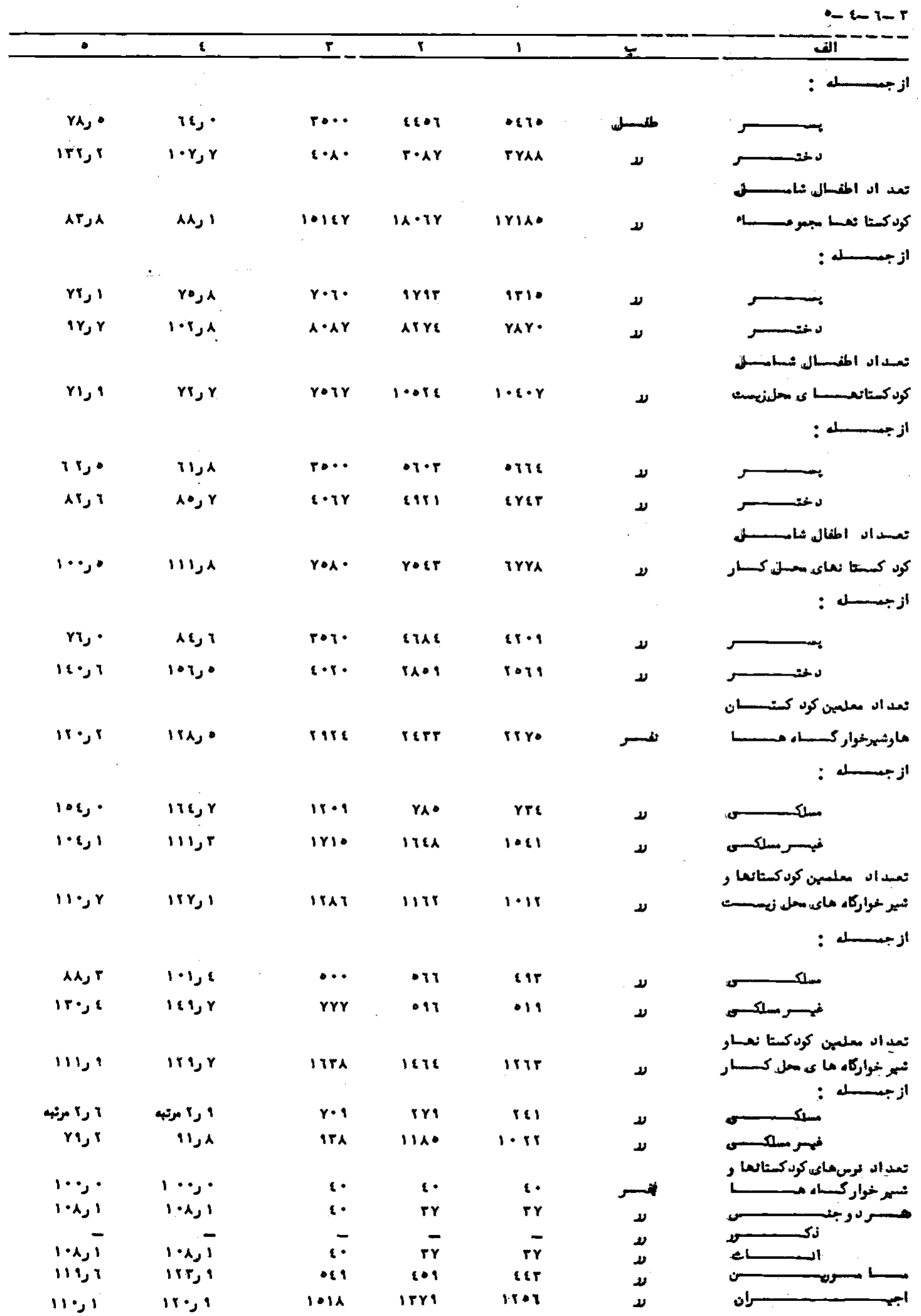




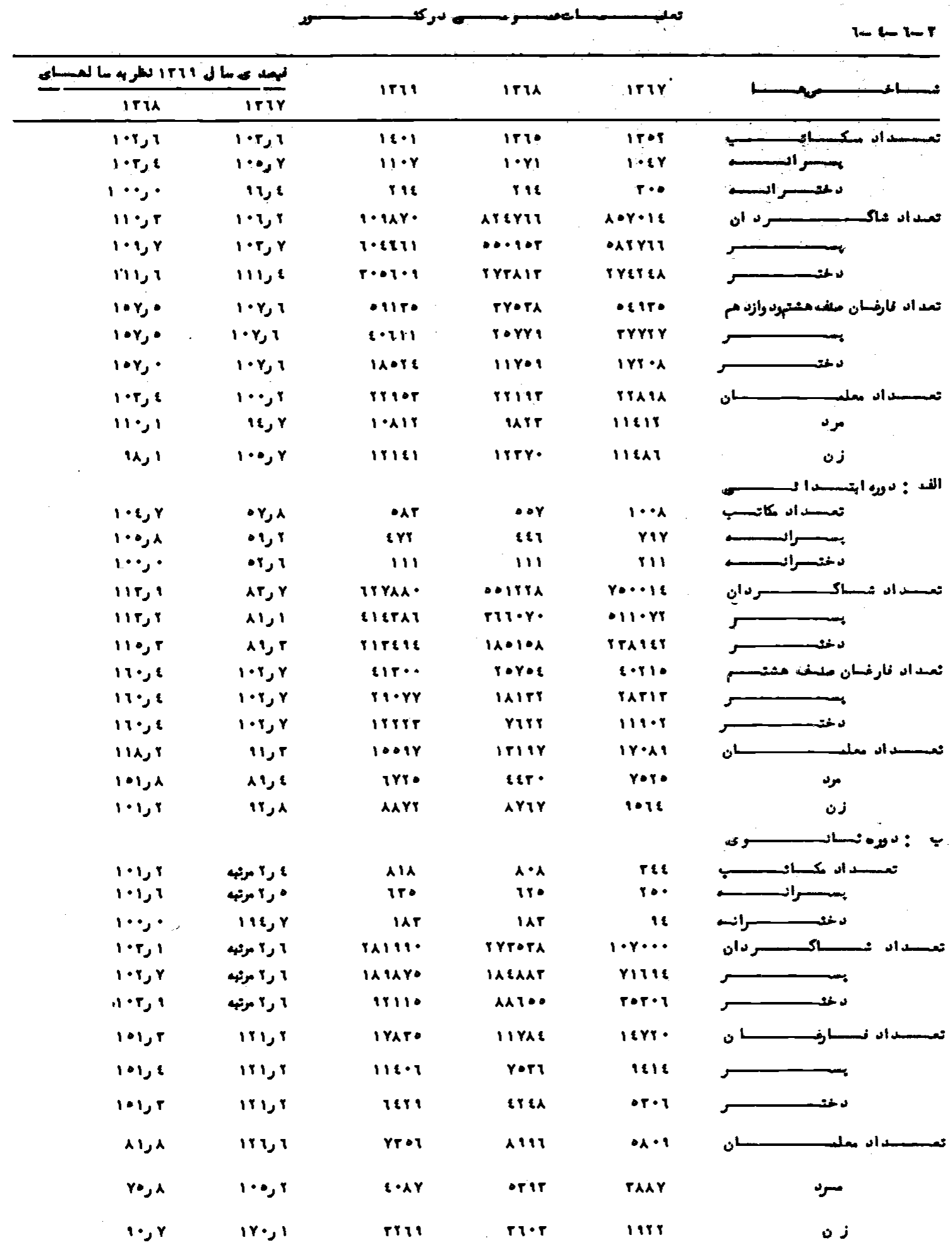




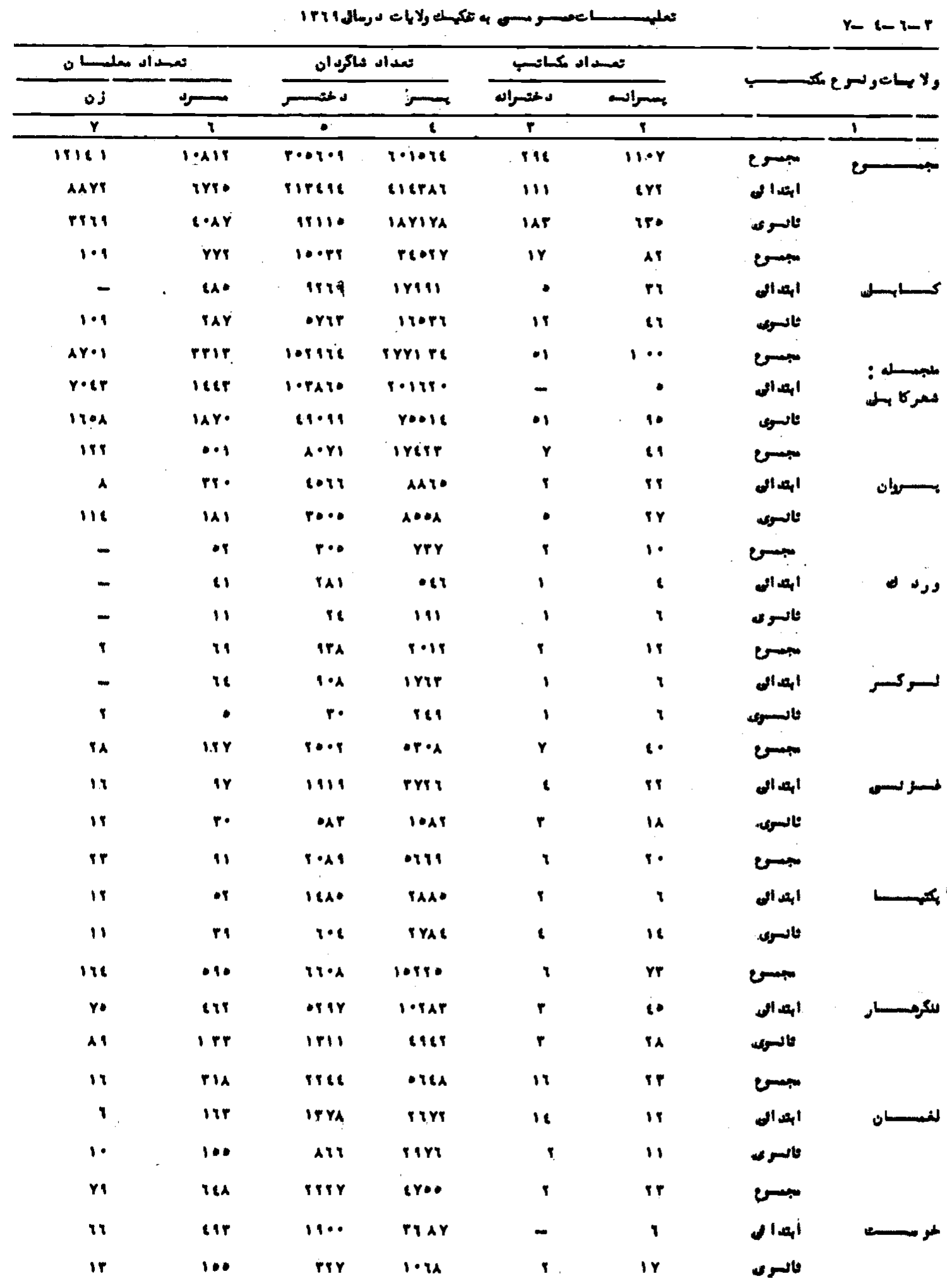




\begin{tabular}{|c|c|c|c|c|c|c|c|}
\hline$Y$ & 1 & - & $\mathrm{t}$ & $r$ & $r$ & & 1 \\
\hline iro & $r \cdot x$ & Aril & IATE & 10 & YI & مبسر ع & \\
\hline is & $8 \cdot 1$ & -7es & 1.900 & 1 & $r$ & اهدأ م. & يدهـــان \\
\hline AY & $r \cdot Y$ & roye & YMYY & 1 & \& & نانسسورى & \\
\hline$r \cdot$ & 108 & orEY & $1 \cdot 918$ & $\boldsymbol{\lambda}$ & rr & مبسر| & \\
\hline 17 & $1 \cdot 9$ & ripo & $Y Y \cdot \varepsilon$ & 8 & • & ايتدا أه & ســـار \\
\hline e. & 80 & irar & rrat & $\varepsilon$ & ir & ثانسسو ى & \\
\hline 111 & 118 & AiYe & $191 \cdot r$ & $\lambda$ & $r A$ & "יجست & \\
\hline Ar & irr & 1000 & irrrr & $r$ & 19 & أبثدا أن. & بهــــان \\
\hline$r r$ & ir & 819 & rer. & 1 & 19 & نالسسرى & \\
\hline$|Y|$ & Yr & •r०Y & $1 \cdots y$ & ir & 19 & مبمسر 2 & \\
\hline ire & eq & 1109 & $A \cdot Y r$ & $\boldsymbol{A}$ & 1 & ابتد ائسى & كتــــــــ ز \\
\hline$r Y$ & 19 & $1 \cdot 91$ & reno & - & ir & ثانسوى & \\
\hline IY & $1 \cdot$ & $r+8$ & YrAY & 1 & $r r$ & "بمس & \\
\hline 8 & $Y=$ & $r y \cdot 1$ & or $\&$ & $r$ & $\lambda$ & ايتدانق & سطكــ ن \\
\hline ry & 10 & $q \cdot r$ & $r \cdot \varepsilon \cdot$ & 8 & 18 & ثالسوي & \\
\hline AY $T$ & Alr & lirar & $r q \cdot 87$ & 19 & $\Lambda^{\circ}$ & "بست & \\
\hline r9o & BAT & $1 \cdots Y$ & Miry & $\boldsymbol{A}$ & $r$ & ايتدا ن نه & ¿ \\
\hline (1) & irt & ery & 1911 & 11 & -r & نالسـوى & \\
\hline ras & $r \&$ & 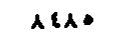 & l8Ak & 1 & .1 & -بعس? & \\
\hline ire & 119 & 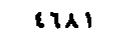 & $1 \cdot \lambda r$ & $r$ & $r r$ & ايترا' ن. & سـرزبان \\
\hline$r r$ & irr & $r A \cdot q$ & $\bullet \boldsymbol{A} \cdots$ & $r$ & $r$ & نـالسوك، & \\
\hline ir & $r$ & $1 \cdots y$ & 11 & 1 & ir & مبسر e & \\
\hline$r$ & $r \cdot$ & -91 & $11 \cdots$ & - & 11 & ايتد اله & \\
\hline IY & 1 & 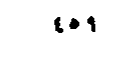 & ixt & 1 & $r$ & ثالسرى & \\
\hline ert & ris & 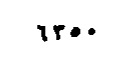 & 1819. & ri & 11 & سبست & \\
\hline reY & $r n$ & e*Ar & 1498 & 11 & ry & الهمد ائه & نساربس ب \\
\hline 119 & EY & iYu & $\notin \cdots 1$ & 1 & 18 & ناسسروب & \\
\hline
\end{tabular}


$r-2-1=r$

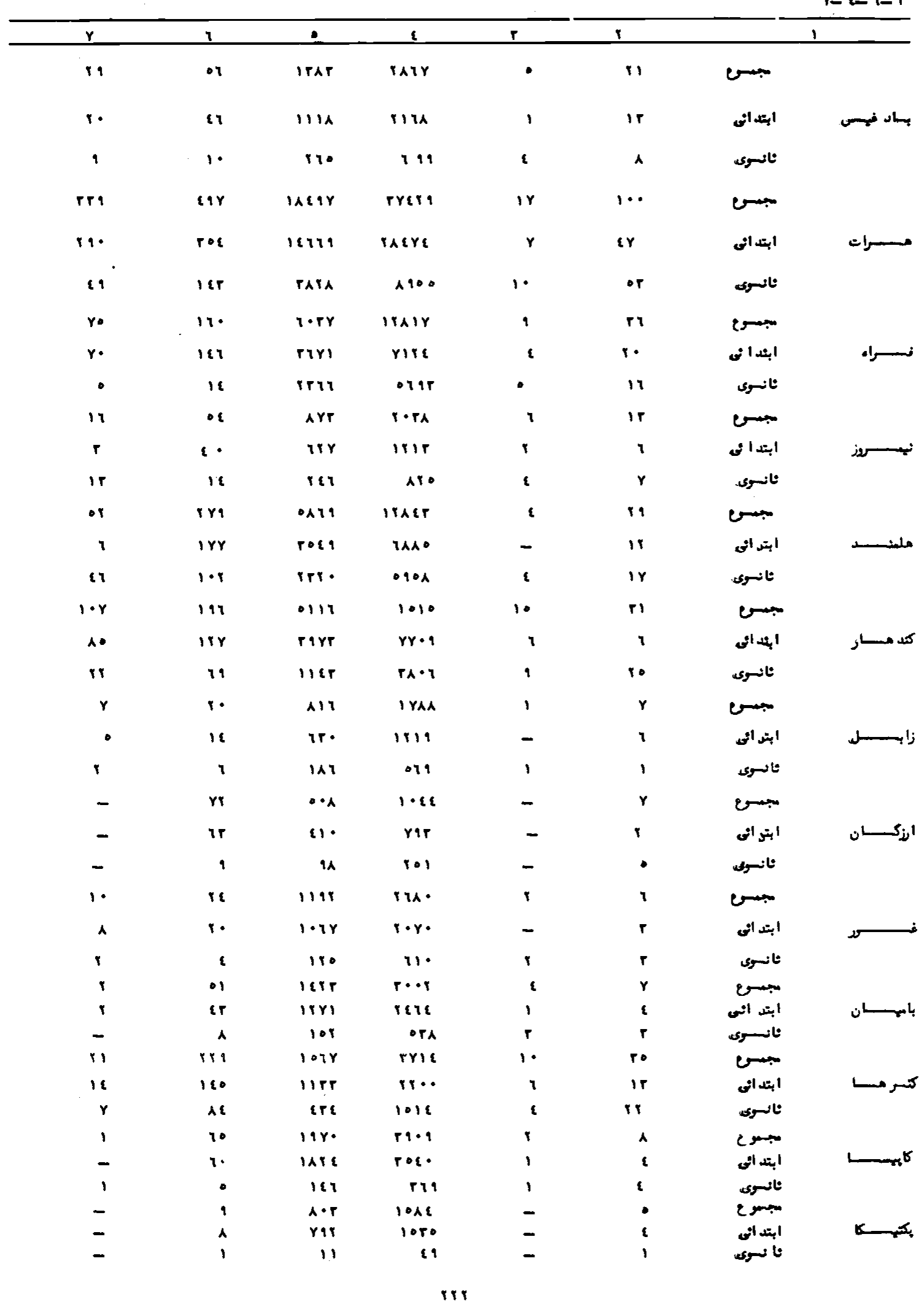




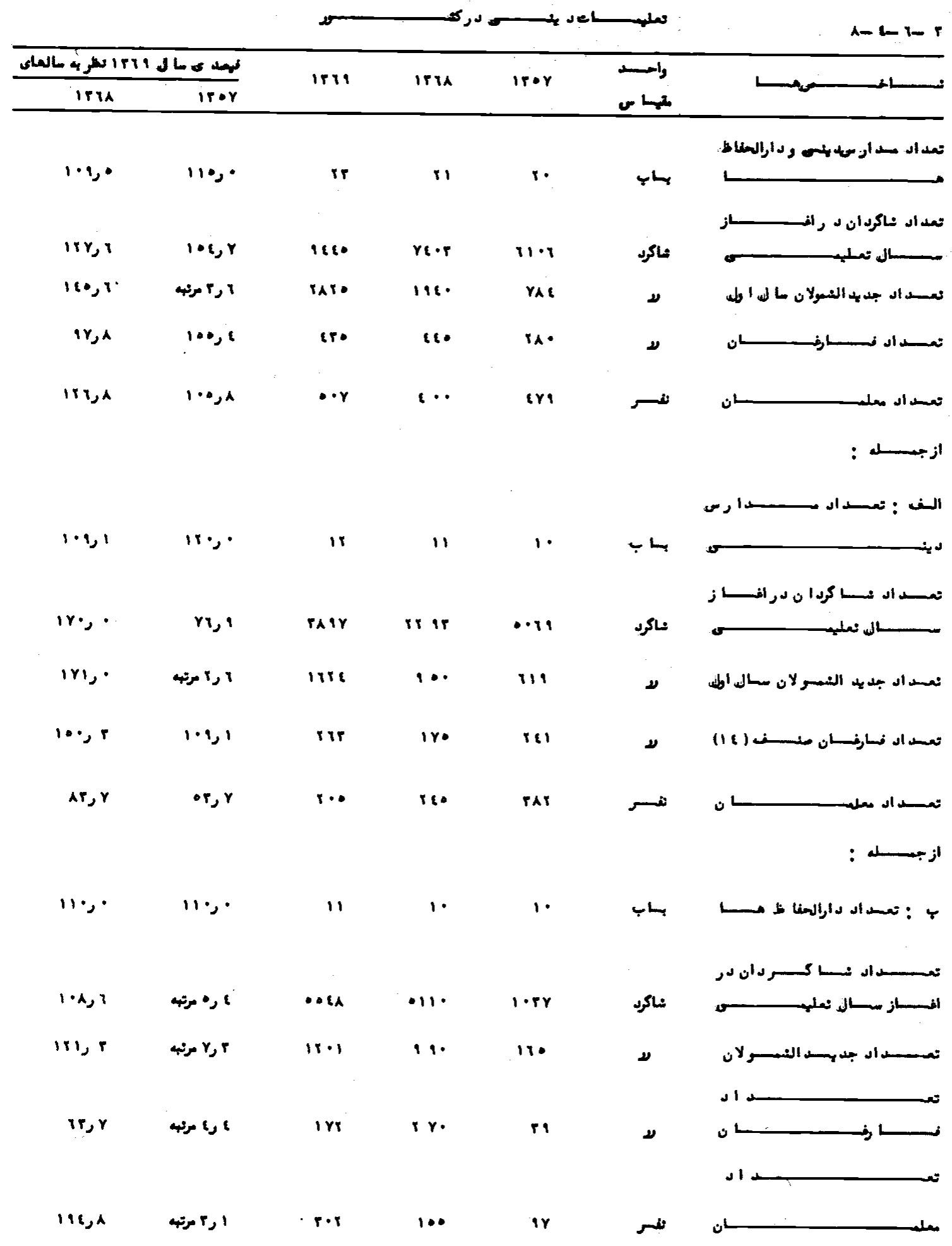




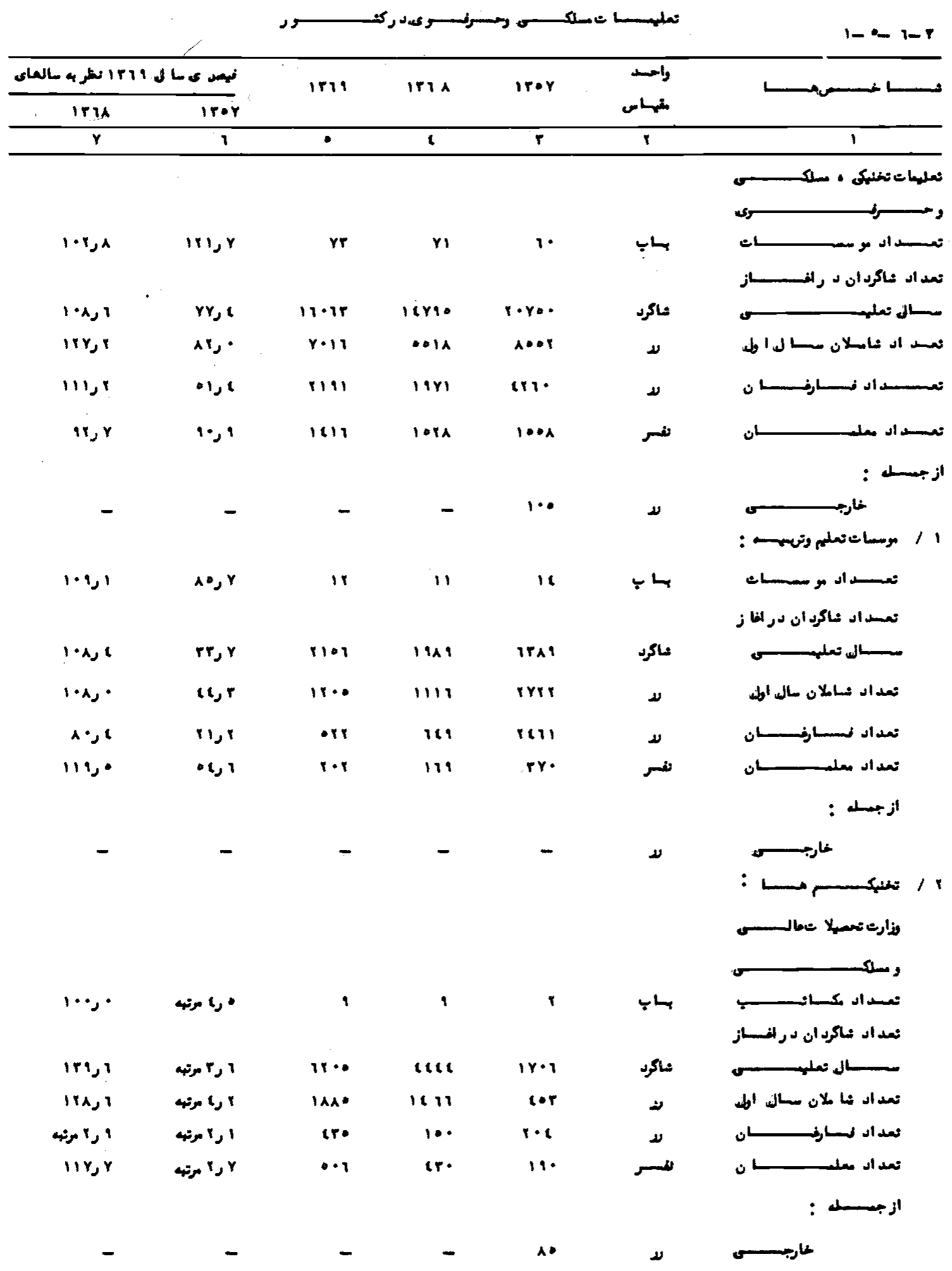




\begin{tabular}{|c|c|c|c|c|c|c|}
\hline$Y$ & 1 & $\cdot$ & $\varepsilon$ & $r$ & 1 & 1 \\
\hline $1 \cdots$, & $\bullet 1,1$ & I & ו & 18 & باب & 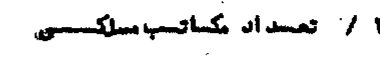 \\
\hline$\Delta A, 1$ & $i$ & rrri & rrry & mo. & 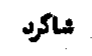 & ســـــال تعله \\
\hline $1 \cdot 1,1$ & $i \lambda\}$, & $1 * r 9$ & iers & -rry & ע & تعداد باملان ســـــالفاله \\
\hline $1 \cdot 1,1$ & $r r_{j} \cdot$ & $\bullet १$ & $0 n$ & $1 \cdot 10$ & ע & 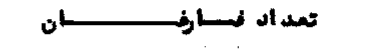 \\
\hline י & $|\lambda|$, & $r_{\lambda} \cdot$ & •rr & 111 & نستر & 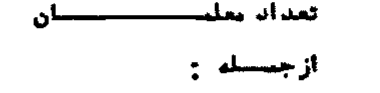 \\
\hline$\therefore$ & - & - & - & r. & $\boldsymbol{\nu}$ & 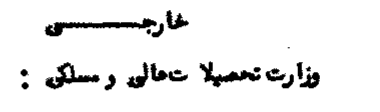 \\
\hline $1 \cdots$, & 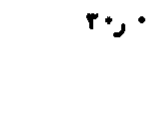 & 1 & 1 & $r \cdot$ & نباب & 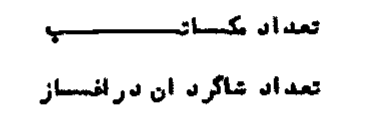 \\
\hline$r, 1$ & $1 \xi \xi$ & 1784 & Pris & 11001 & 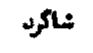 & سال، تعلهـ \\
\hline 10,1 & $r_{1} 1$ & re. & ror & 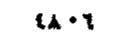 & ע & تعدأد شايسلان سـال أرل \\
\hline - 1, & 11,1 & irr & $r \bullet r$ & irte & $\nu$ & 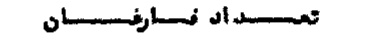 \\
\hline$r i, r$ & ir, & 110 & rus & A & لغسر & 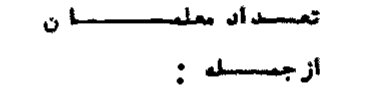 \\
\hline- & - & - & - & $r$ & עل & 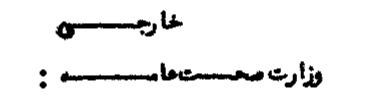 \\
\hline $1 \cdot \cdot \cdot$ & 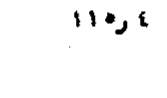 & 10 & 10 & ir & بساب & 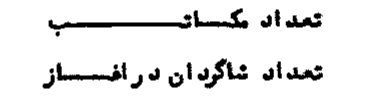 \\
\hline$M, y$ & irr, & Iria & $1 \cdot \operatorname{es}$ & $1 \cdots 1$ & 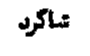 & ســــــالة نمليمس \\
\hline 111,1 & $|\lambda \lambda|$, & $1 \cdot r$ & 118 & 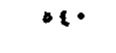 & لد. & تعداد عاملان مستسالالوك \\
\hline $1 \& r, q$ & $\operatorname{lng} r$ & in & iAl & res & ע & تعسداد نســــــــــــان \\
\hline $1 \cdot\{1$ & $\| y$, & 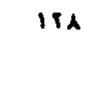 & irr & $1 \cdot 1$ & ل تلنسر & 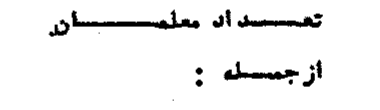 \\
\hline- & - & - & - & r & $\boldsymbol{\nu}$ & 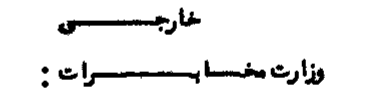 \\
\hline $1 \cdots$, & $1 \cdot \cdot$ & 1 & 1 & 1 & باب & 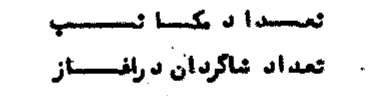 \\
\hline $1 \cdots, r$ & ا & $r+1$ & $r \cdots$ & १४ & 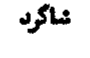 & 5 \\
\hline $1 \cdot \boldsymbol{1} \cdot$ & ا ره مرته & 101 & 10 & $r 1$ & $\nu$ & تعداد شاملان سسسال الط \\
\hline 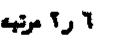 & ires" & ri & 18 & it & $\boldsymbol{\nu}$ & 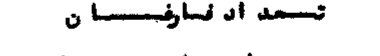 \\
\hline$r_{\lambda}, 1$ & $1 \cdot r_{3} 1$ & $r \cdot$ & rA & is & لفسر & 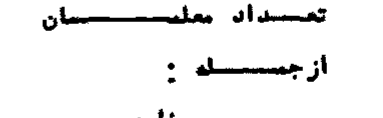 \\
\hline- & - & - & - & $\bullet$ & $\boldsymbol{\nu}$ & 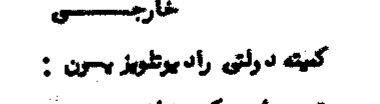 \\
\hline $1 \cdots$, & - & 1 & 1 & - & باب & 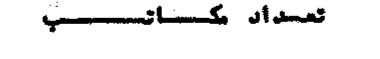 \\
\hline
\end{tabular}




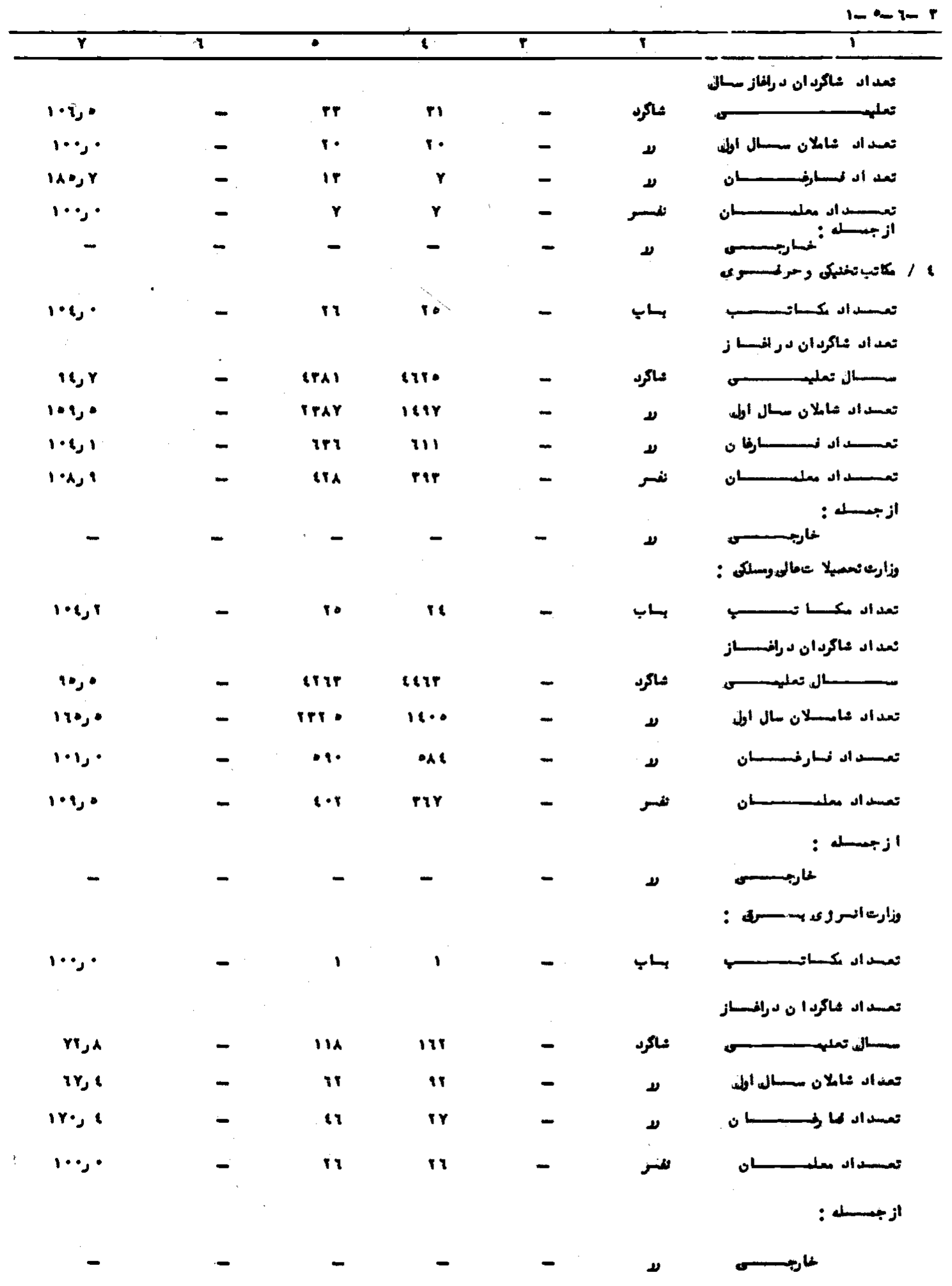




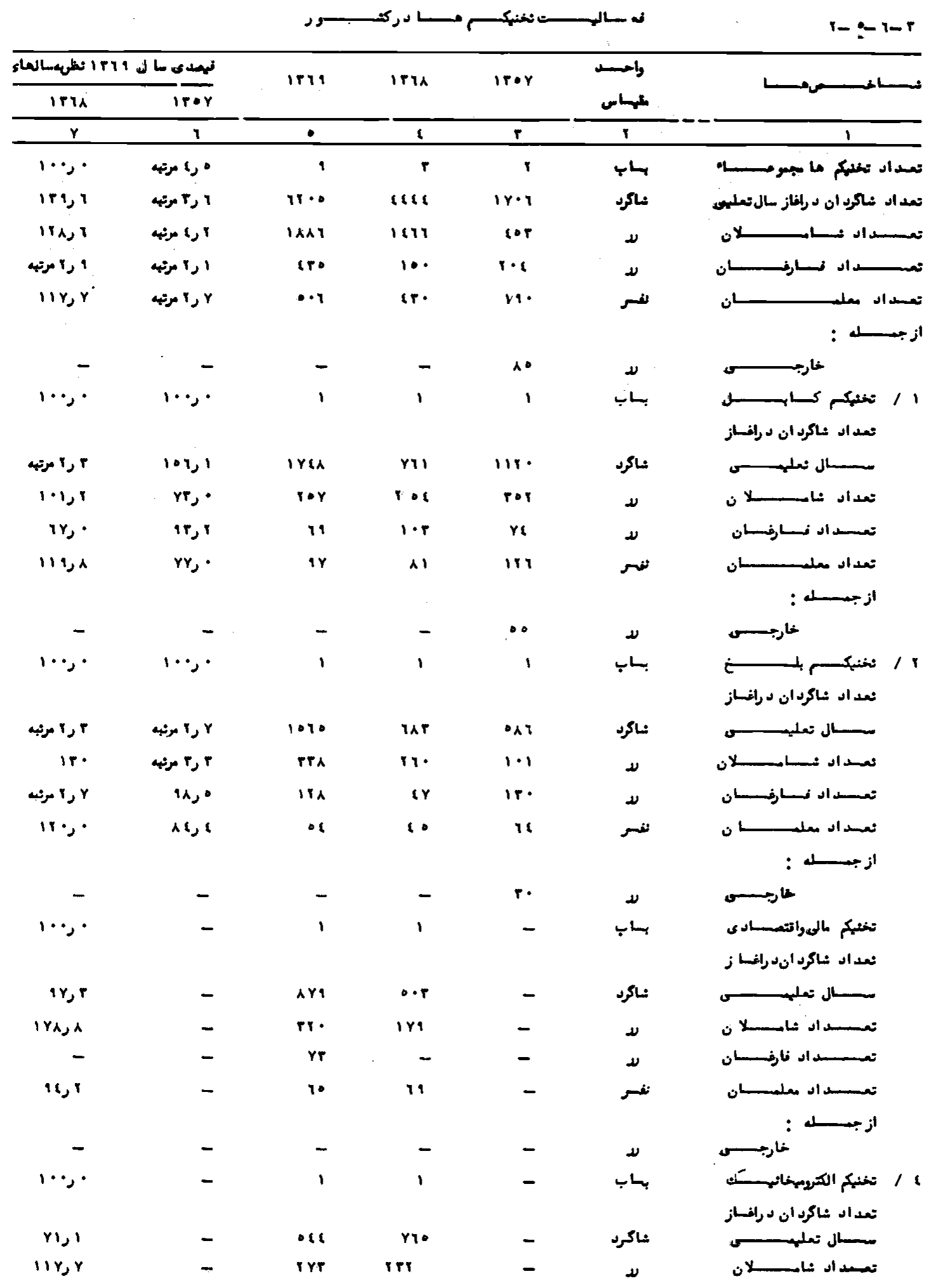




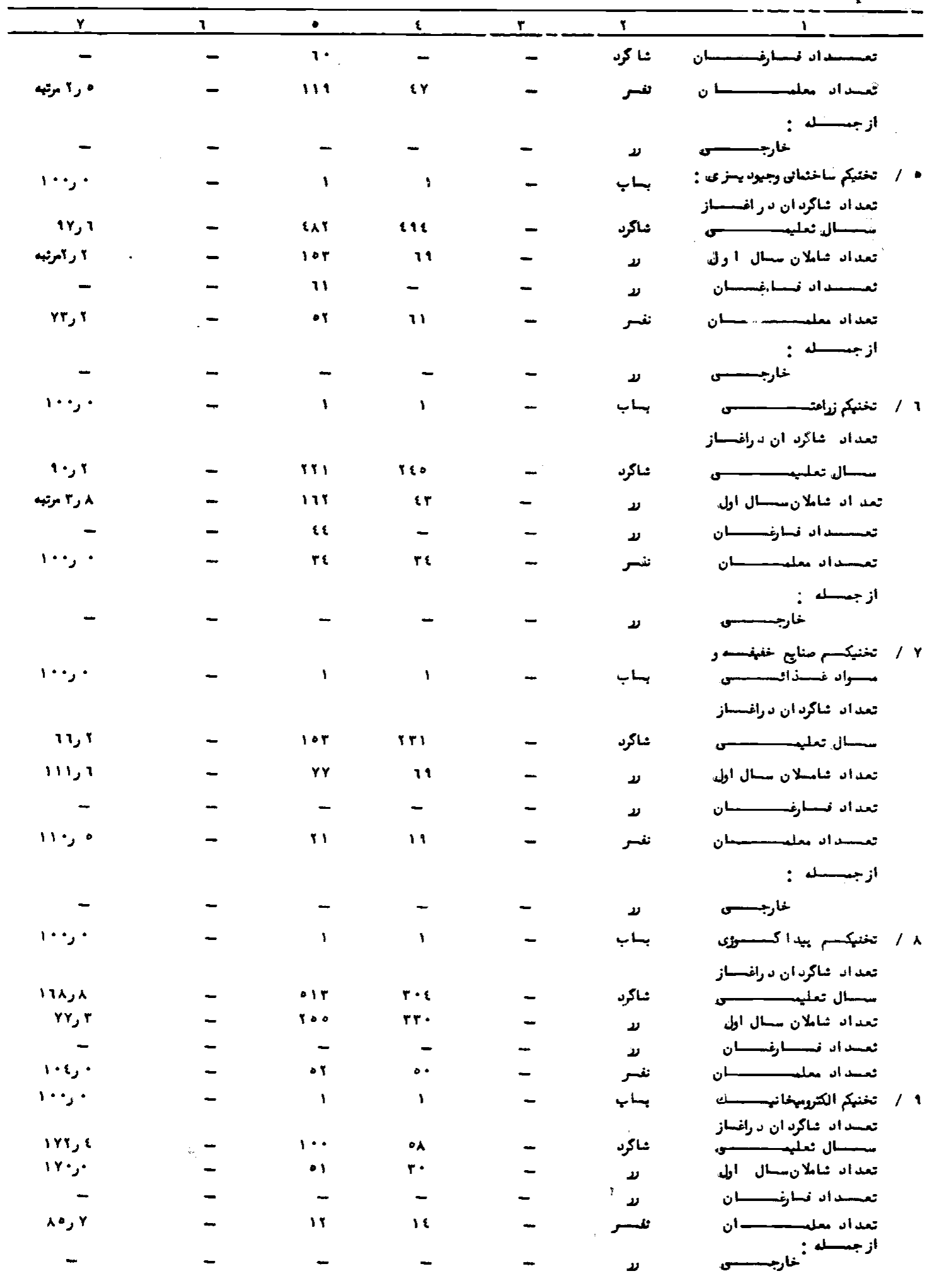




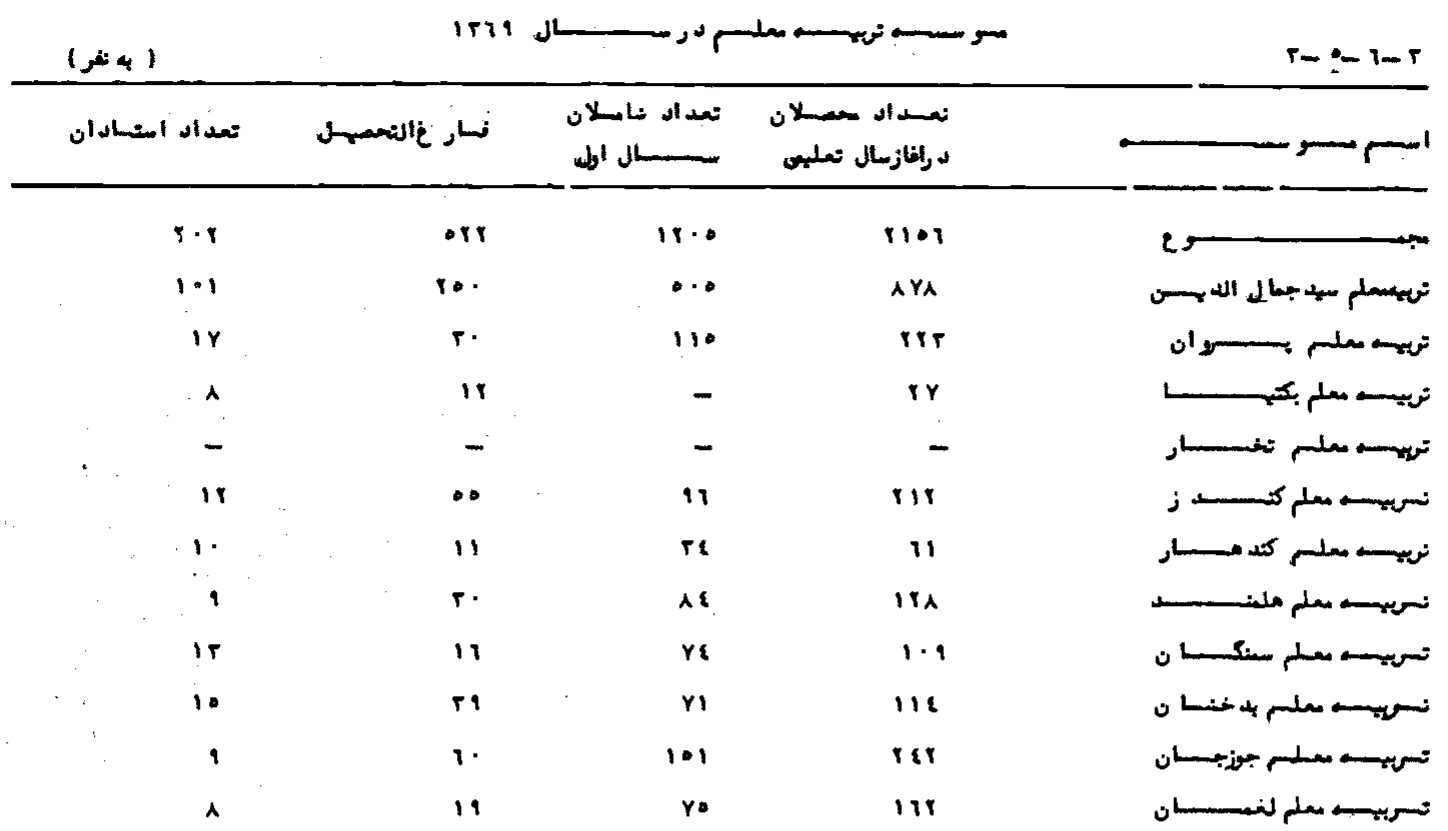

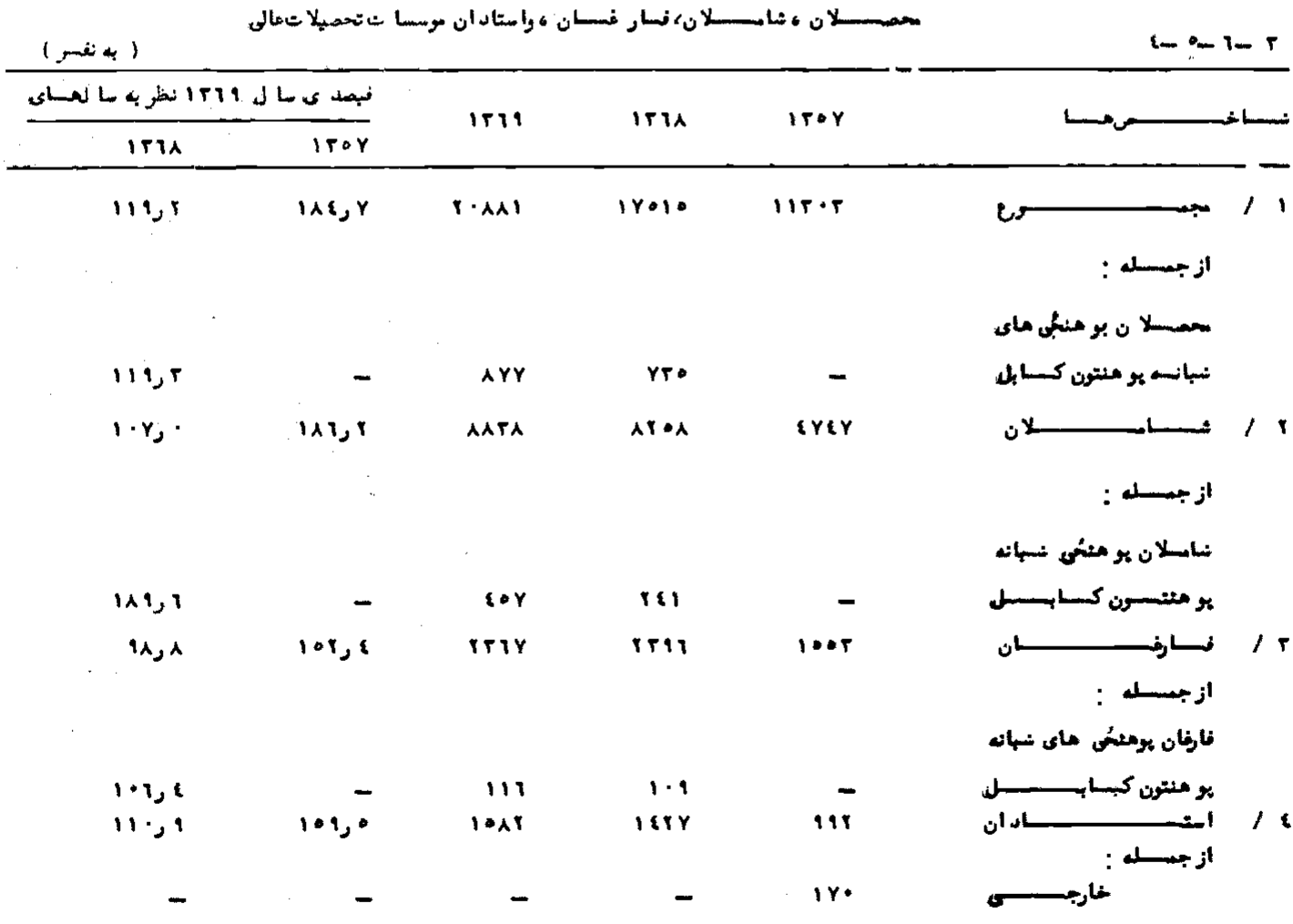




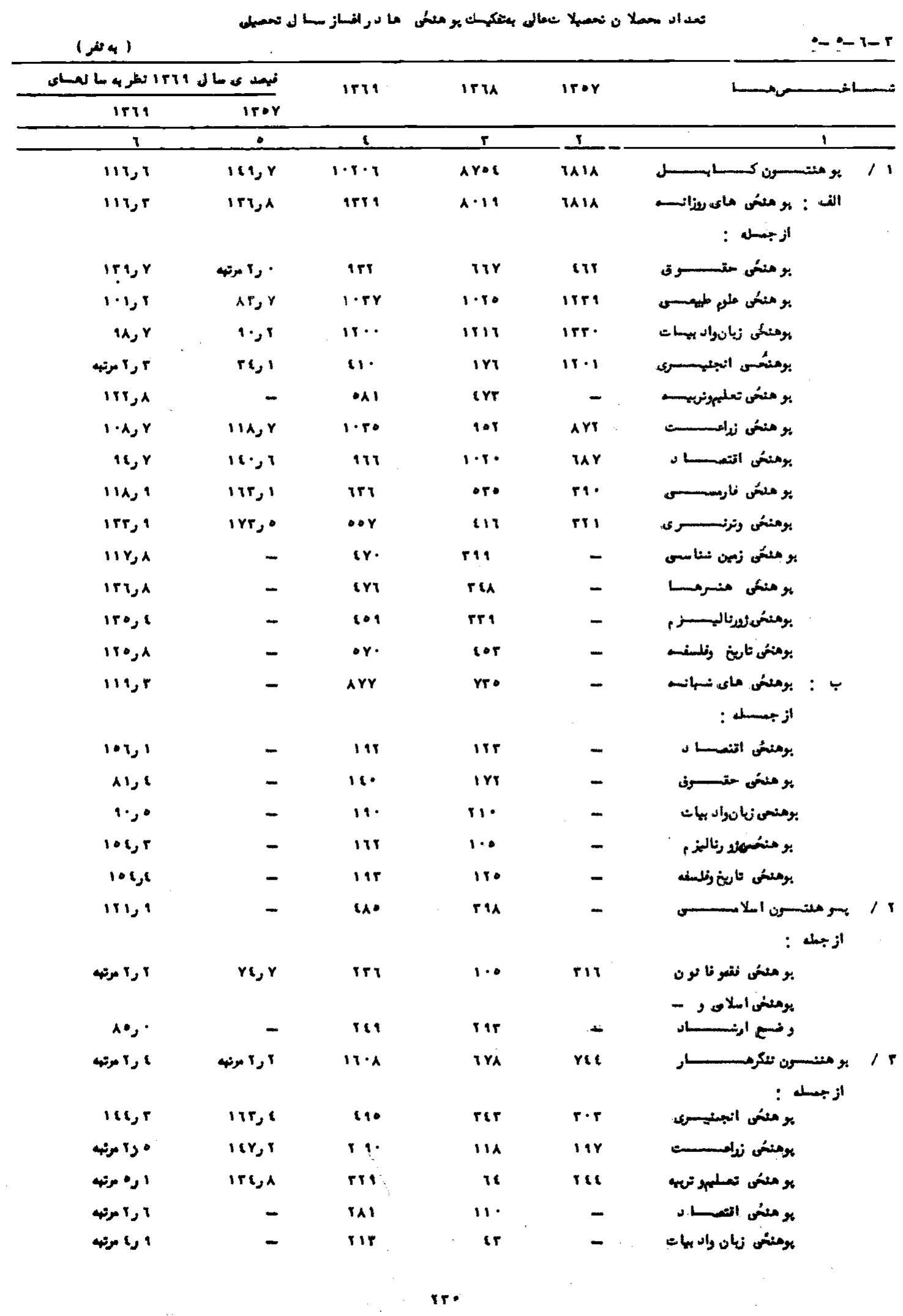




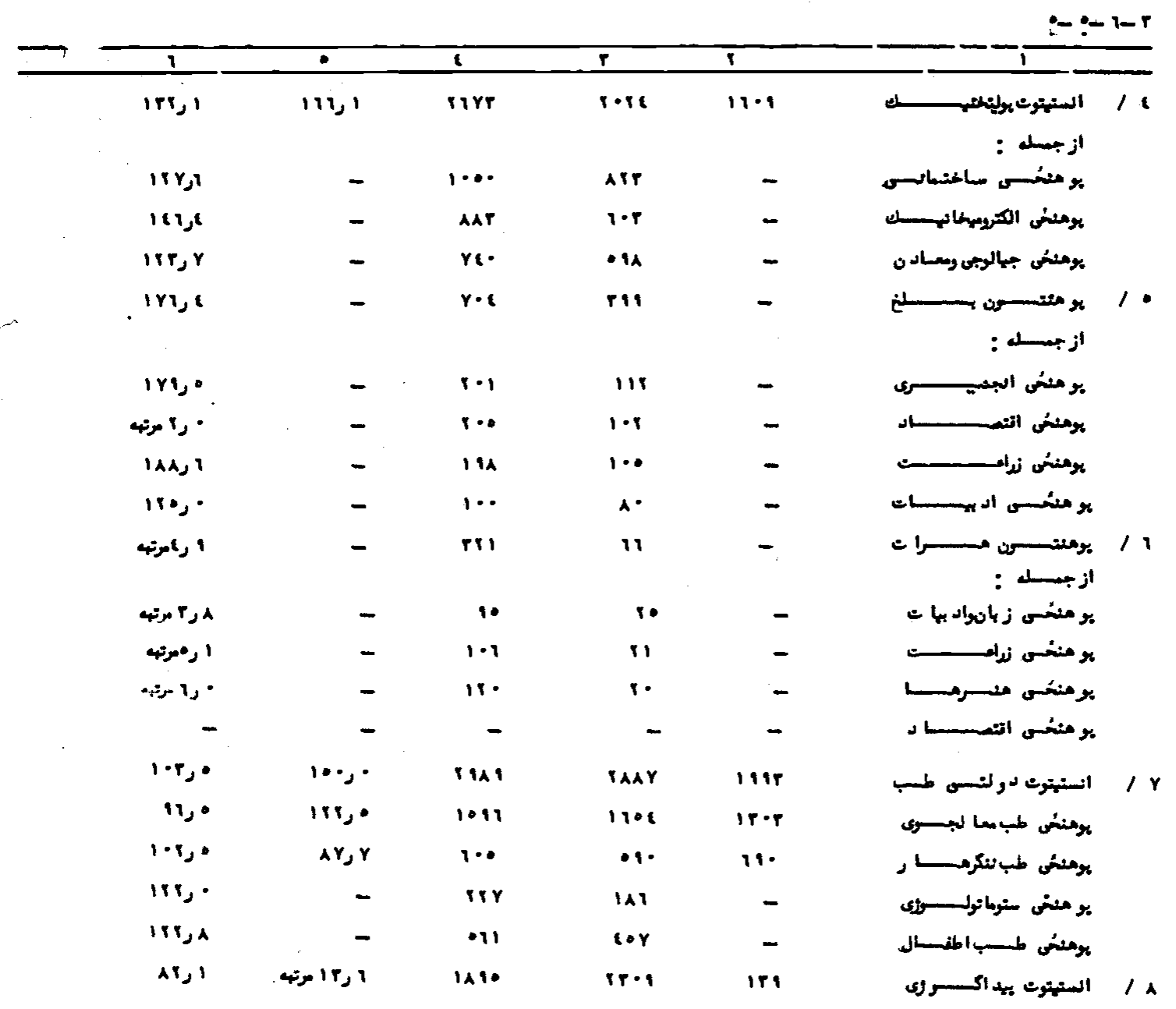

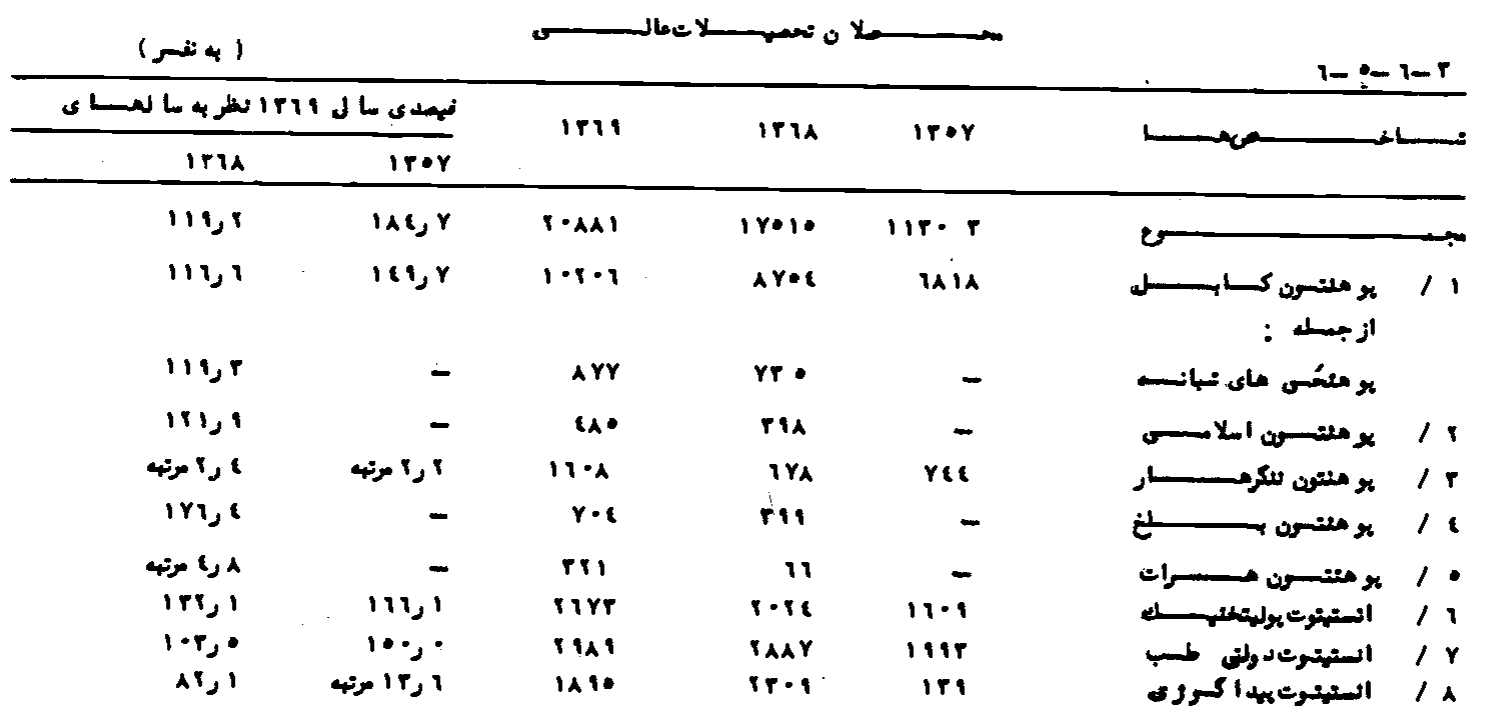




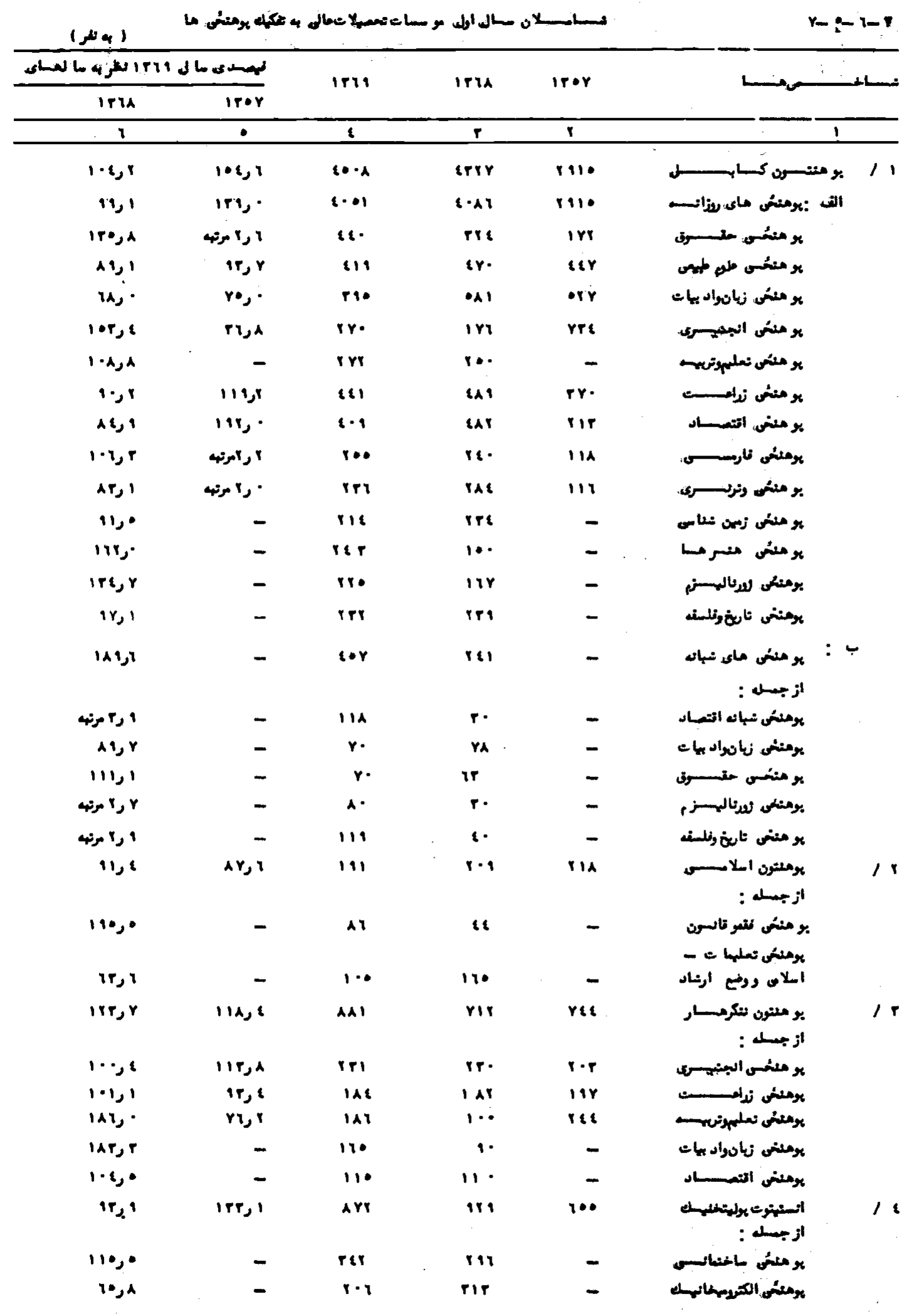


$r-1-r$

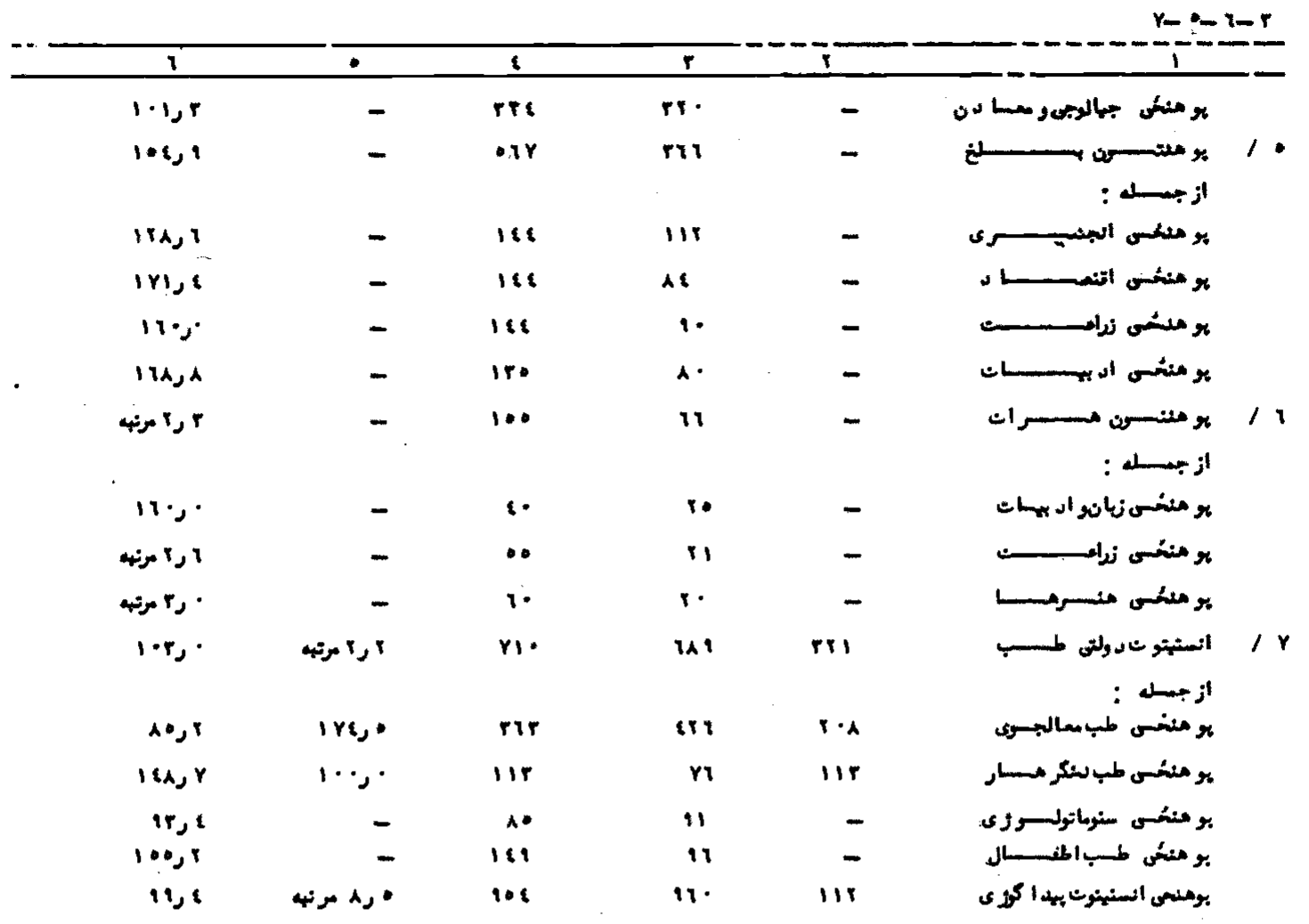

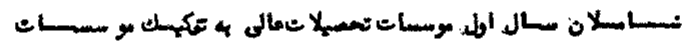

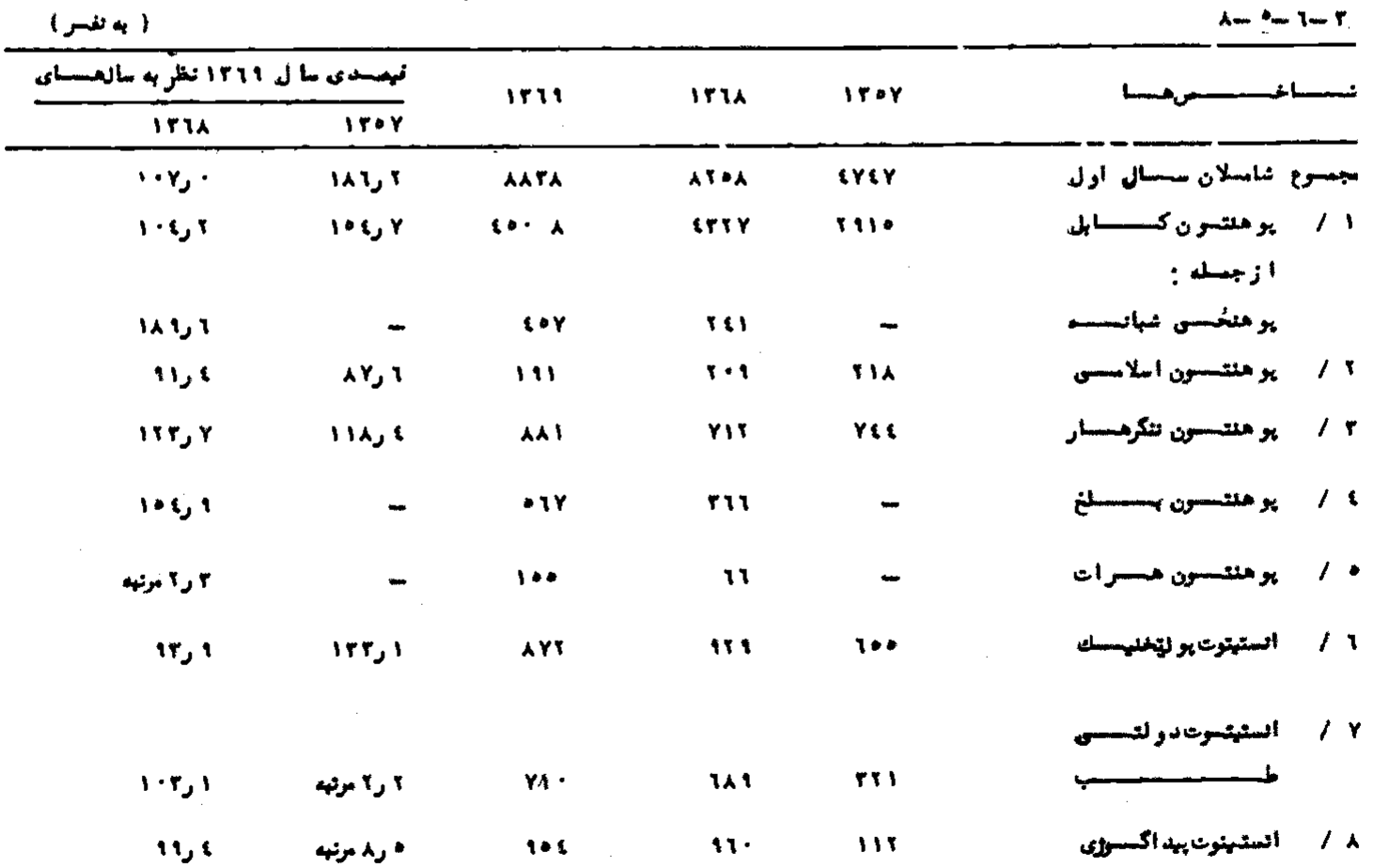




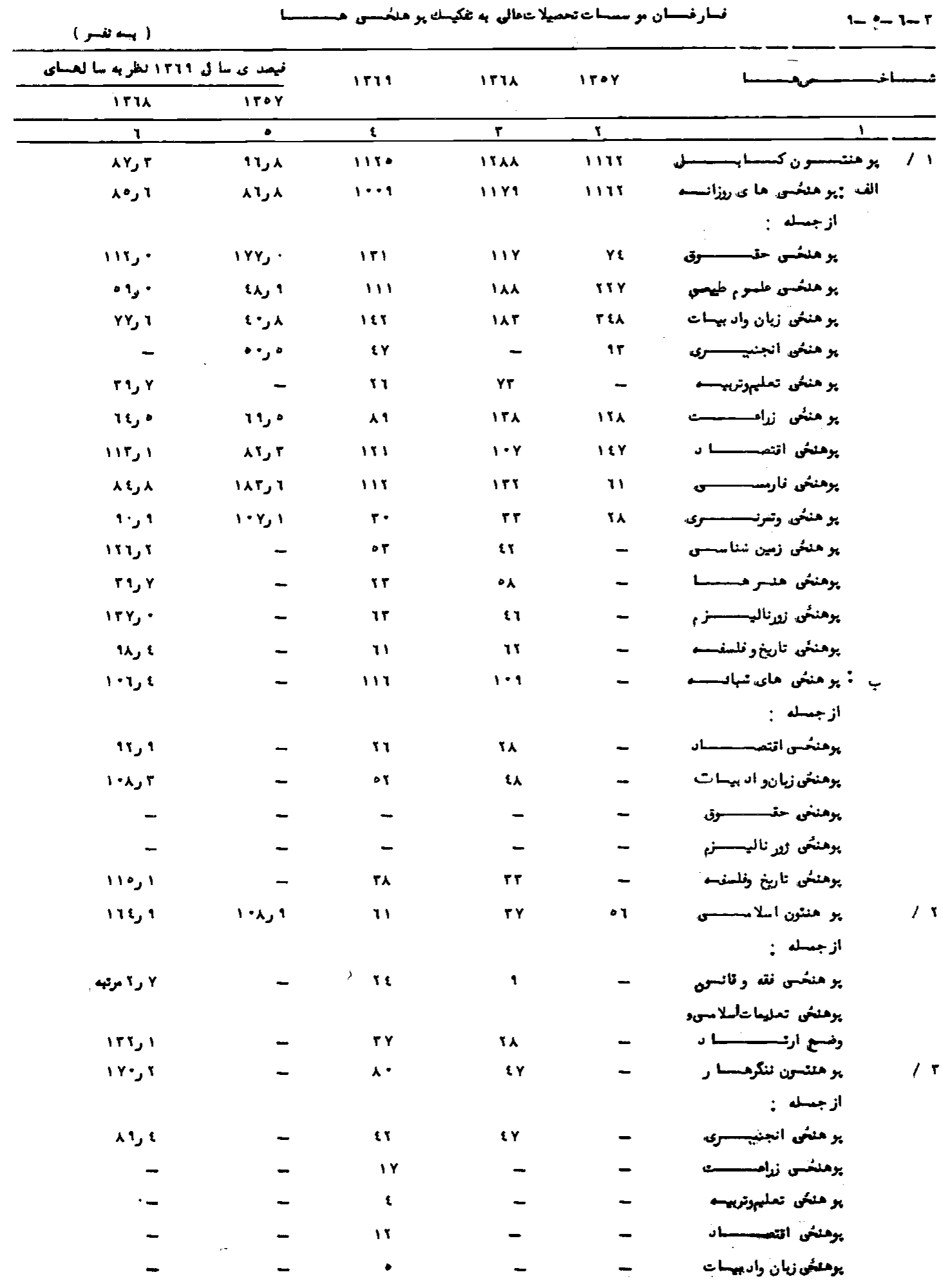




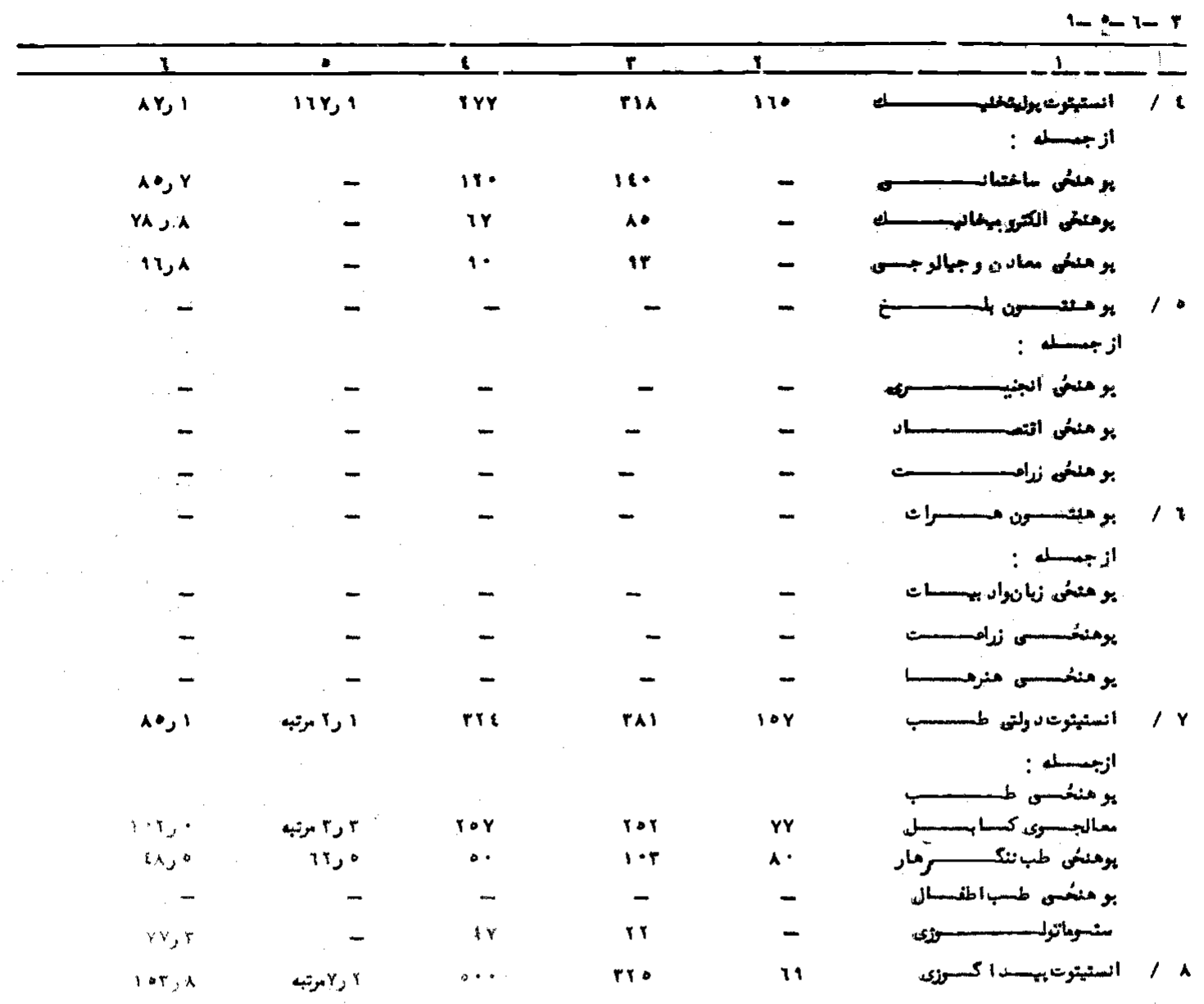

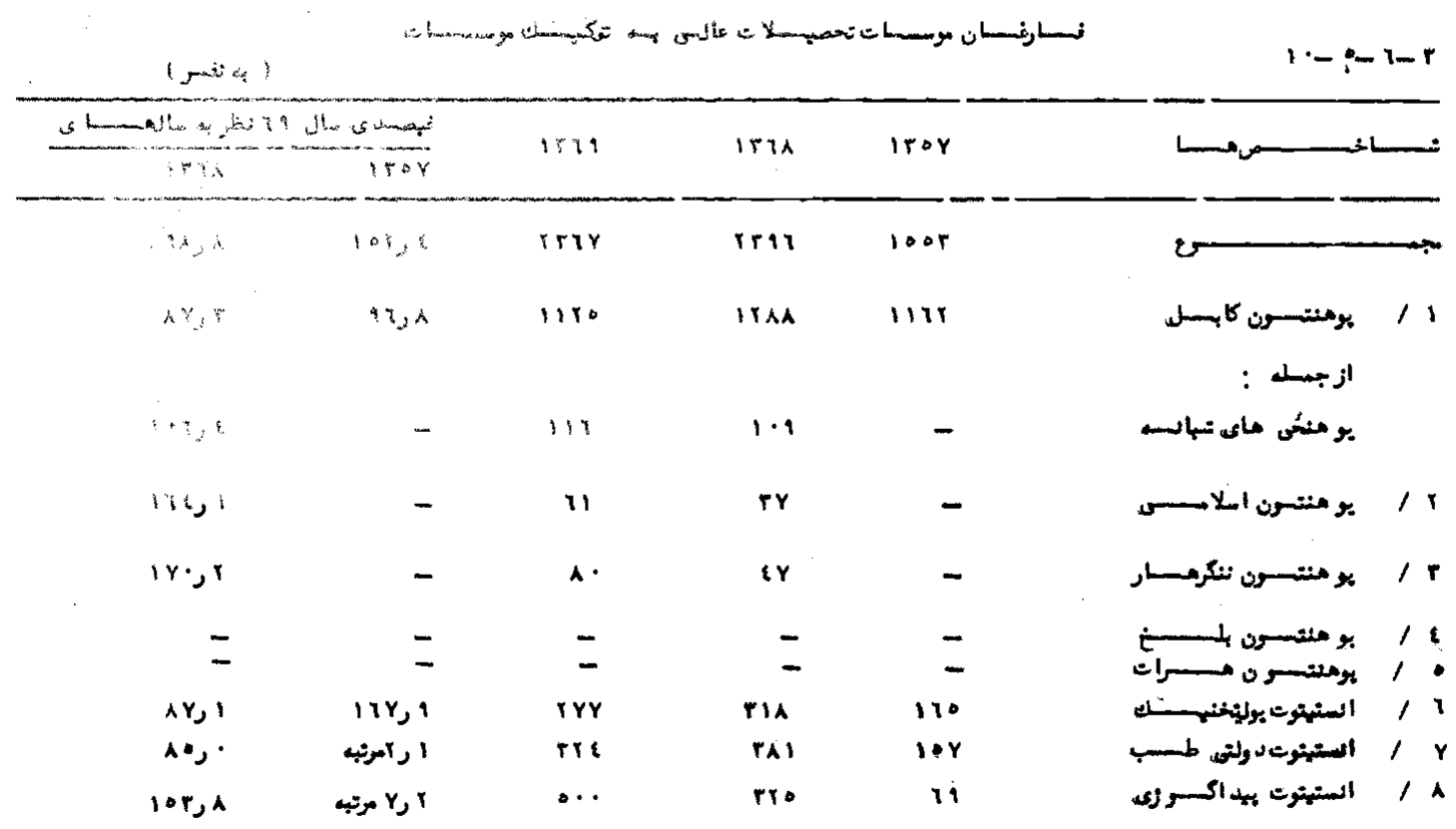




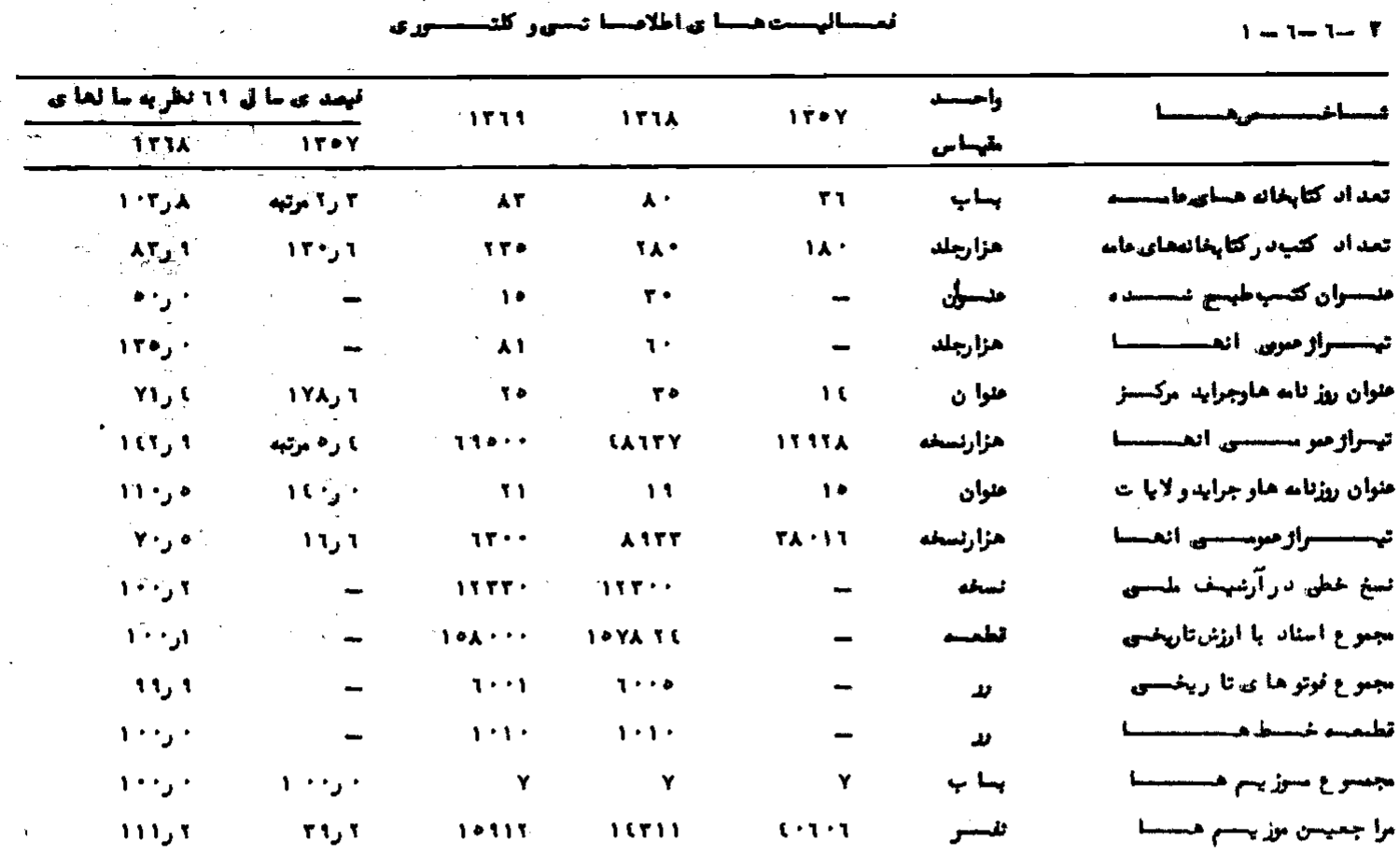

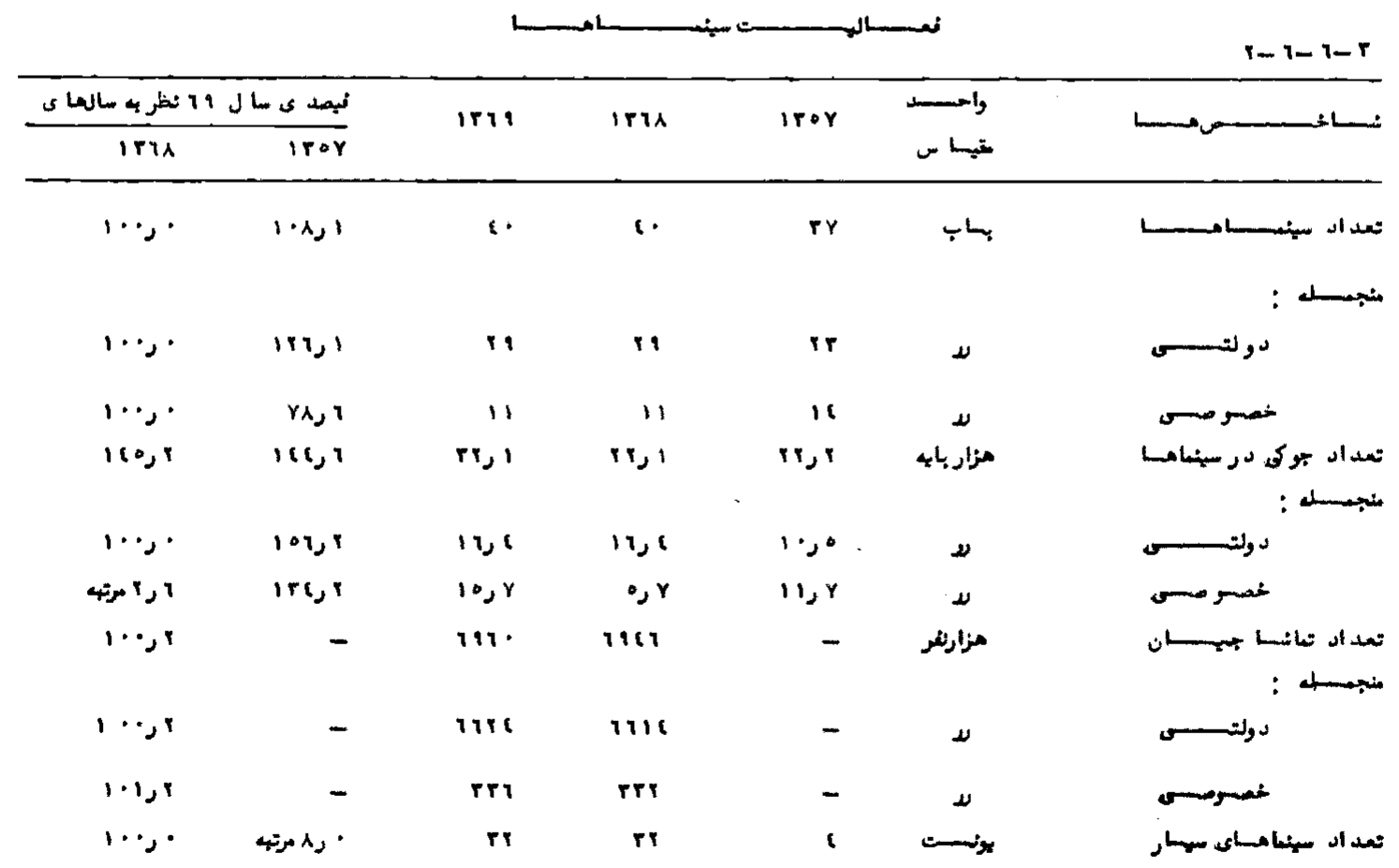




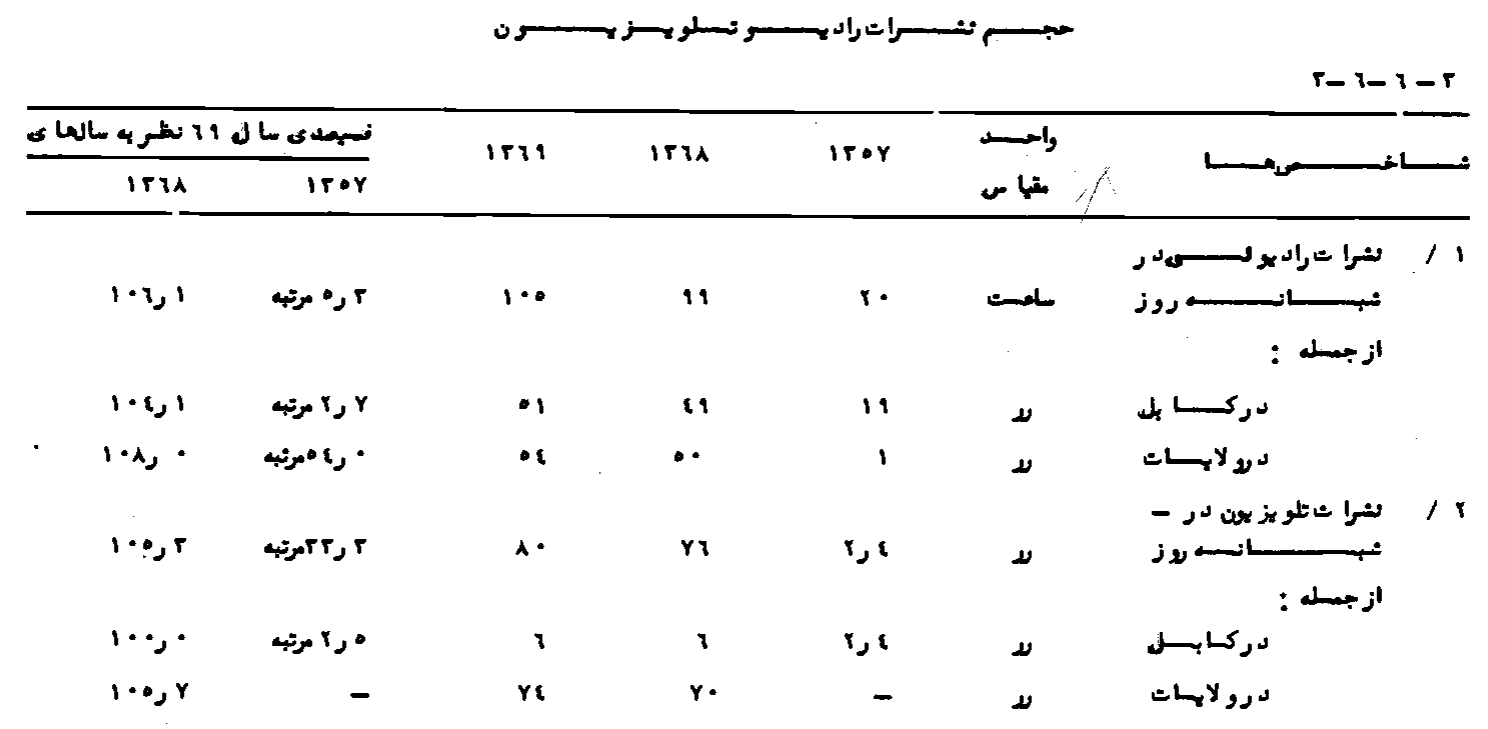

\begin{tabular}{|c|c|c|c|c|c|c|}
\hline \multirow{2}{*}{\multicolumn{2}{|c|}{ 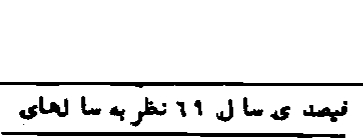 }} & \multicolumn{4}{|c|}{ 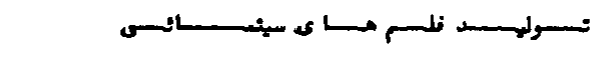 } & $1-1-1-2$ \\
\hline & & \multirow[t]{2}{*}{ irit } & \multirow[t]{2}{*}{ iria } & \multirow[t]{2}{*}{ iror } & \multirow{2}{*}{ متهاس } & \multirow{2}{*}{ 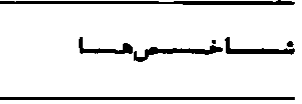 } \\
\hline iriu & 1 iror & & & & & \\
\hline $1 \cdots$, & 10, & 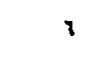 & 3 & 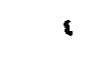 & كاب & مو ســـات توليســد فلــــــــ \\
\hline $1 \cdots$, & $1 \cdots$, & 1 & 1 & 1 & עل & دولتـــــــ \\
\hline $1 \cdots$, & $1 x x, y$ & - & - & $r$ & بـ & غسת مسن \\
\hline $1 \cdot 9,1$ & l०r, & rr & 3 & ir & برناسـ - بر & مجموع تولهـد فلـــــــ \\
\hline \multirow[t]{3}{*}{$11 \cdot, r$} & • ر גו امرته & tr & $r$ & $r$ & لا & 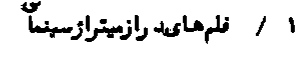 \\
\hline & & & & & & ازجمهل : \\
\hline & & & & & & فلمهاى منرى بنعسولد \\
\hline$r_{0,} \cdot$ & 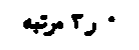 & 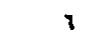 & $\wedge$ & $r$ & لا & فلم ماى تلميز غ 'نسلى \\
\hline- & - & - & - & - & עل & نلمهاى نماهنــــامســـ \\
\hline$r i r$ & - & 17 & $n$ & - & ע & نلماى. ستتد تار بهى \\
\hline - & - & - & - & - & עل & 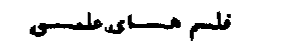 \\
\hline \multirow[t]{2}{*}{$1 \cdot \lambda, 1$} & $\wedge \wedge, 1$ & : & ir & : & & r / لم ماى كو ناه ميترا \\
\hline & & & & & & ازجمسله : \\
\hline $10 .$, & - & 1 & 3 & - & עد & كلـم مــاى منسـر ك. \\
\hline \multirow[t]{2}{*}{-} & - & - & - & - & עل & كله ماكى نمايهناهـــ \\
\hline & & & & & & فله مساى ستئســ \\
\hline $1 \cdot r, 1$ & • " رז مرته & $1 \cdot$ & 18 & • & עل & تسا ريخس \\
\hline 12,1 & 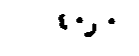 & 17 & ir & 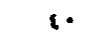 & עد & فلم ماى المهــــــــــ \\
\hline- & - & - & - & - & עد & تلم ماى تعله وتر بئ \\
\hline
\end{tabular}




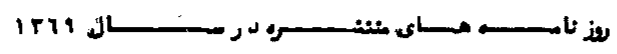

\begin{tabular}{|c|c|c|c|c|c|c|}
\hline تيرازسالاث & ز بسسان & مخسد لنستسر & نانســر & سال، تاسس & $r+1$ & 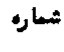 \\
\hline$|r| \cdot \wedge \cdots$ & لدريهمنسو & مس لעذ . & نسواى مركســنه & iris & 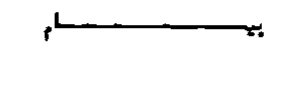 & 11 \\
\hline$|r \cdot r| \cdots$ & $\nu$ & معه لعذه & رياست انيسس & $15 \cdot 1$ & ايم & Ir \\
\hline Mirr. & ע & مه עز & ريا ستصبــا د & irre & 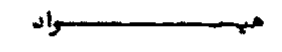 & $/ r$ \\
\hline Ror. & انكسمست & مه لעز • & الهيرونسـسـس & $|r|$ & كســ بل نهـ تايمستســز & 12 \\
\hline $1 \cdot 1 \cdot \cdots$ & ل ل لدرى & ممهـ لעذ م & مســــــان & 1899 & انغســـات استســــــام & $1 \cdot$ \\
\hline$r \ldots$ & ل لدرى & مسم لعذ & 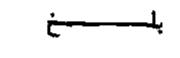 & 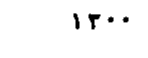 & 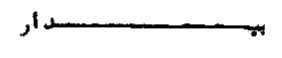 & 11 \\
\hline rro... & لدريا، بنتتو & عمس עند & ينكرمسـســار & irar & نيكسـ & /r \\
\hline$r i \varepsilon \cdots$ & ل لدرى & ممسه صنه & ستســـان & $|r T|$ & - سوان & $1 \wedge$ \\
\hline rY. & لم لدرى & مسه لعذه & سمد قمول & 1 & 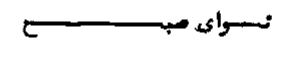 & 19 \\
\hline
\end{tabular}

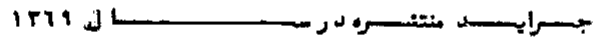

$7-7-1-5$

\begin{tabular}{|c|c|c|c|c|c|}
\hline تيرازسالانسـ & نبسـان & موعسد ينسر & نانستسـر & ساله ناسيس & 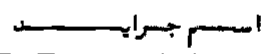 \\
\hline 1 & $\cdot$ & 2 & $r$ & $r$ & 1 \\
\hline - IAYo.. & لدرى & منتهسمرته & وذارت دفاع & 1709 & حتيقستست سر بسـ \\
\hline $1 \cdots$ & لدرى & مامسسـسرار & نسالدكابل & |ry & \\
\hline $\operatorname{rra} \cdots$ & تركمئ|نيك & منته د و - منسم & وذارث - اطلاهات وكنور & $1 r \bullet A$ & - سوبوران \\
\hline YAA $\cdots$ & $\nu$ & منتسموار & ولاهت بلسستخ & $1 T \cdot 1$ & حس \\
\hline $1 \cdot+90$ & لد ركهينتسور & 10 & وذارتعد ليســـ & irer & $\omega$ \\
\hline 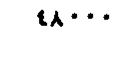 & $\nu$ & منتسو ار & ولا هت ملصنســد & ITtr & 2 \\
\hline$\& \cdots$ & ل ل ل لدرى & مغنسه وار & ولايتككسـدز & $\mid r \cdot 1$ & 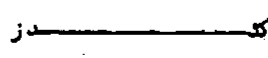 \\
\hline
\end{tabular}




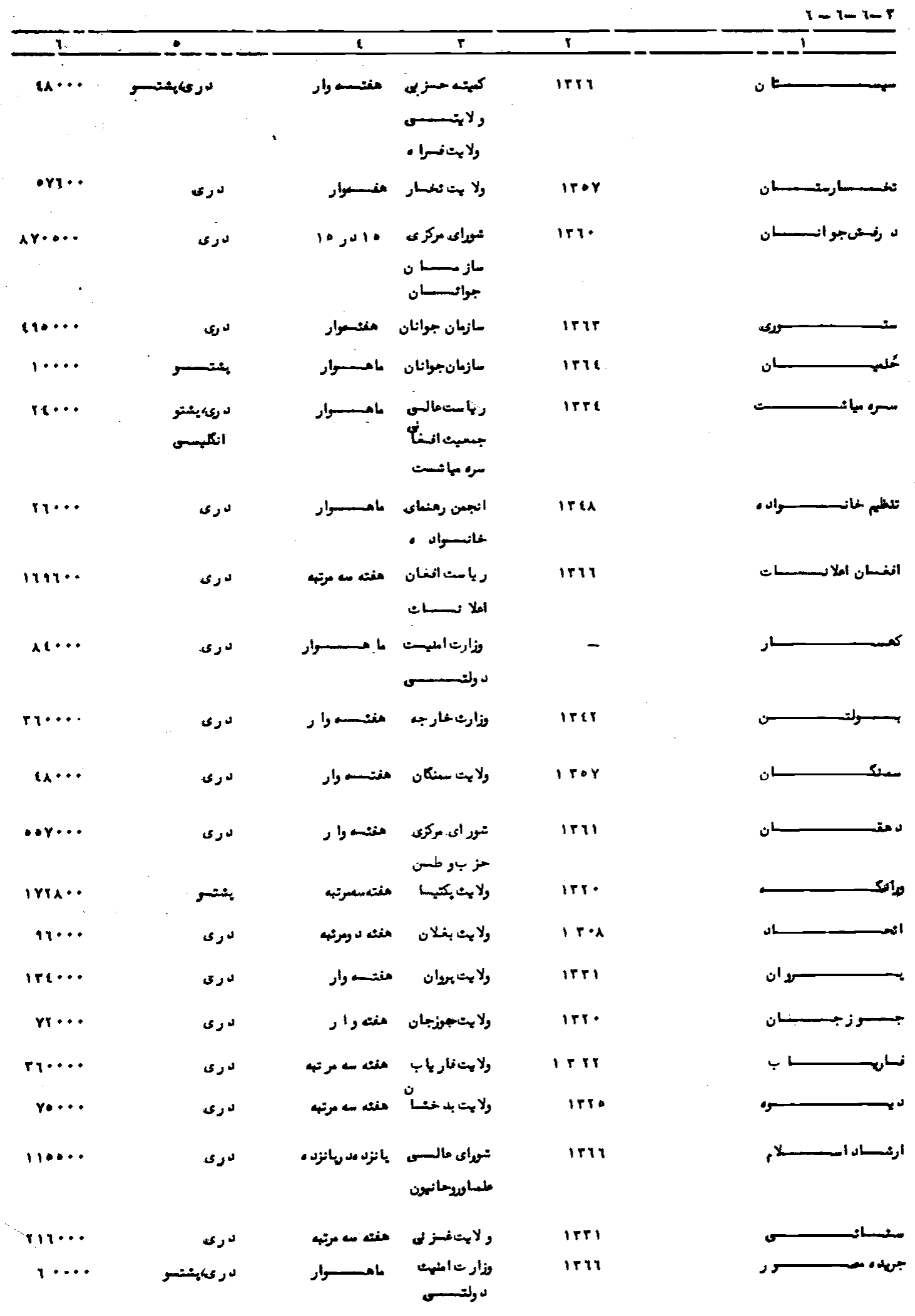




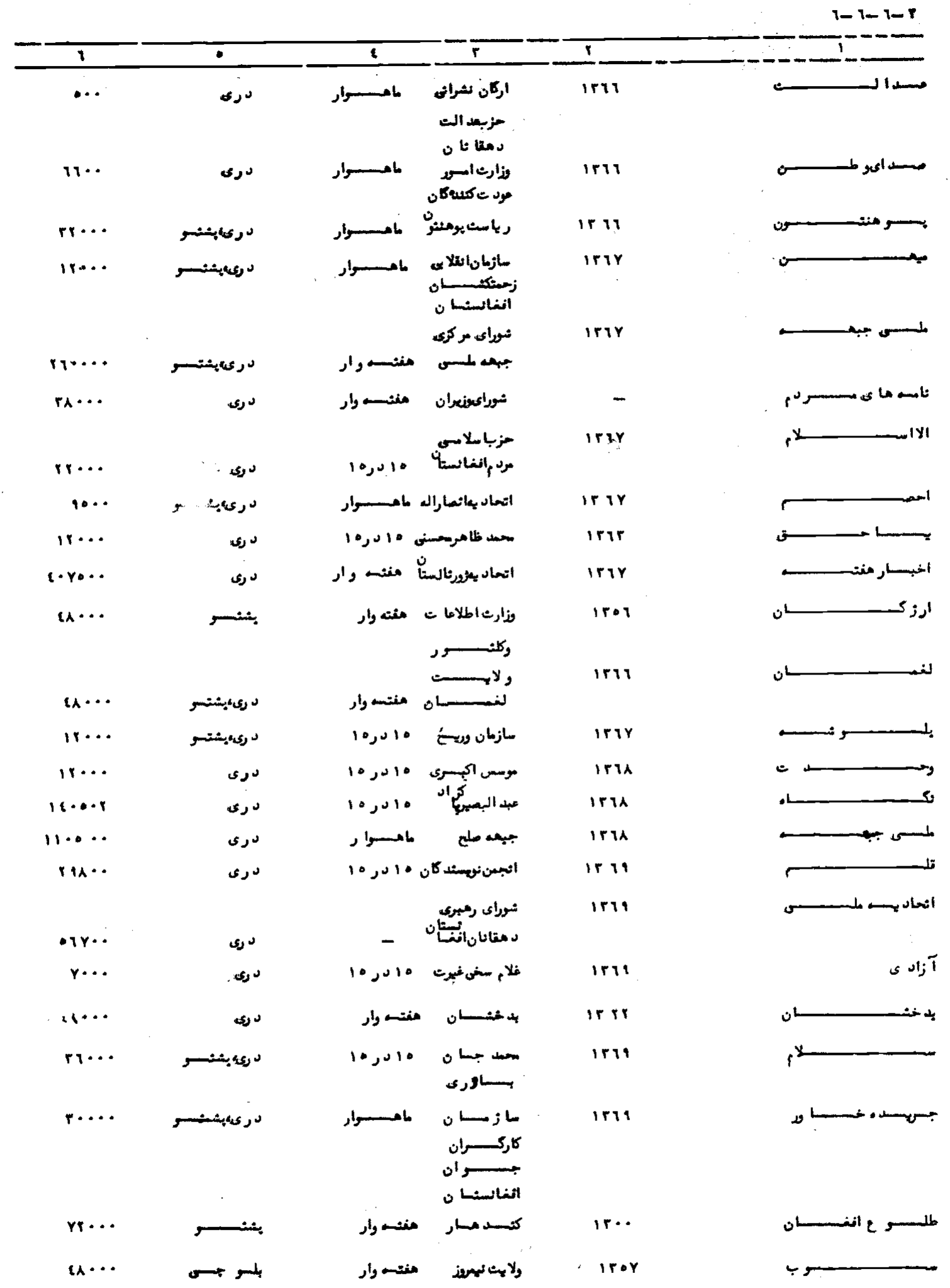




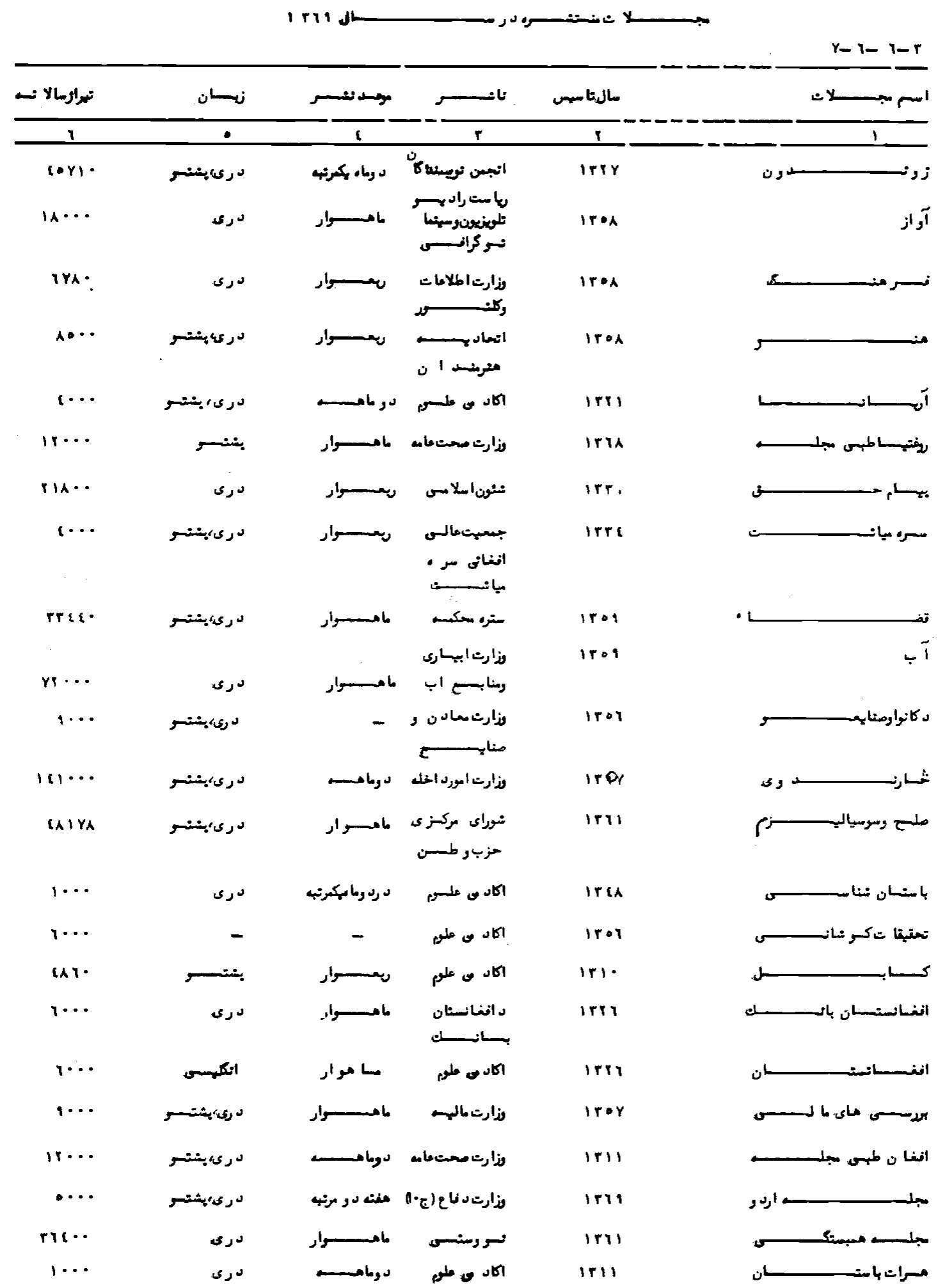


$Y-1-1-7$

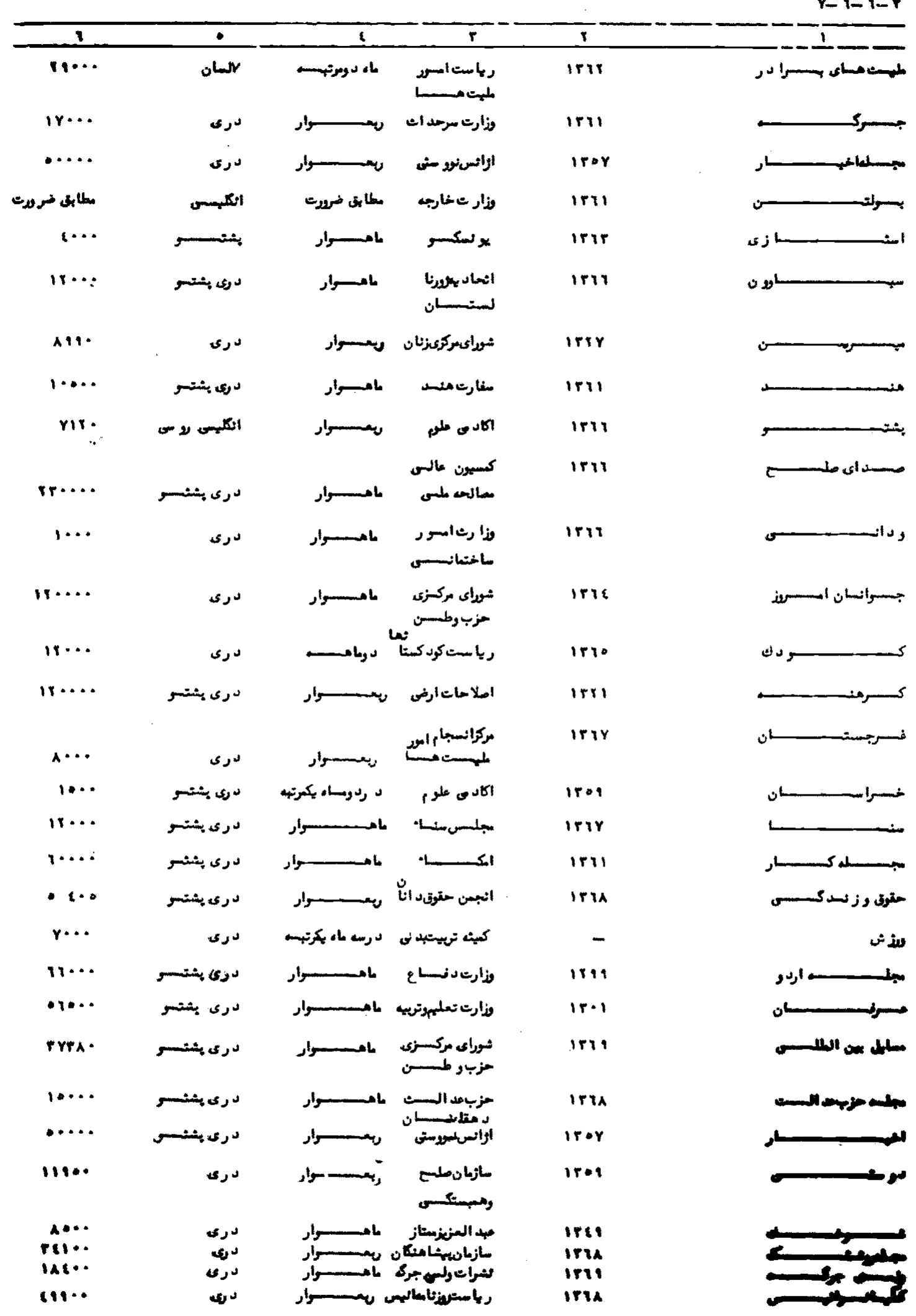




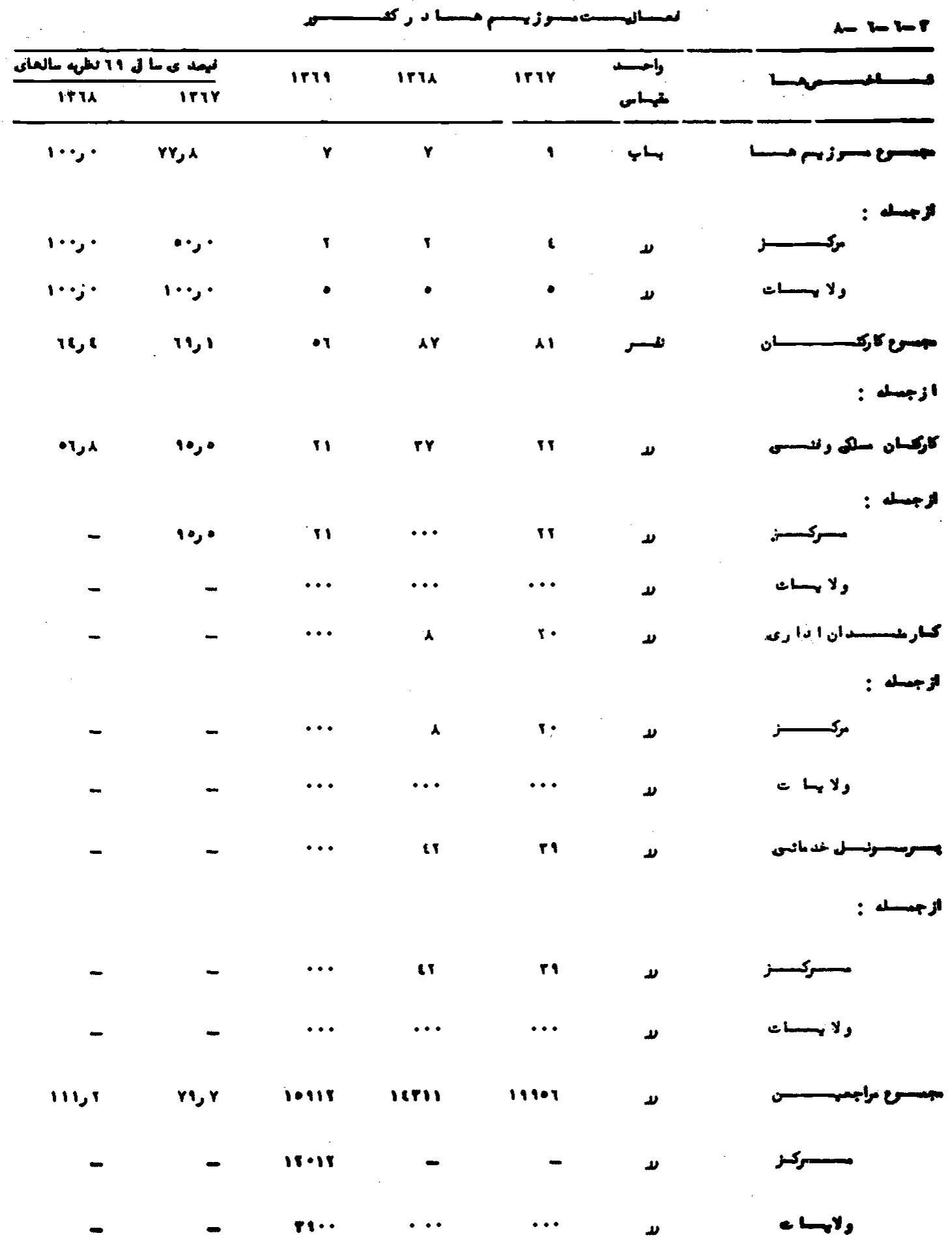




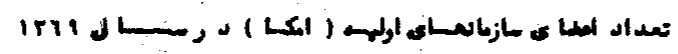

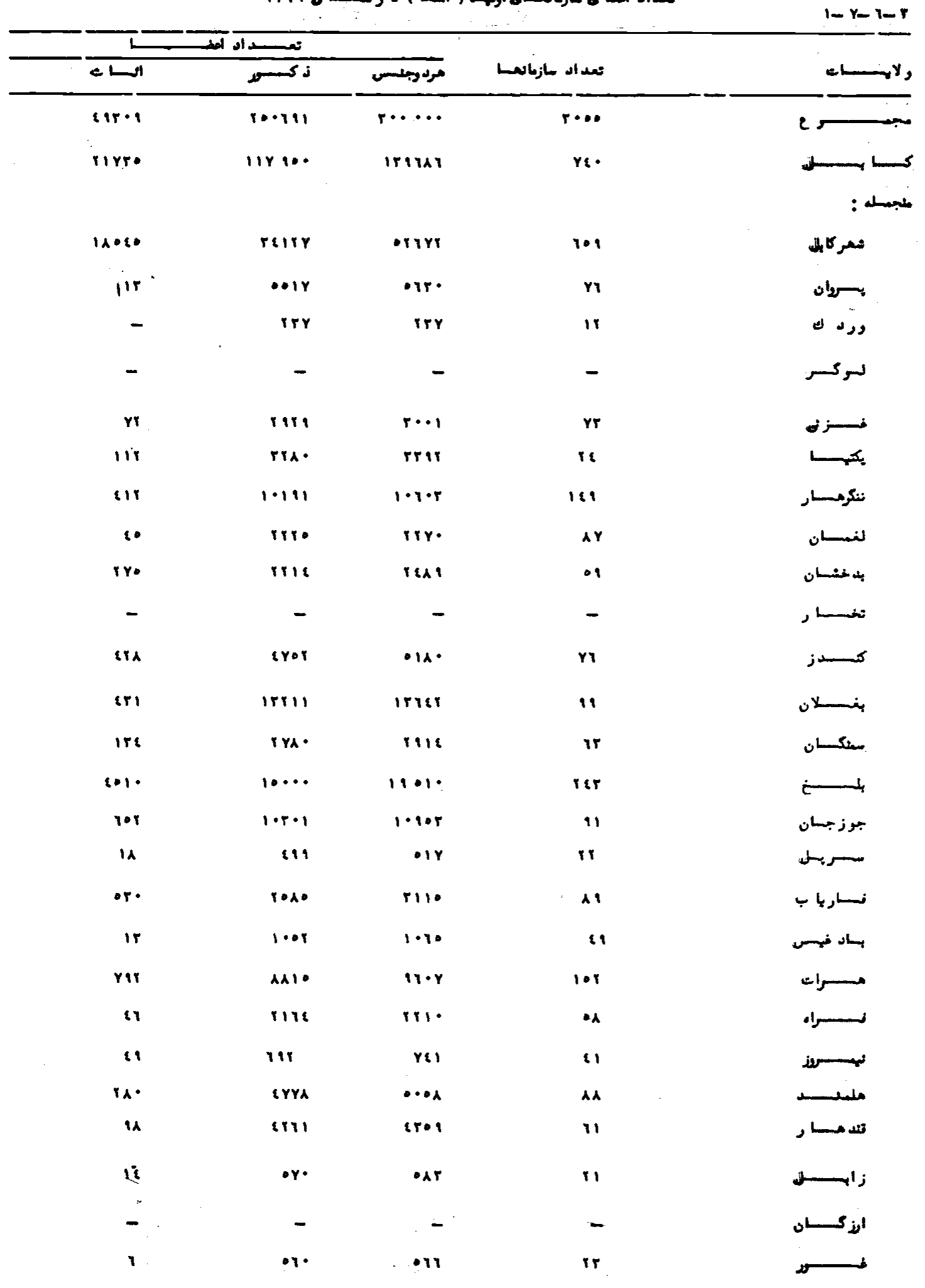




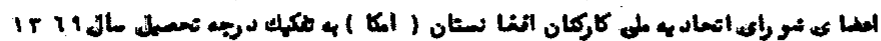

\begin{tabular}{|c|c|c|c|c|c|c|c|c|c|}
\hline 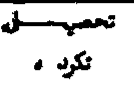 & غسو مس & أهدا لمس & 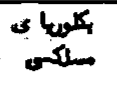 & بأنسوبك & لهمائ & طاستر & دكسمدا & "مبوع & ولا بسـات \\
\hline irorir & reirt & rrath & ryira & EYqY & irra. & $1 \cdot 98$ & iry & $r \cdots$ & \\
\hline Alor. & $1 \cdot 11 \cdot$ & $1 \cdot r \cdot 1$ & 1140 & irrie & Tirt & $11 \cdot 1$ & $\& r_{0}$ & IrIM & 5 \\
\hline •rr & $1 \cdot o r$ & Arer & ires & lorke & Eort & Mis & \&r. & - rirr & \\
\hline $18 \cdot 7$ & IIor & lier & 110 & $\wedge \wedge{ }^{\circ}$ & $\pi$ & ir & - & ort & أن \\
\hline iri & 18 & 10 & 11 & $\cdots$ & ir & $r$ & - & rry & ورد كن \\
\hline - & - & - & - & - & - & - & - & - & ת \\
\hline$I r \cdot Y$ & $u_{0}$ & rrr & rio & $r r \cdot$ & rA & $r$ & - & $r \cdots l$ & نسى. \\
\hline $1 \gamma \cdots$ & $11 \cdot 0$ & $1 \cdot 1$ & 191 & ror & rr & $x$ & 1 & reqr & $L$ \\
\hline ..or & iras & iro & 191 & reir & ro & 11 & ir & $1 \cdot r \cdot r$ & \\
\hline 1889 & 111 & $r \bullet r$ & in & $\varepsilon \cdot y$ & rr & - & - & rry. & سلان \\
\hline$|1 r|$ & rar & reg & $1 \cdot 1$ & rir & 11 & $r$ & 1 & resq & ن \\
\hline - & - & - & - & - & - & - & - & - & \\
\hline ryer & rAY & irr & irr & ros & Aᄉ & $\Lambda$ & 1 & .11. & سلز \\
\hline A.\& 9 & ins & Arr & 1101 & $\| 11 r$ & 11 & ir & 1 & irter & ل \\
\hline lery & Air & rry & rir & 118 & rr & - & - & rals & سم:كسـان \\
\hline AN\& & irir & rery & 1199 & Erro & $r_{\lambda} \cdot$ & 시 & 11 & 1901. & \\
\hline yrir & $11 \cdot$ & loAr & $\gamma \cdots$ & 191 & Ar & ir & 1 & $1.90 \%$ & زبعان \\
\hline roo. & $0 \lambda$ & iro & it & $\gamma \cdot$ & 1 & - & - & oir & \\
\hline irer & ral & $\mathrm{ra}$. & rir & 110 & $M$ & ir & 1 & rito & \\
\hline rio & \&Ar & 111 & ir & $\{1$ & $r$ & 1 & - & $1 \cdot 10$ & \\
\hline$\therefore$ & layr & grog & irin & 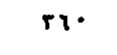 & Yo. & $r$ & 1 & $17 \cdot y$ & \\
\hline หs. & 19 & rr. & 80 & \& & rr & 1 & - & rrie & راه \\
\hline$r \cdot \cdot$ & $r r \cdot$ & 99 & 11 & १u & - & 1 & - & $Y \& 1$ & rvذ \\
\hline riro & irer & $r r$ & ri. & 011 & YT & in & - & $\cdots$ & 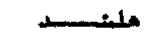 \\
\hline 1191 & irit & $Y r \cdot$ & rir & ire & ir & 11 & 1 & $8 r \cdot 9$ & قلد هـســار \\
\hline$r q$ & ix & rr & $r \cdot$ & Ar & 1 & - & - & •Ar & ز'الهسـل \\
\hline - & - & - & - & - & - & - & - & - & الز كســـان \\
\hline 19. & 11. & 110 & 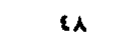 & rr & 1 & - & - & 018 & \\
\hline
\end{tabular}




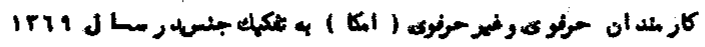

\begin{tabular}{|c|c|c|c|c|c|c|c|c|c|}
\hline \multicolumn{3}{|c|}{ 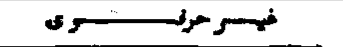 } & \multicolumn{3}{|c|}{ بسـرنسلسـو ى. } & \multicolumn{3}{|c|}{ مجسمس } & \multirow{2}{*}{$={ }^{y}$} \\
\hline$\leftarrow 4$ & ذكسم & مبعو & $\mathrm{eu}$ & ذكسو & يسبو2 & انساك & ذكسم & سبمو & \\
\hline$r A$ & $1 *$ & $r * r$ & $\bullet$ & $1 \lambda \cdot$ & riq & $\wedge \wedge$ & \&q० & oar & 2 \\
\hline 1 & ri & $A$ & $\Pi$ & $1 \cdot$ & AI & $r \cdot$ & irt & ו11 & د ستكاه ثوراى امكســـــــ \\
\hline$\varepsilon$ & 11 & it & $\cdot$ & 18 & 19 & 9 & Pr & $\&$ & اتهادب بِ مسلك طلو وفر منيك \\
\hline$r$ & $1 \cdot$ & ir & $r$ & ir & 10 & $\cdot$ & ir & $\boldsymbol{i A}$ & اتسادي سلكي ما ختشانسه \\
\hline$r$ & ir & $1 \cdot$ & $\varepsilon$ & $1 \varepsilon$ & 11 & 1 & ir & $r r$ & 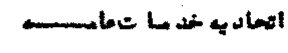 \\
\hline $\boldsymbol{r}$ & 11 & ir & $r$ & 11 & $1 \varepsilon$ & - & ir & ir & اتعاديه تبارت وترانمهو رت \\
\hline$r$ & ir & 11 & 1 & 11 & ir & $\varepsilon$ & vย & $\boldsymbol{\gamma}$ & 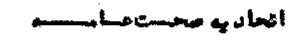 \\
\hline$r$ & $1 \cdot$ & ir & $r$ & 11 & ir & - & 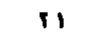 & ir & اتعاد يه نساجب ود وأند، كى \\
\hline$r$ & 11 & ir & $r$ & ir & 10 & $\varepsilon$ & $1 \varepsilon$ & in & اتعاد يه معاد ن و صنايستك \\
\hline - & $\varepsilon$ & $\varepsilon$ & 1 & 1 & $1 \cdot$ & 1 & ir & 18 & بـستسوان \\
\hline- & - & - & - & 1 & 1 & - & 1 & 1 & ورد له \\
\hline- & - & - & - & - & - & - & - & - & لسركسر \\
\hline- & 1 & 1 & - & $r$ & $r$ & - & $r$ & $r$ & نسسز نسى \\
\hline- & 1 & 1 & - & $r$ & $r$ & - & $r$ & $r$ & يكتهبـ \\
\hline$r$ & ir & 10 & 1 & $1 *$ & ix & $r$ & is & $r$ & نيكرمسا ر \\
\hline- & - & - & - & $\mathbf{r}$ & r & - & $r$ & 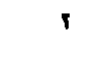 & لغعــــان \\
\hline- & - & - & - & $r$ & $r$ & - & $r$ & $r$ & بد هشا ن \\
\hline- & - & - & - & - & - & - & - & - & \\
\hline 1 & $r$ & $r$ & - & 9 & 9 & 1 & 11 & ir & كنسسسـ ز \\
\hline$r$ & $r$ & - & $r$ & 10 & 11 & - & 11 & ir & بنغـــلا ن \\
\hline - & 1 & 1 & - & $r$ & $r$ & - & $\varepsilon$ & 6 & سمنكسنان \\
\hline$r$ & - & $r$ & $\varepsilon$ & 10 & 19 & 1 & $r$ & ii & بلــــــن \\
\hline 1 & $\varepsilon$ & - & 1 & 18 & 10 & $r$ & 11 & $r$ & جسمز بان \\
\hline- & 1 & 1 & - & 1 & 1 & - & $r$ & $r$ & ستسـريل \\
\hline - & $r$ & $r$ & - & $r$ & $r$ & - & $\varepsilon$ & $\varepsilon$ & فاريسـ ب \\
\hline - & 1 & 1 & - & $r$ & $r$ & - & $r$ & $r$ & بساد غيس \\
\hline 1 & - & 1 & - & ir & ir & 1 & 11 & 19 & مستسرا ت \\
\hline - & 1 & 1. & - & r & $r$ & - & $r$ & $r$ & 'مسسـر ا' \\
\hline- & $\cdot$ & - & - & $r$ & $r$ & - & $\wedge$ & $\wedge$ & نجسسوز \\
\hline 1 & $r$ & $\varepsilon$ & - & 11 & 11 & 1 & 18 & 10 & ملعـــسـد \\
\hline- & $\varepsilon$ & $\varepsilon$ & - & $r$ & $Y$ & - & 11 & 11 & قلد مهســار \\
\hline- & - & - & - & 1 & .1 & - & 1 & 1 & زايستســلة \\
\hline- & - & - & - & - & - & - & - & - & ارزكســان \\
\hline- & 1 & 1 & - & 1 & 1 & - & $r$ & $r$ & خســــرد \\
\hline
\end{tabular}




$$
\begin{aligned}
& \text { بث: بهام } \\
& \text { احصائي هاى بين المللى }
\end{aligned}
$$




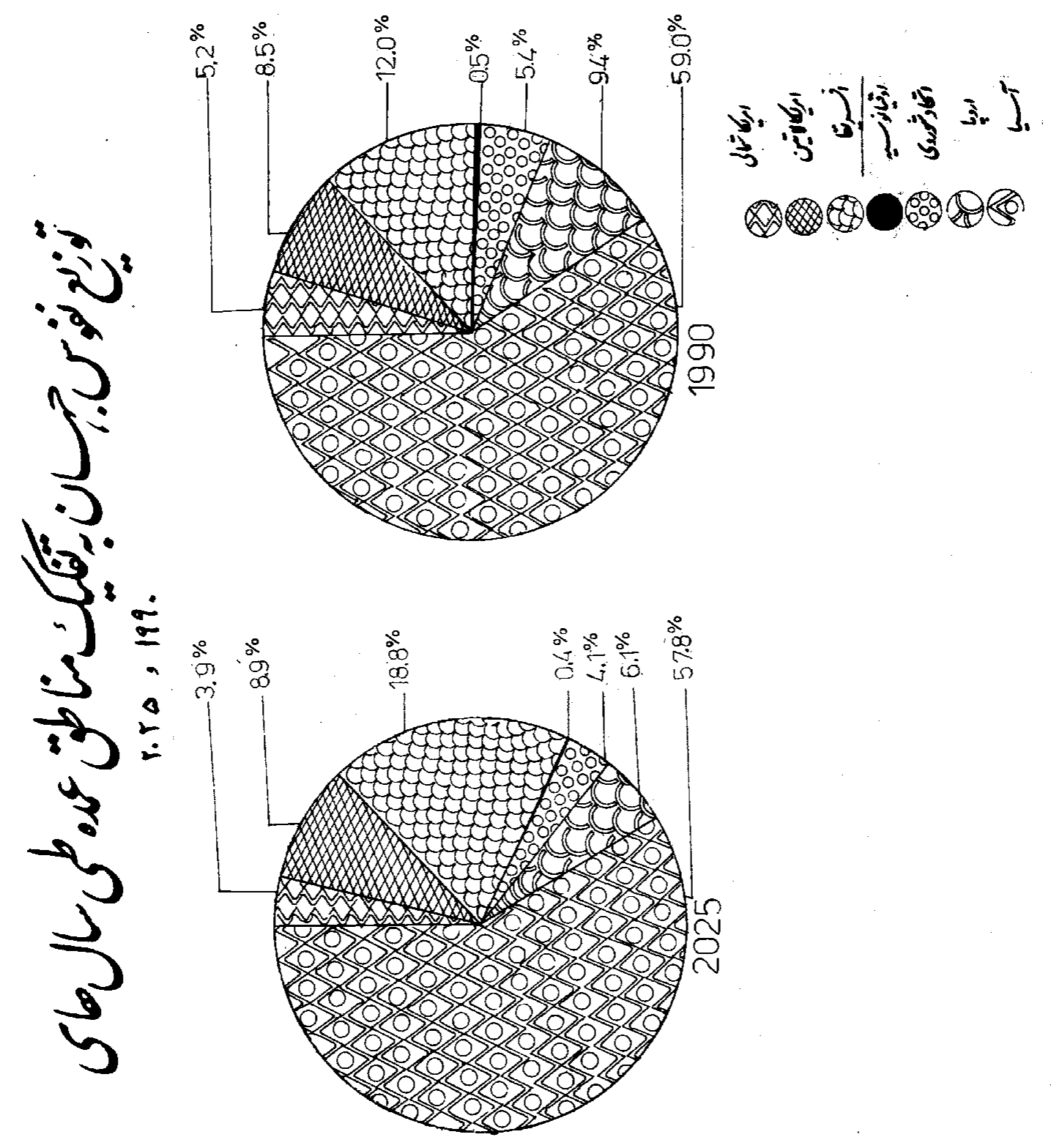




\begin{tabular}{|c|c|c|c|}
\hline 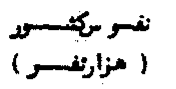 & 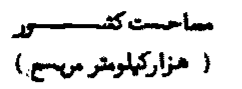 & إيتغستست & 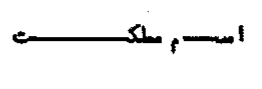 \\
\hline 4 & $r$ & $r$ & 1 \\
\hline $17 \bullet \bullet r$ & $r * r, r$ & كابــــ & انفا نستــــــــــــان \\
\hline rrie & $r A, r$ & تهراسا & 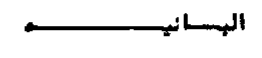 \\
\hline reqr. & rrar & الجزيحسر & الدجبـــزيس \\
\hline$r^{\cdot}$ & $1 r \in y$ & لوانســـا & $y, \ldots$ \\
\hline rurry & ryir & بونسأرس & 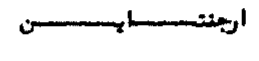 \\
\hline Irarr & riar & كانيهـــرا & 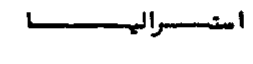 \\
\hline$r \bullet A r$ & $A r, \lambda$ & ويسـانسا & 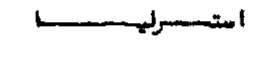 \\
\hline Ho.pr & 168 & داكيســــــ & بنكســ د لحســن \\
\hline 1180 & $r \cdot, \cdot$ & بدكســــل & r \\
\hline izr. & $M r$ & مركسولسسو & بيهـ \\
\hline 1017 & \&r & تخبيخنسـر & 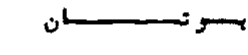 \\
\hline pris & $1 \cdot 99$ & لايلسـسس & سو يستســـ \\
\hline ir $\cdot \varepsilon$ & $r \cdots$ & كبسولسبن & بهوتســـــو انستســـــ \\
\hline $10 \cdot r 41$ & $A \cdot 1 r$ & برانسستسل & بـــرازيتســـــــل \\
\hline $1 \cdot 1 \cdot$ & $n \cdot 1$ & مسرونيسـ & 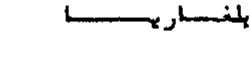 \\
\hline sirve & irr & رنكـــــن & ميان م \\
\hline eirr & $r y, A$ & علغ مبهرا & \\
\hline errrr & ris & لنسـسـن ن & بسر يتــــا نهســــا \\
\hline barr & ing & بولســدى. & كـــامـــ \\
\hline 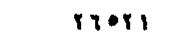 & rivr & الحسـا وا & كســانســــــــــ 1 \\
\hline$r \cdot r q$ & irt & ينكســى & جموي الفهتاي مركئ. \\
\hline - r YA & 18A & انبجامينسا & dL \\
\hline irirr & $r \bullet r$ & سانتيا كـو & جبال- \\
\hline IIrq. & 1०9Y & يككـــــ & 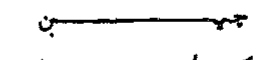 \\
\hline rrira & ira & بوخو تهــا & - \\
\hline rrrs & ris & برازاو يسلد & 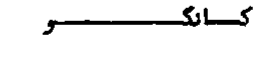 \\
\hline$r \cdot 1 !$ & +1 & من خخونى & كو ستساريك \\
\hline
\end{tabular}




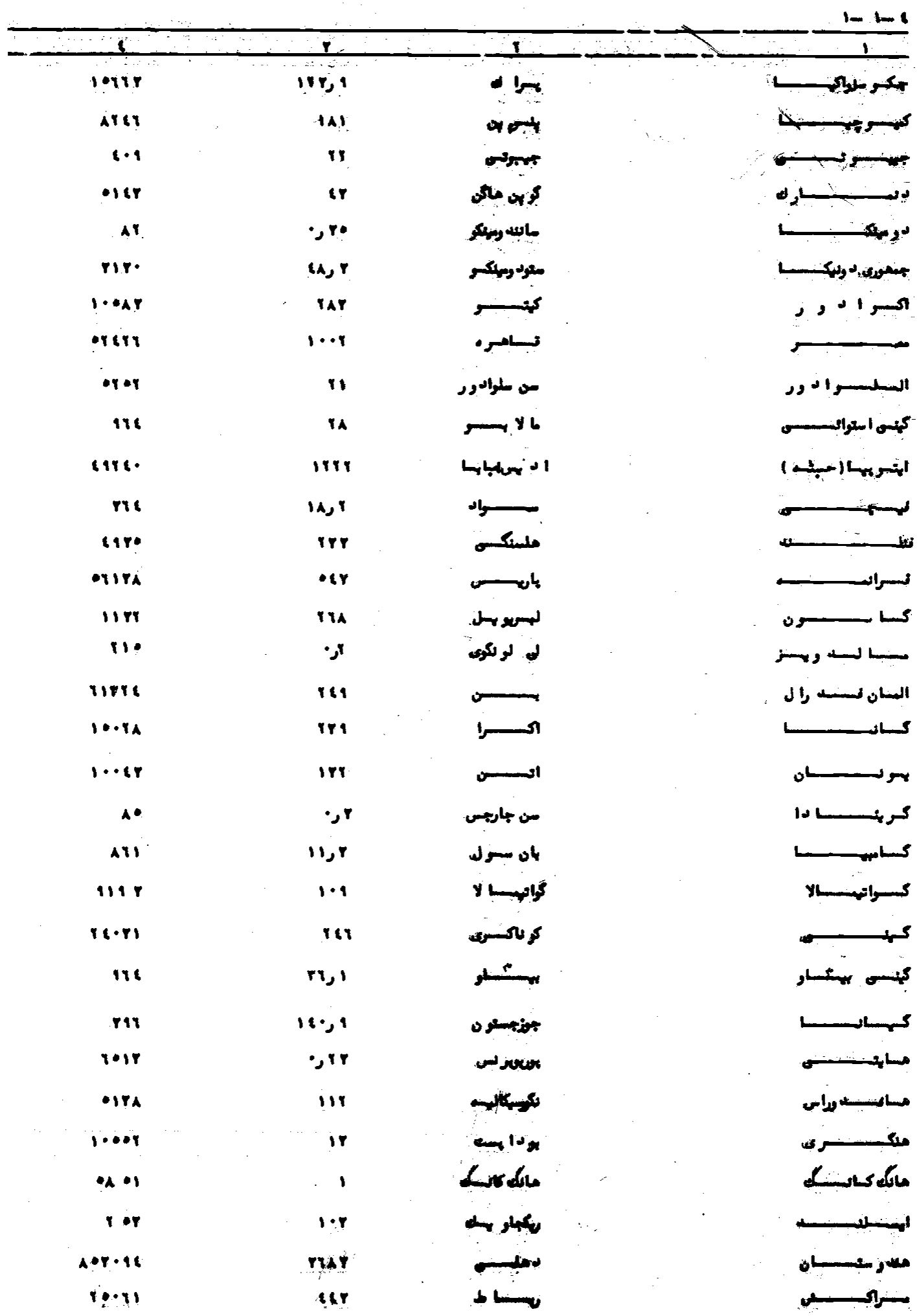




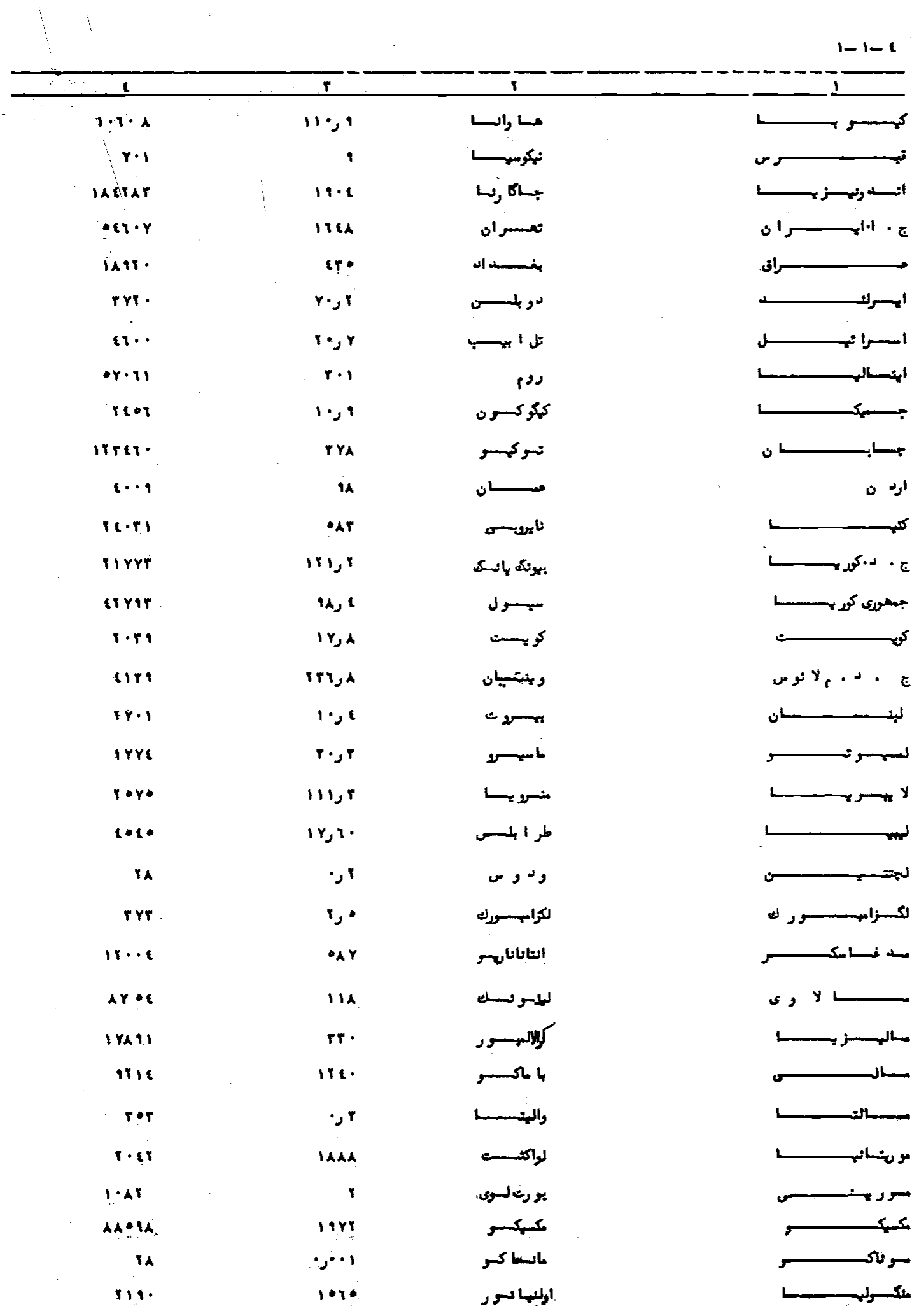




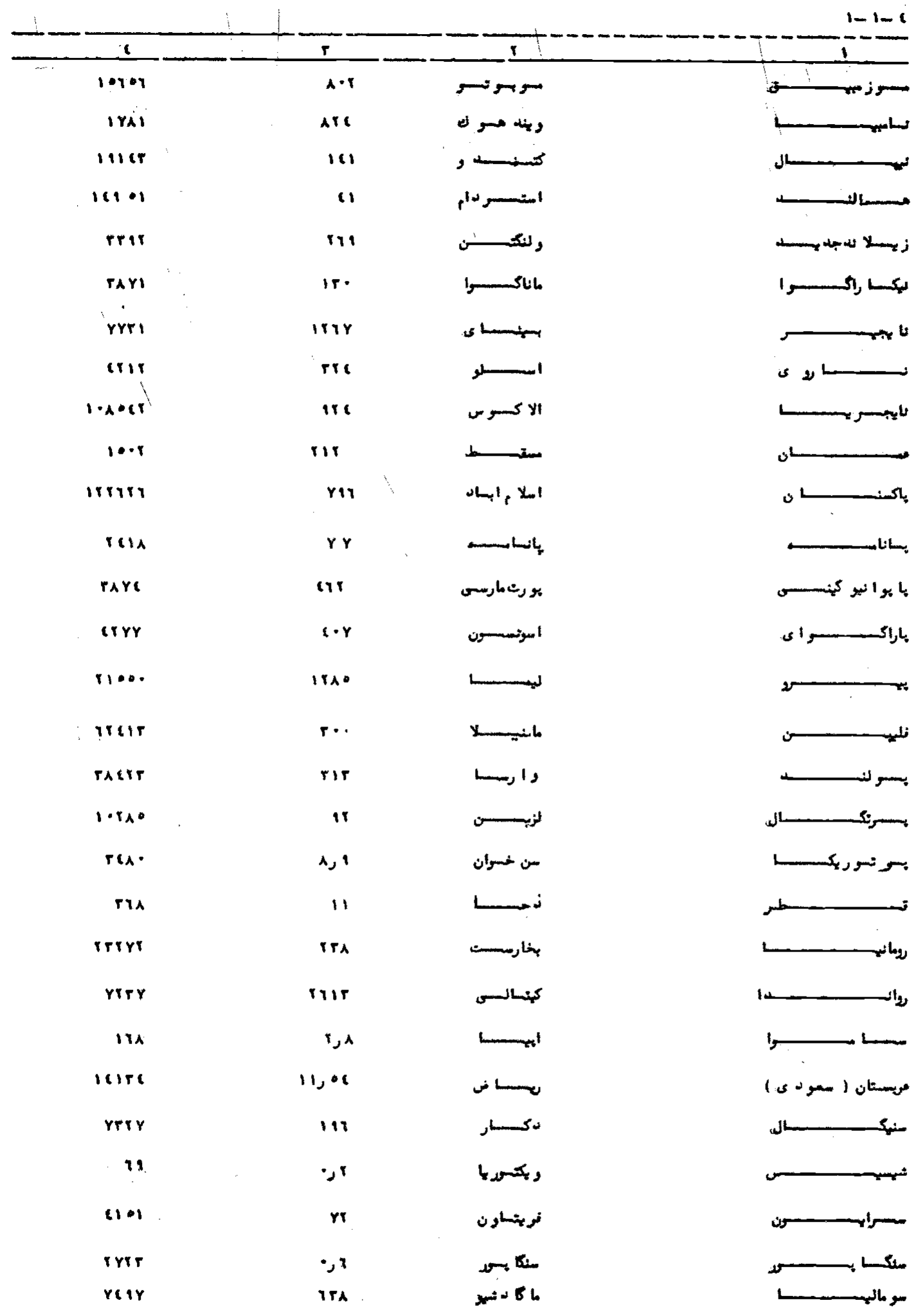




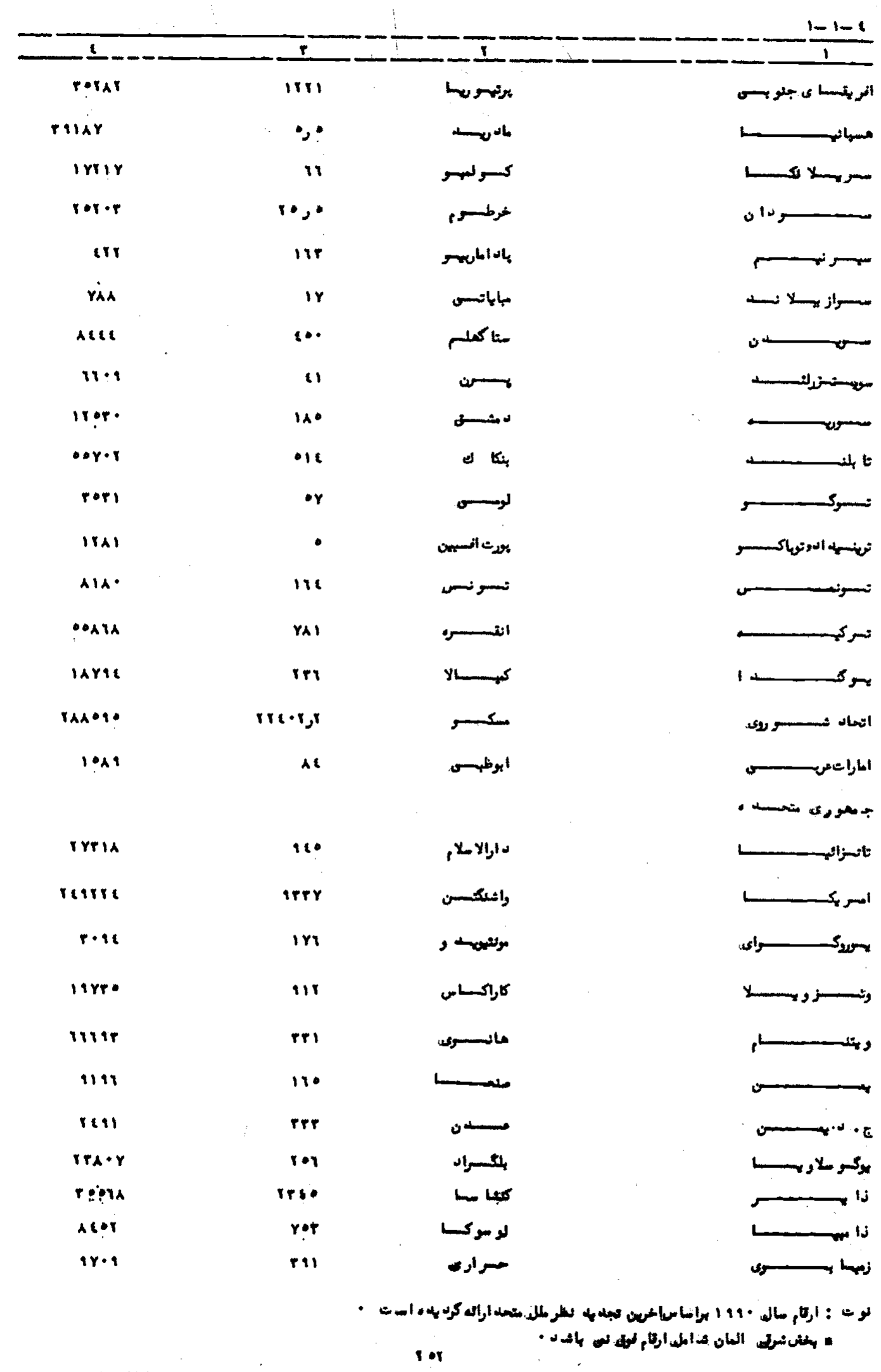




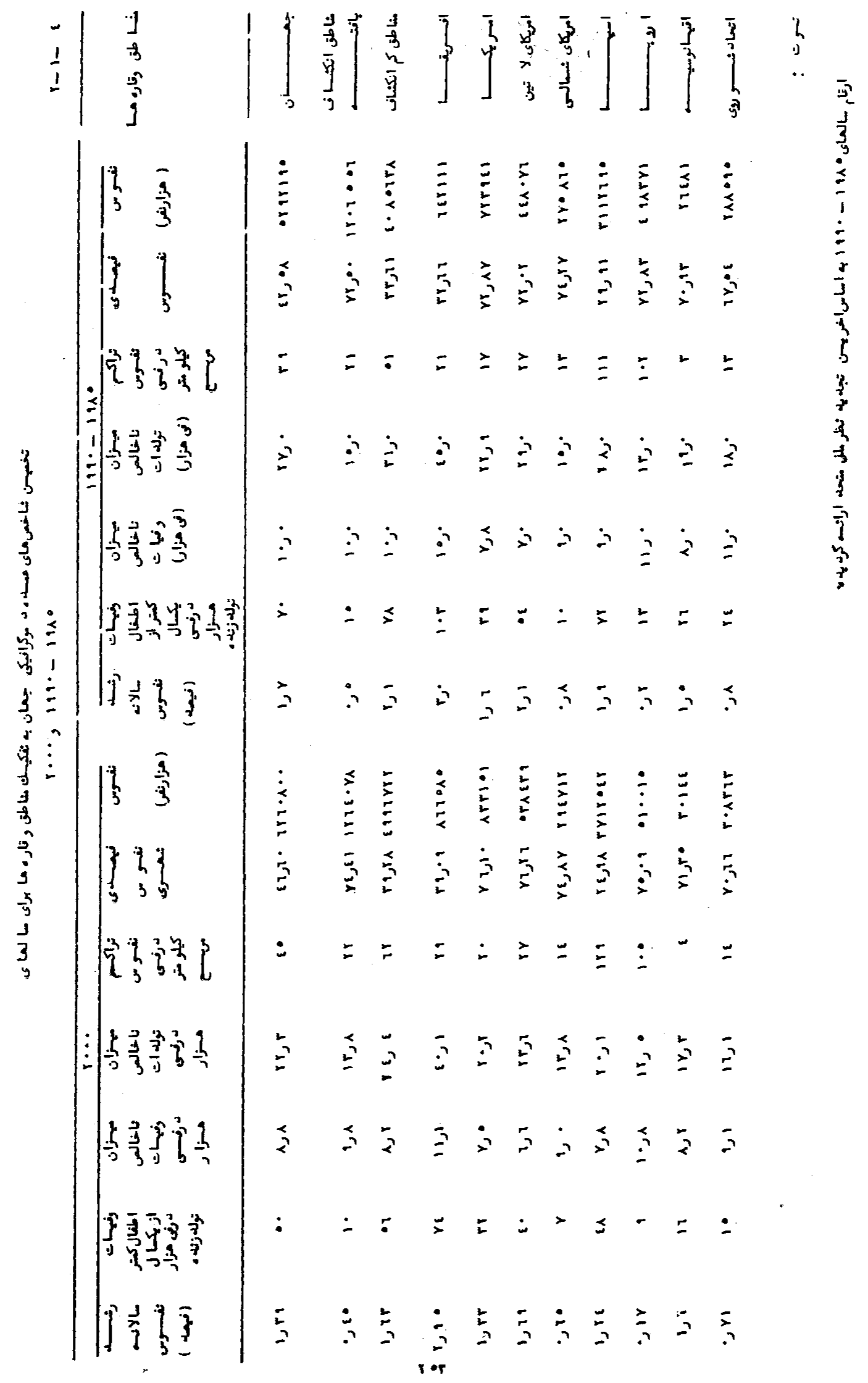




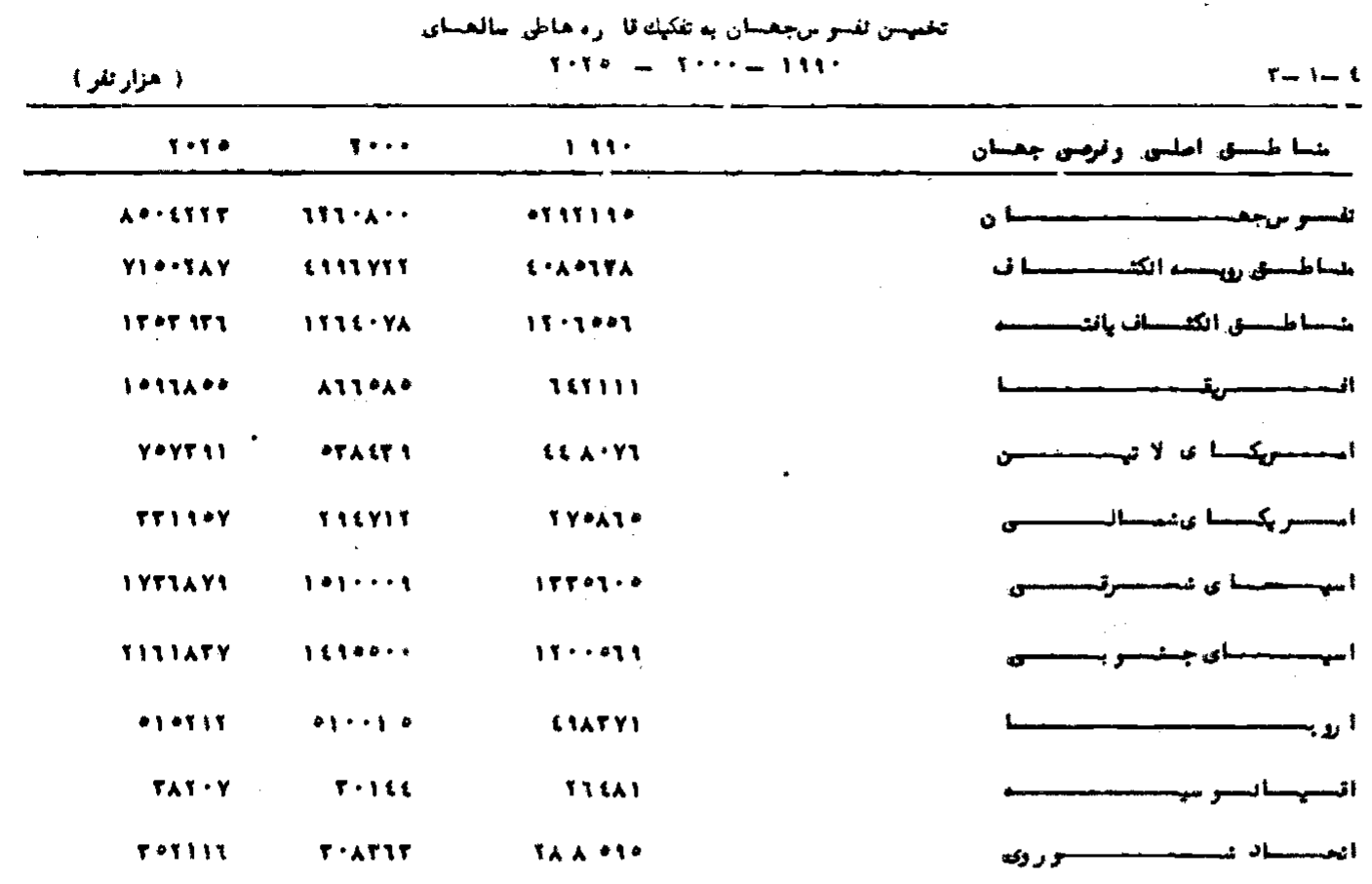

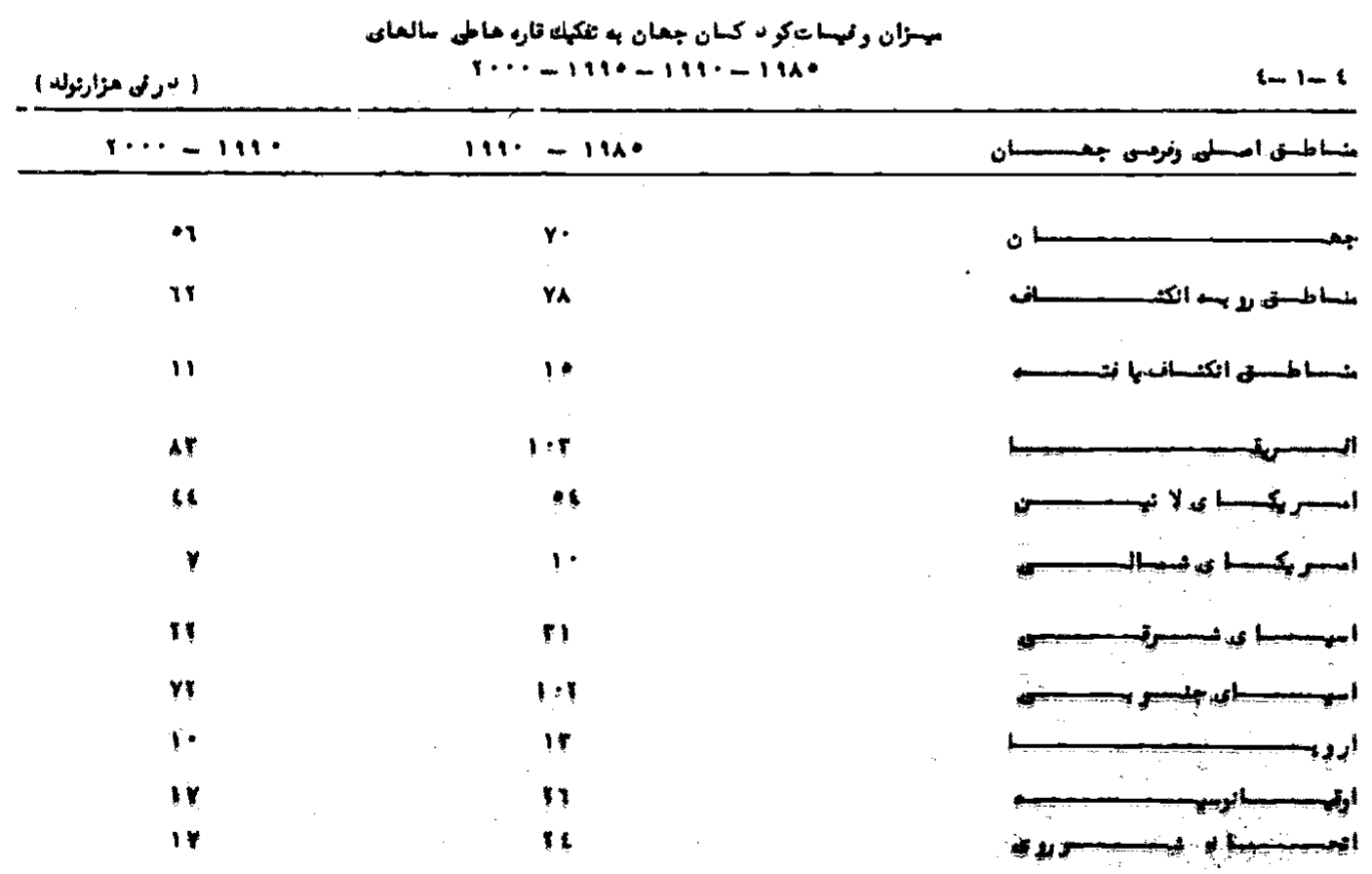




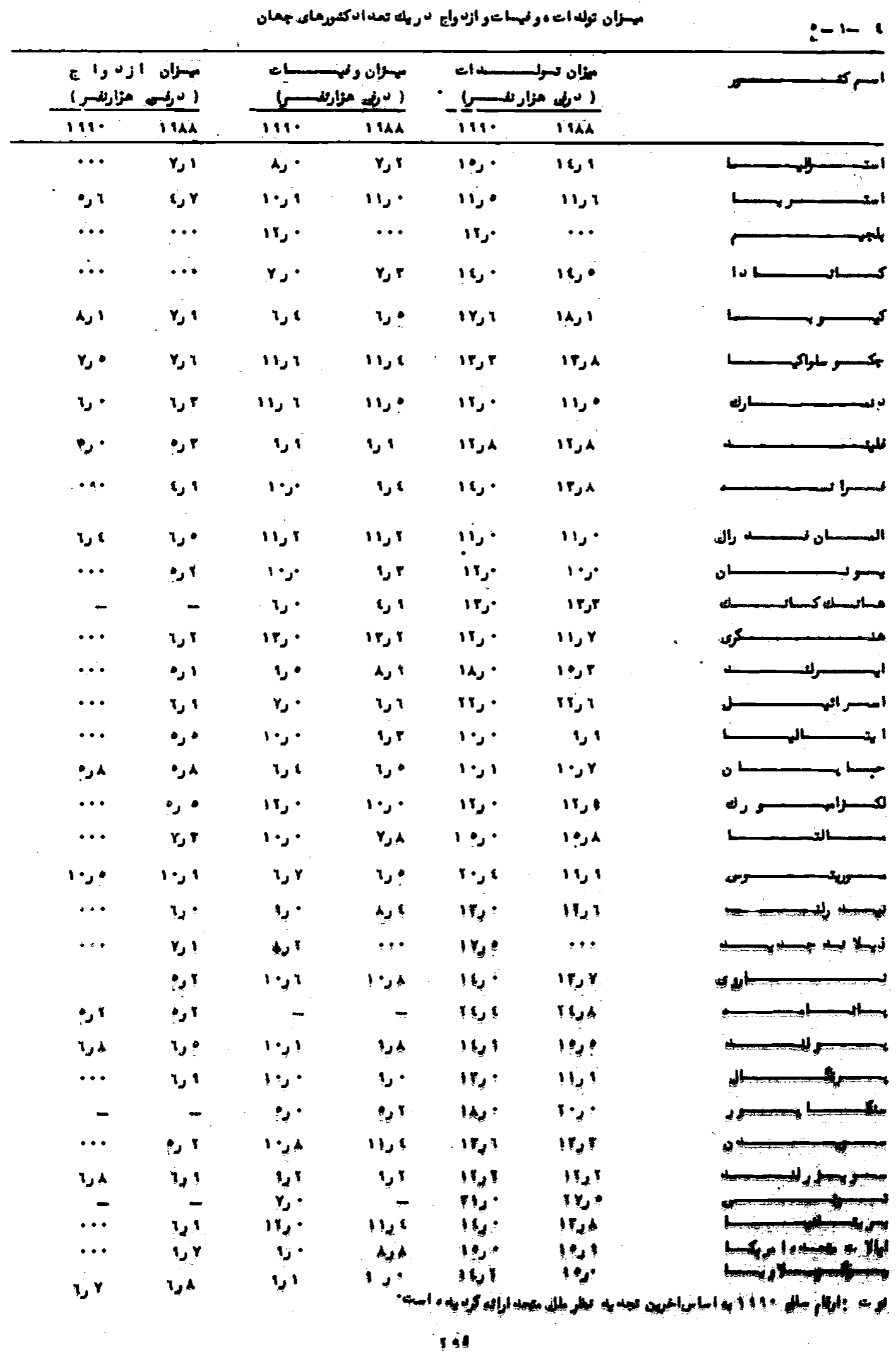




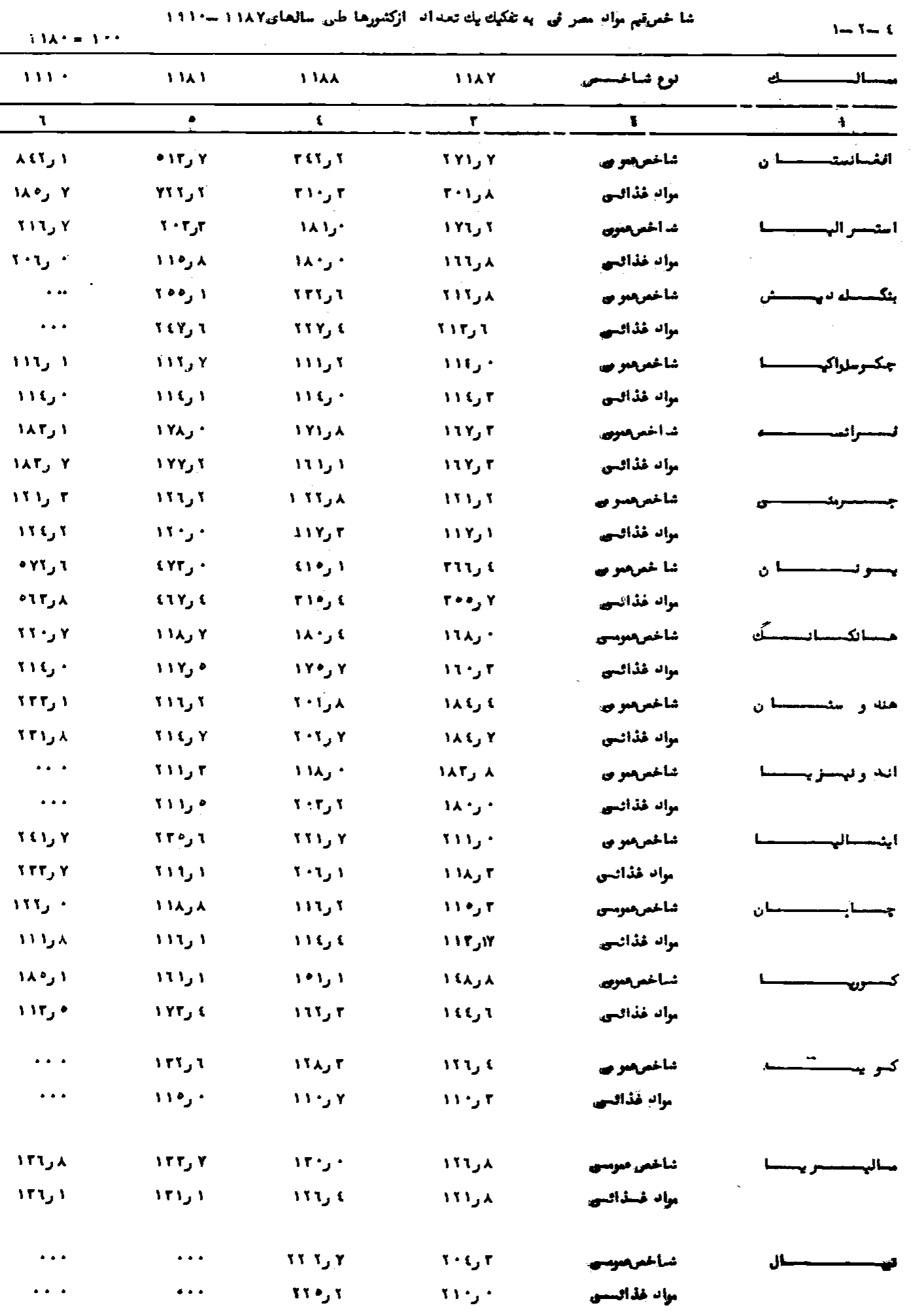


$1-r-8$

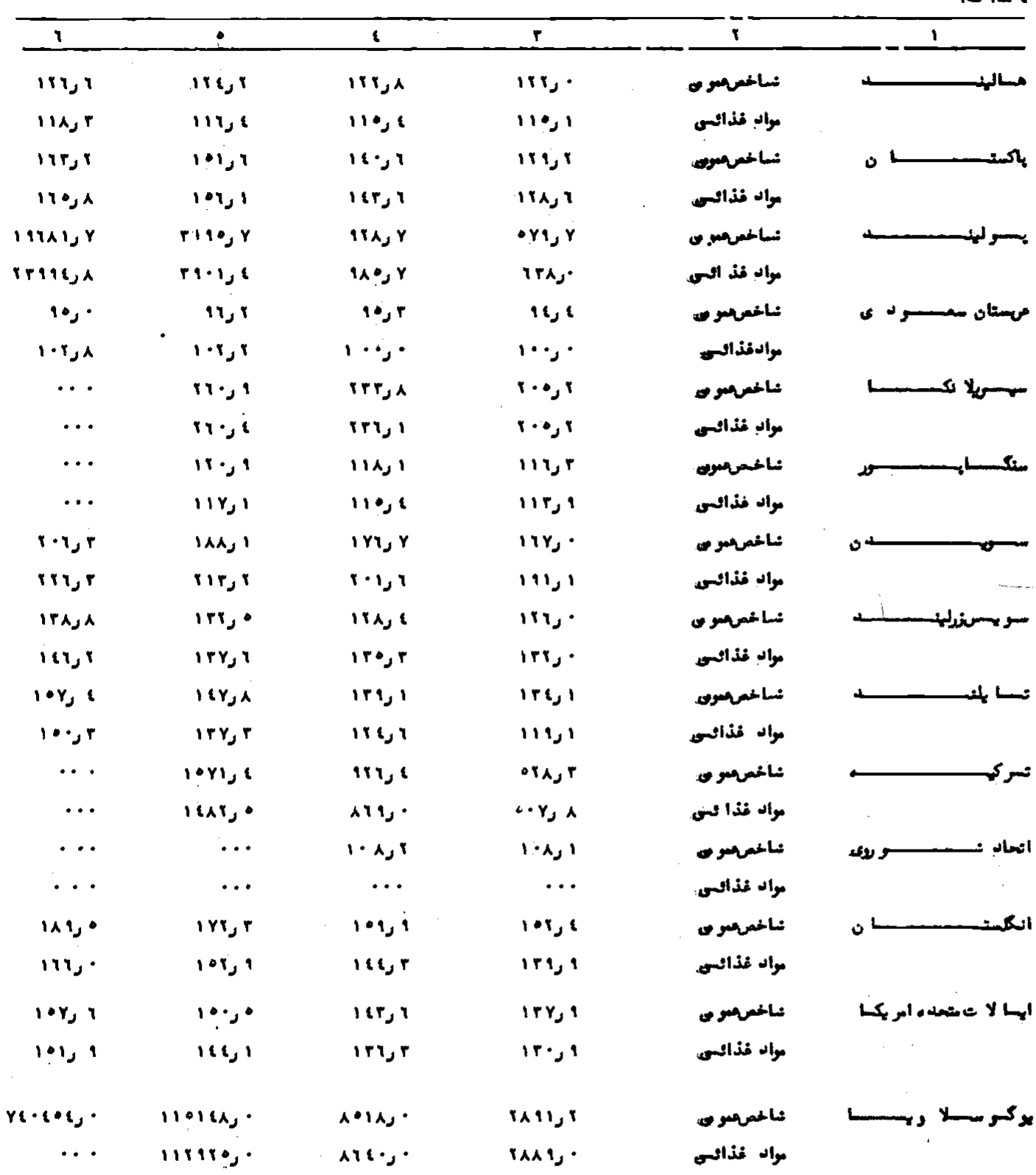




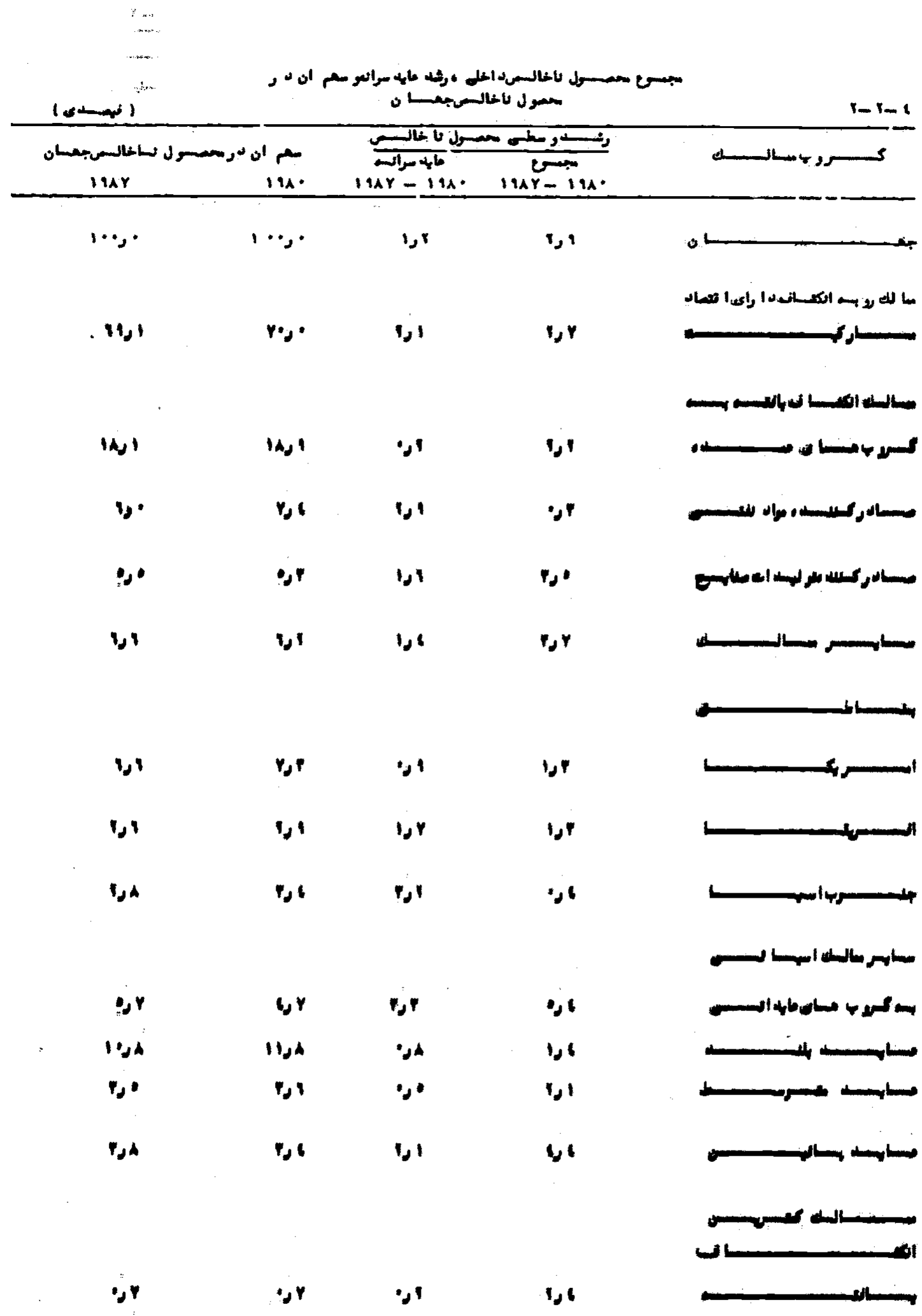




\begin{tabular}{|c|c|c|c|c|c|c|c|}
\hline 199 & | 141 & 11 Aᄉ & linY & 11 A1 & 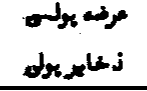 & L & همارو \\
\hline$\cdot$ & $\varepsilon$ & $r$ & $I$ & 1 & E & ب & الف \\
\hline$\cdots$ & $\cdots$ & iratie & irisis & A.11r & عرضش بr d & امغانستـــــــــن & 11 \\
\hline$\cdots$ & 16111 & IYioro & $17: 166$ & ATIIA & j & & \\
\hline $41 \cdot 01$ & GPGY & 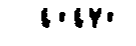 & PIIIA & reaty & $d x=0$ & -1 & 11 \\
\hline IYYAY & 19061 & IYIYA & $1011 Y$ & $|6| 1$ & dumbs & & \\
\hline 111 & IFe & IFI & I6Y & IrI & $d x \rightarrow p$ & 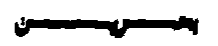 & 17 \\
\hline 160 & 160 & $16 \%$ & 16 & 111 & $d x \mid d$ & & \\
\hline OY'Al & $1 \cdots 1$ & op11! & $\because \cdots$ & 11111 & مמה J & & 11 \\
\hline -YIII & - MAYA & $1 \cdot 11$ & 10116 & lier & dintis & & \\
\hline$\cdots$ & iy & $A \wedge$ & $A *$ & $A^{\prime}$ & مط: & Iot & 1 \\
\hline$\cdots$ & ir & If & 16 & il & durtas & & \\
\hline IP! & or & 16 & boy & PAT & مرنشي لل & & $=11$ \\
\hline$\because$ & $\cdots$ & $\cdots$ & $\because !$ & $\because$ & $d x b^{\prime}$ & & \\
\hline IYI & IA & IYA & If & 110 & $d x=0$ & 5 & $1 v$ \\
\hline$Y Y$ & $r Y$ & $\mathbf{A}$ & $Y Y$ & 1 & d & & \\
\hline IOYY & IIIY & leovi & HA| & leqy & $\Delta n \rightarrow$ & & $1 A$ \\
\hline |IA|| & ||$\cdot A \mid$ & 11641 & |AYI| & 17100 & durlas & & \\
\hline$\cdots$ & $110 \%$ & IOPI & $\mid(y)$ & $16: 4$ & ה & & 11 \\
\hline riy & Fis & 11 & PIA & $m$ & duets & & \\
\hline 111 & |rr & 114 & 19 & $\mathrm{Pl}$ & P & 山車 & 11. \\
\hline 111 & iro & 111 & $\cdots$ & IAY & drats & & \\
\hline vil & YiY & IF & 067 & IYI & $t x=0$ & & 111 \\
\hline YAA & YII & 11 & 11 & |r| & $d x$ & $\cdot$ & \\
\hline$\cdots$ & $1+\infty 1$ & lotil & 1140 & $\mid 11 \%$ & $d x+y$ & & 111 \\
\hline$|\cdot| Y \mid$ & I. YAA & APAI & |'pl & AIY. & durtod & & \\
\hline 11911 & triyry & YAI'YA & periel & Plipl & ع & & II \\
\hline IABII & lastry & $11611 \%$ & 10111 & IFYA' & $d w^{\prime} b s$ & & \\
\hline 114116 & 11668 & 11146 & IIIYY & IAll' & $\Delta x \rightarrow p$ & 0 & 116 \\
\hline HYYY & $16 \cdot 14$ & P14 & Plil. & Pllis & $d x+y=3$ & & \\
\hline INAII & IGYA & Intor & $1 \cdot 1 \cdot y$ & $A A+1$ & مر ب & & $11:$ \\
\hline 1166 & $|1|||$ & IYIA & $Y 111$ & 014 & aturbs & & \\
\hline
\end{tabular}




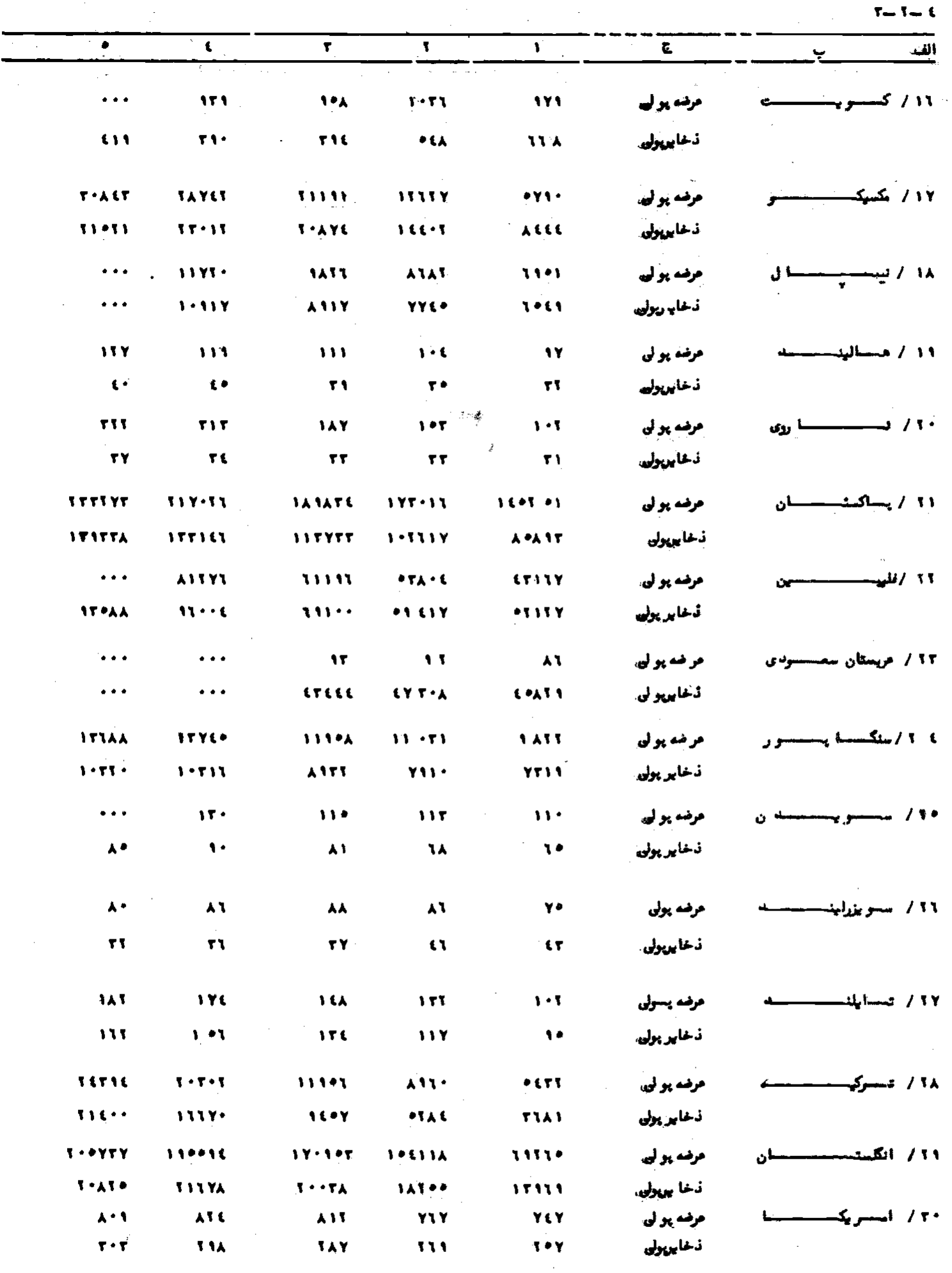

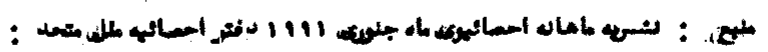




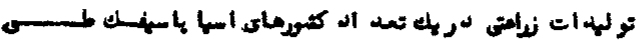

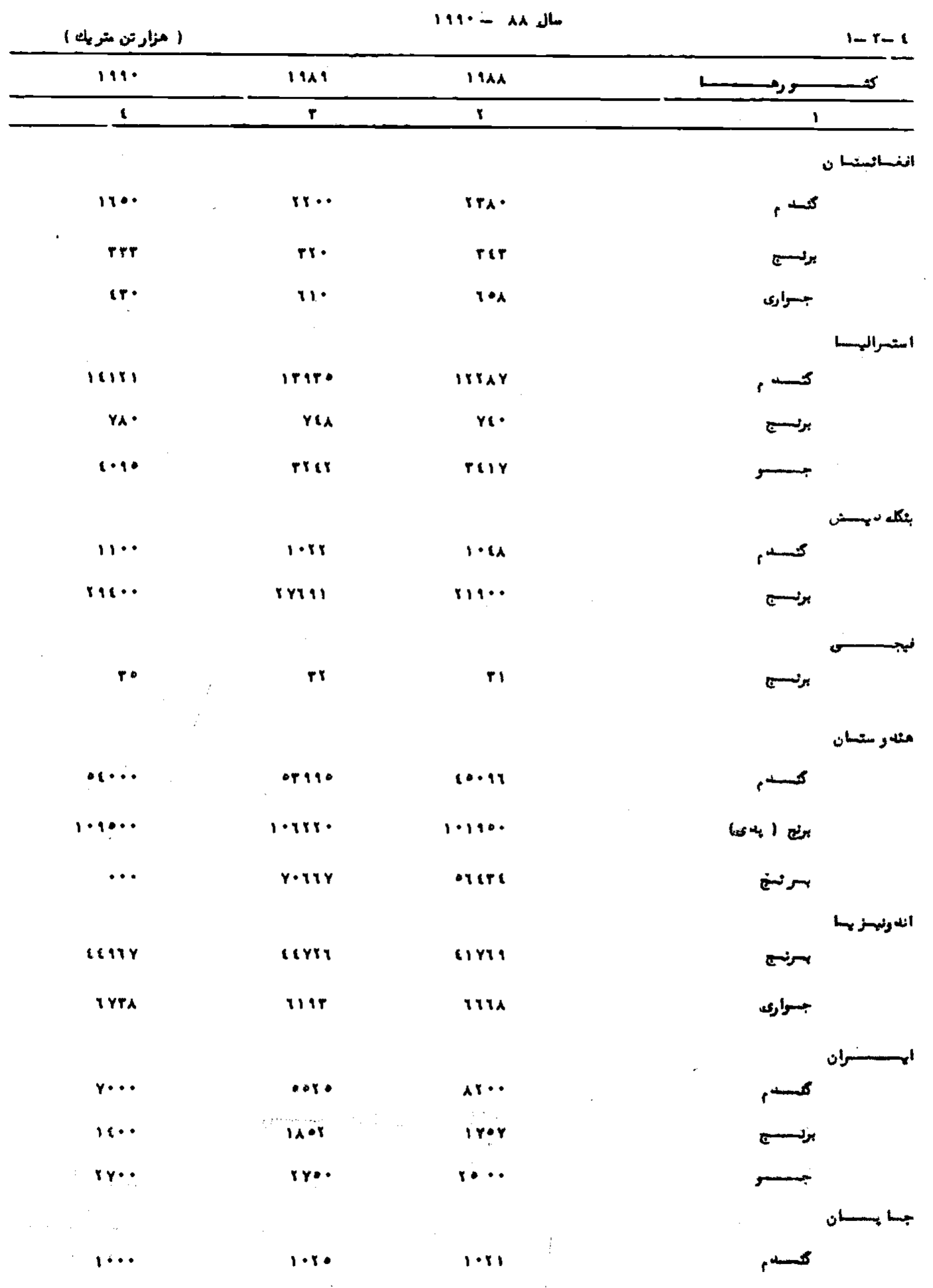




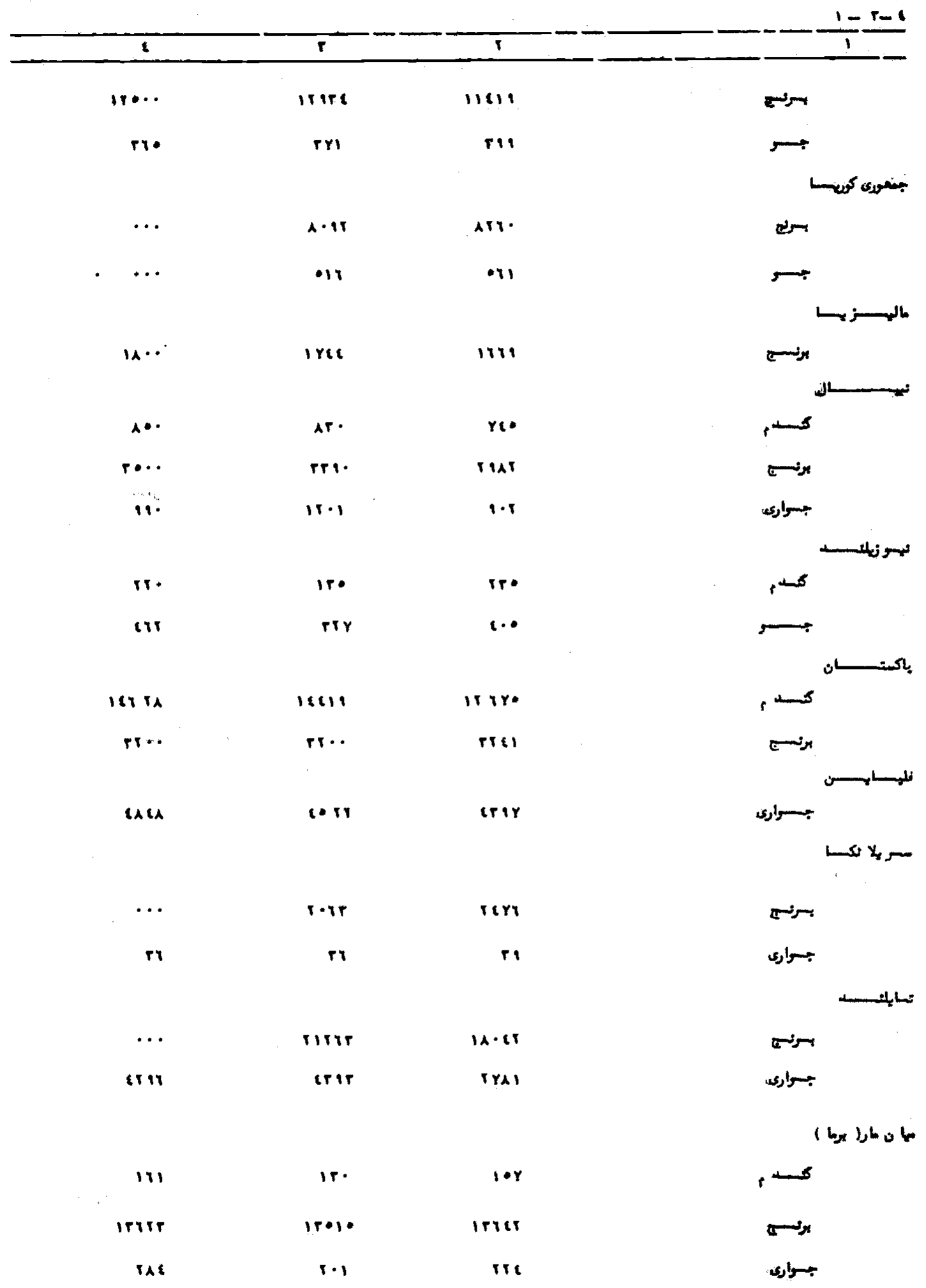




\begin{tabular}{|c|c|c|c|c|c|c|}
\hline 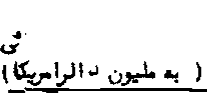 & & -1919 & غنسبك طل & مهاد كثورما & تجسارت & $r-r-\varepsilon$ \\
\hline & 119. & & & 1919 & & \\
\hline بيلانسر. & مان & واردات & بيلانس & $=1,0$ & وارنات & $\ldots$ \\
\hline$-\operatorname{ctr}$ & $\because 1$ & 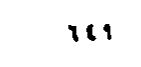 & -110 & יוז & ul & انفاستــــــــــ \\
\hline ri & $r q+r q$ & riA it & -rry. & ris.. & $(\cdots r)$ & استـــر الهـــــــ \\
\hline$\cdots$ & $\cdots$ & $\cdots$ & $-r m$ & $17 \cdot$ & rerc & 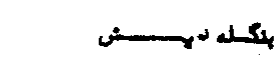 \\
\hline AYr. & $r r \cdot A 9$ & erris & $-n \cdots$ & repe & -nit. & זיז \\
\hline$\cdots \cdot$ & $\cdots$ & $\cdots$ & $-i n$ & rAT & irr & $\sigma$ \\
\hline$-\operatorname{rrr}$ & Arir. & Arcis & ury & reile. & rrior & 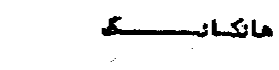 \\
\hline$-\cdots 11$ & Irrar & rtrat & - cre: & Pexrq & rerre & مثيار ســـــــــان \\
\hline TATA & rarro & ruATY & •ris & rrieq & irr. & اله ونهزيز يستســـا \\
\hline -rill & varise & recuer & Terre & ryelrr & $n \cdot A c$ & جسـايســـــــان \\
\hline - tATA & Mitrt & IAYY & irr & irrye & Mine & جسعويكدكديك \\
\hline$\cdots$ & $\cdots$ & $\cdots$ & $r \cdot r r$ & $r: 11 r$ & $r \because n$ & سالهـز بـ \\
\hline$-\cdot 1$ & act: & 1119 & 11 & Axir & Arry & لهـ زهيلانســـ \\
\hline - inre & rיr & rr:ar & -rera & crer & min & بكستــــــــ \\
\hline$\cdots$ & $\cdots$ & $\cdots$ & $-r i x$ & ryer & $1 \cdot r r r$ & نلرسـا بـــــن \\
\hline$\cdots$ & 9 & $\ldots$ & 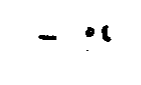 & ir & ir & - \\
\hline$-1 \cdot \cdot 1$ & - & Y. YAY & $-191 x$ & atru & arri & معكـا بـ \\
\hline$\cdots$ & $\cdots$ & $\cdots$ & $-\cdots 9$ & ior & $r \cdot \wedge \Lambda$ & سرحهليا نكسـ \\
\hline$\cdots$ & $\cdots$ & rercer & $-\cdot r \cdot q$ & $r \cdots \cdot$ & rorus & تL الئ \\
\hline$\cdots$ & $\cdots$ & $\cdots$ & $-u$ & 9 & •r & تسانs \\
\hline
\end{tabular}


Republic of Afghanistan

Ministry of Statistics

\section{STATISTICAL YEARBOOK 1990-91}

September 1991

$$
\text { كجناتئي }
$$

